Frameworks transversais: definições, classificações, arquitetura e utilização em um processo de desenvolvimento de software

Valter Vieira de Camargo 



\title{
Frameworks transversais: definições, classificações, arquitetura e utilização em um processo de desenvolvimento de software
}

\author{
Valter Vieira de Camargo
}

Orientador: Prof. Dr. Paulo Cesar Masiero

Tese apresentada ao Instituto de Ciências Matemáticas e de Computação - ICMC-USP, como parte dos requisitos para obtenção do título de Doutor em Ciências - Ciências de Computação e Matemática Computacional.

USP - São Carlos

Agosto de 2006 
Frameworks transversais: definições, classificações, arquitetura e utilização em um processo de desenvolvimento de software

Valter Vieira de Camargo 
Ao meu pai (in memorian) 


\section{Agradecimentos}

Cinco anos se passaram e muitas coisas alegres e tristes aconteceram; casei, meu pai se foi, meus cabelos caíram, minha barriga cresceu, etc. Muitos acontecimentos marcantes, uma quantidade imensa de histórias para contar, muitas amizades conquistadas. Um período de crescimento sem limites. Entretanto, esta página marca o final desse período. Um fim que não vou encarar com tristeza ou saudade, mas sim como uma nova vida, como uma nova rotina que pretendo conduzir com a mesma perseverança, alegria e vontade com que despendi durante o doutorado.

Gostaria de agradecer a Deus por me amparar nos momentos difíceis que passei durante o doutorado e também por me conceder momentos felizes.

Um agradecimento especial ao meu pai. Embora não esteja mais conosco, tenho certeza que está me olhando lá de cima com muito orgulho. Ele foi uma pessoa que me moldou com poucas palavas e sem puxões de orelha. Seus ensinamentos vieram até mim por demonstrações de como viver, como respeitar as pessoas e como valorizar cada momento pequeno da vida. Seu olhar dizia tudo, não eram necessárias palavras. Apesar da pouca escolaridade, sua personalidade e caráter eram de um rei. Muito obrigado meu pai, o Sr. fez de mim um homem.

Um agradecimento especial ao meu orientador Masiero. Sem dúvida, sem ele nada teria se concretizado. Cresci a ponto de saber que, no futuro, quando eu me lembrar desta fase, verei o quanto eu era imaturo e quanto de conhecimento eu ainda faltava adquirir.

Também gostaria de enaltecer minha mãe. O simples fato de ela existir já me fornece o suficiente para continuar lutando com a vida. O término de um trabalho como este sem dúvida não seria possível sem o apoio emocional que ela me concede.

Minha esposa também merece grande parte desta conquista. Só pessoas que já passaram por isso sabem como é conviver com um doutorando em Ciência da Computação. Inúmeros finais de semana perdidos e trancafiados em casa. Liriane, parte deste título de doutorado também é seu.

Também vai um agradecimento especial à minha irmã, meu cunhado e meus dois sobrinhos Murilo e Camilo. Embora o pouco tempo que tenho me dedicado a vocês durante estes cinco anos, os sorvetes de domingo à tarde foram muito importantes para mim.

Outra pessoa que merece um agradecimento especial é a Professora Rosângela Penteado, hoje minha amiga e madrinha de casamento, no passo minha orientador de 
mestrado. Pessoa extraordinária que é uma das grandes responsáveis por eu ter chegado até aqui. Sua bondade e presteza é algo fora do normal. Gosto muito de você.

Grande agradecimento ao velho amigo Ricardo Ramos que esteve presente nos momentos mais importantes de minha vida. Uma pessoa com quem eu sempre pude contar em qualquer tipo de situação.

Aos grandes amigos do condomínio SGF (Santa Guerra Ferro), Dinho, Pablo e Alexandre. É impossível esquecer das peripécias que fazíamos juntos. Tenho muita saudade daquele tempo.

Aos grandes amigos do Labes: Fabiano, Otávio, Marcelo, Stanley, KLB (Sandro), Reginaldo, Erika, Bira, Elisa, Marcella, Débora, Maris, Alessandra, Paula, Antonielly, André, Camila, Rogério, Adenilso, Luciana, Ellen e Rosana.

Também gostaria de agradecer ao professor Fernão Germano, que me apoiou no fim do mestrado/início do doutorado.

Agradeço também ao professor Maldonado por dar espaço em suas disciplinas de pósgraduaçao para a condução de experimentos.

Agradeço a todos funcionários do ICMC que de forma direta ou indireta contribuíram para a realização desta tese de doutorado.

Agradeço à Capes pelo apoio financeiro. 


\section{Sumário}

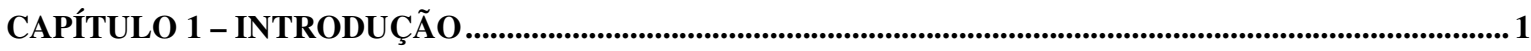

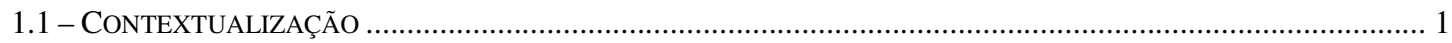

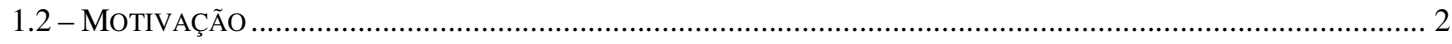

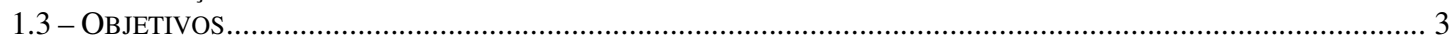

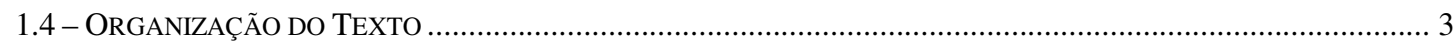

CAPÍTULO 2 - FRAMEWORKS E PROCESSOS NO CONTEXTO DA POA...................................................5

2.1 - CONSIDERAÇÕES INICIAIS ................................................................................................... 5

2.2 - SEPARAÇ̃̃o DE INTERESSES E PROGRAMAÇÃO ORIENTADA A ASPECTOS ................................................... 5

2.2.1 - Apoio Lingüístico para a Programação Orientada a Aspectos........................................................10

2.2.2 - Interfaces de Entrecorte .....................................................................................................12

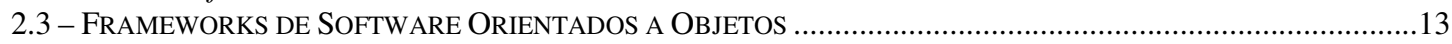

2.3.1 - Modelagem de Frameworks com o Perfil UML-F ....................................................................16

2.3.2 - Linhas de Produtos e Frameworks Orientados a Objetos ................................................................. 17

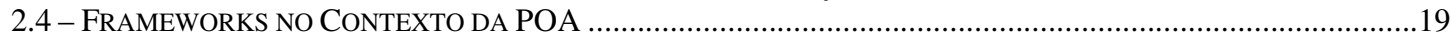

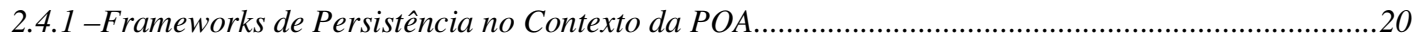

2.4.2 - Frameworks de Segurança no Contexto da POA ………………...............................................22

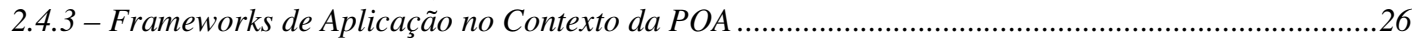

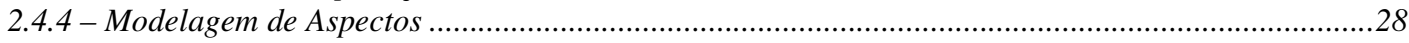

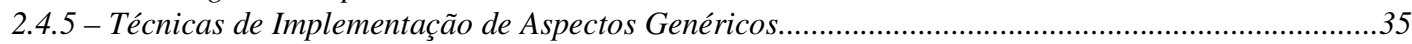

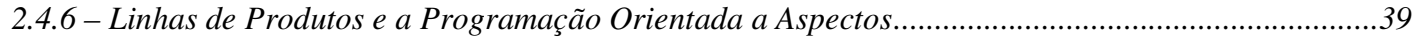

2.5 - PROCESSO DE DESENVOLVIMENTO ORIENTADO A ASPECTOS.....................................................................

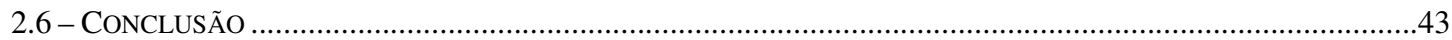

\section{CAPÍTULO 3 - FRAMEWORKS TRANSVERSAIS: DEFINIÇÕES, CLASSIFICAÇÕES E}

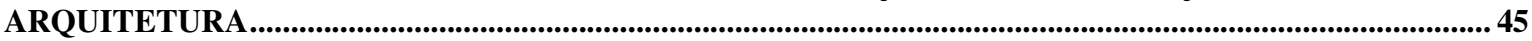

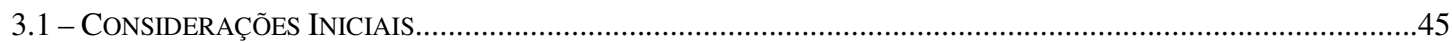

3.2 - FRAMEWORKS ORIENTADOS A ASPECTOS: DEFINIÇõES E CLASSIFICAÇÕES ...................................................

3.3 - PROPOSTA DE UMA ARQUITETURA PARA FraMEWORKS TRANSVERSAIS .................................................51

3.3.1 - Exemplo de Utilização do Padrão Capturador de Dados..................................................................60

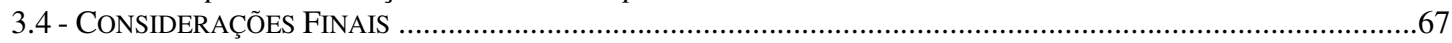

CAPÍTULO 4 - FAMÍLIAS DE FRAMEWORKS TRANSVERSAIS............................................................69

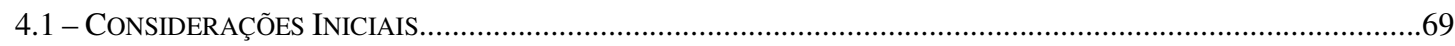

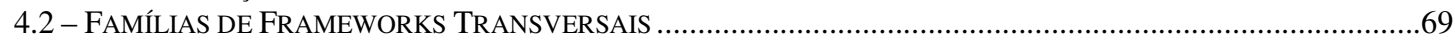

4.3 - FAMÍlIA DE FRAMEWORKS TRANSVERSAIS DE PERSISTÊNCIA ..............................................................

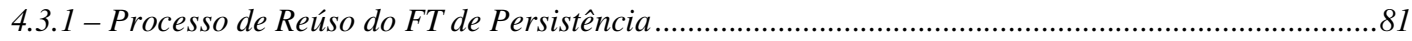

4.3.2 - Adaptações no FT de Persistência................................................................................................ 87

4.3.3 - Acoplamento de Características ao FT de Persistência …………………........................................90

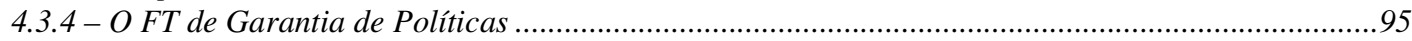

4.4 - FAMÍLIA DE FRAMEWORKS TRANSVERSAIS DE SEGURANÇA ...................................................................97

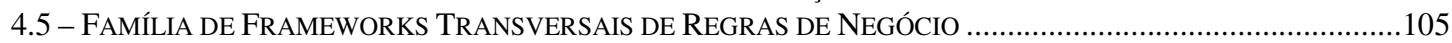

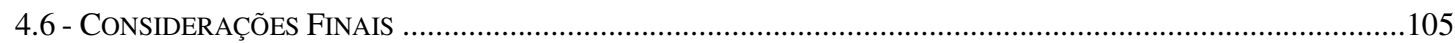

CAPÍTULO 5 - ESTUDOS DE CASO ............................................................................................................. 107

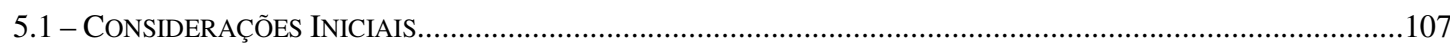

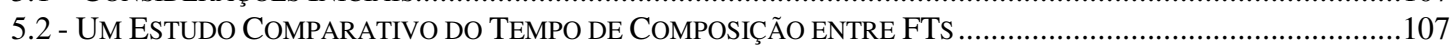

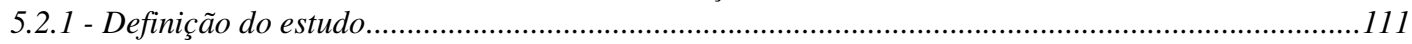

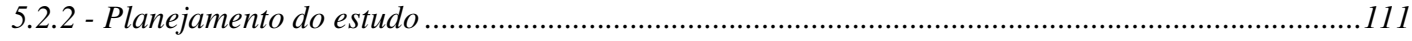

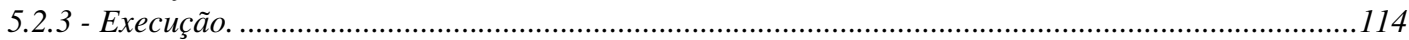

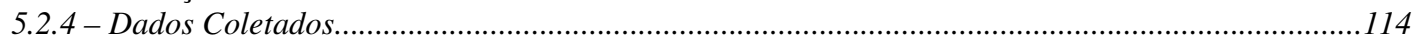

5.2 .5 - Análise dos Dados..........................................................................................................116

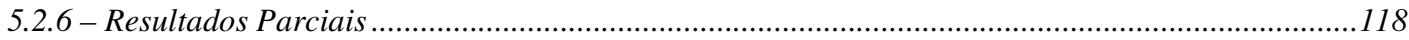

5.2.7 - Ameaças à Validade do Estudo .........................................................................................122

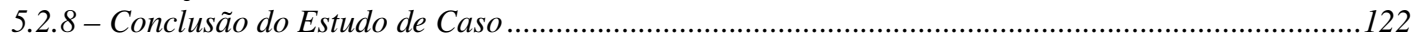

5.3 - ANÁLISE DA DIFICULDADE DE ACOPLAMENTO ...............................................................................123

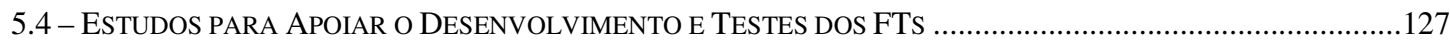

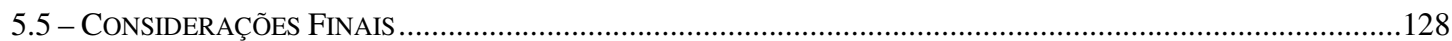




\section{CAPÍTULO 6 - PROFT - UM PROCESSO DE DESENVOLVIMENTO DE SOFTWARE APOIADO POR FRAMEWORKS TRANSVERSAIS.}

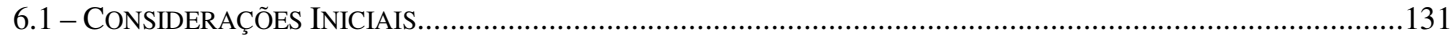

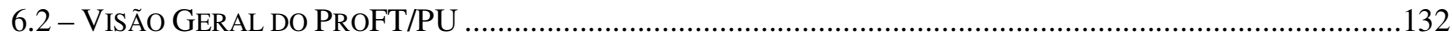

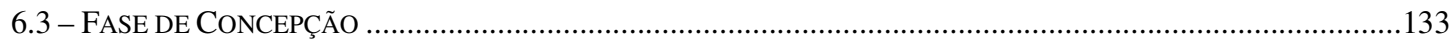

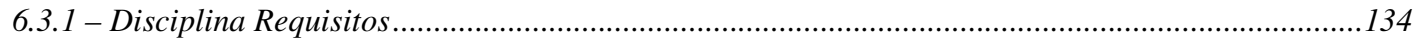

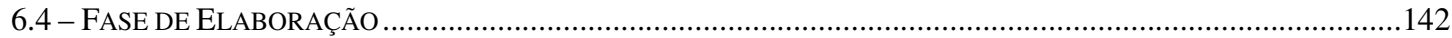

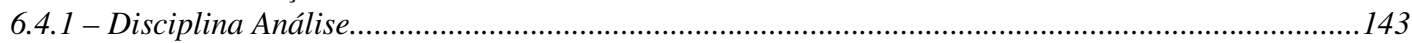

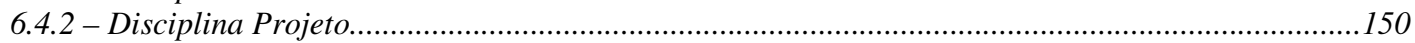

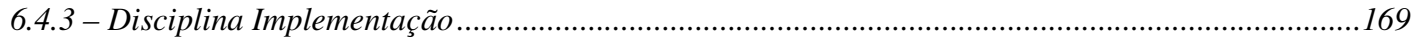

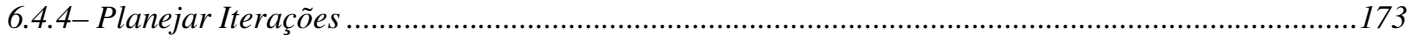

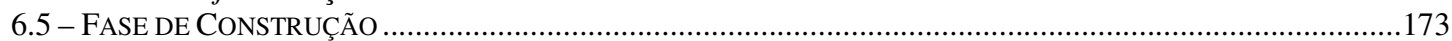

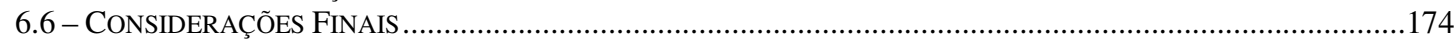

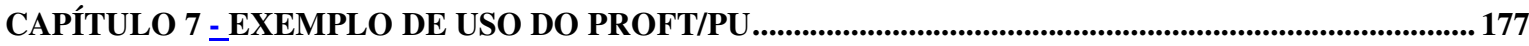

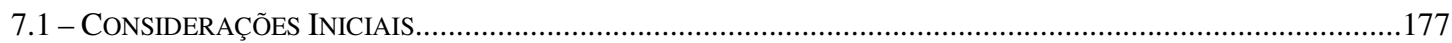

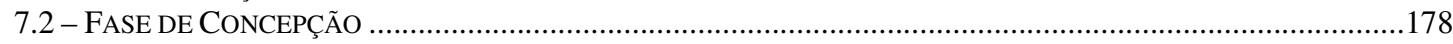

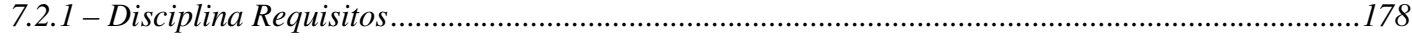

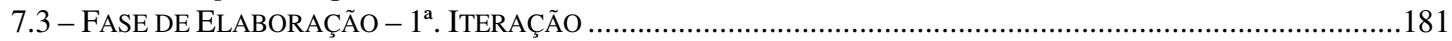

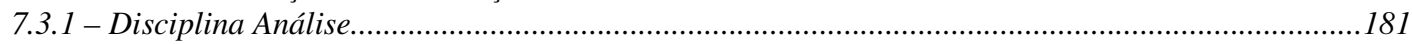

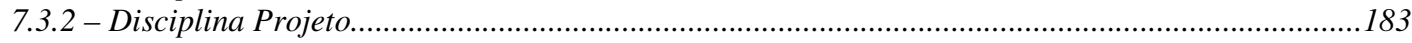

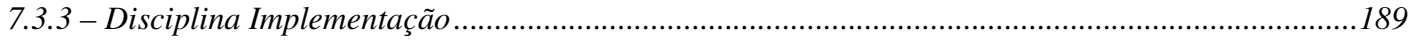

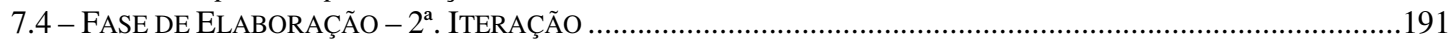

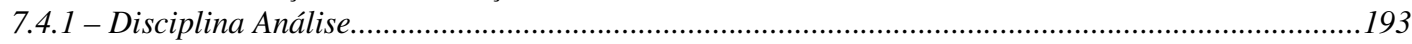

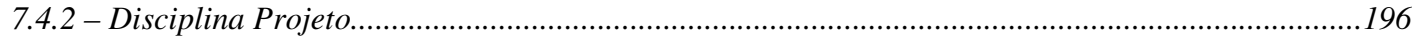

7.4.3 - Projetar Acoplamento dos Aspectos com a Base .....................................................................201

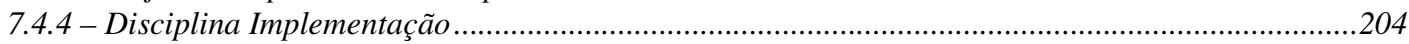

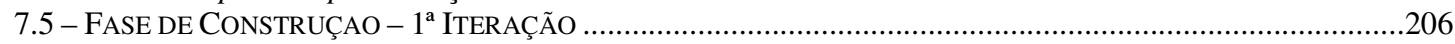

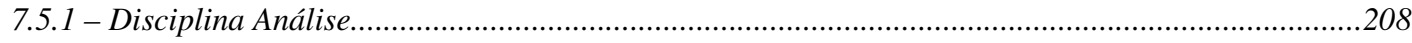

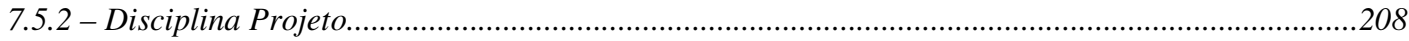

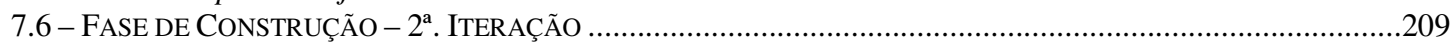

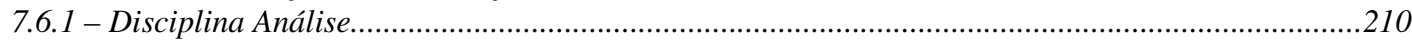

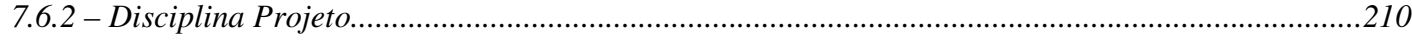

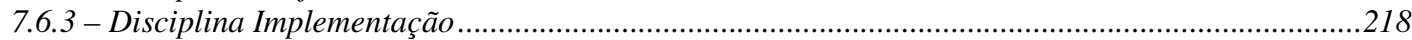

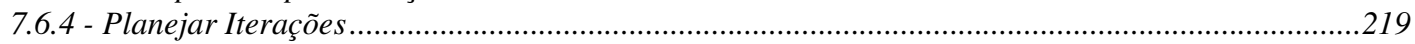

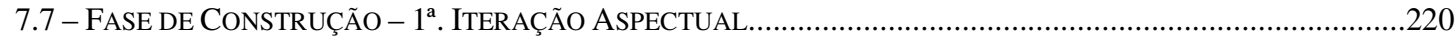

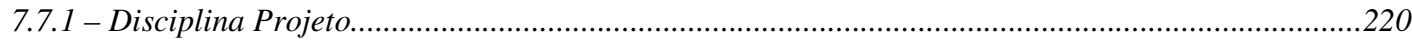

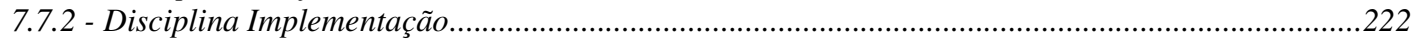

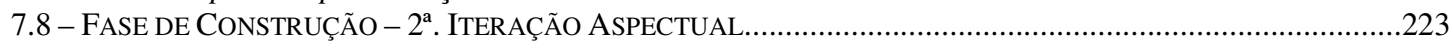

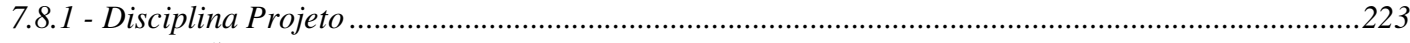

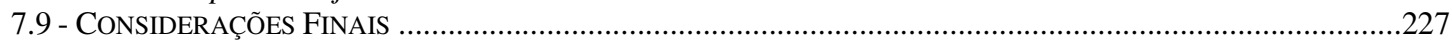

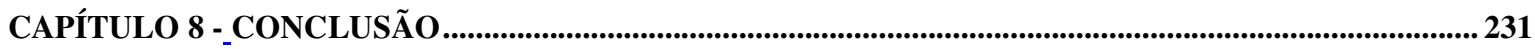

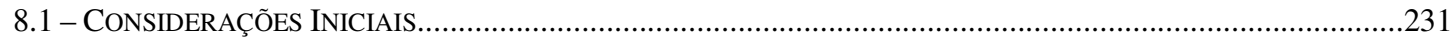

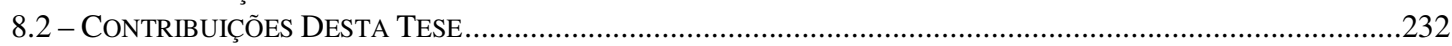

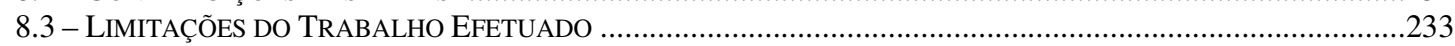

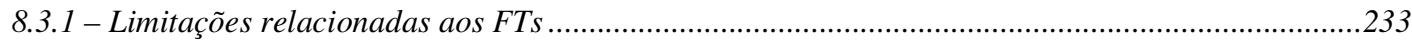

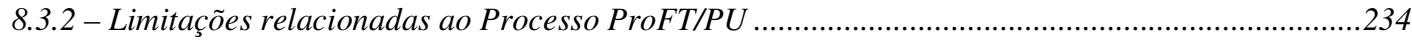

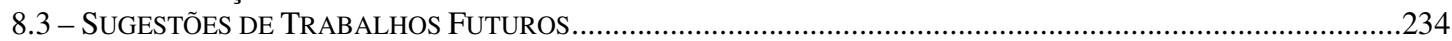

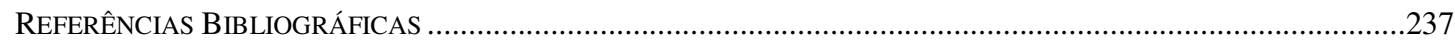

ANEXO 1 - DOCUMENTO DE REQUISITOS DO SISTEMA DE RESERVAS DE UMA REDE DE HOTÉIS ......................247

ANEXO 2 - FORMULÁRIO DE CARACTERIZAÇÃO DO PERFIL ….................................................................251

ANEXO 3 - Q1 - QUESTIONÁRIO INDIVIDUAL PARA PARTICIPANTES DO ESTUDO DE CASO............................253

ANEXO 4 - RELATÓRIO DE IMPLEMENTAÇÃO DO FRAMEWORK DE PERSISTÊNCIA E SEGURANÇA ORIENTADO A

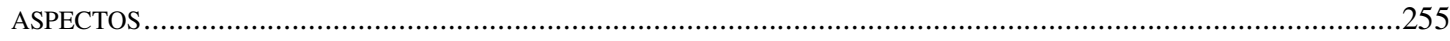




\section{Anexos}

Anexo 1 - Documento de Requisitos do Sistema de Reservas de uma Rede de Hotéis

Anexo 2 - Formulário de Caracterização do Perfil

Anexo 3 - Q1 - Questionário Individual para Participantes do Estudo de Caso

Anexo 4 - Relatório de implementação do framework de persistência e segurança orientado a aspectos 


\section{Lista de Figuras}

Figura 2.1 - Diagrama de Classes de um Editor Gráfico (Elrad et al., 2001) .........................7

Figura 2.2 - Implementação Orientada a Objetos do Interesse de Atualização do Display.......8

Figura 2.3 - Implementação do Mecanismo de Atualização do Display ..................................11

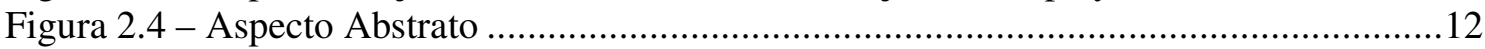

Figura 2.5 - Aspecto Concreto .............................................................................. 12

Figura 2.6 - Framework de Segurança Orientado a Aspectos (Vanhaute et al., 2001) ..........23

Figura 2.7 - Estrutura do Framework (Vanhaute et al., 2001)..........................................23

Figura 2.8 - Aspecto Genérico de Criptografia da Biblioteca JASL .....................................24

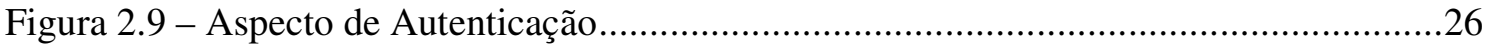

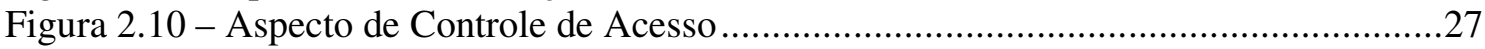

Figura 2.11 - Tema Transversal de Registro de Execução .................................................

Figura 2.12 - Composição entre os Tema Log e Base ........................................................31

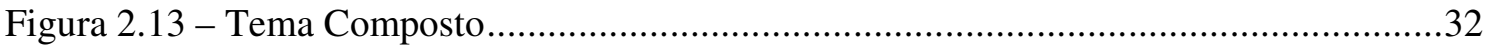

Figura 2.14 - Modelagem de Arquitetura Orientada a Aspectos.......................................34

Figura 2.15 - Exemplos de Conjunto de Junção..................................................................38

Figura 3.1 - Inversão de Controle nos Framelets e nos Frameworks Transversais .................49

Figura 3.2 - Arquitetura de Referência para Frameworks Transversais ...............................52

Figura 3.3 - Representação Esquemática da Instanciação de um Framework Transversal .....52

Figura 3.4 - Implementação Convencional de um FT de Pooling .......................................53

Figura 3.5 - Projeto de um Framework Transversal Genérico ................................................55

Figura 3.6 - Exemplo de Implementação do Padrão...........................................................58

Figura 3.7 - Modelo de Projeto do FT de Cálculo Baseado em Tabela................................61

Figura 3.8 - Framework de Cálculo Baseado em Tabela Instanciado .................................64

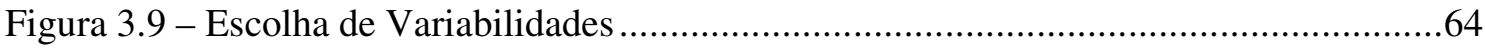

Figura 3.10 - Ponto de Junção na Aplicação......................................................................64

Figura 3.11 - Aspecto da Regra de Negócio de Cálculo do Vale-Refeição...........................65

Figura 3.12 - Ponto de Junção para o Acoplamento do Imposto de Renda ............................66

Figura 4.1 - Diagrama de Características da Linha de Produtos de FTs de Persistência.........75

Figura 4.2 - Estrutura do Framework Transversal de Persistência...........................................77

Figura 4.3 - Código do Aspecto PersistentEntities............................................................. 78

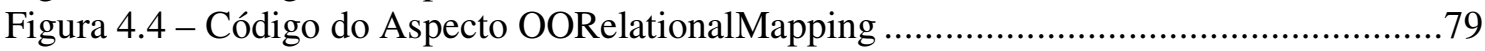

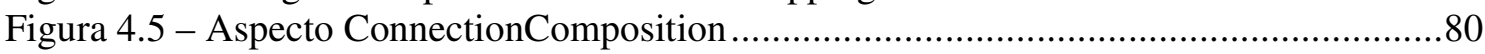

Figura 4.6 - Código do Aspecto PartialAwareness...................................................... 82

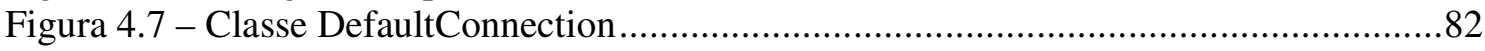

Figura 4.8 - Framework de Persistência como um Tema Transversal ...................................83

Figura 4.9 - Composição do FT de Persistência com uma Aplicação ......................................84

Figura 4.10 - Composição do Framework de Persistência com Classes de aplicação

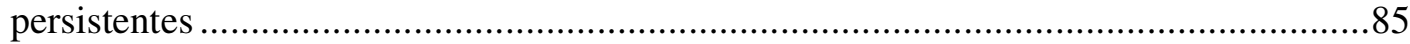

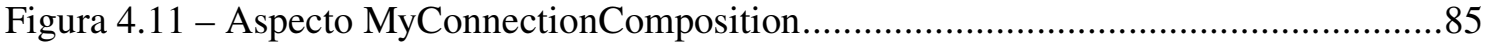

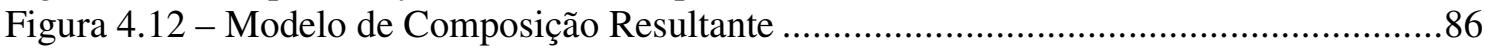

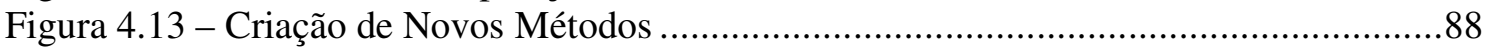

Figura 4.14 - Adaptação do Tipo Sobreposição do FT de Persistência.................................89

Figura 4.15 - Adaptação do Tipo Empacotamento ............................................................90

Figura 4.16 - FT de Pooling como um Tema Transversal .................................................91

Figura 4.17 - Acoplamento do FT de Pooling com o FT de Persistência ...............................93

Figura 4.18 - Código Fonte do Aspecto DefaultPoolingAspect.............................................94

Figura 4.19 - Código Fonte do Aspecto PoolWithoutReturn...............................................94

Figura 4.20 - Modelo de Projeto Composto da Aplicação com a Característica de Pooling...95

Figura 4.21 - Modelo de Projeto do FT de Garantia de Políticas.........................................97 
Figura 4.22 - Código do Aspecto pre_weaved_attributechecker ........................................97

Figura 4.23 - Arquitetura das Aplicações em que o FT de Segurança pode ser Aplicado ......98

Figura 4.24 - Diagrama de Características da Linha de Produtos de FTs de Segurança ..........98

Figura 4.25 - Modelo de Projeto do FT de Autenticação .................................................101

Figura 4.26 - Modelo de Projeto do FT de Políticas de Autenticação................................... 102

Figura 4.27 - Composição entre o FT de Políticas de Bloqueamento e o FT de Autenticação

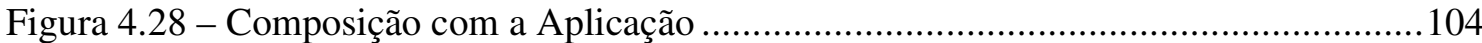

Figura 5.1 - Acoplamento do Comportamento de Persistência - AO .................................109

Figura 5.2 - Acoplamento do Comportamento de Persistência - OO ...................................110

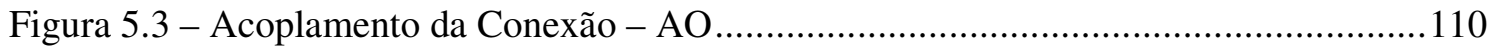

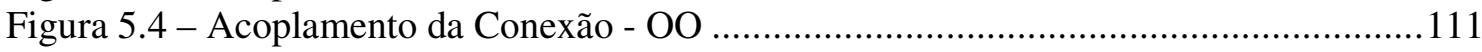

Figura 5.5 - Projeto Experimental ............................................................................. 112

Figura 5.6 - (a) Experiência dos participantes em POA, Java e AspectJ; (b) Experiência dos

participantes nas linguagens JAVA e AspectJ (linhas de código) ................................113

Figura 5.7 - Diferenças Percentuais entre os Tempos de Composição (Primeira Fase) ........116

Figura 5.8 - Diferenças Percentuais entre os Tempos de Composição (Segunda Fase) ........118

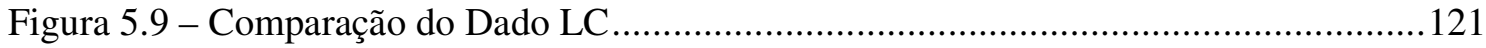

Figura 5.10 - Diagrama de Classes do Sistema de Caixa de Banco ..................................124

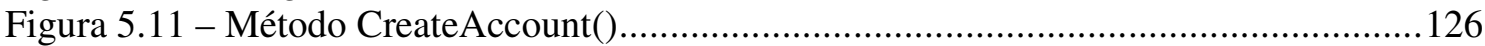

Figura 5.12 - Ponto de Junção Real do Código-Base .....................................................127

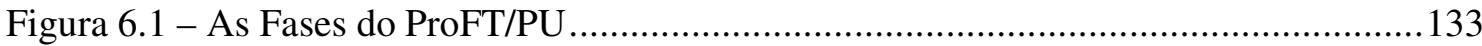

Figura 6.2 - Visão Geral do ProFT/PU ...............................................................................133

Figura 6.3 - Atividades Da Disciplina Requisitos que Despendem Maior Esforço na

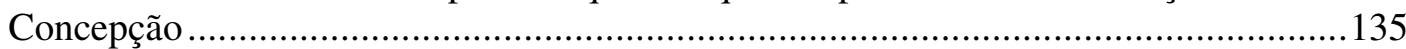

Figura 6.4 - Caso de Uso Não-Funcional Autenticar Usuário - Visão Individual de Caso de

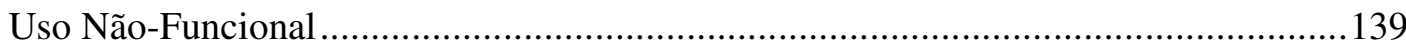

Figura 6.5 - Caso de Uso Hipotético Fazer Reserva................................................... 141

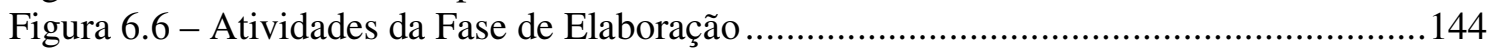

Figura 6.7 - Atividades da Disciplina Projeto ........................................................... 151

Figura 6.8 - Exemplo Hipotético de Caso de Uso Transversal ........................................ 154

Figura 6.9 - Exemplo de Modelo de Projeto Combinado .....................................................164

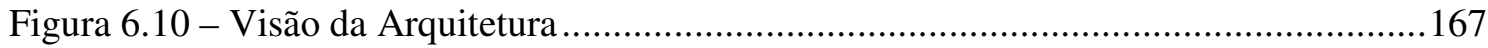

Figura 6.11 - Atividades da Disciplina de Implementação ............................................170

Figura 7.1 - Atores e Diagrama de Casos de Uso Inicial do Sistema de Reservas ...............178

Figura 7.2 - Caso de Uso Não-Funcional Autenticar Usuário - Visão Individual de Caso de Uso.

Figura 7.3 - Caso de Uso Fazer Reserva ................................................................ 180

Figura 7.4 - Visão de Iteração - Fase de Concepção....................................................182

Figura 7.5 - Caso de Uso Enviar Dados por E-mail .......................................................182

Figura 7.6 - Modelo Conceitual do Sistema de Reservas ...................................................183

Figura 7.7 - Visão de Acoplamento do FT de Persistência com o Sistema de reservas ........185

Figura 7.8 - Diagrama de Colaboração para a Operação Fazer Reserva ...............................186

Figura 7.9 - Modelo de Classes de Projeto com Classes Controladoras.............................. 187

Figura 7.10 - Acoplamento da Parte de Conexão do FT de Persistência com a Parte Base da

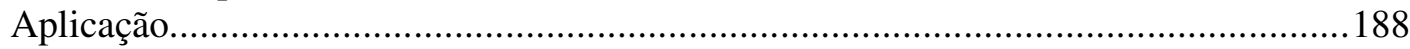

Figura 7.11 - Visão da Arquitetura - 1 ${ }^{\mathrm{a}}$. Iteração da Elaboração ......................................188

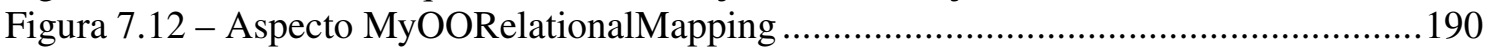

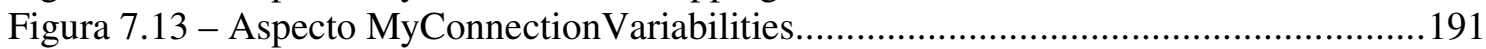

Figura 7.14 - Aspecto de Acoplamento da Conexão ..........................................................191

Figura 7.15 - Visão de Iteração para a Segunda Iteração do Sistema de Reservas ...............192 
Figura 7.16 - Visão Individual para o Caso de Uso Identificar Reserva ..............................193

Figura 7.17 - Visão de Iteração para a Segunda Iteração do Sistema de Reservas ................194

Figura 7.18 - Modelo Conceitual Atualizado..................................................................195

Figura 7.19 - Projeto do Aspecto Funcional Gerenciar Empresas ....................................201

Figura 7.20 - Modelo de Classes de Projeto para o Sistema de Reservas - 2a . Iteração ........201

Figura 7.21 - Composição entre Temas Base..................................................................202

Figura 7.22 - Tema resultante da composição - Modelo de Classes de Projeto - 2a. Iteração

Figura 7.23 - Visão da Arquitetura - 2 . Iteração da Elaboração ......................................203

Figura 7.24 - Visão de Acoplamento para o Sistema de Reservas - 2 ${ }^{\mathrm{a}}$. Iteração da Elaboração

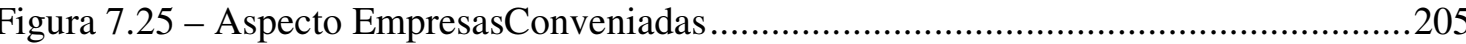

Figura 7.26 - Atualização do Aspecto MyPersistentEntities ............................................206

Figura 7.27 - Atualização das Regras de Composição da Conexão ....................................206

Figura 7.28 - Visão de Casos de Uso da Iteração Atual - 1a . Iteração da Construção ...........207

Figura 7.29 - Modelo de Classes de Projeto para o Sistema de Reservas - 1a. Iteração da

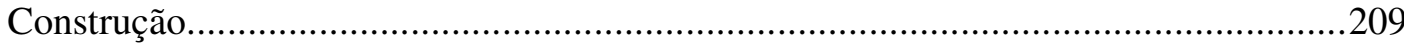

Figura 7.30 - Atualização das Regras de Composição - 1a . Iteração da Construção .............210

Figura 7.31 - Visão de Iteração para o Sistema de Reservas - $2^{\mathrm{a}}$. Iteração da Construção ...211

Figura 7.32 - Caso de Uso Reajustar Valor das Diárias ....................................................213

Figura 7.33 - Modelo de Projeto do FT de Reajuste de Valor Instanciado.........................216

Figura 7.34 - Acoplamento FT de Reajuste de Valor com Aplicação Base ........................217

Figura 7.35 - Visão da Arquitetura - 2a. Iteração da Construção ........................................217

Figura 7.36 - Atualização das Regras de Composição da Conexão ....................................218

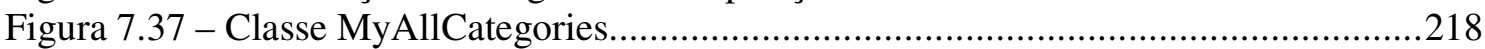

Figura 7.38 - Aspecto MyReadjustmentPolicy ...........................................................219

Figura 7.39 - Visão de Iteração - 3a. Iteração da Construção ..............................................221

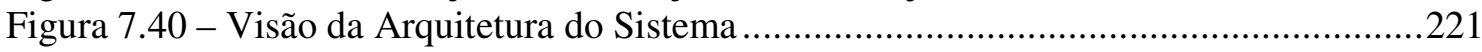

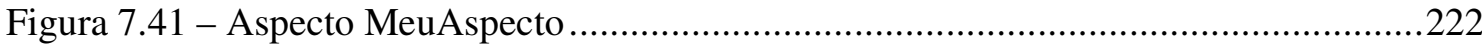

Figura 7.42 - Modelo de Projeto Composto do Sistema de Reservas - 1a. Iteração Aspectual

Figura 7.43 - Visão de Iteração para o Sistema de Reservas - 2ª Iteração Aspectual da Construção. 223

Figura 7.44 - Modelo de Projeto do FT de Controle de Acesso - 3a. Iteração Aspectual ....225

Figura 7.45 - Modelo de Projeto Instanciado ...............................................................226

Figura 7.46 - Acoplamento com o FT de Autenticação...................................................226

Figura 7.47 - Acoplamento com a Aplicação................................................................227

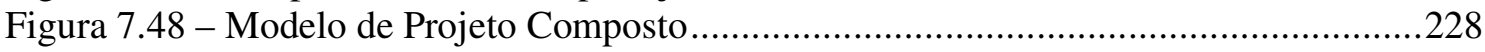

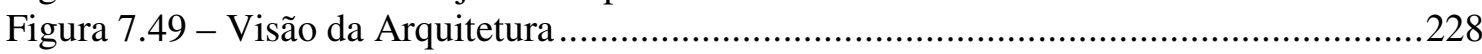




\section{Lista de Tabelas}

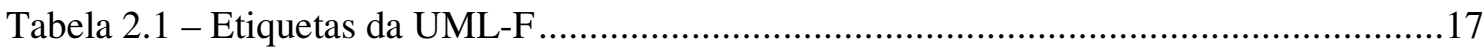

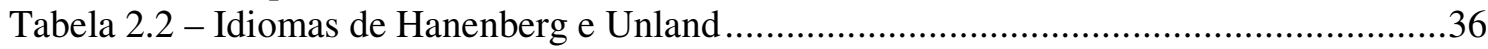

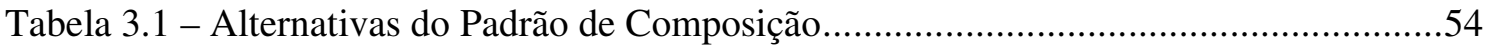

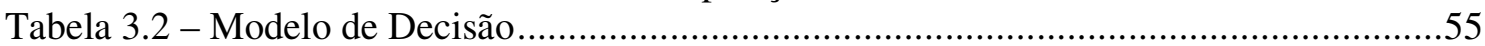

Tabela 3.3 - Tabela do Framework de Regra de Negócio para o Cálculo do Imposto de Renda

Tabela 3.4 - Alternativas de Composição do FT de Cálculo Baseado em Tabela ..................62

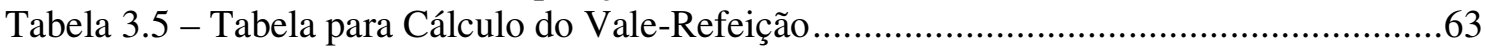

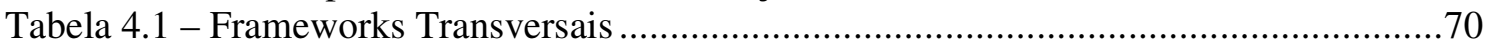

Tabela 4.2 - Operações do FT de Persistência ..................................................................73

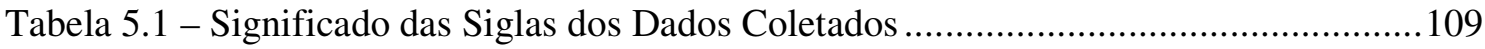

Tabela 5.2 - Hipóteses para o Efeito do Framework de Persistência ..................................111

Tabela 5.3 - Hipóteses para o Efeito do Uso das Aplicações no Resultado .........................112

Tabela 5.4 - Hipóteses para o Efeito do Grupo ou Efeito da Interação ...............................112

Tabela 5.5 - Primeira Etapa da Primeira Fase - Composição com o Framework Orientado a

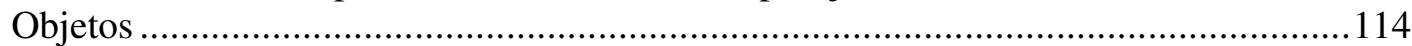

Tabela 5.6 - Segunda Etapa da Primeira Fase - Composição com o FT de Persistência ......115

Tabela 5.7 - Primeira e Segunda Etapas da Segunda Fase do Estudo ..................................115

Tabela 5.8 - Tempo Médio dos Passos de Composição da Primeira e Segunda Fases .........119

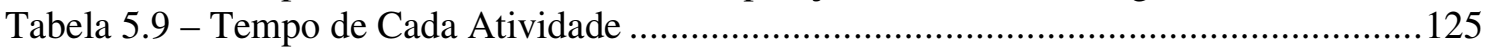

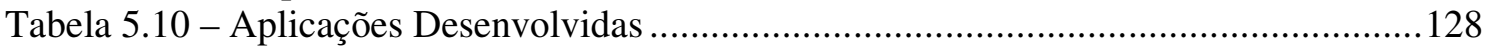

Tabela 6.1 - Atividades do ProFT/PU ........................................................................134

Tabela 6.2 - Modelo para Tabela de Correspondência Caso de Uso/Requisitos ..................137

Tabela 6.3 - Tabela de Correspondência Caso de Uso/Requisitos - Fase de Concepção .....137

Tabela 6.4 - Modelo para Tabela de Interesses Transversais Não-Funcionais.....................138

Tabela 6.5 - Modelo para Tabela de Descrição de Caso de Uso Não-Funcional...................138

Tabela 6.6 - Modelo de Tabela para Classificação de Casos de Uso e Planejamento de Iterações

Tabela 6.7 - Tabela de Decisão para Identificação de Novos Casos de Uso ........................145

Tabela 6.8 - Modelo de Matriz de Comparação de Casos de Uso para a Pergunta 1...........146

Tabela 6.9 - Modelo para Tabela de Candidatos a Aspectos ........................................... 148

Tabela 6.10 - Critérios para Identificação de Aspectos ...................................................153

Tabela 6.11 - Lista de Requisitos Não-Funcionais Clássicos .........................................153

Tabela 6.12 - Modelo para Tabela de Aspectos .............................................................. 158

Tabela 6.13 - Modelo de Tabela de Acompanhamento da Implementação dos Aspectos ....160

Tabela 6.14 - Modelo para o Registro de Pontos de Junção ................................................168

Tabela 7.1 - Tabela de Interesses Transversais Não-Funcionais para o Sistema de Reservas

Tabela 7.3 - Tabela de Planejamento das Iterações do Sistema de Reservas .......................181

Tabela 7.4 - Tabela de Candidatos a Aspectos do Sistema de Reservas (TPCaUT) .............182

Tabela 7.5 - Tabela de Aspectos para o Sistema de Reservas - $1^{\mathrm{a}}$ Iteração ......................... 183

Tabela 7.6 - Tabela de Acompanhamento da Implementação de Aspectos para o Sistema de

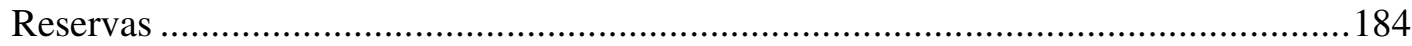

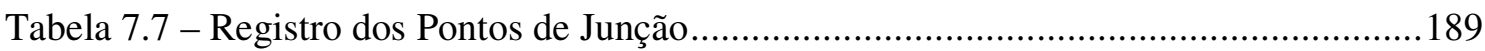

Tabela 7.8 - Tabela de Candidatos a Aspectos.................................................................. 195

Tabela 7.9 - Tabela de Aspectos para o Sistema de Reservas - 2 ${ }^{\mathrm{a}}$ Iteração .........................196

Tabela 7.10 - Faixas de Descontos ........................................................................................ 198 
Tabela 7.11 - Tabela de Acompanhamento da Implementação de Aspectos para o Sistema de

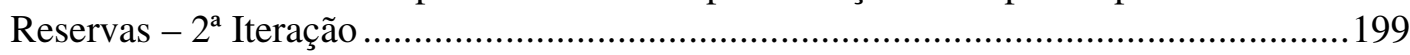

Tabela 7.12 - Registro de Pontos de Junção - 2 ${ }^{\mathrm{a}}$. Iteração da Elaboração............................204

Tabela 7.13 - Registro de Pontos de Junção - 1a. Iteração da Construçãa...........................210

Tabela 7.14 - Tabela de Candidatos a Aspectos..............................................................212

Tabela 7.15 - Tabela de Aspectos para o Sistema de Reservas - 2a. Iteração da Construção

.

Tabela 7.16 - Tabela de Acompanhamento da Implementação dos Aspectos ......................213

Tabela 7.17 - Tabela de Aspectos para o Sistema de Reservas..........................................214

Tabela 7.18 - Tabela de Acompanhamento da Implementação dos Aspectos .......................215

Tabela 7.19 - Registro de Pontos de Junção - 2a. Iteração da Construção...........................218

Tabela 7.20 - Tabela de Aspectos Atualizada ......................................................................220

Tabela 7.21 - Classificação dos Casos de Uso Aspectuais ................................................220

Tabela 7.22 - Tabela de Planejamento das Iterações do Sistema de Reservas.......................220

Tabela 7.23 - Registro de Pontos de Junção .................................................................222

Tabela 7.24 - Registro de Pontos de Junção ...................................................................229 


\section{Resumo}

O paradigma orientado a objetos não dispõe de abstrações adequadas à modularização de interesses transversais - interesses cuja implementação encontra-se entrelaçada e espalhada por todos os módulos de um sistema. Com o surgimento da Programação Orientada a Aspectos e a disponibilidade de abstrações adequadas à modularização de interesses transversais, o reúso desses interesses foi facilitado. Nesta tese são apresentados alguns resultados de esforços de pesquisa que visam a tornar o reúso de interesses transversais mais efetivo. Definições e classificações para frameworks desenvolvidos no contexto da POA - frameworks transversais - são apresentadas com o objetivo de facilitar a comunicação entre usuários e pesquisadores. Uma arquitetura de referência para o projeto e implementação de frameworks transversais, que torna sua estrutura mais clara e facilita a integração de vários frameworks quando a intenção é criar um repositório de aspectos reusáveis, é proposta. Três famílias de frameworks transversais: de persistência, de segurança e de regras de negócio foram desenvolvidas. Cada família de frameworks transversais constitui uma linha de produtos de software, em que membros podem ser configurados com características (features) distintas. Um processo de desenvolvimento, denominado ProFT/PU, baseado no Processo Unificado (PU), que considera as famílias de frameworks ao longo de todo o processo é apresentado, juntamente com um exemplo de sua utilização para uma aplicação típica. Um estudo de caso para comparar o tempo requerido para reusar um framework transversal de persistência e um framework orientado a objetos de persistência é também apresentado e discutido. 
XIX 


\section{Abstract}

The object-oriented paradigm does not provide adequate abstractions to modularize crosscutting concerns - concerns whose implementation end up tangling and spreading throughout the modules of a system. With the emerging of Aspect-Oriented Programming (AOP) and the availability of abstractions suitable to modularize crosscutting concerns, the reuse of such concerns is facilitated. In this thesis, some results of research efforts to make the reuse of crosscutting concerns more effective are presented. Definitions and classifications for frameworks developed in the context of AOP - crosscutting frameworks - with the objective of improving understanding and communication among users and researchers are presented. An architecture specifically to design and implement this type of framework, which makes its structure clearer and facilitates the integration of several frameworks, is proposed. Three families of crosscutting frameworks for persistence, security and business rules, were developed. Each crosscutting framework family is a software product line, in which members can be instantiated with distinct characteristics. A development process, named ProFT/PU, based on Unifed Process (UP), which takes into account the families during the process, is presented, along with an example of its use for a typical application. A case study to compare the time required to reuse a persistence crosscutting framework and a persistence object-oriented framework is also presented and discussed. 



\section{Capítulo 1 \\ Introdução}

\section{1 - CONTEXTUALIZAÇÃo}

Na década de 70 surgiram os primeiros trabalhos que se referiam ao termo "interesse" como um conceito de modularização de software (Dijkstra, 1976). Muito do que se propôs nessa época e em pesquisas subseqüentes foi sendo gradativamente incorporado às linguagens de programação e aos modelos de processo de desenvolvimento de software, culminando na década de 90 com o desenvolvimento orientado a objetos e a padronização propiciada pela UML (Unified Modelling Language) (Jacobson et al., 1999).

A Programação Orientada a Aspectos (POA) (Gregor Kiczales et al., 1997) e a linguagem AspectJ (Kiczales et al., 2001) surgiram no final da década de 90 como uma importante contribuição para modularizar interesses transversais, que até então ficavam misturados e espalhados pelo código orientado a objetos, sem que fosse possível organizá-los em módulos independentes. A POA fornece novas abstrações que contribuem para a separação de interesses (separation of concerns) - um objetivo antigo da engenharia de software que visa a separar os interesses encontrados no código-fonte de um sistema (Dijkstra, 1976). Com a POA é possível implementar separadamente os interesses-base e os interesses transversais, o que até então era dificultado somente com orientação a objetos. Os interesses-base referem-se à funcionalidade principal do sistema e os transversais referem-se a restrições globais e a requisitos não-funcionais, como, por exemplo: persistência, distribuição, autenticação, controle de acesso e concorrência.

A partir desse avanço, outras linguagens de programação orientadas a aspectos surgiram e iniciou-se um processo de revisão das técnicas, métodos e processos usados até então para adaptá-las a essa nova forma de "pensar" o software e modularizá-lo, tais como técnicas de elicitação e modelagem de requisitos (Grundy, 1999; Jacobson e Ng, 2004) 
(Clarke e Baniassad, 2005; Rashid et al., 2002; Baniassad et al., 2006; Araújo e Moreira, 2003; Araújo et al., 2002), linguagens de modelagem para projeto (Berg et al., 2006; Clarke e Baniassad, 2005; Grundy, 2000; Katara e Katz, 2003; Suzuki e Yamamoto, 1999; Pawlak et al., 2002; Stein et al., 2002; Zakaria et al., 2002; Aldawud et al., 2003), técnicas de teste (Lemos et al, 2003a; Lemos et al., 2003b; Zhao, 2003; Zhao, 2002; Zhou et al., 2004) e uso de aspectos para implementar variabilidades em linhas de produto de software (Mezini e Ostermann, 2004; Batory et al., 2006).

Como a implementação de interesses transversais em unidades sintáticas abstratas também é possível com a POA, vários pesquisadores iniciaram pesquisas com o objetivo de implementar esses interesses de forma genérica para investigar seu reúso em outros contextos, criando assim, "frameworks orientados a aspectos" que encapsulam um único interesse transversal (Couto et al., 2005; Hanenberg et al., 2004; Huang et al., 2004; Shah e Hill, 2004; Constantinides et al., 2000; Pinto et al, 2002; Rashid e Chitchyan, 2003; Soares et al., 2002; Vanhaute et al., 2001).

Embora a maioria destes pesquisadores investigue o projeto e a implementação de um único framework, trabalhos mais recentes mostram uma tendência em agrupar aspectos reusáveis em um repositório - bibliotecas ou famílias - para apoiar o reúso durante o processo de desenvolvimento de uma aplicação (Zhang et al., 2004; Mortensen e Ghosh, 2006a; Mortensen e Ghosh, 2006b; Soares, 2004).

\section{2 - MotIVAÇÃO}

A modularização de interesses transversais é difícil quando apenas orientação a objetos é usada. Em conseqüência disso, poucos avanços significativos foram conseguidos em relação ao reúso desses interesses até o aparecimento da POA. Depois de seu surgimento, o reúso de interesses transversais emergiu como uma linha de pesquisa importante, atraindo vários pesquisadores e gerando muitas propostas e iniciativas de desenvolvimento de frameworks orientados a aspectos (Rashid and Chitchyan, 2003; Couto et al., 2005; Camargo e Masiero, 2005a; Soares et al., 2002; Rausch et al., 2003; Vanhaute et al., 2001; Chen e Huang, 2005; Zubairov et al., 2005; Zhang et al., 2004; Mortensen e Ghosh, 2006a; Mortensen e Ghosh, 2006b; Pinto et al., 2001a; Pinto et al., 2001b; Pinto et al., 2002; Hanenberg et al., 2004). Entretanto, o reúso de interesses transversais ainda hoje se encontra em fase de amadurecimento, pois os termos utilizados pelos pesquisadores muitas vezes são diferentes

\footnotetext{
${ }^{1}$ Deste ponto em diante, o termo "framework orientado a aspectos" será usado para designar uma implementação genérica de um único interesse transversal, até que uma definição mais precisa seja apresentada no Capítulo 3.
} 
para conceitos ou soluções semelhantes. Além disso, há uma carência por padrões de arquitetura e de projeto de software bem estabelecidos. Assim, é possível concluir que este é um campo atual e promissor para novas pesquisas. Nesse contexto, a pesquisa apresentada nesta tese visa a contribuir para o réuso de projeto e de código de interesses transversais.

\section{3 - OBJETIVOS}

O objetivo geral desta tese é tornar o reúso de interesses transversais mais efetivo durante o desenvolvimento de uma aplicação. Para isso, propõe uma arquitetura de referência para o projeto e a implementação de frameworks orientados a aspectos. Essa arquitetura padrão separa a parte funcional da parte de composição, contribuindo para uma melhor compreensão de sua estrutura e facilitando a sua evolução. A aderência a uma arquitetura padrão também facilita a integração de vários frameworks em um repositório de apoio ao reúso, como bibliotecas ou famílias de frameworks orientados a aspectos, o que introduz sistematização no processo de reúso.

Como apoio tecnológico, três famílias de frameworks orientados a aspectos são propostas: de persistência de dados, de segurança e de regras de negócio (Weiss e Lai, 1999; Gomaa, 2004). Para facilitar o uso dessas famílias, também é proposto um processo de desenvolvimento de software apoiado por frameworks orientados a aspectos. O processo, denominado ProFT/PU, é baseado no PU (Jacobson et al., 1999); é iterativo e incremental; e considera a identificação e o acompanhamento de interesses transversais ao longo de todo o processo. Ele é sintetizado pela união de conceitos, técnicas de modelagem e critérios de outros trabalhos encontrados na literatura (Clarke e Baniassad, 2005; Jacobson e Ng, 2004; Araújo e Moreira, 2003; Araújo et al., 2002).

\section{4 - ORGANIZAÇÃo DO TEXTO}

No Capítulo 2, os conceitos fundamentais para o entendimento da tese são apresentados juntamente com trabalhos diretamente relacionados com a pesquisa realizada. O objetivo é mostrar o paranorama atual dos campos de pesquisa relacionados a esta tese e justificar o trabalho proposto.

No Capítulo 3, algumas definições e classificações para frameworks orientados a aspectos são propostas com o objetivo de homogeneizar o termo e melhorar a comunicação entre desenvolvedores. Ainda nesse capítulo, uma arquitetura para o projeto e a implementação de frameworks orientados a aspectos é discutida e exemplificada. 
No Capítulo 4, as famílias de frameworks orientados a aspectos para persistência de dados e para segurança são apresentadas e discutidas.

No Capítulo 5, três estudos de caso são relatados. Alguns foram conduzidos com o objetivo de evoluir e testar os frameworks desenvolvidos, enquanto os outros tiveram o propósito de comparar e averiguar algumas de suas particularidades.

No Capítulo 6, um processo de desenvolvimento de software, denominado ProFT/PU, é apresentado. Esse processo é ilustrado no Capítulo 7 com sua aplicação no desenvolvimento de um sistema de reserva de uma rede de hotéis.

As contribuições desta tese e algumas propostas de continuidade das pesquisas aqui coduzida são apresentadas no Capítulo 8. 


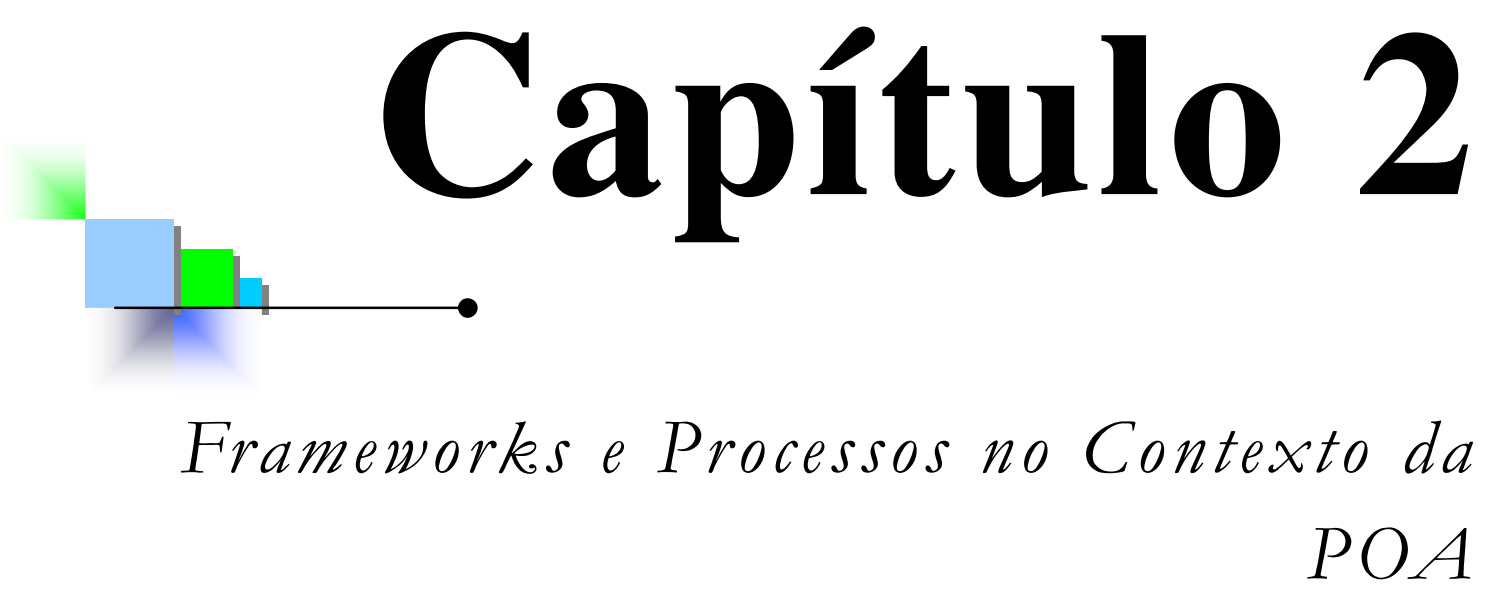

\section{1 - CONSIDERAÇÕES INICIAIS}

Neste capítulo são apresentados e discutidos os conceitos fundamentais para o entendimento desta tese e também os trabalhos diretamente relacionados com a pesquisa conduzida. Uma abordagem histórica mostrando brevemente a evolução das pesquisas desde o aparecimento do conceito de "separação de interesses" até a programação orientada a aspectos é mostrada. O escopo do trabalho é delimitado, discutindo especificamente frameworks orientados a objetos e alguns frameworks orientados a aspectos. Alguns trabalhos que discutem modelagem e implementação de frameworks orientados a aspectos são apresentados e também é feita uma revisão da literatura sobre trabalhos que relacionam linhas de produtos e POA. Por fim, alguns trabalhos que tratam os interesses transversais durante o processo de desenvolvimento são apresentados.

Na Seção 2.2 uma introdução aos conceitos de POA e separação de interesses é mostrada e na Seção 2.3 as principais particularidades dos frameworks orientados a objetos são apresentadas. Na Seção 2.4, o desenvolvimento de frameworks no contexto da POA é discutido, juntamente com exemplos de frameworks orientados a aspectos encontrados na literatura. Na Seção 2.5, trabalhos que tratam de processos de desenvolvimento de software orientados a aspectos são mostrados, e na Seção 2.6, oportunidades de pesquisa com base nos trabalhos apresentados anteriormente são discutidas.

\section{2 - SeParaÇÃo De INTERESSES E ProgramaÇão ORIENTADA A ASPECTOS}


A separação de interesses (separation of concerns) é um princípio bem estabelecido na engenharia de software que se refere à limitação da cognição humana em lidar com a complexidade de um software (Dijkstra, 1976). Apesar de não ter sido um pesquisador de Psicologia Cognitiva, a estratégia proposta por Dijkstra foi amplamente aceita pelas comunidades de Ciência da Computação e de Engenharia de Software para resolver o problema complexo de desenvolver um sistema de software. A estratégia consiste em, a cada momento, focar a atenção em uma porção autocontida, ou interesse, isoladamente, tendo-se ciência de que se está ignorando temporariamente outras partes do problema.

Desde sua criação, a separação de interesses tem sido alvo constante de pesquisas na área de engenharia de software. A cada novo paradigma de programação criado, novas construções sintáticas eram fornecidas para modularizar mais adequadamente os interesses. $\mathrm{O}$ objetivo era que sistemas de softwares complexos pudessem ser decompostos em um conjunto de módulos altamente coesos e com interface claramente definidas. Assim, o processo de evolução passou pela programação procedural, programação estruturada, programação lógica e programação orientada a objetos, entre outras. O objetivo sempre foi melhorar a inteligibilidade do sistema e também sua manutenção, reúso e evolução.

Continuando o processo de evolução dos paradigmas de programação, em 1997, Kiczales et al. (1997) publicaram um artigo apresentando a Programação Orientada a Aspectos. A sua idéia principal é que sistemas são programados de forma mais adequada distinguindo "interesses transversais" de "interesses-base". Interesses-base referem-se à funcionalidade principal do sistema enquanto que um interesse transversal pode variar de requisitos de alto nível como segurança e qualidade de um serviço a noções de baixo nível, como sincronização e manipulações de buffer de memória. Podem ser tanto funcionais, como regras de negócio, quanto não-funcionais, como gerenciamento de transações e persistência de dados. Alguns exemplos mais comuns são: sincronização, interação de componentes, persistência, distribuição, gerenciamento de registros (logging) e controle de acesso (Kiczales et al., 1997).

O termo "interesse transversal" faz analogia ao fato de que sua implementação com técnicas tradicionais de programação entrecorta transversalmente os módulos do sistema, afetando vários módulos e causando entrelaçamento (tangling) e espalhamento (spreading) de código de diferentes interesses. O entrelaçamento ocorre quando o código de um determinado interesse encontra-se misturado com o código de um outro interesse dentro de um mesmo módulo. O espalhamento ocorre quando o código de um interesse encontra-se em vários 
módulos do sistema. O entrelaçamento e o espalhamento de código de diferentes interesses causam problemas de manutenção, reúso e evolução.

A POA foi proposta como uma extensão da orientação a objetos, aproveitando todos os seus conceitos, porém adicionando conceitos específicos para a modularização dos interesses transversais como, por exemplo: aspectos (aspects) e adendos (advices). Assim os interesses transversais são implementados em módulos aspectuais e os interesses-base em classes normais. Uma das motivações para a criação da POA foi o reconhecimento de que os paradigmas de desenvolvimento de software convencionais, mais especificamente o orientado a objetos, sofrem da Tirania da Decomposição Dominante. Consiste na existência de apenas um tipo de módulo ou construção sintática - o módulo dominante - para se encapsular mais de um tipo de interesse (Tarr et al., 2001). Alguns exemplos de módulos dominantes são as classes na programação orientada a objetos, as funções nas linguagens funcionais e as regras na programação baseada em regras. Um paradigma que permite a decomposição em apenas um tipo de módulo é chamado de unidimensional, pois há apenas uma dimensão para a modularização dos interesses, não importando quantos tipos de interesses existem.

A existência de apenas um tipo de módulo para encapsular mais de um tipo de interesse faz com que aqueles interesses que envolvem restrições globais - os interesses transversais - não fiquem adequadamente encapsulados e acabem misturando-se com os interesses-base.

Elrad et al. (2001) ilustram por meio da Figura 2.1 a natureza de um interesse transversal. O diagrama mostrado é de um editor de figuras que deve ser evoluído com a inclusão de um novo interesse, que consiste em notificar o mecanismo de exibição (classe Display) toda vez que um elemento do tipo FigureElement for movimentado.
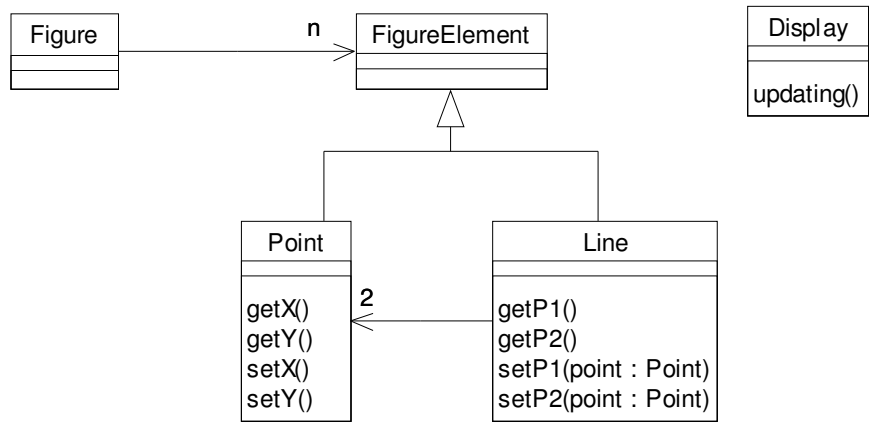

Figura 2.1 - Diagrama de Classes de um Editor Gráfico (Elrad et al., 2001)

Realizar essa operação de manutenção usando programação orientada a objetos resulta em adicionar em todos os métodos que alteram a posição de um ponto ou de uma linha (os métodos set*()) uma chamada ao método updating() da classe Display, como é 
mostrado em negrito na Figura 2.2. Note-se que o código desse novo interesse ficou entrelaçado com o código de cada um dos métodos e espalhado por vários métodos do sistema.

A POA introduz novas abstrações de modularização e mecanismos de composição para melhorar a separação de interesses transversais. As novas abstrações propostas pela POA são: aspectos, pontos de junção (join points), conjuntos de junção (pointcus), adendos e declarações intertipos (inter-type declarations).

Aspecto é o termo usado para denotar a abstração da POA que dá suporte a um melhor isolamento de interesses transversais. Em outras palavras, um aspecto corresponde a um interesse transversal e constitui uma unidade modular projetada para afetar um conjunto de classes e objetos do sistema.

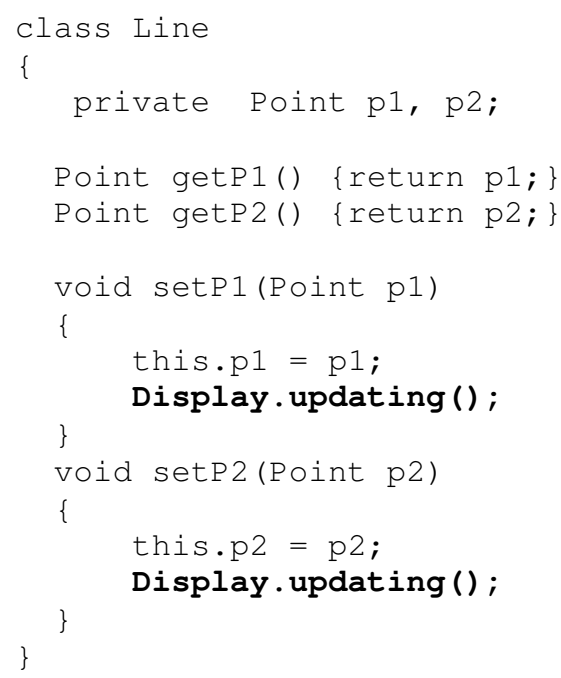

Figura 2.2 - Implementação Orientada a Objetos do Interesse de Atualização do Display

Os pontos de junção são pontos bem definidos da execução de um sistema. Alguns exemplos de pontos de junção são: chamadas a métodos, execuções de métodos, leitura de atributos e modificação de atributos. Por meio dos pontos de junção, torna-se possível especificar o relacionamento entre aspectos e classes. Por exemplo, um aspecto A afeta uma classe $\mathrm{C} 1$ no instante da invocação de um método M1. Em outro exemplo, o aspecto A afeta uma classe $\mathrm{C} 2$ ao final da execução de um método M2. O "instante da invocação do método M1" e o "ponto final da linha de execução do método M2" são exemplos de pontos de junção. Tais pontos de junção são os locais no programa onde os aspectos podem atuar. Eles podem ser especificados em uma linguagem orientada a aspectos por meio da definição de conjuntos de junção. Um conjunto de junção é o mecanismo que especifica os pontos de junção em que aspectos e classes se relacionam. 
A implementação do comportamento transversal modularizado por um aspecto é feita em "adendos". Adendo é um construtor semelhante a um método de uma classe, que define o comportamento dinâmico executado quando são alcançados um ou mais conjuntos de junção definidos previamente. Existem três tipos adendos: os adendos anteriores (before), os posteriores (after) e os de substituição (around). Os adendos anteriores são executados sempre que os pontos de junção associados são alcançados e antes do prosseguimento da computação; os adendos posteriores são executados no término da computação, ou seja, depois que os pontos de junção forem executados e imediatamente antes do retorno do controle ao chamador; os adendos de substituição tomam o controle do código-base, podendo ou não devolver o controle.

As declarações intertipos podem ser utilizadas quando se deseja introduzir atributos e métodos em classes-base do sistema. Ao contrário de adendos, que operam de forma dinâmica, as declarações intertipos operam estaticamente, em tempo de compilação.

Um aspecto pode afetar a estrutura estática ou dinâmica de classes e objetos. A estrutura dinâmica é afetada por meio da especificação de conjuntos de junção e adendos; a estrutura estática é afetada por meio de declarações intertipo.

Além de especificarem elementos que entrecortam classes de um sistema, aspectos podem possuir métodos e atributos internos, como classes OO.

São três as propriedades básicas da POA (Kiczales et al., 1997; Elrad et al., 2001):

- dicotomia aspectos-base: diz respeito à adoção de uma distinção clara entre classes e aspectos. Os sistemas orientados a aspectos são decompostos em classes e aspectos. Os aspectos modularizam os interesses transversais e as classes modularizam os interesses-base;

- inconsciência: propriedade desejável da programação orientada a aspectos. É a idéia de que os componentes não precisam ser preparados para serem entrecortados por aspectos (Elrad et al., 2001). Pela propriedade de inconsciência, os componentes não percebem os aspectos que poderão afetá-los. Embora seja uma propriedade interessante, algumas pesquisas atuais começam a apontar vantagens quando o códigobase possui consciência da existência dos aspectos (Kiczales e Mezini, 2005; Griswold, et al., 2006);

- quantificação: capacidade de escrever declarações unitárias e separadas que afetam muitos pontos de um sistema (Elrad et al., 2001). Pela propriedade de quantificação, é possível fazer declarações do tipo "em programas $\mathrm{P}$, sempre que a condição $\mathrm{C}$ for verdadeira, faça a ação A". 
Combinador é o mecanismo responsável pela composição de classes e aspectos. Quase todo o processo de combinação é realizado como um pré-processamento em tempo de compilação. Entretanto, a versão 5 da linguagem AspectJ já oferece suporte ao processo de combinação dinâmico, pela associação de mecanismos da linguagem com frameworks como AspectWerkz (AspectWerkz Website 2006).

\subsection{1 - Apoio Lingüístico para a Programação Orientada a Aspectos}

Há várias abordagens lingüísticas para a implementação de sistemas orientados a aspectos, como, por exemplo: AspectC para a linguagem C, AspectC\# para a linguagem C\#, AspectS (Hirschfeld, 2002) para a linguagem Smalltalk e AspectJ para a linguagem Java. Porém, como AspectJ é a linguagem mais difundida e a que foi utilizada para a implementação dos frameworks desenvolvidos no contexto desta tese, será a única descrita com detalhes.

O desenvolvimento de software orientado a aspectos possui duas vertentes: abordagens assimétricas e abordagens simétricas. As assimétricas consideram que um sistema possui dois tipos de interesse: os base e os transversais. Assim, as linguagens que apóiam essas abordagens fornecem dois construtores sintáticos para a implementação desses tipos de interesses. Um exemplo de uma linguagem de programação que apóia a abordagem assimétrica é AspectJ, pois ela possui "classes" para a implementação do interesses-base e “aspectos” para a implementação dos interesses transversais. Quando esse tipo de abordagem é usado, modulariza-se com aspectos apenas os interesses transversais existentes em um sistema, considerando todo o código-base restante como um único bloco indivisível que é afetado pelos aspectos. Assim, seria mais correto dizer que esse tipo de abordagem considera que o sistema possui um único interesse-base e vários transversais.

Por outro lado, as abordagens simétricas se concentram em dividir o sistema todo em interesses, não fazendo distinção entre transversais e bases. É chamada de "simétrica" porque a implementação de todos os interesses é feita com um único tipo de construção sintática, por exemplo: classes normais. Cada interesse-base poderia ser, por exemplo, um caso de uso, ou mesmo uma funcionalidade do sistema. Uma linguagem que implementa a abordagem simétrica é a Hyper/J, a qual pode ser utilizada no ambiente CME (Concern Manipulation Environment), um plug-in do ambiente Eclipse.

AspectJ implementa todos os conceitos da programação orientada a aspectos. Por exemplo, na Figura 2.3 é mostrada a implementação de um aspecto que visa a solucionar o problema da atualização do gerenciador de exibição mostrado na Figura 2.2. Esse aspecto possui um conjunto de junção denominado move (), que especifica dois pontos de junção: o 
primeiro são chamadas (call) a todos os métodos que iniciam com as letras "set" da classe Line e o segundo faz o mesmo para a classe Point. Quando há uma chamada a algum método set* da classe Line ou da classe Point, o adendo after chama o método updating () da classe Display após o término da execução desses métodos chamados. O símbolo "I " entre os dois pontos de junção destacados com retângulo significa um operador "or". A declaração returning garante que o adendo after só será executado se os pontos de junção, do conjunto de junção move ( ), retornarem com sucesso de suas execuções. Dessa forma, as chamadas ao método updating() da classe Display mostradas na Figura 2.2 poderiam ser removidas dos métodos set* ( ).

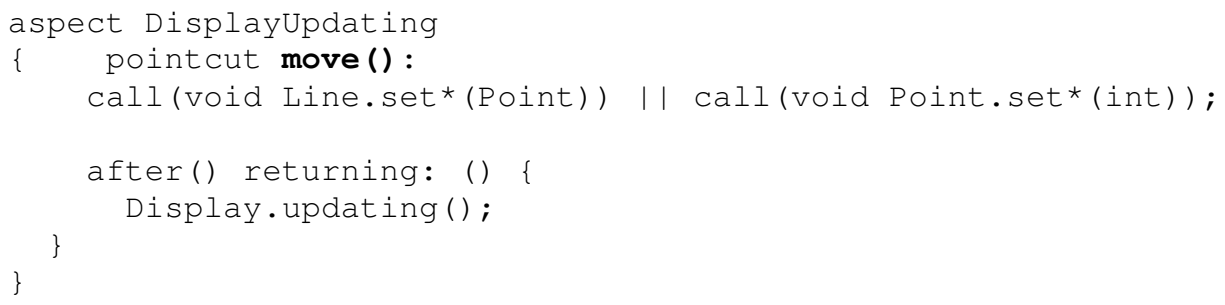

Figura 2.3 - Implementação do Mecanismo de Atualização do Display

A linguagem AspectJ também permite a criação de aspectos abstratos, semelhantemente a uma classe abstrata em Java, porém, além de métodos abstratos o aspecto também pode possuir conjuntos de junção abstratos. Um conjunto de junção abstrato não tem conhecimento dos pontos de junção que serão afetados, pois esses pontos devem ser informados em um aspecto concreto que especializar o aspecto abstrato. Como um adendo pode ser definido sobre um conjunto de junção abstrato, pode-se implementar um comportamento transversal no aspecto abstrato sem saber de antemão quais são os pontos de junção, e conseqüentemente, qual é o código-base em que esse comportamento irá atuar. Aspectos abstratos são a base do desenvolvimento orientado ao reúso, e conseqüentemente, do desenvolvimento de frameworks orientados a aspectos.

Na Figura 2.4 é mostrado um aspecto abstrato cuja tarefa é estabelecer conexões com o banco de dados. Há um conjunto de junção abstrato denominado doconnection () e um adendo do tipo after () que atua sobre ele. O método ConnectDB () sempre será chamado após (after) os pontos de junção que serão informados no aspecto concreto que especializar esse aspecto abstrato. Assim, um aspecto concreto deve ser criado para especializar esse aspecto abstrato e concretizar o conjunto de junção doconnection () com algum ponto de junção em que a conexão deve ser estabelecida, como está sendo exibido na Figura 2.5. Esse 
aspecto concreto indica que sempre que um método init () for executado a conexão deve ser estabelecida.

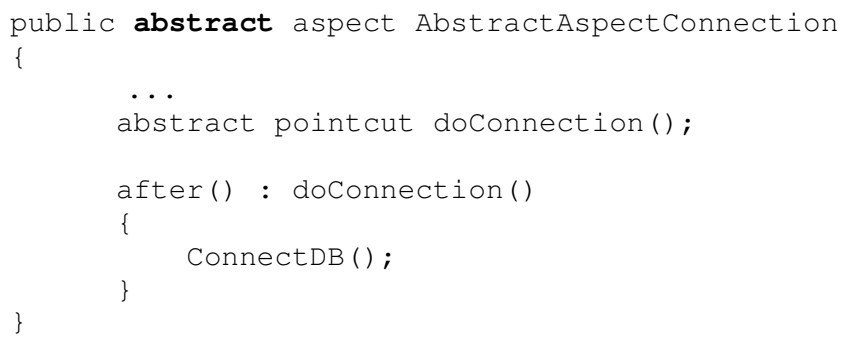

Figura 2.4 - Aspecto Abstrato

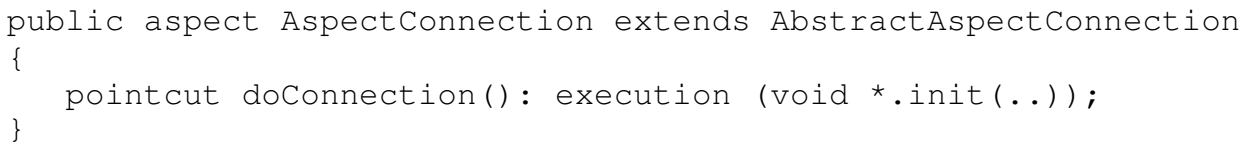

Figura 2.5 - Aspecto Concreto

\subsection{2 - Interfaces de Entrecorte}

Um ponto importante com relação a módulos de um sistema é sua interface. Uma interface é uma descrição ou receita de como o módulo interage com o resto do sistema (Meyer, 1997 apud (Chavez et al., 2005))² (Mezini e Ostermann, 2003 apud (Chavez et al., 2005) $)^{3}$. Na linguagem de programação Java, há um construtor específico para a implementação de interfaces, o que permite expor um subconjunto do comportamento de um módulo para outros módulos. No caso de módulos aspectuais existe o conceito de "interface de entrecorte" (crosscutting interface), que consiste em um conjunto nomeado de "detalhes de entrecorte" (crosscutting features) (Chavez et al., 2005). Detalhes de entrecorte são comportamentos que podem afetar estaticamente ou dinamicamente algum código-base (Chavez, 2004).

No caso da linguagem AspectJ, uma interface de entrecorte é representada por um conjunto de junção juntamente com os pontos de junção que devem ser expostos do códigobase. Diferentemente da linguagem Java, em AspectJ não há um construtor de linguagem específico para implementar uma interface de entrecorte. Assim, nas implementações mais convencionais de aspectos, esse tipo de interface encontra-se implementado no mesmo módulo (aspecto) do comportamento transversal, como pode ser visto na Figura 2.3. A interface de entrecorte consiste no conjunto de junção move() e nas especificações dos

\footnotetext{
${ }^{2}$ Meyer, B. Object-Oriented Software Construction. 2a edição. Prentice Hall, 1997.

${ }^{3}$ Mezini, M., Ostermann, K. Conquering Aspects with Caesar. Proceedings of the Aspect Oriented Software Development Conference (AOSD’03), pp, 90-99, 2003.
} 
pontos de junção. Essa interface de entrecorte está implementada no mesmo aspecto que possui o comportamento transversal que atua sobre ela.

Há propostas que fornecem diretrizes de como implementar interfaces de entrecorte em AspectJ separadamente do comportamento transversal que deve atuar sobre elas (Griswold et al., 2005). Consiste em uma forma de reorganizar o código, criando aspectos que encapsulam apenas os conjuntos de junção e outros aspectos que encapsulam apenas adendos que atuam naqueles naqueles conjuntos de junção.

\section{3 - FrameWORKS DE SOFTWARE ORIENTADOS A OBJETOS}

De acordo com Fayad et al. (1999), frameworks orientados a objetos são soluções de software que têm o objetivo de apoiar o desenvolvimento de aplicações em domínios específicos. $\mathrm{O}$ objetivo principal é a reutilização de projeto e código em um esforço para aumentar a velocidade do desenvolvimento e a qualidade das aplicações desenvolvidas.

A fase de uso e aprendizagem de um framework também é conhecida como fase de instanciação ou fase de desenvolvimento de aplicações (Fayad et al., 1999). Nela, um ou mais frameworks podem ser utilizados na construção de aplicações específicas. No fim do projeto de cada aplicação, novas classes podem ser acrescentadas para atender aos requisitos específicos da aplicação.

Fayad et al. (1999) também comentam que um ponto importante durante a construção de um framework é identificar as partes fixas (frozen spots) e variáveis (hot spots) de um domínio de aplicação. Diferentes aplicações em um mesmo domínio são distinguidas por uma ou mais partes variáveis. Elas representam as partes do framework que são específicas de sistemas individuais. As partes variáveis são projetadas para serem genéricas e podem ser adaptadas às necessidades da aplicação. Partes fixas definem a arquitetura geral de um sistema de software - seus componentes básicos e os relacionamentos entre eles. As partes fixas são usadas sem nenhuma modificação em todas as instanciações de um framework de aplicação.

Uma propriedade importante de um framework é a inversão de controle (Johnson, 1997). No reúso tradicional de componentes ou bibliotecas, desenvolve-se a aplicação específica com chamadas aos componentes que se deseja reutilizar. Assim, a responsabilidade pelas chamadas e pelo fluxo de controle do programa é do desenvolvedor de aplicações. Já em um framework, o programa principal é reusado, ficando a cargo do desenvolvedor de aplicações apenas a tarefa de concretizar alguns métodos abstratos que são chamados pelo código do framework, e não por ele. Essa inversão também é conhecida por principio de 
Hollywood - "não ligue para nós, nós ligaremos para você”. Assim, o framework determina o fluxo de controle do programa e sua estrutura geral.

Uma classificação que pode ser feita dos frameworks é quanto ao tipo de reúso. Eles podem ser: caixa branca (White box), caixa cinza (gray box) e caixa preta (black box) (Yassin \& Fayad, 2000). O comportamento específico de um framework de aplicação é geralmente definido adicionando-se métodos às subclasses de uma ou mais de suas classes. No framework caixa branca o reúso é provido por herança, ou seja, o usuário deve criar subclasses das classes abstratas contidas no framework para criar aplicações específicas. Para tal, ele deve entender detalhes de como o framework funciona para poder usá-lo. No framework caixa preta o reúso é por composição, ou seja, o usuário combina diversas classes concretas existentes no framework para obter a aplicação desejada. Assim, ele deve entender apenas a interface para poder usá-lo. Já no framework caixa cinza há uma mistura entre os frameworks caixa branca e caixa preta. Assim, o reúso é obtido por meio de herança, por ligação dinâmica e também pelas interfaces de definição.

Um framework caixa branca é mais fácil de projetar, pois não há necessidade de prever todas as alternativas de implementação possíveis, o que ocorre no framework caixa preta. No entanto, o framework caixa preta é mais fácil de usar, pois basta escolher a implementação desejada, ao invés de fornecer a implementação completa, como é o caso do caixa branca. Todos os FTs desenvolvidos no contexto desta tese são caixa-branca.

Fayad et al. (1999) comentam que o desenvolvimento de um framework é similar ao desenvolvimento da maioria de qualquer software reutilizável. Inicialmente é feita análise de domínio, seguida do projeto de um framework que implemente os exemplos coletados durante a análise de domínio. O framework é então utilizado para construir outras aplicações, as quais fornecerão indicações de seus pontos fracos. Ele é então modificado, melhorado e submetido a novas utilizações, num processo iterativo. As experiências na aplicação do framework, possivelmente a novos exemplos, servem de entrada para a próxima iteração do framework, que prossegue até que os desenvolvedores o considerem acabado e decidam por sua liberação.

Segundo Pree and Koshimies (2000), o termo "framework" não impõe limite máximo ao número de classes que um framework pode possuir. Dessa forma, eles podem variar de uma ou um conjunto simples de classes a conjuntos grandes de classes complexas. A tendência têm sido o desenvolvimento de grandes frameworks que encapsulam soluções genéricas para um determinado domínio de aplicação, como: sistemas de fabricação, bancos, sistemas de saúde e sistemas de controle de processo. Vários autores (Sparks, 1996 apud 
$(\text { Pree, 2000) })^{4},(\text { Bosch, } 1998 \text { apud (Pree, 2000) })^{5},(\text { Casais, } 1995 \text { apud (Pree, 2000) })^{6}$ discutem alguns problemas associados a frameworks complexos. Segundo esses autores, os seguintes problemas ocorrem com grandes frameworks:

- O projeto de um framework é difícil. Em consequiência da complexidade e tamanho dos frameworks de aplicação, e da dificuldade de compreensão do processo de projeto, frameworks são geralmente projetados iterativamente, exigindo reestruturação substancial de inúmeras classes e ciclos de desenvolvimento;

- O processo de reúso é difícil. Convencionalmente, um framework consiste em um conjunto de classes básicas de um domínio de aplicação. Assim, o responsável pelo reúso deve compreender a arquitetura básica de um tipo de aplicação particular para ser capaz de especializar o framework;

- A combinação de frameworks é difícil. Freqüientemente um framework assume o controle da aplicação. Combinar dois ou mais frameworks que fazem isso, sem quebrar a integridade deles é muito difícil.

- A presença de classes desnecessárias nas aplicações instanciadas. Em geral, as aplicações instanciadas de um framework levam consigo todas as classes do framework, independentemente se todas elas são usadas ou não.

Pree e Koshimies (2000) sugerem que a razão desses problemas é a idéia de que um framework é um esqueleto de uma aplicação complexa. Conseqüentemente, um framework se torna uma grande coleção de classes altamente acopladas que dificulta a modularização e dificulta a integração com frameworks similares. Muitos autores comentam que a solução para isso é criar versões caixa-preta dos frameworks, que são especializados por composição e não por herança. Embora isso facilite o reúso do framework, restringe sua adaptabilidade e os problemas de projeto e combinação de frameworks podem permanecer.

Para Pree e Koshimies (2000) a solução é o desenvolvimento de framelets, que são frameworks pequenos, com menos de dez classes, que não assumem o controle da aplicação e têm uma interface claramente definida. Assim como qualquer framework, um framelet pode ser especializado por meio de herança e composição. Pree defende a idéia de que uma família de framelets relacionados de um determinado domínio é uma alternativa ao uso de um grande

\footnotetext{
${ }^{4}$ Sparks S, Benner K, Faris C. Managing Object-Oriented Framework Reuse. Computer. 1996; Vol. 29, No. 9.

${ }^{5}$ Bosch, J, Mattsson, M., and Fayad, M. Framework Problems, Causes, and Solutions, CACM, 1998.

${ }^{6}$ Casais E. An Experiment in Framework Development. Theory and Practice of Object Systems 1, 4, 269-280, 1995.
} 
e complexo framework. Quando um framelet é utilizado em uma aplicação, o fluxo de controle principal é da aplicação, mas quando o fluxo atinge os pontos em que o framelet está sendo utilizado, o fluxo de controle passa a ser deles, isto é, eles também possuem o princípio de Hollywood, propriedade dos frameworks caixa branca.

Um exemplo de um framelet apresentado por Pree e Koshimies (2000) é uma caixa de listagem (list box) que pode ser usada durante a construção de interfaces gráficas. Essa caixa de listagem, ao contrário da maioria dos frameworks gráficos existentes, já possui implementadas as iterações entre os botões para se adicionar, remover e alterar dados.

Em uma linha de pesquisa parecida com a dos framelets, alguns frameworks um pouco maiores foram criados com o objetivo de encapsular um determinado interesse. Exemplos de frameworks orientados a objetos (FOOs) de persistência que se enquadram nessa categoria são: Hibernate (2006), Cayenne (2006) e OJB (2006).

Outros autores que compartilham a idéia de Pree e Koshimies (2000) em substituir grandes frameworks por um conjunto de componentes menores que podem ser combinados são Batory et al. (2000). Porém, para esses autores, a melhor alternativa é a utilização de linhas de produtos (Parnas, 1976 apud (Batory et al., 2000)) ${ }^{7}$ ao invés de grandes frameworks.

\subsection{1 - Modelagem de Frameworks com o Perfil UML-F}

UML-F é um perfil UML criado para a modelagem de frameworks orientados a objetos (Fontoura et al., 2002). Ele contém elementos notacionais que descrevem a semântica fundamental de conceitos clássicos em frameworks OO. Na UML-F, tanto os estereótipos quanto as etiquetas valoradas da UML foram agrupados em um único elemento chamado de “etiqueta UML-F”. A representação dessa etiqueta é a mesma de um estereótipo clássico da UML, entretanto pode possuir um valor, assim como as etiquetas valoradas. Essas etiquetas são divididas em quatro categorias. A Tabela 2.1 mostra algumas das etiquetas propostas dentro de cada uma de suas categorias.

A categoria "Etiquetas de Modelagem de Framework" possui etiquetas que visam a auxiliar a documentação do framework, principalmente para o desenvolvedor de aplicação. Essas etiquetas permitem identificar quais classes são do framework e quais são da aplicação, quais classes e métodos são fixos e quais podem ser adaptados. A categoria "Etiquetas para Princípios Essenciais de Construção de Frameworks OO” possui etiquetas que representam dois papéis impostos pela utilização do padrão de projeto Método Gabarito (Template Method): os métodos gabarito e os métodos gancho (hook method).

\footnotetext{
${ }^{7}$ PARNAS, D.L. On The Design and Development of Program Families. IEEE Transactions on Software Engineering, March, 1976.
} 
Tabela 2.1 - Etiquetas da UML-F

\begin{tabular}{|c|c|c|}
\hline \multicolumn{3}{|c|}{ 1-Etiquetas de Modelagem de Framework } \\
\hline Etiqueta & \multicolumn{2}{|c|}{ Descrição } \\
\hline$<<$ application>> & \multicolumn{2}{|c|}{ O elemento pertence à aplicação e não ao framework } \\
\hline$<<$ utility $>>$ & \multicolumn{2}{|c|}{ O elemento pertence a uma classe de biblioteca. } \\
\hline$<<$ fixed $>>$ & \multicolumn{2}{|c|}{ O elemento é fixo, isto é, nenhuma alteração pode ser feita nele. } \\
\hline$<<$ adapt-static >> & \multicolumn{2}{|c|}{$\begin{array}{l}\text { O elemento deve ser modificado durante o projeto, mas durante a execução ele é fixo. } \\
\text { Geralmente essa adaptação consiste em especializar o elemento. }\end{array}$} \\
\hline$<<$ adapt-dyn>> & \multicolumn{2}{|c|}{ O elemento pode ser modificado em tempo de execução. } \\
\hline \multicolumn{3}{|c|}{ 2-Etiquetas para Princípios Essenciais de Construção de Frameworks OO } \\
\hline Etiqueta & \multicolumn{2}{|c|}{ Descrição } \\
\hline$<<$ template $>>$ & \multicolumn{2}{|c|}{ O método é um método gabarito ou a classe possui um método gabarito. } \\
\hline$<<$ hook $>>$ & \multicolumn{2}{|c|}{ A existência desta etiqueta denota que o método é um método gancho (hook) } \\
\hline \multicolumn{2}{|c|}{$<<$ PatternName-InterfaceName $>>$} & O mesmo que acima, mas para interfaces. \\
\hline \multicolumn{2}{|c|}{$<<$ PatternName-methodName $>>$} & O mesmo que acima, mas para métodos. \\
\hline \multicolumn{2}{|c|}{$<<$ PatternName-associationLabel $>>$} & O mesmo que acima, mas para rótulos de relacionamentos. \\
\hline \multicolumn{2}{|c|}{$<<$ PatternName-attributeName $>>$} & O mesmo que acima, mas para atributos. \\
\hline
\end{tabular}

A categoria "Etiquetas para Padrões Utilizados em Frameworks" agrupa etiquetas que visam a demonstrar os padrões de projeto utilizados na estrutura do framework. Elas devem ser utilizadas para demonstrar os papéis do padrão que são assumidos pelas classes, atributos ou métodos do framework.

Um ponto importante a ser notado é que Fontoura (2002) conseguiu agrupar em algumas etiquetas os conceitos básicos de frameworks orientados a objetos. O conceito mais importante relacionado à construção e instanciação de um framework é identificar os pontos fixos (frozen spots) e os pontos variáveis (hot spots) de um domínio de aplicação e as etiquetas UML-F são destinadas a esse fim.

\subsection{2 - Linhas de Produtos e Frameworks Orientados a Objetos}

Uma linha de produtos é uma forma de se construir software rapidamente compondo características $^{8}$ (features) de um domínio específico (Weiss e Lai, 1999; Gomma, 2004). Características são abstrações de projeto e código que representam requisitos ou variabilidades de um domínio. Podem ser opcionais, alternativas ou obrigatórias e podem ser acopladas em uma base, ou mesmo em outras características para a construção de aplicações de um determinado domínio. Há várias abordagens que empregam o uso de características como incrementos ou refinamentos sobre outra característica ou programa existente. Algumas

\footnotetext{
${ }^{8}$ A palavra "característica" não está sendo utilizada no texto com seu significado convencional da Língua Portuguesa.
} 
dessas abordagens são: GenVoca (Batory e Malley, 1992 apud (Mezini e Ostermann, 2004)) ${ }^{9}$, mixin-layers (Smaragdakis e Batory, 1998 apud (Mezini e Ostermann, 2004)) ${ }^{10}$, delegation layers (Ostermann, 2002 apud (Mezini e Ostermann, 2004)) ${ }^{11}$ e AHEAD (Batory et al., 2003 apud (Mezini e Ostermann, 2004) ${ }^{12}$.O objetivo dessa nova linha de pesquisa é implementar características que envolvem interesses transversais com aspectos para facilitar o acoplamento e desacoplamento dessas características.

Frameworks são ferramentas que podem ser usadas para a implementação de linhas de produtos (Batory et al., 2000), pois cada aplicação instanciada do framework pode ser caracterizada com um membro da linha com características distintas. Entretanto, algumas pesquisas mostram que a utilização de grandes frameworks em linhas de produtos gera problemas de duplicação de código nos membros da linha e outros problemas relacionados (Batory et al., 2000). Para solucionar os problemas Batory et al. (2000) propuseram uma metodologia de projeto, chamada GenVoca, que consiste em dividir a arquitetura do framework, e também de suas aplicações, em camadas (mixin-layers), em que cada camada consiste em um conjunto de classes que colaboram entre si. Essas camadas são blocos de construção para o desenvolvimento de aplicações e representam as características disponíveis do domínio. Dessa forma, as entidades principais (first class entites) na programação orientada a características são as características - um nível de abstração mais alto do que classes. Cada camada realiza refinamentos na camada anterior adicionando métodos e atributos. Assim, aplicações complexas podem ser desenvolvidas como uma composição de poucos refinamentos, ao invés de centenas de milhares de refinamentos.

Um ponto importante do trabalho de Batory et al. (2006) é a idéia de que a estrutura do framework também pode ser decomposta em características. Isso é interessante porque tradicionalmente, quando uma aplicação é instanciada de um framework, ela contém em sua arquitetura todas as classes do framework, inclusive aquelas que não foram escolhidas como variabilidades da aplicação - um problema conhecido como overfeaturing (Codenie et al., 1997 apud (Batory et al., 2000)1 $)^{13}$. Quando um framework é utilizado de forma tradicional para a geração de vários membros da linha de produtos, haverá muita repetição de classes sem

\footnotetext{
${ }^{9}$ BATORY, D., MALLEY, S. The Design and Implementation of Hierarchical Software Systems with Reusable Componentes. ACM Transactions on Software Engineering and Methodology, 1(4):355-398, 1992.

${ }^{10}$ SMARAGDAKIS, Y., BATORY, D. Implementing Layered Designs With Mixin-Layers. In Proceedings of ECOOP'98, LNCS 1445, pages 550-570, 1998.

11 OSTERMANN, K. Dynamically Composable Collaborations with Delegation Layers. In: Proceedings of ECOOP'02. LNCS 2374, pages 89-110. Springer, 2002.

12 BATORY, D., SARVELA, J.N., RAUSCHMAYER, A. Scaling step-wise refinement. In: Proceedings of International Conference on Software Engineering (ICSE'03), 2003.

${ }^{13}$ CODENIE, W., HONDT, K., STEYAERT, P., VERCAMMEN, A. From Custom Applications to DomainSpecific Frameworks. Communications of the ACM, 40(10), October, 1997.
} 
utilização em todos os membros. Como a estratégia apresentada pelo autor permite a montagem também do framework, as variabilidades que não serão necessárias na aplicação não são escolhidas nessa primeira etapa.

A programação orientada a características é atualmente reconhecida como melhor do que a tecnologia de frameworks porque trabalha com camadas que possuem duas vantagens importantes (Mezini e Ostermann, 2004). A primeira é que cada camada encapsula várias abstrações referentes a uma determinada característica do domínio em uma unidade modular única, que do contrário estariam espalhadas por vários módulos do sistema. FeatureC++ (FeatureC++ WebSite, 2006), por exemplo, é uma extensão da linguagem C++ que pode ser usada para a definição e refinamento de características. A segunda vantagem é que essas camadas possuem abstrações definidas em termos de abstrações de uma parte base, o que permite que essas camadas possam ser conectadas umas nas outras sem necessidade de programação extra, como ocorre durante a instanciação dos frameworks convencionais.

\section{4 - FRAMEWORKS NO CONTEXTO DA POA}

Depois do surgimento da POA e da disseminação da linguagem AspectJ (Kiczales et al., 2001), várias pesquisas começaram a ser conduzidas nas mais variadas linhas de pesquisa. Uma dessas linhas concentra-se no reúso de interesses transversais durante o desenvolvimento de uma nova aplicação. Assim, pesquisadores investigam como que a POA pode ser utilizada para implementar interesses transversais de forma genérica. Apesar da similaridade entre os trabalhos encontrados nessa linha de pesquisa, não há um consenso sobre o termo utilizado para designar esse tipo de implementação. A seguir são mostrados os principais trabalhos encontrados na literatura e o termo original utilizado por cada um dos autores.

O primeiro autor a propor um "framework orientado a aspectos" foi Constantinides (Constantinides et al., 2000). Seu framework encapsula o interesse transversal de concorrência e não é implementado com uma linguagem orientada a aspectos. No ano seguinte, Vanhaute et al. (2001) apresentaram um "framework de aspectos" de segurança e também algumas diretrizes, ainda bastante preliminares, de como construir frameworks utilizando a linguagem AspectJ. Depois disso vários outros frameworks foram desenvolvidos. Pode-se encontrar propostas de frameworks para o interesse persistência (Rashid and Chitchyan, 2003; Couto et al., 2005; Camargo et al., 2003; Soares et al., 2002; Rausch et al., 2003), segurança (Chen e Huang, 2005; Zubairov et al., 2005), distribuição (Soares et al., 2002; concorrência (Soares, 2004), criptografia (Zhang et al., 2004) e de alguns outros interesses (Mortensen e Ghosh, 2006a; Mortensen e Ghosh, 2006b). O objetivo dessa linha de 
pesquisa é permitir que a implementação e o projeto do interesse transversal possa ser reusado durante o desenvolvimento de uma nova aplicação.

Embora também tenham surgido pesquisas utilizando aspectos em frameworks de aplicação orientados a objetos (Pinto et al., 2001a; Pinto et al., 2001b; Pinto et al., 2002; Hanenberg et al., 2004), a maior parte se concentrou em frameworks de um único interesse. É possível também encontrar atualmente propostas que visam a facilitar o processo de reúso de frameworks desse tipo (Mendonça et al., 2005).

\subsection{1 -Frameworks de Persistência no Contexto da POA}

Um framework de persistência baseado em aspectos foi desenvolvido por Rashid e Chitchyan (2003). O objetivo dos autores foi averiguar se o interesse de persistência pode ser acoplado apenas no final do desenvolvimento de uma aplicação, sem que essa aplicação seja desenvolvida com consciência da persistência. Os autores concluíram que o armazenamento e a atualização de dados podem ser completamente aspectualizados, isto é, podem ser adicionados depois que a aplicação está pronta, mas o mesmo não ocorre com a remoção e com as operações de consulta. Isso acontece porque o armazenamento e a atualização possuem pontos de junção explícitos no código-fonte que podem ser associados a essas operações de persistência. Por exemplo, pode-se definir a estratégia que quando a instância de um objeto é criada, o aspecto entrecorta a execução do construtor e armazena esse objeto em um banco de dados. Da mesma forma, a atualização de dados pode ocorrer sempre que algum método set* ( ) é chamado para algum dos objetos da aplicação.

Entretanto, a remoção de objetos de um banco de dados não pode ser associada com algum ponto de junção. Não é possível, por exemplo, entrecortar a execução do mecanismo de coleta de lixo do Java quando ele retira um objeto da memória. E mesmo se isso fosse possível, nada garante que aquele objeto deveria se eliminado do banco de dados naquele momento. O mesmo ocorre para as consultas - deve haver chamadas explícitas a operações de banco de dados quando, de acordo com o algoritmo da aplicação, é necessário realizar algum tipo de consulta.

Portanto, a persistência não pode ser completamente negligenciada durante o desenvolvimento de uma aplicação e acoplada apenas no final do desenvolvimento. $\mathrm{O}$ engenheiro de software precisa estar ciente dos locais do código em que a aplicação precisa remover e consultar dados.

No framework de persistência apresentado por Rashid e Chitchyan (2003) não houve preocupação em generalizar certos pontos do código dos adendos, dificultando o reúso. $\mathrm{O}$ objetivo principal do estudo realizado por eles não foi criar um framework que pudesse ser 
reusado em diversas aplicações, apesar de utilizarem o termo "framework". Os autores também não implementam sub-interesses, como, por exemplo, memória auxiliar (caching) e repositório de conexões (pooling) como aspectos, o que pode auxiliar na modularização.

Um outro trabalho que envolve a criação de aspectos genéricos foi feito por Soares (Soares, 2004; Soares et al., 2002). Esse autor desenvolveu três frameworks de aspectos, um de persistência, um de distribuição e um de concorrência. Os três frameworks foram obtidos reimplementando-se com POA os interesses de persistência, distribuição e concorrência de um sistema orientado a objetos chamado Health Watcher.

Um ponto interessante desse trabalho (Soares, 2004) é a possibilidade de utilizar uma estratégia de gerenciamento de dados não persistentes enquanto a aplicação é desenvolvida. Assim, quando testes precisam ser feitos, pode-se utilizar essa estratégia de armazenamento de dados em memória volátil. No final do desenvolvimento, pode-se substituir a estratégia volátil pela persistente. Outro ponto importante da abordagem de Soares (2004) é o apoio automatizado que foi criado para o acoplamento automático dos frameworks com o códigobase. $\mathrm{O}$ autor desenvolveu um plug-in para o ambiente Eclipse que facilita o acoplamento dos frameworks com o código-base. $\quad$ O framework de Soares (2004) inclui aspectos, classes auxiliares e interfaces que cuidam dos seguintes interesses: conexão com o banco de dados, controle de transações, carregamento de objetos, caching e sincronização do estado de objetos com entidades do banco de dados.

Uma limitação do trabalho de Soares (2004) é que o framework só pode ser utilizado em aplicações que tiverem a mesma arquitetura do sistema Health Watcher, o que limita as possibilidades de reúso do framework. Além disso, não há utilização de algum mecanismo para a geração automática de código SQL, o que faz com que declarações SQL tenham que ser implementadas de forma fixa no frameowork.

Couto et al. (2005) também apresentam um framework orientado por aspectos de persistência que foi dividido nos sub-interesses controle de conexões, controle de transações e controle de sincronização de objetos. O ponto forte do trabalho dos autores é o apoio automatizado para realizar o acoplamento do framework com uma aplicação. Entretanto, a estratégia utilizada para a geração dos aspectos faz com que um aspecto seja criado para cada classe de aplicação persistente. Dependendo do tamanho da aplicação pode haver uma proliferação de aspectos, o que pode dificultar operações de manutenção.

Outra desvantagem do framework proposto por Couto é o fato de não disponibilizar recursos para a recuperação automática de dados do banco. $\mathrm{O}$ arcabouço não constrói nenhuma consulta SQL para que a recuperação de dados possa ser feita. Assim, cabe ao 
programador implementar tais consultas. Além disso, o framework não foi desenvolvido segundo algum padrão de projeto, como, por exemplo, o Camada de Persistência (Yoder et al., 1998).

\subsection{2 - Frameworks de Segurança no Contexto da POA}

Um framework orientado a aspectos que trata apenas do requisito não-funcional segurança é proposto por Vanhaute et al. (2001). O autor comenta que o sub-interesse de controle de acesso, que faz parte do interesse de segurança, possui os mesmos requisitos para a maioria das aplicações, porém, possui algumas políticas específicas da aplicação, como por exemplo, o usuário que acessou o sistema e os recursos disponíveis. Três conceitos são importantes em um sistema de controle de acesso: a entidade a ser autenticada, os recursos que serão disponibilizados e o ponto de acesso entre a entidade e os recursos.

Na Figura 2.6 é apresentada a parte do controle de acesso do framework de segurança.

Utilizam-se três aspectos abstratos: Authorization, Authentication e Identification. As setas tracejadas indicam os conjuntos de junção abstratos que devem ser implementados por aspectos concretos para indicar os pontos de junção do código-base que devem ser entrecortados.

A estrutura do framework é apresentada na Figura 2.7. O Núcleo do Framework contém aspectos abstratos, como aqueles mostrados na Figura 2.6, e a parte Políticas consiste em conjuntos de junção abstratos. Para cada mecanismo abstrato há várias implementações concretas disponíveis. Para usar o framework, o desenvolvedor deve definir uma política concreta de acordo com as necessidades da aplicação.

O maior problema encontrado pelos autores durante o desenvolvimento do framework foram as definições dos conjuntos de junção. Como essas definições são estáticas, só podem ser referenciadas e estendidas estaticamente. Essa restrição impossibilita isolar uma definição de conjunto de junção abstrata em um construtor separado e confiar na delegação para selecionar a versão concreta. Os autores sugerem que uma forma de resolver este problema seria fornecer um processo de composição mais aberto, em que as definições dos conjuntos de junção pudessem ser resultado de uma avaliação funcional da estrutura da aplicação. $\mathrm{O}$ framework apresentado pelos autores é interessante, porém poucos detalhes são fornecidos que permitem uma análise mais profunda da sua arquitetura.

Zhang et al., (2004) apresentam uma biblioteca de aspectos genéricos de segurança implementada em AspectJ, chamada JSAL (Java Security Aspect Library), que consiste em quatro interesses: Autenticação, Autorização (também conhecido como Controle de Acesso), Criptografia e Auditoria. Segundo os autores os interesses são independentes e podem ser 
utilizados em uma aplicação sem a presença dos outros. Além disso, eles também são genéricos e podem ser adicionalmente especializados. Por exemplo, o aspecto genérico de criptografia pode ser refinado em aspectos especializados de algoritmos de criptografia.

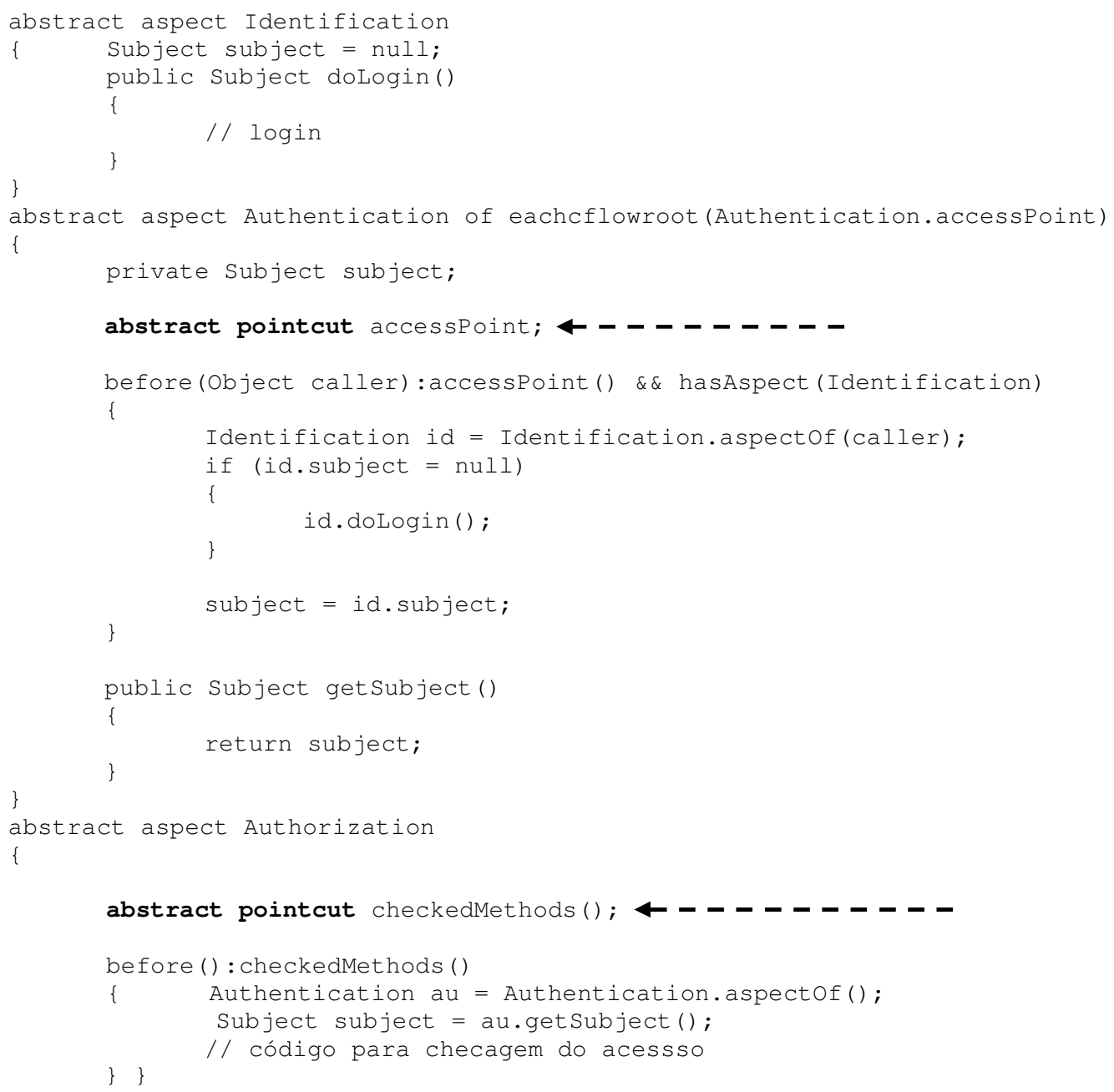

Figura 2.6 - Framework de Segurança Orientado a Aspectos (Vanhaute et al., 2001)

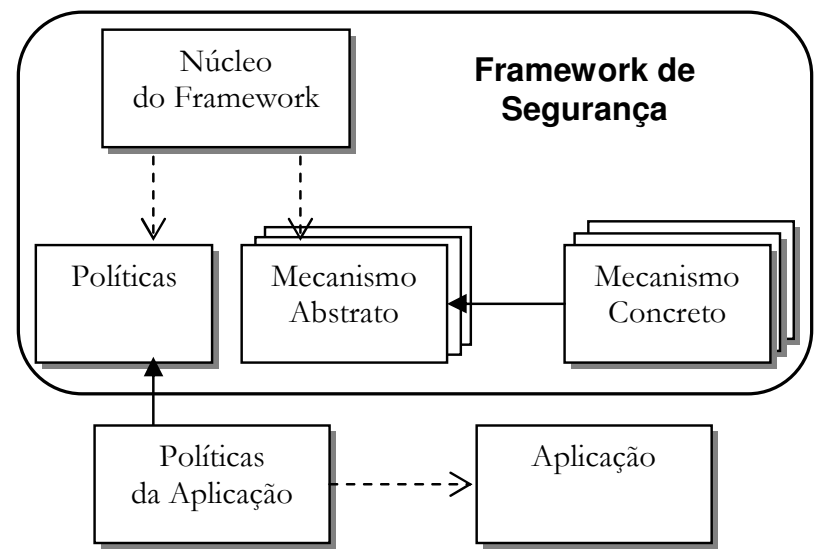

Figura 2.7 - Estrutura do Framework (Vanhaute et al., 2001) 
Na Figura 2.8 é mostrado o aspecto genérico de criptografia pertencente à biblioteca JASL. Há dois conjuntos de junção abstratos que devem ser concretizados pelo engenheiro de aplicação. O primeiro deve ser concretizado informando métodos do código-base que possuem como parâmetro uma String que deve ser criptografada, e o segundo deve ser um método cujo parâmetro é uma String que deve ser descriptografada.

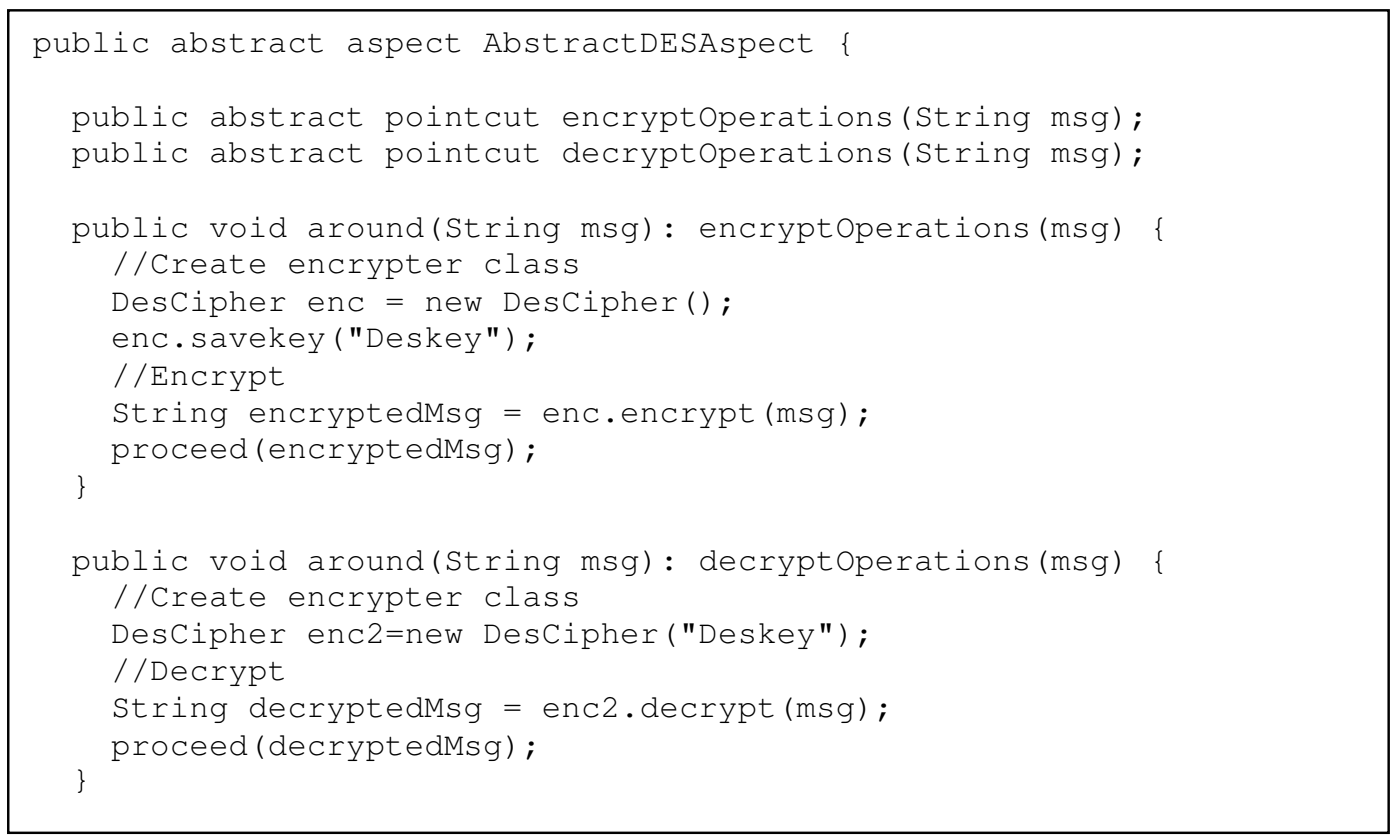

\section{Figura 2.8 - Aspecto Genérico de Criptografia da Biblioteca JASL}

A biblioteca JASL é interessante porque agrupa sub-interesses de apenas um interesse maior, no caso, segurança. A evolução dessa biblioteca pode auxiliar bastante o desenvolvimento de aplicações que necessitam de segurança. Entretanto, algumas limitações podem ser percebidas na implementação mostrada pelos autores. Os conjuntos de junção abstratos possuem parâmetros do tipo String. Isso obriga o engenheiro de software a encontrar no código-base um ponto de junção que seja a chamada ou a execução de um método cujo único parâmetro seja uma String e que esse parâmetro seja o dado que deve ser criptografado. Essa estratégia de implementação limita a reusabilidade da biblioteca, pois não se pode garantir que o código-base sempre terá um ponto de junção nesse formato.

Em sua tese de doutorado, De Win $^{14}$ (De Win, 2004 apud (Zubairov et al., 2005)) procurou estudar o problema da modularização do interesse de segurança para aplicações. A

${ }^{14}$ De Win, B. Engineering Application-Level Security through Aspect-Oriented Software Development. Ph.D. Thesis, Departamento de Ciência da Computação, K.U, Leuven, Bélgica, Março, 2004. 
discussão é conduzida com o objetivo de identificar como as técnicas orientadas a aspectos podem otimizar a modularização de requisitos de segurança no nível de aplicações. A tese contém discussões sobre abordagens de interceptação (interceptors) e abordagens de composição para se modularizar a segurança em um servidor de FTP e uma aplicação de gerenciamento de informação pessoal. Esse autor conclui que o interesse de segurança é altamente transversal.

Zubairov cita que as conclusões de De Win(2004) não podem ser generalizadas porque há muita dependência com a arquitetura das aplicações utilizadas (Zubairov, et al., 2005). A arquitetura do sistema utilizado no estudo de caso conduzido por Zubairov é diferente da arquitetura dos sistemas desenvolvidos por De Win, e isso faz com que algumas conclusões não possam ser generalizadas para o interesse de segurança, de forma geral.

Chen e Huang (2005) realizaram a implementação dos interesses de autenticação e controle de acesso em AspectJ com o objetivo de torná-los reusáveis para aplicações Web baseadas no padrão MVC e no frameworks struts. Os autores comentam que há vários níveis de controle de acesso: nível de classes, nível de funções (métodos) e nível de atributos. No nível de atributos, em que a granularidade é a mais fina de todas, pode-se determinar quais atributos de uma classe podem ou não ser acessados por determinados usuários. Eles não utilizam a API Java JAAS porque a utilização dessa biblioteca faz com que várias chamadas sejam colocadas em vários locais do código, causando espalhamento e entrelaçamento de código de diferentes interesses. Além disso, JAAS fornece um controle de acesso muito simples para funções. Na Figura 2.9 é mostrado o aspecto de Autenticação apresentado pelos autores. Este aspecto tem o objetivo de verificar se o usuário passou pela checagem de identidade ou deve ser redirecionado para uma página de autenticação.

Um ponto que merece destaque na implementação de Chen e Huang (2005) é que o conjunto de junção abstrato pc () é definido com parâmetros. Quando isso ocorre, o adendo que atua sobre ele também deve ser definido com parâmetros. Isso prejudica a reusabilidade do aspecto, pois nada garante que o código-base possuirá um ponto de junção com parâmetros. Uma outra forma de capturar os parâmetros do contexto de execução deveria ser fornecida.

No aspecto de controle de acesso, que pode ser visto na Figura 2.10, o conjunto de junção pc () também é implementado com parâmetros, prejudicando o reúso. Além disso, a implementação do método constraint(), que é responsável por definir uma restrição de acesso, é deixado para o aspecto concreto. Embora isso deixe o código bastante flexível, dificulta um pouco o processo de reúso do framework. 
Mortensen e Ghosh (2006a) (2006b) têm como objetivo desenvolver uma biblioteca de aspectos em AspectC++ que sejam reusáveis. O processo utilizado pelos autores para a criação da biblioteca é a refatoração (refactoring) dos interesses transversais de algumas aplicações. O domínio de aplicação que os autores trabalham é de projeto de chips VLSI. Eles possuem algumas aplicações que utilizam o framework orientado a objetos VLSI CAD, um framework desenvolvido por laboratórios da Hewlett Packard. Até o presente momento, os autores identificaram quatro interesses transversais que foram implementados como aspectos genéricos e adicionados na biblioteca de aspectos. Os interesses implementados como aspectos foram: Depuração de Programas (Debug), temporizador, garantia de políticas e memória auxiliar.

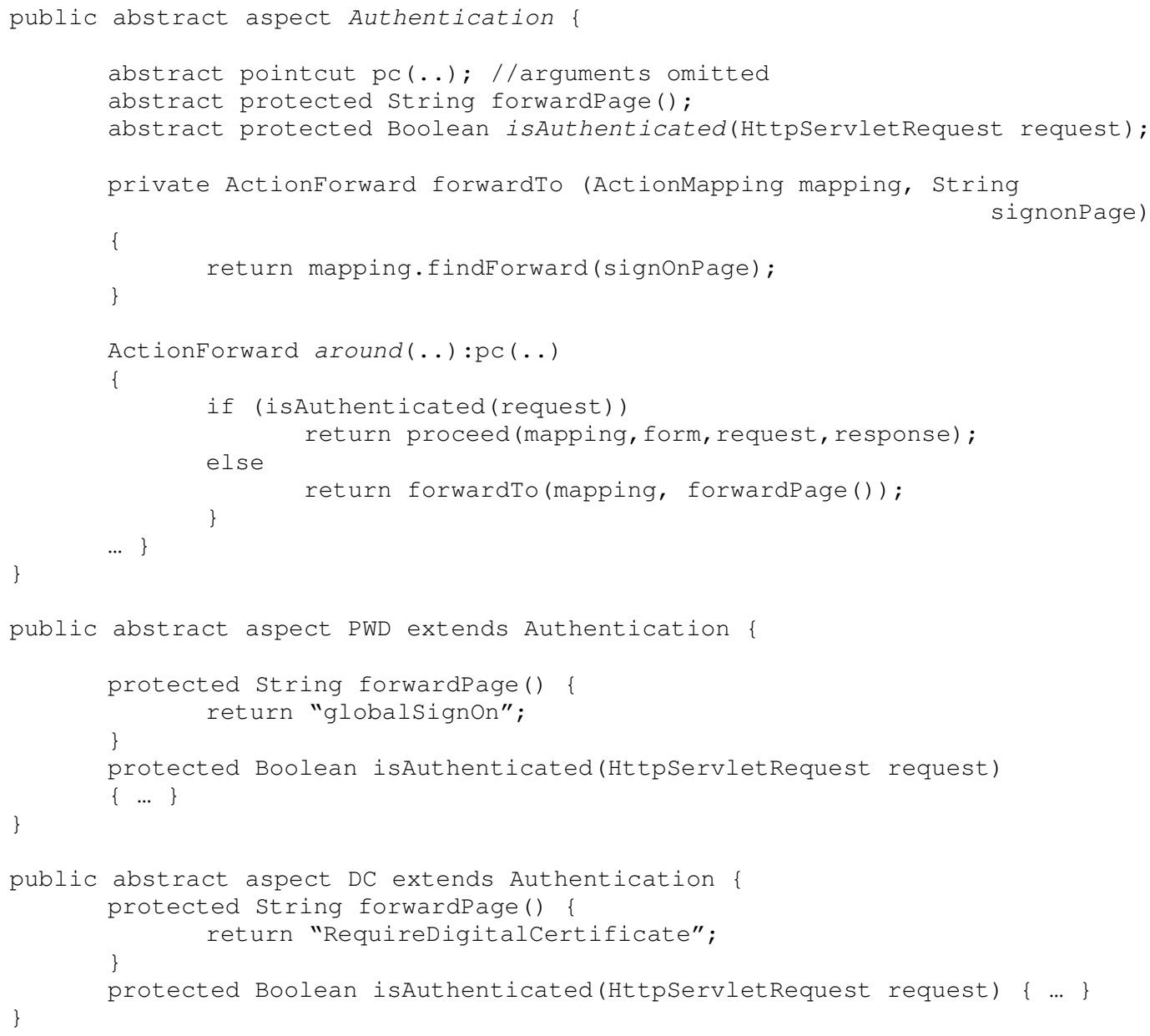

Figura 2.9 - Aspecto de Autenticação

\subsection{3 - Frameworks de Aplicação no Contexto da POA}

Pinto e outros (2001a; 2001b, 2002) apresentam um framework de aplicação orientado a aspectos, totalmente desenvolvido em Java, para o desenvolvimento de ambientes virtuais de colaboração (AVC). Segundo os autores a utilização da POA facilita a configuração, a 
extensão, a evolução e a adaptação desses softwares, bem como das aplicações instanciadas. O desenvolvimento desse framework teve como base a análise de vários AVCs, e identificouse que os componentes: usuário, sala, documento e ferramenta, e os aspectos: persistência, autenticação e visões múltiplas estão sempre presentes nesse tipo de software.

Em consequiência da grande diversidade e da grande quantidade de comportamentos diferentes, os aspectos são classificados em tipos dentro do framework: orientado ao ambiente, orientado ao usuário, orientado ao tipo ou orientado ao componente. Além dessa categorização, o aspecto pode ainda ser um aspecto de entrada ou de saída. Os de entrada realizam ações antes da execução de um determinado método, enquanto que o de saída após a execução do método. Além dessa classificação dos aspectos, os componentes também foram classificados nos tipos mais recorrentes em ambientes virtuais de colaboração: Usuário, Documento e Sala.

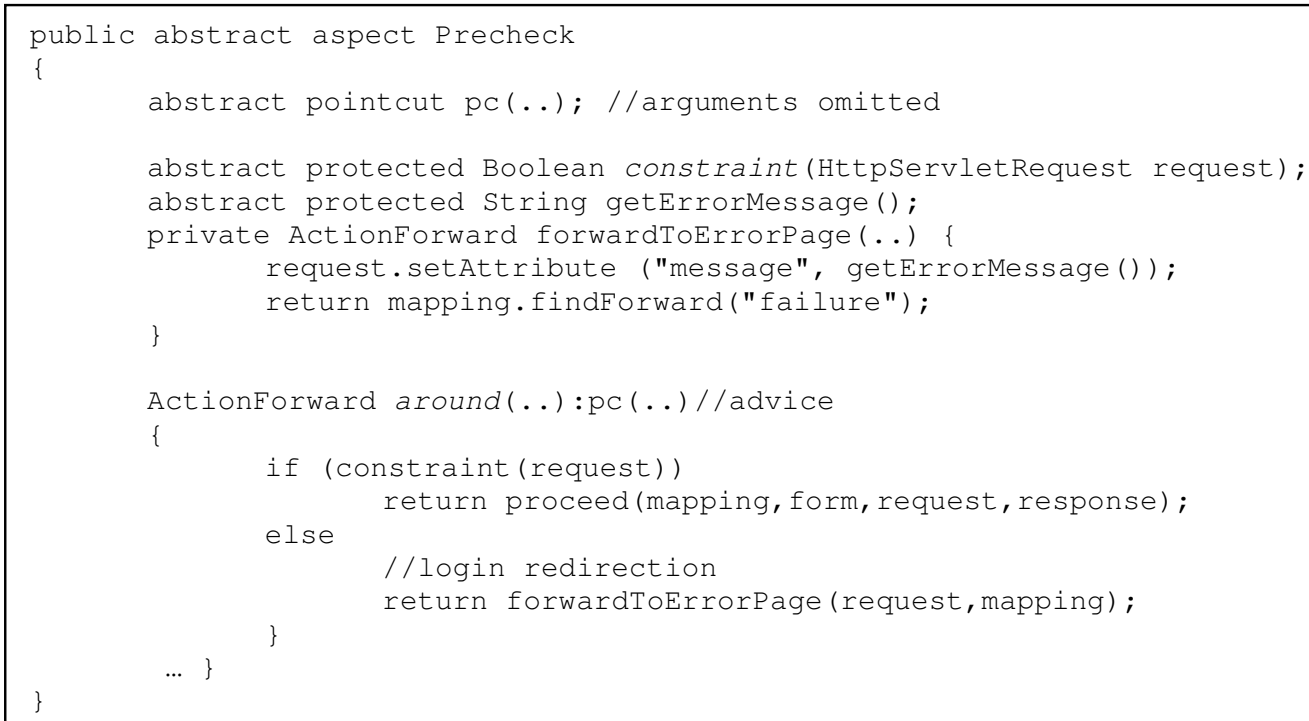

Figura 2.10 - Aspecto de Controle de Acesso

Para realizar uma instanciação com componentes e aspectos específicos de uma aplicação, o usuário deve fornecer informações sobre os tipos dos aspectos específicos, sobre o tipo dos componentes específicos e também sobre o mecanismo de composição entre eles. Esse último tipo de informação controla quais tipos de aspectos devem interceptar as mensagens que são enviadas ou recebidas por um certo componente. Todas essas informações são armazenadas em uma camada intermediária que mantém registrados tanto os componentes quanto os aspectos que afetam o comportamento desses componentes. O processo de registro dos componentes, aspectos e as informações de composição é apoiado por uma linguagem especial. 
Hanenberg et al. (2004) desenvolveram um framework de aplicação orientado a aspectos de estratégias de caminhamento (traversal strategies). A linguagem orientada a aspectos utilizada no desenvolvimento do framework foi AspectS. Cada um dos requisitos do framework (algoritmos de caminhamento, políticas de comportamento, tratamento de nós adjacentes e política de ciclos) foi modelado separadamente em uma hierarquia de classes. A classe principal é chamada Traversal e possui métodos-gancho (hook methods) que permitem que o desenvolvedor da aplicação escolha as variabilidades (requisitos) desejadas.

Segundo os autores, a inadequabilidade do mecanismo de composição OO fica evidente quando essas hierarquias precisam ser combinadas para o fornecimento dos ganchos. Em conseqüência da independência dos requisitos, utilizar herança para realizar o acoplamento causa um aumento de classes com códigos redundantes.

Eles citam que do ponto de vista do desenvolvimento de frameworks, o que é interessante da orientação a aspectos é que o sistema-base naturalmente já possui um conjunto de ganchos - que são os pontos de junção - e que podem ser adaptados por aspectos, e conseqüêntemente pelo desenvolvedor da aplicação. Eles também comentam que esses ganchos são implicitamente contidos e que não há necessidade de projetá-los com mecanismos adicionais. Os autores consideram a existência de ganchos explícitos, representados por estruturas de projeto complexas, como uma desvantagem dos frameworks orientados a objetos. Contudo, isso não implica que frameworks não necessitem de ganchos explícitos.

\subsection{4 - Modelagem de Aspectos}

A abordagem Tema é um método de desenvolvimento de software orientado a aspectos cujo objetivo principal é trabalhar com interesses desde a fase de análise até a fase de composição. Os interesses são modelados como "temas", os quais podem ser do tipo base ou transversal. Os temas-base agrupam as principais funcionalidades do domínio do problema, enquanto que os transversais encapsulam interesses que afetam os temas-base. Vários artefatos de projeto podem existir dentro de um tema, como, por exemplo: diagramas de classe, de seqüência, de colaboração e de estado. A representação gráfica de um tema é um pacote (package) da UML.

Os temas podem se relacionar de duas formas: compartilhando conceitos ou entrecortando-se. O primeiro caso se dá quando o mesmo elemento de projeto aparece em mais de um tema. Neste caso os temas devem ser compostos por relacionamentos de intercalação (merge) ou sobreposição (override), por exemplo, se uma mesma classe aClass aparece em mais de um tema, porém com atributos e métodos diferentes em cada um deles, a composição desses temas resultará em um tema que possui apenas uma classe aClass com 
todos os atributos e métodos oriundos dos temas que estão sendo compostos. Se um mesmo atributo/método existir em ambas as classes de ambos os temas, apenas um será colocado no tema resultante.

Quando um tema encapsula um interesse transversal, sua composição com outros temas se dá por meio de um relacionamento de ligação (bind). Esse tipo de relacionamento indica que o comportamento do tema transversal é disparado quando algum evento ocorre no tema-base, como uma chamada de método. Dessa forma, o comportamento do tema-base é afetado pelo comportamento do tema transversal.

A fase de projeto da abordagem Tema, chamada de Theme/UML, utiliza uma extensão dos gabaritos da UML para projetar os interesses transversais. Assim, pode-se projetar o comportamento transversal independentemente da existência de um código-base, isto é, sem considerar os pontos reais do código-base que serão afetados. Isso torna os gabaritos da abordagem Tema adequados para o projeto de aspectos abstratos, e conseqüentemente, de frameworks orientados a aspectos (Camargo e Masiero, 2005b). Além disso, como diagramas de seqüência são usados dentro dos temas, também é possível modelar a dinâmica de como o interesse transversal afeta o interesse-base.

Na Figura 2.11 é mostrado o Tema transversal Log. O objetivo é registrar informações de contexto de execução de operações antes e após a execução dessas operações. Assim, este interesse é projetado sem consciência do ponto de junção da aplicação que será afetado, o que é possível por meio da utilização de gabaritos. Na caixa tracejada localizada no canto superior direito do pacote é mostrada a classe gabarito LoggedClass e a operação gabarito loggedOp(), que funcionam como uma lista de parâmetros. Esses gabaritos são representações abstratas de classes e operações do código-base que, depois do processo de composição, serão substituídas por classes e operações reais.

Apenas durante a etapa de composição é que uma ou mais operações reais de algum código-base serão associadas com a operação gabarito. O resultado é que o comportamento da operação gabarito irá envolver o comportamento da operação real, como é mostrado pelo diagrama de seqüência dentro do tema. Para representar o comportamento original da operação que será substituída, acrescenta-se o prefixo “_do_” no nome da operação gabarito, como pode ser visto na classe gabarito LoggedClass. Assim, pode-se compreender qual será o comportamento do sistema depois que esse tema estiver composto com um código-base. Neste exemplo, quando um método do código-base for executado, representado pelo loggedop(), o método write() é chamado. Em seguida, executa-se o comportamento 
original do método entrecortado - representado pelo do_loggedop () - e novamente o método write () é invocado.

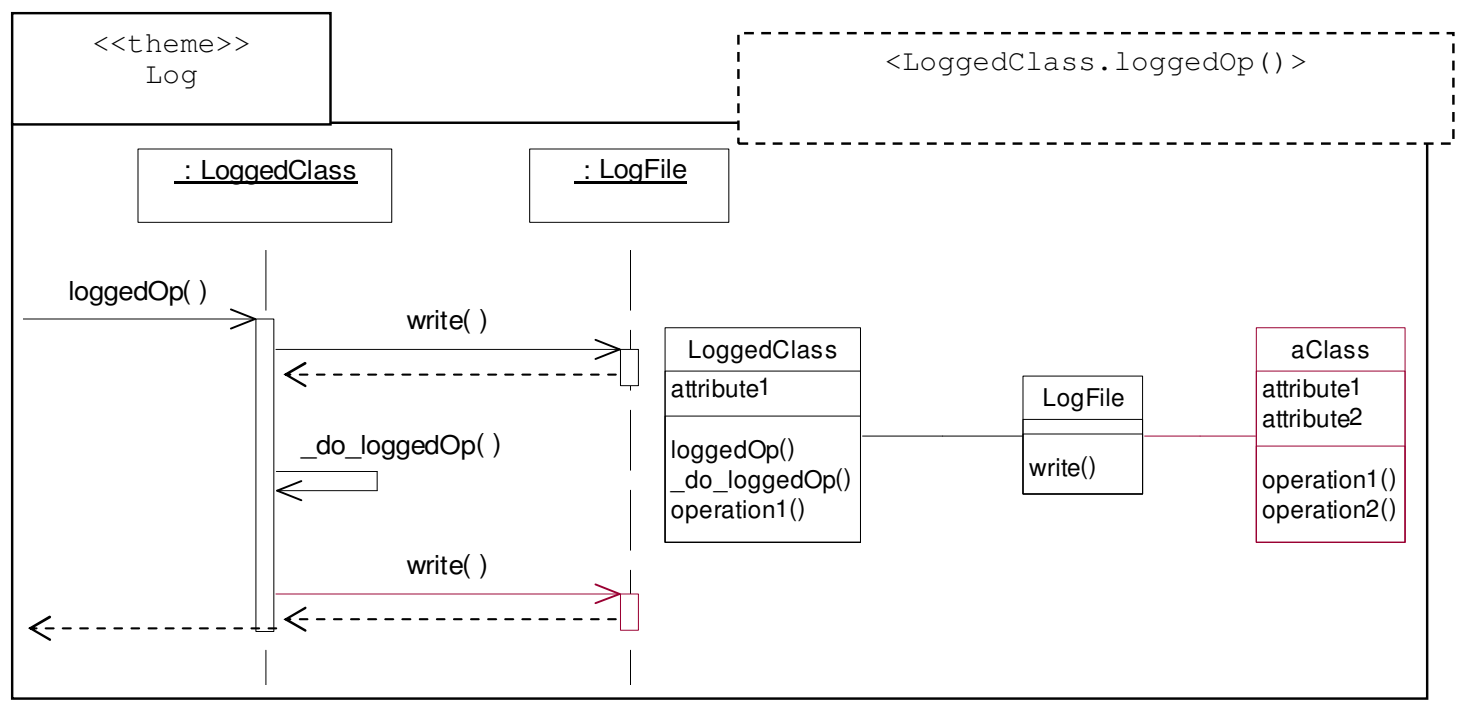

Figura 2.11 - Tema Transversal de Registro de Execução

Observe-se também a existência de um atributo chamado attribute1 e de uma operação chamada operation1() na classe gabarito. Após a etapa de composição, esse atributo e esse método serão adicionados na classe real que fizer correspondência com a classe gabarito. Outro ponto que merece destaque é que dentro de um tema transversal pode existir um número arbitrário de classes. Por exemplo, suponha que a classe aclass é utilizada pela classe LogF i le para alguma computação específica.

O relacionamento de ligação é um super-conjunto do relacionamento de compartilhamento de conceitos. Isso significa que durante uma composição do tipo ligação, os temas que participam da composição e que possuem os mesmos conceitos (classes/atributos/métodos) serão combinados em elementos únicos, como ocorre no relacionamento de intercalação, por exemplo.

Como descrito no algoritmo de mapeamento para AspectJ proposto por Clarke (Clarke e Baniassad, 2005), cada tema deve ser implementado como um aspecto abstrato e as operações gabarito tornam-se conjuntos de junção abstratos (abstract pointcuts) dentro do aspecto. Assim, de posse do projeto apresentado na Figura 2.11, por exemplo, o engenheiro de aplicação sabe da existência de um aspecto abstrato chamado Log e que ele possui um conjunto de junção abstrato chamado loggedop () que deve ser concretizado com pontos de junção da aplicação específica. Além disso, o engenheiro de aplicação também consegue saber qual será o comportamento do sistema após a composição analisando o diagrama de seqüência. 
O algoritmo de mapeamento apresentado por Clarke e Baniassad (2005) possui certas limitações para modelar sistemas implementados em AspectJ. Como a sugestão é que cada tema seja mapeado para um aspecto, não é possível representar hierarquia de aspectos, um recurso bastante útil quando se trabalha com AspectJ. Entretanto, o mapeamento ditado pelo algoritmo também força detalhes importantes de projeto, por exemplo, como o comportamento transversal é modelado como classes dentro de cada tema, a implementação também deve ser feita dessa forma, retirando o código transversal dos adendos e colocando-os em classes. Fazendo com que o adendo possua apenas chamadas para classes que encapsulam os comportamentos transversais. Assim, os aspectos permanecem apenas com o código que liga o comportamento transversal ao código-base.

Na Figura 2.12 é mostrada a composição do tema transversal Log com um tema-base chamado Base. A composição é representada graficamente pela linha tracejada bidirecional que liga os dois temas. Esse relacionamento de bind especifica operações do tema-base que serão associados à operação gabarito, e conseqüentemente, que serão afetadas pelo comportamento transversal. Neste caso, o tema-base possui uma classe chamada Expression com três métodos que devem ter sua execução registrada, o check(), o asString() e o evaluate(), como pode ser visto na descrição textual anexada à linha tracejada. A etiqueta (tag) ThemeName no relacionamento de ligação especifica o nome do tema resultante.

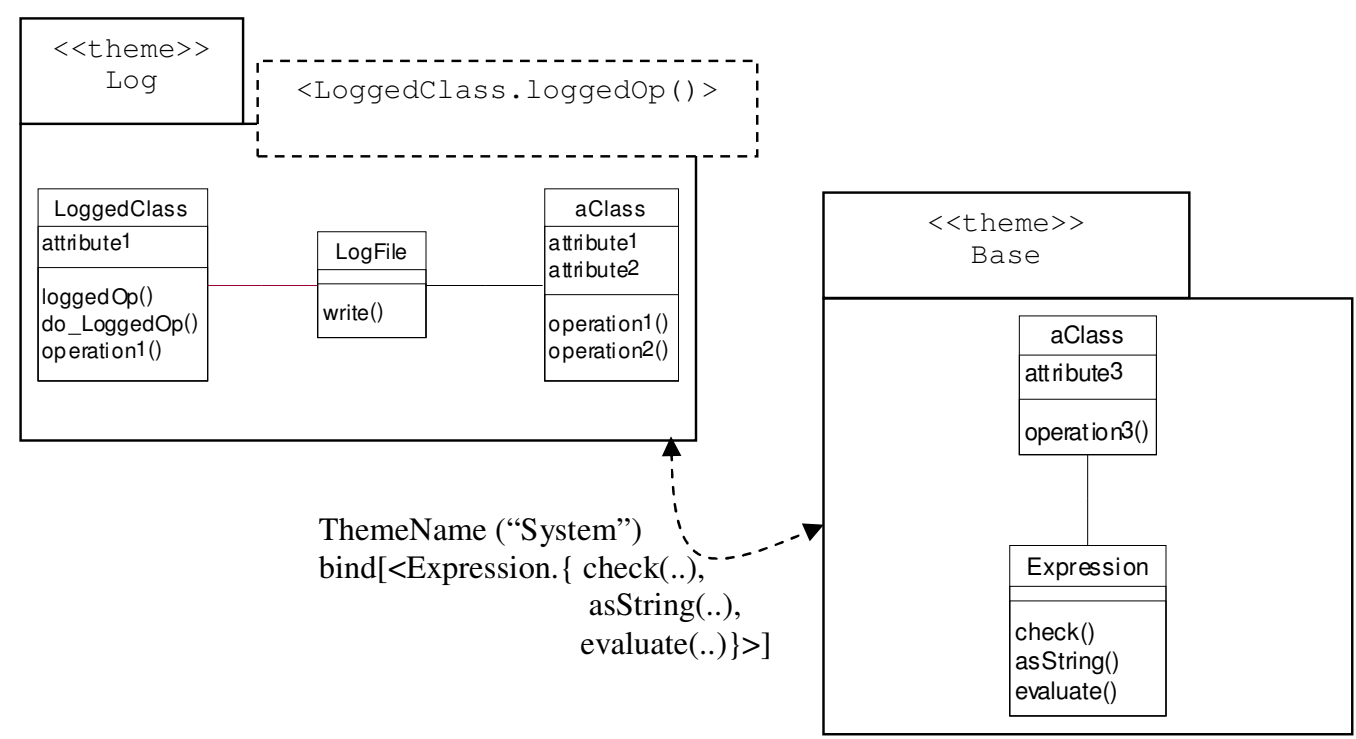

Figura 2.12 - Composição entre os Tema Log e Base

Após a identificação e representação dessas operações no relacionamento de bind, pode-se criar um aspecto concreto estendendo o aspecto Log e implementar o conjunto de 
junção loggedop () com a execução dos três métodos passados como parâmetro para a operação gabarito. A operação gabarito também pode ser associada a um conjunto de operações, e não apenas a uma única operação.

Na Figura 2.13 é mostrado o tema System resultante da composição. Observe-se que a classe Expression possui agora todos os atributos e métodos que ela possuía no tema Base e mais aqueles que havia na classe gabarito LoggedClass. Além disso, também observe-se que as operações originais foram renomeadas com o prefixo do_ para diferenciar entre o comportamento original (sem o prefixo) e o transversal que encapsula o original. Um exemplo de compartilhamento de conceitos ocorreu com a classe aClass. Como essa classe era a mesma em ambos os temas, ela foi combinada em apenas uma com todos os atributos e métodos oriundos dos dois temas que participaram da composição. Também observe-se que foi gerado um diagrama de seqüência para cada operação afetada pelo comportamento transversal.

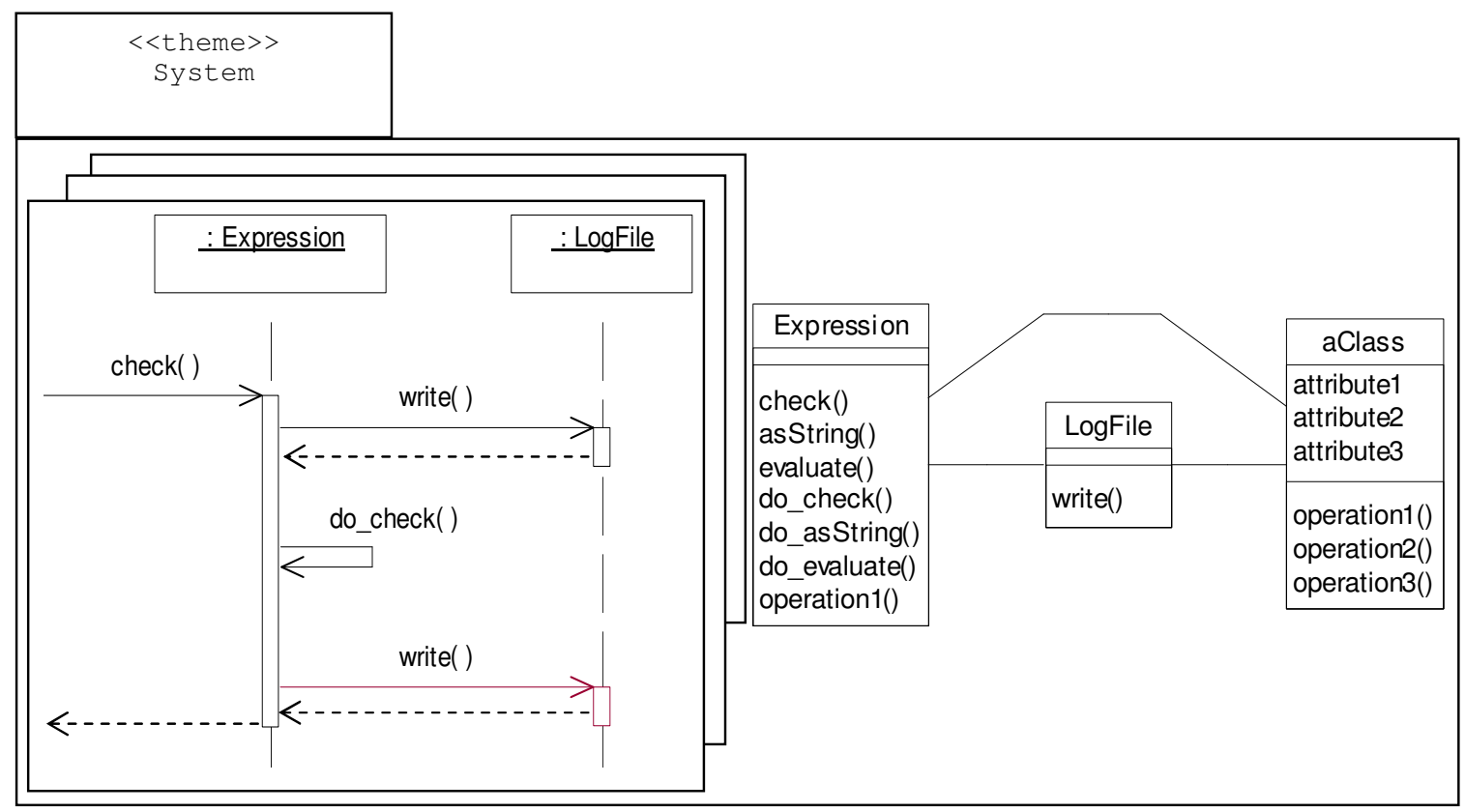

Figura 2.13 - Tema Composto

Este modelo resultante auxilia a entender o comportamento geral do sistema. O diagrama de seqüência da Figura 2.13 mostra o comportamento do método check (), que agora é afetado pelo comportamento transversal de registro de operações. Um ponto importante da abordagem Tema, especificamente da fase de composição, é que é possível representar o comportamento transversal de forma genérica, em seguida seu acoplamento com um código-base (mostrando os pontos de junção que serão afetados), e em seguida o comportamento do sistema após a composição. Em razão disso, os gabaritos da abordagem 
Tema são usados nesta tese para modelar os frameworks que foram desenvolvidos (Camargo e Masiero 2005b).

Outro trabalho que pode ser utilizado para a modelagem de frameworks orientados a aspectos é o de Rausch et al. (2003). Esses autores propuseram uma extensão da UML que modela separadamente o framework, a aplicação e as regras de composição entre eles. O enfoque principal é a modelagem durante o processo de acoplamento. Tem-se inicialmente um modelo de análise que mostra separadamente o framework e um outro modelo que mostra a aplicação. No segundo modelo, já de projeto, os pontos de composição (chamado pelos autores de hot spots) são modelados como aspectos e pontos de junção em um diagrama de classes. O objetivo é deixar claro para o desenvolvedor de aplicações os pontos de acoplamento. A parte dinâmica do modelo de classes é representada por meio de um diagrama de sequiências. Prosseguindo na etapa de projeto, modela-se a composição do framework com a aplicação. As regras de composição entre os dois modelos são feitas por meio de OCL (Object Constraint Language).

Embora o perfil UML-F (Fontoura et al., 2002) tenha sido criado especificamente para frameworks orientados a objetos, muitas de suas etiquetas e estereótipos podem ser utilizados na modelagem de frameworks orientados a aspectos. Isso é possível porque esse tipo de framework também faz uso da orientação a objetos, possuindo métodos-gancho e métodosgabarito, por exemplo.

As duas abordagens mostradas anteriormente - Tema e UML-F - são voltadas para diferentes níveis de abstração. Os gabaritos da abordagem Tema são úteis para representar aspectos e classes, já os estereótipos da UML-F são úteis para representar particularidades de nível mais baixo. Atualmente, pesquisadores começaram a perceber a necessidade de uma notação para representar aspectos em nível de arquitetura. Fornecendo uma visão em um nível mais alto de abstração que represente claramente os componentes transversais (ou aspectuais) que afetam a arquitetura do sistema.

Em um nível de abstração ainda mais alto, Krechetov et al. (2006) apresentam uma abordagem de modelagem orientada a aspectos para o projeto da arquitetura de um software. A abordagem proposta foi criada pela união de detalhes notacionais encontrados em quatro outras abordagens de notação para arquitetura de software. O objetivo é fornecer uma visão de alto nível da arquitetura de um software em termos dos módulos-base e aspectuais que o compõem. A parte superior da Figura 2.14 mostra uma visão geral da arquitetura de um sistema de CVS (Control Version System). Os componentes da arquitetura são representados por classes sem os compartimentos de atributos e operações. Os componentes aspectuais 
utilizam o estereótipo <<aspectual component >> enquanto que os componentes-base utilizam o estereótipo $<<$ component $>>$. O relacionamento entre os componentes é uma dependência convencional da UML, com a diferença de que, no caso dos componentes aspectuais, utilizase 0 estereótipo <<crosscuts >> para indicar que o componente aspectual entrecorta o comportamento de um outro componente. Nesse diagrama não há distinção entre entrecorte estático - com declarações intertipo - ou dinâmico - com conjuntos de junção e adendos. O objetivo é apenas conseguir identificar os módulos-base que são afetados por módulosaspectuais.

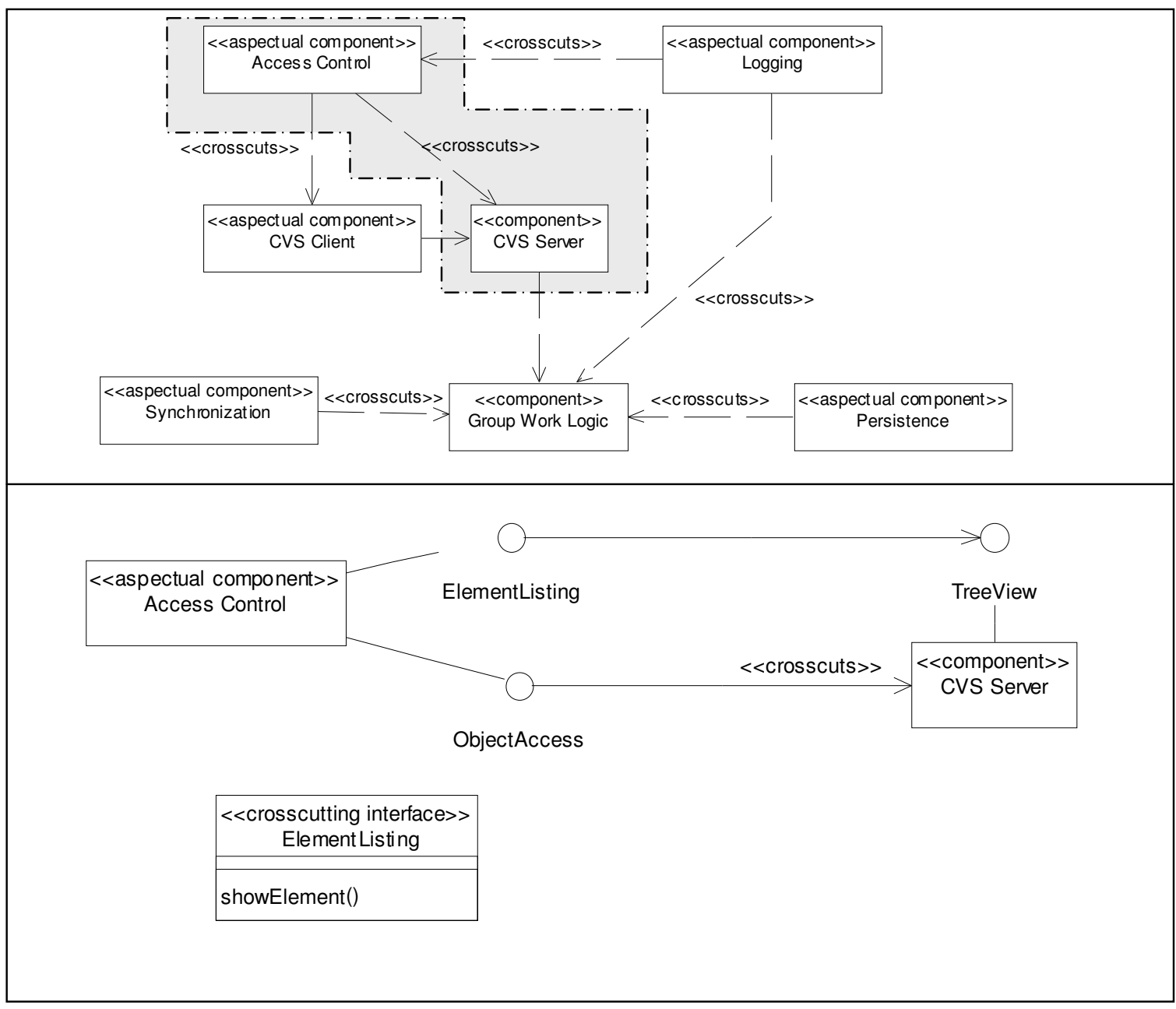

Figura 2.14 - Modelagem de Arquitetura Orientada a Aspectos

A parte inferior da Figura 2.14 diminui o nível de abstração e mostra mais detalhes do relacionamento de entrecorte que o componente aspectual Access Control mantém com CVS Server, destacados na parte superior desta figura. Neste nível de abstração as interfaces de entrecorte dos componentes podem ser exibidas, fornecendo detalhes adicionais sobre o relacionamento. Por exemplo, o componente aspectual Accesscontrol possui duas interfaces de entrecorte, sendo que uma delas afeta outra interface do componente-base e a 
outra afeta a estrutura interna desse componente. Neste nível de abstração também é possível distinguir se o componente aspectual afeta estaticamente ou dinamicamente outro componente. $\mathrm{O}$ entrecorte estático é representado por um relacionamento de associação com estereótipo $<<$ crosscuts $>>$ enquanto que no entrecorte dinâmico esse estereótipo é omitido.

Quando for necessário especificar o conjunto de junção de uma interface de entrecorte, pode-se utilizar uma classe com estereótipo $<<$ crosscutting interface $>>$ que descreve, em seu compartimento de métodos, conjuntos de junção do componente aspectual. Assim, a interface de entrecorte ElementListing define um conjunto de junção chamado showElement(), que pode ser visto no compartimento dos métodos. Essa representação mostra que esse conjunto de junção afeta dinamicamente os métodos que estiverem na interface TreeView. Por outro lado, a interface de entrecorte ObjectAccess afeta estaticamente a estrutura interna do componente-base (Krechetov et al., 2006).

\subsection{5 - Técnicas de Implementação de Aspectos Genéricos}

Hanenberg e Schmidmeier (2003a; 2003b) propuseram um conjunto de oito idiomas para a linguagem AspectJ que podem ser utilizados para a implementação de aspectos genéricos, e consequientemente, de frameworks orientados a aspectos. Segundo Hanenberg et al. (2004), as técnicas de composição da POA são mais adequadas para o projeto de ganchos em frameworks do que as técnicas de composição da orientação a objetos. Na orientação a objetos, as técnicas de composição tradicionais, como herança e composição de objetos, possuem granularidade grossa, no nível de classes e objetos, diferentemente da orientação a aspectos em que a composição pode ser feita diretamente em métodos. Essa granularidade grossa faz com que a estrutura do framework fique prejudicada em relação à evolução e manutenibilidade, bem como ao processo de instanciação. Os oito idiomas, seus papéis, a descrição dos papéis e o objetivo podem ser vistos na Tabela 2.2.

$\mathrm{O}$ idioma Container Introduction permite encapsular propriedades extrínsecas ${ }^{15} \mathrm{em}$ um recipiente, as quais serão introduzidas em um componente ${ }^{16}$ em tempo de composição. Esse idioma possui três papéis: A interface Container, o aspecto ContainerLoader e o aspecto ContainerConnector. O aspecto ContainerLoader é responsável por definir uma propriedade extrínseca e adicioná-la à interface container. $\mathrm{O}$ aspecto ContainerConnector deve fazer com que o componente implemente a interface

\footnotetext{
${ }^{15}$ Uma propriedade extrínseca é um atributo ou método que não diz respeito à funcionalidade da classe.

${ }^{16}$ Um componente é uma unidade modular, possivelmente uma classe, que pertence à parte funcional de uma aplicação.
} 
Container. O principal benefício desse idioma é a transparente introdução de propriedades extrínsecas sem a necessidade de modificar o aspecto ContainerConnector.

Tabela 2.2 - Idiomas de Hanenberg e Unland

\begin{tabular}{|c|c|c|}
\hline Idioma & Papéis & Objetivo \\
\hline \multirow{3}{*}{$\begin{array}{l}\text { Container } \\
\text { Introduction }\end{array}$} & Container & \multirow{3}{*}{$\begin{array}{l}\text { Fazer com que propriedades extrínsecas sejam inseridas nas classes de aplicação em } \\
\text { tempo de composição. }\end{array}$} \\
\hline & Connector & \\
\hline & Container Loader & \\
\hline \multirow{3}{*}{$\begin{array}{l}\text { Marker } \\
\text { Interface }\end{array}$} & Marker Interface & \multirow{3}{*}{$\begin{array}{l}\text { A existência de um tipo base para todos os objetos da aplicação para que o conjunto } \\
\text { de junção apenas referencie esse tipo base. }\end{array}$} \\
\hline & Aspect Specification & \\
\hline & Marker Sticker & \\
\hline \multirow{2}{*}{$\begin{array}{l}\text { Composit } \\
\text { Pointcut }\end{array}$} & Composit Pointcut & \multirow{2}{*}{$\begin{array}{l}\text { Definir um conjunto de junção de forma mais clara quebrando-o em conjuntos de } \\
\text { junção menores. }\end{array}$} \\
\hline & Component Pointcut & \\
\hline $\begin{array}{l}\text { Abstract } \\
\text { Pointcut }\end{array}$ & Pointcut hook & $\begin{array}{l}\text { Definir um conjunto de junção abstrato que deve ser concretizado pelo aspecto } \\
\text { concreto. }\end{array}$ \\
\hline \multirow[t]{2}{*}{$\begin{array}{l}\text { Template } \\
\text { Advice }\end{array}$} & Primitive Operation & \multirow[t]{2}{*}{$\begin{array}{l}\text { Fornecer diferentes comportamentos para um adendo por meio das operações } \\
\text { primitivas. }\end{array}$} \\
\hline & template advice & \\
\hline \multirow{2}{*}{$\begin{array}{l}\text { Pointcut } \\
\text { Method }\end{array}$} & Pointcut method & \multirow{2}{*}{$\begin{array}{l}\text { O objetivo é a existência de um adendo condicional, em que sua execução dependa do } \\
\text { retorno do método conjunto de junção }\end{array}$} \\
\hline & $\begin{array}{l}\text { Candidato } \\
\text { (candidate) }\end{array}$ & \\
\hline \multirow{3}{*}{$\begin{array}{l}\text { Chain } \\
\text { Advice }\end{array}$} & Abstract Chain & \multirow{3}{*}{$\begin{array}{l}\text { Agrupar em um único aspecto vários pontos de junção que são compartilhados por } \\
\text { vários aspectos. Dessa forma os elementos da cadeia apenas definem os adendos e } \\
\text { não os conjuntos de junção }\end{array}$} \\
\hline & Chain Element & \\
\hline & Anchor pointcut & \\
\hline \multirow{4}{*}{$\begin{array}{l}\text { Factory } \\
\text { Advice }\end{array}$} & Known Creator & \multirow{4}{*}{$\begin{array}{l}\text { O objetivo é transferir a responsabilidade de criação de objetos das classes de } \\
\text { aplicação para os aspectos. }\end{array}$} \\
\hline & Concrete Creator & \\
\hline & Creator pointcut & \\
\hline & Abstract Product & \\
\hline
\end{tabular}

Outro idioma é Marker Interface, que especifica propriedades de interceptação (conjuntos de junção e adendos) dependentes de uma interface que é posteriormente relacionada a uma aplicação. Esse idioma possui três papéis: a interface MarkerInterface, o aspecto AspectSpecification e o aspecto MarkerSticker. $\mathrm{O}$ aspecto AspectSpecification possui conjuntos de junção e adendos que apenas referenciam a interface MarkerInterface. O aspecto MarkerSticker faz com que um determinado componente implemente essa interface. Dessa forma, esse idioma faz com que os componentes corretos sejam afetados sem que o aspecto AspectSpecification defina explicitamente seus nomes e tipos. Isso torna esse aspecto reusável, já que não possui dependência de informações específicas da aplicação. Esse idioma é freqüentemente usado em conjunto com o idioma ContainerIntroduction, em que a interface MarkerInterface corresponde à interface Container, e o aspecto AspectSpecification corresponde ao aspecto ContainerLoader.

O idioma Composite Pointcut decompõe um conjunto de junção em outros conjuntos de junção componentes, que sejam logicamente independentes. Esses conjuntos de junção componentes podem ser modificados sem afetar o conjunto de junção composto e podem ser utilizados em outros aspectos. Os autores comentam que a existência de um conjunto de junção com uma definição muito complexa dificulta sua redefinição em classes concretas. Isso acontece porque a linguagem AspectJ não permite a redefinição de partes de um conjunto 
de junção. A existência de conjuntos de junção menores facilita a redefinição de um pequena parte do conjunto de junção, sem precisar redefini-lo completamente. Geralmente esse idioma trabalha em conjunto com o idioma Abstract Pointcut em que um dos conjuntos de junção componentes são abstratos. Da mesma forma, o idioma Marker Interface pode fazer uso de conjuntos de junção componentes quando a definição do conjunto de junção estiver complexa.O idioma Template Advice permite especificar adendos com variabilidades. Isso é possível definindo operações primitivas que são chamadas a partir de um adendo gabarito que agrupa o comportamento comum. As operações primitivas podem ser redefinidas ou sobrepostas nos aspectos concretos para fornecer detalhes específicos da aplicação. Uma vantagem desse idioma é que o desenvolvedor precisa de pouco conhecimento do conjunto de junção ou das propriedades internas do adendo. Esse idioma geralmente trabalha junto com o Abstract Pointcut em que o aspecto ConcreteAspect especifica o conjunto de junção gancho.

Os autores comentam que o idioma Template Advice em conjunto com o Template Method e o Composite Pointcut formam a base fundamental para a construção de frameworks orientados a aspectos em AspectJ.

Outro trabalho que pode ser utilizado como base para a implementação de frameworks orientados a aspectos é apresentdo por Wrampler (2006). Esse autor discute a dificuldade de se criar aspectos genéricos e reusáveis em AspectJ. O autor discorre sobre o assunto no contexto de uma ferramenta chamada Contract4J, que é uma ferramenta para desenvolvimento de programas Java e AspectJ que apóia a utilização de projetos por contratos (Design By Contract). A ferramenta gera aspectos automaticamente para realização dos testes do projeto por contrato. O objetivo do autor é gerar aspectos genéricos e reusáveis em AspectJ.

Wrampler (2006) comenta que a natureza dos aspectos dificulta sua implementação de forma genérica. Geralmente os interesses transversais encapsulados pelos aspectos precisam de alguma cooperação do código-base para funcionar adequadamente. Implementar esses aspectos de forma totalmente genérica é algo difícil. Uma das causas disso é que os conjuntos de junção da linguagem AspectJ, por exemplo, são escritos considerando detalhes do códigobase, e não abstrações de nível mais alto, como deveria ser. Segundo Wrampler, a idéia de que o código-base deve ser inconsciente dos aspectos é inadequada. Ele cita alguns trabalhos recentes em que o código-base possui conhecimento dos pontos que podem ser afetados por aspectos (Kiczales e Mezini, 2005; Griswold, et al., 2006). 
Wrampler comenta que uma forma de tornar os aspectos mais genéricos e reusáveis é a utilização de conjuntos de junção baseados em anotações (annotations), que podem ser usadas com o Java5 e com o AspectJ5. As anotações marcam partes do código-base relacionadas semanticamente e conjuntos de junção podem ser projetados para entrecortarem essas partes, sem fazer com que eles fiquem presos a convenções de nomenclatura e/ou detalhes de implementação.

$\mathrm{O}$ autor discute três diferentes implementações para a geração dos aspectos e conclui que a mais genérica e reusável é a que utiliza anotações (Wrampler, 2006). Na Figura 2.15 são mostrados dois aspectos gerados por diferentes versões da ferramenta Contract4J. O primeiro aspecto tem como objetivo entrecortar execuções do método withDraw() e realizar o teste de pré-condição, verificando se o valor passado por parâmetro é positivo e se o saldo da conta ficará positivo após a retirada. Esse aspecto dificilmente pode ser reusado porque seu conjunto de junção é implementado considerando detalhes do código-base que será entrecortado, por exemplo, a classe BankAccount.

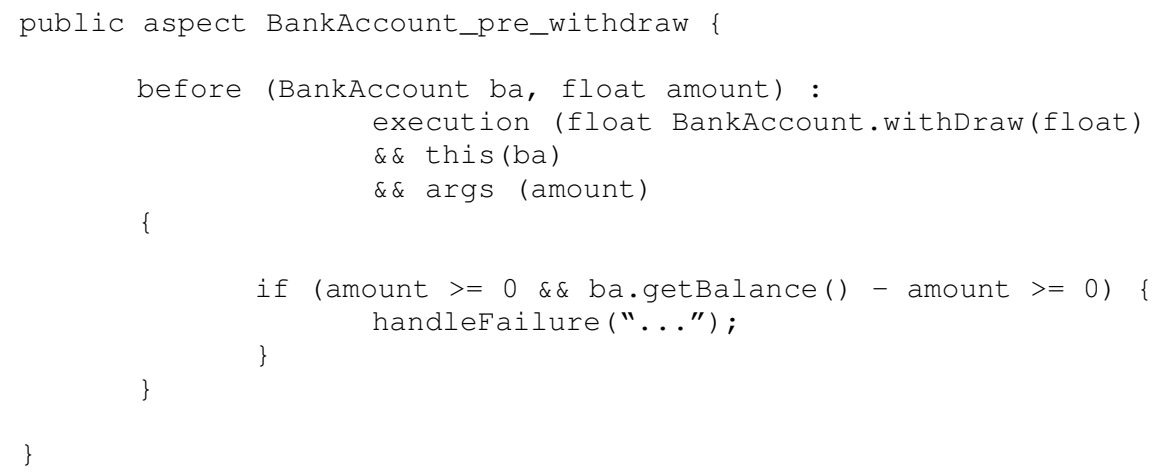

Figura 2.15 - Exemplos de Conjunto de Junção

O segundo aspecto da Figura 2.15 é mais genérico e possui grandes chances de reúso. Seu objetivo também é realizar testes de pré-condições. Nesta segunda alternativa de implementação o conjunto de junção entrecorta a execução de qualquer método que pertença à interface ContractMaker. Essa interface é criada por um outro aspecto especificamente para marcar os objetos que serão submetidos aos testes de contrato, como é feito no idioma MarkerInterface (Hanenberg e Schmidmeier, 2003a). Além disso, os métodos só são entrecortados se não forem estáticos e se possuírem a anotação @Pre, indicando que possuem 
pré-condição. Somado a isso, também só há entrecorte se o método isPreEnabled() retornar verdadeiro e se a execução do método estiver fora do escopo de execução da própria ferramenta, o que é representado pelo conjunto de junção within_c4j(), o qual não é mostrado na figura.

A estratégia de implementação dos autores é interessante, porém não exclui a necessidade de um aspecto informar quais classes devem implementar a interface ContractMaker. Essa é uma estratégia também utilizada no FT de persistência desenvolvido no contexto desta tese.

\subsection{6 - Linhas de Produtos e a Programação Orientada a Aspectos}

Como comentado anteriormente, frameworks podem ser utilizados como ferramentas para a implementação de linhas de produtos e uma estratégia que pode ser utilizada é a divisão da arquitetura do framework em características. Entretanto, a presença de interesses transversais também tem influência negativa nessa linha de pesquisa. Há características que possuem comportamento transversal e que não são adequadamente modularizadas com as técnicas existentes. Assim, Mezini e Ostermann (2004) e Apel et al. (2006) propuseram novas abordagens com vistas a solucionar o problema. A abordagem de Mezini e Ostermann (2004) contempla uma linguagem chamada CAESAR $^{17}$ (Mezini e Osterman , 2003 apud (Mezini e Ostermann, 2004)). Nessa linguagem, as características transversais podem ser definidas em módulos coesos e incorporadas dinamicamente no código-base por meio de conjuntos de junção e adendos. Além disso, também é possível generalizar as características para que elas não fiquem dependentes da estrutura do programa base e possam ser reusadas em outros contextos.

A abordagem proposta por Apel et al. (2006) é chamada de Aspectual Mixin Layers e o diferencial é que aspectos podem ser refinados com o objetivo de aumentar ou diminuir o escopo de atuação de um conjunto de junção. Além disso, também é possível delimitar a quantificação dos aspectos, fazendo com que os conjuntos de junção não afetem características inseridas após a inclusão do aspecto.

\section{5 - Processo de DESENVOLVIMENTO ORIENTADO A ASPECTOS}

Depois do surgimento da POA, vários pesquisadores têm investigado a influência desse novo paradigma em fases específicas do processo de desenvolvimento. Alguns se concentram na

\footnotetext{
${ }^{17}$ MEZINI, M., OSTERMANN, K. Conquering aspects with Caesar. In Proceedings of Conference on AspectOriented Software Development (AOSD’03), pages 90-99. ACM, 2003.
} 
fase de análise e engenharia de requisitos (Grundy, 1999; Clarke e Baniassad, 2005; Rashid et al., 2002; Baniassad et al., 2006), outros na fase de projeto (Berg et al., 2006; Clarke e Baniassad, 2005), (Aspect-Oriented Component Engineering) (Grundy, 2000; Katara e Katz, 2003; Suzuki e Yamamoto, 1999; Pawlak et al., 2002; Stein et al., 2002; Zakaria et al., 2002; Aldawud et al., 2003), outros na fase de implementação (Soares, 2004) e ainda há alguns poucos que discorrem sobre todo o ciclo de vida (Clarke e Baniassad, 2005; Jacobson e Ng, 2004).

A pesquisa de Grundy (1999) consiste em um método de engenharia de requisitos orientado a aspectos para desenvolvimento de software baseado em componentes. Ele desenvolveu uma categorização de diversos aspectos de um sistema que um componente provê para os usuários finais ou para outros componentes.

$\mathrm{Na}$ fase de análise da abordagem Tema (Clarke e Baniassad, 2005), os temas são identificados a partir dos requisitos e, para isso, é estabelecida uma relação de cada requisito (ou conjunto de requisitos) a um tema que o encapsula. Clarke e Baniassad também estabelecem critérios para identificar temas que encapsulam interesses transversais e são candidatos a serem implementados como aspectos. Os temas que encapsulam interesses transversais são chamados de temas transversais e em geral são relacionados a mais de um requisito, enquanto que os outros temas, denominados de temas-base, geralmente são relacionados a um único requisito.

Araújo e Moreira (2003) propuseram uma abordagem dirigida a casos de uso, cujo objetivo é identificar casos de uso aspectuais, que podem ser tanto funcionais quanto nãofuncionais. Para realizar essa identificação, parte-se de um documento de requisitos em que um modelo inicial de casos de uso é elaborado. Em seguida os casos de uso são analisados com o objetivo de fatorar funcionalidades. Isso é representado por relacionamentos que utilizam os estereótipos $<<$ extend $>>$, $<<$ includes $>>$ e $<<$ constrain $>>$. A partir disso, os requisitos não-funcionais do sistema são identificados e modelados como casos de uso com esteréotipo $<<\mathrm{NFR}>>$, que são integrados com os casos de uso funcionais já elaborados. O relacionamento que os casos de uso não-funcionais mantém com os funcionais deve ser representado pelo estereótipo <<constrain>>. O último passo consiste em identificar os casos de uso candidatos a aspectos, que são aqueles que restringem mais de um caso de uso, ou que são incluídos ou estendidos por mais de um caso de uso.

O modelo AORE, (Aspect-Oriented Requirements Engineering) proposto por Rashid et al. (2002), relaciona interesses a requisitos com o objetivo de verificar quais interesses entrecortam os requisitos, qualificando-os como candidatos a aspectos. O modelo permite 
separar a especificação dos requisitos aspectuais, requisitos normais e regras de composição em módulos que seguem gabaritos bem definidos. As regras de composição empregam operadores e ações para especificar como um requisito aspectual influencia ou restringe o comportamento de um conjunto de requisitos normais.

Com relação à fase de projeto, também há um número significativo de trabalhos, sendo que muitos deles se concentram em estender técnicas de projeto orientadas a objetos e também a UML com detalhes que permitem a modularização de interesses transversais. As principais abordagens são Tema/UML (Clarke e Baniassad, 2005), AOCE (Aspect-Oriented Component Engineering) (Grundy, 2000), Visão Arquitetural de Aspectos (Architectural View of Aspects) (Katara e Katz, 2003), aSide (Chavez, 2004; Berg et al., 2006) e a abordagem proposta por Suzuki e Yamamoto (Suzuki e Yamamoto, 1999). Também há outros cujo enfoque é mais restrito à proposta de uma perfil UML específico para AspectJ para a fase de projeto (Pawlak et al., 2002; Stein et al., 2002; Zakaria et al., 2002; Aldawud et al., 2003).

A abordagem AOCE refina os requisitos identificados na abordagem AORE em aspectos de nível de projeto (Grundy, 2000). Essa abordagem é baseada na idéia de que cada componente em um sistema baseado em componentes usa/provê serviços de/para outros componentes. Um conjunto de extensões da UML é empregado para tornar os detalhes aspectuais explícitos.

Na abordagem Visão Arquitetural de Aspectos (Katara e Katz, 2003), os aspectos são representados como pacotes estereotipados contendo artefatos da UML que pertencem a um determinado interesse. Os elementos dentro de cada diagrama podem ter relações, como uses ou defines, e podem se mapeados para outros elementos em aspectos diferentes. A noção de diagrama de interesse (concern diagram) é introduzida e permite visualizar sobreposições de interesses.

Tema/UML (Clarke e Baniassad, 2005) é uma combinação do modelo de projeto orientado a assunto e dos gabaritos da UML. Regras de composição são utilizadas para compor os projetos. Após a identificação dos temas-base e transversais, os temas são projetados separadamente. No projeto de um tema transversal, diagramas de interação são especificados para mostrar o comportamento-padrão do tema quando combinado com algum tema-base da aplicação. Para isso, são adotados gabaritos em que as operações entrecortadas são representadas genericamente nos diagramas e são substituídas pelas operações dos temasbase na composição. A abordagem é baseada na observação de que padrões de comportamentos transversais existem com respeito a projetos-base que eles entrecortam. Assim, o comportamento transversal pode ser projetado sem consciência do código-base. 
$\mathrm{Na}$ abordagem aSide (Chavez, 2004), o modelo de projeto proposto compreende três facetas, a estrutural, a dinâmica e a de composição. A primeira modela a estrutura dos aspectos e componentes, e como se relacionam por meio de interceptações e mecanismos de composição tradicionais. A faceta dinâmica modela as interações entre as instâncias dos aspectos e dos componentes afetados por esses aspectos, e a faceta de composição visa a facilitar a compreensão da combinação dos aspectos com os componentes em um nível mais alto de abstração.

Suzuki e Yamamoto propuseram extensões da UML para modelar aspectos e também uma linguagem de descrição baseada em XML chamada UXF/a para fornecer conversões de modelos baseados em aspectos entre ferramentas de desenvolvimento (Suzuki e Yamamoto, 1999). Um aspecto é representado como uma classe com atributos, operações e relacionamentos. Os atributos são usados pelo conjunto de operações, as quais são as definições de composição do aspecto. As assinaturas dessas definições refletem os elementos afetados pelo aspecto.

Soares (2004) apresenta um método de implementação orientado a aspectos e sua integração com o Processo Unificado da Rational (Rational Unified Process - RUP) (Jacobson et al., 1999). O autor comenta algumas modificações devem ser feitas tanto na estrutura dinâmica (fases) como na estática (disciplinas e atividades) do RUP para a utilização do método. A principal modificação realizada na parte dinâmica é a realização de iterações específicas para requisitos não-funcionais. Assim, casos de uso que devem ser implementados em uma iteração são parcialmente implementados em uma iteração funcional, em que apenas requisitos funcionais, interfaces com o usuário e gerenciamento de dados não persistentes são implementados. Depois que essa implementação é validada, os requisitos não-funcionais de persistência, distribuição e concorrência são incorporados em três iterações não-funcionais.

Jacobson e $\mathrm{Ng}$ (2004) propõem uma abordagem de desenvolvimento de software orientado a aspectos com base em casos de uso. A proposta é identificar interesses transversais a partir dos casos de uso de um sistema e implementá-los em módulos separados. $\mathrm{Na}$ abordagem de Jacobson e $\mathrm{Ng}$ (2004) os casos de uso que implementam interesses transversais são identificados principalmente pelos relacionamentos (include ou extend) que estabelecem com os outros casos de uso. Com base nessa decisão, foram estabelecidos critérios que orientam os desenvolvedores na decisão de quais tipos de relacionamentos os casos de uso têm entre si. Cada interesse do sistema é descrito por um caso de uso e o sistema completo é obtido pela composição dos casos de uso base e transversais. Na implementação, cada caso de uso pode ser composto por uma ou mais classes que possuem métodos e 
atributos relacionados ao interesse descrito. Jacobson e Ng (2004) propõem a codificação de todos os casos de uso com linguagens orientadas a aspectos e que a composição para produzir o sistema completo seja feita por meio de declarações intertipo em entidades vazias previamente criadas.

\section{6 - CONCLUSÃO}

Os trabalhos apresentados nas Seções 2.4.1 e 2.4.2 tratam da implementação de interesses transversais com POA de forma que possam ser reusados durante o desenvolvimento de novas aplicações. Apesar de serem similares com relação à implementação e objetivos, não há um consenso sobre o termo utilizado para designar esse tipo de implementação. Enquanto alguns autores utilizam o termo "framework de aspectos" (Soares, 2004; Hanenberg, 2000), outros utilizam "framework baseado em aspectos" (Rashid e Chitchyan, 2003), outros ainda utilizam "framework orientado a aspectos" (Mendonça et al., 2005; Constantinides et al., 2000; Shah e Hill, 2004; Rausch et al., 2003; Pinto et al., 2001a; Pinto et al., 2001b; Pinto et al., 2002) e também pode ser encontrado "framework (arcabouço) orientado por aspectos" (Couto et al., 2005).

Essa falta de consenso é mais grave em trabalhos que utilizam os mesmos termos citados acima para designar um outro tipo de framework que utiliza aspectos em sua arquitetura interna - os frameworks de aplicação (Pinto et al., 2001a; Pinto et al., 2001b; Pinto et al., 2002; Hanenberg et al., 2004). Esse tipo de framework possui objetivos diferentes e é implementado de forma diferente, pois encapsula uma arquitetura genérica de um domínio de aplicação e o seu reúso resulta em uma aplicação inteira daquele domínio.

Um ponto digno de nota com relação aos "frameworks" apresentados nas Seções 2.4.1 e 2.4.2 é a ausência de uma arquitetura padrão que separe as funcionalidades do framework (por exemplo, suas variabilidades) de seus mecanismos de composição (sua interface de entrecorte). A existência de uma arquitetura desse tipo propicia uma melhor evolução para esse tipo de software porque permite que variabilidades sejam incluídas sem afetar outras partes da implementação.

Entretanto, a existência de uma arquitetura de refêrencia para "frameworks orientados a aspectos" não é suficiente para proporcionar um reúso efetivo. Como comentado na Seção 2.3, frameworks possuem o problema de overfeaturing (Codenie et al., 1997 apud (Batory et al., 2000) $)^{18}$, isto é, o reúso do framework faz com que todas a sua arquitetura seja considerada, independentemente se todas as suas variabilidades estejam sendo utilizadas ou

\footnotetext{
${ }^{18}$ CODENIE, W., HONDT, K., STEYAERT, P., VERCAMMEN, A. From Custom Applications to DomainSpecific Frameworks. Communications of the ACM, 40(10), October, 1997.
} 
não. Uma solução é modularizar a arquitetura do framework em caracterísicas, assim, o framework também deve ser montado antes que seja reusado apenas com as características que serão utilizadas.

A maior parte dos trabalhos encontrados na literatura relacionados com desenvolvimento de software orientado a aspectos concentra-se em fases ou atividades específicas do ciclo de vida, como engenharia de requisitos, análise, projeto, projeto de arquitetura e implementação. Entretanto, apesar de que pesquisas em fases isoladas do ciclo de vida sejam preciosas para definir e aprofundar os conceitos, também é necessário unir essas fases para mostrar como os interesses transversais são identificados, reusados e conduzidos durante todo o processo de desenvolvimento.

Os únicos trabalhos que unem análise e projeto são a abordagem Tema e a abordagem de desenvolvimento orientada a casos de uso proposta por Jacobson e Ng (2004), porém, ambos possuem algumas deficiências. A notação utilizada na fase de análise da abordagem Tema é empregada em um nível de abstração baixo, resultando em um modelo volumoso e que necessita de apoio automatizado para o entendimento (Clarke e Baniassad, 2005). Outro detalhe é que nenhuma das duas abordagens é enquadrada em algum modelo de processo, como, por exemplo, o RUP e o Ágil. Por outro lado, Tema fornece alguns critérios interessantes para a identificação de interesses transversais que não são encontrados na abordagem de Jacobson e Ng. 


\section{Capítulo \\ Frameworks Transversais: Definições, \\ Classificações e Arquitetura}

\section{1 - CONSIDERAÇÕES INICIAIS}

Como pôde ser observado no Capítulo 2, são vários os termos utilizados para designar frameworks que tratam de um único interesse e que são implementados com aspectos. Também destacou-se a ausência de uma arquitetura padrão para o desenvolvimento desse tipo de software. Neste capítulo, apresentam-se propostas de definições e classificações que visam a suprimir a deficiência identificada (Camargo e Masiero, 2005a). O objetivo é facilitar a comunicação entre desenvolvedores quando se referenciam a esse tipo de software. Neste capítulo também é apresentada uma arquitetura de referência para o projeto e implementação desses frameworks. Essa arquitetura pode fazer uso de um padrão que permite fornecer alternativas de composição para o framework.

Na Seção 3.2 são apresentadas as definições e classificações sugeridas para os frameworks desenvolvidos no contexto da POA e na Seção 3.3 discute-se e exemplifica-se a arquitetura proposta para o desenvolvimento desse tipo de framework.

\section{2 - FRAMEWORKS ORIENTADOS A ASPECTOS: DEFINIÇÕES E ClassificAÇÕES}

A definição geral para Frameworks Orientados a Aspectos (FOA) leva em consideração dois pontos de vista: a estrutura e o propósito. Do ponto de vista da estrutura, um FOA é um conjunto formado por unidades básicas de programação OO (classes), cuja presença não é obrigatória, e unidades básicas de programação OA (aspectos), formando uma estrutura semicompleta que necessita ser completada com detalhes de uma aplicação específica. 
Essa definição implica que um FOA pode conter apenas aspectos em sua estrutura, e embora isso não seja comum, é possível que ocorra em situações especiais. Por exemplo, o framework pode conter todo o comportamento do interesse transversal implementado como métodos pelo aspecto. Embora essa não seja uma estratégia de projeto que separe adequadamente os interesses, é possível que ocorra.

Do ponto de vista do propósito, assim como os frameworks orientados a objetos, um FOA pode ser definido como um sistema semi-completo que pode ser reusado no desenvolvimento de novas aplicações, mantendo os interesses transversais separados dos interesses-base. Essa definição implica que o objetivo do FOA é facilitar o desenvolvimento de uma nova aplicação, reusando projeto e código já testados e aprovados, e manter os interesses transversais separados dos interesses-base do sistema, elevando assim, os níveis de qualidade da aplicação.

Além das definições apresentadas anteriormente, a experiência com o desenvolvimento de vários frameworks no contexto da POA mostrou que os FOAs podem ser classificados em dois tipos: Frameworks Transversais e Frameworks de Aplicação Orientados a Aspectos. Embora essas duas classificações tenham sido criadas, o enfoque desta tese é nos Frameworks Transversais.

Um Framework Transversal (Crosscutting Framework) (FT) é um FOA que encapsula comportamento genérico de um único interesse. Possui mecanismos de composição abstratos e pode ou não possuir variabilidades funcionais. Esse tipo de framework é bastante similar a um framelet em seu propósito (Pree e Koshimies, 2000), como é descrito no Capítulo 2, porém diferente na técnica de implementação utilizada, não causando espalhamento e entrelaçamento de código de interesses distintos.

Como um interesse pode ser composto por outros sub-interesses, fica a critério do projetista implementar os sub-interesses com aspectos. Caso isso seja feito, também é sua responsabilidade determinar o nível de granularidade desses sub-interesses e decidir se devem ser implementados genericamente, na forma de um FTs, ou de forma específica, deixando seu acoplamento restrito ao interesse maior.

Quando esses sub-interesses são variabilidades do interesse maior, sua implementação com aspectos, seja como FT ou como aspectos normais, é factível porque facilita o acoplamento e o desacoplamento. Em ambos os casos, quando se trata de uma família de FTs de um domínio específico, esse sub-interesse pode ser usado como uma característica do interesse maior. 
A implementação de características como FTs faz com que elas se tornem-se mais genéricas, podendo possuir variabilidades e aumentando as possibilidades para serem reusadas também fora de sua linha de produtos. Entretanto, como a maior probabilidade de reúso da característica é dentro da linha, deve haver uma camada de implementação independente que forneça o código de acoplamento dela com a característica-base da linha que geralmente é um FT que implementa um interesse maior. No contexto desta tese, esta camada de implementação é chamada de "camada de pré-composição", pois contém o código de acoplamento com o FT que implementa o interesse maior, eliminando essa tarefa do engenheiro de software. O prefixo "pré" é utilizado porque a composição definitiva só ocorre se a característica for considerada no projeto. Outro ponto que merece destaque é que as características que possuem camada de pré-composição também possuem os modelos de projeto da composição prontos com o FT que implementa o interesse maior.

A definição apresentada deixa claro que, obrigatoriamente, deve haver mecanismos de composição abstratos, por exemplo, conjuntos de junção abstratos no caso da linguagem AspectJ. Isso é necessário porque o objetivo é que o comportamento do FT funcione acoplando-o a qualquer código-base. Note-se que um FT não precisa, obrigatoriamente, ter variabilidades. Geralmente a primeira versão de um FT não possui variabilidades funcionais, pois elas são identificadas e implementadas conforme o FT é reusado em novos contextos.

Uma outra propriedade de um FT é que sua utilização é dependente da existência de um código-base (aplicação), isto é, seu reúso não produz uma aplicação. Por isso, seu processo de reúso possui duas etapas distintas: instanciação e composição, e não apenas uma, como ocorre com os FOO. A instanciação é o processo convencional de reúso dos FOOs e consiste em especializar o código que foi especialmente projetado para isso. É o processo pelo qual implementam-se os ganchos do framework, escolhe-se alguma funcionalidade alternativa ou implementa-se uma nova. Isso é feito normalmente sobrepondo-se métodos que retornam valores da aplicação específica.

A etapa de composição por sua vez, consiste em duas atividades: identificação dos pontos de junção e fornecimento de regras de composição. A primeira atividade consiste em identificar no código-base o(s) ponto(s) de junção adequado(s) ao acoplamento. A segunda atividade da etapa de composição consiste em fornecer regras que unem as variabilidades escolhidas com o código-base, e para isso tarefas orientadas a aspectos devem ser realizadas como, por exemplo, a concretização de um mecanismo de composição abstrato ou a utilização de declarações intertipo, no caso da linguagem AspectJ (Gradecki and Lesiecki, 2003). Na maior parte das vezes, a etapa de composição depende de informações que são determinadas 
na etapa de instanciação, o que define uma ordem de realização: primeiro a instanciação e depois a composição.

Embora essas duas etapas sejam distintas com relação a seus propósitos, sua separação "física" pode não existir durante o reúso, pois isso depende do projeto do framework e da linguagem orientada a aspectos utilizada. Visto que algumas abordagens OA tendem a separar as regras de composição do comportamento transversal (Tarr et al, 2002; JAML, 2004), infere-se que o projeto de um framework deste tipo deve ser elaborado com o objetivo de separar as duas etapas tanto quanto possível. Entretanto, como AspectJ é uma abordagem que mantém as regras de composição no mesmo módulo do comportamento transversal, um bom projeto precisa ser elaborado para que essas duas etapas também sejam separadas.

Assim como nos framelets, o fluxo de controle principal é da aplicação, porém nos pontos em que o FT atua, o fluxo de controle é retido por ele. Na Figura 3.1 é mostrada uma comparação entre o fluxo de controle de uma aplicação que utiliza um framelet e uma aplicação que utiliza um FT. Os vértices do grafo representam métodos e as arestas representam chamadas explícitas entre esses métodos. As arestas estão numeradas para representar a ordem das chamadas. No caso do framelet (grafo do lado esquerdo), quando o método b() é atingido pelo fluxo, invoca-se explicitamente o método $\mathrm{c}()$ do framelet, transferindo para ele o controle. Dentro do método $c()$, os métodos abstratos $d()^{\prime}$ e e ()' são invocados, os quais foram concretizados no nível da aplicação pelos métodos d ( ) e e ( ) . Neste momento, como as chamadas dos métodos d ( ) e e () ocorrem do framelet para o nível da aplicação, o fluxo de controle é determinado pelo framelet, o que caracteriza a inversão de controle. Depois que os métodos d() e e () terminam sua execução, o controle retorna para a aplicação, pois o método b () invoca o método $f()$, que por sua vez, que invoca o método $g()$.

No caso do FT (grafo do lado direito), quando o método b ( ) é atingido pelo fluxo não há uma chamada explícita ao método c (), o que ocorre é que a execução do método b ( ) é entrecortada pelo FT, o que está sendo representado pela seta tracejada que parte do método c () em direção ao método b (). Neste momento, o fluxo de controle é transferido para esse framework. Em seguida o processo é o mesmo de um framelet, que consiste em invocar métodos abstratos que encontram-se concretizados no nível da aplicação.

Note-se que a única diferença de um FT e de um framelet, com relação ao fluxo de controle, é que no caso do framelet, a aplicação necessita chamar explicitamente alguma operação ou método do framelet, um procedimento igual à utilização de uma biblioteca de classes. Entretanto, depois que o controle foi transferido para o nível do framework, o 
comportamento de ambos é igual, consistindo de chamadas a métodos concretizados no nível da aplicação, caracterizando o princípio de Hollywood (Johnson, 1997).

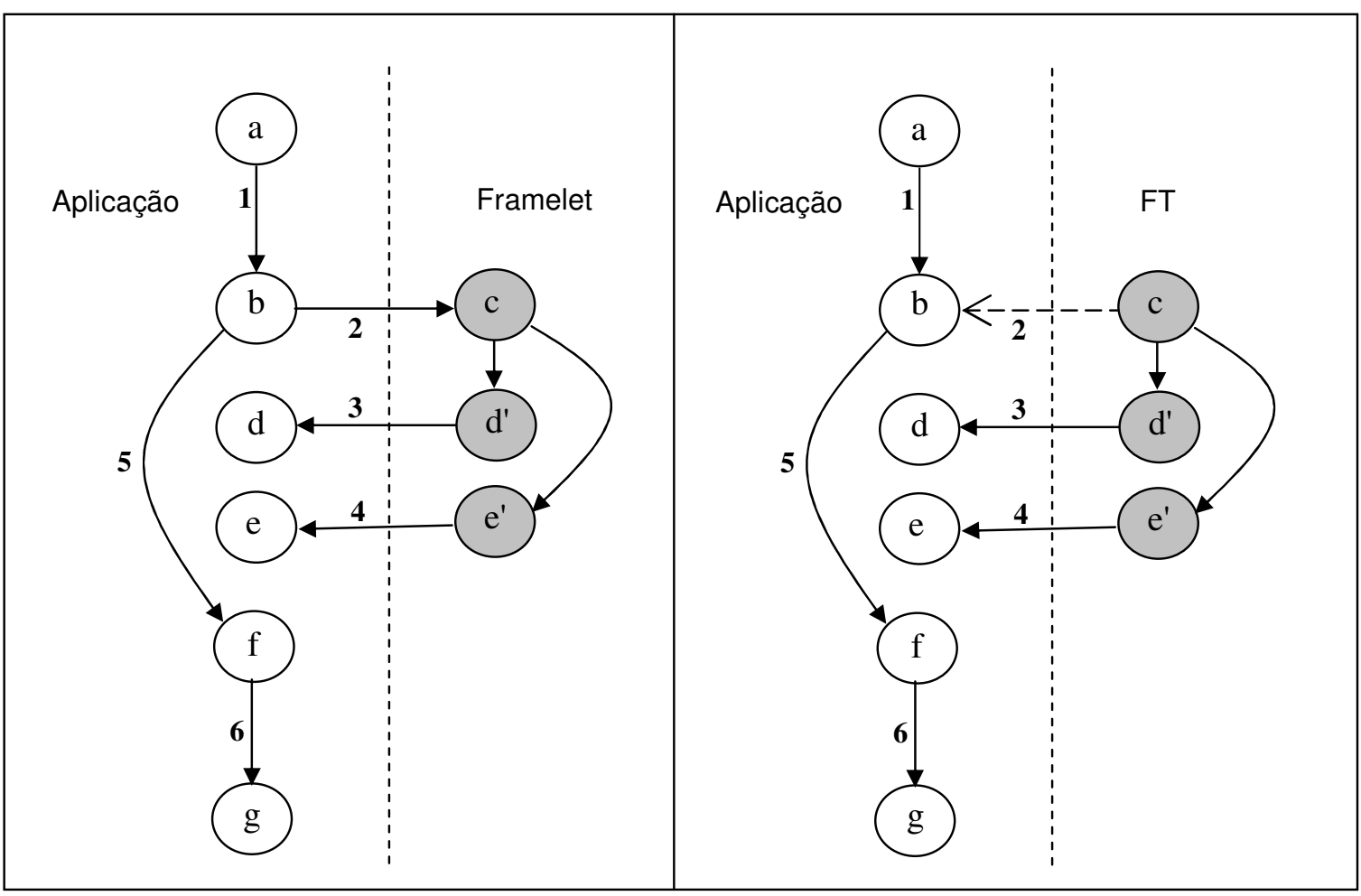

Figura 3.1 - Inversão de Controle nos Framelets e nos Frameworks Transversais

No contexto desta tese, os FTs dividem-se ainda em duas outras classificações: dependentes de contexto e independentes de contexto. Os FTs independentes de contexto são aqueles que podem ser acoplados a qualquer código-base, e que não possuem exigência quanto aos pontos de junção fornecidos. Geralmente FTs de registro e rastreamento de operações se enquadram nessa categoria. Já os FTs dependentes de contexto necessitam capturar algum objeto ou valor do código-base para que possam funcionar adequadamente, isto é, sua interface de entrecorte dinâmica deve expor determinados objetos ou valores do código-base para que o FT possa capturá-los. Exemplos de FTs que se enquadram nessa categoria são Repositório de Conexões, Memória Auxiliar e Autenticação.

Como o conceito de interface de entrecorte está ligado a conjuntos de junção, um único aspecto pode possuir várias interfaces de entrecorte. Como FTs podem possuir vários aspectos, pode ser que tenham várias interfaces de entrecorte. Uma situação que pode ocorrer é a existência de interfaces de entrecorte tanto na arquitetura interna do Framework quando durante o processo de reúso. As interfaces de entrecorte disponíveis durante o processo de reúso geralmente devem ser implementadas pelo engenheiro de aplicação com pontos de junção do código-base. Por exemplo, o FT de persistência, que será mostrado em detalhes na Seção 4.3, possui ambas as interfaces. Entretanto, durante o processo de reúso a única 
interface que é visível ao engenheiro de aplicação é a estática, pois ele deve informar quais são as classes de aplicação em que as operações do framework devem ser introduzidas. A interface de entrecorte dinâmica atua internamente, na estrutura do FT, e só é visível ao engenheiro do framework.

O reúso proporcionado pelos FTs é bastante abrangente, no sentido de que pode ser utilizado em diferentes domínios. Ele pode ser acoplado a aplicações existentes ou em desenvolvimento, a frameworks $\mathrm{OO}$ e a outros frameworks transversais. Muitas vezes esses frameworks são variabilidades de um outro FT, por exemplo, nos FTs desenvolvidos no contexto desta tese, o FT de políticas de bloqueamento é uma variabilidade opcional do FT de Autenticação.

Além da classificação apresentada de FTs, também foi cunhada uma outra classificação que envolve frameworks que utilizam aspectos em sua estrutura interna e que geram uma aplicação em um determinado domínio. Assim, Um Framework de Aplicação Orientado a Aspectos (FAOA) é um FOA que implementa uma arquitetura genérica de um domínio de aplicação e sua instanciação produz uma aplicação desse domínio. A arquitetura do FAOA é projetada com classes e aspectos de forma integrada dentro da arquitetura do framework

Os FAOA são bastante parecidos com os frameworks de aplicação OO com relação ao seu propósito e suas diferenças estão na sua arquitetura, que usa aspectos abstratos e concretos, bem como classes abstratas e concretas para implementar partes variáveis de seu código e que, portanto, são concretizados quando ocorre a instanciação de uma aplicação. Nesses frameworks o princípio de inversão de controle continua válido.

Há três formas possíveis de reúso quando se trata de FOAs e, muitas vezes, sua natureza (FT ou FAOA) determina essa forma. As formas possíveis são: 1) apenas instanciação, 2) apenas composição, e 3) instanciação e composição.

A primeira forma ocorre somente com FAOAs porque esses já possuem o código-base embutido em sua estrutura, não necessitando ser acoplados a nenhum outro código-base. Além disso, a maioria de seus interesses transversais já está codificada internamente, assim como suas regras de composição. A segunda ocorre somente com FTs com uma única funcionalidade. Um exemplo é um FT de rastreamento (tracing), em que a única funcionalidade é o armazenamento das informações em arquivos de texto. Nesse caso, a única etapa de reúso é a composição. Frameworks desse tipo são muito simples e limitados com relação aos benefícios do reúso. A terceira forma de reúso é um pouco mais complexa porque utiliza as duas etapas. Um exemplo é um FT de conexão em que suas variabilidades 
funcionais são relacionadas com a escolha do banco de dados e com o driver de conexão. Reusar esse framework consiste em escolher a variabilidade desejada na etapa de instanciação e também fazer a composição com algum código-base.

Nas duas últimas formas de reúso, a composição pode ocorrer entre dois ou mais FTs e regras de prioridade de atuação precisam ser definidas. Os FTs são os que ocorrem mais comumente nessa categoria, entretanto, nada impede a existência de FAOA cujo processo de instanciação também inclua a etapa de composição.

As formas de reúso apresentadas são válidas para frameworks caixa-branca. Quando o framework é caixa-preta, não importa como foi projetada a arquitetura da parte variável, pois todas as variabilidades já foram concretizadas e trata-se apenas de um processo de escolha que geralmente é feito com auxílio automatizado.

\section{3 - Proposta de UMA ARQUiTETURA PARA FRAMEWORKS TRANSVERSAIS}

Embora vários artigos tenham sido publicados sobre FTs, nenhum deles propõe uma arquitetura para o desenvolvimento desse tipo de software. A arquitetura proposta é esquematicamente mostrada na Figura 3.2. Há duas partes distintas, uma que implementa o comportamento transversal encapsulado pelo framework e outra que possui o papel de "conector" com algum código-base. A parte destacada com a letra (a) possui apenas classes que implementam a parte fixa (preenchido com a cor preta) e variável (sem preenchimento) do comportamento transversal encapsulado pelo framework. Essa parte geralmente é implementada com padrões de projeto comumente usados no desenvolvimento de frameworks, como por exemplo, Estratégia (Strategy), Método Gabarito (Template Method) e Fábrica de Objetos (Object Factory) (Gamma et al., 1995). A parte destacada com a letra (b) possui apenas aspectos que implementam a parte fixa e variável da composição. A parte variável desses aspectos é implementada por meio de mecanismos de composição abstratos, como por exemplo, conjuntos de junção abstratos. As setas tracejadas que partem dos aspectos em direção às classes representam dependências. Quando os FTs são dependentes de contexto, essa parte deve ser implementada com o padrão Capturador de Dados (Data Catcher), um padrão de projeto proposto no contexto desta tese.

Essa divisão em duas partes consiste em retirar dos aspectos todo o código que diz respeito ao comportamento funcional do framework e colocá-lo em classes, deixando nos aspectos apenas o código responsável por expor um determinado conjunto de pontos de junção e o código responsável por invocar métodos das classes. Essa divisão facilita 
manutenções tanto na parte do comportamento quanto na parte dos aspectos, pois não há entrelaçamento de interesses entre essas partes. Além disso, também facilita a implementação de FTs em outras abordagens orientadas a aspectos, como por exemplo JBoss-AOP (JBoss, 2006) e JASCO (Suvée et al., 2003), pois essas linguagens também trabalham com a idéia de conectores.

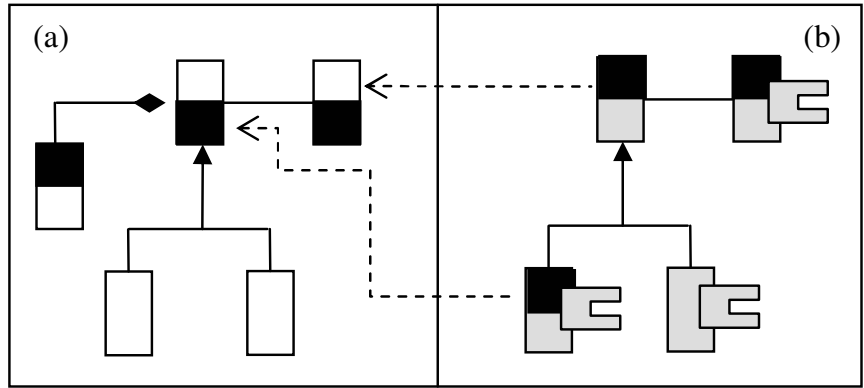

Figura 3.2 - Arquitetura de Referência para Frameworks Transversais

Na Figura 3.3 é mostrado esquematicamente o processo de reúso de um framework transversal desenvolvido com base na arquitetura proposta. Do lado esquerdo da figura encontra-se o FT e do lado direito uma aplicação hipotética. Do lado do FT, a letra (c) destaca uma divisão - na parte superior encontram-se as classes do FT e na parte inferior as classes e aspectos criados pelo engenheiro de aplicação durante o processo de reúso.

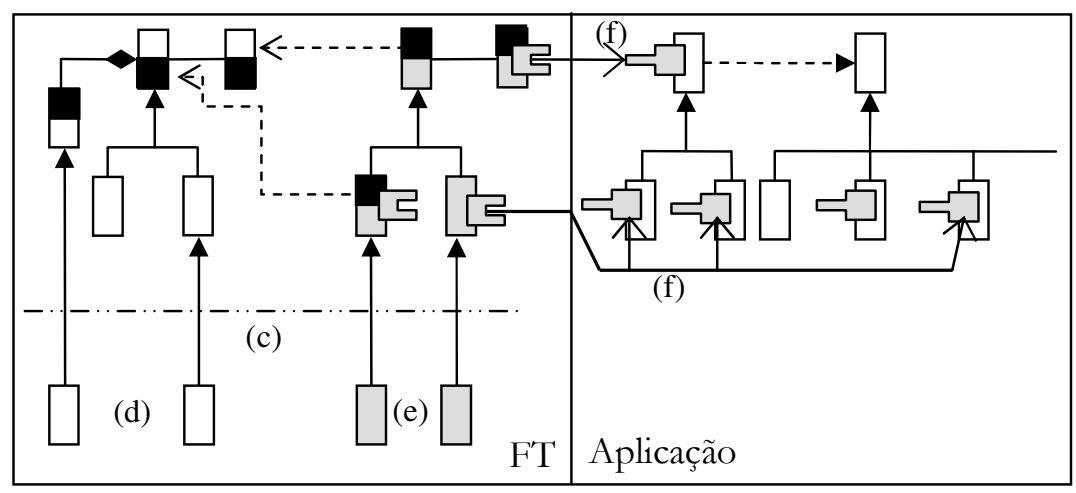

Figura 3.3 - Representação Esquemática da Instanciação de um Framework Transversal

$\mathrm{Na}$ etapa de instanciação (escolha de variabilidades), subclasses são criadas e métodos são concretizados com o objetivo de escolher alguma variabilidade do comportamento disponível no FT, o que está sendo representado pela letra (d). Na segunda etapa do processo de reúso, que é a composição, aspectos especializados são criados com o objetivo de fornecer regras de composição, isto é, pontos de junção da aplicação alvo onde a variabilidade 
(comportamento) escolhida na primeira etapa deve atuar, o que está sendo representado pela letra (e). Assim que as regras de composição forem definidas, os aspectos sabem os pontos da aplicação que devem ser entrecortados, o que está sendo representado pelas setas marcadas com as letras (f).

Ainda em relação à arquitetura de referência apresentada na Figura 3.2, sugere-se que a parte responsável pela composição com o código-base seja implementada com um padrão de projeto, proposto no contexto desta tese, denominado de Capturador de Dados (Data Catcher) (Camargo e Masiero, 2005a). Convém ressaltar que esse padrão só faz sentido se for utilizado com FTs dependentes de contexto, isto é, aqueles cuja interface de entrecorte necessita capturar dados do código-base para que possam funcionar.

Para justificar a importância desse padrão, na Figura 3.4 é mostrada a implementação convencional de um aspecto que faz parte de um FT dependente de contexto de Pooling. O objetivo desse FT é interromper a criação de conexões do código-base impedindo que a aplicação crie uma nova conexão se houver alguma disponível no repositório. Se não houver, o FT devolve o controle para a aplicação, permitindo que ela gere uma nova conexão, porém captura esse novo objeto Connection e o coloca no repositório. Há um conjunto de junção abstrato denominado poolconcrete () e um adendo que implementa o comportamento que irá atuar no ponto de junção fornecido pelo engenheiro de aplicação.

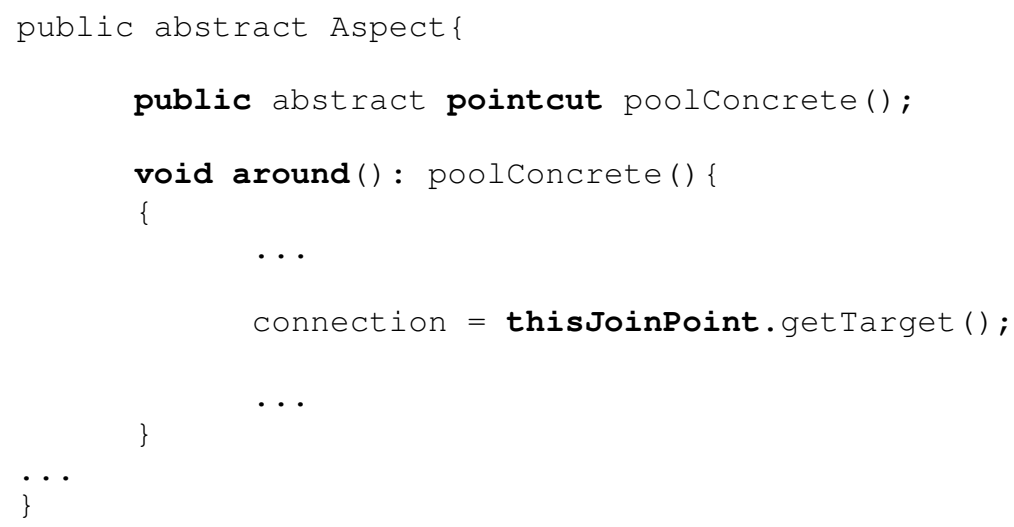

Figura 3.4 - Implementação Convencional de um FT de Pooling

Note-se que nesta implementação o código do adendo sempre realiza a captura do objeto Connection por meio da declaração thisJoinPoint.getTarget(), mas nada garante que em todo código-base ao qual esse FT for acoplado haverá um ponto de junção cujo objeto alvo da chamada/execução de um método seja o objeto Connection. Nesse contexto, uma alternativa é fornecer alternativas de composição, dando mais flexibilidade ao código e permitindo que o responsável pelo desenvolvimento escolha uma alternativa 
adequada. Como está implementado, pode não ser possível reusar o FT em determinados contextos. Uma alternativa ao uso desse padrão é modificar o código-base para se adequar ao FT, mas nada garante que o código-fonte sempre estará disponível.

Na Tabela 3.1 encontram-se as seis alternativas de composição do padrão Capturador de Dados. A segunda coluna contém o nome da alternativa e a terceira uma descrição que explica os detalhes das regras de composição que devem ser fornecidas e que aspecto deve ser estendido, o qual pode ser visto no diagrama apresentado pela Figura 3.5. Por exemplo, a alternativa "WithReturn" exige que o aspecto WithReturn seja estendido e que a regra de composição fornecida pelo engenheiro de aplicação identifique um ponto de junção no código-base que seja a chamada ou a execução de um método que retorne o dado requerido pelo FT.

Tabela 3.1 - Alternativas do Padrão de Composição

\begin{tabular}{|c|c|c|}
\hline № & $\begin{array}{c}\text { Alternativa de } \\
\text { Composição }\end{array}$ & Descrição \\
\hline 1 & WithReturn & $\begin{array}{l}\text { Esta alternativa consiste em estender o aspecto WithReturn e fornecer um ponto } \\
\text { de junção que seja a chamada ou a execução de um método cujo retorno é o } \\
\text { objeto/valor requerido pelo FT. }\end{array}$ \\
\hline 2 & This & $\begin{array}{l}\text { Esta alternativa consiste em estender o aspecto This e fornecer um ponto de } \\
\text { junção cujo objeto this possa ser utilizado para a obtenção do valor sujeito ao } \\
\text { cálculo por meio do método get GetMethodInChargeofGettingValue (). } \\
\text { Também deve ser possível atribuir o valor modificado a esse mesmo objeto por } \\
\text { meio do método get SetMethodInChargeofSettingValue (). Esse ponto de } \\
\text { junção pode ser uma chamada ou execução de um método, ou o acesso a um } \\
\text { atributo. }\end{array}$ \\
\hline 3 & Target & $\begin{array}{l}\text { Semelhante à alternativa anterior, porém o aspecto a ser estendido é Target e o } \\
\text { objeto target do ponto de junção fornecido é que será utilizado para obtenção e } \\
\text { atribuição do valor modificado. }\end{array}$ \\
\hline 4 & Args & $\begin{array}{l}\text { Semelhante à alternativa anterior, porém o aspecto a ser estendido é o Args e o } \\
\text { parâmetro do ponto de junção fornecido será determinado pelo índice fornecido } \\
\text { pelo engenheiro de aplicação por meio da concretização de um método abstrato. }\end{array}$ \\
\hline 5 & WithTwoParameters & $\begin{array}{l}\text { Esta alternativa consiste em estender o aspecto WithTwoParameters e fornecer } \\
\text { um ponto de junção com dois parâmetros, em que o primeiro parâmetro é um } \\
\text { objeto que pode ser utilizado para obter o valor a ser modificado, e o segundo } \\
\text { objeto deverá poder receber o valor modificado. }\end{array}$ \\
\hline 6 & OneArgument & $\begin{array}{l}\text { Esta alternativa consiste em estender o aspecto OneArgument e fornecer um } \\
\text { ponto de junção que seja a chamada ou a execução de um método cujo único } \\
\text { parâmetro seja o valor sujeito ao cálculo. }\end{array}$ \\
\hline
\end{tabular}

A escolha da alternativa que deve ser utilizada depende dos dados que o framework requer do ponto de junção, isto é, de sua interface, e também da estrutura do código-base. Na Tabela 3.2 é mostrado um modelo de decisão que auxilia na escolha da melhor alternativa. Cada linha da tabela consiste em uma pergunta que conduz à alternativa de composição correta da Tabela 3.1. Esse modelo de decisão deve ser utilizado cada vez que uma variabilidade do framework é instanciada durante o processo de reúso. 
Na Figura 3.5 é mostrada uma hierarquia de classes que representa os papéis do padrão. Apenas ilustrativamente, cada classe da hierarquia do aspecto Aspect representa um aspecto. Os aspectos abstratos marcados com um asterisco (*) representam as seis alternativas de composição que podem ser especializadas pelo engenheiro de aplicação. A parte que trata das variabilidades está representada com a letra (a) e as classes/aspectos que devem ser criadas durante o processo de reúso são representados pelas letras (c) e (d).

Tabela 3.2 - Modelo de Decisão

\begin{tabular}{|l|c|}
\hline \multicolumn{1}{|c|}{ Modelo de Decisão } & $\begin{array}{c}\text { Alternativa de } \\
\text { Composição }\end{array}$ \\
\hline Há no código-base um ponto de junção cujo retorno é o dado requerido pelo FT? & 1 \\
\hline $\begin{array}{l}\text { Há no código-base um ponto de junção cujo objeto target possui métodos de leitura e } \\
\text { escrita do dado requerido pelo FT? }\end{array}$ & 2 \\
\hline $\begin{array}{l}\text { Há no código-base um ponto de junção cujo objeto this possui métodos de leitura e } \\
\text { escrita do dado requerido pelo FT? }\end{array}$ & 3 \\
\hline $\begin{array}{l}\text { Há no código-base um ponto de junção para o qual algum de seus argumentos seja um } \\
\text { objeto que tenha métodos de leitura e escrita do dado requerido pelo FT? }\end{array}$ & 4 \\
\hline $\begin{array}{l}\text { Há no código-base um ponto de junção cujo objeto target tenha método de leitura do } \\
\text { valor sujeito ao cálculo e que o objeto this tenha método de escrita, ou vice-versa? }\end{array}$ & 5 \\
\hline $\begin{array}{l}\text { Há no código-base um ponto de junção para o qual o seu único argumento seja o valor } \\
\text { sujeito ao cálculo? }\end{array}$ & 6 \\
\hline
\end{tabular}

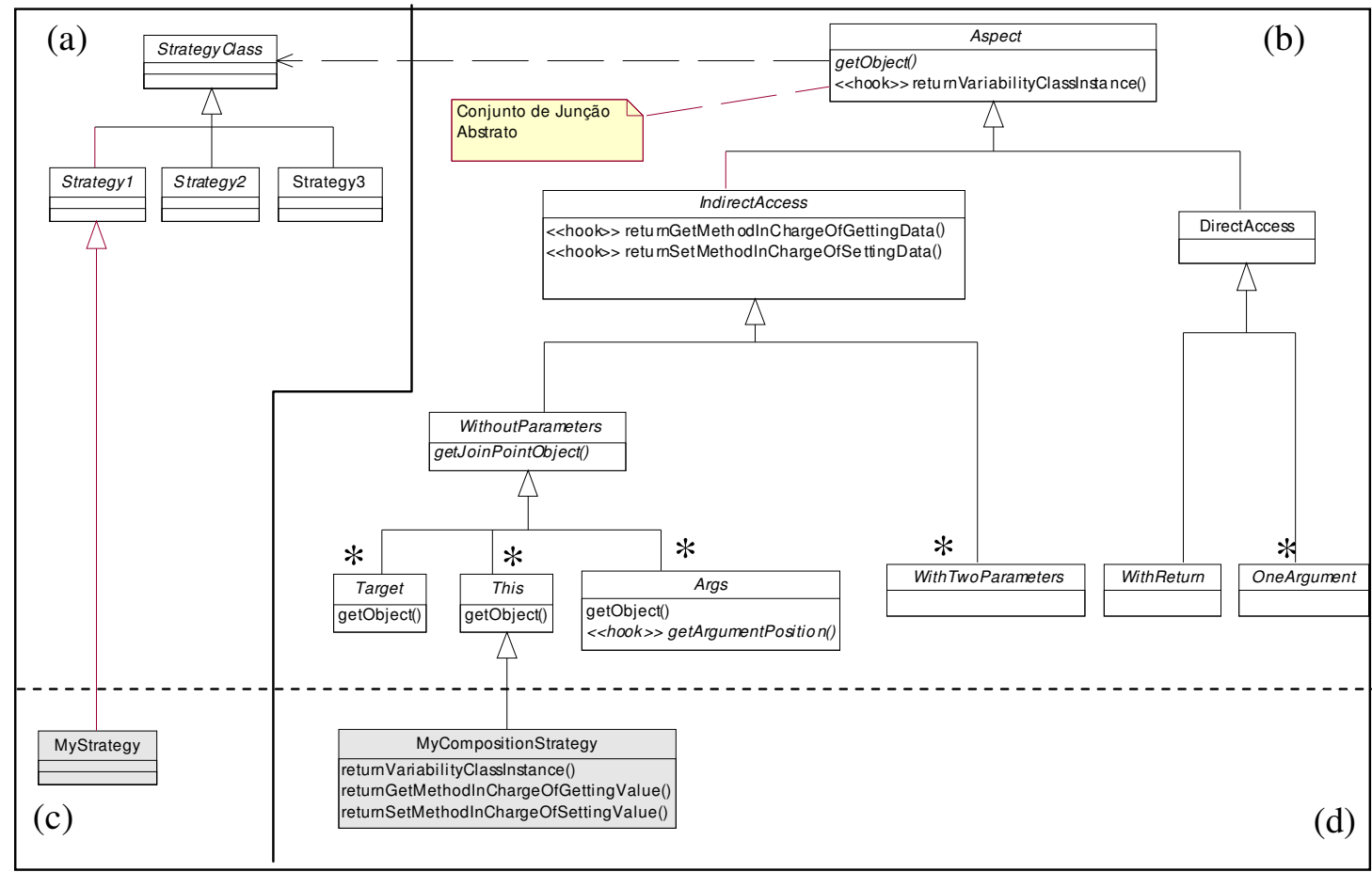

Figura 3.5 - Projeto de um Framework Transversal Genérico

A idéia de um FT com essa arquitetura é permitir que as variabilidades escolhidas/implementadas por meio da especialização realizada na parte (c), sejam acopladas 
a um código-base que é identificado pelas regras de composição fornecidas pelos aspectos criados na parte (d). Por exemplo, a classe MyStrategy representa que a variabilidade escolhida foi a Estratégia número 1 (classe Strategy1), e que ela será acoplada a algum código-base utilizando a alternativa de composição This (aspecto This), por meio das regras de composição definidas no aspecto MyCompositionStrategy.

Geralmente, a parte que trata das variabilidades é projetada com padrões de projeto já conhecidos, como o Strategy, Factory Method e/ou Template Method (Gamma et al., 1995). Como a implementação desses padrões com orientação a objetos pode causar problemas de entrelaçamento e espalhamento, aspectos também podem ser usados para projetar essa parte (Hanemann e Kiczales, 2002). Entretanto, deve-se inicialmente averiguar as vantagens e desvantagens dessa decisão em termos de separação de interesses e de modularidade. Por exemplo, o padrão Strategy apresenta benefícios em termos de separação de interesses, mas não em modularidade (Garcia et al., 2005).

Do lado direito superior da Figura 3.5, representado pela letra (b), é mostrado o diagrama de projeto genérico do padrão. Toda a hierarquia do padrão é baseada em duas formas de obtenção do dado requerido: direta, representada por meio do aspecto DirectAcces, e indireta, representada pelo aspecto IndirectAccess. A forma direta consiste em alternativas de composição que capturam o dado desejado sem a necessidade de ação reflexiva, isto é, o valor é obtido diretamente a partir do ponto de junção, por exemplo a chamada de um método que retorna o valor desejado (aspecto WithReturn). A forma indireta ocorre por meio de algum objeto intermediário, isto é, primeiramente obtém-se um objeto do contexto de execução, por exemplo o target ou o this, e a partir dele obtém-se reflexivamente o valor desejado, por meio dos métodos-gancho, getGetMethodInChargeofGettingData e getSetMethodInChargeofSettingData, pertencentes ao aspecto IndirectAccess. Alguns estereótipos utilizados nesse modelo facilitam a documentação e a identificação dos pontos de extensão do framework, como, por exemplo, o estereótipo $<\langle$ hook $>>$, que representa métodos-gancho que devem ser sobrepostos pelo engenheiro de aplicação (Fontoura et al., 2002).

A nota anexada ao aspecto Aspect mostra a existência de um conjunto de junção abstrato, que deve ser definido durante o processo de reúso. Esse conjunto de junção deve ser projetado adequadamente dentro da estrutura do framework para garantir, tanto quanto possível, que as regras de composição entrecortem somente os pontos de junção permitidos. Isso deve ser feito para preservar a integridade do comportamento da aplicação e do framework, justamente quando regras de composição não adequadas são fornecidas. Por 
exemplo, nada impede que o engenheiro de aplicação forneça uma regra de composição que entrecorte chamadas de todos os métodos em todas as classes do sistema. Isso causaria um funcionamento incorreto do framework que poderia danificar o sistema. Se diretrizes de projeto forem seguidas (Camargo et al, 2004) e idiomas forem utilizados (Hanenberg e Schimidmeier, 2003a; Hanenberg e Schimidmeier, 2003b), como o Composit Pointcut e o Template Advice, esses problemas podem ser amenizados.

As letras (c) e (d) da Figura 3.5 representam esquematicamente como ocorre o processo de reúso. A etapa de instanciação é feita somente na parte OO e a etapa de composição na parte que possui os aspectos, separando fisicamente essas duas etapas. Cada aspecto criado na etapa de composição é específico de uma classe criada na etapa de instanciação, pois o método-gancho returnVariabilityclassInstance() deve ser implementado pelo engenheiro de aplicação com o objetivo de retornar uma instância da subclasse criada. Essa abordagem de projeto se aproxima de algumas abordagens orientadas a aspectos em que as regras de composição são informadas separadamente do comportamento transversal, como por exemplo JBoss-AOP, AspectWerkz e JAML (JAML, 2004).

Muitas vezes a utilização desse padrão também impõe uma ordem no processo de reúso, pois os nomes das sub-classes criadas na etapa de instanciação podem ser utilizados na etapa de composição, já que cada variabilidade escolhida possui pelo menos um aspecto correspondente.

Um detalhe interessante de projeto ocorre na hierarquia do aspecto WithoutParameters. Esse aspecto utiliza o método abstrato getJoinPointobject() para obter um objeto do contexto de execução que possa ser utilizado para capturar o dado desejado. Esse método é redefinido em cada um dos aspectos especializados (This, Target e Args) com o objetivo de retornar diferentes objetos do contexto de execução, fornecendo assim três alternativas de composição. Na Figura 3.6 é mostrado parcialmente o código fonte dos aspectos WithoutParameters e This. O adendo do aspecto WithoutParameters utiliza o método abstrato getJoinPointobject() para obter um objeto do contexto de execução a partir do ponto de junção passado por parâmetro. Esse objeto pode ser o target, o this ou um argumento, dependendo do aspecto que foi especializado. Esse método é implementado nos aspectos Target, This e Args, retornando o objeto apropriado, como pode ser visto no código do aspecto This. Se o adendo do aspecto WithoutParameters não utilizasse esse método abstrato, ele deveria fixar o objeto capturado do contexto, o que restringiria bastante as chances de acoplamento do framework. Por exemplo, se o objeto capturado fosse sempre o target, as regras de composição fornecidas pelo engenheiro da 
aplicação deveriam sempre identificar no código-base um ponto de junção cujo objeto target fosse o objeto ideal, o que pode não acontecer em muitas situações.

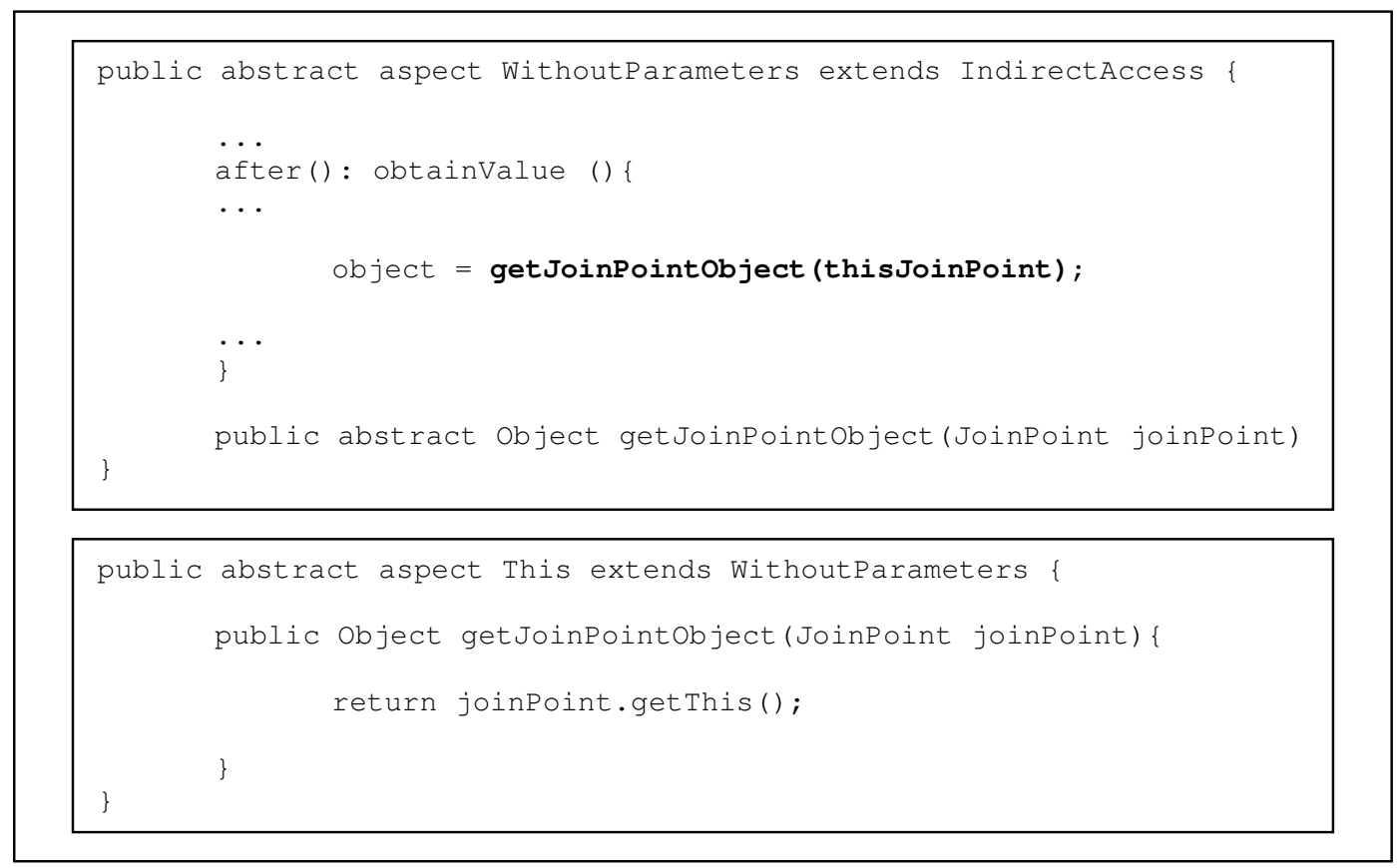

Figura 3.6 - Exemplo de Implementação do Padrão

O projeto mostrado na Figura 3.5 possui os elementos (aspectos, conjuntos de junção e métodos abstratos) básicos para se projetar um FT. Entretanto, outros elementos podem ser adicionados nessa hierarquia de acordo com o problema e o interesse transversal que está sendo encapsulado. Também ressalta-se que em determinadas situações não é necessário aplicar o padrão em sua totalidade, podendo-se remover partes da hierarquia, evitando assim trechos de códigos desnecessários na aplicação final.

As alternativas do padrão formam um conjunto de opções para o acoplamento quando se necessita capturar dados do código-base. Elas também podem ser vistas como interfaces de entrecorte que requerem determinadas propriedades para o acoplamento (Griswold et al., 2006). Elas foram identificadas com base na experiência com o desenvolvimento de FTs e estudo de trabalhos relacionados, mas nada impede que novas alternativas sejam necessárias, principalmente quando o acoplamento for feito com códigos-base já existentes. Nesse caso, o engenheiro de aplicação pode criar novas alternativas estendendo os aspectos mais genéricos da hierarquia, como por exemplo o DirectAccess ou o IndirectAccess. As novas alternativas criadas podem ser incluídas no padrão caso sejam soluções para problemas recorrentes.

Embora cada classe dessa hierarquia mostrada na Figura 3.5 represente um aspecto, esse padrão também pode ser implementado como uma hierarquia de classes, desde que uma 
hierarquia de aspectos correspondentes seja mantida. Como os FTs desenvolvidos no contexto desta tese são projetados como temas, se houver interesse que a hierarquia do padrão fique explícita no modelo, ela deve ser implementada com classes.

Uma propriedade interessante de um FT projetado com esta arquitetura é que ele pode ser instanciado mais de uma vez para uma mesma aplicação ou código-base, isto é, diferentes variabilidades podem ser escolhidas para atuarem em pontos de junção diferentes ou iguais no mesmo código-base. Quando atuam no mesmo ponto de junção deve haver algum mecanismo que controle a precedência de atuação dos aspectos, como por exemplo o declare precedence da linguagem AspectJ. Na próxima seção é mostrado um exemplo que reusa o FT mais de uma vez para a mesma aplicação.

Outro ponto interessante a analisar são as possibilidades de acoplamento permitidas com o uso do padrão:

1. (1:1) Quando uma variabilidade é acoplada ao código-base utilizando uma única alternativa de composição. Neste caso, cada classe que representa uma variabilidade é acoplada ao código-base usando uma única alternativa de composição. Note-se que pode haver mais de um aspecto correspondente à classe, porém o mais comum é que haja apenas um, e que as regras de composição fornecidas atuem em vários pontos.

2. (1:N) Quando uma variabilidade é acoplada ao código-base com mais de uma alternativa de composição. Neste caso a classe que representa a variabilidade terá mais de um aspecto correspondente, em que cada um especializa uma alternativa diferente de composição.

3. (N:1) Quando várias variabilidades utilizam uma mesma alternativa de composição. Neste caso cada classe de variabilidade também possui um aspecto correspondente, porém todos eles utilizam a mesma alternativa de composição, isto é, especializam o mesmo aspecto do framework.

4. (N:N) Quando várias variabilidades utilizam várias alternativas de composição. Ocorre quando as possibilidades de acoplamento 1:N e $\mathrm{N}: 1$ ocorrem simultaneamente no mesmo reúso do framework.

Depois que o processo de reúso foi completado e que o sistema final foi obtido, devese decidir por manter ou eliminar as alternativas de composição que não foram utilizadas. Por exemplo, se o framework foi reusado em um sistema que utilizou as alternativas WithoutParameters, OneArgument e WithReturn (Figura 3.5), pode-se decidir por eliminar a hierarquia do aspecto WithoutParameters. Essa decisão depende da natureza da aplicação que foi desenvolvida, pois se ela possui uma alta probabilidade de mudança de 
requisitos é interessante que essas alternativas permaneçam na arquitetura do framework, pois será mais fácil instanciar uma nova variabilidade caso a alternativa de composição já exista. A hierarquia do padrão não possui muito código e não causa muitos problemas de degradação de desempenho caso permaneçam no sistema.

\subsection{1- Exemplo de Utilização do Padrão Capturador de Dados}

Com o objetivo de exemplificar a utilização do padrão Capturador de Dados e o processo de reúso de um FT, será mostrado nesta seção um estudo de caso que faz uso de um dos FTs desenvolvidos no contexto desta tese: o FT de Cálculo Baseado em Tabela. Esse framework modulariza uma regra de negócio que tem o objetivo de incrementar ou decrementar um valor capturado do código-base por meio de um cálculo percentual, o qual depende da faixa em que o valor capturado se enquadra. Esse cálculo pode ainda fazer uso de um redutor, que é um valor fixo que será subtraído do cálculo percentual. Regras de negócio típicas que podem ser tratadas por esse framework são: um valor de vale-refeição que pode ou não ser acrescido ao salário do funcionário dependendo de sua faixa salarial; um desconto na conta de água para usuários cujo consumo esteja, por exemplo entre 11 e $15 \mathrm{~m}^{3}$ e um bônus para funcionários cujo número de horas extras mensal é superior a 30. A estrutura da tabela utilizada no cálculo é fixa, mas os valores podem variar conforme a regra de negócio em uso. Na Tabela 3.3 é mostrada a estrutura da tabela e valores para o cálculo do imposto de renda, que também é uma das regras de negócio que pode ser tratada por esse framework e que faz uso do redutor.

Tabela 3.3 - Tabela do Framework de Regra de Negócio para o Cálculo do Imposto de Renda

\begin{tabular}{|l|l|l|}
\hline \multicolumn{1}{|c|}{ Base de cálculo } & \multicolumn{1}{|c|}{ Porcentagem } & \multicolumn{1}{c|}{ Redutor } \\
\hline Até $\mathrm{R} \$ 1.164,00$ & 0 & 0 \\
\hline De RS 1.164,01 a R $\$ 2.326,00$ & $15 \%$ & $\mathrm{R} \$ 176,60$ \\
\hline Acima de $\mathrm{R} \$ 2.326,00$ & $27,5 \%$ & $\mathrm{R} \$ 465,35$ \\
\hline
\end{tabular}

O modelo de projeto do framework de cálculo baseado em tabela pode ser visto na Figura 3.7. Os aspectos estão sendo representados apenas ilustrativamente por classes em cinza. Os métodos que possuem o estereótipo $<<$ hook $>>$ são abstratos e devem ser estendidos pelo engenheiro da aplicação. Esse estereótipo auxilia a documentar o framework, facilitando a identificação dos pontos de extensão (Fontoura et al, 2002).

Este FT possui quatro variabilidades funcionais e seis alternativas de composição. A instanciação deve ser feita por meio das classes abstratas WithoutDeductible e WithDeductible, a primeira deve ser escolhida quando a regra de negócio possui um redutor e a segunda quando não possui. Para fazer a instanciação o engenheiro de aplicação deve criar uma subclasse que representa a regra de negócio que se deseja tratar, definir seus 
construtores e implementar o método-gancho is Increment (), o qual permite escolher o algoritmo de incremento ou de decremento. Deve ser criada uma subclasse e uma tabela no banco de dados para cada regra de negócio a ser tratada pelo framework. Caso seja de interesse do engenheiro de aplicação, uma nova variabilidade pode ser adicionada na hierarquia especializando-se a classe Calculation.

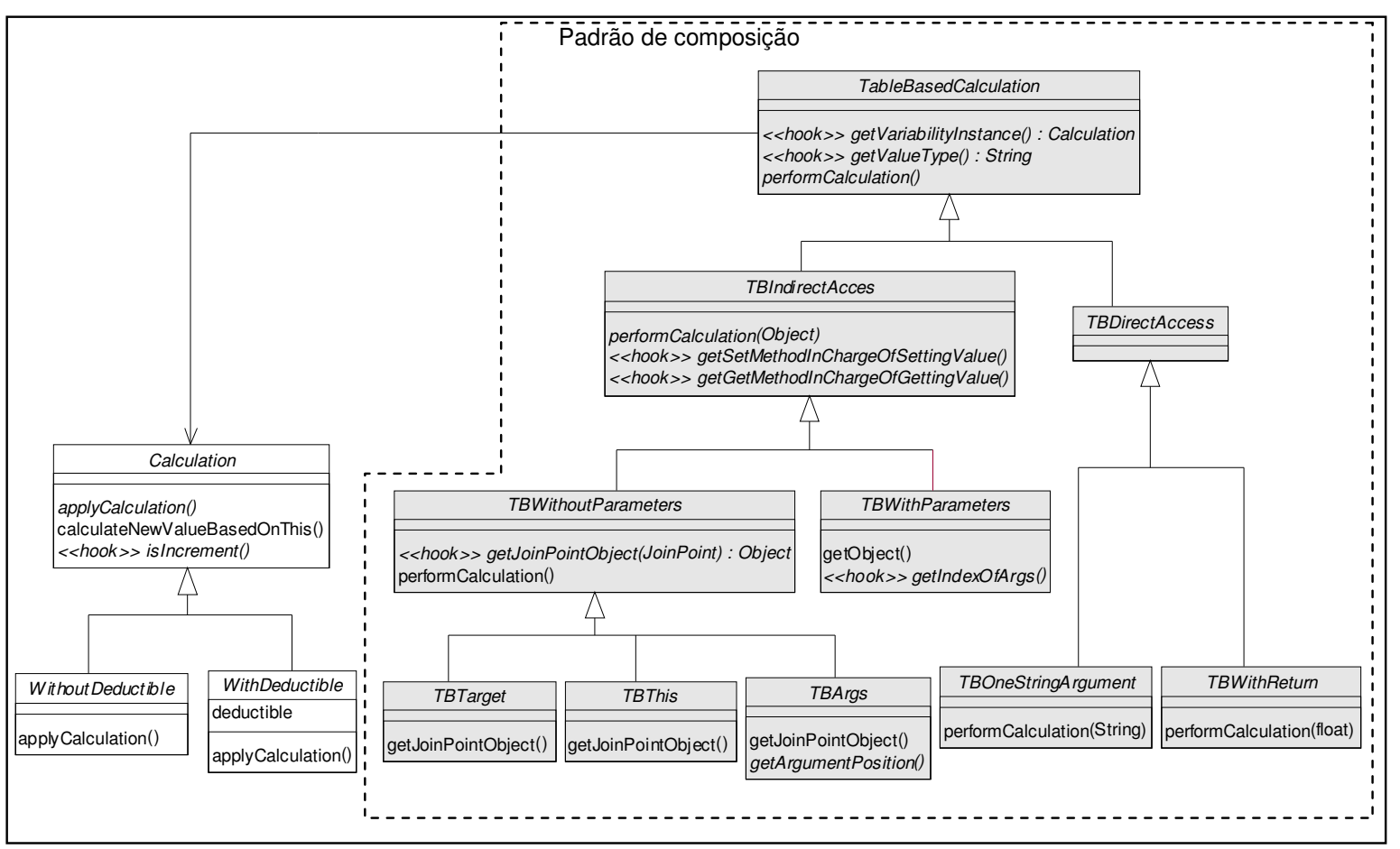

Figura 3.7 - Modelo de Projeto do FT de Cálculo Baseado em Tabela

Como descrito anteriormente, a etapa de composição consiste em duas atividades: identificação dos pontos de junção e fornecimento das regras de composição. Para identificar o(s) ponto(s) de junção mais adequado(s) deve-se analisar nas especificações do framework o que ele requer dos pontos de junção e verificar quais são as alternativas de composição disponíveis. No caso deste framework, o importante é que por meio do ponto de junção escolhido seja possível obter o valor que será submetido ao cálculo da regra de negócio. Como há várias formas de se obter esse valor deve-se analisar as alternativas de composição do framework para identificar como cada uma delas obtém o valor e procurar um ponto de junção adequado. Com isso, pode-se decidir que ponto de junção será fornecido na regra de composição e, assim, qual será a forma de captura do valor, se por meio de um método que retorna o valor, se por meio de um objeto que possui o valor, ou alguma outra forma. As seis alternativas de composição disponíveis podem ser vistas na Tabela 3.4. Note-se que essa tabela é a instanciação da tabela genérica (Tabela 3.1) para o contexto do FT de Cálculo. 
O fornecimento das regras de composição deve ser feito criando-se aspectos especializados que correspondem a cada regra de negócio tratada, isto é para cada subclasse de WithoutDeductible e/ou WithDeductible. Os aspectos que podem ser estendidos pelo engenheiro de aplicação são: TBTarget, TBThis, TBArgs, TBWithParameters, TBOneStringArgument e TBWithReturn, os quais representam cada uma das alternativas de composição do padrão mostrado na Tabela 3.4. A criação desses aspectos também exige a implementação de alguns métodos-gancho, como, por exemplo, getVariabilityInstance(), que é um método-gancho do aspecto TableBasedCalculation. Esse método deve retornar o nome da classe que representa a regra de negócio tratada, fazendo uma correspondência com a subclasse que foi criada na etapa de instanciação. Corresponde ao método returnVariabilityclass Instance () do aspecto Aspect mostrado na Figura 3.5. A implementação do método getVariabilityInstance() é um fator que determina a ordem do processo de reúso deste framework. Como o nome da classe retornada é determinado na etapa de instanciação, não seria possível realizar a composição antes da instanciação.

Tabela 3.4 - Alternativas de Composição do FT de Cálculo Baseado em Tabela

\begin{tabular}{|l|l|}
\hline \multicolumn{1}{|c|}{ Nome } & \multicolumn{1}{c|}{ Descrição } \\
\hline $\begin{array}{l}\text { Com Retorno } \\
\text { (WithReturn) }\end{array}$ & $\begin{array}{l}\text { Esta alternativa consiste em estender o aspecto TBWithRet urn e fornecer um ponto de junção cujo retorno é o valor } \\
\text { ser modificado. Esse ponto de junção pode ser tanto uma chamada, quanto a execução de um método. }\end{array}$ \\
\hline This & $\begin{array}{l}\text { Esta alternativa consiste em estender o aspecto TBThis e fornecer um ponto de junção que a partir do seu objeto this } \\
\text { pode-se obter o valor a ser modificado. Também deve ser possível atribuir o valor modificado a esse mesmo objeto. } \\
\text { Esse ponto de junção pode ser uma chamada ou execução de um método, ou o acesso a um atributo. }\end{array}$ \\
\hline Target & $\begin{array}{l}\text { Semelhante à alternativa anterior, porém o aspecto a ser estendido é o TBTarget e objeto target do ponto de junção } \\
\text { fornecido é que será utilizado para obtenção e atribuição do valor modificado. }\end{array}$ \\
\hline Args & $\begin{array}{l}\text { Semelhante às duas alternativas anteriores, porém o aspecto a ser estendido é o TBArgs e o primeiro argumento do } \\
\text { ponto de junção fornecido é que será utilizado para obtenção e atribuição do valor modificado. }\end{array}$ \\
\hline $\begin{array}{l}\text { Com } \\
\text { parâmetros }\end{array}$ & $\begin{array}{l}\text { Esta alternativa consiste em estender o aspecto TBWithParameters e fornecer um ponto de junção com dois } \\
\text { parâmetros, em que o primeiro parâmetro é um objeto que pode ser utilizado para obter o valor a ser modificado, e o } \\
\text { segundo objeto deverá poder receber o valor modificado. }\end{array}$ \\
\hline
\end{tabular}

É interessante destacar que o projeto mostrado na Figura 3.7 evidencia algumas características da definição de FTs apresentada na Seção 3.2. Por exemplo, a existência de mecanismos de composição abstratos e conjuntos de junção. As variabilidades são tratadas por classes normais. A divisão semântica entre escolha de variabilidades e composição mantém-se fisicamente separada neste projeto, em que a primeira etapa é feita por meio de classes e a segunda por meio de aspectos. Além disso, pode-se perceber que não é possível instanciar este framework sem um código-base, o que não ocorre com os FAOAs.

Ressalta-se também que o processo de escolha de alternativas de composição pode incluir uma atividade de exclusão das alternativas que não foram escolhidas, deixando a aplicação apenas com o código que é estritamente necessário. Por exemplo, caso a alternativa de composição TBWithReturn tenha sido utilizada, toda a hierarquia do aspecto 
TBWithoutReturn e inclusive ele, poderiam ser eliminados, facilitando manutenções e não sobrecarregando o código objeto com trechos não executáveis. Além disso, o FT pode ser projetado com um sub-conjunto das alternativas de composição existentes, como é o caso dos FT de Persistência e de Segurança que serão mostrados na próxima seção.

Para ilustrar o reúso de FTs projetado com o padrão, foi desenvolvido um sistema de oficina de aparelhos eletrônicos. Esse sistema inclui um sub-sistema de pessoal que controla a remuneração dos funcionários, além de realizar o fechamento mensal e gerar a folha de pagamento. O salário-base varia conforme a função que exercem na oficina. $O$ cálculo do salário mensal ocorre com base em eventos variáveis, eventos fixos e deduções legais que ocorrem durante o mês. Os eventos variáveis podem ser, por exemplo: uma falta, algumas horas de atraso, determinadas comissões e horas extras. Um exemplo de evento fixo é o cálculo do valor do vale-refeição e um exemplo de uma dedução legal é o imposto de renda. O cálculo do imposto de renda segue as regras definidas na Tabela 3.3 e o cálculo do valerefeição as definidas na Tabela 3.5. A diferença entre essas regras é que o cálculo do imposto de renda é uma regra de decremento com redutor, enquanto que o do vale-refeição é de incremento sem redutor.

Tabela 3.5 - Tabela para Cálculo do Vale-Refeição

\begin{tabular}{|l|l|}
\hline \multicolumn{1}{|c|}{ Base de cálculo } & \multicolumn{1}{c|}{ Porcentagem } \\
\hline Até $\mathrm{R} \$ 600$ & $10 \%$ \\
\hline De $\mathrm{R} \$ 600,01$ a RS $1.000,00$ & $8 \%$ \\
\hline Acima de R $\$ 1.000,01$ & $5 \%$ \\
\hline
\end{tabular}

O framework de cálculo baseado em tabela foi utilizado para tratamento das regras de negócio referentes ao vale-refeição e ao imposto de renda. Na Figura 3.8 é mostrado esse FT acoplado ao sub-sistema de pessoal. Novamente os aspectos estão sendo representados por classes destacadas na cor cinza e os relacionamentos de dependência que partem dos aspectos myIncomeTax e MyMealTicket em direção às classes PayRoll e Employee representam que esses aspectos entrecortam pontos de junção dessas classes. Para economizar espaço, na parte superior da figura é mostrada apenas uma parte do FT apresentado pela Figura 3.7. Na parte intermediária são mostradas as classes e aspectos criados pelo engenheiro de aplicação durante o processo de reúso e na parte inferior as classes do sistema de pessoal.

A instanciação é feita estendendo-se as classes WithoutDeductible e WithDeductible. Assim, as classes IncomeTax (Imposto de renda) e MealTicket (vale-refeição) foram criadas para representar as regras de negócio que devem ser tratadas. Na Figura 3.9 é mostrado o código fonte dessa segunda classe com os métodos que ela deve conter, isto é, com dois construtores, um vazio e um normal, e o método is Increment (), que permite escolher um dos algoritmos alternativos do framework. 
Como mencionado anteriormente, a etapa de composição consiste em identificar os pontos de junção apropriados no código-base e escolher a alternativa de composição mais adequada. O ponto de junção que foi identificado no código-base para a composição da regra de cálculo do vale-refeição é mostrado na Figura 3.10. O método apresentado é responsável por efetuar o fechamento mensal com base nos eventos fixos e variáveis do funcionário. $\mathrm{O}$ cálculo realizado por este método inicia obtendo o valor do salário-base da função exercida pelo funcionário e prossegue realizando acréscimos e deduções baseados nos eventos variáveis ocorridos durante o mês.

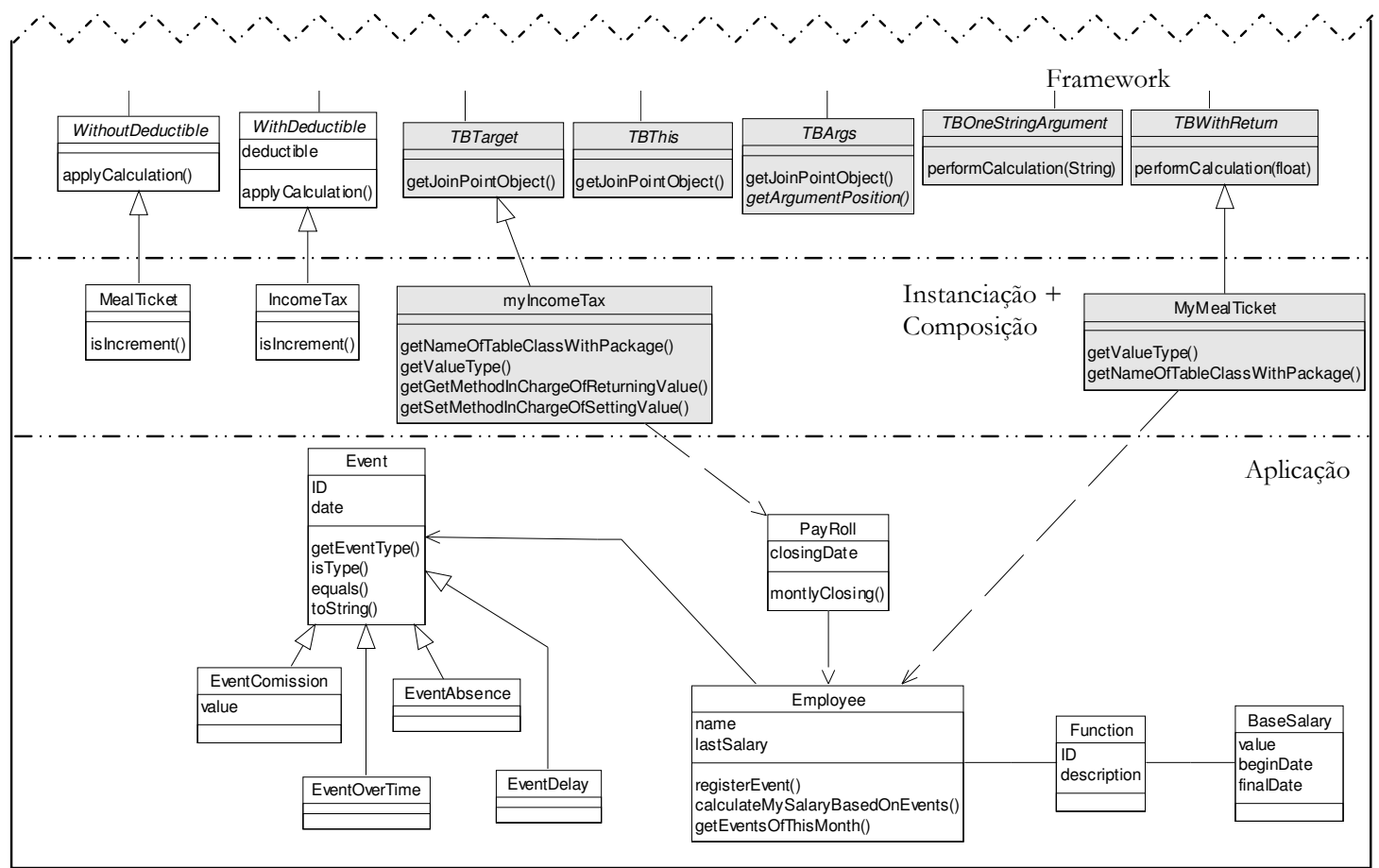

Figura 3.8 - Framework de Cálculo Baseado em Tabela Instanciado

public class MealTicket extends WithoutDeductible \{

public MealTicket ()

public MealTicket (...

$\{\operatorname{super}(\ldots) ;\}$

public boolean isIncrement() \{ return true; \}

Figura 3.9 - Escolha de Variabilidades

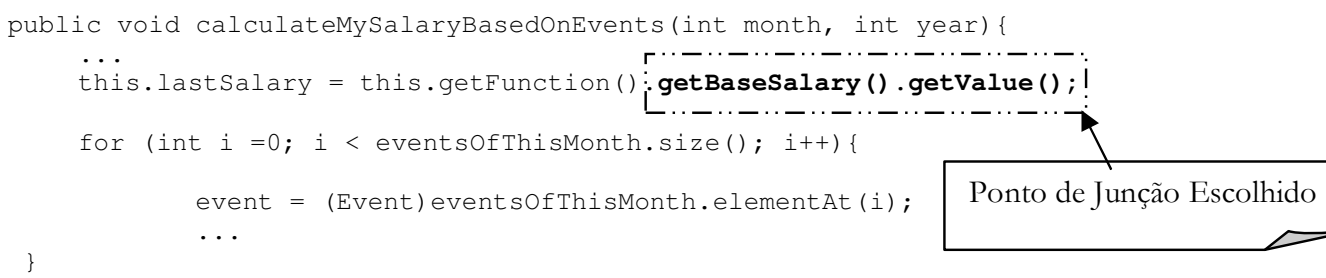

Figura 3.10 - Ponto de Junção na Aplicação 
Assumindo-se que o valor do vale-refeição deve ser acrescido ao salário do funcionário antes dos descontos legais, este é um bom momento para realização do cálculo. Portanto, foi identificado que por meio da chamada do método getvalue() o valor do salário-base poderia ser capturado com a alternativa de composição "com retorno", já que esse método retorna o valor sujeito ao cálculo. Assim, foi criado o aspecto MyMealTicket (Figura 3.11), que estende o aspecto TBWithReturn e que permite compor a regra de negócio de cálculo do vale-refeição (representada pela classe MealTicket) com o códigobase.

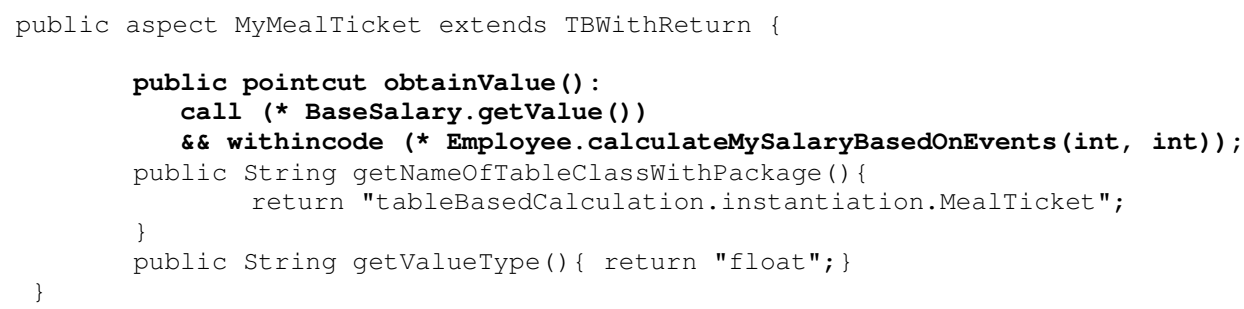

Figura 3.11 - Aspecto da Regra de Negócio de Cálculo do Vale-Refeição

Na Figura 3.11 é mostrado o código do aspecto MyMealTicket. Como definido na especificação do framework, quando se utiliza a alternativa de composição "Com Retorno", o ponto de junção fornecido pelo engenheiro de aplicação deve ser uma chamada ou execução de um método que retorne o valor a ser modificado. Portanto, a regra de composição definida entrecorta chamadas ao método getValue () da classe BaseSalary originadas do método calculateMysalaryBasedonEvents() da classe Employee, como representado pela dependência entre o aspecto MyMealTicket e a classe Employee na Figura 3.7. Essas chamadas retornam o valor do salário-base do funcionário, que é o valor a ser modificado com base na tabela de vale-refeição. Nesse mesmo aspecto, o método getNameofTableClassWithPackage () também deve ser implementado para informar ao framework o nome da classe que representa a regra de negócio a ser considerada. Isto é, quando a chamada ao método getvalue() acontecer, a regra de negócio que deve ser aplicada é definida pela classe MealTicket. A implementação do método getValueType() também é obrigatória pois define o tipo primitivo do valor que será modificado.

A existência de um ponto de junção que retorne o valor desejado é a situação ideal de acoplamento, como ocorreu no exemplo acima. Entretanto, isso pode não ocorrer e, neste caso, uma outra alternativa de composição deve ser escolhida. Por exemplo, o acoplamento da regra de negócio de cálculo do imposto de renda foi feito com a alternativa "sem parâmetro 
(target)", pois não havia um ponto de junção no código-base que retornasse o salário que é base para esse cálculo. Na Figura 3.12 é mostrado o ponto de junção que foi utilizado para essa composição. Essa linha de código pertence a um método do sistema de folha de pagamento responsável por efetuar o fechamento mensal. Utilizando a alternativa de composição "sem parâmetro (target)" o framework captura o objeto employee e usa reflexividade para capturar e alterar o valor do salário.

Note-se que a utilização de reflexividade é fundamental para bons projetos de acoplamento, principalmente para frameworks que necessitam obter valores da aplicação. Geralmente a obtenção desses valores não é tão simples e o responsável pelo fornecimento das regras de composição deve ter conhecimento dos pontos de junção adequados e de como esses valores podem se capturados.

employee.calculateMySalaryBasedOnEvents (initialDate.getMonth (), 2004);

$\cdots$

Figura 3.12 - Ponto de Junção para o Acoplamento do Imposto de Renda

Os cálculos do imposto de renda e do vale-refeição são apenas exemplos concretos de possíveis instanciações do framework de cálculo baseado em tabela. Em sistemas de grande porte o cálculo generalizado por este framework pode ser utilizado por outras regras de negócio, com características próprias e que podem ou não ser temporárias. O uso do mesmo cálculo a partir de vários pontos do sistema torna o código de diferentes interesses espalhado e entrelaçado. Além disso, como geralmente as regras de negócio tendem a se alterar com muito mais freqüência do que a funcionalidade do sistema, mantê-las em módulos separados traz benefícios para modularidade e, conseqüentemente, para a manutenção.

Um ponto que pode ser questionado é se a implementação do interesse mostrado nesta seção é factível com aspectos, ou se deveria ser implementado de forma convencional com orientação a objetos. Nesse sentido, há dois fatores que devem ser analisados. O primeiro é a volatilidade do interesse, isto é, sua probabilidade de mudança. Visto que regras de negócio, como imposto de renda e vale-refeição tem alta probabilidade de mudança durante o tempo de vida do sistema, sua implementação com técnicas que facilitem a remoção e inclusão no código-fonte, como a POA, pode ser uma estratégia que apresente benefícios durante a manutenção do sistema.

Outro fator é quanto à transversalidade do interesse. As regras de negócio mostradas nesta seção não são transversais, já que cada uma afeta apenas um ponto de junção do códigobase. Contudo, embora as regras de negócio em si não sejam transversais, o algoritmo utilizado por ambas as regras é o mesmo, e é utilizado, portanto, em dois locais do código. O 
sistema utilizado como estudo de caso é de pequeno porte, entretanto, um sistema de grande porte poderia utilizar esse mesmo algoritmo em vários locais do código para o tratamento de regras de negócio diferentes, caracterizando o algoritmo como transversal. Assim, argumentase que, embora algumas regras de negócio específicas não sejam transversais, os algoritmos utilizados para tratamento dessas regras podem ser, o que justifica sua implementação de forma genérica e conseqüentemente com POA.

\section{4 - CONSIDERAÇÕES FINAIS}

O objetivo neste capítulo foi analisar o panorama atual da literatura de FTs e propor uma homogeneização com relação aos termos e à arquitetura utilizada no desenvolvimento desses softwares. A ausência de termos bem definidos prejudica o crescimento da área gerando dúvidas sobre o que realmente é um determinado software. Um exemplo disso é a utilização do termo "framework orientado aspectos" para designar frameworks completamente diferentes.

A arquitetura proposta para FTs deve auxiliar desenvolvedores na criação de FTs dependentes de contexto com uma arquitetura mais clara e padronizada. A utilização do padrão Capturador de Dados auxilia no fornecimento de alternativas de composição, cujo objetivo é prover formas alternativas de acoplamento com um código-base. A adoção de uma arquitetura padrão também se torna particularmente importante quando famílias de FTs devem ser criadas.

No Capítulo 4 é apresentado o repositório desenvolvido no contexto desta tese como famílias de FTs. Assim linhas de produtos de FTs são definidas permitindo a configuração de diversos FTs com características distintas. Uma particularidade dessas famílias é a implementação de características como FTs, o que facilita o acoplamento e o desacoplamento com uma característica-base. Além disso, a implementação de características como frameworks propicia seu reúso também fora de sua linha de produtos original. 


\section{Capítulo 4}

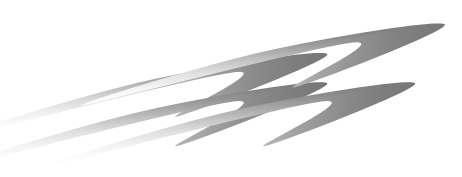

Familias de Frameworks Transversais

\section{1 - CONSIDERAÇÕES INICIAIS}

Neste capítulo, os FTs desenvolvidos no contexto desta tese são apresentados na forma de três famílias: persistência, segurança e regras de negócio. Cada família caracteriza uma linha de produtos de FTs para um determinado interesse. Cada linha de produtos possui características também implementadas na forma de FTs que podem ser usadas durante a configuração de membros da família. Com o objetivo de exemplificar a estrutura e a forma de utilização de uma família, o FT de persistência e o de Segurança são discutidos detalhadamente.

$\mathrm{Na}$ Seção 4.2 é fornecida uma visão geral das famílias de FTs desenvolvidas no contexto desta tese. Na Seção 4.3 é mostrada uma linha de produtos de FTs de persistência e como utilizá-la. Na Seção 4.4 discute-se, com um nível de detalhes menor, uma linha de produtos de FTs de segurança e na Seção 4.5 são apresentadas as considerações finais.

\section{2 - FAMÍLIAS DE FRAMEWORKS TRANSVERSAIS}

Na Tabela 4.1 são apresentados os FTs desenvolvidos no contexto desta tese. A primeira coluna divide os FTs em três famílias: persistência, segurança e regras de negócio, de acordo com o interesse que eles implementam. Dentro das famílias de Persistência e Segurança há FTs de nível mais alto e FTs de nível mais baixo. Os FTs de nível mais alto estão destacados em cinza e só podem ser acoplados diretamente a uma aplicação, pois é somente neste nível que suas funcionalidades podem ser utilizadas. Já os FTs de nível mais baixo foram projetados de forma que possam ser acoplados a outros FTs ou outros interesses que estejam implementados ou não com aspectos. 
Tabela 4.1 - Frameworks Transversais

\begin{tabular}{|c|c|c|c|c|c|}
\hline Familia & No. & $F T$ & Processo de Reúso & Alternativas de composição & Variabilidades funcionais \\
\hline \multirow{23}{*}{ 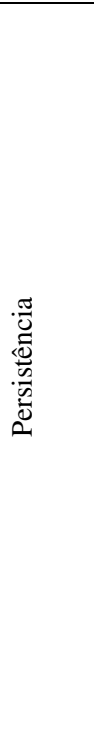 } & \multirow{2}{*}{1} & \multirow{2}{*}{$\begin{array}{l}\text { Operações } \\
\text { Persistentes }\end{array}$} & \multirow{2}{*}{ Instanciação/ composição } & \multirow{2}{*}{ Padrão } & Consciência total* \\
\hline & & & & & Consciência parcial \\
\hline & \multirow{5}{*}{2} & \multirow{5}{*}{ Conexão } & \multirow{5}{*}{$\begin{array}{l}\text { Instanciação, } \\
\text { composição }\end{array}$} & \multirow{5}{*}{ Padrão } & Driver nativo \\
\hline & & & & & Driver de ODBC* \\
\hline & & & & & mySql $^{*}$ \\
\hline & & & & & Interbase \\
\hline & & & & & SyBase \\
\hline & \multirow{5}{*}{3} & \multirow{5}{*}{$\begin{array}{l}\text { Memória } \\
\text { auxiliar } \\
\text { "Carregador } \\
\text { de Objetos" }\end{array}$} & \multirow{5}{*}{ Composição } & Com retorno* & \multirow{5}{*}{ Não } \\
\hline & & & & Target & \\
\hline & & & & This & \\
\hline & & & & Args & \\
\hline & & & & Com parametros & \\
\hline & \multirow{5}{*}{4} & \multirow{5}{*}{$\begin{array}{l}\text { Memória } \\
\text { auxiliar } \\
\text { "Todas } \\
\text { Tuplas" }\end{array}$} & \multirow{5}{*}{ Composição } & Com retorno* & \multirow{5}{*}{ Não } \\
\hline & & & & Target & \\
\hline & & & & This & \\
\hline & & & & Args & \\
\hline & & & & Com parametros & \\
\hline & \multirow{4}{*}{5} & \multirow{4}{*}{ Pooling } & \multirow{4}{*}{ Composição } & Com retorno & \multirow{4}{*}{ Não } \\
\hline & & & & This* & \\
\hline & & & & Target & \\
\hline & & & & Args & \\
\hline & \multirow{2}{*}{6} & \multirow{2}{*}{$\begin{array}{l}\text { Garantia de } \\
\text { Políticas }\end{array}$} & \multirow{2}{*}{ Composição } & \multirow{2}{*}{ Padrão } & Checagem de Atributos \\
\hline & & & & & Checagem de métodos sets e gets \\
\hline & & & & Target & \\
\hline & 7 & Autenticação & Composição & This & Não \\
\hline & & & & Args & \\
\hline ت્ّ & 8 & $\begin{array}{l}\text { Controle de } \\
\text { acesso }\end{array}$ & Composição & Padrão & Não \\
\hline$\stackrel{\widetilde{\sigma}}{\exists}$ & & & & This & \\
\hline ర్లు & 9 & Registro de & Instanciação, Composição & Target & Não \\
\hline & 3 & acessos & mistailctaçao, Composiçao & Args & Nao \\
\hline & & & & Com parâmetros* & \\
\hline & 10 & Políticas de & Instanciacão Composicão & Com retorno* & Erros sucessivos* \\
\hline & 10 & Bloqueamento & instancraçao, Composiçao & Target & Erros não sucessivos \\
\hline & & & & & Reajuste linear para todas categorias \\
\hline & 11 & $\begin{array}{l}\text { Reajuste de } \\
\text { valor }\end{array}$ & Instanciação, Composição & Padrão & Reajuste linear para categorias específicas \\
\hline : & & & & & Reajuste Não - linear \\
\hline$\stackrel{0}{7}$ & & & & Com retorno & Incremento com redutor \\
\hline$Z_{0}$ & & & & Sem parâmetro (this) & increntento cont redutor \\
\hline$\underbrace{0}_{\infty}$ & & Cálculo & & Sem parâmetro (target) & Incremento sem redutor \\
\hline ț & 12 & $\begin{array}{l}\text { baseado em } \\
\text { tabela }\end{array}$ & Instanciação, Composição & Sem parâmetro (args) & Decremento com redutor \\
\hline a & & & & Com parâmetros & \\
\hline & & & & Um argumento & Decremento sem redutor \\
\hline
\end{tabular}

Na família "Regras de Negócio" há apenas dois FTs de nível mais alto que são exemplos de requisitos transversais funcionais implementados como aspectos. Na Seção 3.3.1 o FT de Cálculo Baseado em Tabela foi utilizado para exemplificar a utilização do padrão Capturador de Dados e por isso não será discutido neste capítulo. Há na literatura algumas menções ao uso de aspectos para a codificação de regras de negócios (Suvée et al., 2005; Cibrán et al., 2003; Cibrán et al., 2006), mas não foram encontradas publicações que apresentam exemplos de implementação de aspectos desse tipo na forma de FTs.

Os FTs de nível mais baixo foram projetados como funcionalidades e/ou variabilidades dos FTs de nível mais alto, podendo ser vistos como características do FT de nível mais alto. Por exemplo, o FT de memória auxiliar, pode ser visto como uma característica do FT de persistência. Assim, cada família é uma linha de produtos de FTs, em que vários FTs podem ser gerados com determinadas configurações (Gomma, 2004). Vale 
ressaltar que embora os FTs de nível mais baixo tenham sido projetados de forma genérica, não foi realizado nenhum estudo de caso para averiguar seu reúso fora da linha de produtos original.

A quarta coluna da Tabela 4.1 classifica cada FT com relação ao seu processo de reúso, mostrando que alguns possuem apenas a etapa de composição. A separação por uma "barra" indica que as duas etapas podem ser feitas em paralelo e a "vírgula" representa que o processo é seqüencial.

A quinta coluna contém as alternativas de composição que alguns frameworks possuem. Para alguns deles apenas uma forma de composição é suficiente, representada como "Padrão". Já para os FTs dependentes de contexto, a existência de mais de uma alternativa é necessária, o que justifica a aplicação completa ou parcial do padrão Capturador de Dados. Como pode ser visto, alguns FTs utilizam as seis alternativas de composição do padrão enquanto que outros não. Por exemplo, o FT de cálculo baseado em tabela foi projetado com todas as alternativas, porém o mesmo não ocorre com o de pooling e o de políticas de autenticação. A decisão de utilizar completamente ou parcialmente o padrão depende das características do interesse transversal implementado pelo FT.

Os FTs que possuem mais de uma alternativa de composição geralmente possuem uma alternativa default (representada por um asterisco), que será utilizada caso nenhuma outra seja escolhida. Isso normalmente ocorre com FTs que são características de outros FTs. Por exemplo, como o FT de Pooling é uma característica do FT de persistência (Camargo et al., 2003), já existe uma alternativa de composição escolhida e conseqüentemente, uma regra de composição pré-definida com o framework de persistência. Isso implica que quando o FT de pooling é escolhido para ser utilizado em uma aplicação que usa o framework de persistência, não será necessário fornecer regras de composição para o acoplamento, será necessário apenas adicionar esse FT no projeto. Na sexta coluna também é possível encontrar asteriscos representando variabilidades default.

Na sexta coluna são apresentadas as variabilidades funcionais de cada FT, sejam eles do nível de aplicação ou do nível de frameworks. Note-se que alguns FTs não possuem variabilidades funcionais, como por exemplo o FT de Controle de Acesso.

\section{3 - FAMÍLIA DE FRAMEWORKS TRANSVERSAIS DE PERSistênCIA}

O FT de persistência desenvolvido no contexto desta tese (Camargo et al., 2003), assim como outros frameworks de persistência orientados a objetos, como Hibernate (2006), Cayenne 
(2006) e $O J B$ (2006), tem como objetivo facilitar o desenvolvimento de uma aplicação orientada a objetos que utiliza banco de dados relacional. Os mecanismos necessários para tratar as incompatibilidades entre os dois paradigmas (relacional e orientado a objetos) são implementados pelo framework e podem ser reusados durante o desenvolvimento de novas aplicações. Esse FT é uma evolução de um trabalho anterior (Camargo et al., 2003; Ramos et $a l .$, 2004) e possui como base o padrão de projeto Camada de Persistência (Persistence Layer) (Yoder et al., 1998).

O FT consiste em duas partes com objetivos distintos e que foram implementadas em módulos distintos. A primeira parte, chamada de "operações persistentes", é um conjunto de operações de persistência que devem ser herdadas por classes de aplicação persistentes e que podem ser utilizadas para armazenar, remover, atualizar e realizar consultas no banco de dados. A estratégia de implementação adotada no projeto do FT foi introduzir todas as operações de persistência em uma interface e fazer com que as classes de aplicação persistentes $^{19}$ implementem essa interface. A maioria das operações de persistência disponibilizada pelo FT pode ser vistas na Tabela 4.2. Essas operações constituem a interface disponibilizada pelo FT para a aplicação.

Por causa da diversidade de situações que podem ocorrer em um sistema, não há garantia que o número de operações providas pelo FT seja suficiente para apoiar a implementação de qualquer sistema. Antecipar todas as funcionalidades é um problema já constatado por vários pesquisadores (Fayad, 2000; Johnson e Foote, 1988; Johnson e Russo, 1991). Assim, um ponto importante é que o FT seja extensível, isto é, que permita que o engenheiro de aplicação possa criar novas operações. Na Seção 4.3.2 são mostradas três formas de adaptação para o FT de persistência.

A segunda parte, chamada de "conexão", é referente ao interesse de conexão com o banco de dados, que tem como objetivo identificar locais do código-base em que a conexão deve ser aberta e fechada. A primeira parte depende da segunda para conseguir executar as operações de persistência.

\footnotetext{
${ }^{19}$ Uma classe de aplicação persistente é uma classe cujos objetos devem ser persistidos em alguma tabela do banco de dados. Cada classe de aplicação persistente possui uma tabela correspondente no banco de dados com o mesmo nome da classe.
} 
Tabela 4.2 - Operações do FT de Persistência

\begin{tabular}{|c|c|}
\hline Assinatura da Operação & Descrição \\
\hline public int getNextID() & $\begin{array}{l}\text { Utilizada para retornar o próximo ID disponível na tabela do banco de } \\
\text { dados que é representada pela classe do objeto alvo. }\end{array}$ \\
\hline public boolean save() & $\begin{array}{l}\text { Utilizada para armazenar o objeto alvo da chamada em sua respectiva } \\
\text { tabela do banco de dados. Retorna "true" se a operação foi realizada } \\
\text { com sucesso. }\end{array}$ \\
\hline public boolean delete() & $\begin{array}{l}\text { Utilizada para remover o objeto alvo da chamada de sua respectiva } \\
\text { tabela do banco de dados. Retorna "true" se a operação foi realizada } \\
\text { com sucesso. }\end{array}$ \\
\hline public Resultset findlike() & $\begin{array}{l}\text { Utilizada para localizar e recuperar o objeto alvo no banco de dados. Se } \\
\text { o objeto foi encontrado, retorna um Result Set com os dados desse } \\
\text { objeto, caso contrário retorna um Result Set vazio. }\end{array}$ \\
\hline $\begin{array}{l}\text { public Resultset findlikeByField } \\
\text { (String columnName, String columnValue) }\end{array}$ & $\begin{array}{l}\text { Utilizada para recuperar todos os registros da tabela do banco de dados, } \\
\text { representada pela classe do objeto alvo, que a coluna columnName } \\
\text { tenha o valor String columnValue. }\end{array}$ \\
\hline $\begin{array}{l}\text { public Resultset findlikeByField } \\
\text { (String columnName, int columnValue) }\end{array}$ & $\begin{array}{l}\text { Utilizada para recuperar todos os registros da tabela do banco de dados, } \\
\text { representada pela classe do objeto alvo, que a coluna columnName } \\
\text { tenha o valor columnValue do tipo int. }\end{array}$ \\
\hline $\begin{array}{l}\text { public Resultset findlikeByField } \\
\text { (String columnName, FrameworkDate } \\
\text { columnValue) }\end{array}$ & $\begin{array}{l}\text { Utilizada para recuperar todos os registros da tabela representada pelo } \\
\text { objeto alvo que a coluna columnName tenha o valor columnValue } \\
\text { do tipo FrameworkDate. }\end{array}$ \\
\hline $\begin{array}{l}\text { public ResultSet findlikeByField } \\
\text { (String columnName1, String columnName2, } \\
\text { String columnValue1, string columnValue2) }\end{array}$ & $\begin{array}{l}\text { Utilizada para recuperar todos os registros da tabela do banco de dados, } \\
\text { representada pela classe do objeto alvo, que a coluna columnName } 1 \\
\text { tenha o valor String columnValue1 e que a coluna columnName } 2 \\
\text { tenha o valor String columnValue2. }\end{array}$ \\
\hline $\begin{array}{l}\text { public Resultset findlikeByField } \\
\text { (String columnName1, String columnName2, } \\
\text { Integer columnValue1, Integer } \\
\text { columnValue2)\{ }\end{array}$ & $\begin{array}{l}\text { Utilizada para recuperar todos os registros da tabela do banco de dados, } \\
\text { representada pela classe do objeto alvo, que a coluna columnName1 } \\
\text { tenha o valor Integer columnValue } 1 \text { e que a coluna } \\
\text { columnName } 2 \text { tenha o valor IntegercolumnValue2. }\end{array}$ \\
\hline $\begin{array}{l}\text { public Resultset findlikeByField } \\
\text { (String tableName, String } \\
\text { columnParameterName, Integer } \\
\text { parameterValue)\{ }\end{array}$ & $\begin{array}{l}\text { Utilizada para recuperar todos os registros da tabela tableName, que } \\
\text { coluna columnName tenha o valor columnValue. }\end{array}$ \\
\hline $\begin{array}{l}\text { public ResultSet findlike } \\
\text { (String columnName, FrameworkDate } \\
\text { columnValue) }\end{array}$ & $\begin{array}{l}\text { Utilizada para recuperar todos os registros da tabela representada pelo } \\
\text { objeto alvo que a coluna columnName tenha o valor columnValue } \\
\text { do tipo FrameworkDate. }\end{array}$ \\
\hline $\begin{array}{l}\text { public Resultset } \\
\text { findlikeByField_intervalofDates } \\
\text { (String columnName1, String columnName2, } \\
\text { String columnName3, String columnName4, } \\
\text { Integer columnValue1, FrameworkDate } \\
\text { initialDate, FrameworkDate finalDate, } \\
\text { Integer columnValue2) }\end{array}$ & $\begin{array}{l}\text { Utilizada para recuperar os registros da tabela representada pela classe } \\
\text { do objeto alvo que a coluna columnName1 tenha o valor } \\
\text { columnValue1 e que a coluna columnName } 2 \text { tenha o valor } \\
\text { initialdate, e que a coluna columnName } 3 \text { tenha o valor finaldate } \\
\text { e que a coluna columnName } 4 \text { tenha o valor columnValue2. }\end{array}$ \\
\hline $\begin{array}{l}\text { public Resultset } \\
\text { findlikeByField_intervalofDates } \\
\text { (String columnName1, String columnName2, } \\
\text { String columnName3, Integer columnValue, } \\
\text { FrameworkDate initialDate, FrameworkDate } \\
\text { finalDate) }\end{array}$ & $\begin{array}{l}\text { Utilizada para recuperar todos os registros da tabela representada pela } \\
\text { classe do objeto alvo em que a coluna columnName1 tenha o valor } \\
\text { columnValue e que a coluna columnName } 2 \text { tenha um valor maior ou } \\
\text { igual a initialdate e que a coluna columnName } 3 \text { tenha um valor } \\
\text { menor ou igual a finaldate. }\end{array}$ \\
\hline public static Result Set findAll() & $\begin{array}{l}\text { Utilizada para recuperar todos os registros da tabela representada pela } \\
\text { classe do objeto alvo. Retorna um Result Set com todos os registros. }\end{array}$ \\
\hline public Object setDBToObject (Resultset) & $\begin{array}{l}\text { Utilizada para preencher o objeto alvo da chamada com os valores } \\
\text { disponíveis no Result Set. Essa operação retorna um objeto que deve } \\
\text { ser convertido (Cast) para algum tipo específico da aplicação. }\end{array}$ \\
\hline public Object setDBToObject() & $\begin{array}{l}\text { Utilizada para preencher o objeto alvo da chamada com seus } \\
\text { respectivos valores de sua respectiva tabela do banco de dados. Similar } \\
\text { à operação anterior, porém sem a necessidade de passar um } \\
\text { ResultSet por parâmetro. O ID do objeto alvo deve possuir um valor } \\
\text { antes que essa operação possa ser utilizada. }\end{array}$ \\
\hline
\end{tabular}

Como já comentado por alguns pesquisadores, alguns interesses não podem ser implementados de forma totalmente ortogonal ao interesse-base de um sistema, como é caso da persistência (Rashid and Chitchyan, 2003), da concorrência e do gerenciamento de falhas 
(Kienzle e Guerraoui, 2002). No caso da persistência, durante o desenvolvimento da aplicação é necessário ter consciência de algumas operações. As operações que tratam de armazenamento e atualização podem ser completamente tratadas pelo FT e assim, podem ser negligenciadas durante o desenvolvimento de um sistema. Por exemplo, pode-se implementar um aspecto que armazena um objeto no banco de dados sempre que o construtor desse objeto for executado. Também pode ser implementado um aspecto de atualização, que entrecorta as chamadas aos métodos que modificam os valores dos atributos (sets) e realizam as atualizações no banco de dados. Note-se que, nesses dois casos, há pontos de junção adequados que podem ser entrecortados, independentemente da linguagem de programação utilizada.

O mesmo não ocorre com as operações de remoção e busca, pois elas devem ser explicitamente chamadas em momentos definidos pelo engenheiro da aplicação. Quando a linguagem Java é utilizada, não há pontos de junção adequados no código-base que podem ser entrecortados para a remoção de um objeto. Um possível ponto de junção para a remoção de um objeto seria sua destruição, isto é, quando o seu destrutor é executado. Porém, no caso da linguagem Java isso é feito pela JVM (Java Virtual Machine) em momentos não determinísticos. Isso pode ser solucionado quando uma outra linguagem, por exemplo $\mathrm{C}$, é utilizada. Contudo, as operações de busca continuam com o problema.

Em virtude dessa particularidade do interesse de persistência, o FT foi implementado com as variabilidades de Consciência Total e Consciência Parcial, diferentemente do framework de persistência apresentado por Rashid e Chitchyan (2003), que possui apenas a estratégia Consciência Parcial. Quando a primeira estratégia é utilizada, o engenheiro de software é responsável por invocar todos os métodos de persistência disponibilizados pelo FT (Tabela 4.2), enquanto que na segunda, esse profissional deve se preocupar apenas com as operações de remoção (delete ()) e busca (findlike ()).

Além da própria natureza do interesse, a forma como ele é implementado também influencia na consciência (obliviousness) que o código-base possui de sua existência. Por exemplo, para o correto funcionamento do FT de Persistência, as seguintes políticas devem ser seguidas durante o desenvolvimento do código-base:

1. Toda classe de aplicação persistente deve possuir construtores com e sem parâmetros;

2. Cada classe de aplicação persistente deve ter uma tabela correspondente no banco de dados com o mesmo nome da classe; 
3. Toda classe de aplicação persistente deve possuir métodos de acesso aos atributos (sets e gets);

4. Cada atributo de uma classe de aplicação persistente deve possuir uma coluna na tabela correspondente no banco de dados com o mesmo nome do atributo.

5. Todo método que altera um atributo do tipo int deve receber um parâmetro do tipo Integer.

Essas políticas de implementação podem ser vistas como contratos que devem ser seguidos para o correto funcionamento do FT (Griswold, et al., 2006). Mais à frente será mostrado o FT de Garantia de Políticas, o qual foi desenvolvido para verificar se duas dessas políticas existem no código-base.

Na Figura 4.1 é mostrado um diagrama de características que representa a linha de produtos de FTs de Persistência seguindo a notação proposta por Gomma (2004). Algumas características foram implementadas como FTs, mas também há outras que foram implementadas como aspectos normais e com mecanismos tradicionais da orientação a objetos, como métodos e classes abstratas. Apenas a título de ilustração, as características implementadas como FTs/aspectos estão destacadas em cinza. A única característica implementada como aspecto normal é a consciência parcial (Partial), que está destacada com uma nota.

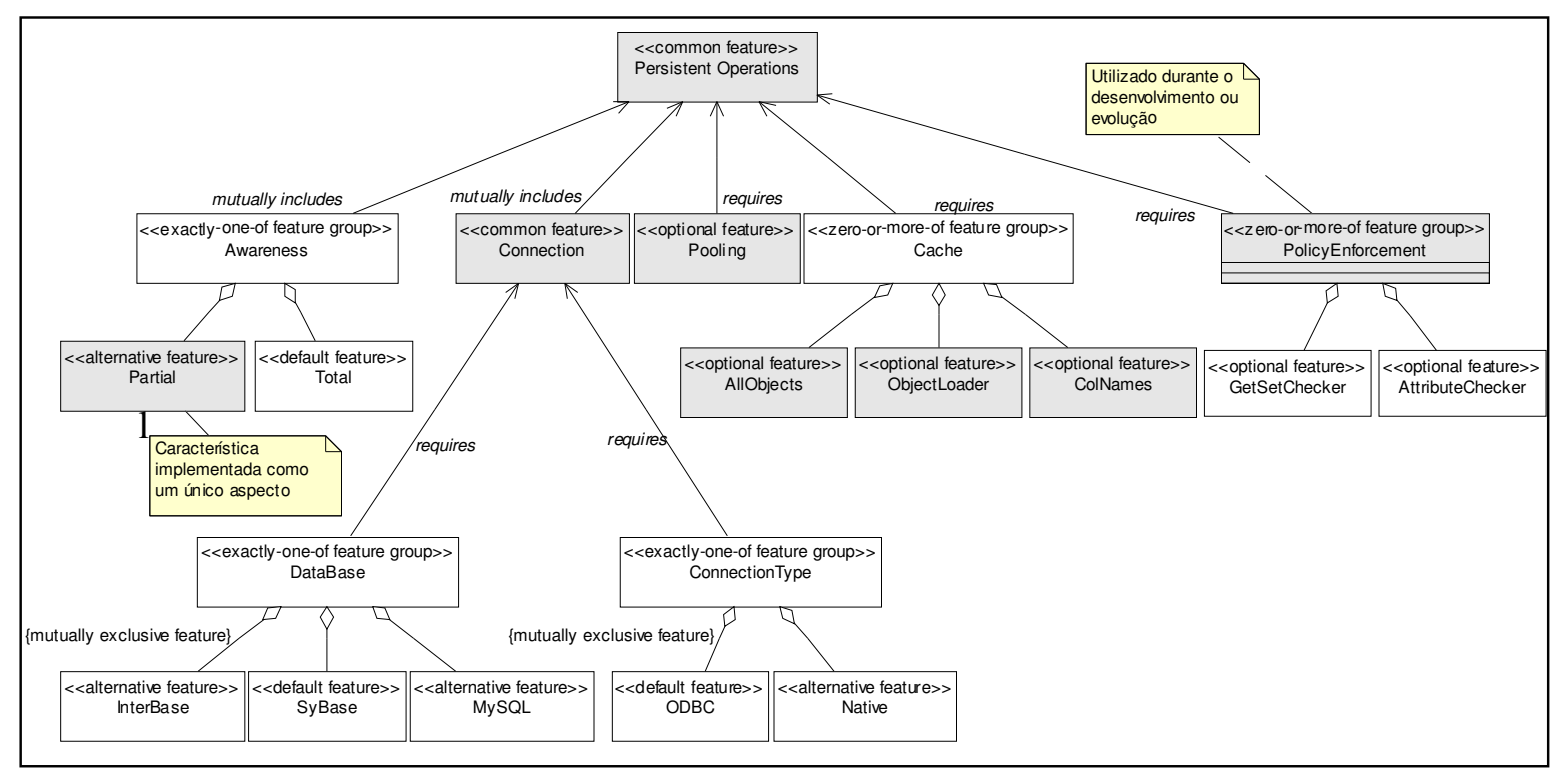

Figura 4.1 - Diagrama de Características da Linha de Produtos de FTs de Persistência

As características Operações Persistentes (Persistent Operations) e Conexão

(Connection), ambas implementadas como FTs, são comuns a todos os membros da linha de 
produtos e representam as operações de persistência que devem ser inseridas nas classes de aplicação persistentes e o interesse de conexão com o banco de dados, respectivamente. Assim, a etapa de instanciação do FT de persistência consiste em escolher as variabilidades da característica Operações Persistentes e também da Conexão. Essa é a configuração mínima do FT de Persistência, já que as demais características são opcionais. Embora os FTs de Operações Persistentes e Conexão estejam sendo mostrados como duas características, poderiam ser representados em apenas uma, já que ocorrem sempre juntos nos membros da linha de produtos. Em virtude disso, no decorrer do texto o termo "FT de Persistência" é utilizado para representar essas duas características.

O FT Operações Persistentes possui duas variabilidades - Total e Parcial - que se encontram agrupadas sob o grupo de características Consciência (Awareness). Uma dessas variabilidades deve, obrigatoriamente, estar presente em qualquer membro da linha de produtos, como destaca o estereótipo <<exactly-one-of feature group >>. Entretanto se o engenheiro de software responsável pelo desenvolvimento não realizar a escolha, a alternativa Total será automaticamente adotada. A Conexão, por sua vez, possui dois grupos de características - Connection Type e DataBase - que também devem ter uma de suas variabilidades obrigatoriamente escolhidas.

As características de Repositório de Conexões e Memória Auxiliar são opcionais e podem ser utilizadas para melhorar o desempenho do FT de persistência. A característica Garantia de Políticas (Policy Enforcement) é um FT usado geralmente apenas durante o desenvolvimento para testar se as seguintes duas políticas exigidas pelo FT de Persistência estão presentes no código-base: presença de métodos de acesso aos atributos nas classes de aplicação persistentes e existência de atributos com o mesmo nome das colunas da tabela do banco de dados correspondente a uma determinada classe de aplicação persistente (Rocha et al., 2004a; Rocha et al., 2004b), que constituem suas duas variabilidades. Esse FT será mostrado com mais detalhes na Seção 4.3.4.

Todas as características implementadas como FTs contém camada de pré-composição, o que é feito para facilitar a adoção da característica em um novo membro da linha de produtos, sem a necessidade, ou minimizando o trabalho, de instanciação e composição. Por exemplo, a característica de Memória Auxiliar "Object Loader" está implementada como um FT. Embora essa característica esteja projetada como um framework, visando seu reúso em outros contextos, é dentro da linha de produtos que provavelmente ela será mais utilizada. Assim, a existência a camada de pré-composição já fornece o código de acoplamento com esse FT. 
Na Figura 4.2 é mostrado um diagrama que representa ilustrativamente as classes e aspectos que compõem as características Operações Persistentes e Conexão, distinguidas pelas formas geométricas com linhas tracejadas. Nessa figura, os aspectos estão sendo representados por retângulos destacados em cinza, e os relacionamentos de associação que partem dos aspectos para alguma entidade representam que o aspecto afeta a entidade entrecortando (crosscutting) a execução/chamada de seus métodos ou introduzindo (inter type declaration) operações, por meio de declarações intertipo. Os demais relacionamentos possuem semântica convencional da UML. Um sub-conjunto do perfil UML-F (Fontoura et al., 2002) está sendo usado para evidenciar os ganchos que devem ser sobrepostos pelo engenheiro de aplicação. Todos os métodos com o estereótipo <<hook >> são abstratos e devem ser sobrepostos pelo engenheiro de aplicação em classes concretas. Esse pefil é utilizado em todos os outros FTs desenvolvidos no contexto desta tese.

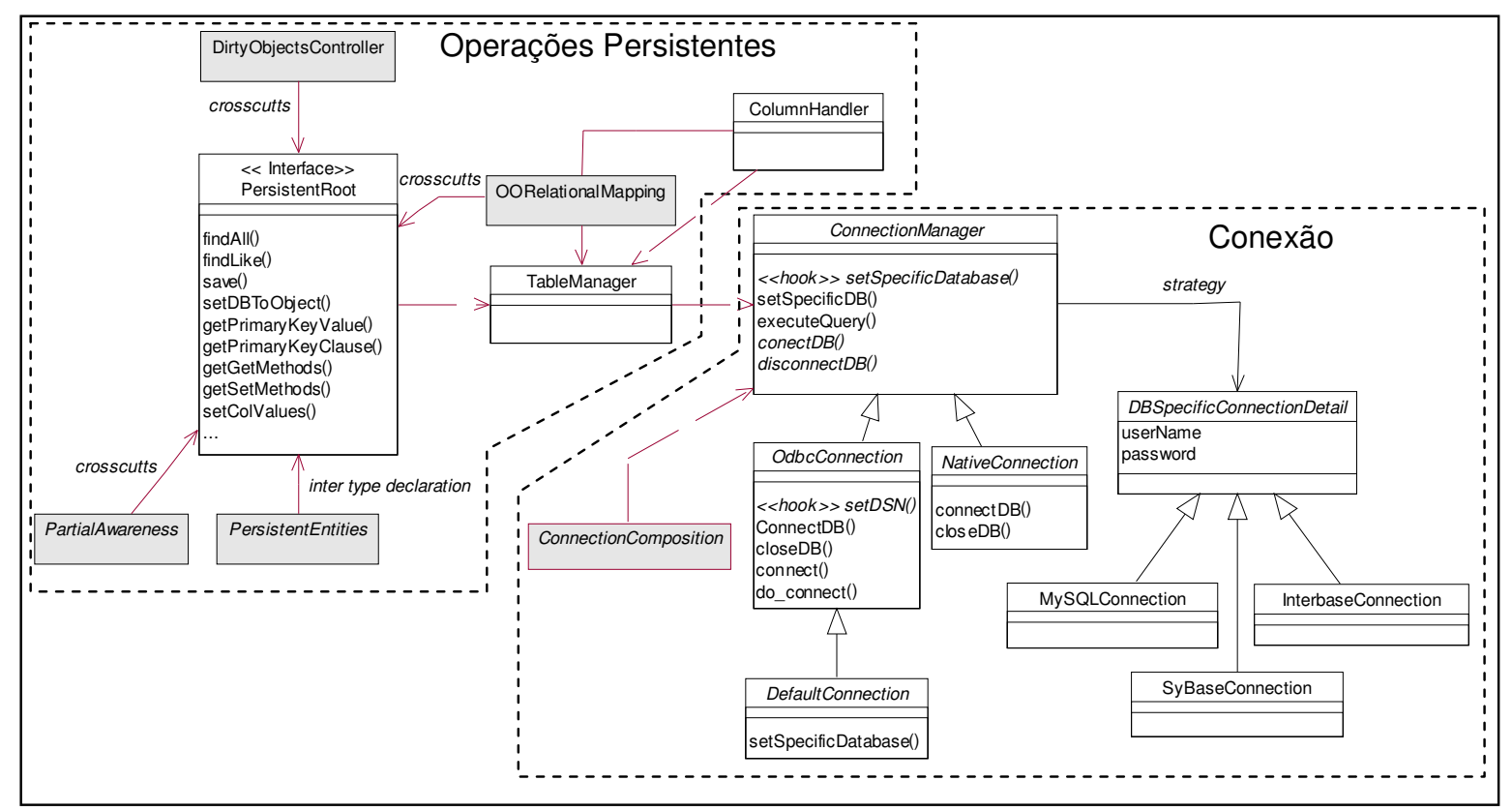

Figura 4.2 - Estrutura do Framework Transversal de Persistência

A classe TableManager é responsável por montar dinamicamente as declarações SQL e executar as operações de persistência. Para que essa classe seja capaz de executar os comandos de persistência ela possui uma dependência com o FT de conexão que não está sendo mostrada. No framework de persistência proposto por Soares (Soares, 2004), as declarações SQL são implementadas de forma fixa dentro do sistema. O aspecto DirtyObjectsController é responsável por "marcar" objetos que foram alterados em memória para que essas alterações sejam refletidas no disco em momentos apropriados. É um 
exemplo de um sub-interesse de persistência que foi implementado como um aspecto fixo dentro da arquitetura do framework.

Em relação ao FT Operações Persistentes, a utilização de aspectos ocorre em dois pontos distintos. Durante o processo de reúso do FT, ao invés de realizar modificações invasivas em todas as classes de aplicação, introduzindo a declaração implements PersistentRoot em todas elas, um aspecto deve ser criado para fazer isso utilizando declarações intertipo da linguagem AspectJ. Esse aspecto concreto, que deve ser criado pelo engenheiro de software deve estender o aspecto abstrato PersistentEntities, cujo código está sendo mostrado parcialmente na Figura 4.3. Esse aspecto introduz na interface PersistentRoot um conjunto de atributos e operações de persistência que será herdado pelos sub-tipos dessa interface. Como já comentado, esses sub-tipos são classes de aplicação que devem possuir correspondência com o banco de dados e são determinadas pelo engenheiro de aplicação em tempo de reúso.

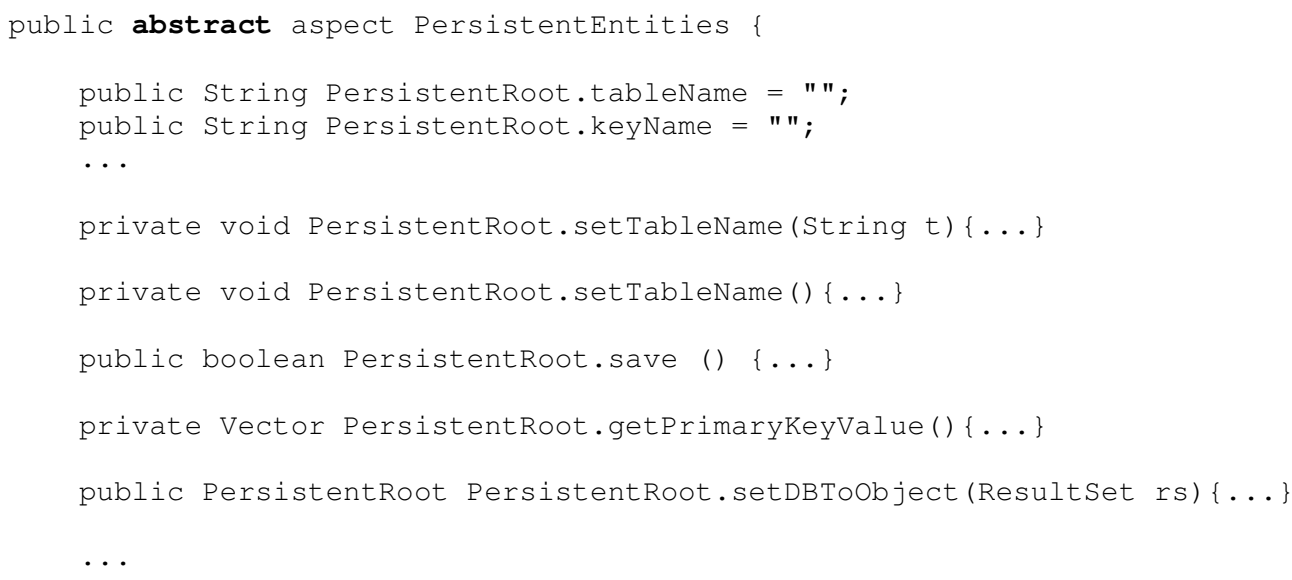

Figura 4.3 - Código do Aspecto PersistentEntities

O segundo ponto importante em que aspectos são utilizados é na realização do mapeamento com o banco de dados, que é feito internamente pelo FT quando os objetos das classes que são sub-tipos da interface PersistentRoot são criados. Assim, ao invés do código do mapeamento estar dentro do construtor de cada uma das classes, ele está encapsulado no aspecto ooRelationalMapping, mostrado parcialmente na parte superior da Figura 4.4. Esse aspecto define comportamento adicional no construtor de cada objeto subtipo da interface PersistentRoot quando esses construtores são executados. O objetivo é inserir em cada um desses objetos meta-informações sobre sua correspondência com o banco de dados, como por exemplo: o nome da tabela correspondente, o número de colunas da tabela e o nome dessas colunas. 
Note-se que os conjuntos de junção utilizados pelos adendos do aspecto OORelationalMapping estão no aspecto XOORelationalMapping. Esse aspecto, que está sendo mostrado na parte inferior da Figura 4.4, representa a interface de entrecorte dinâmica do aspecto OORelationalMapping, e segue a forma de implementação sugerida por Griswold et al. (2006). Essa estratégia desacopla o comportamento do aspecto de sua interface, facilitando evoluções paralelas e distintas de ambas as partes. Note-se também que essa interface dinâmica não é visível durante o processo de reúso do FT, pois ela se encontra na estrutura interna do FT.

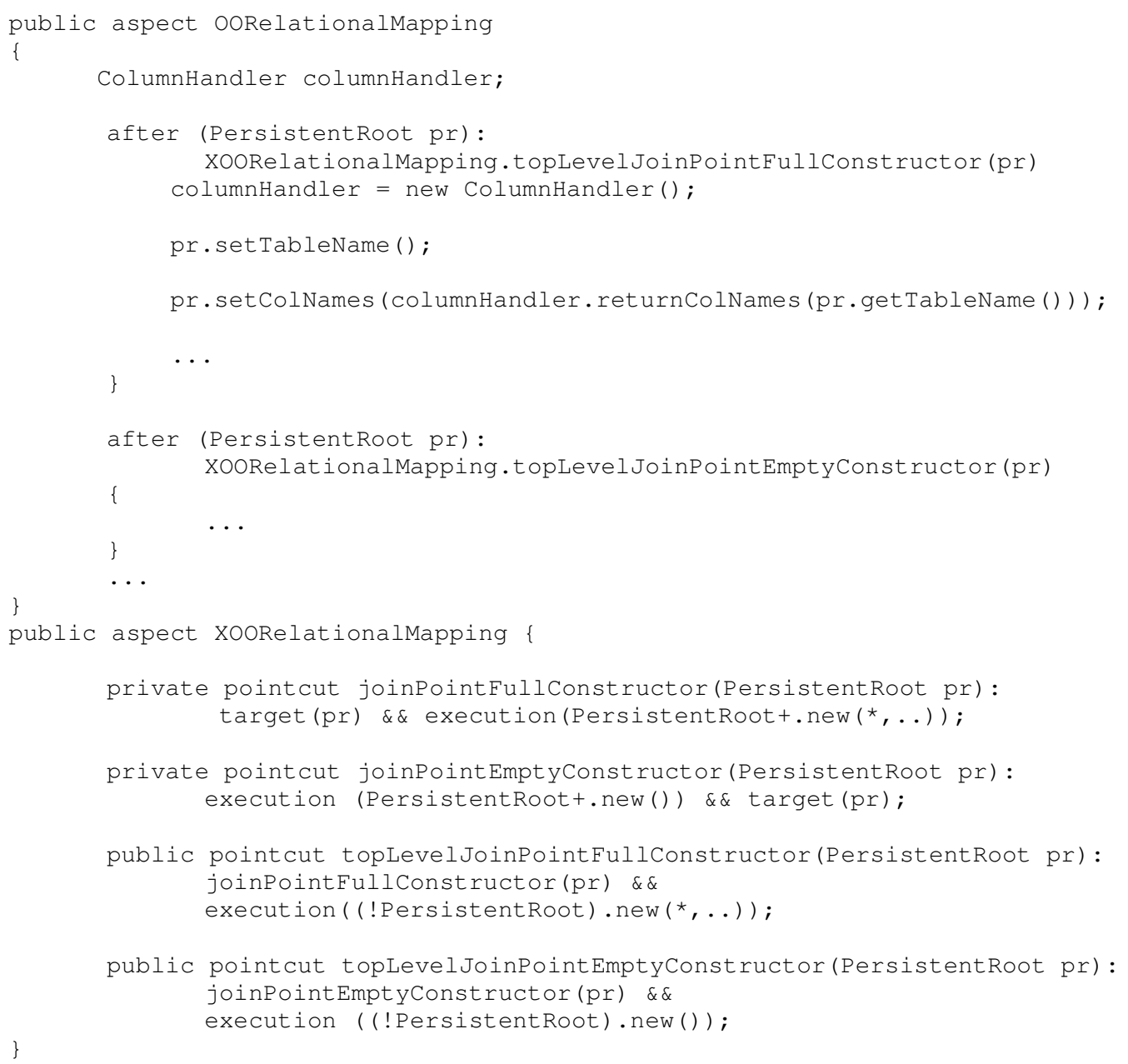

Figura 4.4 - Código do Aspecto OORelationalMapping

A implementação do FT Operações Persistentes utiliza os idiomas Marker Interface e Container Introduction propostos por Hanenberg e Schimidmier (Hanenberg and Schimidmeier, 2003a). A interface PersistentRoot assume tanto o papel de MarkerInterface quanto de Container e o aspecto PersistentEntities assume o papel de ContainerIntroduction. A utilização desses idiomas faz com que os aspectos internos do FT, 
por exemplo, o ooRelationalMapping, possuam dependência apenas com a interface PersistentRoot, evitando dependência com nomenclaturas utilizadas na aplicação.

Em relação à característica de Conexão, o único aspecto existente é o Connectioncomposition, que é responsável por entrecortar pontos de junção do códigobase, possivelmente uma aplicação, e utilizar os métodos connectDB () e disconnectDB () da classe ConnectionManager para abrir e fechar conexões com o banco de dados, como mostrado na Figura 4.5. Os pontos de junção devem ser fornecidos pelo engenheiro de aplicação por meio da criação de um aspecto concreto que estende o aspecto ConnectionComposition em tempo de composição.

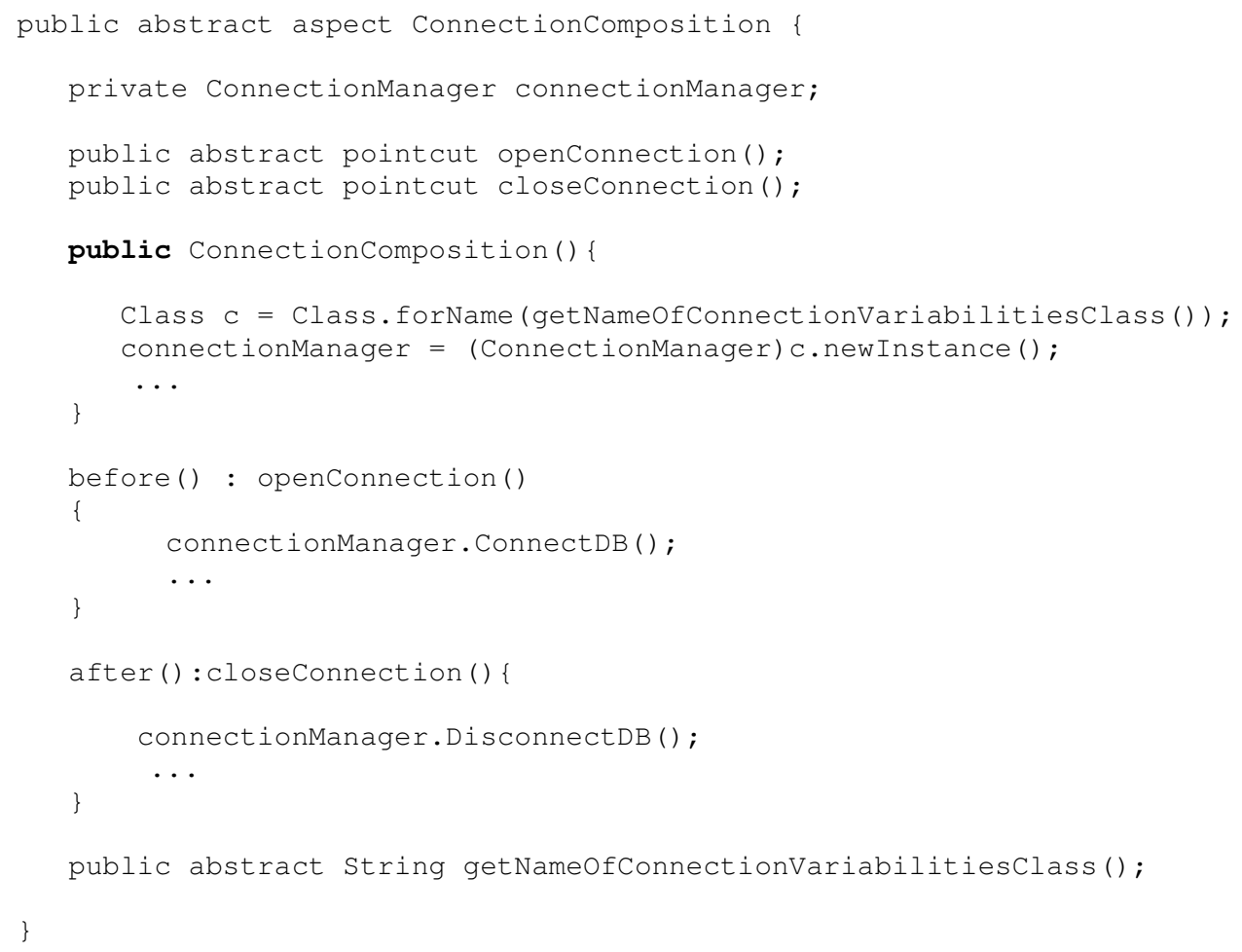

Figura 4.5 - Aspecto ConnectionComposition

A escolha das variabilidades da conexão é feita estendendo-se uma das classes filhas de ConnectionManager. Note-se na Figura 4.2 a existência de uma classe abstrata chamada DefaultConnection. Essa classe é responsável por definir as variabilidades padrão para a conexão, que consiste em uma conexão feita via ODBC do Windows com banco de dados $M y S Q L$. Caso a conexão padrão seja escolhida, o responsável pelo desenvolvimento deve estender diretamente essa classe do FT de conexão. Se alguma outra variabilidade for desejada, basta estender qualquer das outras classes.

A etapa de composição da maioria dos FTs com algum código-base é feita por meio de regras de composição que operam dinamicamente. Todavia, no caso do framework de 
persistência, particularmente em relação as Operações Persistentes, a composição é feita por meio de regras de composição estáticas, que operam em tempo de compilação. Isso ocorre com maior freqüência em FTs que modularizam interesses que não podem ser totalmente negligenciados durante o desenvolvimento da aplicação.

\subsection{1 - Processo de Reúso do FT de Persistência}

O processo de reúso do FT de Persistência, que consiste em acoplá-lo a uma determinada aplicação, possui as etapas de instanciação e de composição. Na instanciação, três variabilidades precisam ser determinadas: o tipo da consciência (Total ou Parcial), o tipo da conexão com o banco de dados (ODBC ou driver nativo) e o próprio banco de dados. $\mathrm{Na}$ etapa de composição é necessário informar quais são as classes de aplicação persistentes e quais os locais do código-base em que a conexão deve ser aberta e fechada. Esses passos são o mínimo necessário para se acoplar o FT de persistência a um código-base.

A adição de características, como Memória Auxiliar e Repositório de Conexões, pode ser feita antes ou depois que o FT for acoplado a um código-base. Neste exemplo é mostrado primeiro o acoplamento do FT de persistência a uma aplicação hipotética e depois a característica de pooling é adicionada. No framework de segurança que será mostrado adiante, essa ordem de acoplamento será invertida.

Para escolher a variabilidade "consciência parcial" basta que o aspecto PartialAwareness, mostrado parcialmente na Figura 4.6 seja adicionado ao projeto. Esse aspecto é uma característica específica do FT de persistência, por isso ele já tem conhecimento dos pontos que devem ser entrecortados, não havendo necessidade de concretização por parte do engenheiro de software. Como pode ser observado, esse aspecto, assim como outros FTs desenvolvidos, utiliza o idioma Composite Pointcut (Hanenberg e Schimidmeier, 2003a; Hanenberg e Schimidmeier, 2003b).

Para escolher a variabilidade "consciência total", basta não adicionar o aspecto PartialAwareness no projeto, já que essa variabilidade é a default, como pode ser visto no digrama de características mostrado na Figura 4.1.

A escolha das variabilidades da conexão é feita estendendo-se uma das classes filhas de ConnectionManager (Figura 4.2). Caso a classe DefaultConnection, mostrada na Figura 4.7, seja estendida, a configuração padrão da conexão será escolhida, bastando apenas que o usuário informe o nome do DSN criado no painel de controle do Windows em uma classe concreta que estenda DefaultConnection.

Na Figura 4.8 é mostrada a modelagem do FT de Persistência como um tema transversal (Clarke e Baniassad, 2005), representando o FT depois da etapa de instanciação. 
Note-se que o FT de Conexão já se encontra instanciado com sua variabilidade padrão (default), o que é representado pela classe myConnectionVariabilities. Essa classe deve ser criada pelo engenheiro de aplicação com o objetivo de retornar o nome do DSN criado no painel de controle do Windows.

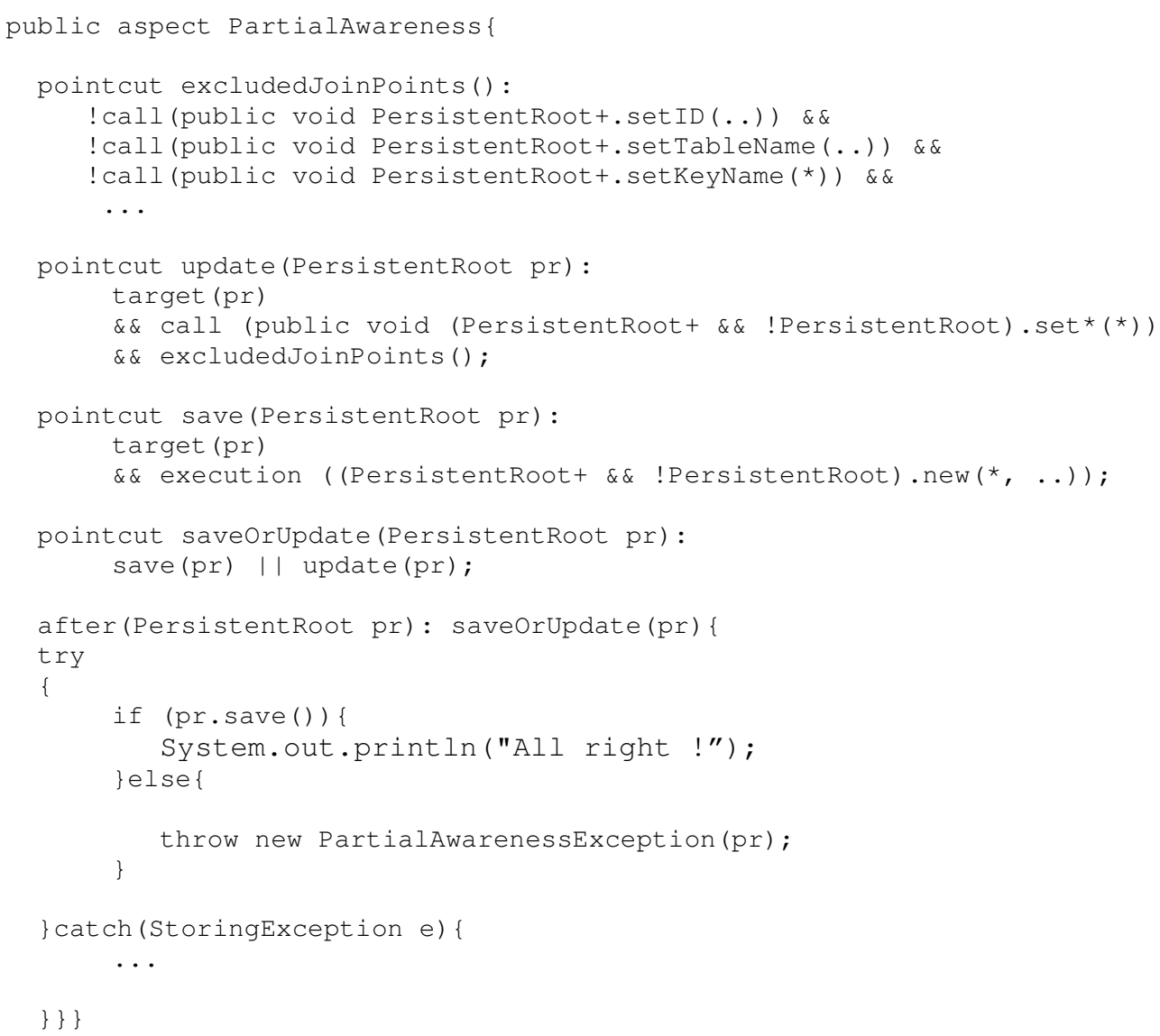

Figura 4.6 - Código do Aspecto PartialAwareness

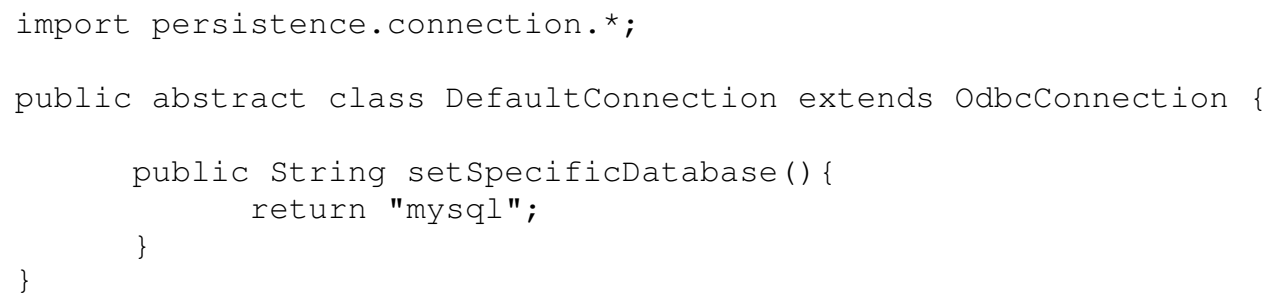

Figura 4.7 - Classe DefaultConnection

Esse tema deve ser composto com um código-base para adicionar as operações de persistência (disponíveis na interface PersistentRoot) em classes de aplicação persistentes e também para identificar pontos do código-base em que a conexão deve ser aberta e fechada, o que caracteriza os passos da etapa de composição. A lista de gabaritos no canto superior esquerdo do pacote mostra dois métodos-gabarito. O primeiro representa pontos de junção do 
código-base em que a conexão deve ser aberta e o segundo pontos em que a conexão deve ser fechada. Os dois diagramas de seqüência mostram o comportamento do FT para cada um desses métodos-gabarito. Note-se que a abertura da conexão ocorre antes do comportamento original do método que será entrecortado, enquanto que o fechamento ocorre depois.

Na Figura 4.9 é mostrado como deve ser o projeto da composição com uma aplicação hipotética. Por questões de legibilidade, a parte superior da figura mostra o tema transversal de persistência apenas com as classes significativas para a composição. As setas tracejadas que ligam a classe Baseclass com algumas classes de aplicação representam que essas classes são correspondentes e que serão fundidas, fazendo com que as classes de aplicação assumam o lugar da BaseClass depois da composição dos dois temas. Assim, as operações existentes na interface PersistentRoot serão herdadas por essas classes de aplicação.

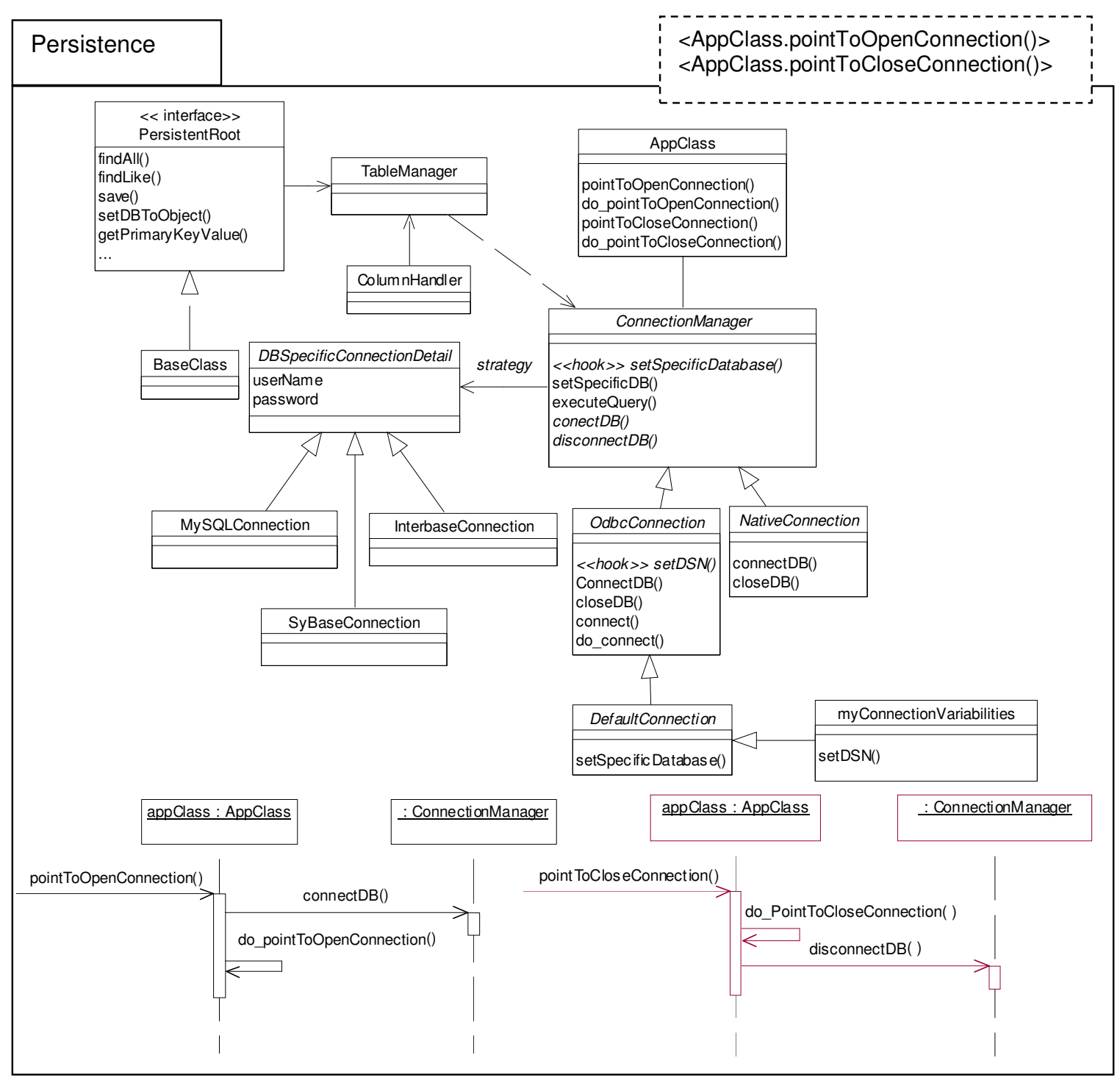

Figura 4.8 - Framework de Persistência como um Tema Transversal 


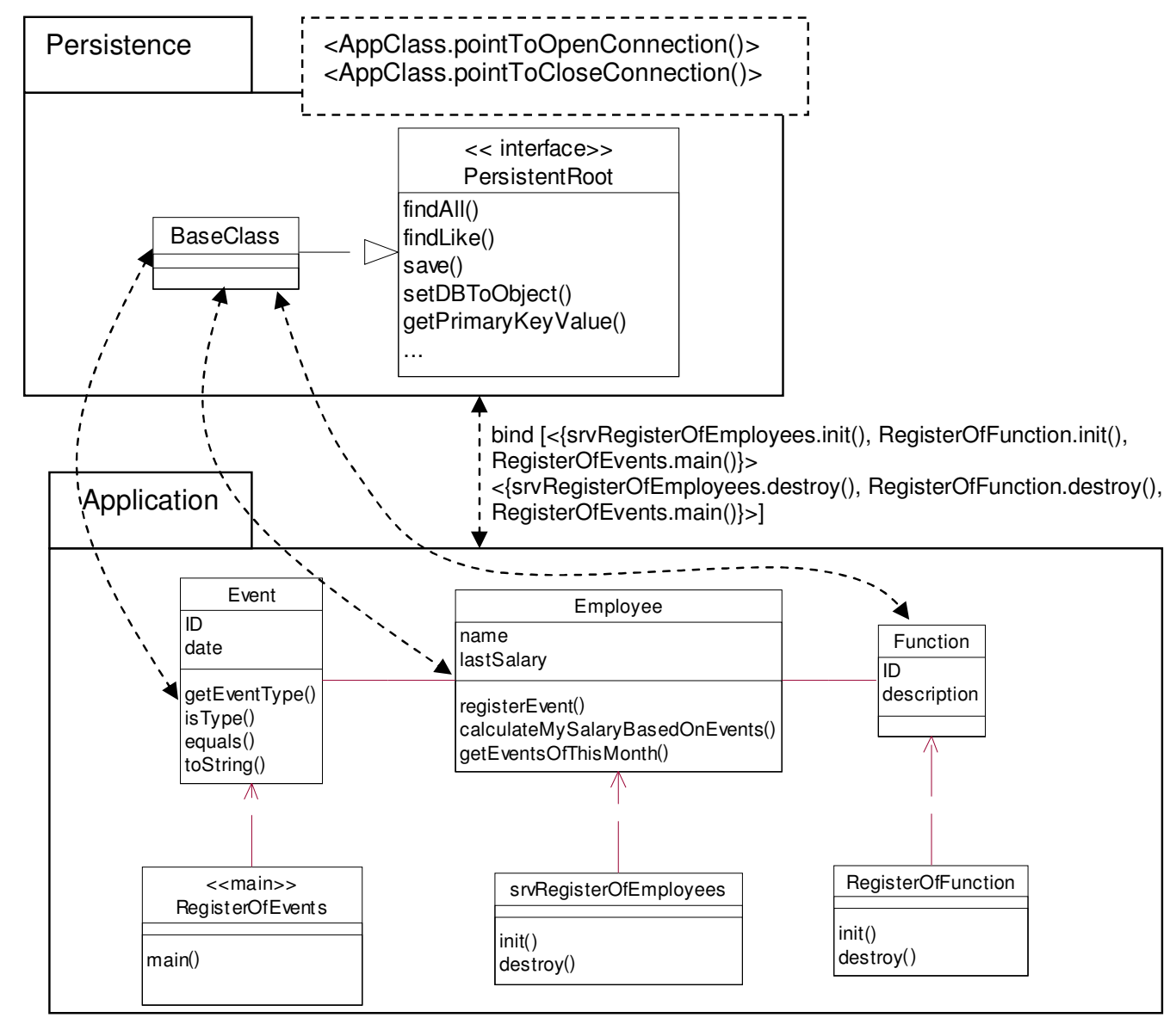

Figura 4.9 - Composição do FT de Persistência com uma Aplicação

O relacionamento de ligação entre os dois pacotes contém dois conjuntos de operações que serão mapeados para os dois gabaritos do tema transversal. $\mathrm{O}$ primeiro conjunto de métodos, que consiste em uma série de métodos init (), são locais da aplicação adequados para abrir a conexão, e o segundo, que consiste em uma série de métodos destroy (), são locais adequados para fechar a conexão.

A implementação correspondente ao modelo mostrado na Figura 4.9 consiste em estender o aspecto PersistentEntities e declarar quais são as classes de aplicação persistentes, o que deve ser feito por meio de declarações intertipo da linguagem AspectJ. Na Figura 4.10 é mostrado um trecho de código do aspecto MyPersistentEntities que é uma especialização do aspecto Persistententities e que declara que as classes Employee, Function e Event são sub-tipos da interface PersistentRoot. Fazendo isso, os objetos dessas classes agora dispõem de operações de persistência para armazenar (save()), remover (delete()), atualizar (update()) e localizar (find*()) registros no banco de dados. 
Depois que o FT de Operações Persistentes foi composto, resta fazer o mesmo com a Conexão. A Figura 4.11 mostra o aspecto MyConnectionComposition, que representa a composição da Conexão com o código-base. Note-se que os métodos descritos no relacionamento de ligação da Figura 4.9 são os pontos de junção do código-base que devem ser afetados. Note-se também que o método getNameofConnectionVariabilitiesclass() deve ser concretizado pelo engenheiro de aplicação para retornar o nome da classe criada na etapa de instanciação.

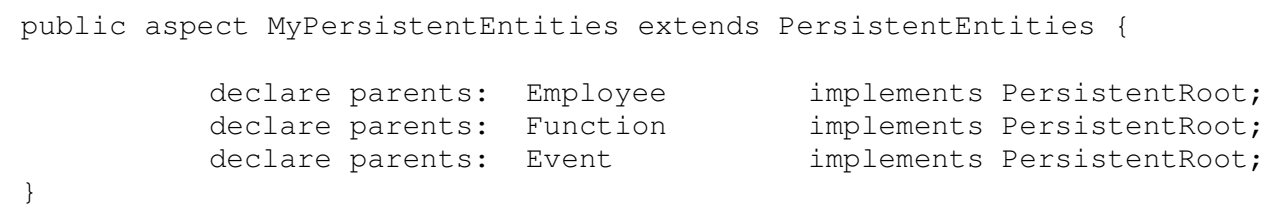

Figura 4.10 - Composição do Framework de Persistência com Classes de aplicação persistentes

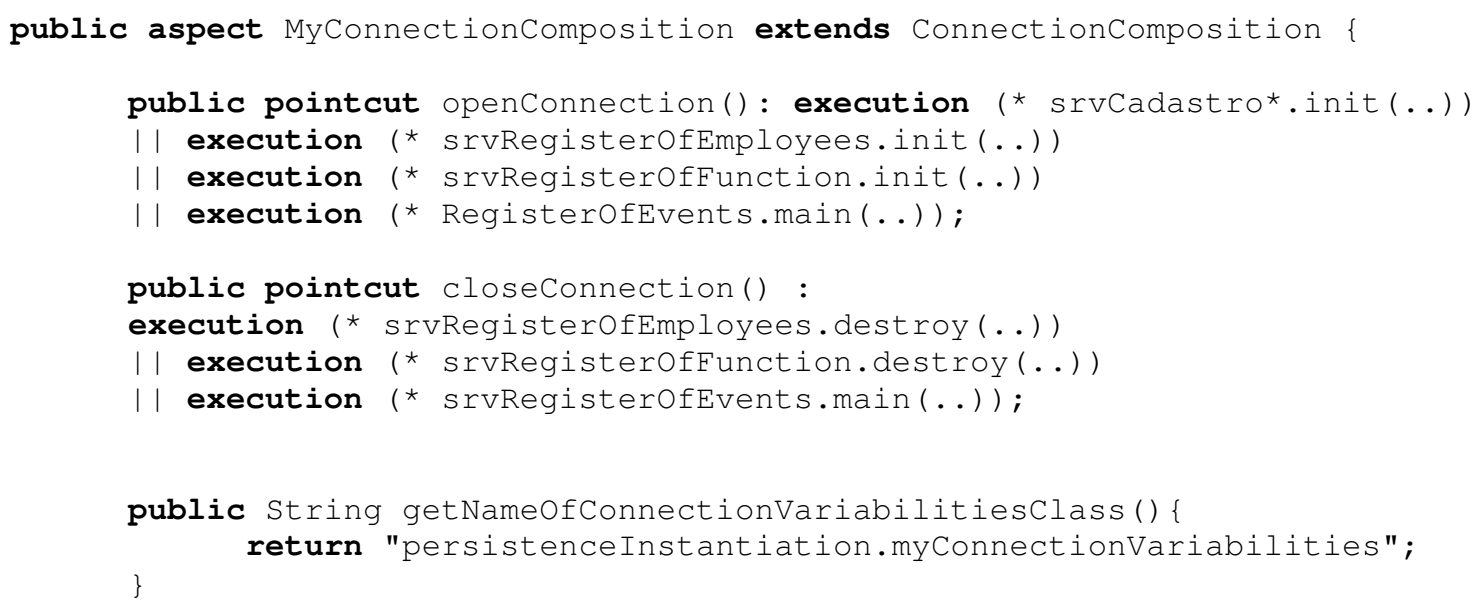

Figura 4.11 - Aspecto MyConnectionComposition

A Figura 4.12 mostra o modelo resultante da composição entre os dois temas mostrados anteriormente. A classe Baseclass foi substituída pelas classes Event, Employee e Function, representando que essas classes agora implementam a interface PersistentRoot e, conseqüentemente, herdam as operações de persistência.

A classe gabarito Appclass foi substituída pelas classes srvRegisteroffunction, srvRegisterofEmployees e RegisterofEvents, representando que os métodos init() e destroy () das duas primeiras classes e o método main() da última, são afetados pelo interesse de conexão. Os diagramas de seqüência mostram o novo comportamento do método init() e do método destroy() da classe srvRegisterofEmployees. Os retângulos posicionados atrás dos diagramas de sequiência 
representam que outros diagramas de seqüência também foram gerados para os outros métodos entrecortados. Por questões de legibilidade, os relacionamentos entre as classes de aplicação foram suprimidos.

Um detalhe importante de desenvolvimento é que as classes de aplicação persistentes precisam ser projetadas e implementadas seguindo as seguintes convenções exigidas pelo FT. Aconselha-se que a decisão por utilizar ou não o FT de persistência seja feita logo no início do processo, para que modificações não sejam necessárias depois que as Operações Persistentes já estiverem implementadas. As convenções exigidas são:

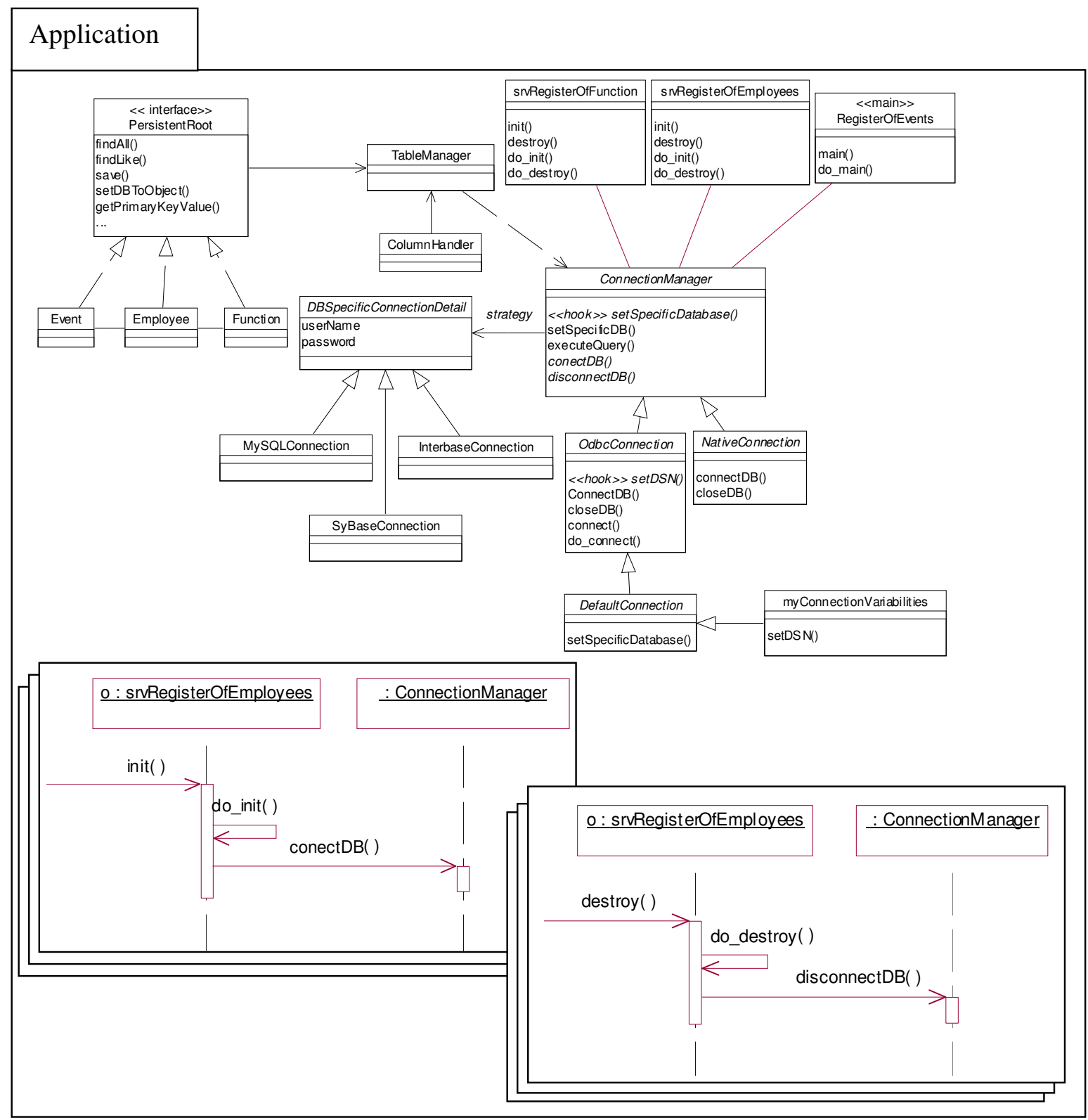

Figura 4.12 - Modelo de Composição Resultante 
- Toda classe deve possuir um construtor vazio e um normal, sendo que esse último deve possuir como parâmetros todos os atributos da classe;

- Todo método set* () que altera um atributo do tipo int, o tipo do parâmetro deve ser Integer, e realizar a conversão internamente;

- Os relacionamentos de associação com cardinalidade 1 para 1 são representados por atributos do tipo da classe. Por exemplo, uma classe A possui um relacionamento de associação com a classe B. Assim, a classe A deve possuir um atributo denominado b do tipo B;

- Os relacionamentos com cardinalidade maior que 1 , devem ser implementados com vetores (classe Vector). Por exemplo, se a classe A possui um relacionamento de 1 para $n$ com a classe B, então na classe A deve existir um atributo denominado b do tipo Vector;

Outra forma de implementação que poderia ter sido adotada para disponibilizar as operações de persistência para as classes de aplicação é transformar todas as operações em métodos estáticos e introduzi-los em uma classe de fachada, a qual poderia ser utilizada estaticamente pelas classes de aplicação. Entretanto, considera-se que a forma que foi utilizada seja mais adequada, pois não há a necessidade de passar para outra entidade a responsabilidade da persistência.

\subsection{2 - Adaptações no FT de Persistência}

Durante o desenvolvimento de uma aplicação que utiliza um FT, há um ponto em que deve-se decidir se o FT pode ser usado como está ou se necessita de adaptações. No caso do FT de persistência, essas adaptações consistem em verificar se as operações disponibilizadas por ele são suficientes ou não para implementar os requisitos. Geralmente essa necessidade surge quando as operações disponibilizadas pelo FT devem ser utilizadas como parte do comportamento de métodos da aplicação, e isso pode ocorrer durante a elaboração dos modelos de interação ou mesmo durante a implementação. As operações do FT de persistência que geralmente são adaptadas são as consultas, pois é muito difícil antecipar todos os tipos possíveis de consultas no FT.

As adaptações podem ser de três tipos: 1) criação de novas operações; 2) sobreposição de operações e 3) empacotamento (wrapping) de operações. Sugere-se que as adaptações sejam feitas no aspecto criado pelo engenheiro de aplicação durante a composição da persistência, isto é, naquele que estende o aspecto PersistentEntities do framework.

O primeiro tipo de adaptação consiste na criação de novas operações, como está sendo mostrado pela Figura 4.13. O método findlike_selectRegistersBetweenDates() é 
uma operação nova criada pelo engenheiro de aplicação para fornecer mais uma opção de consulta. Todos os métodos do framework responsáveis por executar consultas no banco de dados seguem o mesmo formato, isto é, há um vetor que representa as cláusulas SQL e um outro vetor que representa os parâmetros. Depois que as cláusulas e os parâmetros foram definidos, deve-se invocar o método findlikeDB () da classe TableManager passando o nome da Tabela, o vetor de cláusulas e o vetor de parâmetros. Note-se também que os novos métodos devem ser introduzidos (por meio de declarações intertipos) na interface PersistentRoot.

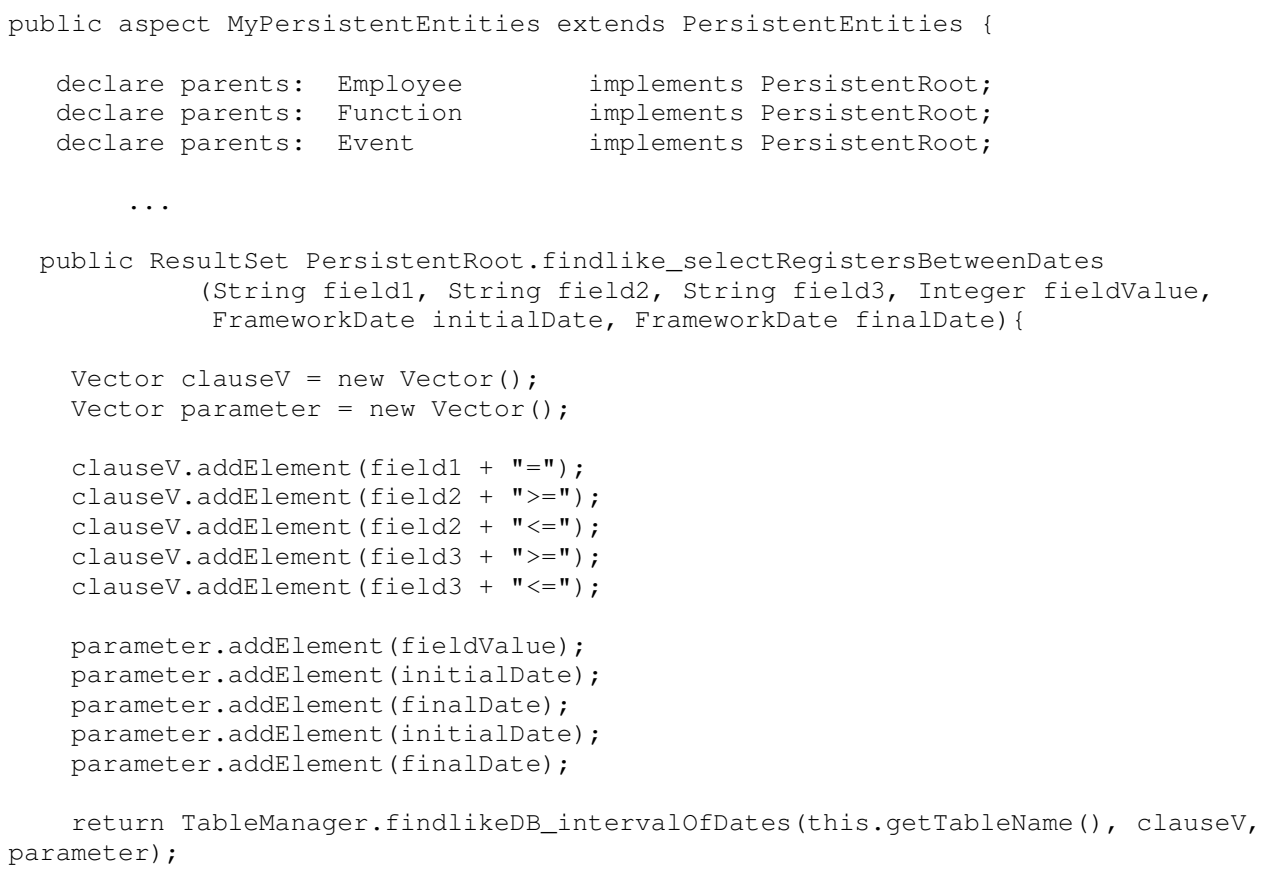

Figura 4.13 - Criação de Novos Métodos

O segundo tipo de adaptação é a sobreposição, que deve ser utilizada quando a funcionalidade de alguma operação do framework não é adequada e deve ser modificada. Uma característica desse tipo de adaptação é que as operações modificadas continuam com os mesmos nomes, não exigindo que a equipe de desenvolvimento que já conhece o framework necessite de treinamento extra. Por exemplo, suponha que no FT exista um método denominado findlikeByField_intervalofDates() que retorna registros que se encontram em um determinado intervalo de datas, incluindo as datas iniciais e finais. Dependendo das características do negócio, pode ser que as datas iniciais e finais não devessem ser incluídas na consulta. Quando essa situação ocorre pode-se sobrepor o método do framework, como esta sendo mostrado pela Figura 4.14. Assim, o método continua com o 
mesmo nome do original, porém a montagem do vetor de cláusulas não inclui operadores relacionais $>=\mathrm{e}<=\mathrm{e} \operatorname{sim}$ apenas $>\mathrm{e}<$, para que as datas iniciais e finais não façam parte da consulta, como é feito originalmente.

O terceiro tipo de adaptação é o empacotamento, que é um caso especial de sobreposição, pois as operações também continuam com o mesmo nome. A diferença principal é que no caso do empacotamento o comportamento original do framework continua sendo utilizado, enquanto que na sobreposição ele é descartado. O tipo de empacotamento mostrado aqui difere um pouco de sua definição original, a qual pode mudar o nome do método. A idéia do empacotamento é reaproveitar a funcionalidade de uma operação e adicionar comportamento extra antes ou depois de sua execução. A forma de empacotamento sugerida é mostrada pela Figura 4.15. A idéia é criar um adendo do tipo around que entrecorte chamadas ou execuções do método que se deseja empacotar. No corpo desse adendo pode-se invocar o método original por meio do proceed() e adicionar funcionalidades antes ou depois de sua execução. Dessa forma, quando o método original do framework for utilizado, seu comportamento será alterado por meio do adendo criado. Também podem ser utilizados adendos do tipo before () e after ().

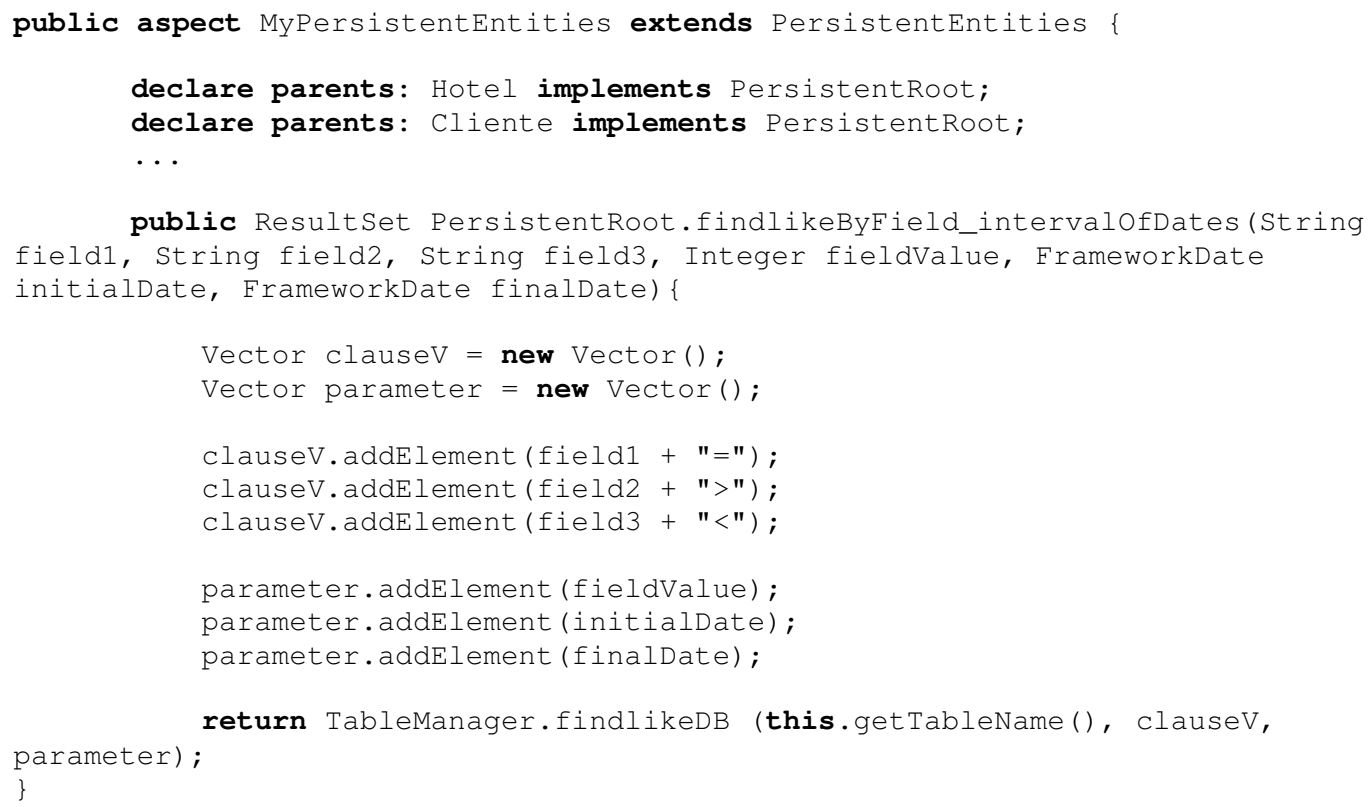

Figura 4.14 - Adaptação do Tipo Sobreposição do FT de Persistência

O empacotamento difere um pouco dos outros tipos de adaptação porque é feito com tecnologia de aspectos. Em se tratando de orientação a objetos, a estratégia de empacotamento seria sobrepor a operação e invocar seu comportamento original por meio do comando super ( ) . Entretanto, isso não pode ser feito no framework e por isso é necessária a definição de um adendo. 
As adaptações mostradas nas Figuras 4.13, 4.14 e 4.15 consideram que o engenheiro de aplicação está utilizando um FT caixa preta, em que ele não possui acesso ao código fonte do framework. Quando o FT é caixa branca, as adaptações podem ser feitas diretamente no código do framework. Por exemplo, a operação criada na Figura 4.13 poderia ser implementada no aspecto PersistentEntities, incorporando essa nova operação ao framework. No caso da sobreposição e do empacotamento, se não houver preocupação em manter a funcionalidade original do framework, as operações poderiam ser modificados no próprio framework.

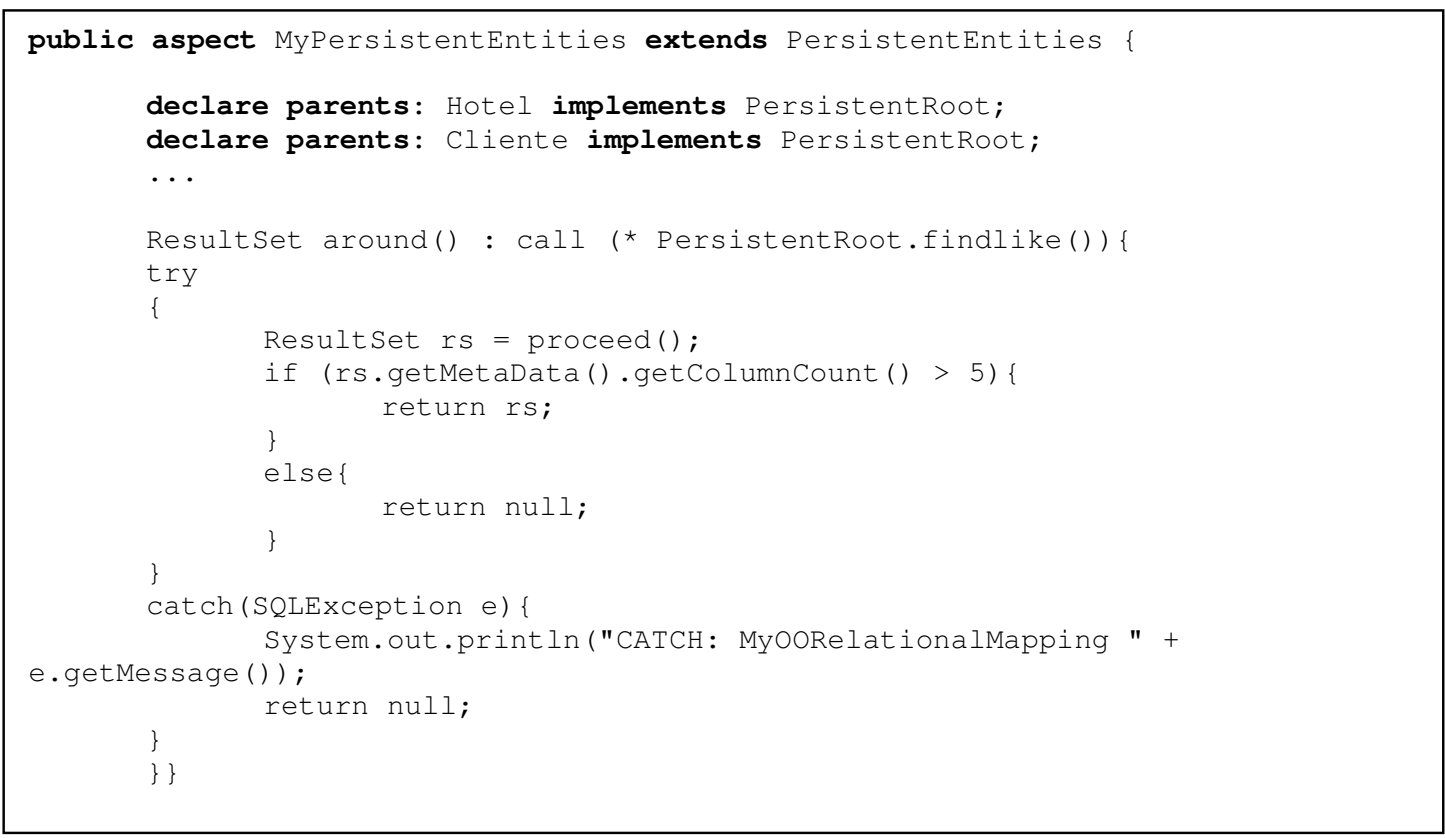

Figura 4.15 - Adaptação do Tipo Empacotamento

\subsection{3 - Acoplamento de Características ao FT de Persistência}

Como comentado anteriormente, a utilização das características pode ser feita antes ou depois que o FT foi acoplado a uma aplicação. Não há uma ordem obrigatória porque as características afetam apenas o FT, independentemente de já estar acoplado a um código-base ou não. Com o objetivo de exemplificar como deve ser realizado o acoplamento de uma característica com o FT de Persistência, a característica de Pooling será utilizada.

O objetivo do Pooling é melhorar o desempenho do FT mantendo um repositório de conexões. Na Figura 4.16 é mostrado o FT de Pooling como um tema transversal. A hierarquia da classe PoolDataCatcher corresponde à implementação do padrão Data Catcher, que é utilizado porque a interface desse FT necessita capturar um objeto do tipo Connection no ponto de junção em que a composição é realizada. Esse objeto será 
armazenado em um repositório de conexões e pode ser usado posteriormente quando novas conexões forem necessárias.

O diagrama de seqüência mostra que quando o método-gabarito pointsThatCreateConnection() for executado, a operação empty() verifica se o repositório está vazio. Em caso positivo, o comportamento original desse método-gabarito é chamado para criar um novo objeto Connection, que é retornado e colocado no repositório. Em caso negativo, o objeto Connection que estiver no topo da pilha é retornado ao invés de criar uma nova conexão.

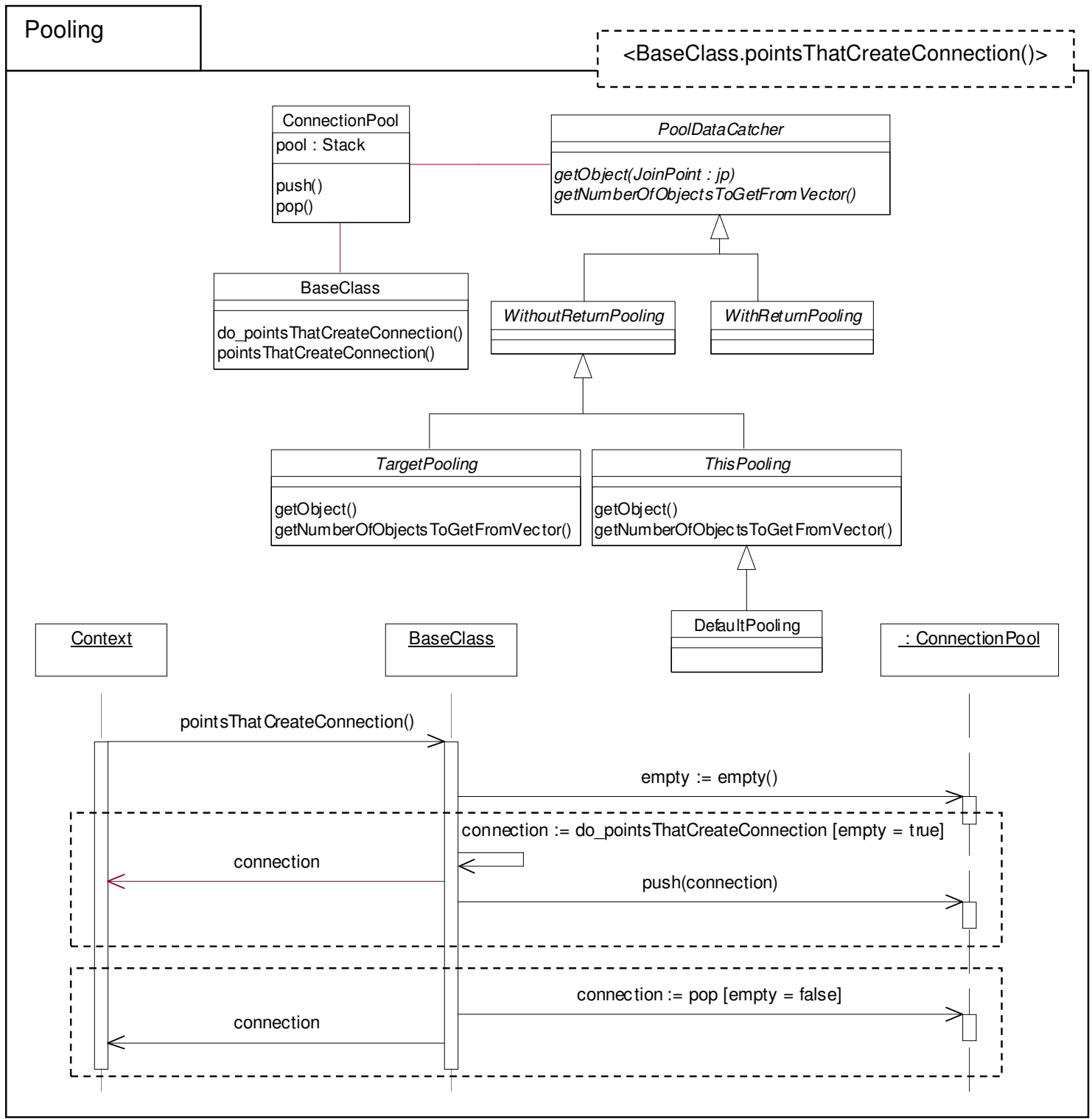

Figura 4.16 - FT de Pooling como um Tema Transversal

Como comentado anteriormente, as características implementadas como FTs possuem camada de pré-composição. O modelo mostrado na Figura 4.16 faz uso dessa camada 
definindo a alternativa de composição This como padrão, o que pode ser notado pela existência da classe concreta DefaultPooling. Essa alternativa foi definida como padrão porque o acoplamento da característica de Pooling com o FT de Persistência pode ser feito com essa alternativa de composição. A alternativa Target também é mantida para permitir que esse FT também seja reusado fora de sua linha de produtos. Entretanto, apenas com a experiência de um novo reúso é que seria possível determinar as alternativas de composição necessárias.

$\mathrm{Na}$ camada de pré-composição também há um aspecto concreto chamado DefaultPoolingAspect que realiza a composição propriamente dita com o FT de persistência. Tanto a classe DefaultPooling quanto o aspecto encontram-se em um pacote Java separado que devem ser adicionados no projeto somente se o objetivo for o acoplamento com o FT de persistência. Caso contrário, basta não incluir esse pacote no projeto e escolher a alternativa de composição e um outro ponto de junção de um outro código-base. Vale ressaltar que as características que possuem essa camada de implementação também possuem os modelos de projeto da composição prontos.

Na Figura 4.17 é mostrado o projeto da composição entre a aplicação (que já foi acoplada ao FT de Persistência) e a característica de Pooling. Apenas algumas classes estão sendo mostradas para facilitar a visualização. O relacionamento de ligação entre os temas destaca que o FT de Pooling afeta o FT de persistência no método connect () da classe OdbcConnection. O relacionamento de ligação entre os pacotes e a existência da classe DefaultPooling representam a camada de pré-composição.

$\mathrm{Na}$ Figura 4.18 é mostrado o aspecto DefaultPoolingAspect, que realiza a composição com o FT de Persistência. Note-se que o método connect() da classe OdbcConnection, destacado no relacionamento e ligação entre os pacotes da Figura 4.9, é o ponto de junção usado na concretização do conjunto de junção abstrato poolPushPop () do aspecto abstrato PoolWithoutReturn.

Alguns métodos também são concretizados para informar detalhes específicos do código-base. Por exemplo, os métodos getMethodResponsibleForSettingTheConnection() e getMethodResponsibleForGettingTheConnection() são usados internamente pelo FT de Pooling para conseguir capturar reflexivamente o objeto Connection do contexto de execução, como pode ser visto na Figura 4.19. Essa figura mostra parcialmente o código do aspecto Pool_WithoutReturn. Note-se que o método returninstanceofPooldataCatcherclass() é usado para obter uma instância da 
classe DefaultPooling. Isso é feito porque essa instância sabe como obter o objeto do código-base que contém o objeto Connection desejado, que é por meio do objeto This. Esse objeto é uma instância da classe OdbcConnection, que possui métodos de acesso ao objeto Connection, como getConnection() e setConnection(). Se o FT de Pooling fosse acoplado a um outro código-base esses mesmos métodos deveriam ser concretizados pelo engenheiro de aplicação.

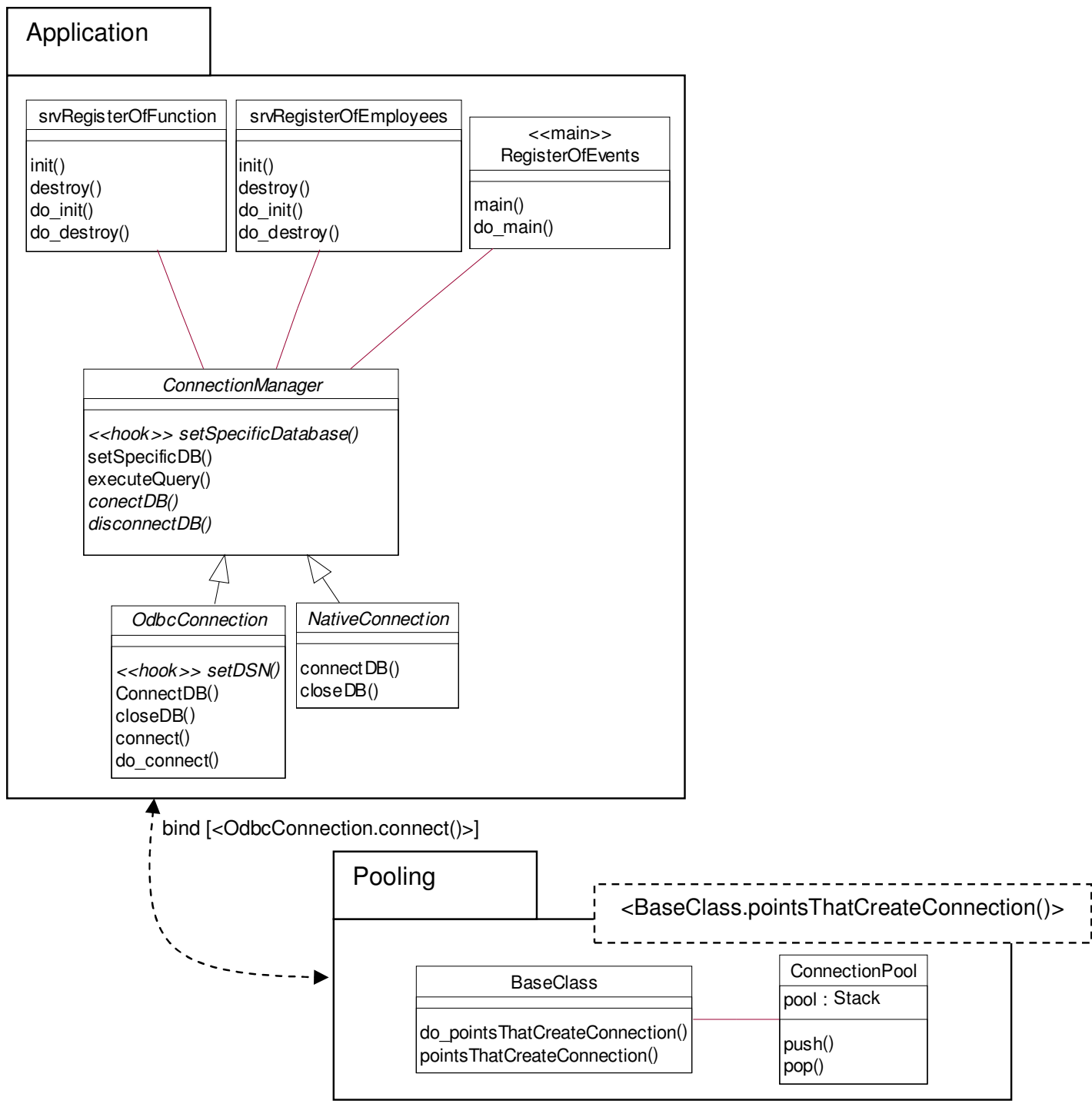

Figura 4.17 - Acoplamento do FT de Pooling com o FT de Persistência

Na Figura 4.20 é mostrado parcialmente o modelo de projeto composto do sistema, agora com a característica de Pooling. Note-se que a classe gabarito Baseclass foi substituída pela classe OdbcConnection do FT de Persistência.

Esta tese também inclui uma proposta de desenvolvimento de software apoiado por FTs chamado ProFT/PU. Este processo inclui alguns artefatos que devem ser elaborados com o objetivo de rastrear e controlar o acoplamento dos FTs na aplicação. Dois artefatos 
utilizados com esse fim são Visão da Arquitetura e Registro de Pontos de Junção. Esse último é um registro dos aspectos que se encontram acoplados ao sistema e também dos pontos de junção que eles afetam. Esse artefato é uma ferramenta conceitual que auxilia a identificar pontos de junção afetados por mais de um aspecto e se será necessário elaborar algum mecanismo de precedência de atuação entre eles. Maiores detalhes sobre ProFT/PU e seus artefatos serão apresentados no Capítulo 6.

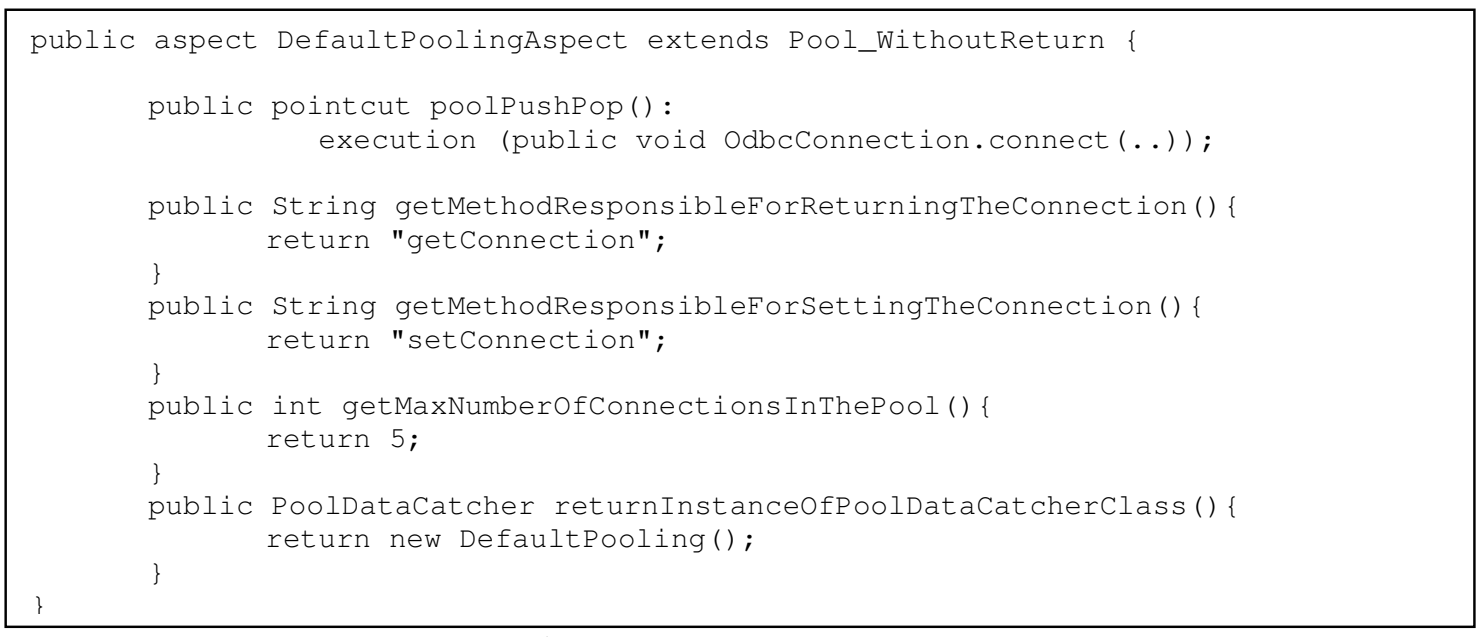

Figura 4.18 - Código Fonte do Aspecto DefaultPoolingAspect

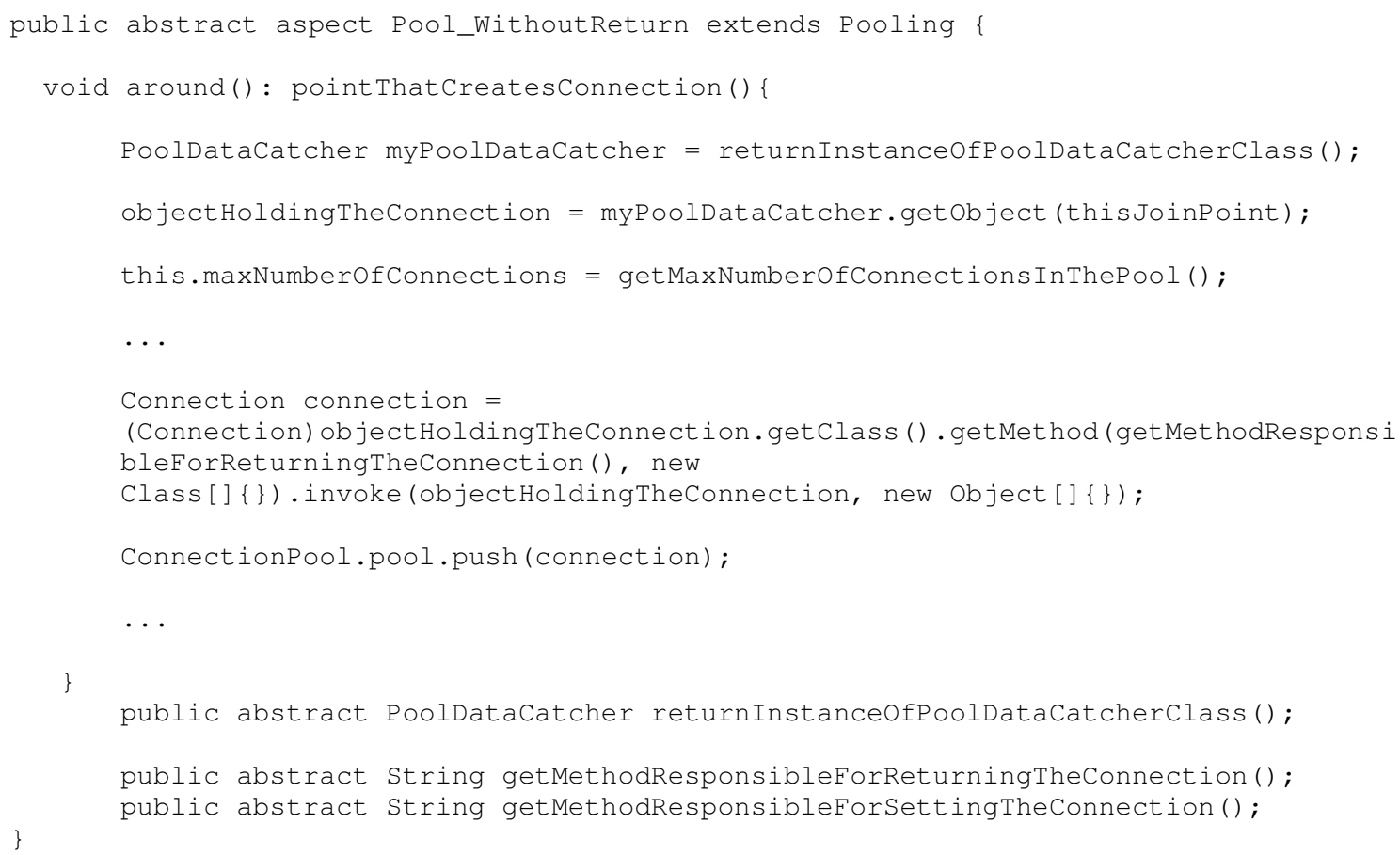

Figura 4.19 - Código Fonte do Aspecto PoolWithoutReturn 


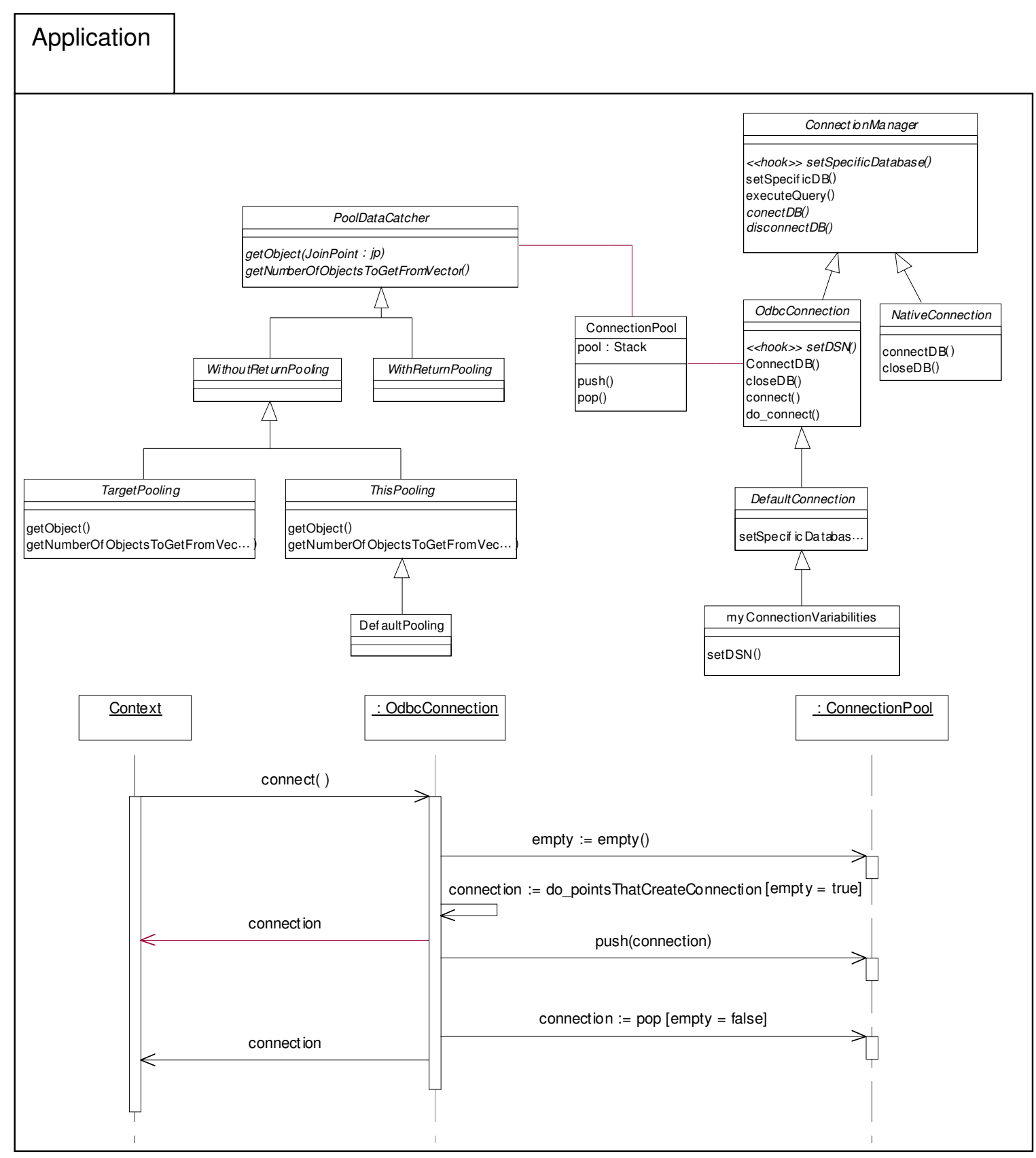

Figura 4.20 - Modelo de Projeto Composto da Aplicação com a Característica de Pooling

\subsection{4 - O FT de Garantia de Políticas}

Como comentado anteriormente, a decisão de utilizar o FT de Persistência em uma aplicação exige que a aplicação seja desenvolvida seguindo certas políticas ou regras. Essas políticas podem ser checadas estaticamente, em tempo de compilação, ou dinamicamente, em tempo de execução (Eicheberg, et al., 2004). Checagens em tempo de compilação baseiam-se na análise estática do programa e portanto os resultados são válidos para qualquer execução do programa, independentemente dos dados de entrada fornecidos. Algumas checagens, no 
entanto, envolvem valores só disponíveis durante a execução e portanto não podem ser realizadas dessa forma. As checagens dinâmicas, ainda que exijam a execução do programa, antecipam potenciais problemas que podem ocorrer posteriormente, durante o funcionamento do sistema ou que, sob condições específicas, não poderiam ser detectados.

A implementação de um mecanismo que realize essa verificação de propriedades utilizando apenas orientação a objetos leva ao entrelaçamento e espalhamento do código que implementa esse mecanismo com o código que implementa a funcionalidade do sistema. A implementação de assertivas usando orientação a objetos é um exemplo que ilustra esse problema.

Com o objetivo de verificar o cumprimento de duas dessas políticas foi criado o FT de Garantia de Políticas como uma característica opcional da linha de produtos de FTs de Persistência (Rocha et al., 2004a; Rocha et al., 2004b). As duas políticas que são verificadas por esse FT são: a presença de métodos de acesso aos atributos (sets e gets) e a existência de atributos com os mesmos nomes de colunas da tabela do banco de dados, constituindo duas variabilidades desse FT.

Assim como o FT de Repositório de Conexões apresentado na seção anterior, o FT de Garantia de Políticas é uma característica opcional do FT de Persistência, porém com a diferença que é geralmente usado apenas durante o desenvolvimento da aplicação, com o objetivo de testar os contratos exigidos pelo FT. Isso permite classificar o FT de Garantia de Políticas com uma "característica de desenvolvimento".

Na Figura 4.21 é mostrado um modelo de classes, em que cada classe representa um aspecto do FT de Garantia de Políticas. Os aspectos Pre_weaved_Attributechecker e Pre_weaved_GetSetChecker representam a camada de pré-composição com o FT de Persistência. Um ponto importante desta camada é que ela utiliza os conjuntos de junção da interface de entrecorte XOORelationalmapping (Figura 4.4) pertencente ao FT de Persistência, ao invés de definir novamente os pontos de junção, como pode ser observado na Figura 4.22. Assim como foi comentado anteriormente, se o objetivo for reusar esse FT em outros contextos, basta que o engenheiro de software crie aspectos concretos que estendam diretamente AttributeChecker e GetSetChecker.

$\mathrm{O}$ aspecto Checker encapsula o comportamento comum aos dois tipos de checagem e também possui um atributo estático denominado enabled e um método setEnabled () que muda o estado desse atributo. O objetivo é permitir que o FT possa ser ligado e desligado durante a execução da aplicação, recurso útil quando a aplicação já foi verificada e não 
necessita mais de verificação. Também pode ser utilizado apenas um tipo de checagem ao invés das duas, o que pode ser controlado removendo-se alguma camada de pré-composição.

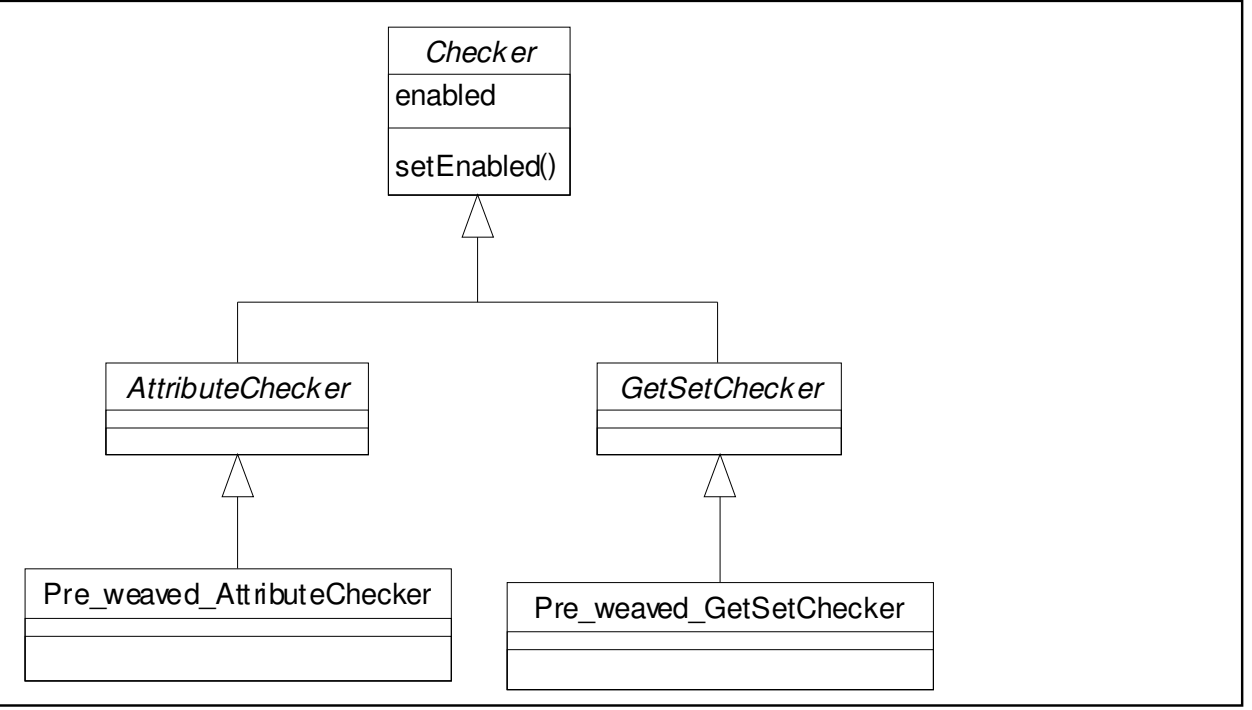

Figura 4.21 - Modelo de Projeto do FT de Garantia de Políticas

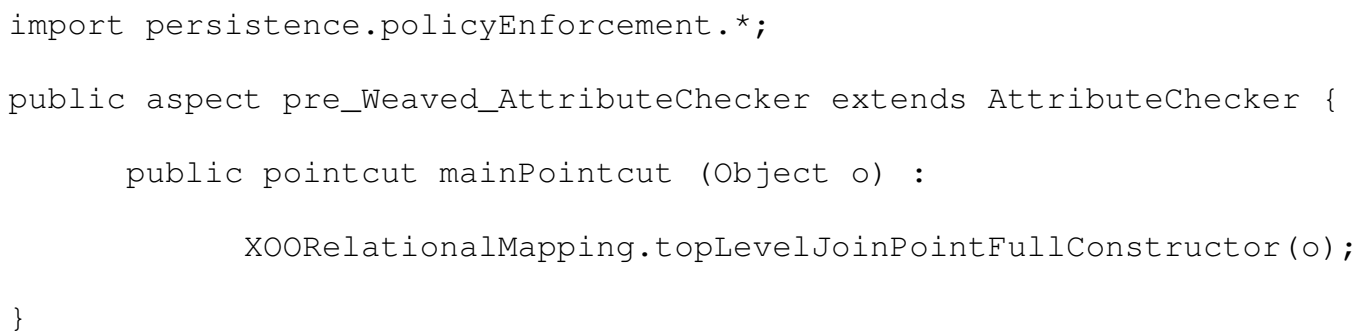

Figura 4.22 - Código do Aspecto pre_weaved_attributechecker

\section{4 - FAMÍlIA DE FRAMEWORKS TRANSVERSAIS DE SEGURANÇA}

A família de FTs de Segurança desenvolvida no contexto desta tese (Camargo e Masiero, 2005b) visa a facilitar a inserção de segurança em aplicações Web, permitindo que apenas usuários autorizados acessem o sistema ou parte dele. A arquitetura das aplicações em que o FT pode ser acoplado é mostrada na Figura 4.23. Nessa arquitetura, as interfaces com o usuário podem ser implementadas com HTML, JSP ou Servlets; as interfaces que possuem operações que serão obrigatoriamente entrecortadas devem ser implementadas com Servlets ou JSPs. A comunicação com o servidor também deve ser feita com Servlets, que instanciam objetos da aplicação e invocam seus métodos e operações.

A família de FTs de Segurança possui um FT de Autenticação, um de Controle de Acesso, um de Registro de Acessos e um de Políticas de Bloqueamento, como pode ser visto 
na Tabela 4.1. Na Figura 4.24 é mostrado o diagrama de características que representa a linha de produtos de FTs de segurança (Gomma, 2004). As características destacadas em cinza foram implementadas como FTs. O FT de autenticação, que é uma característica obrigatória, exige que o FT de persistência esteja acoplado ao sistema para que possa funcionar adequadamente. Isso é necessário porque o FT de Autenticação precisa acessar o banco de dados para efetuar a validação do nome do usuário e da senha.

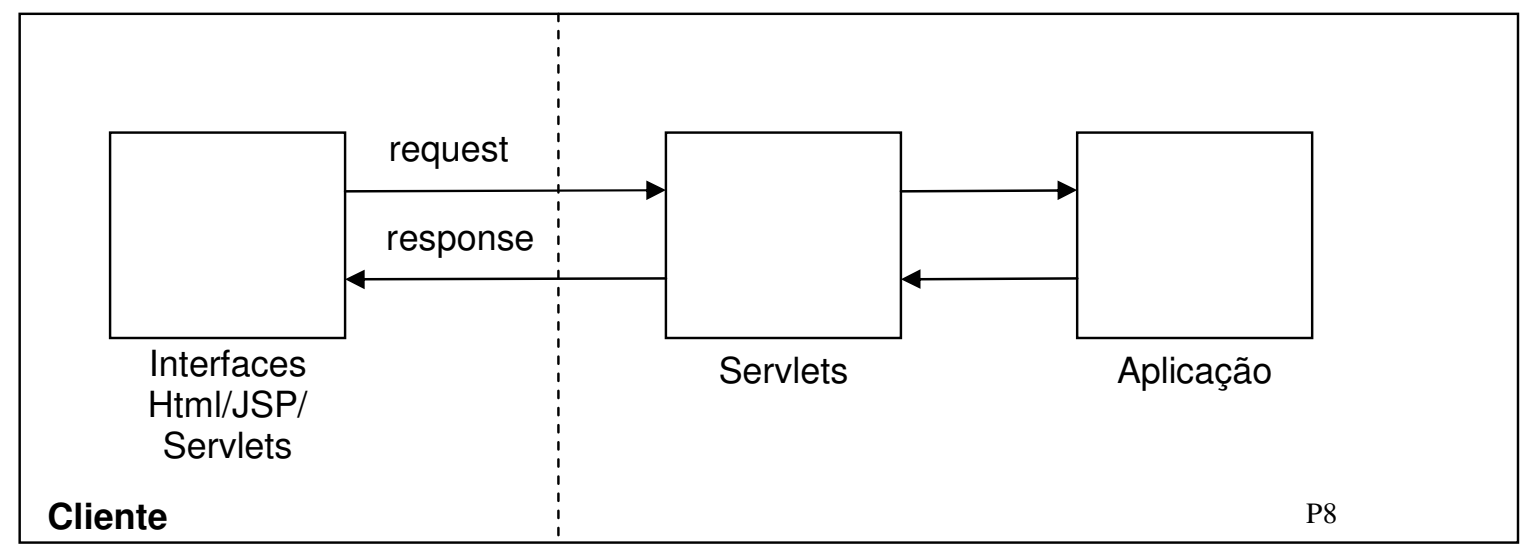

Figura 4.23 - Arquitetura das Aplicações em que o FT de Segurança pode ser Aplicado

O FT de Autenticação tem como objetivo permitir que apenas usuários autorizados possam acessar o sistema. Quando esse FT é utilizado, uma interface de gerenciamento de usuários torna-se disponível para que o administrador do sistema possa gerenciar os usuários e suas contas. O funcionamento desse FT ocorre da seguinte forma: quando alguém tenta acessar o sistema, o framework entrecorta a execução da operação que deve ser protegida e exibe uma interface solicitando o nome do usuário e a senha. Em seguida, o framework realiza a validação dos dados e permite ou não o acesso ao sistema.

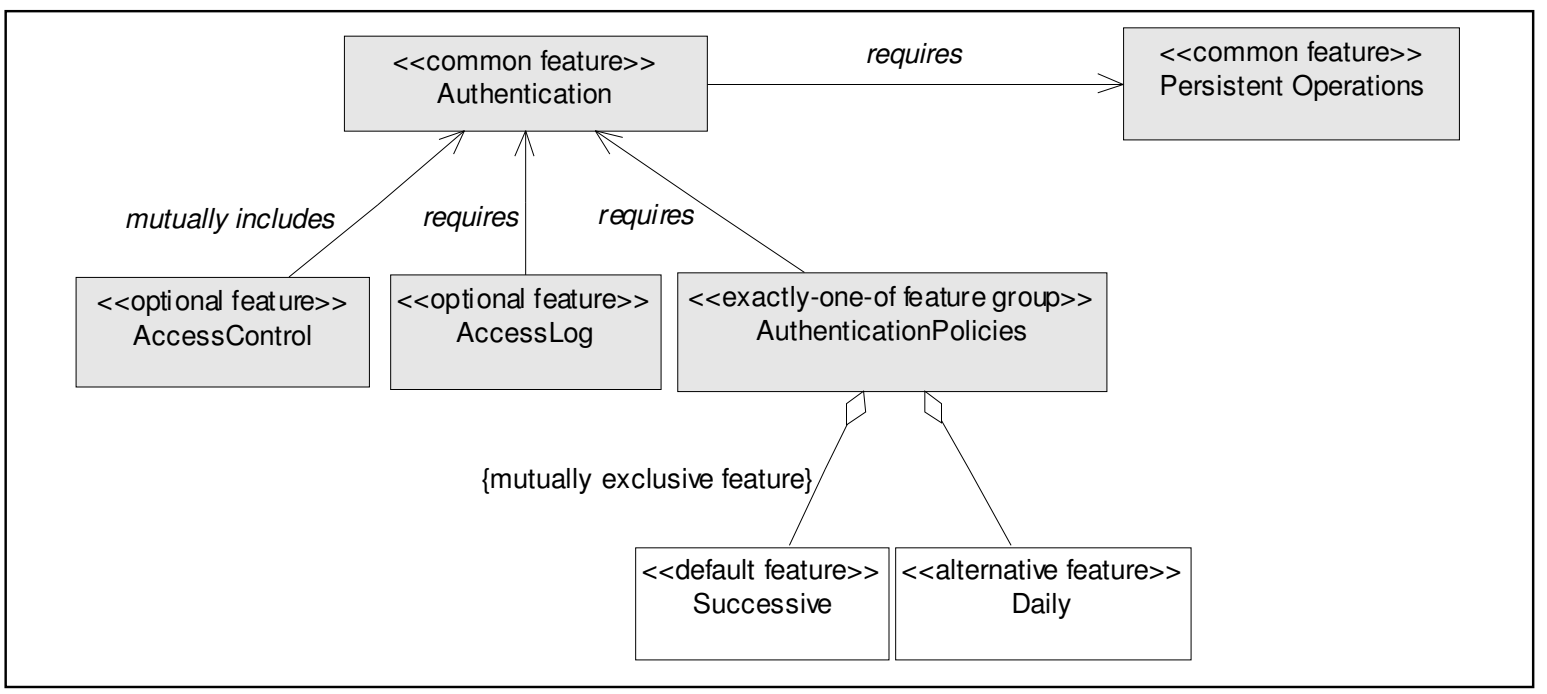

Figura 4.24 - Diagrama de Características da Linha de Produtos de FTs de Segurança 
Do ponto de vista do engenheiro de aplicação, o FT de Autenticação possui apenas interface de entrecorte dinâmica, pois esse profissional não tem a responsabilidade de chamar métodos e operações a partir do código-base. Entretanto, do ponto de vista do engenheiro do framework, também há interface de entrecorte estática. A interface de gerenciamento de usuários disponibilizada é um exemplo desse tipo de interface. Quem decide o momento de criar, remover ou alterar os usuários do sistema é o administrador. Assim como o FT de Persistência, não há pontos de junção que podem ser determinados no código-base. A diferença entre esses FTs é que, no caso do FT de Autenticação, a interface com o usuário também é disponibilizada, eliminando essa tarefa do engenheiro de aplicação, o que não ocorre com o FT de Persistência.

O FT de Autenticação é dependente de contexto, isto é, ele precisa capturar dados do código-base para realizar suas responsabilidades. Ele deve ser acoplado a um sistema em um ponto de junção em que seja possível capturar os objetos HttpservletRequest e HttpServletResponse, pois ele utiliza esses objetos para ter acesso à sessão do usuário.

O FT de Controle de Acesso tem como objetivo controlar o acesso a determinadas partes do sistema dependendo do papel que o usuário possui. Quando esse FT é utilizado, um sub-sistema de gerenciamento se torna disponível para que o administrador possa gerenciar os papéis que os usuários possuem e as operações do sistema que podem ser executadas por cada papel. Para que esse FT tenha condições de gerenciar papéis, é necessário que o FT de autenticação já esteja presente no sistema. Esse FT possui interface de entrecorte dinâmica e estática, sendo que apenas a dinâmica é tratada durante o processo de reúso. Sua interface de entrecorte estática introduz métodos e atributos em classes do FT de Autenticação, mas nenhuma tarefa precisa ser feita pelo engenheiro de aplicação. Basta que esse FT seja incluído no projeto para que essa interface atue corretamente.

O FT de Registro de Acesso armazena informações em uma tabela de banco de dados sobre os usuários que entram e saem do sistema, como, por exemplo: data de entrada, hora de entrada, data de saída e hora de saída. Esse FT é opcional e depende da presença do FT de autenticação para que possa funcionar adequadamente. A única interface de entrecorte desse FT é dinâmica, pois entrecorta pontos de junção do FT de Autenticação.

O FT de políticas de bloqueamento fornece ao FT de Autenticação duas formas de controlar o número de vezes que um usuário pode errar a senha, sob pena de bloqueamento da conta. Esse FT possui duas variabilidades: diária e sucessiva. Caso a política de bloqueamento "diária” seja escolhida, o usuário não pode errar sua senha um número estipulado de vezes no mesmo dia. Caso a "sucessiva" seja escolhida, o usuário não pode errar sua senha um 
determinado número de vezes consecutivamente. O tempo máximo entre uma tentativa e outra deve ser estipulado pelo administrador. Esse FT possui apenas interface de entrecorte dinâmica com o FT de Autenticação.

Como mostrado na Tabela 4.1, os FTs de Autenticação e de Controle de Acesso devem ser diretamente acoplados a uma aplicação, e não a outros FTs. Já os FTs de registro de acesso e de políticas de bloqueamento são características opcionais do FT de Autenticação e só podem ser acoplados a esse FT. Embora Access Control seja uma característica opcional, é um FT que deve ser acoplado a uma aplicação e não a outro FT. A escolha dessa característica automaticamente inclui o FT de Autenticação.

A adição de características no FT de persistência foi mostrada após esse FT ter sido acoplado a uma aplicação. Nesta seção será mostrado que o acoplamento das características também pode ser feito antes que o FT seja acoplado à aplicação. Assim, será mostrado o acoplamento do FT de Políticas de Bloqueamento com o FT de Autenticação gerando um FT com os requisitos exigidos. Depois disso a composição com a aplicação pode será feita.

O projeto do FT de autenticação é mostrado na Figura 4.25. Este modelo também mostra as classes criadas durante a etapa de instanciação, que estão destacadas em cinza. Como esse FT é dependente de contexto e foi implementado com três alternativas de composição do padrão Capturador de Objetos, optou-se por representar cada alternativa em um diagrama de seqüência. Dessa forma, o engenheiro de aplicação sabe quantas alternativas de composição estão disponíveis e consegue visualizar o comportamento de cada uma. Por exemplo, o primeiro diagrama de sequiência representa a alternativa WithParameters, como mostra a nota. Observe-se que na lista de parâmetros do método-gabarito protectedoperation() aparecem dois objetos, um do tipo HttpServletRequest, e outro do tipo HttpServletResponse. Isso mostra que, para utilizar essa alternativa de composição, o engenheiro de software deve fornecer um ponto de junção que seja a chamada ou a execução de algum método que possua esses dois objetos como parâmetros. Como esse FT é dependente de plataforma Web, é fácil encontrar métodos que possuam esses dois objetos, como por exemplo o doPost () e o doGet () dos servlets. Observe-se também que o método defineRequestAndResponse () utiliza esses dois objetos capturados.

O segundo diagrama de seqüência representa a alternativa de composição Target. Essa alternativa deve ser usada quando o ponto de junção a ser fornecido consiste em uma chamada ou execução de método cujo objeto alvo possua os dois objetos requeridos pelo FT. Observe que a lista de parâmetros do método-gabarito possui dois pontos (..), indicando que não importa se o método que será fornecido como ponto de junção possui ou não parâmetros. 
Isso acontece porque o FT irá utilizar o objeto alvo da chamada, que é o objeto app. Note-se que esse objeto é utilizado pelo framework no método defineRequestAndResponse ( ).

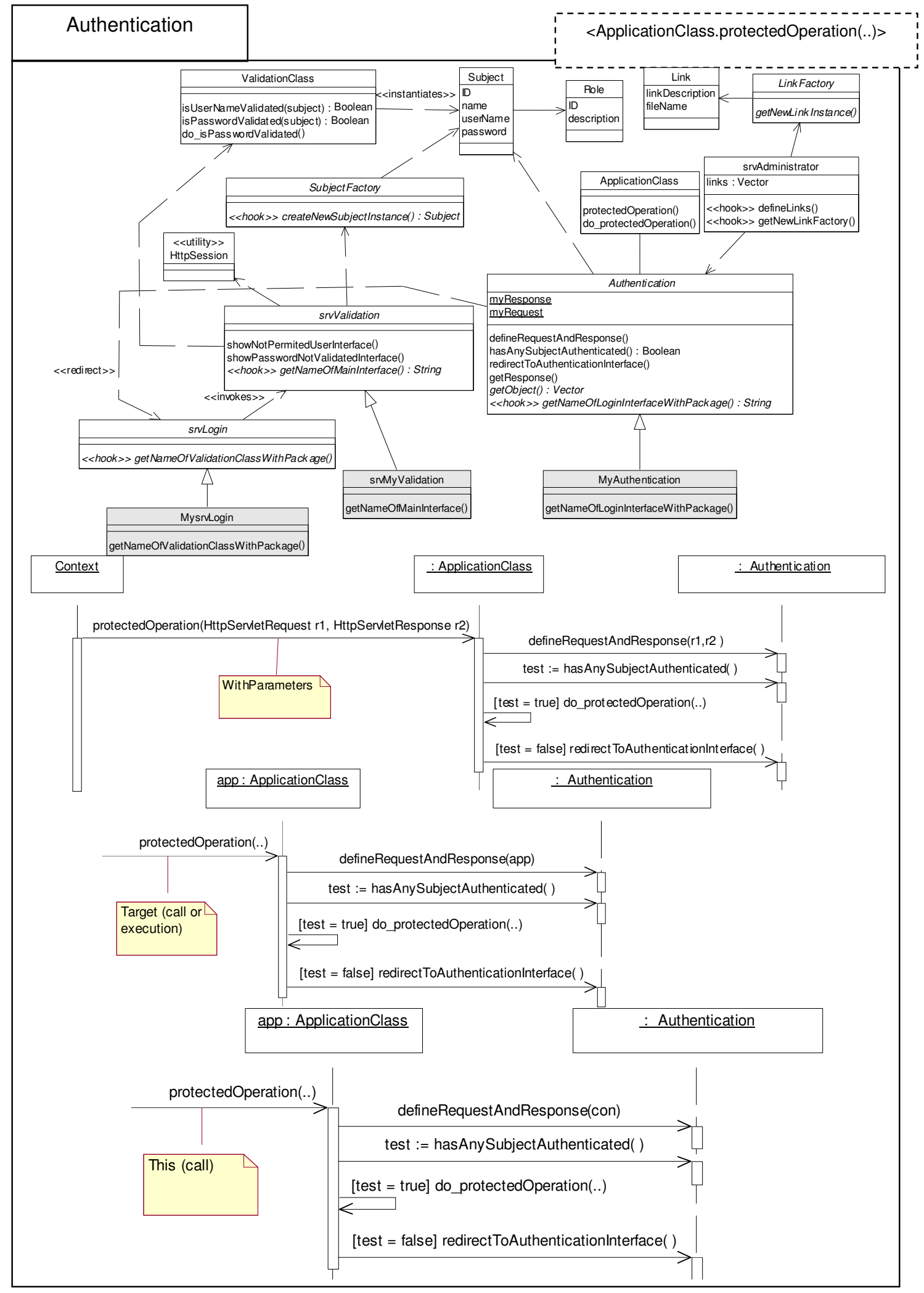

Figura 4.25 - Modelo de Projeto do FT de Autenticação 
A terceira alternativa de composição implementada por este FT é a This. Nesse caso, o objeto capturado pelo FT será o objeto this e não o target, como no diagrama de seqüência anterior.

Na Figura 4.26 é mostrado o modelo de projeto do FT de Políticas de Bloqueamento, que é uma característica opcional do FT de Autenticação. Como esse FT é uma variabilidade do FT de Autenticação, ele foi implementado apenas com a alternativa de composição Args, como pode ser visto no diagrama de seqüência. Isso foi feito já com vistas ao acoplamento com o FT de Autenticação. O diagrama de seqüência também mostra que o ponto de junção que deve se fornecido deve se a chamada ou execução de um método que possua como parâmetro um objeto do tipo sub ject, que é um tipo pré-definido do FT de Autenticação.

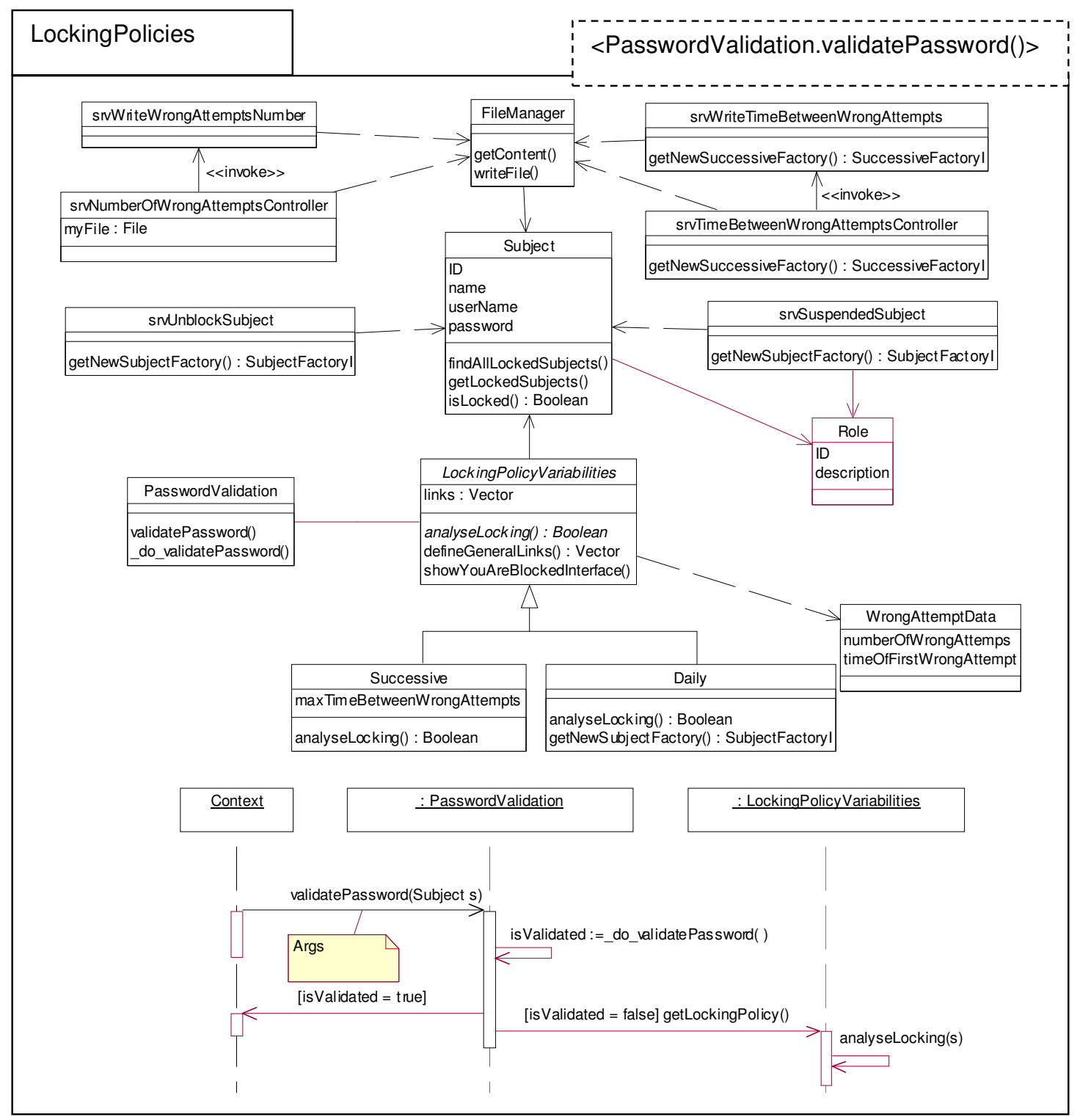

Figura 4.26 - Modelo de Projeto do FT de Políticas de Autenticação 
Na Figura 4.27 é mostrada a composição entre o FT de Autenticação e o de Políticas de Bloqueamento. Esse último não está sendo mostrado completamente porque pode ser visto na Figura 4.26. O relacionamento de ligação (bind) entre eles destaca o ponto de junção do FT de Autenticação que será afetado pelo FT de Políticas, que é o método isPasswordValidated() da classe Validation. A etiqueta ThemeName é utilizada para nomear o tema resultante.

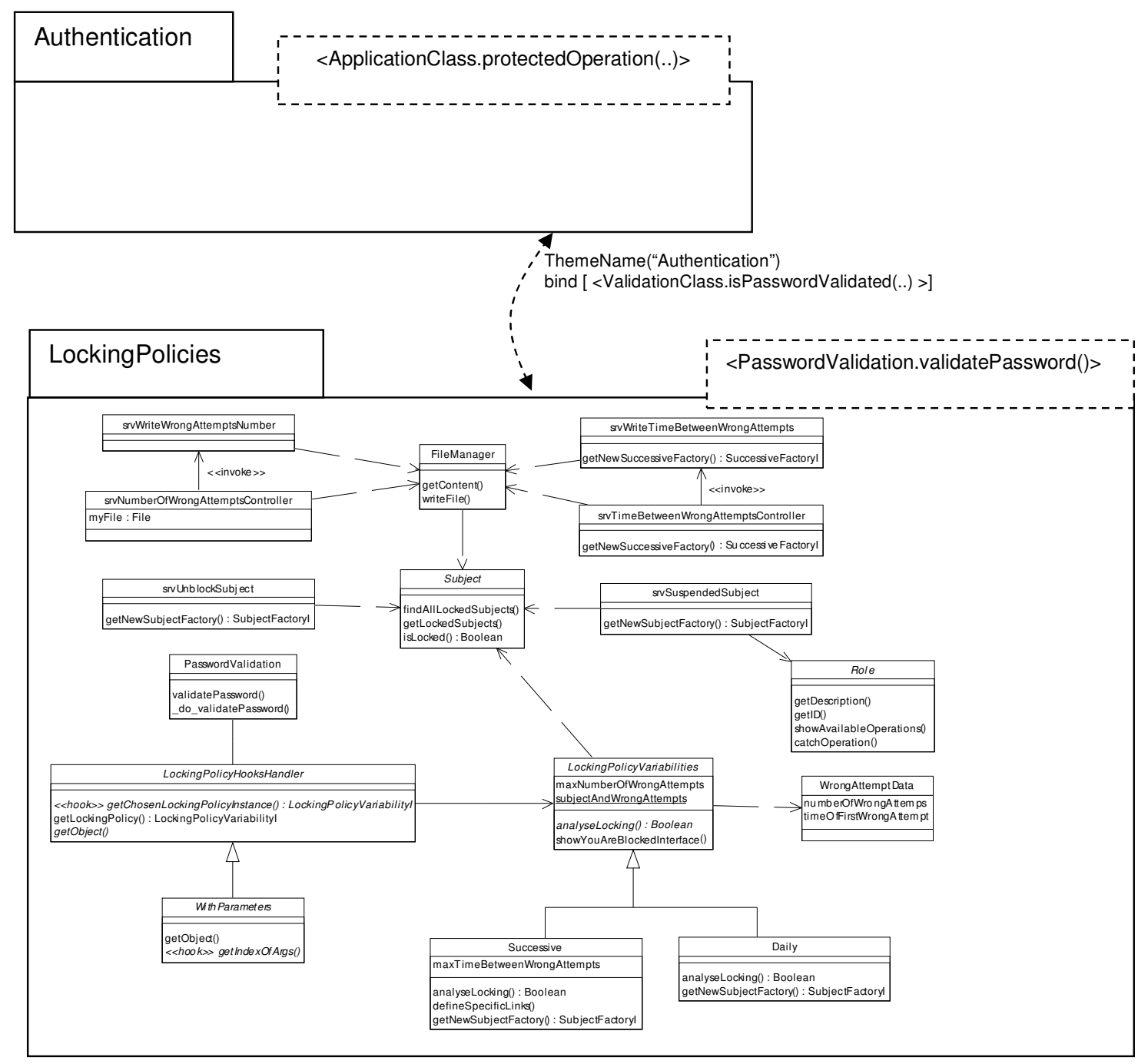

Figura 4.27 - Composição entre o FT de Políticas de Bloqueamento e o FT de Autenticação

As classes subject e Role se repetem em ambos os FTs, caracterizando o conceito de compartilhamento de conceitos da abordagem Tema. O FT resultante desta composição, mostrado parcialmente na parte superior da Figura 4.28, contém todas as classes do FT de autenticação e mais todas as classes do FT de políticas de bloqueamento. As classes que se repetem em ambos FTs (Subject e Role) aparecerão apenas uma vez no FT resultante, porém com todos os atributos e métodos oriundos dos dois FTs. Por motivos de simplicidade apenas as classes mais importantes estão sendo exibidas, porém todas as outras também estão 
presentes. Observe-se que a classe Subject possui todos os atributos oriundos do FT de Autenticação e mais todos os métodos oriundos do FT de políticas de bloqueamento.

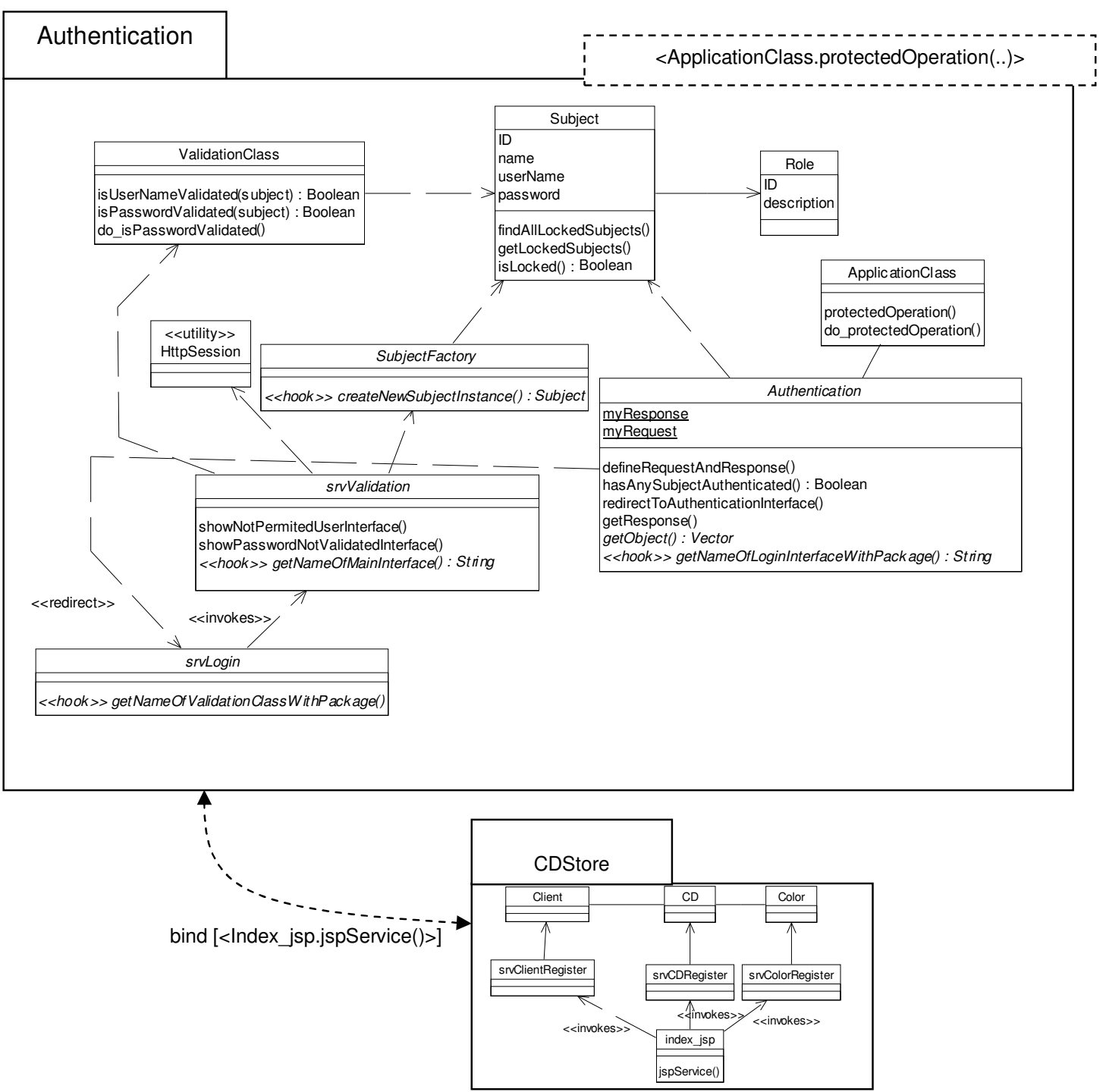

Figura 4.28 - Composição com a Aplicação

Na Figura 4.28 também é mostrada a composição entre o FT de autenticação resultante e uma aplicação hipotética. O relacionamento de ligação representa que quando o método jspservice() da classe de interface index.jsp for executado o comportamento transversal encapsulado pelo framework será executado.

Todos os FTs que manipulam dados persistentes com um banco de dados, assim como o FT de Autenticação, são dependentes do FT de Persistência. No diagrama de características ilustrado na Figura 4.24 pode-se notar que o FT de Persistência é uma característica obrigatória quando o FT de Autenticação é utilizado. Dessa forma, uma situação que pode ocorrer é a necessidade acoplar o FT de Autenticação em um código-base que já possua 
persistência implementada com alguma outra técnica, seja de forma convencional ou com o apoio de algum framework de persistência, como, por exemplo, o Hibernate (Hibernate, 2006).

Quando isso ocorre, uma opção é eliminar todo o código de persistência que já está implementado e fazer com que a aplicação utilize a persistência disponibilizada pelo FT. A vantagem dessa opção é que o interesse de persistência dentro da aplicação torna-se bem modularizado e que a arquitetura da aplicação torna-se mais clara. Entretanto, dependendo do tamanho da aplicação e do nível de entrelaçamento da persistência que já está implementada, o esforço para isso pode ser bastante significativo, podendo inviabilizar essa decisão. A outra opção consiste em acoplar o FT na aplicação juntamente com o FT de Persistência, fazendo com que a aplicação possua o interesse de persistência implementado de duas formas diferentes. Assim, a aplicação continua utilizando a persistência que já estava implementada e o FT de Autenticação utiliza o FT de Persistência. A desvantagem dessa opção é que o interesse de persistência estará implementado de duas formas dentro da mesma aplicação, tornando o projeto confuso. Porém, é uma opção interessante quando os prazos estão apertados porque não serão necessárias modificações no código-base, agilizando o processo.

\section{5 - FAMÍlIA DE FRAMEWORKS TRANSVERSAIS DE REGRAS DE NEGÓCIO}

Os FTs de regras de negócio são exemplos do uso de aspectos para encapsular requisitos funcionais (Suvée et al., 2005; Cibrán et al., 2003; Cibrán et al., 2006) e se assemelham à idéia de implementar características transversais funcionais de um domínio com aspectos (Mezini e Ostermann, 2004; Apel et al., 2006). Esses FTs foram criados durante o desenvolvimento de um sistema de reservas de uma rede de hotéis, que será exemplificado em detalhes no Capítulo 7.

Como o FT de Cálculo Baseado em Tabela já foi discutido na Seção 3.3.1, não será discutido novamente neste capítulo. O FT de Reajuste de Valor será exemplificado com mais detalhes no Capítulo 7, em que um exemplo de uso do ProFT/PU é mostrado.

\section{6 - CONSIDERAÇÕES FINAIS}

Os FTs apresentados e discutidos nesta seção não procuram cobrir todas as funcionalidades dos interesses por ele encapsulados. No caso do FT de persistência, gerenciamento de transações, tratamento de objetos sujos, acesso a dados sob demanda, conexões com banco de dados orientados a objetos, e outros detalhes poderiam ter sido implementados na arquitetura. 
O mesmo pode ser dito com relação ao FT de Segurança. Entretanto, o objetivo foi averiguar a viabilidade e a possibilidade de implementar linhas de produtos de FTs em que determinadas características também são FTs. Assim, antes que o FT seja composto com uma aplicação, suas características são escolhidas e acopladas para prover os requisitos exigidos, fazendo com que apenas as variabilidades utilizadas estejam presentes na arquitetura do FT.

O nível de maturidade dos FTs também é um detalhe importante a ser ressaltado. O FT com o maior nível de maturidade é o de persistência, pois já foi utilizado no desenvolvimento de seis sistemas acadêmicos, como pode ser visto na Tabela 5.10. Assim, grande parte de sua arquitetura já foi testada. Entretanto, o mesmo não ocorre com o FT de Segurança, que foi utilizado no desenvolvimento de apenas três sistemas. Somente com o reúso dessa família no desenvolvimento de outros sistemas é que novas variabilidades poderão ser identificadas.

Quando vários aspectos são utilizados durante o desenvolvimento de uma aplicação, um ponto importante é a precedência de atuação entre eles. Os FTs apresentados anteriormente possuem mecanismos de precedência já implementados em sua arquitetura para que os problemas de precedência seja minimizados. Isso é possível porque já se conhece de antemão os FTs que podem ser utilizados no projeto. Quando novos FTs são desenvolvidos, deve-se também cuidar para que esses mecanismos de precedência sejam atualizados. Entretanto, mesmo com os mecanismos já implementados, é interessante que o desenvolvedor tenha consciência dos pontos de junção que são afetados por dois ou mais aspectos.

A maior parte dos trabalhos encontrados na literatura que tratam de frameworks orientados a aspectos de um único interesse tem enfoque em detalhes arquiteturais e de implementação. Alguns mais recentes já se preocupam com o agrupamento de vários desses frameworks em algum repositório que facilite o reúso, como, por exemplo, bibliotecas de aspectos reusáveis. Porém, não foram encontrados trabalhos na literatura especializada que mostrassem processos de desenvolvimentos apoiados por aspectos reusáveis. 


\section{Capítulo 5}

Estudos de Caso

\section{1 - CONSIDERAÇÕES INICIAIS}

Neste capítulo são apresentados estudos que foram conduzidos com o objetivo de testar, comparar ou, simplesmente, averiguar determinadas particularidades dos FTs desenvolvidos. Foram conduzidos vários estudos informais com o objetivo de testar os FTs e identificar novas funcionalidades. Também foi conduzido um estudo em que o objetivo foi averiguar a dificuldade de acoplamento de um FT em uma aplicação. Um outro estudo, mais formal, teve o objetivo de comparar o tempo de composição de um FT de persistência com o tempo de composição de um framework orientado a objetos de persistência.

Na Seção 5.2, um estudo que comparou o tempo de composição de dois frameworks de persistência - um orientado a objetos e outro orientado a aspectos - é apresentado. $\mathrm{Na}$ Seção 5.3, um outro estudo, menos formal, cujo objetivo foi averiguar a dificuldade de encontrar um ponto de junção adequado em um código-base desestruturado é mostrado. $\mathrm{Na}$ Seção 5.4, outros estudos informais que foram conduzidos como parte desta pesquisa são discutidos.

\section{2 - UM ESTUdO COMPARATIVO DO TEMPO DE COMPOSIÇÃO ENTRE FTS}

Nesta seção é apresentado um estudo quantitativo que comparou o tempo de composição de um framework OO de persistencia com o FT de persistencia desenvolvido no contexto desta tese (Camargo et al., 2006). Vários trabalhos relatam que o uso da POA na implementação de frameworks de um único interesse resulta em benefícios de manutenção, reúso e legibilidade 
de código. Em particular, o interesse de persistência tem sido bastante pesquisado nesse sentido (Soares et al., 2002; Couto et al., 2005; Rashid and Chitchyan, 2003). Contudo, não foram encontrados trabalhos cujo foco fosse averiguar se a POA também afeta o tempo de composição desses frameworks com o código-base. Esse é um fator importante porque a adoção de uma nova tecnologia, por exemplo, um framework, pode depender, além de outros fatores, da produtividade e eficiência que essa nova técnica traz para a equipe de desenvolvimento.

O estudo segue a estrutura proposta por Wohlin (2000) e foi conduzido no primeiro semestre de 2006. Para a realização do estudo foram utilizadas duas versões do FT de persistência: uma orientada a objetos e uma orientada a aspectos. A versão orientada a objetos foi desenvolvida a partir da versão orientada a aspectos, e manteve a arquitetura e a funcionalidade dessa versão, sendo modificada apenas a técnica utilizada para a composição com o código-base.

Como o FT de persistência foi desenvolvido com a preocupação de utilizar aspectos apenas onde fosse necessário, a criação de uma versão OO foi facilitada. Por exemplo, no FT de persistência, uma das tarefas da etapa de composição é fazer com que as classes persistentes da aplicação estendam a interface PersistentRoot, o que é feito com declarações inter-tipo da linguagem AspectJ. No caso do framework de persistência OO, as classes persistentes da aplicação também devem estender a mesma interface, porém isso é feito introduzindo-se declarações "extends PersistentRoot" em cada uma das classes. Outro exemplo é a composição da conexão, que no FT é feita concretizando-se dois conjuntos de junção (pointcuts) por meio da criação de um aspecto concreto. Já no framework OO, essa composição é feita por meio da invocação de métodos para abrir e fechar a conexão em vários pontos do código.

Como comentado anteriormente, o processo de reúso de um framework que trata de um único interesse é feito em duas etapas: instanciação e composição. A etapa de instanciação para as duas versões do frameworks de persistência é idêntica, e consiste em escolher o tipo de conexão com o banco de dados. Como o objetivo do estudo foi comparar apenas a etapa de composição, os participantes do estudo receberam os frameworks com a instanciação já realizada, bastando apenas realizar a etapa de composição do framework com o código-base.

O framework de persistência utilizado no estudo, independentemente da versão (OO ou OA), possui duas partes distintas. A primeira corresponde ao que é chamado de "operações persistentes": um conjunto de operações básicas de persistência que devem ser adicionadas às classes persistentes da aplicação. A segunda parte corresponde à "conexão" com o banco de 
dados, a qual consiste em determinar pontos da aplicação em que a conexão deve ser aberta e fechada. A etapa de composição do FT foi definida em três passos para a condução do experimento, sendo que os dois primeiros correspondem ao acoplamento dessas duas partes com o código base, e o último aos testes de acoplamento. Embora essas duas partes formem a persistência como um todo, estão sendo tratadas de forma separada porque a composição com o código-base utiliza técnicas diferentes de programação, tanto na versão OO quanto na OA. Coletando separadamente os dados foi possível averiguar qual das partes tem mais impacto no tempo de composição total.

Os passos da etapa de composição foram definidos como: 1) Acoplar Comportamento de Persistência; 2) Acoplar Conexão e 3) Testar Acoplamento. Esses são os passos realizados pelos participantes do estudo para a coleta de dados. Para os dois primeiros passos, os participantes registraram o tempo de realização do passo, a quantidade de linhas de código escritas, a quantidade de locais modificados e a quantidade de unidades criadas, isto é, classes, pacotes e aspectos. Para o último passo apenas o tempo foi registrado. Na Tabela 5.1 são mostrados os dados que foram coletados e a respectiva sigla de cada um.

O primeiro passo da etapa de composição do FT consiste em criar um aspecto que estende o aspecto abstrato PersistentEntities do framework e que declare, por meio de declarações inter-tipo, todas as classes persistentes da aplicação que devem implementar a interface PersistentRoot, como é mostrado na Figura 5.1.

Tabela 5.1 - Significado das Siglas dos Dados Coletados

\begin{tabular}{|l|l|}
\hline \multicolumn{1}{|c|}{ Legenda dos Dados Coletados } \\
\hline \multicolumn{1}{|c|}{ Dados para Coletar } & \multicolumn{1}{c|}{ Siglas } \\
\hline Tempo de Acoplamento do Comportamento de Persistência (Passo 1) & TACP \\
\hline Tempo de Acoplamento da Conexão (Passo 2) & TAC \\
\hline Tempo de Teste do Acoplamento (Passo 3) & TTeste \\
\hline Quantidade de Linhas de Código Escritas & LC \\
\hline Quantidade de Unidades (classes, aspectos, pacotes) Criadas & UC \\
\hline Número de Locais modificados & LM \\
\hline
\end{tabular}

public aspect MyPersistentEntities extends PersistentEntities \{

declare parents : Departamento implements PersistentRoot;

declare parents : Endereco implements PersistentRoot;

declare parents: Funcionario implements PersistentRoot;

Figura 5.1 - Acoplamento do Comportamento de Persistência - AO

Já no caso do framework OO de persistência, a realização do primeiro passo consiste em inserir a declaração "extends PersistentRoot" e a declaração de importação "import persistence.PersistentRoot", em cada classe persistente de aplicação, assim como está sendo mostrado na Figura 5.2.

O segundo passo da etapa de composição consiste em estabelecer os locais do código onde a conexão deve ser aberta e fechada. Geralmente isso deve ser feito em programas 
(código-cliente) que usam objetos das classes persistentes definidas no passo anterior. No caso do FT, um aspecto concreto deve ser criado para estender o aspecto abstrato ConnectionComposition do FT, como está sendo mostrado na Figura 5.3. O aspecto abstrato ConnectionComposition possui dois conjuntos de junção abstratos: openConnection() e closeConnection() que devem ser concretizados. O conjunto de junção openConnection() deve ser concretizado de forma a entrecortar pontos da aplicação em que a conexão deve ser aberta, e o closeConnection() deve entrecortar pontos em que a conexão deve ser fechada. Além disso, também deve-se implementar o método-gancho getNameOfConnectionVariabilitiesClass(). Esse método deve ser implementado de forma a retornar o nome da classe que foi criada na etapa de instanciação. Como a instanciação já havia sido realizada, o nome dessa classe também foi informado aos participantes.

import persistence.PersistentRoot; public class [ClassName] extends PersistentRoot $\{\ldots\}$

Figura 5.2 - Acoplamento do Comportamento de Persistência - OO

Para o framework OO, a realização do segundo passo consiste em instanciar um objeto da classe MyConnectionVariabilities e chamar o método ConnectDB() em todos os pontos do código-base onde a conexão deve ser aberta e fechada. O estabelecimento da conexão deve ser feito logo no início dos programas e o encerramento deve ser feito no final. Na Figura 5.4 são mostradas em negrito as linhas de código que devem ser inseridas para que a composição possa ser realizada com um programa.

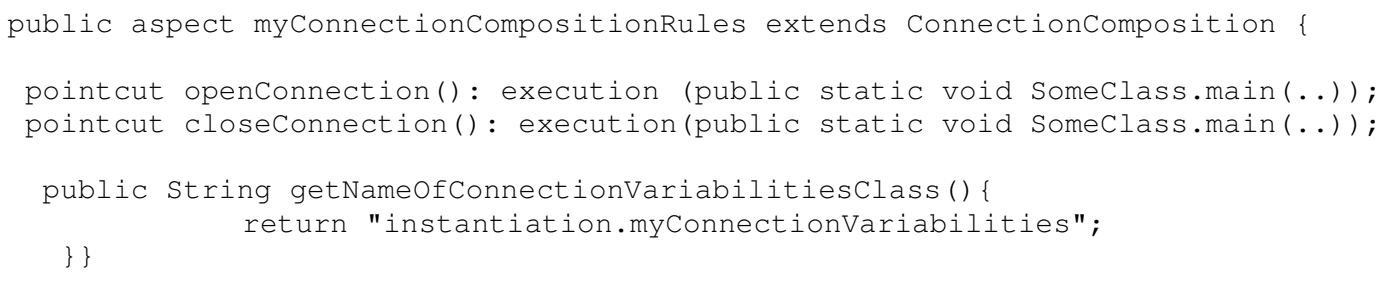

Figura 5.3 - Acoplamento da Conexão - AO

A etapa de teste foi idêntica para ambos os frameworks. Consistia em executar determinados programas e verificar se a saída correspondia à saída esperada. Por exemplo, uma das aplicações usadas no estudo possui um programa chamado RegisterofEvents, cujo objetivo é armazenar em várias tabelas do banco de dados eventos que os funcionários podem gerar durante o mês, por exemplo faltas, horas extras e atrasos. Se a execução desse programa não armazenar todos os dados esperados, a etapa de composição não pode ser considerada concluída e o erro deve ser rastreado e corrigido. Optou-se por não fornecer 
interfaces gráficas para as aplicações para que o tempo dos testes não fosse influenciado. $\mathrm{O}$ fornecimento dos programas fez com que todos realizassem os mesmos testes em tempos bastante próximos.

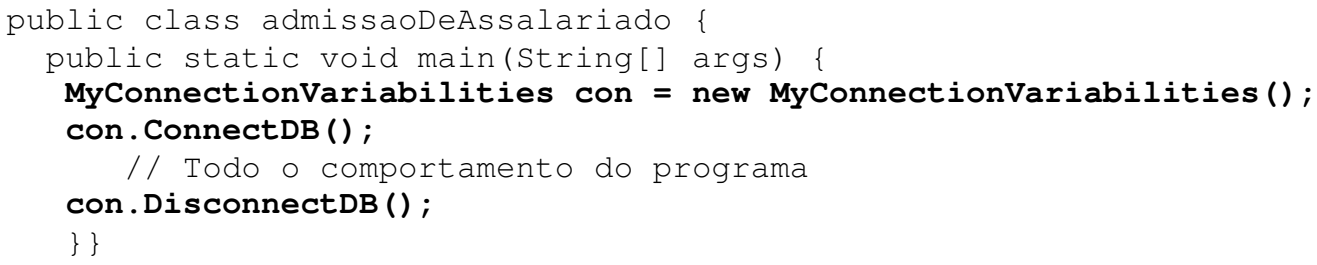

Figura 5.4 - Acoplamento da Conexão - OO

\subsection{1 - Definição do estudo}

O objetivo foi Analisar o tempo de composição de um FT de persistência com uma aplicação e de um FOO de persistência com uma aplicação para o propósito de avaliação com respeito à eficiência do ponto de vista de desenvolvedores de software no contexto de estudantes de pós-graduação em Ciências da Computação.

\subsection{2 - Planejamento do estudo}

a) Seleção do contexto. O estudo foi realizado com estudantes de pós-graduação em Ciência da Computação, no contexto da disciplina de Tópicos Avançados em Engenharia de Software, utilizando aplicações de domínio genérico (Loja de CDs e Oficina Eletrônica).

b) Formulação de hipóteses. Foram elaborados três tipos de hipóteses para o estudo: as hipóteses para o efeito do uso do Framework de Persistência no resultado podem ser vistas na Tabela 5.2; as hipóteses para o efeito do uso das Aplicações no Resultado encontram-se na Tabela 5.3, e as hipóteses para o efeito do grupo ou efeito da Interação Aplicação X Framework estão na Tabela 5.4.

c) Seleção de variáveis. As variáveis independentes são todas aquelas que são manipuladas e controladas durante o estudo. No estudo realizado essas variáveis são os Frameworks de persistência (OO e OA) e as aplicações (Loja de CDs e de Oficina Eletrônica).

As variáveis dependentes são aquelas que estão sob análise. Devem-se observar suas variações com base nas mudanças feitas nas variáveis independentes. No caso do estudo realizado a variável dependente é o tempo de composição.

Tabela 5.2 - Hipóteses para o Efeito do Framework de Persistência

\begin{tabular}{|l|l|}
\hline $\mathrm{H}_{0}:$ & $\begin{array}{l}\text { Não há diferença entre desenvolvedores utilizando Framework de Persistência OA e } \\
\text { desenvolvedores utilizando Framework de Persistência OO com respeito à eficiência individual. }\end{array}$ \\
\hline $\mathrm{Ha}:$ & $\begin{array}{l}\text { Há diferença entre desenvolvedores utilizando Framework de Persistência OA e desenvolvedores } \\
\text { utilizando Framework de Persistência OO com respeito à eficiência individual. }\end{array}$ \\
\hline
\end{tabular}


Tabela 5.3 - Hipóteses para o Efeito do Uso das Aplicações no Resultado

\begin{tabular}{|l|l|}
\hline $\mathrm{H}_{0}:$ & $\begin{array}{l}\text { Não há diferença entre desenvolvedores fazendo o acoplamento na Aplicação Loja de CDs e } \\
\text { desenvolvedores fazendo o acoplamento na Aplicação Oficina Eletrônica com respeito à eficiência } \\
\text { individual. }\end{array}$ \\
\hline $\mathrm{Ha}:$ & $\begin{array}{l}\text { Há diferença entre desenvolvedores fazendo o acoplamento na Aplicação Loja de CDs e } \\
\text { desenvolvedores fazendo o acoplamento na Aplicação Oficina Eletrônica com respeito à eficiência } \\
\text { individual. }\end{array}$ \\
\hline
\end{tabular}

Tabela 5.4 - Hipóteses para o Efeito do Grupo ou Efeito da Interação

\begin{tabular}{|l|l|}
\hline $\mathrm{H}_{0}:$ & $\begin{array}{l}\text { Não há diferença entre o grupo que fez o acoplamento de um FOA com uma aplicação e o grupo } \\
\text { que fez o acoplamento de um FOO em relação a eficiência. }\end{array}$ \\
\hline Ha: & $\begin{array}{l}\text { Há diferença entre o grupo que fez o acoplamento de um FOA com uma aplicação e o grupo que fez } \\
\text { o acoplamento de um FOO em relação a eficiência. }\end{array}$ \\
\hline
\end{tabular}

d) Seleção dos participantes. Os participantes do estudo foram selecionados por meio de amostragem não-probabilística por conveniência. Eram alunos de pós-graduação da disciplina de Tópicos Avançados em Engenharia de Software, ministrada no ICMC/USP.

e) Projeto do estudo realizado. O estudo foi planejado em bloco e balanceado para assegurar que os tratamentos tivessem igual número de participantes e para possibilitar a comparação dos efeitos das variáveis independentes, como pode ser visto na Figura 5.5. Na segunda fase do estudo, os 4 participantes mais experientes em OO e OA e nas linguagens Java e AspectJ executaram novamente as etapas do projeto experimental anterior, sendo invertidas as combinações dos frameworks com as aplicações (Figura 5.5).

f) Tipo de projeto: dois fatores com dois tratamentos ( $2 * 2$ fatorial)

A distribuição dos participantes nos grupos foi realizada visando a colocar a mesma quantidade de participantes experientes nos dois grupos. A experiência dos participantes foi avaliada pelo questionário de caracterização dos participantes, que pode ser encontrado no anexo 3 desta tese. O gráfico mostrado na Figura 5.6 (a) mostra a experiência dos participantes em Java, AspectJ e POA, e o gráfico (b) mostra a experiência com programação em Java e AspectJ. Os participantes P1, P2, P7 e P8 foram considerados experientes em POA.

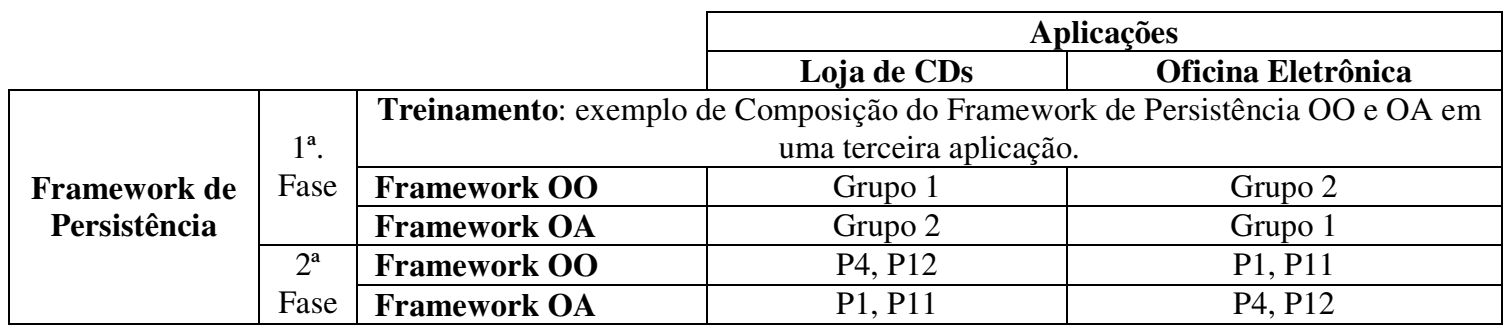

Figura 5.5 - Projeto Experimental

g) Instrumentação. Os participantes deveriam contabilizar o tempo gasto para realizar a composição utilizando cada um dos frameworks. 
Os documentos utilizados no estudo foram: formulário de caracterização dos participantes, para obtenção da experiência profissional e nos assuntos relacionados diretamente ao estudo; Formulário de registro, para preenchimento de todas as informações durante a execução do estudo; Roteiro de execução, roteiro com todos os passos a serem seguidos para execução do estudo.

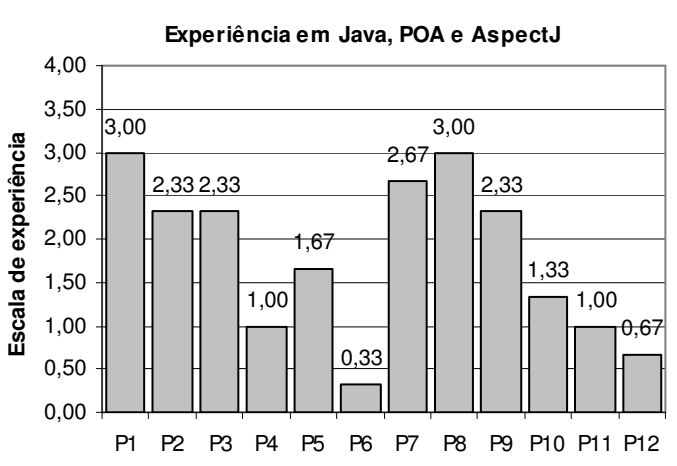

(a)

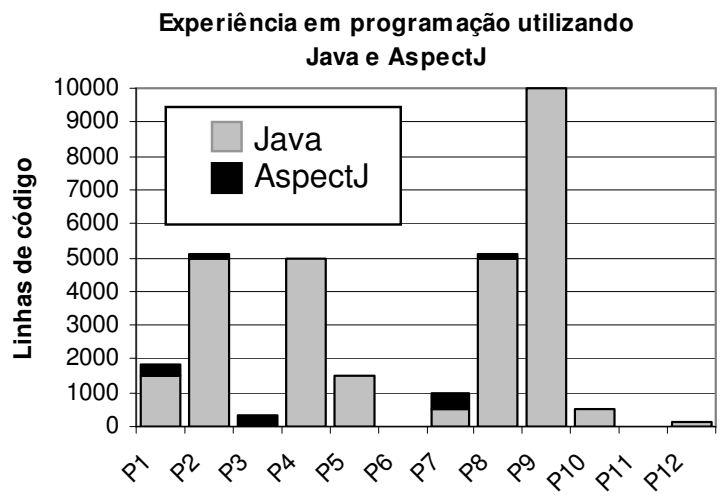

(b)

Figura 5.6 - (a) Experiência dos participantes em POA, Java e AspectJ; (b) Experiência dos participantes nas linguagens JAVA e AspectJ (linhas de código)

Os frameworks utilizados foram um de persistência orientado a objetos e um de persistência orientado a aspectos. As duas aplicações utilizadas foram um sistema para loja de CDs e um sistema para Oficina Eletrônica. A aplicação de loja de CDs possui 6 classes e 13 programas. O sistema de oficina eletrônica possui 7 classes e 12 programas. As aplicações possuem complexidade similar e aproximadamente o mesmo número de linhas de código. Assim como os frameworks, essas aplicações foram desenvolvidas no meio acadêmico.

Foi realizado um pequeno treinamento visando a uniformizar o conhecimento sobre programação orientada a aspectos e de Frameworks (OO e OA). Também fez parte do treinamento a utilização de uma terceira aplicação, com a qual deveriam ser feitos os acoplamentos utilizando os frameworks $\mathrm{OO}$ e $\mathrm{OA}$ e todos os formulários que seriam utilizados no estudo posteriormente, para que o aprendizado sobre como fazer uma composição utilizando os frameworks e como preencher os formulários não interferisse no tempo de acoplamento durante o estudo.

O objetivo da primeira fase foi realizar uma avaliação pura do tempo de composição e por isso, os pontos de acoplamento do código-base foram informados. Já na segunda fase, o objetivo foi avaliar se a existência de uma nova dificuldade também interfere nos resultados, não informando aos participantes os pontos de acoplamento. 


\subsection{3 - Execução.}

Os participantes executaram as atividades planejadas seguindo o projeto experimental. Primeiro treinaram a composição de um framework de persistência OO e depois de um FT em uma aplicação desenvolvida para exemplo.

Na primeira etapa da execução, o Grupo 1 utilizou o Framework de Persistência OO com a aplicação Loja de CDs, enquanto que o Grupo 2 utilizou o mesmo Framework com a aplicação Oficina Eletrônica. Na segunda etapa, os grupos utilizaram o Framework de Persistência OA, com as aplicações trocadas: o grupo 1 utilizou a aplicação Oficina Eletrônica e o Grupo 2 utilizou a aplicação Loja de CDs.

\subsection{4 - Dados Coletados}

Nas Tabelas 5.5 e 5.6 são mostrados os dados da primeira fase do estudo, em que havia tanto participantes experientes quanto novatos, e na Tabela 5.7, são mostrados os dados da segunda fase, em que havia apenas participantes experientes. Os significados das siglas dos dados coletados podem ser visto na Tabela 5.1.

Tabela 5.5 - Primeira Etapa da Primeira Fase - Composição com o Framework Orientado a Objetos

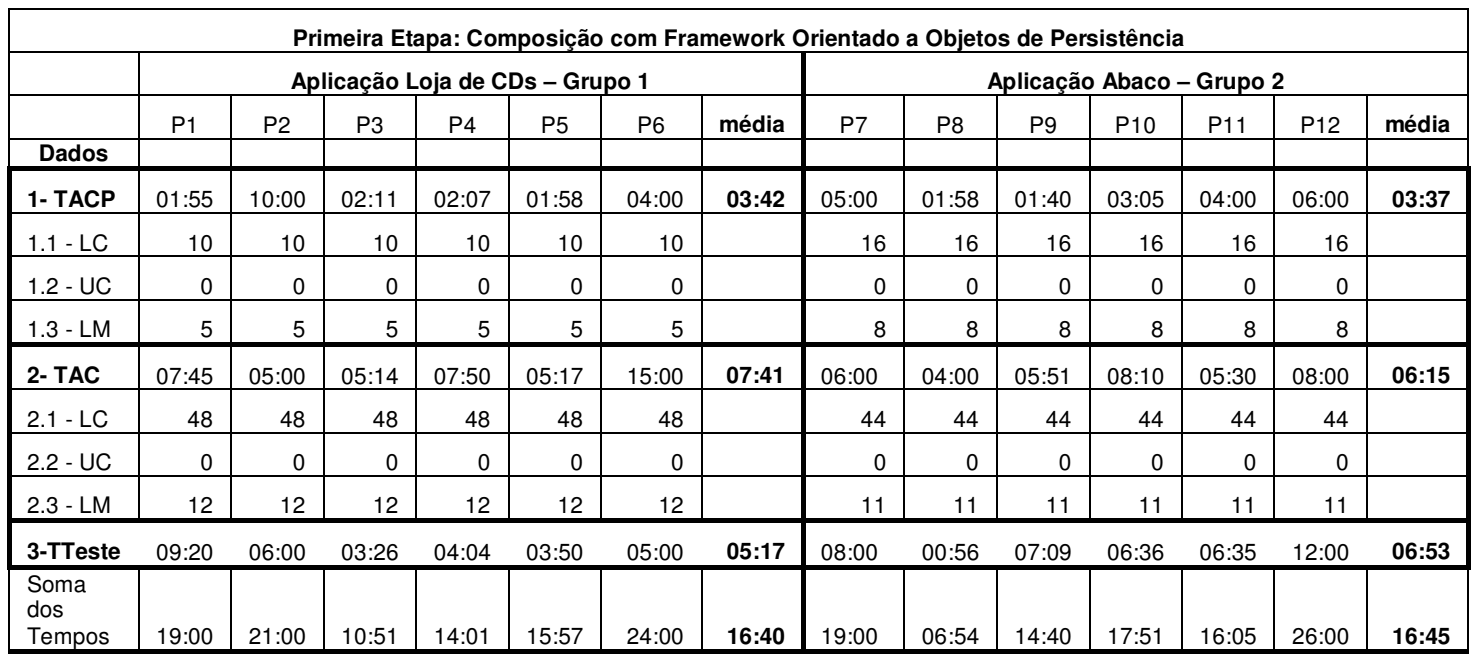

Os dados foram coletados separadamente para cada passo da etapa de composição do framework, isto é, foram coletados tempo, número de linhas de código escritas, número de locais modificados e número de unidades criadas para cada um dos três passos do processo de composição, a menos do passo de teste, em que foi contabilizado apenas o tempo. Os dados mostrados nas Tabelas 5.5, 5.6 e 5.7 estão agrupados pelos três passos da composição. No primeiro passo, representado pelo dado "1 - TACP" (veja Tabela 5.1), os dados "1.1 - LC", "1.2 - UC" e "1.3 - LM", que se encontram logo abaixo desse dado e que estão numerados como subseções, representam os dados coletados durante a realização desse primeiro passo. $\mathrm{O}$ 
mesmo ocorre com o segundo passo "Acoplar Conexão", representado pelo dado "2 - TAC". A letra "T" significa "tempo".

Tabela 5.6 - Segunda Etapa da Primeira Fase - Composição com o FT de Persistência

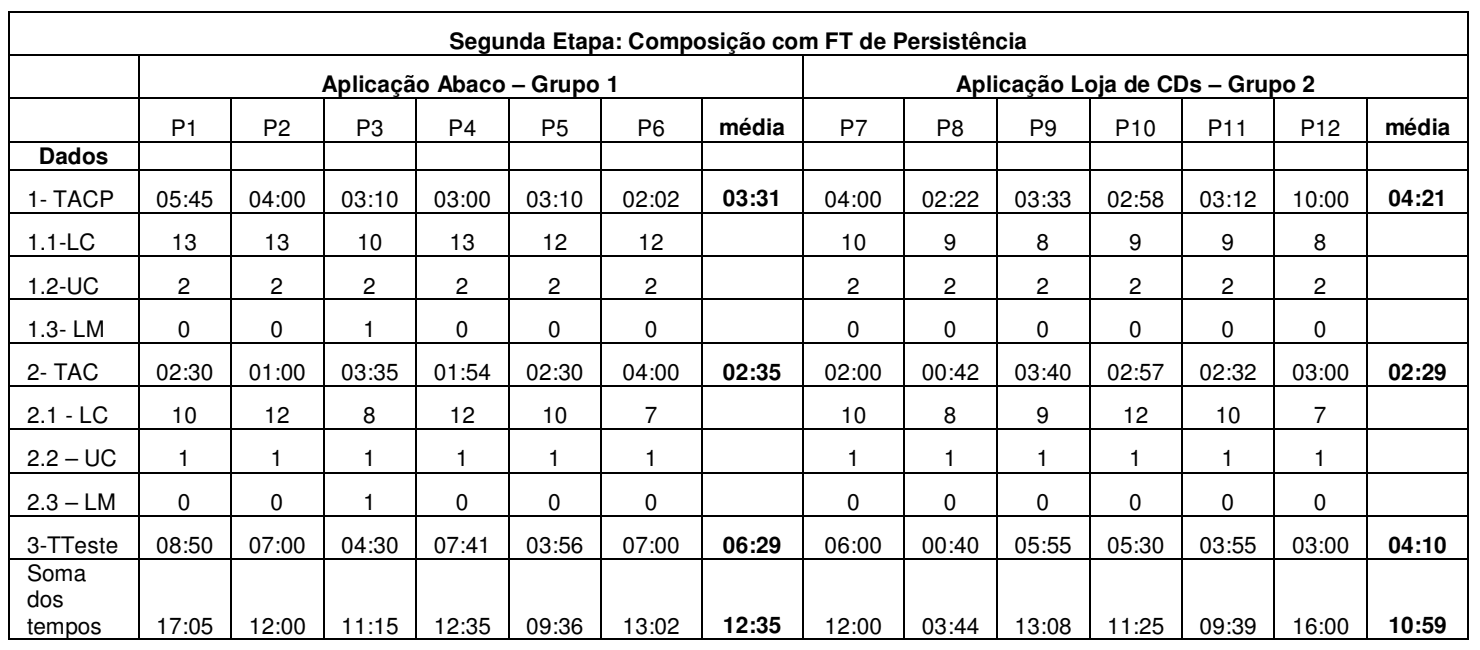

A coluna "média" mostra a média de tempo que os participantes gastaram na realização de cada um dos três passos e a última linha mostra a soma dos tempos de cada participante e também a soma dessas médias, o que representa o tempo médio de composição do framework com a aplicação.

Tabela 5.7 - Primeira e Segunda Etapas da Segunda Fase do Estudo

\begin{tabular}{|c|c|c|c|c|c|c|c|c|c|c|c|c|}
\hline \multicolumn{7}{|c|}{ Primeira Etapa - Framework Orientado a Objetos } & \multicolumn{6}{|c|}{ Segunda Etapa - Framework Transversal } \\
\hline & \multicolumn{3}{|c|}{ Abaco - Grupo1 } & \multicolumn{3}{|c|}{ Loja de CDs - Grupo 2} & \multicolumn{3}{|c|}{ Loja de CDs - Grupo 1} & \multicolumn{3}{|c|}{ Abaco - Grupo 2} \\
\hline & P1 & $\mathbf{P 2}$ & média & P7 & P8 & Média & P1 & $\mathbf{P 2}$ & Media & P7 & P8 & Média \\
\hline Dado & & & & & & & & & & & & \\
\hline 1- TACP & 07:42 & 07:00 & 07:21 & 06:35 & 03:10 & $04: 53$ & 03:20 & 03:00 & 03:10 & 04:00 & $04: 25$ & 04:13 \\
\hline 1.2-LC & 16 & 16 & & 10 & 10 & & 10 & 11 & & 9 & 14 & \\
\hline 1.3-UC & 0 & 0 & & 2 & 0 & & 1 & 1 & & 1 & 1 & \\
\hline 1.4- LM & 8 & 8 & & 5 & 5 & & 0 & 0 & & 0 & 0 & \\
\hline 2-TAC & $06: 30$ & 07:00 & $06: 45$ & $06: 15$ & 06:24 & $06: 19$ & $03: 15$ & 02:00 & $02: 38$ & 05:00 & $00: 45$ & 02:53 \\
\hline $2.1-\mathrm{LC}$ & 44 & 44 & & 36 & 48 & & 12 & 12 & & 9 & 9 & \\
\hline $2.2-U C$ & 0 & 0 & & 0 & 0 & & 1 & 1 & & 1 & 1 & \\
\hline $2.3-$ LM & 11 & 11 & & 12 & 12 & & 0 & 0 & & 0 & 0 & \\
\hline Teste & 06:05 & 07:00 & 06:32 & 05:00 & $04: 25$ & $04: 43$ & $04: 18$ & 07:00 & 05:39 & 04:00 & $04: 10$ & 04:05 \\
\hline $\begin{array}{l}\text { Soma } \\
\text { dos } \\
\text { Tempos }\end{array}$ & $20: 17$ & $21: 00$ & 20:39 & $17: 50$ & $13: 59$ & $15: 54$ & $10: 53$ & $12: 00$ & $11: 27$ & $13: 00$ & 09:20 & $11: 10$ \\
\hline
\end{tabular}

Note-se na Tabela 5.5 que a média de tempo de composição do FOO com a aplicação de loja de CDs (16:40) foi muito similar à média de tempo da composição desse mesmo framework com a aplicação Abaco (16:45), o que evidencia que as aplicações são similares em tamanho e funcionalidades. Mesmo no caso do FT, essa mesma similaridade é mantida, como pode ser visto na Tabela 5.6, a composição com a aplicação de loja de CDs foi realizada 
em 10:59 e com a aplicação Abaco em 12:35. Não se pode afirmar que a hipótese Ha mostrada na Tabela 5.3 pode ser refutada, porém há mais indícios que sim do que não.

Sempre que problemas ocorriam durante a coleta dos dados, os participantes eram instruídos a relatar o problema. Por exemplo, durante a realização da primeira etapa da primeira fase, o participante P2 realizou o acoplamento do comportamento de persistência (TACP) em 10 minutos, um valor bem acima da média dos outros participantes. Contudo, ele relatou que teve problemas com o ambiente Eclipse e que demorou cerca de 7,5 minutos para corrigir o problema. Note-se que se esse valor fosse descontado do tempo relatado pelo participante, ele estaria na média. Isso não foi feito porque problemas desse tipo são comuns durante qualquer desenvolvimento.

\subsection{5 - Análise dos Dados}

\subsubsection{1 - Primeira Fase do Estudo}

Os dados coletados na primeira fase do estudo mostraram que a composição utilizando o FT foi mais eficiente do que com o framework OO para 11 dos 12 participantes, como pode ser observado na Figura 5.7. Nessa figura, cada par de colunas representa os tempos de composição de um determinado participante. As colunas brancas representam o tempo gasto na composição com o framework OO e as colunas cinza com o FT. As etiquetas sobrepostas sobre cada par de colunas representam a diferença percentual entre os tempos. Por exemplo, o participante P2 realizou a composição com o FT 42,8\% mais rápido do que com o framework OO. Note-se que apenas o participante P3 gastou mais tempo com o FT do que com o framework OO, porém foi uma diferença muito pequena: 21 segundos. Analisando-se os formulários de coleta de dados desse participante não foi constatado nenhum problema.

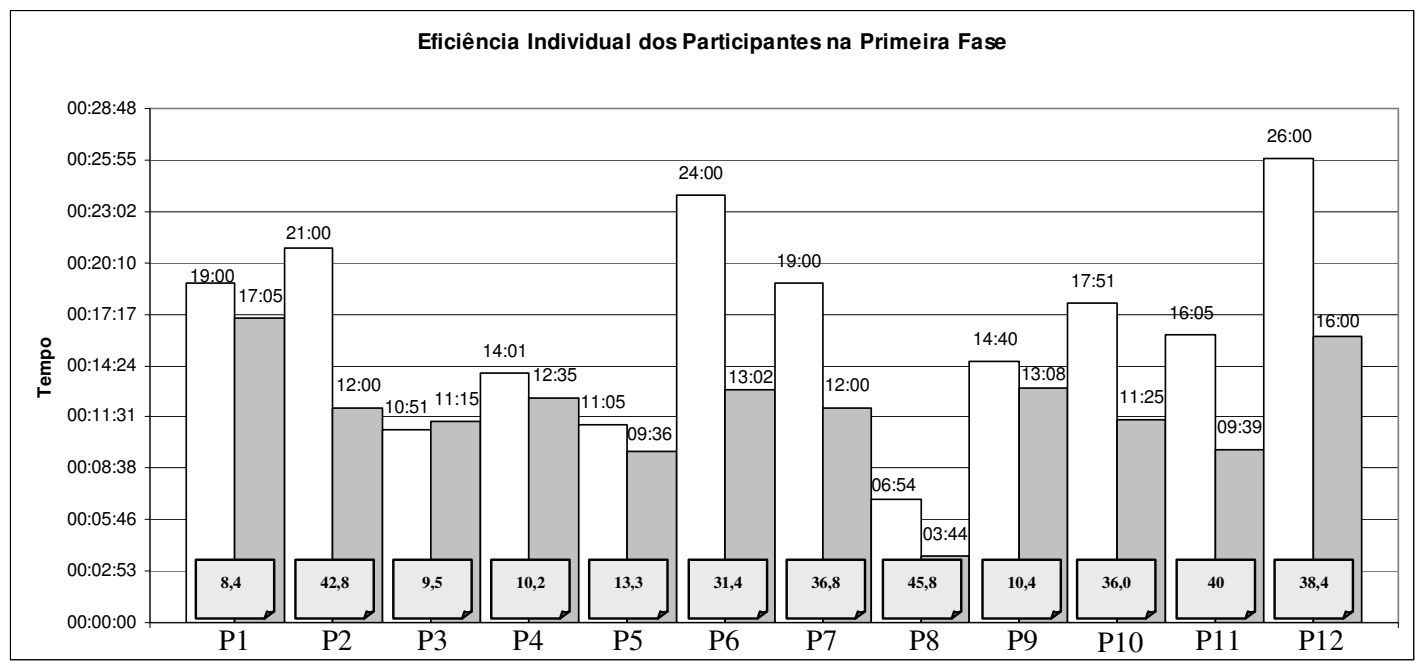

Figura 5.7 - Diferenças Percentuais entre os Tempos de Composição (Primeira Fase) 
Um fato interessante foi que os participantes com menos experiência em linguagens de programação obtiveram um nível de eficiência elevado com o FT. Por exemplo, o participante P6 fez a composição com o FT 31,4\% mais rápido do que com o FOO, e o participante P12 obteve um índice ainda melhor, $38,4 \%$.

Desconsiderando os participantes experientes (P1, P2, P7 e P8), a média de tempo de composição dos novatos com o FT foi $23,65 \%$ menor do que usando o framework OO. Mesmo se os dados dos participantes P6 e P12, que são inexperientes em programação, forem desconsiderados, ainda assim os demais novatos foram $21,27 \%$ mais eficientes com o FT do que com o framework OO.

Os participantes experientes também foram mais eficientes com o FT do que com o framework OO. A média do tempo de composição foi 8,33\% mais rápida com o FT do que os novatos - enquanto os experientes realizaram a composição com o FT 31,98\% em média mais rápido do que com o framework $\mathrm{OO}$, a média dos novatos foi de $23,65 \%$.

Apenas o P1 obteve uma diferença percentual pequena entre os tempos, como pode ser observado na Figura 5.7. Porém, analisando-se os formulários desse participante, pôde-se constatar que ele obteve problemas com o ambiente durante a composição com o FT, o que elevou o tempo de composição com esse framework. Isso também pode ser constatado observando que o tempo de composição usando o FT desse participante foi superior ao de todos os outros participantes (17:05).

Sem considerar a diferença entre experientes e novatos, o tempo médio de composição do FT com a aplicação de loja de CDs foi de 10:59 (Tabela 5.6), um valor 34,1\% menor do que o tempo médio de composição dessa mesma aplicação com o framework OO, que foi de 16:40 (Tabela 5.5). Da mesma forma, o tempo médio de composição do FT com a aplicação Abaco foi de 12:35 (Tabela 5.6), um valor 24,87\% menor do que com o framework OO, que foi de 16:45 (Tabela 5.5). Assim, a média de tempo utilizada pelos dois grupos para a composição do FT foi de 11:47, enquanto que utilizando o framework OO foi de 16:42. O FT foi $29,3 \%$ mais rápido em média do que com o framework OO nessa primeira fase do estudo.

\subsubsection{2 - Segunda Fase do Estudo}

Os dados obtidos na segunda fase do estudo podem ser vistos no gráfico da Figura 5.8. Assim como na Figura 5.7, as notas sobrepostas sobre cada par de colunas representam a diferença percentual do tempo de composição usando cada um dos frameworks. Nesta fase, que só envolveu participantes com experiência em POA, o tempo de composição com o FT foi menor do que com o framework $\mathrm{OO}$ para todos os participantes. A eficiência média também foi melhorada para os participantes experientes, enquanto que na primeira fase a composição 
com o FT foi $31,98 \%$ mais rápida, nessa segunda fase foi de 37,37\%. Uma diferença provavelmente ocasionada pelo conhecimento do framework.

Considerando-se as médias de tempo, a composição da aplicação Abaco com o framework OO foi realizada em 20:39, enquanto que com o FT o tempo foi de 11:10, uma diferença de 54,0\% a favor da orientação a aspectos. Já, com a aplicação de Loja de CDs a diferença foi bem menor, mas ainda assim favoreceu o FT: a composição com o framework OO foi realizada em 15:54, enquanto que com o FT foi realizada em 11:27, uma diferença de $27,98 \%$.

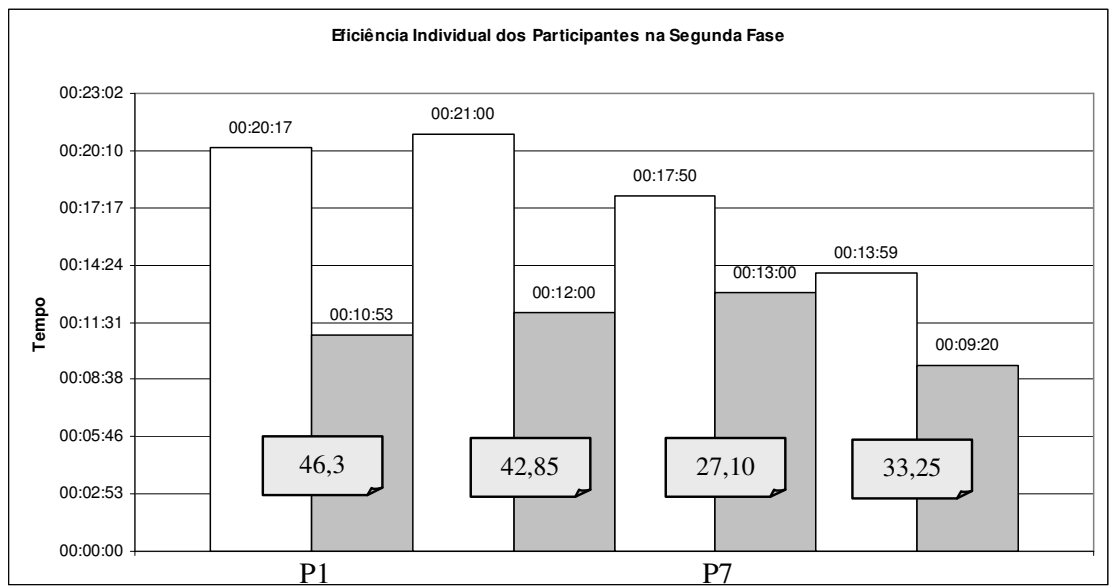

Figura 5.8 - Diferenças Percentuais entre os Tempos de Composição (Segunda Fase)

A média de tempo utilizada pelos dois grupos de experientes para a composição do FT foi de 11:18 nesta segunda fase, enquanto que na primeira foi de 11:12, uma diferença insignificante. Embora também pequena, a diferença com o framework OO foi maior entre as duas fases. Enquanto que na primeira fase a composição com o framework OO foi realizada pelos experientes em 16:28 em média, na segunda foi realizada em 18:17.

\subsection{6 - Resultados Parciais}

Como pode ser observado, tanto na primeira fase quanto na segunda, a média de tempo da composição utilizando o FT foi menor do que utilizando o framework OO, mostrando evidências de que a hipótese $\mathrm{H}_{0}$ mostrada na Tabela 5.2 talvez pudesse ser refutada se experimentos formais fossem conduzidos.

Se os tempos forem analisados individualmente para cada um dos três passos da composição, tanto na primeira fase quanto na segunda, observa-se que a diferença de tempo relevante ocorre na verdade durante o acoplamento da conexão, e não durante o acoplamento do comportamento da persistência ou dos testes. 
Na Tabela 5.8 é mostrado o tempo médio de cada um dos passos da composição para as duas fases do estudo. Essas médias foram obtidas calculando-se a média das médias obtidas para cada passo do estudo comparativo. Por exemplo, o tempo médio de acoplamento do comportamento da persistência da primeira fase é 03:40 com o framework OO (considerando as duas aplicações). Esse valor foi obtido calculando-se a média das médias das duas aplicações com o mesmo framework, não fazendo distinção entre experientes e novatos - 3:42 e 3:37, como pode ser visto na terceira linha na Tabela 5.5. O mesmo foi feito para os demais valores.

Tabela 5.8 - Tempo Médio dos Passos de Composição da Primeira e Segunda Fases

\begin{tabular}{|c|c|}
\hline \multicolumn{2}{|c|}{ Primeira Fase } \\
\hline \multicolumn{2}{|c|}{ Composição com Framework OO } \\
\hline Média do Tempo de Acoplamento da Persistência com FOO & $03: 40$ \\
\hline Média do Tempo de Acoplamento da Conexão com FOO & $|--06: 58---|$ \\
\hline Média do Tempo de Realização dos Testes com FOO & $06: 05$ \\
\hline \multicolumn{2}{|c|}{ Composição com Framework Transversal } \\
\hline Média do Tempo de Acoplamento da Persistência com FT & 03:56 \\
\hline Média do Tempo de Acoplamento da Conexão com FT & $|--02: 32---|$ \\
\hline Média do Tempo de Realização dos Testes com FT & $05: 20$ \\
\hline \multicolumn{2}{|c|}{$\begin{array}{ll} & \text { Segunda Fase } \\
\end{array}$} \\
\hline \multicolumn{2}{|c|}{ Composição com Framework OO } \\
\hline Média do Tempo de Acoplamento da Persistência com FOO & 06:07 \\
\hline Média do Tempo de Acoplamento da Conexão com FOO & |--- 06:32---| \\
\hline Média do Tempo de Realização dos Testes com FOO & $05: 37$ \\
\hline \multicolumn{2}{|c|}{ Composição com Framework Transversal } \\
\hline Média do Tempo de Acoplamento da Persistência com FT & $03: 41$ \\
\hline Média do Tempo de Acoplamento da Conexão com FT & $|--02: 45---|$ \\
\hline Média do Tempo de Realização dos Testes com FT & $04: 52$ \\
\hline
\end{tabular}

O passo de acoplamento da persistência possui diferenças muito sutis de tempo entre as versões $\mathrm{OO}$ e OA. A justificativa para isso é que a quantidade de linhas de código escritas para realizar esse passo é bastante similar entre as duas versões, como pode ser visto comparando a Figura 5.1 com a Figura 5.2. A diferença entre as versões OO e OA é que nessa última todas as linhas de código estarão em um único aspecto e não espalhadas pelo sistema. Dessa forma, pode-se deduzir que embora determinados interesses transversais tenham um impacto significativo na manutenção e legibilidade do código, influenciam minimamente o tempo da composição.

Com base nesses dados, observa-se que a diferença de tempo significativa somente ocorre no passo de acoplamento da conexão. Na primeira fase do estudo, o tempo médio de realização desse passo usando o FOO foi de 6:58, enquanto que usando o FT foi de 2:32, uma diferença de 63,63\%. Na segunda fase a diferença foi de 57,90\%.

Observando-se os dados coletados pôde-se concluir que essa diferença de tempo está diretamente relacionada com a quantidade de locais do código que devem ser manipulados, mas principalmente, com a quantidade de linhas de código que são escritas para a realização do acoplamento. Tanto na primeira fase quanto na segunda, houve uma diferença significativa 
na quantidade de linhas de código escritas quando a conexão é acoplada utilizando-se o FT, fazendo com que o tempo de acoplamento diminua. Comparando-se a Tabela 5.5 e a 5.6 pode-se observar que a quantidade de linhas de código escritas (LC) para o acoplamento da aplicação de loja de CDs com o framework OO foi de 48 linhas, enquanto que o acoplamento do FT com essa mesma aplicação utilizou entre 7 e 12 linhas. O mesmo ocorreu com a aplicação Abaco, que utilizou 44 linhas de código para o acoplamento com o framework OO e entre 7 e 12 para o acoplamento com o FT.

Mesmo considerando a escrita de uma linha com orientação a aspectos mais difícil e demorada do que a escrita de uma linha com orientação a objetos, a grande diferença na quantidade de linhas escritas favorece a orientação a aspectos. Contudo, para interesses cuja quantidade de linhas de código escritas para o acoplamento é similar entre as duas versões, a orientação a objetos pode ser beneficiada. Note-se, por exemplo, o passo de acoplamento da persistência na primeira fase do estudo, que envolveu tanto participantes experientes quanto novatos. Na Tabela 5.8 é mostrado que a média de tempo usando orientação a objetos (3:40) foi $6,7 \%$ mais rápida do que usando orientação a aspectos (3:56). Embora seja uma diferença pequena, está diretamente relacionada com o tamanho das aplicações usadas no estudo. Para aplicações maiores essa diferença tende a aumentar. Note-se também que na segunda fase do estudo, que só envolveu participantes experientes, o tempo de realização do primeiro passo favoreceu a orientação a aspectos. Isso ocorre porque, para esse caso, a dificuldade de se escrever uma linha de código com orientação a aspectos é similar à dificuldade com orientação a objetos.

Os gráficos mostrados na Figura 5.9 apresentam uma comparação entre o número médio de linhas de código escrito durante a composição com o framework OO e com o FT. Cada coluna representa um passo da etapa de composição: a primeira é o acoplamento da persistência e a segunda o acoplamento da conexão. As colunas brancas representam a quantidade média de linhas de código escritas durante a composição com o framework OO e as cinza com o FT. Sobre cada coluna também é encontrado o tempo médio que os participantes gastaram na realização de cada um dos passos, sem fazer distinção entre experientes ou novatos. Os dois gráficos da parte superior da figura correspondem à primeira fase e os dois da parte inferior correspondem à segunda fase. Note-se que em todos os casos, a quantidade de linhas de código necessárias para se realizar o acoplamento da conexão é maior quando se utiliza o framework OO.

Os resultados da primeira e segunda fase do estudo mostraram uma pequena diferença no tempo de composição a favor do FT, cerca de 4 minutos em média em ambas as fases, com 
pode ser observado na Tabela 5.8. Embora seja uma diferença pequena, o tamanho das aplicações tem influência direta sobre esse número. A composição do framework $\mathrm{OO}$ foi em média 30\% mais demorada do que com o FT tanto na primeira fase quanto na segunda.

Para muitas organizações essa diferença pode ser insignificante, principalmente para aquelas que trabalham com aplicações de pequeno porte. Além disso, para essas organizações, os recursos investidos no treinamento em uma nova tecnologia pode inviabilizar a adoção de uma nova técnica de programação. Contudo, observa-se que, como essa diferença de tempo está ligada com a quantidade de locais modificados do código, aplicações de grande porte podem se beneficiar com a adoção de um FT, embora novos experimentos devam ser feitos para apresentar dados quantitativos mais sólidos.

Composição com Aplicação de Loja de CDs - FOO e FT

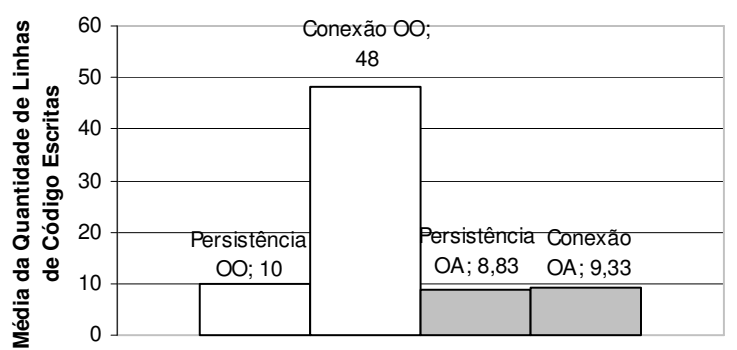

Acoplamento do Comportamento da Persistência e Acoplamento da Conexão Composição com Aplicação de Loja de CDs - FOO e FT

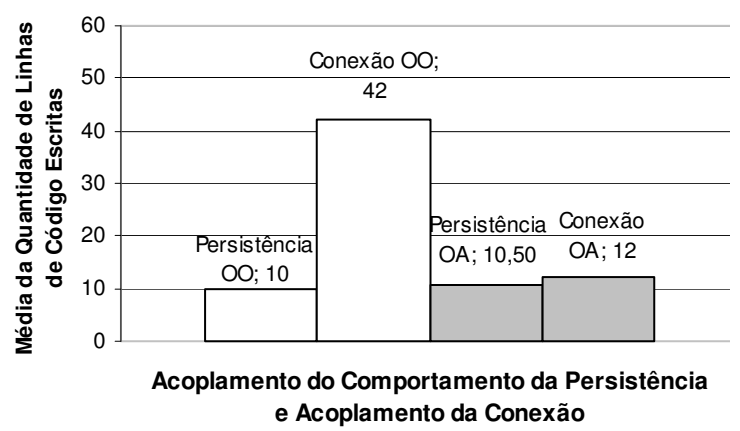

Composição com Aplicação Abaco - FOO e FT
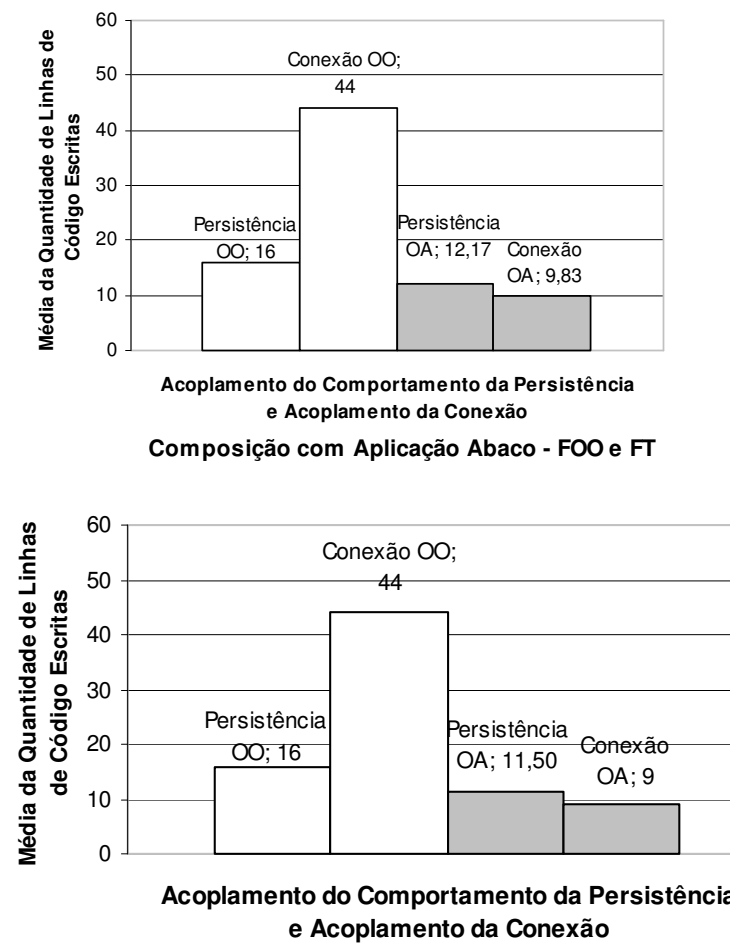

Figura 5.9 - Comparação do Dado LC

Considerando apenas o passo de acoplamento da conexão a diferença percentual é bem maior. Por exemplo, na primeira fase do estudo, a média do tempo de acoplamento da conexão usando o framework OO foi de 6:58, enquanto que com o FT foi de 2:32, uma diferença de $63,64 \%$, um número bastante significativo em se tratando de tempo. Um número relativamente similar é encontrado na segunda fase: 57,91\%. Com essa última análise pode-se inferir que determinados interesses transversais que afetam um grande número de locais do 
código, como ocorre com a conexão, possuem uma diferença significativa no tempo de composição.

\subsection{7 - Ameaças à Validade do Estudo}

Um ponto que pode influenciar os resultados é a forma de implementação dos frameworks. Apesar dos frameworks utilizados no estudo seguirem basicamente a mesma estrutura da maioria dos outros frameworks pesquisados na literatura, pode ser que haja alguma implementação orientada a objetos que diminua o trabalho de acoplamento, e conseqüentemente o tempo total de acoplamento.

O fato de apenas a etapa de composição ter sido submetida à análise não influencia os resultados, pois geralmente a etapa de instanciação de um framework, seja OO ou OA, é feita com mecanismos orientados a objetos. Com base nos resultados obtidos, infere-se que mesmo se a etapa de instanciação de algum FT utilizasse mecanismos orientados a aspectos, o tempo diminuiria, o que não inviabilizaria os resultados. Entretanto, experimentos formais precisam ser conduzidos também nesse sentido.

Outro ponto que pode ter influenciado é a utilização de alunos de pós-graduação como participantes do estudo. Contudo, procurou-se não influenciar os alunos demonstrando expectativas a favor ou contra algum dos frameworks.

\subsection{8 - Conclusão do Estudo de Caso}

Embora o estudo tenha sido realizado com frameworks, os resultados mostram indícios de que o tempo de composição de outros interesses implementados com aspectos, desde que sejam transversais, é menor do que de um interesse implementado com orientação a objetos. Isso se dá pela quantidade de linhas de código que devem ser escritas quando a implementação do interesse se espalha pelos módulos do sistema.

Após a realização do estudo concluiu-se que há diferença no tempo de composição quando se utiliza orientação a aspectos. Em conseqüência da quantidade de linhas de código que deve ser escrita para realizar a composição, a orientação a aspectos é beneficiada pelo mecanismo de quantificação, em que vários pontos de acoplamento são informados em poucas linhas.

Note-se que os dados apresentados só são válidos para frameworks caixa branca, em que a composição é realizada com acesso ao código-fonte do framework. No caso de frameworks caixa preta o tempo de composição passa a ser algo irrelevante, pois será realizado rapidamente independentemente se a implementação é feita com orientação a aspectos ou não. 
Como trabalhos futuros, pretende-se replicar o experimento para aplicações maiores, com o objetivo de averiguar se o tempo de composição continua aumentando conforme o tamanho da aplicação. Além disso, pretende-se também realizar o mesmo tipo de experimento com outros frameworks, por exemplo, controle de acesso, autenticação e frameworks que tratam de requisitos funcionais.

Espera-se que o pacote de experimentação, que está disponível em www.icmc.usp.br/ valter, seja utilizado por outros pesquisadores e/ou profissionais em novos experimentos que utilizam aplicações de grande e médio porte.

\section{3 - ANÁlise dA DifiCULdADE DE ACOPLAMENTO}

Nesta seção é apresentado um segundo estudo conduzido em uma disciplina de pós-graduação do ICMC/USP São Carlos no primeiro semestre de 2005 (Camargo e Masiero, 2005c). O objetivo foi averiguar a dificuldade de localizar um ponto de junção em um código-base (aplicação) que não segue boas práticas de programação. Vale ressaltar que foi considerado que os participantes não possuíam acesso ao código-fonte do sistema. Assim, nenhuma modificação poderia ser feita.

O FT utilizado no estudo foi o de Cálculo Baseado em Tabela, que foi exemplificado no Capítulo 3. Para a realização do estudo foi obtida na Internet uma aplicação com código desestruturado, o que permitiu simular situações reais do cotidiano, em que não há garantias da utilização de boas práticas de programação e/ou padrões de projeto (Gamma et al., 1995).

A aplicação utilizada no estudo é um sistema de caixa de banco em que clientes podem ser adicionados e contas podem ser criadas. Também é possível realizar depósitos e retiradas nas contas. O sistema está implementado em Java e utiliza banco de dados MySQL. Embora os participantes tivessem acesso ao código fonte da aplicação, ele não poderia ser modificado para a realização do acoplamento. O modelo de classes da aplicação é mostrado na Figura 5.10.

Os participantes do estudo deveriam realizar uma operação de manutenção na aplicação. O tipo da evolução é a adição (enhancive), que consiste em modificações e adições no conjunto de regras de negócio implementadas pela aplicação. Isso pode ocorrer por meio da inserção de novos componentes, algoritmos ou subsistemas e até alterando os existentes para aumentar ou estender o seu escopo (Chapin et al., 2001).

A nova regra de negócio que deveria ser adiconada na aplicação era a seguinte: toda vez que uma nova conta fosse criada com um valor acima de $\mathrm{R} \$ 5.000,00$, haveria um prêmio de $1 \%$ do valor depositado que seria adicionado no valor da conta. Por exemplo, se uma conta 
fosse criada com um valor de $\mathrm{R} \$ 10.000,00$, o valor que realmente haveria na nova conta seria $\mathrm{R} \$ 10.100,00$.

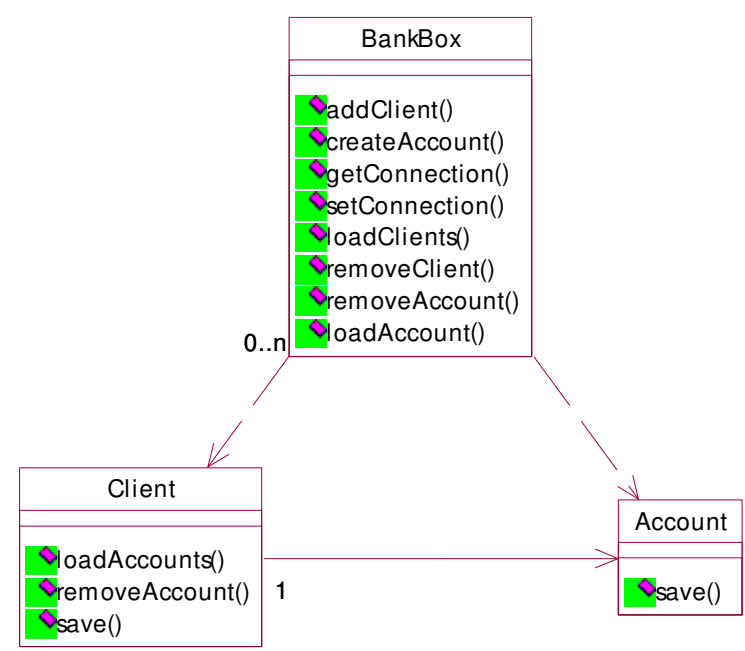

Figura 5.10 - Diagrama de Classes do Sistema de Caixa de Banco

Três alunos participaram do estudo. Os três possuíam o mesmo nível de conhecimento da linguagem Java, mas nunca haviam tido contado com os conceitos da programação orientada a aspectos, portanto foi realizado um treinamento com os novos conceitos, com a linguagem AspectJ e com o FT de cálculo baseado em tabela.

Na Tabela 5.9 são mostrados os tempos que foram gastos com cada atividade de cada etapa do processo de reúso do framework. Como pode ser observado, a etapa de instanciação foi realizada rapidamente pelos alunos. Para cada atividade, marcou-se o tempo de estudo do manual (coluna "manual”) e de implementação (coluna "impl”). Os questionários e relatórios podem ser encontrados no Anexo 3 desta tese.

A segunda etapa foi a que consumiu mais tempo. As primeiras três atividades dessa etapa foram realizadas rapidamente. O problema ocorreu na atividade 4, em que os alunos deveriam identificar na aplicação-base um ponto de junção que fosse adequado ao acoplamento com o framework. Para realizar essa identificação, o manual do framework dispõe do modelo de decisão apresentado na Tabela 3.2. Esse modelo auxilia o engenheiro de aplicação a escolher por uma alternativa de composição adequada do framework.

Analisando os relatórios dos alunos (Anexo 3), observou-se que a demora na identificação do ponto de junção mais adequado foi a qualidade da aplicação-base. O código do sistema de gerenciamento de contas não seguia boas práticas de programação, violando princípios básicos da programação orientada a objetos, o que dificultava a identificação do ponto de junção ideal. 
Como o framework deveria capturar o valor da conta quando essa era criada, o local mais adequado parecia ser o método createAccount () da classe BankBox (Figura 5.11), já que esse método possui um parâmetro chamado Value, que é o valor da conta. Contudo, uma análise na documentação do framework revela que não há uma alternativa de composição que possa ser utilizada para capturar um tipo primitivo do parâmetro e modificá-lo. Na verdade, a captura do valor e sua modificação até pode ser feita, porém como a passagem de parâmetros de tipos primitivos em Java é feita por valor, a modificação efetuada dentro do framework não é refletida no código da aplicação. A alternativa TBargs poderia ser utilizada se o parâmetro fosse um objeto que contivesse um atributo representando o valor sujeito ao cálculo.

Tabela 5.9 - Tempo de Cada Atividade

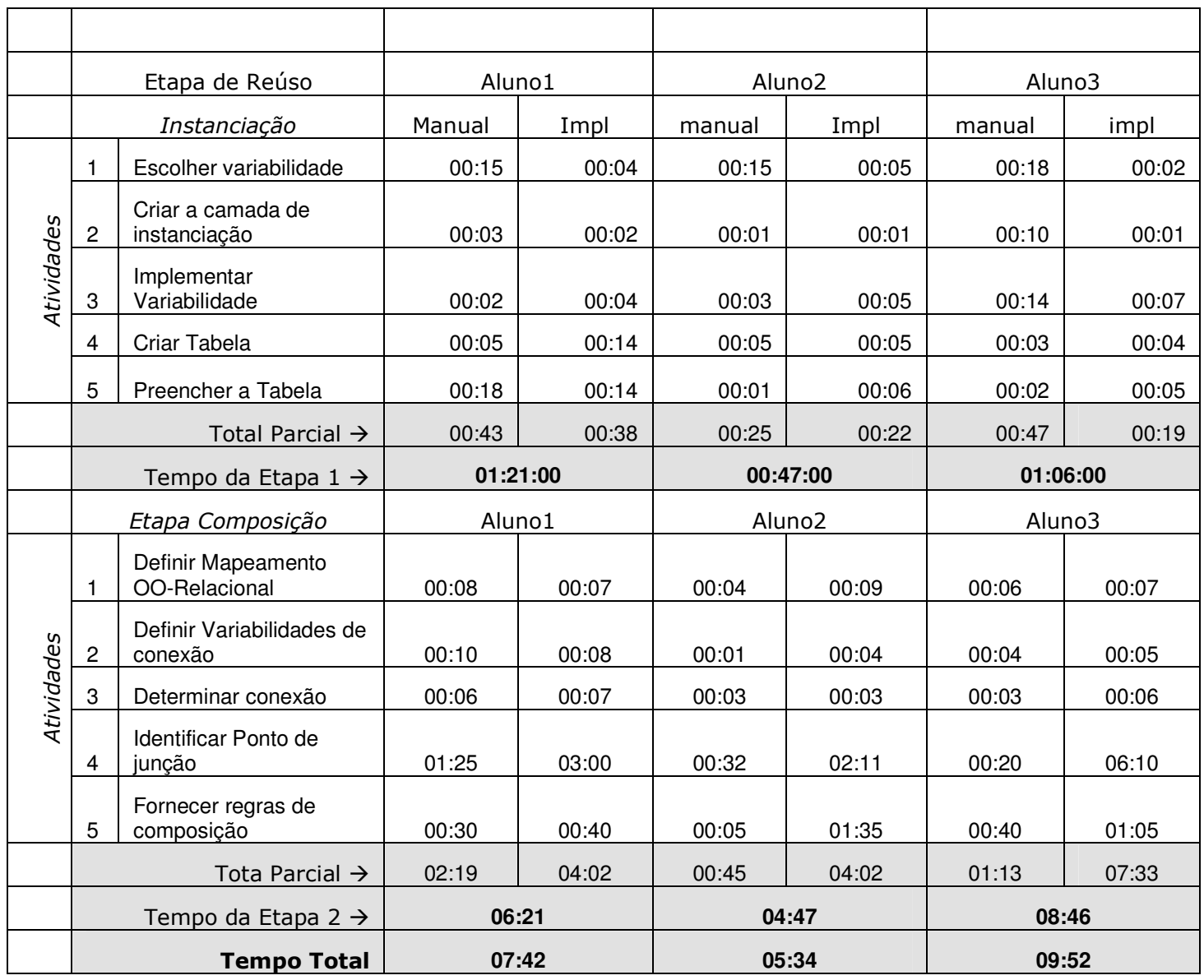

Outro ponto de junção que parecia ser conveniente era a chamada do método setvalue(), destacado em negrito na Figura 5.11. Como o objeto alvo da chamada é um objeto Account, a alternativa de composição TBTarget poderia ser utilizada para capturar o objeto alvo Account, recuperar o valor da conta e modificá-lo. Entretanto, o problema foi que neste momento da execução, o valor da conta já havia sido inserido no banco de dados, como pode ser visto na parte do código destacada com um retângulo, e não adiantava mais 
alterar o seu valor apenas em memória. Uma estratégia de implementação muito ruim para um programa orientado a objetos.

Depois de muitas tentativas de acoplamento em locais errados, o engenheiro do framework indicou aos alunos o ponto de junção correto, que é mostrado na Figura 5.12. O método getText () do objeto value captura da interface gráfica o valor da conta que está sendo criada na forma de uma String e em seguida o método parseDouble () o converte para o tipo Double. Como a alternativa de composição OneArgument exige que o ponto de junção seja uma chamada/execução de um método cujo único parâmetro seja uma String (que é o valor sujeito ao cálculo), a chamada ao método parseDouble () é um ponto de junção que pode ser utilizado para o acoplamento. Depois que o ponto de junção foi informado aos alunos, o acoplamento foi feito rapidamente.

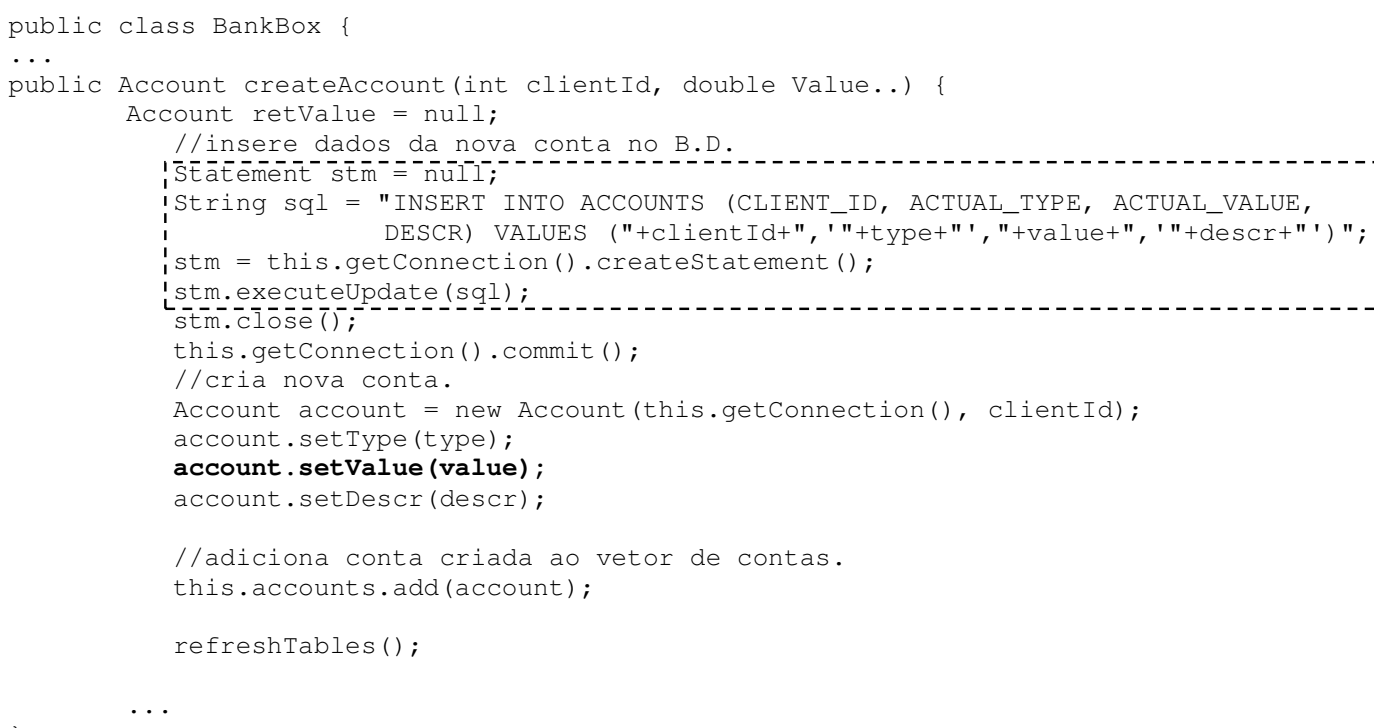

\section{Figura 5.11 - Método CreateAccount()}

Os alunos comentaram que uma das maiores dificuldades para identificar o ponto correto de acoplamento foi a falta de qualidade no código da aplicação e a falta de relacionamento semântico que o ponto de junção tinha com o negócio em si. Como pode ser visto na Figura 5.12 a chamada do método parseDouble () realmente não é semanticamente relacionada com o objetivo do acoplamento, e sim uma chamada de método para conversão de valores. Segundo os alunos, algo que também dificultou a identificação foi que a chamada ao método parseDouble() era um parâmetro do método createAccount() da classe BankBox, e não estava claro no manual que isso poderia ser feito.

Embora não tenha sido realizado nenhum experimento controlado com uma aplicaçãobase bem estruturada, a experiência do autor desta tese com o desenvolvimento de FTs têm revelado um tempo menor de acoplamento. Isso também pode ser inferido pelo estudo 
mostrado aqui. $\mathrm{O}$ primeiro ponto de junção que os três alunos tentaram foi a chamada do construtor da classe Account dentro do método createAccount() (Figura 5.11). Se os comandos de inserção no banco de dados não estivessem antes dessa chamada, (como deveria ser em um código bem estruturado), o tempo de acoplamento seria muito menor. Outra evidência é que depois que o engenheiro do framework informou qual era o ponto, os alunos realizaram o acoplamento rapidamente, em um média de dois minutos.

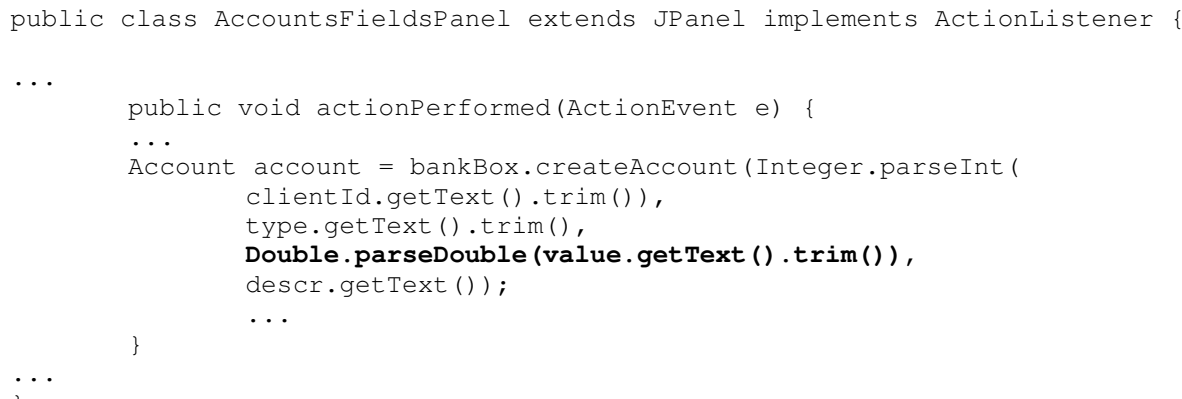

Figura 5.12 - Ponto de Junção Real do Código-Base

\section{4 - EsTUdos PARA APOIAR O DESENVOLVIMENTO E TESTES DOS FTS}

Outros estudos informais foram conduzidos durante o programa de doutorado com o objetivo de testar e aprimorar os frameworks. No segundo semestre de 2003 quatro alunos de uma disciplina de pós-graduação desenvolveram parte de um sistema de uma clínica veterinária utilizando o FT de persistência. Nesta época, o FT de persistência ainda era bastante prematuro (Camargo et al., 2003) e o estudo foi bastante útil para evidenciar alguns problemas que ele possuía. A modificação mais radical que foi realizada em sua arquitetura foi a utilização de reflexividade para realizar o mapeamento objeto-relacional. Até então, cada classe de aplicação persistente deveria possuir um aspecto que era responsável pelo mapemento. Depois desse estudo, eliminou-se a necessidade de criar um aspecto para cada classe persistente de aplicação. Há apenas um aspecto responsável pelo mapeamento.

No segundo semestre de 2004 os alunos de uma outra disciplina participaram de um estudo que envolvia a utilização dos frameworks de persistência e de segurança. O exercício consistia no desenvolvimento de uma aplicação de gerenciamento de contas bancárias. Um relatório deveria ser prenchido pelos alunos ao fim do exercício, o qual pode ser visto no Anexo 4. Esse estudo teve um objetivo mais abrangente, que foi averiguar o processo, o tempo gasto em cada fase do processo, o manual e colher comentários sobre os frameworks de persistência e de segurança. Embora vários comentários e sugestões importantes tenham 
sido feitos pelos alunos, o experiento em si não foi muito satisfatório. Problemas ocorreram com a configuração do ambiente, o que influenciou muito o tempo gasto em cada uma das fases do processo.

No geral, seis aplicações foram desenvolvidas durante o programa de doutorado com o intuito de testar os frameworks, as quais podem ser vistas na Tabela 5.10. O símbolo marca os FTs que foram utilizados em cada uma das aplicações.

Tabela 5.10 - Aplicações Desenvolvidas

\begin{tabular}{|c|c|c|c|c|c|c|}
\hline Applications & $\begin{array}{l}\text { Oficina de } \\
\text { Aparelhos } \\
\text { Eletrônicos }\end{array}$ & $\begin{array}{c}\text { Folha de } \\
\text { Pagamento }\end{array}$ & $\begin{array}{c}\text { Loja de } \\
\text { Vendade } \\
\text { CDs }\end{array}$ & $\begin{array}{c}\text { Gerenciamento } \\
\text { de Contas } \\
\text { Bancárias }\end{array}$ & $\begin{array}{c}\text { Caixa } \\
\text { Eletrônico }\end{array}$ & Hotel \\
\hline Persistence & 4 & $\mathbb{1}$ & $\Psi$ & $\Psi$ & & $\mathbb{1}$ \\
\hline Caching - all tuples & 4 & & $\Psi$ & & & $\Psi$ \\
\hline Caching - object loader & 肯 & & 蛋 & & & $\mathbb{A}$ \\
\hline Connection & 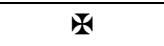 & $\mathbf{E}$ & 4 & 4 & & జ \\
\hline Pooling & 正 & & 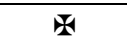 & & & $\Psi$ \\
\hline Access control & 番 & & & 4 & & W \\
\hline Authentication & 4 & & & 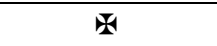 & & 幽 \\
\hline Authentication policies & 4 & & & 4 & & H \\
\hline Access log & 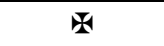 & & & 4 & & $\mathbb{A}$ \\
\hline Table-based calculation & & 承 & & & $\mathbf{E}$ & జ \\
\hline Value readjustment & & 承 & 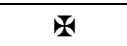 & & & $\Psi$ \\
\hline Tracing & 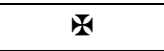 & $\Psi$ & $\mathbf{A}$ & $\Psi$ & & 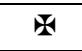 \\
\hline Policy enforcement & 4 & 番 & 4 & 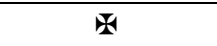 & & \\
\hline
\end{tabular}

\section{5 - CONSIDERAÇÕES FINAIS}

O estudo de caso apresentado na Seção 5.4 foi conduzido no contexto de uma operação de manutenção, mostrando que é possível realizar manutenção evolutiva com apoio de FTs (Camargo e Masiero, 2005c). Contudo, a dificuldade na identificação do ponto de junção revelou que melhores técnicas deviam ser elaboradas para auxiliar o responsável pela manutenção, como por exemplo, um modelo de decisão mais elaborado, mais alternativas de composição no FT, outros artefatos de projeto da aplicação-base, técnicas de leitura, etc. Outro ponto que poderia ser considerado em outros experimentos similares é alterar o código da aplicação-base para facilitar o acoplamento. Entretanto, como o objetivo deste estudo era realizar a manutenção sem modificações invasivas, isso não foi permitido.

Um ponto que ainda precisa ser analisado é o impacto de realização de várias manutenções evolutivas com vários frameworks, o que pode comprometer o desempenho e também a qualidade da própria aplicação. Também é importante destacar que o uso freqüente do FT faz com que ele possa ser evoluído. Por exemplo, um dos alunos descreveu em seu 
relatório uma forma de fazer a composição sem utilizar as alternativas de composição do framework. Esse comentário revelou que o FT necessitava de mais uma alternativa de composição.

No caso do estudo comparativo apresentado na Seção 5.3, a decisão por utilizar um FT desenvolvido pelo próprio grupo de pesquisa se deu pelo acesso livre ao código-fonte, e pelo conhecimento total das funcionalidades disponíveis no framework. Além disso, o acesso ao código-fonte desse FT facilitou o desenvolvimento do framework OO de persistência, já que grande parte do código foi reaproveitada. O desenvolvimento do framework OO com funcionalidades idênticas faz com que o nível de confiabilidade do estudo de caso aumente. Não faria sentido comparar o FT que já estava disponível com o framework OO de persistência Hibernate (Hibernate, 2006), por exemplo, pois ambos possuem arquiteturas diferentes, com funcionalidades e técnicas de instanciação diferentes. Isso poderia acarretar diferenças favorecendo ou prejudicando o tempo de composição de um dos frameworks. 


\title{
Capítulo 6
}

\author{
ProFT/PU - Um Processo de \\ Desenvolvimento de Software apoiado por \\ Frameworks Transversais
}

\section{1 - CONSIDERAÇÕES INICIAIS}

Um processo de desenvolvimento de software orientado a aspectos é apresentado neste capítulo. Há quatro pontos que diferenciam este processo dos demais encontrados na literatura (Clarke e Baniassad, 2005) (Jacobson e Ng, 2004). O primeiro é que ele é formado pela união de conceitos, critérios e técnicas de modelagem de outros trabalhos já consagrados na literatura e especializados em fases específicas do desenvolvimento (Clarke e Baniassad, 2005; Jacobson e Ng, 2004; Baniassad et al., 2006; Krechetov et al., 2006; Araújo e Moreira, 2003; Araújo et al., 2002). O segundo é que ele é fortemente baseado na identificação e acopanhamento de interesses transversais durante o decorrer do processo. O terceiro é que ele é apoiado por FTs em atividades específicas e, o quarto e último é que ele se trata de um processo iterativo e incremental.

O processo é denominado ProFT/PU e segue a estrutura de fases e disciplinas do Processo Unificado (PU) (Jacobson et al., 1999) apresentado por Larman (2004). Dessa forma, ele e é iterativo e incremental, isto é, o sistema é desenvolvido em iterações, em que cada iteração se concentra no desenvolvimento de um subconjunto de casos de uso, até que o sistema todo seja implementado.

ProFT/PU é levemente influenciado pelos FTs desenvolvidos no contexto desta tese, pois algumas atividades, como a identificação de aspectos, leva em conta a existência de FTs que possam ser utilizados para apoiar a implementação de um determinado interesse transversal. Entretanto a implementação é independente dos FTs, isto é, pode ser feita de 
forma convencional, sem o uso de frameworks. No Capítulo 7 o processo é ilustrado com o desenvolvimento de um sistema de reservas de uma rede de hotéis.

Na Seção 6.2, uma visão geral do ProFT/PU é apresentada. Na Seção 6.3, a fase de Concepção é descrita e na Seção 6.4 o enfoque é dado à fase de Elaboração. Na Seção 6.5 a fase de Construção é comentada e na Seção 6.6 as considerações finais são realizadas.

\section{2 - Visão GERAL do ProfT /PU}

O ProFT/PU tem como objetivo apoiar o desenvolvimento de um sistema de software orientado a aspectos por meio de diretrizes, disciplinas (em versões anteriores do PU chamadas de fluxos de trabalho (workflow)) e um repositório que consiste em famílias de FTs.

Assim como o PU, o ProFT/PU é iterativo e orientado pelos riscos e as atividades que devem ser realizadas são acomodadas dentro das fases do PU, que podem ser vistas na Figura 6.1. Na fase de concepção, uma visão aproximada do sistema é criada, casos de uso funcionais e não funcionais simples são elaborados e algumas estimativas são delineadas. Na elaboração, os primeiros interesses transversais são identificados, a visão do sistema é refinada, a arquitetura central é implementada iterativamente, a maioria dos requisitos é identificada e os casos de uso que serão implementados como aspectos são escolhidos. Em cada uma das iterações da fase de elaboração, os casos de uso selecionados para a iteração atual são projetados e adicionados aos casos de uso já desenvolvidos, gerando uma versão executável. $\mathrm{Na}$ fase de construção implementa-se iterativamente os elementos restantes de menor risco e prepara-se para a implantação. Na fase de transição são realizados testes e a implantação propriamente dita é conduzida (Larman, 2004). Vale ressaltar que a fase de transição não é coberta pela pesquisa apresentada nesta tese.

O PU é baseado em um conjunto de disciplinas que devem ser realizadas, como por exemplo, requisitos, análise, projeto e implementação. Essas disciplinas se repetem dentro de todas as fases, porém com ênfases diferentes conforme o processo progride. Dependendo da fase, a ênfase nessas disciplinas é maior ou menor. Por exemplo, na fase de concepção, a ênfase dada na disciplina de requisitos é maior do que na fase de construção. Nas fases iterativas, por exemplo, na elaboração e na construção, as primeiras iterações possuem uma ênfase maior na análise e projeto, enquanto que nas últimas iterações a ênfase é maior na implementação. Na Figura 6.2 são mostradas as disciplinas do PU e a ênfase que deve ser dada durante o desenvolvimento é representada pela área das formas abstratas. 


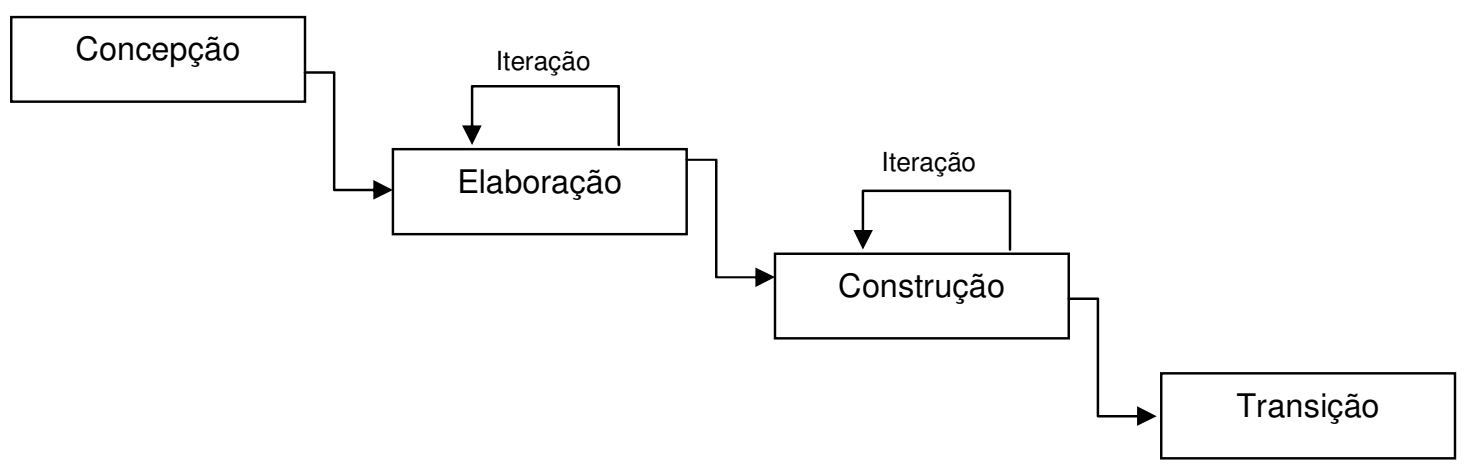

Figura 6.1 - As Fases do ProFT/PU

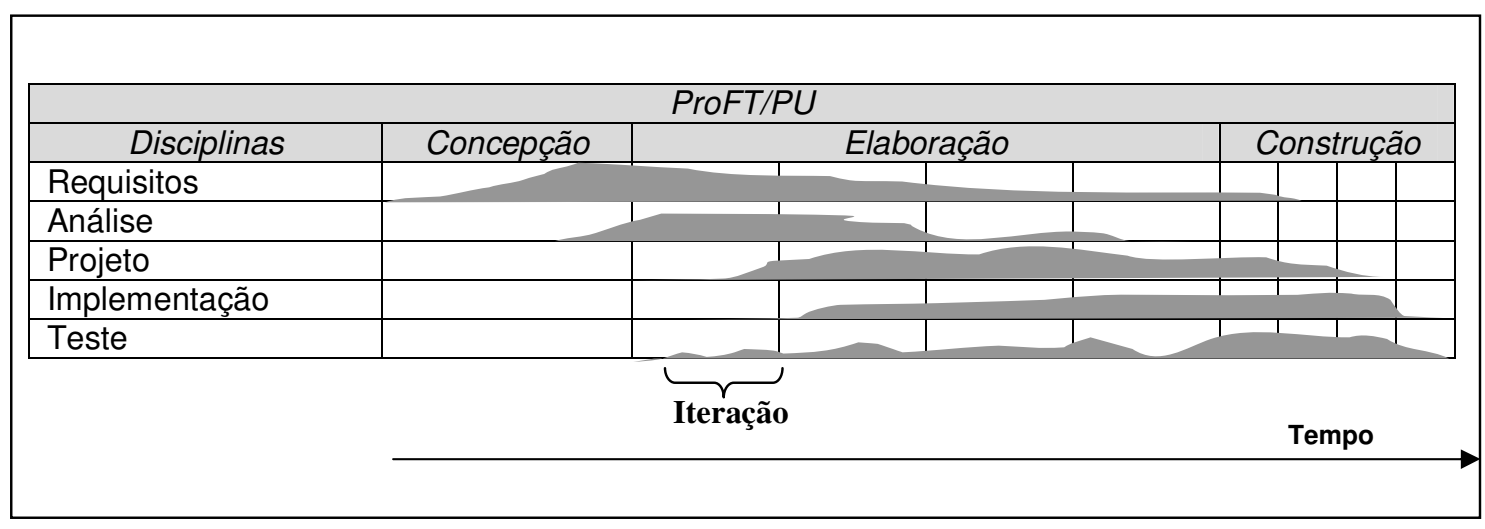

Figura 6.2 - Visão Geral do ProFT/PU

O ProFT/PU utiliza a mesma estrutura de processo do PU, porém possui atividades específicas para o tratamento de interesses transversais. Na Tabela 6.1 são mostradas as atividades do ProFT/PU em cada disciplina. As atividades que estão em negrito são particulares deste processo de desenvolvimento. Já as atividades que não estão em negrito são normais a qualquer processo de desenvolvimento baseado no PU, mas possuem alguma modificação ou influência das demais atividades ou da existência dos FTs. Essas atividades podem ocorrer em qualquer uma das fases do PU, porém é mais comum que as atividades da disciplina Requisitos, por exemplo, sejam executadas mais na Concepção do que na Construção.

Nas subseções seguintes são descritas as atividades mostradas na Tabela 6.1. Essas atividades são detalhadas em cada disciplina de cada fase do PU onde são mais prováveis de ocorrer.

\section{3 - FASE DE CONCEPÇÃO}

A fase de concepção deve ser relativamente curta para a maioria dos projetos e não é realizada em iterações, tendo geralmente uma ou poucas semanas de duração. O propósito é estabelecer 
uma visão inicial comum para os objetivos do projeto, determinar se é viável e decidir se realmente deve passar por uma investigação mais profunda na fase de elaboração. Como a disciplina que possui mais modificações dentro desta fase é a de requisitos, esta seção mostra apenas as atividades que devem ser realizadas nessa disciplina.

Tabela 6.1 - Atividades do ProFT/PU

\begin{tabular}{|l|}
\multicolumn{1}{|c|}{ Atividades da Disciplina Requisitos } \\
\hline Identificar Atores e Detalhar Casos de Uso Funcionais \\
\hline Identificar e Especificar Casos de Uso Não-Funcionais \\
\hline Planejar Iterações \\
\hline \multicolumn{1}{|c|}{ Atividades da Disciplina Análise } \\
\hline Identificar e Registrar Casos de Uso Colaboradores \\
\hline Identificar e Registrar Casos de Uso Candidatos a Aspectos \\
\hline Criar Diagramas de Seqüência do Sistema \\
\hline Definir Contratos das Operações do Sistema \\
\hline Desenvolver Modelo Conceitual \\
\hline \multicolumn{1}{|c|}{ Atisciplina Projeto } \\
\hline Identificar Aspectos \\
\hline Selecionar Aspectos para a Iteração Atual \\
\hline Projetar Aspectos \\
\hline Acoplar Aspectos com a Base \\
\hline Desenvolver Diagramas de Interação \\
\hline Desenvolver Modelo de Classes de Projeto \\
\hline Projetar Modelo de Dados \\
\hline Atualizar Regras de Composição \\
\hline Desenvolver Modelo de Projeto Composto \\
\hline Desenvolver Visão da Arquitetura \\
\hline Registrar Pontos de Junção \\
\hline \multicolumn{1}{|c|}{ Atividades da Disciplina Implementação } \\
\hline Implementar Classes de Domínio \\
\hline Implementar Banco de Dados \\
\hline Atualizar Regras de Composição \\
\hline Implementar Aspectos \\
\hline Implementar Classes Controladoras \\
\hline Implementar Interfaces \\
\hline Testar \\
\hline
\end{tabular}

\subsection{1 - Disciplina Requisitos}

Na Figura 6.3 são mostradas as atividades da disciplina de Requisitos juntamente com os artefatos de entrada e saída de cada uma. Nesta e em outras figuras que aparecem no decorrer deste capítulo é utilizada a notação SADT (Ross, 1977), cuja legenda pode ser vista na parte inferior da figura. As atividades marcadas com a letra "M" possuem alguma modificação em relação à forma tradicional. Essas modificações podem ser, por exemplo, decisões influenciadas pela existência dos FTs. As atividades que possuem a letra "N" são atividades novas, particulares deste processo de desenvolvimento; e as que não possuem marcação não foram modificadas e podem ser conduzidas de forma convencional. Esta disciplina é a que tem mais ênfase dentro da fase de Concepção, pois é nela que os requisitos são especificados. As próximas subseções descrevem as atividades desta disciplina. 


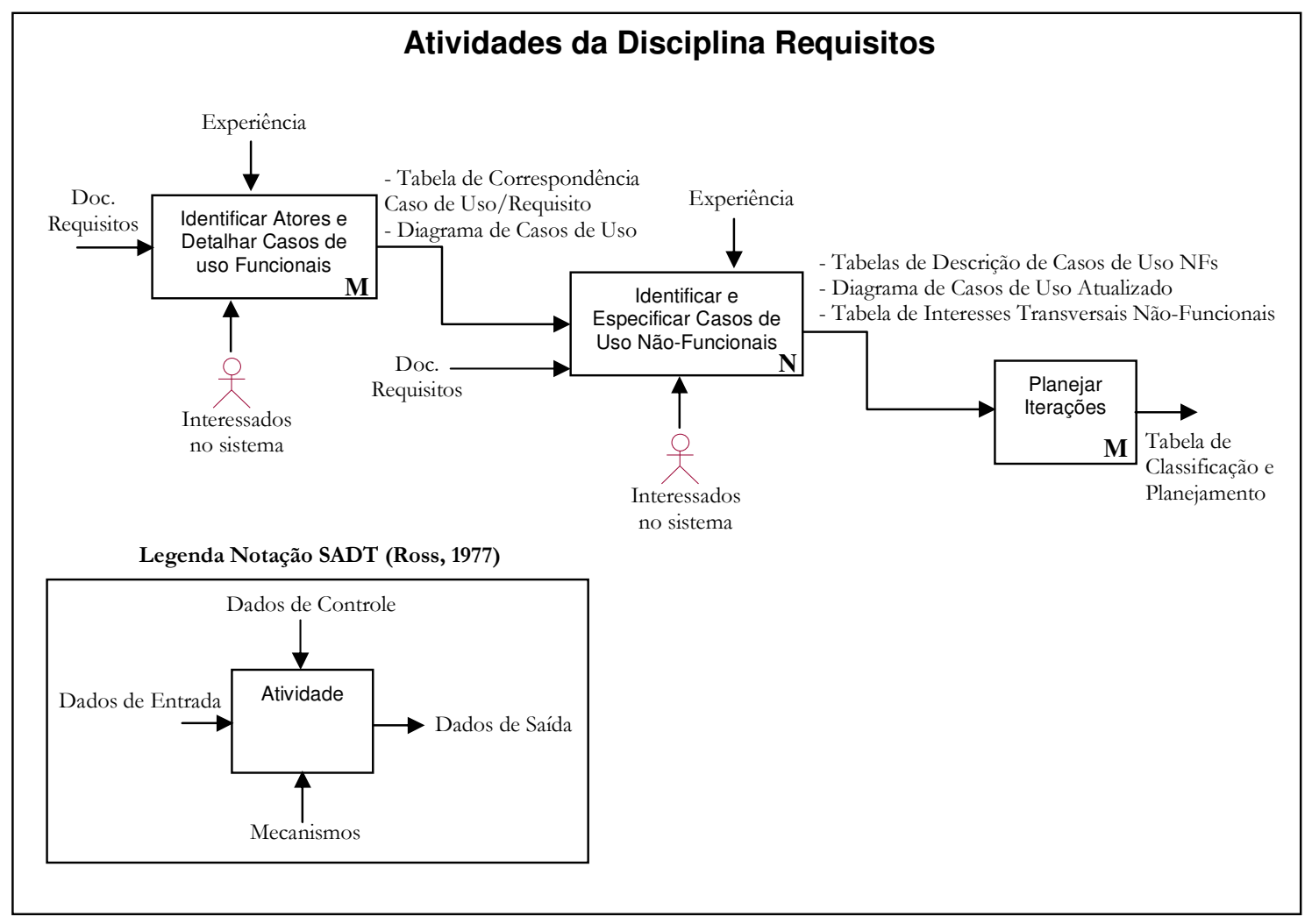

Figura 6.3 - Atividades Da Disciplina Requisitos que Despendem Maior Esforço na Concepção

\subsubsection{1 - Identificar Atores e Detalhar Casos de Uso Funcionais}

A identificação de casos de uso deve ser feita de forma que um conjunto inicial de casos de uso possa ser obtido rapidamente, fornecendo uma visão de alto nível das funcionalidades do sistema. Embora não seja comum nesta altura do processo, também podem ser identificados casos de uso "colaboradores", que são os que colaboram para a realização do comportamento de um outro caso de uso, denominado "base", relacionando-se a ele.

Os dois tipos mais comuns de relacionamentos entre casos de uso base e colaboradores são o de inclusão - que utiliza o estereótipo <<include >> - e o de extensão que utiliza o estereótipo $<<$ extend $>>$. O relacionamento de inclusão ocorre quando o caso de uso colaborador possui funcionalidade que é parte integrante do comportamento do caso de uso base, isto é, sempre que o caso de uso base for executado, o caso de uso colaborador também será. Já o relacionamento de extensão ocorre quando uma determinada funcionalidade é acrescentada ao comportamento de um caso de uso base já existente, modificando o seu comportamento.

Note-se que o caso de uso base é auto-suficiente, isto é, seu comportamento principal pode ser executado independentemente da presença do caso de uso que o estende. Uma forma de se entender um relacionamento de extensão é imaginar o caso de uso base sendo executado sem o comportamento do caso de uso colaborador. Se fizer sentido, então pode-se dizer que o 
caso de uso colaborador estende o caso de uso base. As definições mais antigas desse tipo de relacionamento enfatizam que ele deve ser utilizado apenas para comportamentos opcionais, isto é, comportamentos que só são executados se uma determinada regra for verdadeira. Definições mais recentes (Jacobson e Ng, 2004) mostram que ele também pode ser utilizado para comportamentos que não são opcionais, isto é, que são executados toda vez que o comportamento base é executado.

A diferença desta atividade em relação às tradicionais é que, além dos relacionamentos de inclusão e de extensão, sugere-se que também sejam utilizados os relacionamentos de generalização - que utilizam o estereótipo <<generalize>> - e os relacionamentos de restrição - que utilizam o estereótipo <<constrain>>. O relacionamento de generalização ocorre quando um caso de uso é uma generalização de dois ou mais casos de uso presentes no sistema. Já o relacionamento de restrição ocorre quando algum caso de uso restringe o comportamento de outro caso de uso, como ocorre com restrições de tempo, de desempenho e de segurança (Araújo e Moreira, 2003; Araújo et al., 2002). Por exemplo, pode haver um caso de uso que impõe a restrição de que o caso de uso Calcular Folha de Pagamento não deve exceder 15 minutos. Também pode haver um caso de uso de controle de acesso que restringe o acesso a uma funcionalidade de geração de relatórios de custos. Esse tipo de relacionamento é mais aplicável para requisitos não-funcionais.

Depois que os casos de uso foram identificados e especificados sugere-se iniciar a elaboração do artefato "Tabela de Correspondência Caso de Uso/Requisitos" (TCCaU-R), utilizando o modelo mostrado na Tabela 6.2. Esse artefato é iniciado nesta atividade e será continuamente atualizado nas fases posteriores deste processo, facilitando o acompanhamento do progresso do processo. Essa tabela permite registrar os casos de uso identificados até o momento e os requisitos que deram origem aos casos de uso. A coluna "É proprietário do" representa um relacionamento de propriedade entre o caso de uso e o requisito. Os relacionamentos de propriedade são aqueles em que o caso de uso corresponde a exatamente um requisito, isto é, o caso de uso foi gerado com base em um requisito numerado do documento de requisitos e por isso seu objetivo principal é satisfazer àquele requisito. Nesse caso, diz-se que o caso de uso é proprietário do requisito, caracterizando um relacionamento de propriedade entre eles. A coluna "Colabora com" deve listar os casos de uso que possuem um relacionamento de colaboração com o caso de uso em questão. Um relacionamento de colaboração ocorre quando a funcionalidade de um caso de uso é utilizada como parte do comportamento de um outro caso de uso mais geral. Assim, diz-se que o caso de uso mais específico colabora para a realização do comportamento do caso de uso mais geral. Na Tabela 
6.3 é mostrado um exemplo da Tabela de Correspondência Caso de Uso/Requisitos do sistema de reservas que será exemplificado no capítulo seguinte.

Tabela 6.2 - Modelo para Tabela de Correspondência Caso de Uso/Requisitos

\begin{tabular}{|c|c|c|c|c|}
\hline \multicolumn{5}{|c|}{ Tabela de Correspondência Caso de Uso/Requisitos } \\
\hline \multicolumn{2}{|r|}{ Caso de Uso } & \multirow{2}{*}{ É proprietário do } & \multirow{2}{*}{ Colabora com } & D.C.U \\
\hline $\mathbf{N}^{\mathbf{0}}$ & Descrição & & & \\
\hline 1 & Nome do caso de uso 1 & Número do Req & --- & \\
\hline 2 & Nome do caso de uso 2 & Numero do Req. & $\begin{array}{l}\text { Nome do Caso } \\
\text { de Uso }\end{array}$ & \\
\hline
\end{tabular}

\subsubsection{2 - Identificar e Especificar Casos de Uso Não-Funcionais}

Esta atividade é particular do ProFT/PU e o objetivo é identificar e especificar os casos de uso não-funcionais do sistema. O processo de identificação consiste em analisar o documento de requisitos em busca de interesses/requisitos não-funcionais clássicos da literatura, como por exemplo: Persistência, Concorrência, Autenticação, Controle de Acesso, Distribuição, Tratamento de Exceções, Memória Auxiliar, Criptografia e Sincronização.

Dependendo do formato do documento de requisitos, pode haver seções específicas para os interesses não-funcionais, o que facilita essa identificação. Entretanto, isso pode não ocorrer e a experiência do engenheiro de software pode ser fundamental para o sucesso desta atividade. Alguns interesses não-funcionais, como, por exemplo, "desempenho", podem não levar à criação de casos de uso porque sua implementação pode implicar, por exemplo, na escolha de melhores algoritmos, e não em trechos de código que podem afetar a estrutura da aplicação.

Tabela 6.3 - Tabela de Correspondência Caso de Uso/Requisitos - Fase de Concepção

\begin{tabular}{|c|c|c|c|c|}
\hline \multicolumn{5}{|c|}{ Tabela de Correspondência Caso de Uso/Requisitos } \\
\hline \multicolumn{2}{|r|}{ Caso de Uso } & \multirow{2}{*}{ É proprietário do } & \multirow{2}{*}{ Colabora com } & \multirow[t]{2}{*}{ D.C.U } \\
\hline $\mathbf{N}^{\mathbf{0}}$ & Descrição & & & \\
\hline 1 & Gerenciar Hotel & Req. 1 & & \\
\hline 2 & Gerenciar Acomodação & Req. 2 & & \\
\hline 3 & Gerenciar Tipo de Acomodação & Req. 3 & & \\
\hline 4 & Gerenciar Clientes & Req. 4 & & \\
\hline 5 & Gerenciar Usuários & Req. 5 & & $\square$ \\
\hline 6 & Fazer Reserva & Req. 6 & & 邓 \\
\hline 7 & Cancelar Reserva & Req. 7 & & $\bigotimes$ \\
\hline 8 & Alterar Reserva & Req. 7 & & $\bar{\bigotimes}$ \\
\hline 9 & Ocupar Reserva & Req. 8 & & $\triangle$ \\
\hline 10 & Gerar dados para faturamento & Req. 9 & $\begin{array}{l}\text { Ocupar } \\
\text { Reserva, } \\
\text { Não } \\
\text { comparecer }\end{array}$ & $\bar{\bigotimes}$ \\
\hline 11 & Gerenciar Empresas & Req. 10 & & $\square$ \\
\hline 12 & Não Comparecer & Req. 9 & & Х \\
\hline 13 & Reajustar o Valor das Diárias & Req. 10 & & $\bigotimes$ \\
\hline 14 & $\begin{array}{l}\text { Consultar se acomodação está } \\
\text { disponível }\end{array}$ & Req. 11 & & L \\
\hline 15 & Consulta número de reservas & Req. 12 & & $\square$ \\
\hline
\end{tabular}


Embora a identificação dos interesses não-funcionais pareça simples, muitas vezes a forma como o documento de requisitos é escrito e o uso incorreto de termos pode esconder requisitos relevantes.

Neste ponto do desenvolvimento deve ser iniciada a elaboração da Tabela de Interesses Transversais Não-Funcionais, como mostra o modelo na Tabela 6.4. Essa tabela é utilizada para documentar os interesses não-funcionais identificados até o momento e sua correspondência com os requisitos numerados do documento de requisitos.

Depois que os casos de uso não-funcionais foram identificados, devem ser especificados e integrados no diagrama de casos de uso obtido até o momento. Para especificar uma descrição mais detalhada de seu comportamento, deve-se entrevistar o responsável pelo sistema ou revisitar o documento de requisitos. Note-se que o objetivo não é obter uma descrição muito detalhada do caso de uso, mas sim refinar sua descrição original do documento de requisitos para compreender melhor o seu comportamento. Nas fases posteriores do processo, essas descrições podem ser aprimoradas com detalhes sobre a tecnologia e arquitetura do sistema se for necessário.

Tabela 6.4 - Modelo para Tabela de Interesses Transversais Não-Funcionais

\begin{tabular}{|l|l|}
\hline \multicolumn{2}{|c|}{ Interesses Não-Funcionais Identificados } \\
\hline Interesse Não-Funcional & Requisitos Cobertos \\
\hline Interesse NF 1 & $1,2,3$ \\
\hline Interesse NF 2 & $1,5,6$
\end{tabular}

Para documentar os casos de uso não-funcionais, deve-se iniciar a elaboração da Tabela de Descrição de Caso de Uso Não-Funcional, como o modelo mostrado na Tabela 6.5, para cada interesse não-funcional. Nessa tabela deve ser feita uma descrição refinada cujo objetivo é explicar o funcionamento do caso de uso não-funcional. Essa descrição pode ser tanto um cenário de uso do sistema, quanto uma descrição mais direta que mostre os requisitos desse caso de uso. A elaboração dessa descrição geralmente exige que sejam feitas entrevistas com os interessados no sistema, pois muitos detalhes são difíceis de serem obtidos apenas por meio do documento de requisitos.

Tabela 6.5 - Modelo para Tabela de Descrição de Caso de Uso Não-Funcional

\begin{tabular}{|l|l|}
\hline Caso de Uso Não-Funcional: & - Nome do caso de uso \\
\hline Casos de Uso Relacionados: & - Casos de uso que são afetados por este caso de uso não-funcional \\
\hline Descrição Original: & - Descrição original encontrada no documento de requisitos \\
\hline Descrição Refinada: & - Descrição refinada \\
\hline
\end{tabular}

À medida que uma Tabela de Descrição é elaborada para um determinado caso de uso, pode-se paralelamente incluir esse caso de uso no diagrama de casos de uso. $\mathrm{O}$ 
relacionamento que os casos de uso não-funcionais mantém com os outros casos de uso é de restrição (constrain), indicando que o caso de uso não-funcional afeta ou restringe o comportamento do outro caso de uso (Araújo e Moreira, 2003; Araújo et al., 2002).

Com relação ao diagrama de casos de uso, aconselha-se a elaboração de visões individuais tanto para os casos de uso não-funcionais, quanto para os casos de uso funcionais. Essas visões individuais auxiliam na legibilidade do modelo. Por exemplo, na Figura 6.4 é mostrada a visão individual do caso de uso hipotético Autenticar Usuário. A presença de outros casos de uso não-funcionais neste diagrama poluiria o modelo e dificultaria o entendimento.

\subsubsection{3 - Planejar Iterações}

Nesta atividade o objetivo é planejar o número de iterações que serão realizadas e alocar os casos de uso que devem ser implementados em cada iteração. Para isso, o primeiro passo é classificar os casos de uso identificados até o momento. Assim como no PU, os casos de uso relacionados com a funcionalidade principal do sistema e que apresentam riscos ao projeto devem ser implementados nas primeiras iterações da fase de elaboração, enquanto que os casos de uso que oferecem menos riscos ao projeto podem ser implementados nas últimas iterações.

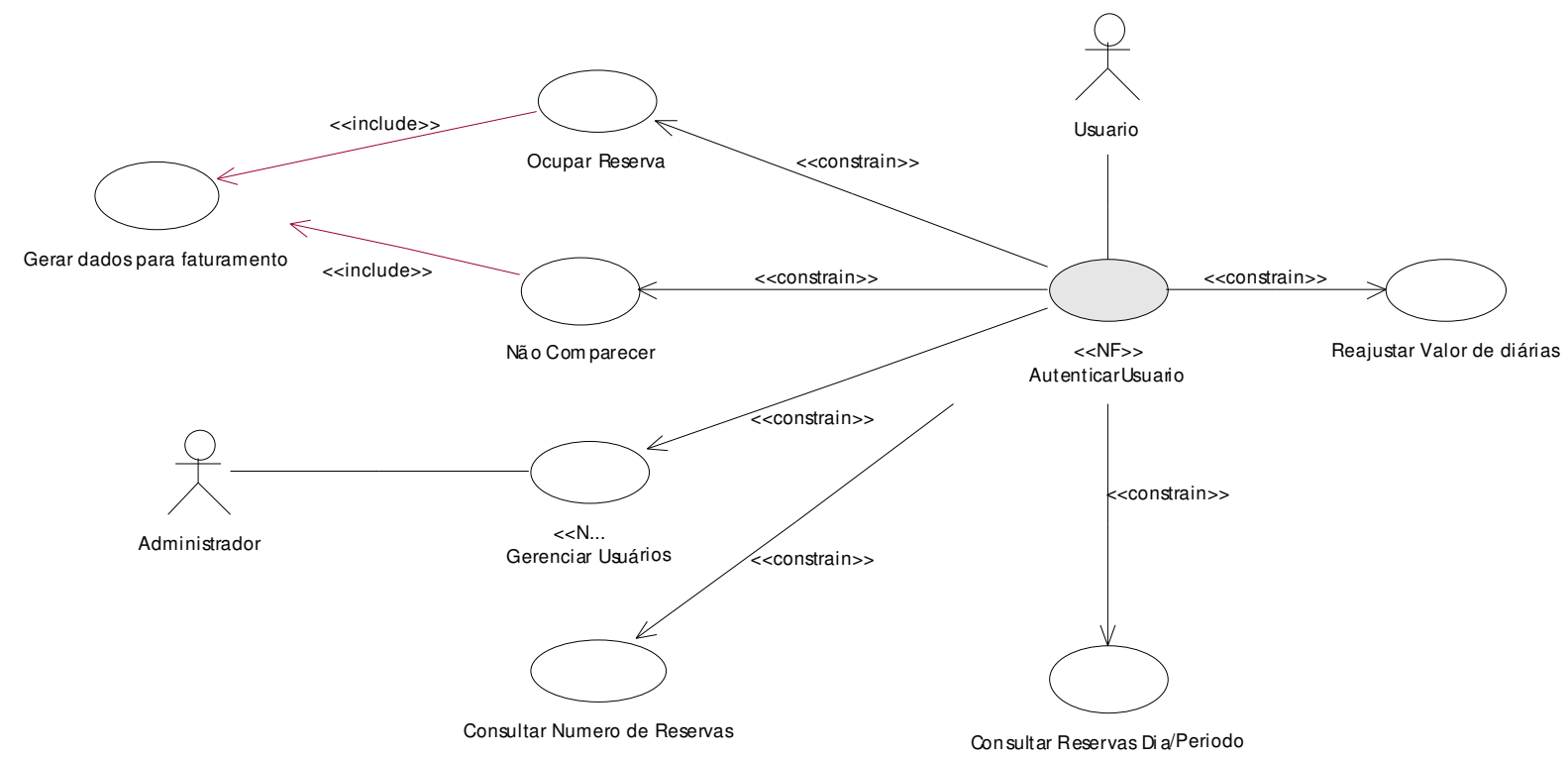

Figura 6.4 - Caso de Uso Não-Funcional Autenticar Usuário - Visão Individual de Caso de Uso NãoFuncional

Os casos de uso não-funcionais não devem ser levados em conta nessa classificação para que o enfoque seja nos casos de uso funcionais. Entretanto, apesar de não serem considerados durante a classificação, decisões arquiteturais e/ou de projeto podem fazer com que eles devam ser implementados logo nas primeiras iterações para dar apoio aos casos de 
uso funcionais. Uma situação comum é o replanejamento da iteração seguinte, tendo que considerar casos de uso funcionais e/ou não-funcionais que não haviam sido considerados anteriormente. Note-se que casos de uso gerenciadores de $\operatorname{dados}^{20}$ são considerados funcionais no contexto desta tese e devem ser considerados durante a classificação.

Um problema que pode ocorrer com a classificação inicial obtida é que geralmente os casos de uso das posições iniciais da lista precisam trabalhar com conceitos persistentes que ainda não foram implementados. Isso ocorre porque os casos de uso gerenciadores de dados desses conceitos geralmente encontram-se em posições intermediárias da classificação, e por isso, sua implementação só ocorrerá nas iterações intermediários e finais.

Há duas alternativas para solucionar este problema. A primeira é manter a classificação como está e simular a persistência dos conceitos até que os casos de uso gerenciadores de dados sejam implementados, inserindo manualmente registros no banco de dados ou trabalhando com dados em memória volátil, como é feito por Soares (Soares, 2004). A segunda é deslocar os casos de uso gerenciadores de dados para as posições iniciais da lista e implementá-los antes que os conceitos sejam utilizados. Isso implica em considerar a persistência logo na primeira iteração. Quando não há um framework de persistência disponível, geralmente a primeira alternativa é adotada pela dificuldade em implementar do zero o requisito não-funcional de persistência. Como o processo descrito por este documento é apoiado por um FT de persistência, a segunda alternativa torna-se mais factível, pois uma versão operacional do sistema será obtida já com a arquitetura real que será utilizada no sistema final. Um problema de se utilizar uma técnica de simulação é que quando ela precisar ser substituída por uma estratégia real, algum retrabalho é necessário.

Uma terceira alternativa é manter a classificação obtida e utilizar uma estratégia de simulação da persistência no início e depois substitui-la pelo FT quando os casos de uso gerenciadores de dados forem desenvolvidos. Entretanto, cuidado adicional deve ser tomado porque o FT de persistência impõe certas restrições de projeto que precisam ser levadas em conta desde o início da elaboração do modelo de projeto. Se essas restrições forem negligenciadas, o acoplamento ${ }^{21}$ do FT de persistência com o sistema pode ser dificultado, exigindo mudanças significativas de projeto.

\footnotetext{
${ }^{20}$ Dentro do contexto desta tese, um caso de uso gerenciador de dados é um caso de uso que manipula funcionalidades de persistência, como inclusão, alteração e remoção.

${ }^{21}$ O termo "acoplamento" está sendo usado neste trabalho em um sentido mais amplo do que "composição". O processo de reúso de um FT possui as etapas de instanciação e composição. Quando se diz que o FT será "acoplado" à parte base da aplicação, assume-se que as duas etapas citadas devem ser realizadas. Assim, o termo acoplamento torna-se sinônimo de "processo de reúso".
} 
Assim, se a opção for por deslocar os casos de uso gerenciadores de dados para posições superiores da classificação deve-se identificar casos de uso que possuem dependência com conceitos persistentes. Para a identificação dos conceitos persistentes, cada caso de uso da classificação obtida deve ser analisado com vistas a identificar quais são os conceitos que ele provavelmente utiliza para cumprir suas responsabilidades. Por exemplo, o caso de uso Fazer Reserva mostrado na Figura 6.5 possui, destacado em negrito, alguns conceitos que provavelmente são persistentes, como reserva, hotel, acomodação, tipo de acomodação e cliente. Os casos de uso gerenciadores de dados desses conceitos devem ser movidos para posições mais altas da classificação em relação ao caso de uso Fazer Reserva.

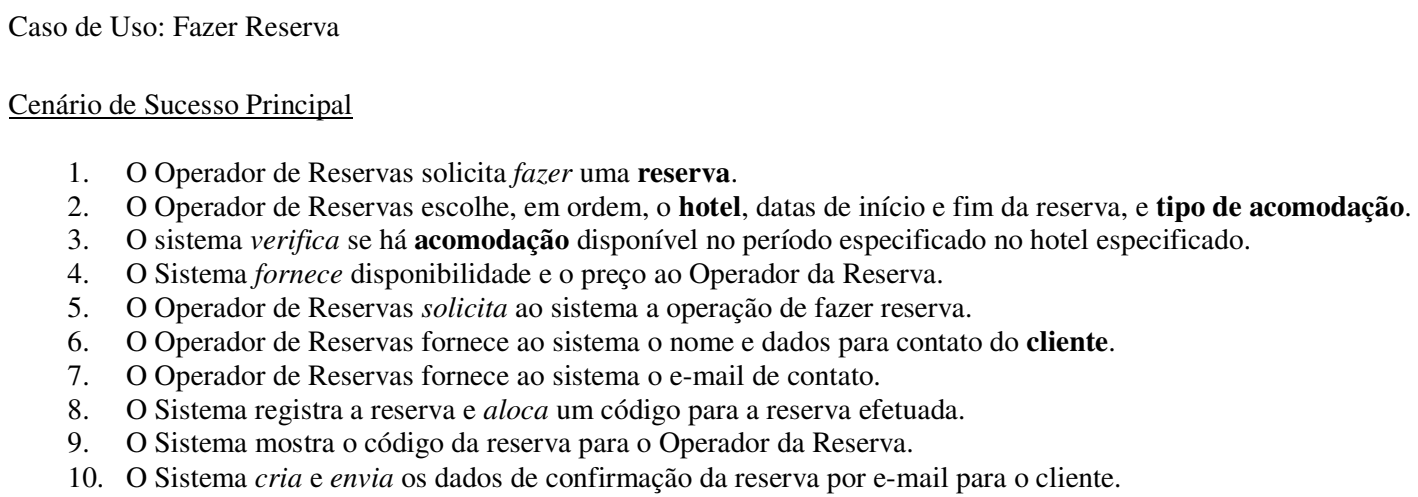

Figura 6.5 - Caso de Uso Hipotético Fazer Reserva

Note-se que os casos de uso gerenciadores de dados que devem ser movidos para as posições iniciais são apenas os que manipulam conceitos que serão utilizados pelos casos de uso em análise. Não se deve mover todos os casos de uso gerenciadores de dados para as posições iniciais da lista de uma única vez porque isso pode gerar trabalhos desnecessário nas primeiras iterações.

Depois que uma classificação mais realista for obtida, deve-se planejar quantas iterações devem ser realizadas e quais casos de uso devem ser trabalhados em cada iteração. Como o levantamento de requisitos feito até o momento não está completo, novos casos de uso podem surgir durante as iterações, havendo a necessidade de modificação no planejamento das iterações seguintes. Lidar com essas modificações é uma particularidade do PU, pois o plano é adaptativo e não congelado de modo especulativo logo no início do projeto. Dessa forma, o engenheiro de software deve despender mais esforço no planejamento da próxima iteração, e não se preocupar muito com as iterações posteriores, já que podem ser bastante influenciados pelas descobertas feitas na iteração anterior.

O critério sugerido para a identificação do número de iterações é o "prazo estipulado para o término". Considerando hipoteticamente que um sistema tenha que ser desenvolvido 
em um período máximo de seis meses, pode-se estipular quatro iterações de um mês e meio cada, que é um número sugerido pelo PU. A distribuição dos casos de uso em cada iteração deve ser feita pelos critérios de "tamanho" e "importância dos casos de uso".

Na Tabela 6.6 é mostrado um modelo que pode ser utilizado para a classificação dos casos de uso e planejamento das iterações.

Tabela 6.6 - Modelo de Tabela para Classificação de Casos de Uso e Planejamento de Iterações

\begin{tabular}{|l|l|l|}
\hline \multicolumn{1}{|c|}{ Iteração } & Classificação & \multicolumn{1}{c|}{ Caso de Uso } \\
\hline \multirow{2}{*}{${ }^{\circ}$ Iteração } & 1 & Caso de Uso 1 \\
\cline { 2 - 4 } & 2 & Caso de Uso 2 \\
\hline $2^{\circ}$ Iteração & 6 & Caso de Uso 3 \\
\cline { 2 - 4 } & 7 & Caso de Uso 4 \\
\hline \multirow{2}{*}{$3^{\circ}$ Iteração } & 10 & Caso de Uso 5 \\
\cline { 2 - 3 } & 11 & Caso de Uso 6 \\
\hline
\end{tabular}

Um dos artefatos que deve ser desenvolvido quando o ProFT/PU é utilizado é a "visão de iteração". Esse artefato consiste em um diagrama de casos de uso que mostra apenas os casos de uso alocados para a iteração atual. O objetivo é auxiliar a equipe de desenvolvimento a acompanhar a evolução do sistema com base nos casos de uso que são adicionados em cada iteração. Esse diagrama de casos de uso é constantemente evoluído conforme o processo progride, até que o sistema todo esteja modelado.

Está sendo considerado no contexto deste trabalho que cada iteração possui acesso a três tipos de casos de uso: 1) os casos de uso funcionais originalmente alocados para a iteração; 2) os casos de uso não-funcionais que se relacionam com os casos de uso originalmente alocados e 3) a todos os casos de uso, implementados ou não, das iterações anteriores. Assim, quando os casos de uso originalmente alocados para a iteração são trazidos para o ambiente de desenvolvimento, todos os outros citados também os acompanham.

Os casos de uso originalmente alocados para a iteração são denominados de "originais" e os que aparecem na visão porque são não-funcionais relacionados aos originais são denominados de "apoiadores". Recebem esse nome porque geralmente apóiam de alguma forma a funcionalidade dos originais. A iteração atual só não possui acesso aos casos de uso alocados para as iterações seguintes.

\section{4 - FASE DE ELABORAÇÃO}

A fase de elaboração se concentra no projeto e na implementação dos casos de uso alocados para a iteração atual e é realizada em iterações. Os casos de uso originais devem ser obtidos 
na visão de iteração. O objetivo principal é implementar uma porção do sistema que esclareça os detalhes arquiteturais e de maior risco.

As primeiras iterações da elaboração possuem grande ênfase nos requisitos e na análise, já que muitos requisitos ainda não foram descobertos e registrados. Entretanto, com o decorrer das iterações, a ênfase deixa de ser nos requisitos e passa a ser na análise, no projeto e na implementação.

Embora as atividades das fases de elaboração e construção estejam sendo mostradas de forma seqüencial neste capítulo, o leitor deve estar atento ao fato de que elas podem se repetir várias vezes, dependendo da quantidade de iterações planejadas para o desenvolvimento. Assim, durante a leitura de uma determinada atividade, deve-se estar ciente de que ela pode ser executada sobre uma parte já desenvolvida do sistema, no caso de não ser a primeira iteração. Nesse caso, os artefatos gerados por ela são simplesmente atualizados e não são gerados novamente.

Nas seções seguintes são mostradas as três disciplinas que possuem mais ênfase dentro desta fase: Análise, Projeto e Implementação.

\subsection{1 - Disciplina Análise}

Nesta disciplina o objetivo é refinar os casos de uso alocados para a iteração atual, descobrir novos requisitos e elaborar o modelo de domínio (ou modelo conceitual). Com o andamento das iterações, o trabalho diminui nesta disciplina e a ênfase passa a ser maior na disciplina de projeto e implementação.

Na Figura 6.6 são mostradas as atividades desta disciplina no formato SADT (Ross, 1977). Apenas a atividade Identificar e Registrar Casos de Uso Candidatos a Aspectos é particular do ProFT/PU. Cada uma dessas atividades é detalhada nas subseções seguintes.

\subsubsection{1 - Identificar e Registrar Casos de Uso Colaboradores}

O objetivo nesta atividade é identificar casos de uso de nível mais baixo, os quais não são facilmente identificáveis por inspeção do documento de requisitos. Deve-se analisar a descrição dos casos de uso escolhidos para esta iteração e identificar trechos ${ }^{22}$ que são funcionalidades que mereçam ser transformadas em novos casos de uso. Essa atividade também é conhecida como fatoração de casos de uso.

De acordo com a terminologia definida neste processo, quando um trecho de um caso de uso é transformado em um novo caso de uso, diz-se que o caso de uso que já existia é o “criador" e o novo caso de uso é o "colaborador". O novo caso de uso tem esse nome porque

\footnotetext{
${ }^{22}$ Um trecho de um caso de uso pode ser uma única linha ou um conjunto de linhas que descrevem um determinado comportamento.
} 
colabora para a realização dos requisitos do caso de uso criador, já que ele é na verdade parte do caso de uso criador. Esses papéis que os casos de uso podem assumir são específicos de cada relacionamento, isto é, um caso de uso $\mathrm{C}$ pode ter o papel de criador no relacionamento que mantém com o caso de uso B e de colaborador no relacionamento que mantém com o caso de uso D, por exemplo. Isso ocorre quando um caso de uso colaborador é novamente analisado e um de seus passos é transformado em um novo caso de uso.

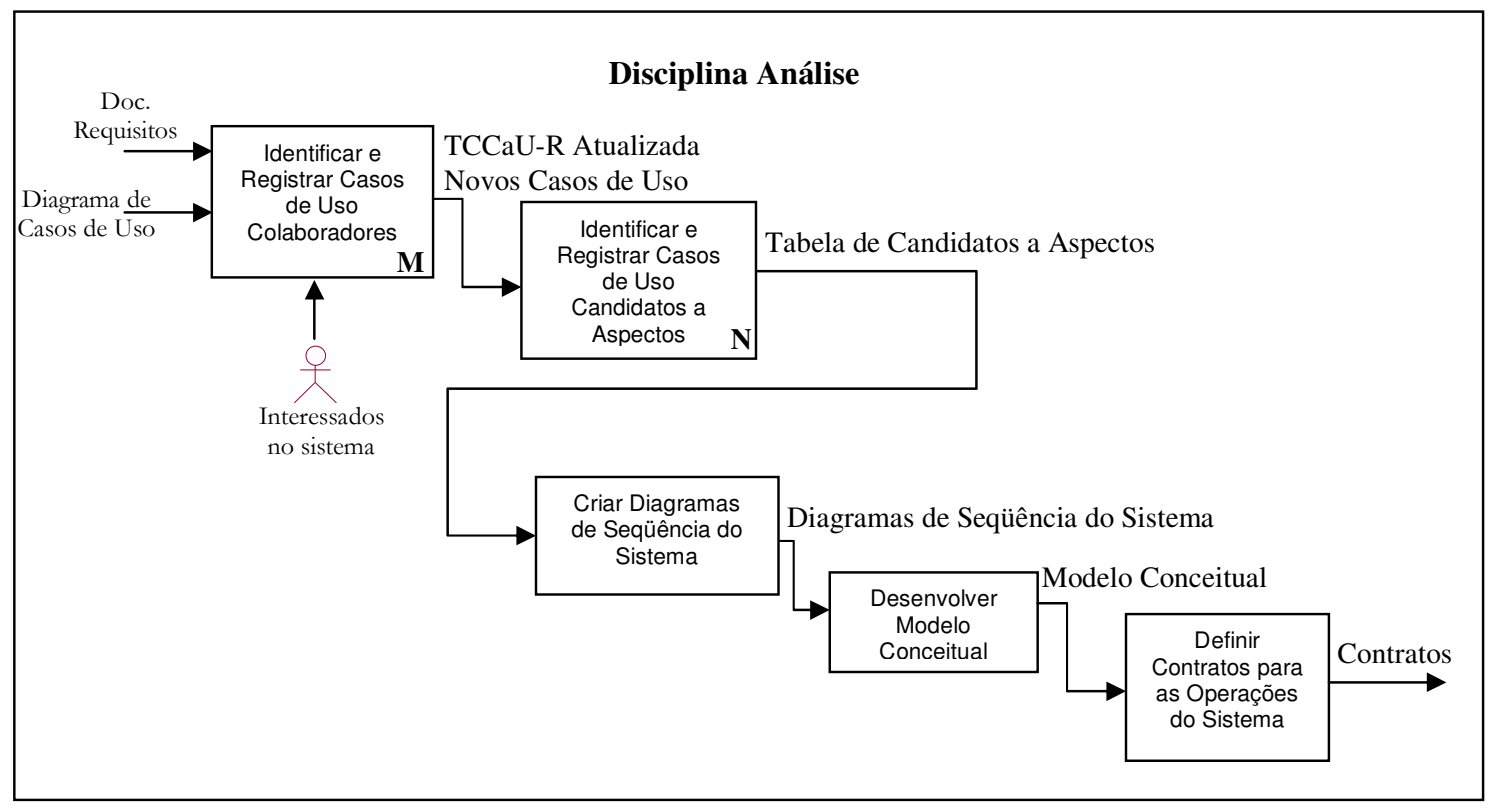

Figura 6.6 - Atividades da Fase de Elaboração

A fatoração de casos de uso realizada nesta atividade tem como um de seus objetivos facilitar a identificação de interesses transversais em outras atividades do processo. Como os interesses transversais são funcionalidades que geralmente atuam em pontos específicos de um outro comportamento, a fatoração de casos de uso pode auxiliar na identificação de casos de uso que ocorrem como parte do comportamento de outros casos de uso, caracterizando interesses transversais. Outro objetivo desta fase é alcançar um bom nível de modularização do sistema. Mesmo se os casos de uso colaboradores identificados não forem interesses transversais, a fatoração realizada resulta em uma arquitetura mais legível e compreensível.

Algumas perguntas que auxiliam a descobrir se um trecho de um caso de uso merece ser transformado em um novo caso de uso colaborador podem ser vistas no Modelo de Decisão apresentado na Tabela 6.7, que é uma ferramenta conceitual particular desta atividade.

A pergunta número 1 auxilia na identificação de funcionalidades que são compartilhadas por dois ou mais casos de uso. Os casos de uso que podem ser analisados são os que estão presentes na visão de iteração. Se a resposta para essa pergunta for "sim", não há 
necessidade de continuar o processo de decisão, pois somente isso já justifica a transformação do trecho em um novo caso de uso. Normalmente, o tipo de relacionamento que deve ser criado neste caso é de inclusão ou de extensão. Não é comum que relacionamentos de restrição sejam identificados com esse critério.

Tabela 6.7 - Tabela de Decisão para Identificação de Novos Casos de Uso

\begin{tabular}{|l|l|c|c|}
\hline No. & \multicolumn{1}{|c|}{ Pergunta } & Resposta & $\begin{array}{c}\text { Decisão } \\
\text { (Deve Fatorar?) }\end{array}$ \\
\hline 1 & $\begin{array}{l}\text { A funcionalidade descrita pelo trecho é utilizada pelos outros } \\
\text { casos de uso disponíveis na visão de iteração? }\end{array}$ & Sim & Sim \\
\cline { 2 - 4 } & $\begin{array}{l}\text { A funcionalidade descrita pelo trecho é essencial para o } \\
\text { comportamento do caso de uso? }\end{array}$ & Sim & Pergunta 2 \\
\cline { 2 - 3 } & Não & Sim \\
\hline
\end{tabular}

A pergunta número 2 auxilia na identificação de trechos cuja funcionalidade não é essencial ao comportamento do caso de uso, isto é, o objetivo principal do caso de uso pode ser alcançado mesmo se o trecho for removido. Uma diretriz é imaginar o caso de uso sem aquele passo; se mesmo assim seu comportamento faz sentido, pode ser que ele mereça ser transformado em um novo caso de uso. O tipo mais comum de relacionamento nesta situação é o de extensão, pois geralmente a funcionalidade encontrada é alguma política que estende o comportamento do caso de uso base.

A utilização da tabela de decisão deve ser vista apenas como um auxílio ao processo de decisão, e não como uma obrigatoriedade do processo descrito. A experiência do engenheiro de software e o conhecimento no domínio são outros fatores que devem ser levados em conta durante a decisão.

A pergunta número 1 do modelo de decisão exige que os casos de uso funcionais sejam comparados aos pares, isto é, elege-se um determinado caso de uso e prossegue-se com a pergunta para os demais. Sugere-se montar uma matriz como o modelo mostrado pela Tabela 6.8. A diagonal principal da matriz delimita as comparações que já foram realizadas. Deve-se colocar a letra "n" quando "não" há trechos com funcionalidades comuns entre os dois casos de uso, e "s" quando há. A existência de trecho de funcionalidade comum entre dois casos de uso é motivo para fatorá-lo, não sendo necessário prosseguir com o processo de decisão. Entretanto, a segunda pergunta auxilia a identificar se o relacionamento entre o caso de uso base e o colaborador é de inclusão ou de extensão.

Observe-se que como o processo descrito aqui é iterativo e incremental, nas iterações futuras os casos de uso alocados para a iteração serão comparados com todos os outros das iterações anteriores, e não apenas entre si. Assim, pode ser que uma determinada funcionalidade comum entre um caso de uso alocado para a iteração atual e um que já foi 
implementado já tenha sido fatorada em um novo caso de uso, fazendo surgir apenas um novo relacionamento entre os casos de uso e não um novo caso de uso colaborador.

Tabela 6.8 - Modelo de Matriz de Comparação de Casos de Uso para a Pergunta 1

\begin{tabular}{|l|c|c|c|c|c|}
\hline Pergunta 1 $\rightarrow$ & \multicolumn{5}{|c|}{ Há trecho com funcionalidade compartilhada pelos outros casos de uso? } \\
\hline & Caso de Uso 1 & Caso de Uso 2 & Caso de Uso 3 & Caso de Uso 4 & Caso de Uso 5 \\
\hline Caso de Uso 1 & - & $\mathrm{n}$ & $\mathrm{n}$ & $\mathrm{n}$ & $\mathrm{s}$ \\
\hline Caso de Uso 2 & - & - & $\mathrm{s}$ & $\mathrm{n}$ & $\mathrm{n}$ \\
\hline Caso de Uso 3 & - & - & - & $\mathrm{s}$ & $\mathrm{n}$ \\
\hline Caso de Uso 4 & - & - & - & - & $\mathrm{n}$ \\
\hline Caso de Uso 5 & - & - & - & - & - \\
\hline
\end{tabular}

Depois que novos casos de uso foram identificados, deve-se atualizar a "Tabela de Correspondência Caso de Uso/Requisitos" com os novos casos de uso. Esses novos casos de uso identificados também devem ser acrescentados na visão de iteração.

\subsubsection{2 - Identificar e Registrar Casos de Uso Candidatos a Aspectos}

Esta atividade é particular do ProFT/PU e o objetivo é identificar casos de uso que apresentam indícios de que sua implementação com aspectos é factível. Esses casos de uso são denominados "candidatos a aspectos", porque não há certeza se essa tecnologia deve ser usada em sua implementação. A decisão final sobre a utilização da tecnologia será feita durante a disciplina de projeto.

Quatro critérios devem ser utilizados para identificar os casos de uso que são candidatos a aspectos: quantidade de relacionamentos, tipo do caso de uso, extensão e essencialidade. O critério da quantidade de relacionamentos seleciona casos de uso que possuem relacionamento com mais de um caso de uso. Em analogia ao problema do espalhamento de código, provavelmente a implementação desses casos de uso possuirá trechos de código relacionados a sua funcionalidade espalhados por vários locais do sistema. São aqueles que são incluídos por dois ou mais casos de uso (relacionamento <<include >>), que estendem dois ou mais casos de uso (relacionamento $<<$ extend $>>$ ) ou que restringem dois ou mais casos de uso (relacionamento $<<$ constrain $>>$ ).

O critério da quantidade de relacionamentos deve ser utilizado com cautela, pois em um processo iterativo e incremental como este, a quantidade de relacionamentos de um caso de uso em uma iteração pode ser muito diferente da quantidade real que ele possuirá no final do desenvolvimento. Assim, uma situação que pode ocorrer é justamente não selecionar um caso de uso que é um bom candidato a aspecto porque ele possui apenas um relacionamento, implementá-lo com técnicas tradicionais, e só perceber que ele é adequado para ser implementado como aspecto nas iterações posteriores. Essa é uma particularidade de um processo iterativo e incremental, pois a visão de todo o sistema só será possível depois que a maioria das iterações estiver concluída. Em processos seqüenciais, em que a análise e o 
projeto são realizados completamente antes de passar para a implementação, o critério da quantidade de relacionamentos pode ter um peso maior. Por isso, sugere-se que este critério tenha um peso menor do que os demais no processo de decisão.

O critério do tipo seleciona casos de uso do tipo não-funcional, isto é, aqueles que possuem estereótipo $<<\mathrm{NF}>>$. Essa identificação é facilitada porque a atividade Identificar e Especificar Casos de Uso não-Funcionais que ocorreu na fase de concepção, já identificou alguns casos de uso não-funcionais. Assim, basta verificar se os casos de uso alvo desta iteração se encontram no artefato Tabela de Interesses Transversais Não-Funcionais.

O terceiro seleciona casos de uso que se relacionam por extensão $(<<$ extend $>>)$ com um ou mais casos de uso. Como o comportamento dos casos de uso de extensão são funcionalidades extras que são adicionadas ao comportamento de um caso de uso base, podem tratar de funcionalidades adequadas para serem implementadas como aspectos. Este critério pode, aparentemente de forma errada, selecionar casos de uso que possuem apenas um relacionamento de extensão, entretanto há quatro justificativas para realizar essa seleção:

1. Pode ocorrer que novos relacionamentos apareçam nas outras iterações. Como cada iteração adiciona casos de uso sobre a iteração anterior, um caso de uso pode possuir apenas um relacionamento nesta iteração porque os outros casos de uso que ele estende ainda não estão presentes, isto é, serão tratados nas próximas iterações;

2. Pode existir um FT para implementar o caso de uso. Mesmo se depois de todas as iterações o caso de uso permanecer com apenas um relacionamento, mas existir um FT que possa ser utilizado para implementá-lo, pode ser conveniente usar a tecnologia de aspectos pela facilidade de implementação fornecida pelo framework;

3. Pode ser que o caso de uso colaborador encapsule um requisito volátil. Em conseqüência de grande possibilidade de modificação, requisitos voláteis são adequados para serem implementados com aspectos, independentemente do seu grau de ocorrência dentro do sistema.

4. Pode ser que o caso de uso encapsule um interesse que é uma característica de um FT já existente. Implementando-o também como um FT, uma nova característica pode ser adicionada na linha de produtos permitindo, que novos membros da linha sejam criados. 
O critério da essencialidade visa a identificar se o comportamento do caso de uso colaborador é essencial ao comportamento genérico do caso de uso base, ou se é apenas uma adição de funcionalidade que é exclusiva do sistema que está sendo desenvolvido. Relacionamentos de extensão geralmente se enquadram nessa situação. Por exemplo, um dos sistemas que foi desenvolvido no contexto desta tese realiza o controle de reservas de um hotel. Esse sistema possui um caso de uso de uso responsável pelo cálculo de descontos para clientes que possuem convênio com determinadas empresas. Se a análise se restringir ao sistema em questão, essa funcionalidade é essencial, pois os requisitos do sistema deixam claro que ela deve existir. Contudo, sabe-se que podem existir sistemas de reservas que não possuem descontos para empresas conveniadas. Dessa forma, a funcionalidade de cálculo de descontos é essencial ao sistema de reserva, mas não é essencial à funcionalidade geral de realização de reservas, pois uma reserva pode ter seu preço calculado sem qualquer tipo de desconto.

Um contra-exemplo é o caso de uso Verificar Disponibilidade de Acomodação, também pertencente ao sistema de reservas desenvolvido. Esse caso de uso é incluído por três outros e consiste em verificar se existe acomodação disponível no hotel no período desejado pelo cliente. Essa funcionalidade é considerada parte integrante do caso de uso Fazer Reserva, pois dificilmente haverá um sistema de reservas que não verifique as acomodações disponíveis antes de efetuar uma reserva. O uso restrito deste critério pode muitas vezes selecionar relatórios e consultas como candidatos a aspectos, mas, em princípio, não devem ser considerados.

Ressalta-se que os quatro critérios são independentes, isto é, um não influencia o outro, basta que um seja satisfeito para que o caso de uso seja considerado candidato a aspecto. Os casos de uso identificados como candidatos devem ser listados em uma tabela denominada Tabela de Candidatos a Aspectos, cujo modelo pode ser visto na Tabela 6.9. Na primeira coluna é colocado o nome do caso de uso, na segunda seu tipo (se é funcional ou não-funcional), e na terceira o critério utilizado. A quarta coluna é reservada para atualizações que ocorrerão nas próximas iterações. Caso algum caso de uso selecionado venha a ser implementado com aspectos, a caixa da coluna "implementado" deve ser marcada com um "X". A análise deve se restringir aos casos de uso que podem ser acessados na iteração, os quais podem ser vistos na visão de iteração.

Tabela 6.9 - Modelo para Tabela de Candidatos a Aspectos

\begin{tabular}{|c|c|c|c|}
\hline Caso de Uso & Tipo (F/NF) & Critério & Implementado \\
\hline & & & $\square$ \\
\hline
\end{tabular}


Algo importante a ser observado é que esta atividade é apenas um apoio para a identificação de casos de uso que podem ser implementados como aspectos. Não significa que outros casos de uso candidatos não possam ser descobertos durante a realização de outras atividades. Por exemplo, durante a elaboração dos diagramas de interação na disciplina de projeto, o comportamento do caso de uso é projetado com detalhes de implementação, o que pode auxiliar na descoberta de requisitos voláteis, os quais talvez sejam adequados para serem implementados como aspectos. Outro ponto do processo em que podem surgir novos aspectos de granularidade mais fina é durante o processo de reúso do FT. Isso ocorre porque é durante esse processo que se pode constatar a carência de uma nova variabilidade ou característica, fazendo com que o projeto e implementação dessa nova característica possam ser feitos como um novo FT.

A adição de novos casos de uso na Tabela de Candidatos a Aspectos é a situação mais convencional desta atividade. Entretanto, a reavaliação dos critérios também deve ser feita porque muitas vezes um critério que levou à seleção de um caso de uso em uma iteração pode não ser mais válido em iterações subseqüentes. Isso geralmente ocorre em conseqüência do aparecimento de novos casos de uso. A situação mais comum é um caso de uso que foi selecionado por meio do critério "um relacionamento de extensão" em uma iteração, ter seu critério alterado para "quantidade de relacionamentos", por causa do aparecimento de novos relacionamentos de extensão ou inclusão.

\subsubsection{3 - Criar Diagramas de Seqüência do Sistema}

O objetivo nesta atividade é criar um diagrama de sequiência do sistema (DSS) para cada caso de uso ou cenário que está sendo tratado nesta iteração. Esses diagramas representam o comportamento do sistema em resposta a eventos gerados por entidades externas e auxiliam a identificar as principais operações do sistema.

As operações de sistema que são casos de uso candidatos a aspectos devem ser representadas normalmente nos DSS, mesmo sem saber a técnica de implementação que será utilizada para elas. Como um DSS não é uma representação de software, e sim um modelo comportamental, não importa como as operações de sistema serão implementadas, pois elas ocorrerão da mesma forma, e possivelmente, na mesma ordem.

\subsubsection{4 - Desenvolver Modelo Conceitual}

Da mesma forma que a atividade anterior, a criação do modelo conceitual deve se concentrar apenas nos casos de uso que estão sendo tratados nesta iteração. Para a elaboração desse modelo deve-se analisar os casos de uso que estão sendo trabalhados nesta iteração, em busca de conceitos do domínio. 
Durante a elaboração do modelo conceitual, os conceitos que forem oriundos de casos de uso candidatos a aspectos devem ser marcados com uma nota, informando que são "conceitos candidatos a aspectos". Isso deve ser feito para rastrear esses conceitos até a disciplina de projeto, onde podem ou não se transformar em classes de software e, conseqüentemente, podem introduzir relacionamentos indesejados na arquitetura do sistema. Se eles forem considerados como aspectos na disciplina de projeto, deverão ser projetados e implementados como aspectos, para que não influenciem na parte base da aplicação.

\subsubsection{5 - Definir Contratos das Operações do Sistema}

Nesta atividade o objetivo é descrever com mais detalhes as operações mais complexas de sistema. Com essa descrição pode ser possível identificar comportamentos que ocorrem como pré e pós-condições e que talvez possam ser implementadas com aspectos. Em muitos casos, as pré-condições podem ser implementadas como adendos tipo before (), enquanto que as pós-condições como adendos do tipo after ( ).

\subsection{2 - Disciplina Projeto}

O objetivo nesta disciplina é criar um modelo de classes de projeto, modelos de interação, e quaisquer outros modelos que auxiliem a documentar e registrar o comportamento e a estrutura do sistema. Nesta atividade também podem ser identificados e projetados alguns aspectos do sistema.

Na Figura 6.7 são mostradas as atividades desta disciplina e suas interdependências. As atividades que não são particulares do ProFT/PU são Desenvolver Diagramas de Interação, Desenvolver Modelo de Classes de Projeto e Desenvolver Modelo de Dados. Na figura é mostrado que há dois caminhos que podem ser realizados paralelamente ou sinergicamente. No caminho que se inicia do lado esquerdo da figura encontram-se atividades específicas para a identificação, projeto e acoplamento dos aspectos com o código-base. Do lado direito encontram-se algumas atividades convencionais de qualquer processo de desenvolvimento, que são atividades para elaboração de diagramas de interação e de classes.

Procura-se mostrar que não há uma seqüência obrigatória de execução entre esses caminhos. Por exemplo, a atividade Identificar Aspectos pode ser iniciada logo que a iteração começar ou durante a execução das atividades de desenvolvimento dos diagramas de iteração ou diagramas de classe de projeto, como esta sendo mostrado pelas setas com espaçamento mais distante, que partem dessas atividades em direção à atividade Identificar Aspectos. Isso destaca uma propriedade importante da orientação a aspectos que cita que aspectos são propriedades emergentes que podem surgir durante o decorrer das atividades do desenvolvimento do sistema. 
A atividade Projetar Acoplamento dos Aspectos com a Base pode ser realizada sempre que um aspecto foi selecionado para a iteração atual e projetado. Note-se que essa atividade só pode ser realizada se houver um modelo de classes da parte base do sistema. Quando o processo se encontra em sua primeira iteração, a atividade Desenvolver Modelo de Classes de Projeto deve, obrigatoriamente, ser realizada antes da atividade Projetar Acoplamento dos Aspectos com a Base. Mas o mesmo não ocorre nas iterações seguintes, pois um aspecto pode ser identificado e projetado com o modelo de classes oriundo da iteração anterior.

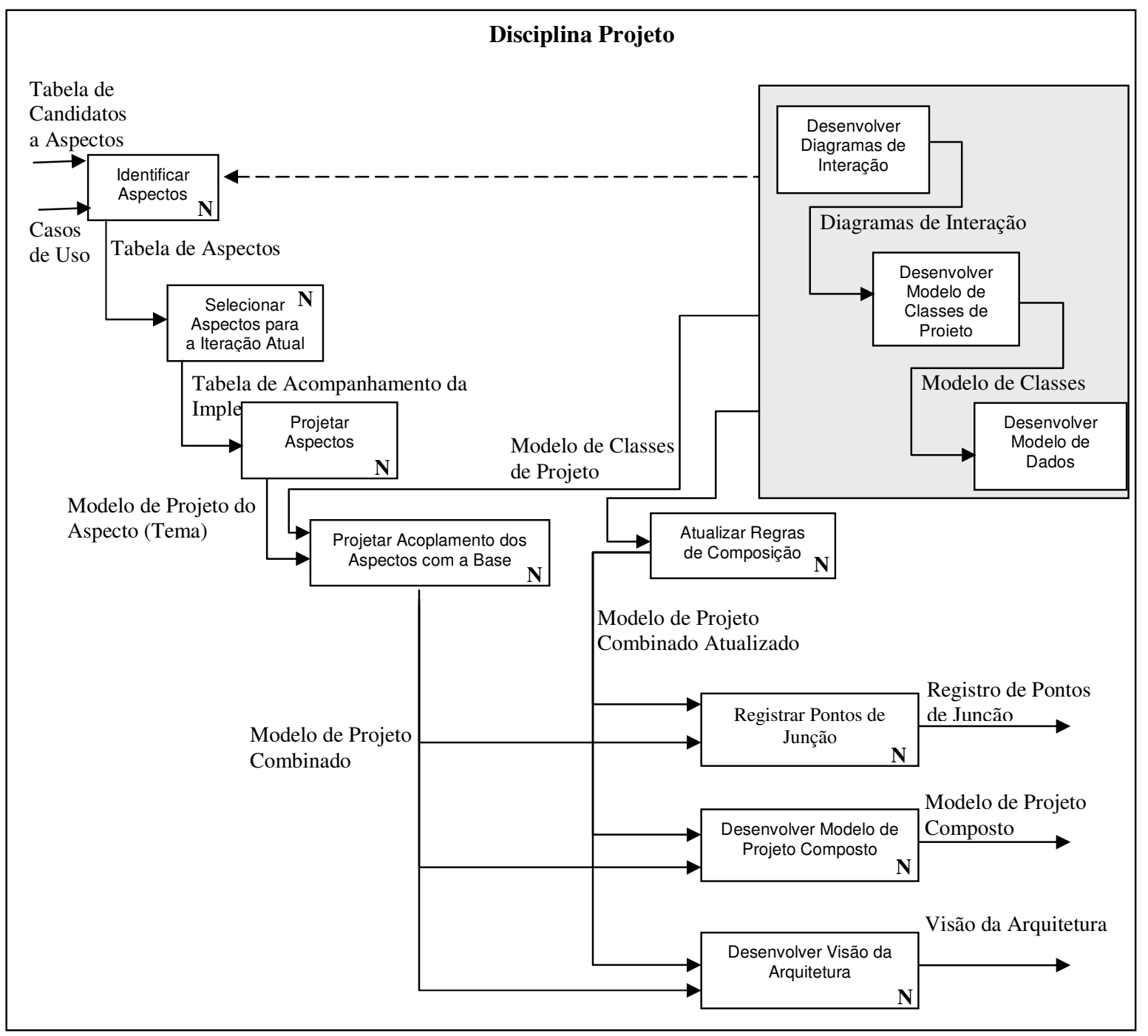

Figura 6.7 - Atividades da Disciplina Projeto

A atividade Atualizar Regras de Composição está sendo representada por um retângulo com cantos arredondados para destacar que é uma atividade opcional. Ela deve ser realizada somente se o desenvolvimento do diagrama de classes da iteração atual incluir alguma classe, método ou atributo que deve ser afetado pelos aspectos que já se encontram acoplados ao sistema. 
As três últimas atividades devem ser realizadas sempre que um determinado aspecto é acoplado com a parte base do sistema ou as regras de composição são atualizadas. Essas atividades geram artefatos importantes que auxiliam no acompanhamento e na visão geral do prosseguimento do processo.

Os artefatos gerados por cada uma das atividades são constantemente atualizados conforme as iterações são realizadas. As atividades mostradas na Figura 6.7 são descritas com mais detalhes nas próximas subseções.

\subsubsection{1 - Identificar Aspectos}

O objetivo nesta atividade é identificar quais dos casos de uso candidatos a aspectos, listados na Tabela de Candidatos a Aspectos devem ser implementados com a tecnologia de aspectos. Os artefatos utilizados para essa tomada de decisão são o modelo de casos de uso da iteração atual, a descrição dos casos de uso, o documento de requisitos e, se necessário, diagramas de interação. Note-se que a identificação de que um caso de uso deve ser implementado com aspectos não significa que isso será feito na iteração atual, a decisão sobre a iteração em que ele será implementado é tomada durante a próxima atividade.

Para identificar se um caso de uso candidato a aspecto realmente deve ser implementado com tal paradigma, os critérios mostrados na Tabela 6.10 devem ser utilizados. O primeiro critério consiste em averiguar se o caso de uso trata de um requisito não-funcional que é um exemplo clássico de aspecto relatado na literatura. A Tabela 6.11 exibe uma lista não exaustiva de requisitos não-funcionais clássicos da literatura que são adequados para serem implementados como aspectos. Em caso afirmativo, a sugestão é que o caso de uso seja implementado com aspectos, mas a decisão final ainda pode ser influenciada por outros fatores, como, por exemplo: a existência de um framework orientado a objetos para a implementação do requisito - o que consumiria menos tempo do que implementá-lo do zero com aspectos; a habilidade que a equipe de desenvolvimento possui com orientação a aspectos; o risco que um paradigma ainda recente pode trazer, etc.

Em geral, os casos de uso não-funcionais devem ser implementados como aspectos pelos seguintes motivos:

- Não fazem parte da funcionalidade básica do sistema e é interessante que sejam implementados em módulos separados e independentes da aplicação básica;

- Geralmente são recorrentes em muitas aplicações e possuem características comuns, o que possibilita a generalização e maior facilidade de reúso; 
- A separação da implementação não-funcional da funcional permite que as funcionalidades básicas do sistema sejam testadas independentemente, ou em conjunto com a parte não-funcional.

Tabela 6.10 - Critérios para Identificação de Aspectos

\begin{tabular}{|l|l|l|l|}
\hline No & Critérios & Descrição & \multicolumn{1}{c|}{ Pergunta } \\
\hline 1 & NF clássico & $\begin{array}{l}\text { Procura identificar se o caso de uso } \\
\text { transversal é um exemplo clássico de } \\
\text { aspecto não-funcional relatado na literatura }\end{array}$ & $\begin{array}{l}\text { O caso de uso transversal é um aspecto } \\
\text { clássico da literatura? }\end{array}$ \\
\hline 2 & Atomicidade & $\begin{array}{l}\text { Procura fazer comparações aos pares entre } \\
\text { casos de uso com o objetivo de averiguar se } \\
\text { o compartilhamento é fruto de um requisito } \\
\text { transversal ou simplesmente um requisito } \\
\text { mal redigido. }\end{array}$ & O caso de uso transversal é atômico? \\
\hline 3 & Volatilidade & $\begin{array}{l}\text { Procura identificar se o caso de uso envolve } \\
\text { um requisito volátil, isto é, requisitos que } \\
\text { possuem uma alta probabilidade de } \\
\text { mudança. }\end{array}$ & $\begin{array}{l}\text { O comportamento do caso de uso transversal } \\
\text { entila }\end{array}$ \\
\hline 4 & $\begin{array}{l}\text { Framework } \\
\text { Transversal }\end{array}$ & $\begin{array}{l}\text { Identifica se há um FT disponível que possa } \\
\text { ser utilizado para a implementação do caso } \\
\text { de uso. }\end{array}$ & $\begin{array}{l}\text { Há um FT que pode ser utilizado para a } \\
\text { implementação do caso de uso? }\end{array}$ \\
\hline
\end{tabular}

Tabela 6.11 - Lista de Requisitos Não-Funcionais Clássicos

\begin{tabular}{|l|}
\hline Persistência \\
\hline Autenticação \\
\hline Controle de acesso \\
\hline Registro de acesso \\
\hline Rastreamento \\
\hline Memória Auxiliar \\
\hline Repositório de Conexões \\
\hline Distribuição \\
\hline Concorrência \\
\hline Tratamento de exceções \\
\hline Criptografia \\
\hline Depuração de Programs \\
\hline Garantia de políticas \\
\hline Padrões de projeto \\
\hline Tratamento de erros (exceções) \\
\hline Regras de Negócio \\
\hline
\end{tabular}

O segundo critério, que é oriundo do trabalho de Clarke e Baniassad (2005), só pode ser aplicado para os casos de uso que possuem mais de um relacionamento com outros casos de uso. O objetivo é averiguar se o caso de uso é atômico ou não, isto é, se ele manipula apenas uma funcionalidade. Isso deve ser feito porque os requisitos numerados do documento de requisitos podem envolvem, erroneamente, mais de uma funcionalidade, gerando casos de uso que também tratam de mais de uma funcionalidade. Assim, esses casos de uso acabam sendo compartilhados por outros casos de uso porque tratam de mais de uma funcionalidade e não porque tratam de requisitos transversais.

Por exemplo, na Figura 6.8 é mostrado hipoteticamente um caso de uso colaborador que estende o comportamento de dois casos de uso base, isto é, o caso de uso colaborador é 
compartilhado pelos casos de uso base. Como os casos de uso são gerados a partir dos requisitos do documento de requisitos, o compartilhamento existente pode ser oriundo de um requisito que envolva duas funcionalidades, fazendo com que cada caso de uso base utilize uma das funcionalidades. O critério de atomicidade tem como objetivo verificar se o requisito que originou o caso de uso colaborador não pode ser dividido, para a eliminar o compartilhamento. Nesse sentido, a Tabela de Correspondência Caso de Uso/Requisitos deve ser analisada com o objetivo de verificar qual foi o requisito numerado originador do caso de uso transversal. Deve-se tentar dividir a sentença textual originadora do requisito para eliminar o compartilhamento.

Outra forma de realizar essa verificação é analisar a própria descrição do caso de uso. Quando o relacionamento entre eles é de extensão, o caso de uso colaborador possui uma seção específica chamada "fluxo de extensão", que descreve tanto o comportamento que deve ser inserido quanto o ponto de extensão no caso de uso base onde o comportamento será inserido. Considerando a Figura 6.8, se o comportamento inserido nos caso de uso base forem diferentes, então o caso de uso colaborador pode ser divido em dois, em que cada um trate de um dos comportamentos, eliminando assim, o compartilhamento. A impossibilidade de eliminar o compartilhamento é um indício de que o comportamento descrito pelo caso de uso é transversal, e talvez possa ser implementado como aspectos.

O critério de volatilidade consiste em averiguar se o requisito tratado pelo caso de uso colaborador é volátil. Um requisito volátil representa regras de negócio que os interessados no sistema desejam mudar rapidamente, a qualquer hora, dependendo das demandas de mercado. Exemplos de requisitos voláteis são: "se o valor das movimentações financeiras de determinado cliente durante o ano for superior a quinhentos mil dólares, ele receberá um prêmio", ou "Os dez clientes que mais gastaram na loja durante a semana ganharão cinco por cento de desconto na próxima compra”. Os valores das regras de negócio, como os quinhentos mil dólares e o valor da porcentagem de desconto dos clientes da loja, e as próprias estratégias de cálculo são muito suscetíveis a situações do mercado e políticas organizacionais, podendo mudar a qualquer momento.

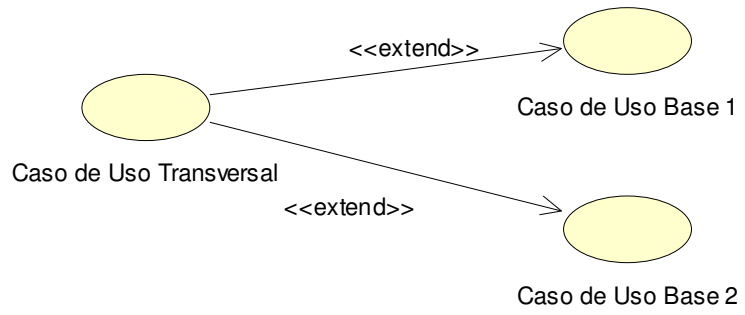

Figura 6.8 - Exemplo Hipotético de Caso de Uso Transversal 
Quando requisitos voláteis são implementados com técnicas tradicionais de programação, geralmente tornam-se fixos dentro do sistema, dificultando modificações futuras, que só podem ser feitas recompilando o sistema todo, ou parte dele. Além disso, também é comum aparecer dependências estruturais da parte base para a parte volátil, por exemplo, uma classe da parte base com um relacionamento de associação com uma classe da parte volátil. Isso implica na adição de um atributo, do tipo da classe volátil, na classe-base, e em uma série de outras modificações, como por exemplo: o construtor da classe-base deve ser alterado para considerar o novo atributo, dois novos métodos de acesso devem ser criados, um set e um get, e as operações de interface agora também devem considerar o novo atributo.

Quando essas dependências estruturais ocorrem da parte base para a parte volátil, sugere-se que o atributo que representa o relacionamento seja introduzido na classe-base por meio de algum mecanismo de declarações intertipo, como, por exemplo, aquele existente na linguagem AspectJ. Segundo Moreira e Araújo (2004), a implementação de requisitos voláteis com aspectos é uma estratégia interessante porque facilita a inclusão/remoção/alteração desses requisitos depois que o sistema estiver pronto.

Para descobrir se um caso de uso envolve um requisito volátil, deve-se analisar a descrição do caso de uso, ou dos casos de uso, e buscar por regras de negócio com tendência de mudanças. Geralmente esse tipo de requisito possui uma parte estável, que é genérica e aplicável a vários sistemas de um domínio, e uma parte variável, que é específica do sistema que está sendo desenvolvido. Um caso de uso que calcula descontos, por exemplo, envolve um requisito volátil, pois os valores e as estratégias de descontos podem variar de sistema para sistema. Por exemplo: pode haver descontos que são feitos em porcentagens, descontos de valores fixos, descontos promocionais de fim de semana ou de algum período festivo do ano. Caso a descrição do caso de uso não apresente detalhes suficientes para a decisão, devese buscar informações mais detalhadas em outras fontes para que a decisão possa ser tomada com mais certeza. Uma alternativa é a elaboração de diagramas de interação para o caso de uso. Como esses diagramas representam unidades de software, sua elaboração detalha as operações e métodos necessários para a realização do caso de uso.

Como comentado anteriormente, casos de uso que envolvem requisitos voláteis podem surgir durante a realização de outras atividades de projeto em conseqüência do nível de detalhes obtido. $\mathrm{O}$ critério da volatilidade apresentado aqui deve ser aplicado aos casos de uso listados na Tabela de Candidatos a Aspectos, mas também deve servir como diretriz para a identificação de novos requisitos voláteis durante outras atividades do processo. 
O último critério - Framework Transversal - procura identificar se há um FT que possa ser utilizado na implementação do caso de uso. Esse critério é importante e pode ser decisivo na opção de implementar o caso de uso com aspectos. A ausência de um FT pode inviabilizar a implementação de um interesse que é transversal por causa da dificuldade que um novo paradigma traz para a equipe de desenvolvimento. Já a existência de um FT também pode ser um fator decisivo em se implementar com aspectos, mesmo se o caso de uso não satisfizer a todos os critérios que o qualificam como aspecto.

O processo para identificar se há um FT que pode ser usado na implementação de um caso de uso consiste em dois passos. O primeiro é consultar o repositório disponível biblioteca ou família de FTs - com o objetivo de identificar um FT que implementa o interesse tratado pelo caso de uso. Essa identificação pode ser feita pelo nome do FT; por exemplo, se o caso de uso trata do interesse de Autenticação, deve-se localizar um FT que possua esse nome. Embora pareça simples, a quantidade de FTs disponíveis e a utilização de vários termos que representam um mesmo interesse podem dificultar a busca. O interesse de controle de acesso, por exemplo, também é referenciado na literatura como "Autorização" (Zhang et al., 2004). Mesmo assim, a busca por FTs que implementam interesses transversais não-funcionais é facilitada, pois não há muita variação.

Entretanto, a busca por FTs que implementam interesses transversais funcionais tornase um pouco mais complicada porque o FT pode não possuir um nome muito significativo em decorrência da generalização do algoritmo que ele encapsula. Por exemplo, no contexto desta tese o FT funcional "Cálculo Baseado em Tabela" pode ser usado para vários tipos de regras de negócio: um valor de vale-refeição que pode ou não ser acrescido ao salário do funcionário dependendo de sua faixa salarial; um desconto na conta de água para usuários cujo consumo esteja, por exemplo, entre 11 e $15 \mathrm{~m}^{3}$ e um bônus para funcionários cujo número de horas extras mensal é superior a 30. Assim, uma estratégia que foi adotada é incluir na documentação do FT algumas palavras-chave e exemplos de sua utilização.

Depois de constatado que existe um FT que trata do interesse desejado, o segundo passo consiste em averiguar se as funcionalidades desse FT cobrem os requisitos do caso de uso. Para isso, os requisitos explícitos do caso de uso, ou do documento de requisitos, devem ser analisados e contrastados com as características do FT representadas em seu diagrama de características (como aquele mostrado na Figura 4.1). Se as características do FT forem suficientes para a implementação do caso de uso é um forte indício que ele pode ser usado. Se esse não for o caso, deve-se comparar o esforço necessário para a implementação da(s) nova(s) característica(s) com as vantagens que isso pode trazer, o que dependerá de 
particularidades da organização, da equipe de desenvolvimento e da quantidade de recursos disponíveis.

Mesmo quando as características do FT forem suficientes, o processo de análise deve ainda continuar. Uma situação que pode ocorrer é o FT possuir todas as características necessárias para cobrir os requisitos, porém, os requisitos da aplicação exigirem certas particularidades que exigem modificações nas características. Por exemplo, pode ser que o interesse de autenticação que deve ser implementado exija que o controle de tentativas erradas seja limitado pelo tempo entre uma tentativa e outra. Pode ser que essa característica do FT possua apenas a opção para fazer esse tipo de controle diariamente. Dessa forma, deve-se ponderar o esforço necessário para realizar adaptações no FT para que ele possua a nova funcionalidade. Na Seção 4.3.2. foram mostrados três tipos de adaptações que podem ser feitas no FT de persistência. Dependendo do nível de conhecimento da equipe de desenvolvimento e de sua familiaridade com o FT, esse tipo de adaptação pode ser feito rapidamente.

Quando não há um FT que possa ser utilizado, há basicamente três caminhos que podem ser seguidos. O primeiro é implementar o caso de uso normalmente com orientação a objetos. Entretanto, se o interesse já foi considerado como transversal isso resultará nos problemas de entrelaçamento e espalhamento já comentados anteriormente. O segundo é implementar o caso de uso com POA, mas sem a intenção de transformá-lo em um FT. É uma estratégia melhor do que a primeira porque evita os conhecidos problemas, porém, não colabora para a evolução do repositório disponível. A terceira opção consiste em implementar o novo caso de uso como um FT e adicioná-lo no repositório disponível. Essa opção é a mais interessante do ponto de vista de evolução do repositório, pois o novo FT deve ser adicionado a ela.

Os critérios devem ser aplicados para cada caso de uso listado na Tabela de Candidatos a Aspectos. O processo de aplicação dos critérios envolve a criação de uma tabela, chamada Tabela de Aspectos, em que os critérios devem ser aplicados para cada caso de uso. Essa tabela contém um parecer final optando pela implementação com aspecto, pela implementação convencional ou pelo adiamento da decisão, o que coloca o caso de uso em situação pendente, que deve ser resolvida futuramente. É importante destacar que nem sempre é possível realizar o adiamento dessa decisão porque o caso de uso pode ser necessário na iteração atual. Nesse caso, deve-se tomar uma decisão com base no que há disponível sobre o caso de uso, isto é, sua descrição e sua natureza. Se a incerteza for grande, talvez seja melhor optar por uma implementação convencional. 
Um modelo para essa tabela pode ser visto na Tabela 6.12. A sexta coluna consiste no parecer final, informando se o caso de uso deve ser implementado com aspectos ou não. Os casos de uso que devem ser implementados com aspectos são chamados de "casos de uso aspectuais". A sétima coluna deve ser marcada com um "x" depois que o caso de uso for implementado. Note-se que o preenchimento da tabela consiste em responder sim ou não para as perguntas da Tabela 6.10. A coluna Framework Transversal deve ser preenchida com $S$ ou $\mathrm{N}$ informando se há ou não um FT que possa ser utilizado para apoiar a implementação do caso de uso. Em caso de dúvida deve-se colocar um ponto de interrogação, que servirá como marcação, indicado que em iterações posteriores esse caso de uso deverá ser analisado com mais cautela com o objetivo de identificar se algum dos FTs disponíveis poderá ser usado para apoiar sua implementação. A coluna "Implementa como Aspecto?" também pode ser preenchida com a palavra "Adiada" indicado que ainda há dúvida se o caso de uso deve ser implementado com aspectos ou não. Dessa forma, as próximas iterações devem novamente reavaliar esse caso de uso com o objetivo de esclarecer a dúvida.

Tabela 6.12 - Modelo para Tabela de Aspectos

\begin{tabular}{|l|c|c|c|c|c|c|}
\hline Casos de Uso & Tipo & Atomicidade & Volatilidade & $\begin{array}{c}\text { Framework } \\
\text { Transversal }\end{array}$ & $\begin{array}{c}\text { Implementa } \\
\text { como } \\
\text { Aspecto? }\end{array}$ & Implementado \\
\hline Caso de Uso 1 & nf & - & - & $\mathrm{S}$ & sim & $\square$ \\
\hline Caso de Uso 2 & $\mathrm{f}$ & $\mathrm{s}$ & $\mathrm{s}$ & $\mathrm{S}$ & sim & $\square$ \\
\hline Caso de Uso 3 & $\mathrm{f}$ & $\mathrm{n}$ & - & $\mathrm{N}$ & não & $\square$ \\
\hline Caso de Uso 4 & $\mathrm{f}$ & $\mathrm{s}$ & $\mathrm{n}$ & $\mathrm{N}$ & Adiado & $\square$ \\
\hline
\end{tabular}

Em se tratando de requisitos não-funcionais, não há muita dúvida se devem ou não ser implementados com aspectos, vide a grande quantidade de trabalhos publicados nesse sentido. Entretanto, o mesmo não ocorre quando os requisitos são funcionais (Suvée et al, 2005; Cibrán et al, 2003). Entre os motivos para implementar requisitos funcionais como aspectos está o fato de serem extensões, adicionarem comportamentos a outros casos de uso em pontos específicos e serem independentes. Além disso, os casos de uso funcionais podem ser variabilidades, pontos de extensão, implementação de requisitos voláteis, ou seja, requisitos que se sabe previamente que podem mudar durante o ciclo de vida do software, o que também justificaria sua implementação como um aspecto (Moreira e Araújo, 2004).

Por outro lado, dentre os motivos para implementar os casos de uso transversais funcionais com orientação a objetos está o fato de que esses casos de uso podem ter características de negócio específicas para uma aplicação, não possuir possibilidades de generalização e reúso e a implementação como aspecto ser mais complexa do que simplesmente criar módulos internos aos componentes e implementar o comportamento 
apenas com chamadas a operações. Além disso, separar funcionalidades fortemente acopladas em componentes distintos aumenta a necessidade de comunicação entre os componentes, e, conseqüentemente, a complexidade da composição. É necessário que se avalie as vantagens e desvantagens em implementar um determinado caso de uso como aspecto ou não, se realmente é mais fácil e se auxilia no melhor entendimento do sistema, na manutenção e na evolução.

\subsubsection{2 - Selecionar Aspectos para a Iteração Atual}

Esta atividade consiste em selecionar os aspectos da Tabela de Aspectos, criada na atividade anterior, que devem ser implementados na iteração atual. A decisão de implementar ou não um determinado aspecto na iteração atual depende de vários fatores, entre eles está a natureza do aspecto, que pode impossibilitar seu acoplamento em um momento posterior, o tempo inicial que foi planejado para a iteração atual e também a necessidade do aspecto na iteração atual. Em relação a esse último tópico, o aspecto pode implementar alguma funcionalidade necessária na iteração atual, então ele deve ser implementado rapidamente. Geralmente isso ocorre com aspectos funcionais que precisam ter sua funcionalidade validada.

A decisão por não implementar um aspecto na iteração atual deve ser feita com cautela, pois há determinados interesses que não são totalmente ortogonais à funcionalidade do sistema e seu acoplamento pode ser dificultado se for protelado para o final (Colyer et al., 2004). Entretanto, há interesses, e conseqüentemente FTs, que podem ser acoplados depois que a parte base do sistema estiver pronta, por exemplo, Registro de Acesso e Rastreamento de Operações.

Tomando ciência desses fatores que podem influenciar a tomada de decisão nesta atividade, a pessoa responsável pelo desenvolvimento tem várias alternativas, por exemplo, acoplar os aspectos no momento em que são identificados, ou deixar para o final todos os aspectos cuja natureza seja completamente ortogonal, ou ainda pode ser realizado um misto das alternativas anteriores, acoplando alguns aspectos durante o desenvolvimento e deixando alguns para o final.

Os aspectos que serão implementados na iteração atual devem ser listados na Tabela de Acompanhamento da Implementação de Aspectos, cujo modelo pode ser visto na Tabela 6.13. Essa tabela deve ser continuamente atualizada à medida que o desenvolvimento progride, registrando os aspectos que foram implementados em iterações anteriores. Depois que esta tabela foi elaborada e o aspecto foi implementado, deve-se atualizar as tabelas Tabela de Aspectos e a Tabela de Candidatos a Aspectos para que a coluna "implementado" de ambas as tabelas seja marcada com um "X". 
Um ponto que merece destaque aqui é quanto ao momento correto de se efetuar o projeto e o acoplamento dos aspectos com a parte base do sistema. Isso depende do tipo do aspecto; se o aspecto selecionado para esta iteração for completamente ortogonal à funcionalidade da parte base, ele pode ser projetado e acoplado apenas no final da iteração ou mesmo no final de todo o processo. Já aspectos que disponibilizam operações e métodos para as classes da parte base utilizarem, devem ser acoplados antes que os diagramas de interação sejam elaborados. Isso ocorre porque durante a elaboração desses diagramas os métodos e operações introduzidos pelos aspectos devem ser considerados. Um exemplo clássico desse tipo de aspecto é a persistência.

Tabela 6.13 - Modelo de Tabela de Acompanhamento da Implementação dos Aspectos

\begin{tabular}{|l|l|}
\hline \multicolumn{1}{|c|}{ No. Iteração } & \multicolumn{1}{|c|}{ Aspecto } \\
\hline $1^{\mathrm{a}}$. da Elaboração & Aspecto1 \\
\hline $2^{\mathrm{a}}$. da Elaboração & $\begin{array}{l}\text { Aspecto2 } \\
\text { Aspecto3 }\end{array}$ \\
\hline $1^{\mathrm{a}}$. Da Construção & $\begin{array}{l}\text { Aspecto4 } \\
\text { Aspecto5 } \\
\text { Aspecto6 }\end{array}$ \\
\hline
\end{tabular}

\subsubsection{3 - Projetar Aspectos}

Esta atividade tem como objetivo desenvolver modelos de projeto para os aspectos alocados para a iteração atual. Se esses aspectos possuírem FTs que podem ser utilizados para sua implementação, não há necessidade de desenvolver modelos de projeto para eles, pois os FTs já possuem esses modelos prontos. Caso contrário há três opções possíveis. A primeira é projetar o novo aspecto de forma tradicional, sem a preocupação de tornar seu código genérico. Essa opção faz com que o novo aspecto se torne parte integrante da arquitetura da aplicação, dificultando seu reúso durante o desenvolvimento de novas aplicações.

A segunda e a terceira opções possuem como objetivo projetar o aspecto de forma genérica para que possa ser reusado posteriormente. Isso pode resultar em uma nova família de FTs ou em uma nova característica de uma das famílias já existentes. Geralmente o aspecto é adicionado em uma família já existente se ele é uma característica de algum interesse que já está implementado como um FT, caso contrário inicia-se uma nova família.

Quando os aspectos devem ser projetados de forma genérica, como é o caso para a segunda e a terceira opções, o projeto deve ser feito utilizando os gabaritos da abordagem Tema (Clarke e Baniassad, 2005), que permite projetar o interesse transversal sem saber os pontos de junção do código-base que serão afetados.

A segunda opção consiste em projetar somente a parte de composição do aspecto de forma abstrata, com conjuntos de junção abstratos, por exemplo. Não há preocupação inicial 
em generalizar o comportamento ou incluir variabilidades e alternativas de composição (padrão Capturador de Dados). Assim, o aspecto é projetado rapidamente, facilitando também sua posterior implementação. A inclusão de variabilidades e alternativas de composição se dá conforme esse aspecto vai sendo reusado em outros contextos. Essa opção é factível quando os prazos estão apertados e não há uma equipe especializada no desenvolvimento de FTs.

A terceira opção consiste em já projetar o aspecto como um FT, generalizando não apenas a parte de composição, mas também o comportamento, o que muitas vezes exige o uso de reflexividade. Também já devem ser incluídas, na medida do possível, variabilidades e alternativas de composição (no caso de interesses dependentes de contexto). Para a identificação de variabilidades deve ser realizada análise de domínio, o que também pode auxiliar a identificar se o interesse é dependente de contexto, o que exigiria a utilização do padrão Capturador de Dados. Durante a análise de domínio também pode surgir a possibilidade de implementar alguma variabilidade/característica como um FT.

Assim como na segunda opção, e como qualquer processo de evolução de frameworks, a identificação de todas variabilidades de um domínio é difícil inicialmente. Novas variabilidades, características e alternativas de composição podem surgir quando o FT for reusado em algum contexto novo.

Um dos fatores que pode colaborar com a adoção da terceira opção é a experiência da equipe de desenvolvimento no domínio do interesse. Nesse caso, não seria gasto muito tempo com análise de domínio para a identificação de algumas variabilidades. Outro fator que pode direcionar a escolha dessa opção é a existência de outras aplicações em desenvolvimento que também farão uso do FT.

Tanto na segunda quanto na terceira opção, a arquitetura para FTs apresentada no Capítulo 3 pode ser utilizada. Em particular, na segunda alternativa, mesmo que não haja mais de uma variabilidade e de uma alternativa de composição aconselha-se a utilização da arquitetura proposta, pois isso pode facilitar a evolução do FT quando novas variabilidades e alternativas tiverem que ser adicionadas.

\subsubsection{4 - Acoplar Aspectos com a Base}

Esta atividade tem como objetivo projetar o acoplamento dos aspectos com a parte base do sistema, o que pode ser feito com os gabaritos da abordagem Tema (Clarke e Baniassad, 2005). Consiste em desenvolver um modelo de projeto que una o modelo da parte base que foi desenvolvida até este momento, com o modelo de projeto do aspecto desenvolvido na atividade anterior. Esse modelo de projeto é chamado de "modelo de projeto combinado" ou "visão de composição". 
No caso da existência de um FT, a integração dos modelos consiste basicamente em determinar os pontos da aplicação em que os aspectos irão atuar e as classes que devem ser criadas durante a utilização do framework. Em outras palavras, o processo de integração dos modelos consiste no processo de reúso de um FT, o qual possui as etapas de instanciação e de composição. Essa tarefa de combinar os modelos de projeto auxilia na identificação das classes que devem ser criadas durante a implementação, quando o FT deve ser efetivamente instanciado e acoplado com a aplicação.

Neste momento, algumas particularidades do FT podem influenciar a ordem da composição. Por exemplo, o FT de persistência possui duas partes bem distintas que podem ser acopladas em tempos diferentes a um código-base. A primeira é a persistência em si, que consiste em um conjunto de operações de armazenameto/consulta/remoção que são introduzidas nas classes da camada de domínio e que são utilizadas pelas classes da camada de interface e classes controladoras. Essa parte deve ser acoplada antes que os diagramas de interação sejam construídos. A segunda é a parte que trata da conexão com o banco de dados, que exige a definição de pontos do código-base onde a conexão deve ser aberta e fechada. Geralmente as conexão são estabelecidas e encerradas quando eventos de sistema são disparados, que geralmente ocorrem nas classes de interface e controladoras.

A primeira parte do FT de persistência deve ser acoplada às classes de domínio antes do projeto e da implementação das operações de sistema porque a implementação dessas operações geralmente exige que as operações fornecidas pelo framework estejam disponíveis. Entretanto o acoplamento da segunda parte talvez não possa ser feito nos "pontos reais" (pontos de junção do código-base em que o acoplamento será definitivo, isto é, depois que o sistema for colocado em produção serão os pontos em que o framework irá atuar) do códigobase ao mesmo tempo em que a primeira. Isso ocorre porque a funcionalidade de conexão com o banco de dados geralmente é acoplada em classes de interface que talvez ainda não tenham sido projetadas. O problema é que para testar as operações de sistema é necessário que a conexão esteja funcionando, caso contrário não haverá acesso ao banco de dados. Dessa forma, depois que as classes controladoras e suas operações de sistema forem projetadas, a parte de conexão do FT de persistência deve ser acoplada, mesmo se o acoplamento tiver que ser feito em pontos fictícios, como por exemplo nas operações de sistema das classes controladoras ou em programas criados especificamente para isso. Por outro lado, se as classes reais em que a conexão deve ser aberta e fechada já estiverem implementadas não há a necessidade de simulação. Isso evidencia uma particularidade importante da programação orientada aspectos, que é a capacidade de se acoplar e desacoplar facilmente de variados 
pontos do código-base. Fazer o mesmo com uma implementação orientada a objetos exigiria modificações invasivas nesses pontos fictícios. Note-se que mesmo utilizando uma técnica de simulação da conexão, a infra-estrutura real de desenvolvimento está presente na arquitetura do sistema.

Outro ponto importante é que os requisitos da aplicação que está sendo desenvolvida podem exigir determinadas particularidades no FT. Assim, como foi mostrado no Capítulo 4, o acoplamento de características no FT pode ser feito antes ou depois da composição com a aplicação.

Na Figura 6.9 é mostrado como deve ser feito o projeto da etapa de composição entre dois modelos. O pacote OperationLog representa um tema transversal que irá afetar a aplicação nos pontos de junção fornecidos no relacionamento de ligação entre os pacotes. Assim, os métodos gerarFatura() da classe SistemaFaturamento, o método doGet () da classe srvocuparReserva e o método dopost() da classe srvConsultarNumeroReservas serão afetados pelo comportamento de registro de operações como é mostrado no diagrama de seqüência. Quando algum desses métodos for executado, o método writefileBefore() será invocado para armazenar em algum dispositivos persistente informações sobre o contexto de execução do método. Em seguida, o comportamento original do método é chamado, como representa o método do_operationToBeLogged(), e em seguida o método writeFileAfter() também é executado.

\subsubsection{5 - Desenvolver Diagramas de Interação}

O objetivo desta atividade é a identificação de operações, métodos e classes de software. Para isso, devem ser elaborados diagramas de interação - de seqüência ou colaboração - para os eventos importantes do sistema que estão sendo tratados nesta iteração. Também deve-se cuidar para que diagramas de interação desenvolvidos em iterações anteriores sejam atualizados se for necessário.

Quando o FT de persistência já foi acoplado neste ponto do processo, um ponto importante desta atividade é considerar, durante a elaboração dos diagramas, que alguns métodos de persistência já existem e não precisam ser identificados, como por exemplo findlike(), setDBToobject() e save(). Portanto, o engenheiro de software pode se concentrar na identificação e refinamento de operações de nível mais alto de abstração.

Apesar deste processo possuir atividades específicas para a identificação de aspectos, nada impede que candidatos a aspectos sejam descobertos no decorrer das atividades convencionais do processo, como criação de diagramas de interação, diagramas de classes e 
elaboração de contratos. Isso pode acontecer porque nas atividades que são específicas para a identificação de aspectos aplicam-se os critérios para os caso de uso, que tem um nível de abstração alto comparado com os artefatos gerados durante o projeto. Assim, funcionalidades menores que são parte do comportamento de um caso de uso, e que são adequadas para serem implementadas como aspectos, podem passar despercebidas durante o processo de identificação em conseqüência do nível de abstração com que os critérios são utilizados. Isso pode ocorrer com requisitos voláteis, variabilidades e características que, muitas vezes, são funcionalidades menores que fazem parte do comportamento de um caso de uso, e que só são percebidos quando o nível de detalhes aumenta.

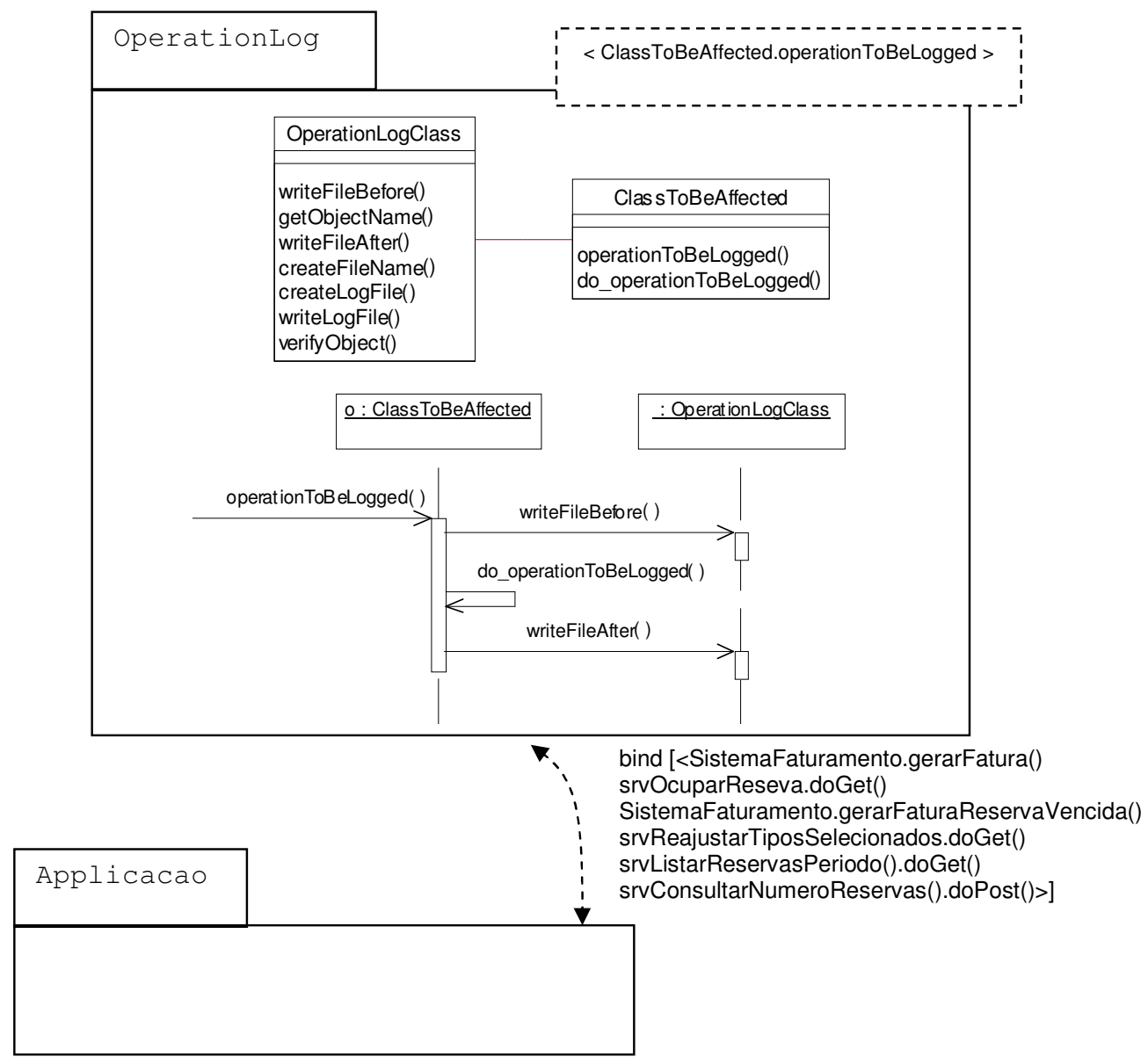

Figura 6.9 - Exemplo de Modelo de Projeto Combinado

Note-se que o aparecimento de candidatos a aspectos durante o decorrer do processo não significa que as atividades específicas falham. O que ocorre é que essas atividades são mais direcionadas à identificação de interesses transversais que atuam diretamente na aplicação e não de requisitos voláteis ou outras funcionalidades menores que atuam como parte de outras funcionalidades. 
Embora a atividade Identificar Aspectos utilize um critério específico para a identificação de requisitos voláteis, que é o critério "volatilidade", ele é aplicado para casos de uso, visando a identificar se o caso de uso é volátil. Portanto, as funcionalidades candidatas a aspectos com maior possibilidade de emergir durante o decorrer do processo são os requisitos voláteis e não interesses transversais.

\subsubsection{6 - Desenvolver Modelo de Classes de Projeto}

Esta atividade tem como objetivo elaborar o modelo de classes de projeto para os casos de uso selecionados para esta iteração. Esta atividade possui uma sinergia muito grande com a atividade de elaboração dos diagramas de interação, pois elas se complementam na construção dos modelos.

A elaboração do modelo de classes de projeto deve ser feita com cuidado quando a decisão foi utilizar o FT de persistência. Isso ocorre porque seu uso impõe certas restrições à arquitetura do sistema e se essas restrições não forem consideradas no modelo de classes de projeto, o acoplamento do FT de persistência, seja neste ponto do processo ou no final, pode exigir mudanças de projeto significativas. Um exemplo de uma restrição arquitetural imposta pelo framework é que, quando há associações 1 para n, o atributo que representa a associação deve estar em uma das classes, e não nas duas. Outro exemplo é no caso de classes de associação, em que o nome deve obrigatoriamente ser formado pela junção dos nomes das duas classes relacionadas.

Com a criação dos diagramas de colaboração e a descoberta de métodos e outras restrições de projeto, o modelo conceitual começa a ser transformado no modelo de classes de projeto, em que as classes agora representam tipos de uma linguagem de programação.

\subsubsection{7 - Projetar Modelo de Dados}

O objetivo nesta atividade é desenvolver o modelo de banco de dados para o sistema. Se o FT de persistência estiver sendo utilizado, o desenvolvimento do modelo deve ser feito sinergicamente com a atividade anterior, pois há um mapeamento que deve ser seguido entre o modelo de classes de projeto e o modelo do banco de dados. Os detalhes desse mapeamento são encontrados na documentação do FT de persistência.

\subsubsection{8 - Atualizar Regras de Composição}

Esta atividade tem como objetivo atualizar as regras de composição do modelo de projeto combinado. Essas atualizações são necessárias quando o conjunto de casos de uso alocado para a iteração atual deu origem a novos elementos (classes/métodos/atributos) que também precisam ser afetados pelos aspectos que já estão presentes no sistema. Por exemplo, suponha 
que o FT de persistência já esteja acoplado ao sistema e que suas regras de composição explicitam cinco classes de domínio afetadas. Se novas classes de domínio são incluídas no sistema e precisam de operações de persistência, as regras de composição do FT precisam ser atualizadas para também considerar essas novas classes.

\subsubsection{9 - Desenvolver Modelo de Projeto Composto}

Esta atividade tem como objetivo gerar o modelo de projeto composto para os casos de uso considerados nesta iteração. Mesmo quando não houve a identificação de novos aspectos na iteração atual, o modelo de projeto composto talvez tenha que ser gerado novamente. Isso ocorre sempre que as novas entidades (classes/métodos/atributos) adicionadas na parte base do sistema precisam ser afetadas pelos aspectos que já estão acoplados. Em outras palavras, se a atividade Atualizar Regras de Composição foi realizada, é porque foram acrescentadas certas entidades na parte base do sistema que precisaram ser afetadas pelos aspectos que já estavam acoplados.

O modelo de projeto combinado representa a união entre o modelo de projeto do aspecto e o modelo de projeto de uma determinada parte do sistema que está sendo desenvolvido. O modelo de projeto do aspecto, que no caso é um FT, não será modificado com o decorrer das iterações, mas o mesmo não ocorre com o modelo de projeto da parte base. Isso exige que as regras de acoplamento sejam constantemente atualizadas. Assim, esta atividade também tem como objetivo atualizar as regras de acoplamento no decorrer das iterações.

\subsubsection{0 - Desenvolver Visão da Arquitetura}

O objetivo desta atividade é elaborar um modelo em alto nível de abstração que mostra a arquitetura do sistema. O objetivo é conseguir identificar facilmente os aspectos e FTs que estão acoplados à porção do sistema projetada até este momento. Esse modelo deve ser constantemente atualizado à medida que novos aspectos/FTs são adicionados ao sistema durante o decorrer das iterações.

O modelo é denominado Visão da Arquitetura e a notação sugerida é a proposta por Krechetov et al. (2006). O nível de detalhes exibidos no diagrama fica a cargo do desenvolvedor. Na Figura 6.10 é mostrada a Visão da Arquitetura para um sistema hipotético em um alto nível de abstração. Há três FTs acoplados à aplicação e um aspecto normal chamado Empresa, que está sendo representado pela nota. Assim, pode-se facilmente obter uma visão ampla da arquitetura do sistema visualizando os módulos (componentes-base e aspectuais) que o compõem. Note-se que, neste nível de abstração, não é possível identificar se o relacionamento que os componentes aspectuais mantém com os outros componentes é 
estático ou dinâmico. Entretanto, a notação permite que detalhes adicionais sejam fornecidos (Krechetov, et al., 2006). Como essa abordagem de modelagem é baseada na UML, uma vantagem é que apoio automatizado é facilmente obtido.

A próxima atividade complementa este modelo, pois mantém um registro dos pontos de junção da aplicação que são afetados por cada um dos FTs mostrados neste modelo. Uma alternativa seria manter esse registro de pontos de junção no modelo, entretanto como isso poderia comprometer a sua legibilidade optou-se por manter o registro em uma tabela, que é mostrado na atividade seguinte.

\subsubsection{1 - Registrar Pontos de Junção}

Quando aspectos são utilizados durante o desenvolvimento de um sistema, pode ocorrer que o mesmo ponto de junção seja afetado por mais de um aspecto, o que pode gerar inconsistências e conflitos se um dos aspectos altera dados que o outro utiliza. Nesse sentido, o objetivo nesta atividade é averiguar a necessidade de criação de algum esquema de precedência de atuação entre os aspectos.

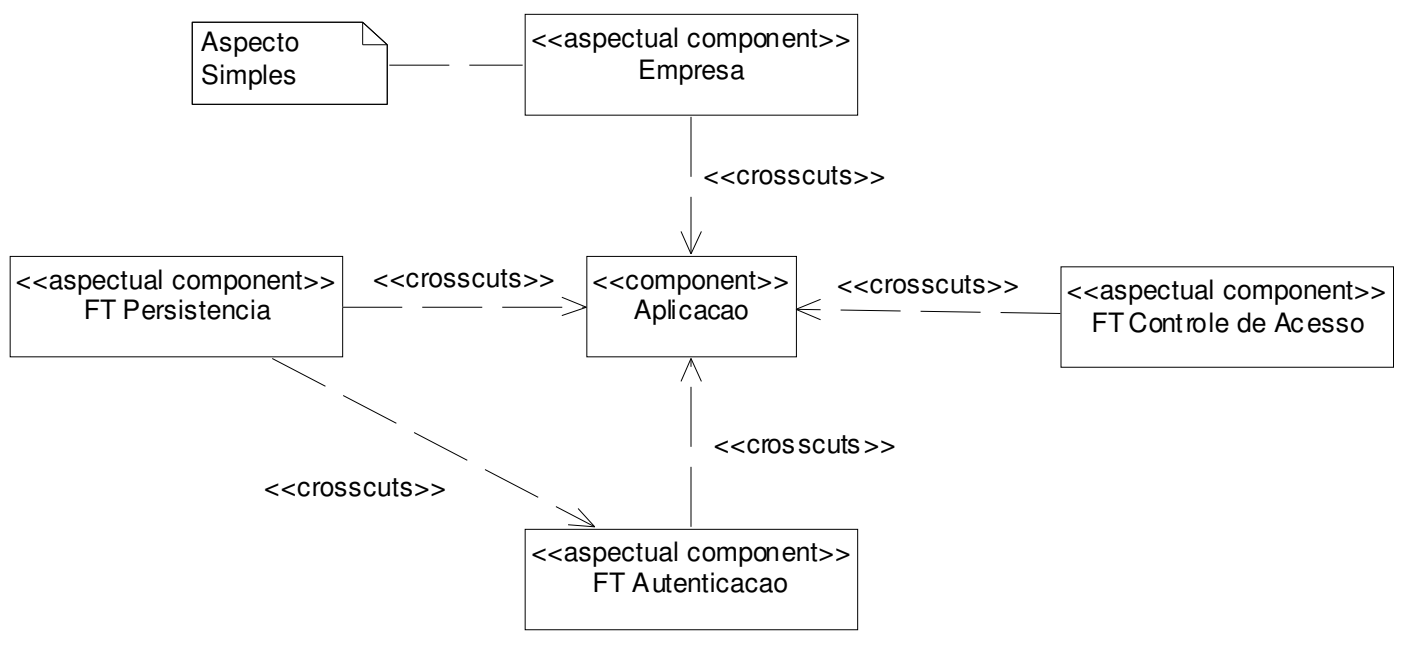

Figura 6.10 - Visão da Arquitetura

Para isso, aconselha-se manter um registro dos pontos de junção afetados e dos aspectos que afetam esses pontos de junção. Esse registro auxilia a identificar pontos de junção que são afetados por aspectos diferentes e, nesse caso, deve-se averiguar se é necessário elaborar um esquema de precedência de atuação entre eles, o que pode ser feito com as declarações declare precedence da linguagem AspectJ, por exemplo.

Dessa forma, uma atividade que deve ser conduzida é o Registro de Pontos de Junção. Esse registro consiste em uma tabela em que são relatados os pontos de junção do sistema afetados por FTs e outros aspectos. Como aspectos e FTs também possuem pontos de junção, eles devem ser considerados durante a elaboração da tabela. 
A Tabela 6.14 é o modelo que deve ser utilizado para a elaboração do Registro dos Pontos de Junção. Na primeira coluna devem ser colocados os FTs ou aspectos, e na segunda, terceira e quarta colunas devem ser discriminados os pontos de junção afetados por cada um. Podem ser utilizados caracteres coringa para representação dos pontos de junção, como por exemplo, asterisco (*) e dois pontos horizontais (..). Dessa forma, aspectos homogêneos que afetam um número grande de pontos de junção podem ser representados de forma mais legível, como o FT1. Esse FT afeta o método someMethod () de qualquer classe presente no sistema, como está representado pelo asterisco na coluna "Classe". A Tabela também deve ser utilizada para registrar pontos de junção de aspectos ou FTs afetados por outros aspectos ou FTs. Por exemplo, o Aspecto2 afeta o advice1 e o método methodD () do aspecto Aspecto3.

Tabela 6.14 - Modelo para o Registro de Pontos de Junção

\begin{tabular}{|c|c|c|c|}
\hline \multirow{3}{*}{$\begin{array}{c}\text { FT/Aspecto } \\
\downarrow\end{array}$} & \multicolumn{3}{|c|}{ Pontos de Junção Afetados } \\
\hline & \multirow{2}{*}{ Método/atributo/construtor/adendo } & \multicolumn{2}{|c|}{ Unidades de Software } \\
\hline & & Classe & Aspecto \\
\hline FT1 & someMethod () & $\star$ & \\
\hline \multirow{3}{*}{ FT2 } & methodA () & Class1 & \\
\hline & methodB () & Class1 & \\
\hline & methodC () & Class1 & \\
\hline FT3 & new () & Class 2 & \\
\hline \multirow[t]{3}{*}{ Aspecto1 } & init*() & Class 3 & \\
\hline & methodA () & Class1 & \\
\hline & methodB () & Class1 & \\
\hline \multirow[t]{2}{*}{ Aspecto2 } & Advice1 & & Aspecto3 \\
\hline & methodD ( ) & & Aspecto3 \\
\hline Aspecto3 & methodE () & Class 4 & \\
\hline
\end{tabular}

A elaboração desta tabela facilita a identificação de pontos de junção que são compartilhados por dois ou mais aspectos, por exemplo: o FT2 afeta os métodos methodA () e methodB () da classe Class1, que também são afetados pelo Aspecto1. Quando esse tipo de situação é encontrado, aconselha-se destacar os FTs e os pontos de junção compartilhados. Dessa forma, o FT2 e o Aspecto1 deverão ser analisados para de averiguar se há necessidade de criar um esquema de precedência entre eles.

Embora a elaboração desta tabela seja feita na disciplina de projeto, é natural que ela seja atualizada durante a implementação, pois é só durante essa disciplina que os pontos de junção projetados aqui são realmente utilizados, podendo haver modificações significativas. Sempre que as regras de composição dos FTs que já estão acoplados ao sistema são atualizadas, o Registro de Pontos de Junção também deve ser atualizado e uma análise deve novamente ser feita com o objetivo de verificar a existência de pontos de junção afetados por dois ou mais FTs e/ou aspectos.

O FT de persistência e o de controle de acesso são exceções aos problemas que podem ocorrer com o compartilhamento de pontos de junção. O FT de persistência já possui 
implementado internamente um mecanismo de precedência sobre qualquer outro aspecto do sistema. Isso é necessário para que a conexão seja estabelecida antes que qualquer operação possa ser executada. Da mesma forma, o FT de controle de acesso também já possui implementado internamente um mecanismo que fornece prioridade de atuação ao FT de autenticação. Não há como verificar se um usuário pode executar determinadas operações se ele não estiver autenticado no sistema.

Além do problema de que dois ou mais aspectos podem afetar o mesmo ponto de junção, outra situação que pode ocorrer é a interação inesperada entre aspectos (aspect interactions). Ocorre quando o comportamento de um aspecto é afetado pelo comportamento de outro aspecto. O tratamento para este problema está fora do escopo desta tese, mas pode ser tratado pela abordagem desenvolvida por Douence et al. (2002) (Douence et al., 2002 apud (Blair et al., 2005) $)^{23}$.

\subsection{3 - Disciplina Implementação}

Nesta disciplina o objetivo é traduzir os modelos de projeto em código-fonte. É comum que certos detalhes de projeto sejam identificados durante a realização desta disciplina, exigindo atualizações nos modelos já obtidos.

As atividades desta disciplina podem ser vistas na Figura 6.11 no formato SADT (Ross, 1977). As atividades que não são particulares do ProFT/PU são Implementar Classes de Domínio, Implementar Banco de Dados, Implementar Classes Controladoras e Testar Sistema, já que são encontradas em qualquer processo de desenvolvimento. Entretanto, elas também possuem algumas diferenças por conta da presença de aspectos durante 0 desenvolvimento. A atividade Atualizar Regras de Composição só deve ser realizada se a porção do sistema recém-implementada na iteração atual também precisa ser afetada pelos aspectos já presentes no sistema. A atividade Implementar Aspectos só deve ser realizada se a Tabela de Acompanhamento da Implementação de Aspectos contém aspectos que devem ser implementados na iteração corrente. A posição dessas atividades pode variar ligeiramente dentro desta disciplina, por exemplo, a atividade Implementar Aspectos pode também ser realizada depois que as interfaces e classes controladoras foram desenvolvidas. Nas próximas seções cada uma das atividades é descrita com mais detalhes.

\subsubsection{1 - Implementar Classes de Domínio}

\footnotetext{
${ }^{23}$ Douence, R., Fradet, P., Südholt, M. A framework for the detection and resolution of aspect interactions. In: $1^{\text {st }}$ ACM Conference on Generative Programming and Component Engineering (GPCE), LNCS, vol 2487. Springer-Verlag, Berlim, 173-188, 2002.
} 
O objetivo nesta atividade é implementar as classes de domínio, seus atributos, métodos de acesso (set's e get's) e relacionamentos com outras classes para os casos de uso selecionados para esta iteração. As classes que pertencem a aspectos funcionais também devem ser implementadas nesta atividade, já que fazem parte da funcionalidade do sistema. Contudo, como não é conveniente que a parte base dependa da parte transversal, se houver algum relacionamento nessa direção, sua implementação deve ser feita de forma a não criar dependência da classe base com a classe que pertence ao interesse transversal. Assim, sugerese que, nesta situação, a classe que pertence ao interesse transversal seja desenvolvida normalmente, porém o atributo que representa o relacionamento deve ser introduzido na classe base por meio de declarações intertipo da linguagem AspectJ, por exemplo.

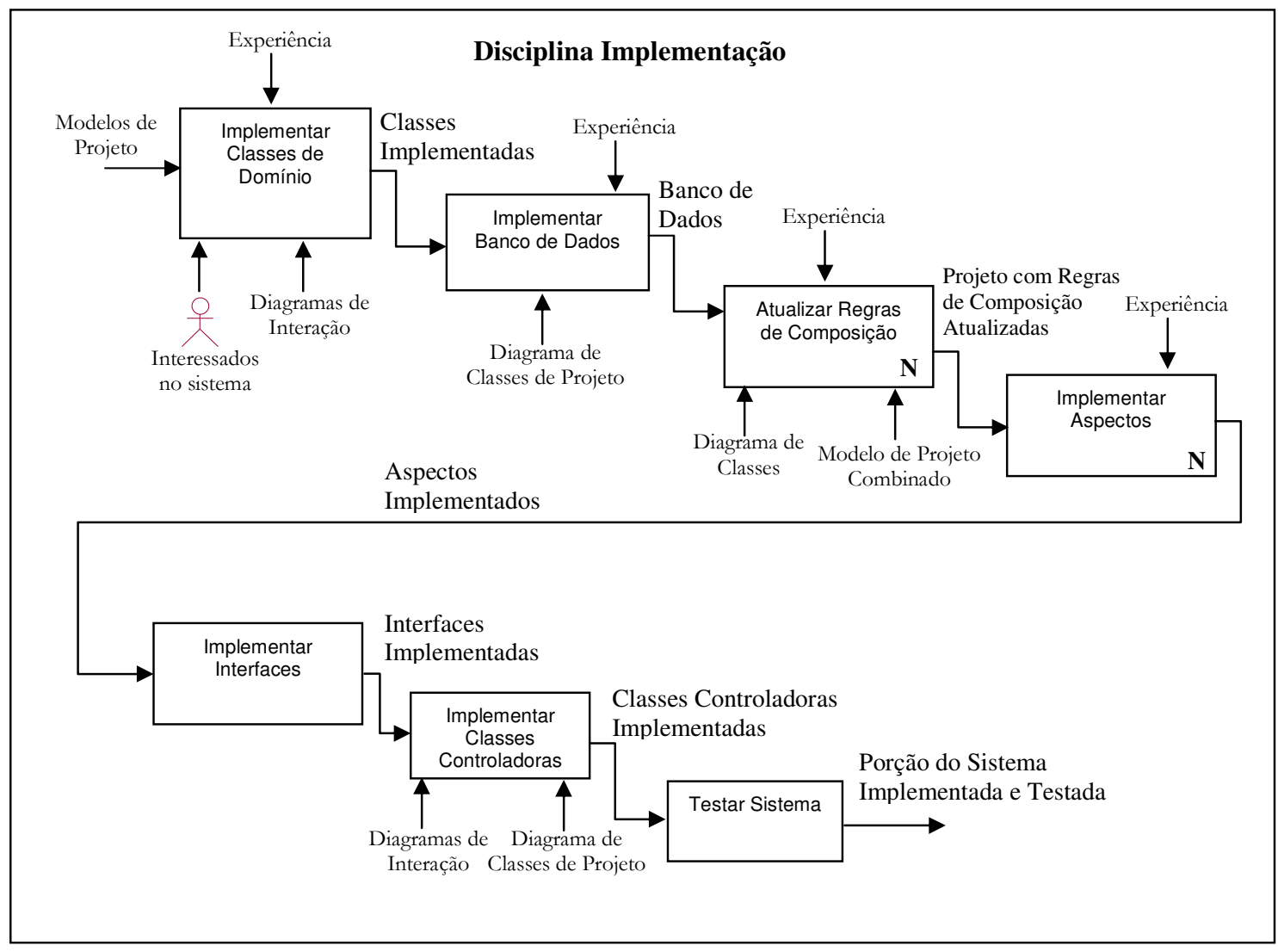

Figura 6.11 - Atividades da Disciplina de Implementação

\subsubsection{2 - Implementar o Banco de Dados}

Esta atividade tem como objetivo implementar o banco de dados. Isso deve ser feito de forma convencional traduzindo o modelo de dados em tabelas de banco de dados. Caso o FT de persistência esteja sendo utilizado, deve-se cuidar para que as convenções exigidas sejam seguidas como é descrito na documentação desse FT.

\subsubsection{3 - Atualizar Regras de Composição}


Nesta atividade o objetivo é atualizar as regras de composição dos aspectos que já estão acoplados à porção desenvolvida do sistema. Essas atualizações são necessárias quando os novos elementos (classes/métodos/atributos) introduzidos no sistema na iteração atual precisam ser afetados pelos aspectos que já estavam acoplados ao sistema. Uma maneira de descobrir se as regras de composição devem ser atualizadas é verificar se houve atualizações na atividade Atualizar Regras de Composição da disciplina Projeto. Em caso positivo, as atualizações também devem refletidas nesta atividade.

A posição desta atividade nesta disciplina pode variar, dependendo do aspecto ou do FT que estiver acoplado ao sistema. No caso do FT de persistência, este é o momento correto de fazer atualizações referentes à parte de persistência propriamente dita, isto é, a parte do FT responsável pela introdução das operações de persistência. Isso ocorre porque durante a atividade Desenvolver Classes Controladoras a maior parte das operações de sistema e métodos de granularidade mais fina é desenvolvida, que geralmente precisa das operações de persistência. Em relação à parte de conexão com o banco de dados, o momento adequado para se fazer atualizações é após o desenvolvimento das classes controladoras e interfaces do sistema. Isso ocorre porque as atualizações irão necessitar do nome das classes e dos métodos dessas classes.

\subsubsection{4 - Implementar Aspectos}

Esta atividade tem como objetivo implementar os aspectos selecionados para esta iteração. A posição desta atividade na disciplina de implementação pode variar dependendo do FT que está sendo implementado. Por exemplo, se a implementação de várias operações de negócio necessitam das operações de baixo nível introduzidas pelo FT de persistência, seu acoplamento deve ser feito antes que essas operações de negócio sejam implementadas. É por isso que esta atividade encontra-se antes da atividade Desenvolver Classes Controladoras, pois é nessa atividade que a maior parte das operações e métodos de negócio é implementada. Para aspectos completamente ortogonais à funcionalidade do sistema (Colyer et al., 2004), como, por exemplo, registro de operações, a posição desta atividade no processo não é importante porque a parte base não possui dependência com esse tipo de aspecto.

Pode ocorrer que esta atividade tenha que ser repetida em vários pontos ao longo da disciplina de implementação, uma para cada FT, ou até mesmo uma para cada parte de um FT. Isso acontece porque, em alguns casos, as regras de composição para determinados FTs só podem ser implementadas depois que alguma parte do sistema seja desenvolvida. Por exemplo, se o FT de persistência estiver sendo utilizado, pode ser necessário seu acoplamento logo na primeira iteração para que as operações de persistência, disponibilizadas por esse FT, 
estejam disponíveis para a implementação de algumas classes da aplicação. Entretanto, pode ser que a conexão com o banco de dados, que também faz parte do FT de persistência, só possa ser acoplada ao sistema depois que as classes de interface forem implementadas, exibindo que essa atividade seja novamente repetida nas próximas iterações ou mesmo posteriormente, dentro da mesma iteração.

No caso do cenário descrito no parágrafo anterior, uma alternativa que pode ser tomada é realizar o acoplamento da conexão em pontos de junção fictícios apenas para a realização de testes, e posteriormente, assim que as classes reais estivessem implementadas as regras de composição seriam atualizadas.

\subsubsection{5 - Implementar Classes Controladoras}

Este passo tem como objetivo implementar as classes controladoras e suas operações. $\mathrm{O}$ modelo de classes de projeto é a base para a implementação das classes controladoras e os diagramas de colaboração e os casos de uso são a base para a implementação das operações e métodos de granularidade mais fina.

Uma decisão importante que pode ocorrer neste ponto do processo é decidir se o framework pode ser usado como está, ou se necessita de adaptações. No caso do FT de Persistência, três tipos possíveis de adaptação foram mostrados na Seção 4.3.

\subsubsection{6 - Implementar Interfaces}

Esta atividade tem como objetivo implementar as classes de interface para o sistema que está sendo desenvolvido. No caso do sistema de reservas, deve-se desenvolver uma interface para a realização de uma reserva e interfaces para os casos de uso gerenciadores de dados. Como o sistema de reservas está sendo desenvolvido com plataforma Web, optou-se por implementar as interfaces com servlets, como pôde ser visto nos diagramas de colaboração elaborados na disciplina de projeto.

\subsubsection{7 - Testar Sistema}

Esta atividade deve ser conduzida com o objetivo de testar a porção do sistema desenvolvida na iteração atual. Como o sistema provavelmente utiliza POA é necessário utilizar alguma estratégia de teste específica para esse paradigma. Sugere-se a utilização de algumas técnicas de teste já apresentadas na literatura (Lemos et al, 2003a; Lemos et al., 2003b; Zhao, 2003; Zhao, 2002; Zhou et al., 2004). Entretanto, como os FTs já se encontram testados, o enfoque deve ser na porção do sistema que foi desenvolvida.

A realização de testes funcionais deve ser feita com o objetivo de averiguar se a funcionalidade esperada para a iteração corresponde com o esperado. Testes de integração 
também devem ser conduzidos sempre que um novo aspecto ou FT for acoplado ao sistema. A Visão de Arquitetura é um artefato que pode ser utilizado para averiguar a necessidade de testes de integração, já que ele mostra os FTs e aspectos acoplados ao sistema. Quando o FT de persistência é utilizado, o FT de Garantia de Políticas pode ser empregado para averiguar se o processo de reúso foi feito corretamente.

Sempre que regras de composição forem atualizadas tem-se um indício de que testes devem ser novamente conduzidos. Isso ocorre porque as atualizações mostram que determinados FTs/Aspectos começaram a afetar novos elementos. A Visão de Arquitetura e o Registro de Pontos de Junção podem ser utilizados para analisar qual FT/aspecto deve ser novamente testado.

\subsection{4- Planejar Iterações}

Esta atividade tem como objetivo avaliar o andamento do processo e realizar ajustes nas iterações seguintes, caso ele tenha se desviado do plano inicial. Esses ajustes geralmente consistem em realocações de casos de uso para outras iterações, ou mesmo a decisão por implementar parte de um caso de uso, ao invés dele todo.

\section{5 - FASE DE CONSTRUÇÃo}

Esta fase tem como objetivo finalizar o desenvolvimento do sistema concentrando-se nos casos de uso restantes, os quais possuem um impacto menor na arquitetura do sistema e não são tão importantes do ponto de vista da funcionalidade principal. A estrutura de disciplinas e atividades dentro desta fase é a mesma da fase de elaboração, contudo, a ênfase é bem maior no projeto e implementação.

Dependendo da estratégia de desenvolvimento que foi adotada, no final das iterações planejadas para a fase de construção pode ser necessário que vários aspectos ainda tenham que ser projetados e implementados. Para identificar os aspectos que ainda não foram implementados deve-se analisar a coluna "Implementado?" da Tabela de Aspectos. Se esse for o caso, deve-se realizar novamente um replanejamento com o objetivo de classificar esses aspectos e planejar como serão desenvolvidos.

Em relação à classificação, sugere-se que os aspectos funcionais sejam implementados primeiro e depois os não-funcionais. A razão disso é que geralmente os casos de uso nãofuncionais afetam a parte base do sistema, e é interessante que ela esteja pronta antes que eles sejam implementados. A existência de FTs para apoiar a implementação dos casos de uso não deve ser um critério de classificação. A prioridade de implementação deve ser ditada por dependências intrínsecas existentes entre os interesses, por exemplo, a implementação do 
interesse de controle de acesso só pode ser feita depois que o interesse de autenticação já esteja implementado, caso contrário não será possível identificar qual usuário possui acesso a uma determinada parte do sistema.

Em relação ao planejamento, uma estratégia que pode ser adotada é tratar apenas um FT em cada iteração, assim como foi feito por Soares (2004), a não ser que haja aspectos intrinsecamente relacionados ou que haja prioridade de implementação entre eles. Tratar cada aspecto em uma iteração distinta facilita o descobrimento de problemas com o acoplamento, visto que eles podem ser acoplados e testados individualmente. Pela terminologia definida neste processo, as iterações que tratam apenas de aspectos são denominadas "iterações aspectuais". As disciplinas que possuem mais ênfase dentro das iterações aspectuais são projeto, implementação e testes. As atividades que ocorrem nas disciplinas mencionadas são apenas aquelas relacionadas com o projeto e a implementação dos aspectos, por exemplo: Projetar Aspectos, Desenvolver Visão da Arquitetura, Registrar Pontos de Junção e Implementar Aspectos.

\section{6 - CONSIDERAÇÕES FINAIS}

O processo de desenvolvimento orientado a aspectos apresentado neste capítulo foi elaborado com base: a) na experiência de desenvolvimento e reúso dos FTs apresentados no Capítulo 4; b) no estudo de trabalhos relacionados com desenvolvimento de software orientado aaspectos e c) no desenvolvimento do sistema de reservas apresentado no Capítulo 7. Durante a criação do processo procurou-se mantê-lo independente de tecnologia. Entretanto, se o FT de Segurança for utilizado a arquitetura que deve ser empregada é a mostrada na Figura 4.23.

A maior parte das tabelas utilizadas durante o processo são utilizadas apenas durante o desenvolvimento e podem ser eliminadas depois que o sistema estiver em produção. Quando as informações descritas nas tabelas não puderem ser descartadas, uma alternativa é criar mecanismos para manter as informações nos modelos de classes, de interação e de pacotes, porém isso está fora do escopo desta tese.

Uma contribuição do processo apresentado aqui frente aos tradicionais é a união e o aprimoramento de conceitos, critérios e técnicas de modelagem de outros trabalhos (Clarke e Baniassad, 2005; Jacobson e Ng, 2004; Araújo e Moreira, 2002) em um único processo. ProFT/PU possui grande enfoque na identificação dos interesses transversais, mas fornece flexibilidade para que os desenvolvedores possam decidir pela técnica de implementação que pode ser usada. Outro diferencial é a existência dos FTs que, em muitos casos, influenciam as decisões tomadas. Por exemplo, a decisão de implementar ou não determinado interesse 
transversal em uma iteração é grandemente influenciado pela existência de um FT que apóia a implementação do interesse.

Embora diretrizes de análise, projeto e implementação tenham sido fornecidas, nada impede a adoção de abordagens mais específicas em cada fase do ciclo de vida. Por exemplo, na fase de análise a abordagem de Jacobson e Ng (2004) poderia ser usada para modelar os casos de uso transversais, desde que fosse adaptado ao modelo iterativo e incremental e que as atividades das fases seguintes a considerassem. Da mesma forma, a engenharia de requisitos pode ser mais profundamente tratada se um modelo, como, por exemplo, AORE (Rashid et al., 2002), fosse utilizado. O objetivo do ProFT foi cobrir todo o ciclo de vida mostrando como o processo todo pode ser conduzido, acompanhando os interesses transversais desde a análise até a implementação em um processo iterativo e incremental.

Um ponto interessante seria fornecer, juntamente com a documentação dos FTs, não apenas seu projeto, mas também seus modelos de análise. Assim, durante o processo de desenvolvimento, além dos modelos de projeto, seus casos de uso e modelos conceituais também poderiam ser reusados.

Embora o processo descrito neste capítulo forneça diretrizes para a utilização da família de FTs, pode ser usado com qualquer repositório de aspectos reusáveis. A identificação de interesses transversais e os pontos de decisão são independentes da tecnologia que está disponível para ser reusada. 


\section{Capítulo 7 \\ Exemplo de Uso do ProFT/PU}

\section{1 - CONSIDERAÇÕES INICIAIS}

Neste capítulo é mostrado o desenvolvimento de um sistema de reserva de uma rede de hotéis utilizando o ProFT/PU. A ênfase é dada nas fases, disciplinas e atividades que foram modificadas do PU, ou que foram acrescentadas. As fases e atividades que não diferem do PU são conduzidas de forma convencional e não são mostradas no decorrer do texto.

No decorrer do capítulo, ênfase maior é dada em atividades ligadas à identificação de interesses transversais e em como a aplicação evolui a cada iteração. Assim, mostram-se todas as iterações realizadas para o desenvolvimento do sistema. Como as últimas iterações cuidam de alguns FTs já exemplificados em capítulos anteriores, são descritas com menos detalhes.

O sistema utilizado como exemplo é um sistema de reservas de acomodações de uma rede de hotéis retirado e adaptado do livro de Chessman e Daniels (2000), cujo documento de requisitos pode ser encontrado no anexo 1 desta tese. Nesse sistema, as reservas podem ser feitas por telefone ou pela Internet. Cada hotel tem diferentes tipos de acomodação que podem ser reservados por um cliente, cujos dados devem ser registrados no sistema. O cliente pode confirmar, modificar, cancelar ou ocupar sua reserva (iniciar estada) e receber uma acomodação do tipo escolhido, nesta última situação. No hotel, deve ser possível fazer as reservas nos balcões de atendimento e nos escritórios. Cada hotel tem um gerente responsável por controlar as reservas, mas qualquer usuário autorizado pode fazê-las. O tempo desejado para fazer uma reserva por telefone ou pessoalmente é de três minutos. Para agilizar o processo, detalhes de clientes que já estiveram no hotel serão armazenados e disponibilizados para uso. O controle do pagamento das locações de quarto e taxas por reserva não ocupada sem cancelamento será realizado por um sistema de pagamento existente. O hotel possui um gerente que é responsável pelo gerenciamento do hotel, acomodações, funcionários, etc, e um 
administrador do sistema que é responsável por gerenciar o sistema, atribuir permissões de acesso, etc.

Na Seção 7.2, a fase de concepção para o sistema de reservas é mostrada. Nas Seções 7.3 e 7.4, as duas iterações planejadas para a fase de elaboração são apresentadas e nas Seções 7.5 e 7.6 as duas iterações planejadas para a fase de construção são delineadas. Nas últimas três seções as iterações aspectuais, que são iterações que cuidam especificamente de casos de uso selecionados para serem implementados como aspectos, são descritas.

\section{2 - FASE DE CONCEPÇÃO}

\subsection{1 - Disciplina Requisitos}

\subsubsection{1 - Identificar Atores e Detalhar Casos de Uso Funcionais}

Na Figura 7.1 é mostrado o diagrama de casos de uso para o sistema e hotel e também alguns dos atores identificados.

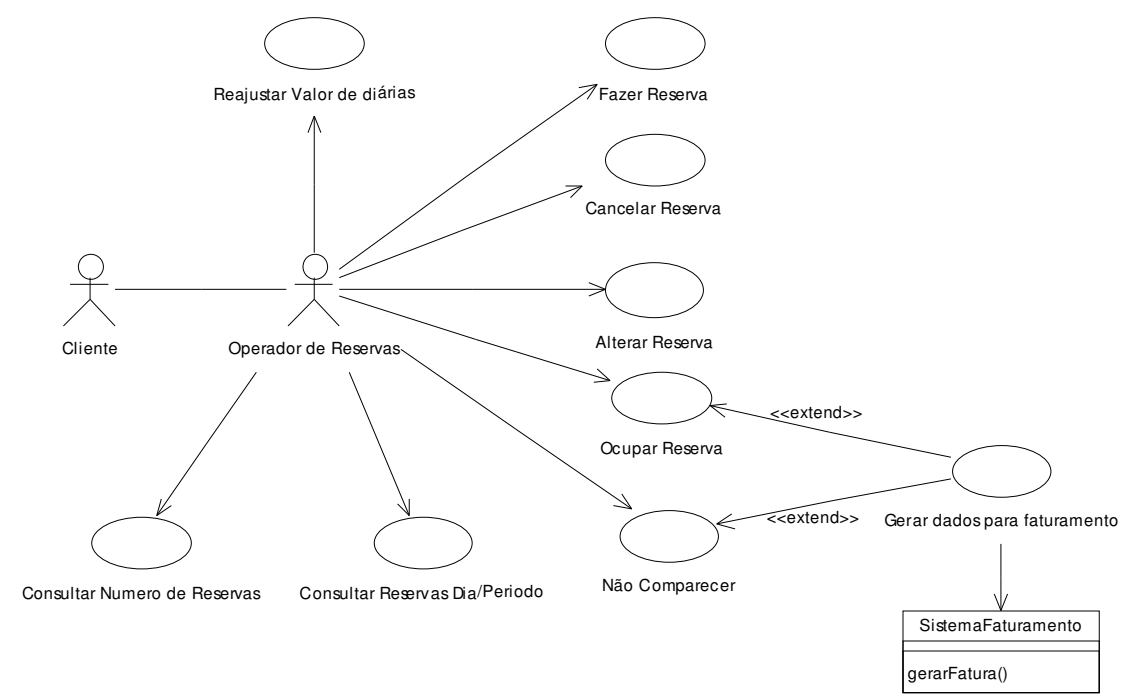

Figura 7.1 - Atores e Diagrama de Casos de Uso Inicial do Sistema de Reservas

\subsubsection{2 - Identificar e Especificar Casos de Uso Não-Funcionais}

Neste ponto do desenvolvimento deve ser iniciada a elaboração da Tabela de Interesses Transversais Não-Funcionais. Na Tabela 7.1 são mostrados os interesses não-funcionais identificados para o sistema de reservas.

Tabela 7.1 - Tabela de Interesses Transversais Não-Funcionais para o Sistema de Reservas

\begin{tabular}{|l|l|}
\hline \multicolumn{2}{|c|}{ Interesses Não-Funcionais Identificados } \\
\hline \multicolumn{1}{|c|}{ Interesse Não-Funcional } & \multicolumn{1}{c|}{ Requisitos Cobertos } \\
\hline Autenticação & 13 \\
\hline Controle de Acesso & $16.1,16.2$ \\
\hline Registro de operações & 15 \\
\hline Persistência & 17 \\
\hline
\end{tabular}


Depois que os casos de uso não-funcionais foram identificados, devem ser especificados e integrados no diagrama de casos de uso obtido até o momento. Sugere-se a elaboração de visões individuais, como mostrado na Figura 7.2.

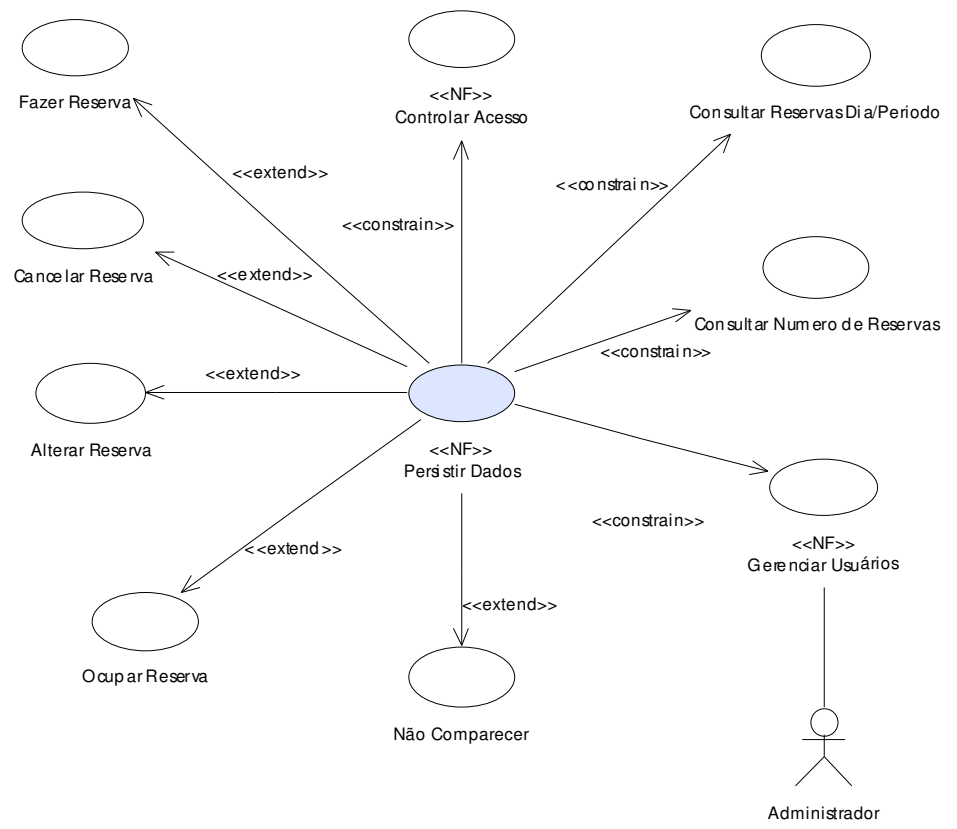

Figura 7.2 - Caso de Uso Não-Funcional Autenticar Usuário - Visão Individual de Caso de Uso

\subsubsection{3 - Planejar Iterações}

Na Tabela 7.2 é mostrada a classificação inicial obtida para o sistema de reservas. Os casos de uso que trabalham mais diretamente com a funcionalidade da reserva estão em posições mais altas da classificação, os casos de uso gerenciadores de dados ocupam o meio da classificação e os relatórios, consultas e funcionalidades de apoio estão no final da lista.

Tabela 7.2 - Classificação de Casos de Uso para o Sistema de Reservas

\begin{tabular}{|l|l|}
\hline Classificação & \multicolumn{1}{|c|}{ Caso de Uso } \\
\hline 1 & Fazer Reserva \\
\hline 2 & Ocupar Reserva \\
\hline 3 & Alterar Reserva \\
\hline 4 & Cancelar Reserva \\
\hline 5 & Não Comparecer \\
\hline 6 & Gerenciar Usuários \\
\hline 7 & Gerenciar Acomodação \\
\hline 8 & Gerenciar Empresas \\
\hline 9 & Gerenciar Hotel \\
\hline 10 & Gerenciar Tipo de Acomodação \\
\hline 11 & Gerenciar Cliente \\
\hline 12 & Consulta se acomodação está disponível \\
\hline 13 & Gerar Dados para Faturamento \\
\hline 14 & Consulta Número de Reservas \\
\hline 15 & Reajustar Valor de Diárias \\
\hline & Listar Reservas por Período \\
\hline
\end{tabular}


O caso de uso Fazer Reserva mostrado na Figura 7.3, por exemplo, possui cinco conceitos necessários para sua implementação - cliente, acomodação, tipo de acomodação, reserva e hotel. Se esses conceitos não estiverem disponíveis não será possível efetuar uma reserva. Portanto, os casos de uso que envolvem operações básicas de persistência sobre esses conceitos - conhecidos como casos de uso gerenciadores de dados - devem ser deslocados para posições superiores da classificação. Portanto, os casos de uso gerenciadores de dados que cuidam da persistência desses conceitos foram deslocados para as posições iniciais da classificação, como é mostrado na Tabela 7.3.

Caso de Uso: Fazer Reserva

Cenário de Sucesso Principal

11. O Operador de Reservas solicita fazer uma reserva.

12. O Operador de Reservas escolhe, em ordem, o hotel, datas de início e fim da reserva, e tipo de acomodação.

13. O sistema verifica se há acomodação disponível no período especificado no hotel especificado.

14. O Sistema fornece disponibilidade e o preço ao Operador da Reserva.

15. O Operador de Reservas solicita ao sistema a operação de fazer reserva.

16. O Operador de Reservas fornece ao sistema o nome e dados para contato do cliente.

17. O Operador de Reservas fornece ao sistema o e-mail de contato.

18. O Sistema registra a reserva e aloca um código para a reserva efetuada.

19. O Sistema mostra o código da reserva para o Operador da Reserva.

20. O Sistema cria e envia os dados de confirmação da reserva por e-mail para o cliente.

\section{Figura 7.3 - Caso de Uso Fazer Reserva}

Como o caso de uso Ocupar Reserva utiliza todos os conceitos persistentes exigidos pelo caso de uso Fazer Reserva e mais o conceito Empresas, ele também só pode ser implementado se o caso de uso Gerenciar Empresas estiver implementado, fazendo com que esse caso de uso gerenciador de dados também seja deslocado para posições iniciais da lista. Além disso, o caso de uso Ocupar Reserva também depende da existência do caso de uso Gerar Dados para Faturamento, o que também conduz esse caso de uso para posições mais prioritárias.

Depois que essa classificação inicial foi obtida, deve-se planejar quantas iterações devem ser realizadas e quais casos de uso devem ser trabalhados em cada iteração. Na Tabela 7.3 também são mostradas as iterações estipuladas para o sistema de reserva e os casos de uso que foram alocados para cada uma. Optou-se por desenvolver quatro casos de uso gerenciadores de dados e mais o caso de uso Fazer Reserva na primeira iteração. Dessa forma, uma versão operacional do sistema poderá ser obtida no final da primeira iteração, que não permite alteração, cancelamento, ocupação e cobrança.

$\mathrm{Na}$ segunda iteração, as funcionalidades de cobrança, de ocupação da reserva e de alteração de uma reserva devem ser implementadas. Na primeira iteração da construção, a 
funcionalidade de reservas é complementada, permitindo que o sistema possa cancelar uma reserva, e efetuar as operações cabíveis quando o cliente não comparece para ocupar a reserva. Na segunda iteração da construção consultas e relatórios e o gerenciamento de usuários são tratados. Entretanto, o planejamento da segunda iteração em diante pode sofrer alterações em conseqüência de imprevistos que podem surgir na primeira iteração.

Tabela 7.3 - Tabela de Planejamento das Iterações do Sistema de Reservas

\begin{tabular}{|c|c|c|c|}
\hline & Iterações & Classificação & Caso de Uso \\
\hline \multirow{9}{*}{ 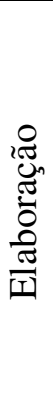 } & \multirow[t]{5}{*}{$1^{\mathrm{a}}$ Iteração } & 1 & Gerenciar Acomodação \\
\hline & & 2 & Gerenciar Hotel \\
\hline & & 3 & Gerenciar Tipo de Acomodação \\
\hline & & 4 & Gerenciar Cliente \\
\hline & & 5 & Fazer Reserva \\
\hline & \multirow[t]{4}{*}{$2^{\mathrm{a}}$ Iteração } & 6 & Gerenciar Empresas \\
\hline & & 7 & Gerar Dados para Faturamento \\
\hline & & 8 & Ocupar Reserva \\
\hline & & 9 & Alterar Reserva \\
\hline \multirow{7}{*}{ 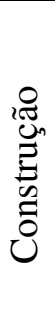 } & \multirow[t]{2}{*}{$1^{\mathrm{a}}$ Iteração } & 10 & Cancelar Reserva \\
\hline & & 11 & Não Comparecer \\
\hline & \multirow[t]{5}{*}{$2^{\mathrm{a}}$ Iteração } & 12 & Gerenciar Usuários \\
\hline & & 13 & $\begin{array}{l}\text { Consulta se acomodação está } \\
\text { disponível }\end{array}$ \\
\hline & & 14 & Consulta Número de Reservas \\
\hline & & 15 & Reajustar Valor de Diárias \\
\hline & & 16 & Listar Reservas por Período \\
\hline
\end{tabular}

Um artefato que deve ser desenvolvido quando se trabalha com desenvolvimento incremental e evolutivo é a "visão de iteração". A primeira iteração do sistema de reservas terá acesso aos casos de uso mostrados no diagrama mostrado na Figura 7.4. Apesar dos casos de uso não-funcionais não aparecerem na classificação mostrada na Tabela 7.3 , eles são considerados na iteração, porém isso não significa que devem, obrigatoriamente, ser implementados na iteração atual.

\section{3 - FASE DE ELABORAÇÃo - 1ª ITERAÇÃO}

\subsection{1 - Disciplina Análise}

\subsubsection{1 - Identificar e Registrar Casos de Uso Colaboradores}

Depois de finalizado o processo de análise, identificou-se a ausência de trechos com funcionalidades comuns entre os casos de uso desta iteração. Entretanto, uma nova funcionalidade foi considerada como um caso de uso, que é o Enviar Dados por E-mail. 


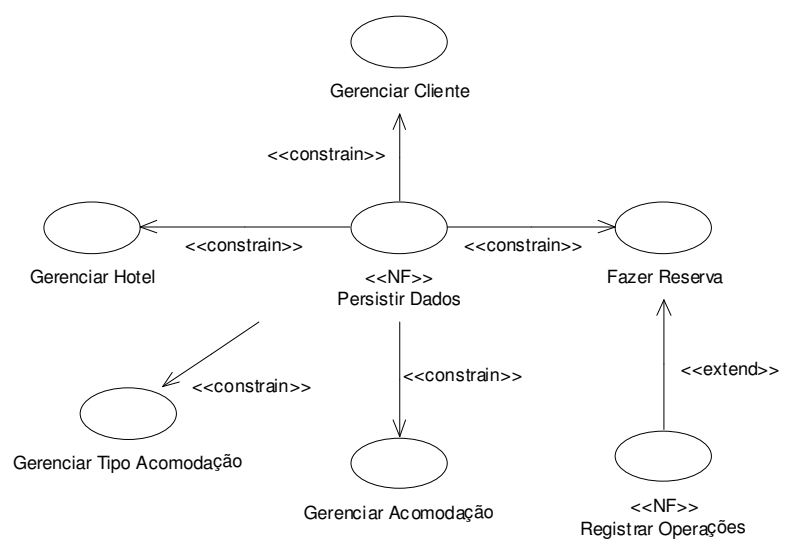

Figura 7.4 - Visão de Iteração - Fase de Concepção

\subsubsection{2 - Identificar e Registrar Casos de Uso Candidatos a Aspectos}

A análise deve se restringir aos casos de uso que podem ser acessados na iteração, os quais podem ser vistos na visão de iteração mostrada na Figura 7.5. Para o sistema de reservas em questão, três casos de uso foram considerados como candidatos a aspectos: Persistir Dados, Registrar Operações e Enviar Dados por E-Mail. Na Tabela 7.4 são mostrados esses casos de uso e o critério que foi utilizado para selecioná-lo.

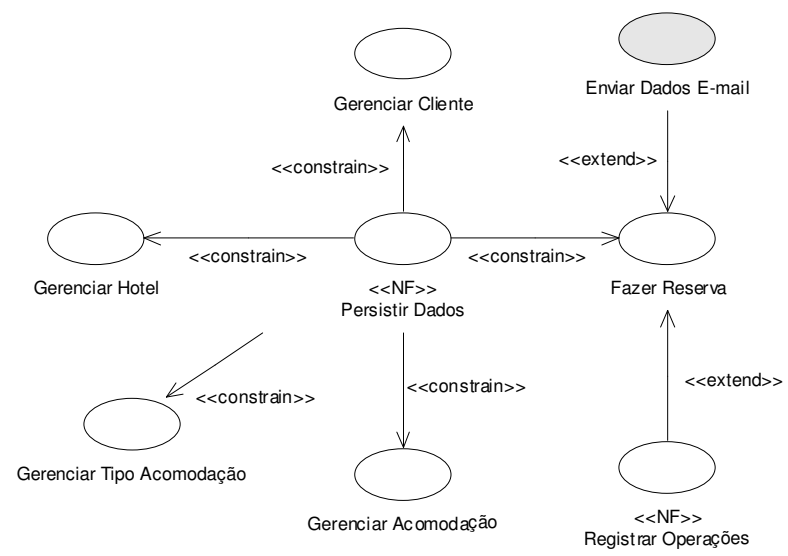

Figura 7.5 - Caso de Uso Enviar Dados por E-mail

Tabela 7.4 - Tabela de Candidatos a Aspectos do Sistema de Reservas (TPCaUT)

\begin{tabular}{|l|c|l|c|}
\hline \multicolumn{1}{|c|}{ Caso de Uso } & Tipo (F/NF) & \multicolumn{1}{c|}{ Critério } & Implementado \\
\hline Persistir Dados & Não-funcional & Número de relacionamentos e Tipo & $\square$ \\
\hline Registrar Operações & Não-funcional & Tipo & $\square$ \\
\hline $\begin{array}{l}\text { Enviar Dados por E- } \\
\text { mail }\end{array}$ & Funcional & Um relacionamento de extensão & $\square$ \\
\hline
\end{tabular}

\subsubsection{3 - Desenvolver Modelo Conceitual}

Analisando os casos de uso alocados para a iteração atual, o modelo conceitual mostrado na Figura 7.6 foi obtido. 


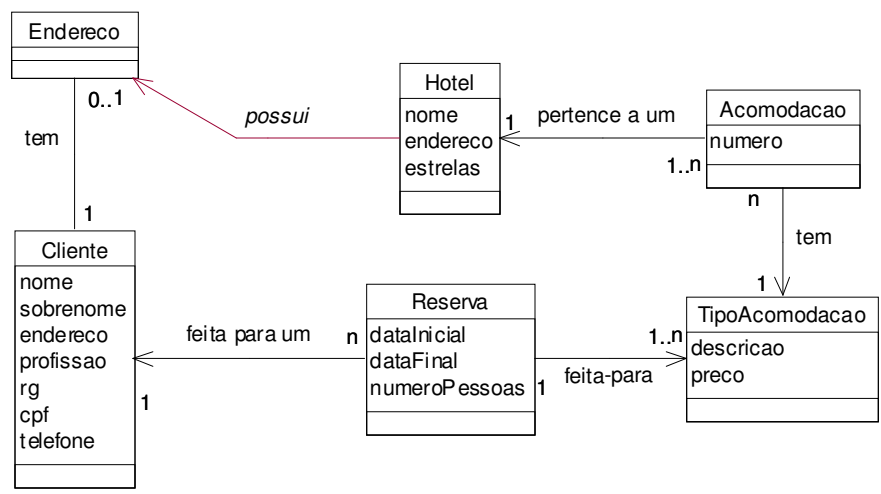

Figura 7.6 - Modelo Conceitual do Sistema de Reservas

\subsection{2 - Disciplina Projeto}

\subsubsection{1 - Identificar Aspectos}

A Tabela de Candidatos a Aspectos do sistema de reserva (Tabela 7.4) possui apenas três casos de uso: Persistir Dados, Registrar Operações e Enviar Dados por E-mail. Como os dois primeiro são exemplos clássicos de aspectos, os demais critérios não precisaram ser aplicados para decidir se devem ser implementados como aspectos. Já o caso de uso Enviar Dados por E-mail é funcional, é atômico e não é essencial ao comportamento do caso de uso Fazer Reserva. Entretanto, mesmo com bons indícios de que sua implementação com aspectos é factível, optou-se por postergar essa decisão para as próximas iterações. Quatro motivos levaram a essa decisão: o primeiro é que nesta iteração, esse caso de uso estende apenas um caso de uso base. Como outros relacionamentos podem aparecer nas próximas iterações, optou-se por esperar o aparecimento de novos relacionamentos - algo que justificaria melhor a implementação dele com aspectos. O segundo motivo é sua simplicidade. Talvez sua implementação com aspectos seja mais complicada e não traga benefícios suficientes. $\mathrm{O}$ terceiro motivo é o fato dele não caracterizar um requisito volátil. Na Tabela 7.5 é mostrada a Tabela de Aspectos para esta iteração do desenvolvimento do sistema de reservas.

Tabela 7.5 - Tabela de Aspectos para o Sistema de Reservas - $1^{\text {a }}$ Iteração

\begin{tabular}{|l|l|l|l|l|l|l|c|}
\hline $\begin{array}{c}\text { Casos de } \\
\text { Uso }\end{array}$ & Tipo & Atomicidade & Essencialidade & Volatilidade & FT & $\begin{array}{c}\text { Implementa } \\
\text { como } \\
\text { Aspecto? }\end{array}$ & Implementado \\
\hline $\begin{array}{l}\text { Persistir } \\
\text { Dados }\end{array}$ & NF & - & - & - & S & Sim & $\square$ \\
\hline $\begin{array}{l}\text { Registrar } \\
\text { Operações }\end{array}$ & NF & - & - & - & S & Sim & $\square$ \\
\hline $\begin{array}{l}\text { Enviar } \\
\text { Dados por } \\
\text { E-mail }\end{array}$ & F & s & n & n & N & adiada & $\square$ \\
\hline
\end{tabular}

\subsubsection{2. - Selecionar Aspectos para a Iteração Atual}


Com relação ao sistema de reservas, há dois casos de uso que certamente devem ser implementados com aspectos: Persistir Dados e Registrar Operações. A situação do Enviar Dados por E-mail ainda é pendente. Como já havia sido previsto na atividade de planejamento, Persistir Dados será implementado nesta iteração em conseqüência da necessidade de alguns conceitos persistentes para efetuar uma reserva. Além disso, a existência de um FT de persistência que pudesse ser prontamente reusado também colaborou para essa decisão. Já a implementação de Registrar Operações, embora também haja um FT para implementá-lo, será adiada, pois considera-se que ele poderá atrasar o desenvolvimento desta versão inicial do sistema e, além disso, a reutilização de dois FTs logo na primeira iteração pode gerar algumas incompatibilidades que poderiam atrasar o projeto. Outra razão é que ele é um requisito não funcional que pode ser facilmente acoplado depois que o sistema estiver pronto. Na Tabela 7.6 é mostrada a Tabela de Acompanhamento da Implementação dos Aspectos para o sistema de reservas em questão.

Tabela 7.6 - Tabela de Acompanhamento da Implementação de Aspectos para o Sistema de Reservas

\begin{tabular}{|c|c|}
\hline No. Iteração & Aspecto \\
\hline $1^{\text {a }}$. da elaboração & Persistir Dados \\
\hline
\end{tabular}

\subsubsection{3 - Projetar Aspectos}

Como pode ser visto na Tabela 7.6, o requisito não-funcional de persistência é o único que foi selecionado para ser implementado nesta iteração. Como esse requisito não-funcional possui um FT correspondente, ele não precisa ser projetado do zero, pois seu modelo de projeto pode ser reusado, o qual pode ser visto na Figura 4.8.

Se o caso de uso selecionado para ser implementado nesta iteração não tivesse um FT para apoiar sua implementação, ele poderia ser implementado como um aspecto normal, sem a preocupação de generalizar seu comportamento. Outra opção é implementar o caso de uso já como um FT. Nesse caso, a arquitetura mostrada no Capítulo 3 pode ser utilizada.

Uma decisão importante que deve ser tomada neste momento é se o FT de persistência deve ser utilizado com sua variabilidade default, ou se a variabilidade escolhida deve ser a consciência parcial. No caso do sistema de reservas optou-se pela variabilidade default por possuir um melhor desempenho, já que esse era um requisito do sistema.

Outro ponto importante é quanto ao desempenho da aplicação. Como os requisitos do sistema de reservas deixam claro que o desempenho da aplicação é importante, é interessante que todas as características do FT de persistência que dizem respeito a desempenho sejam utilizadas, como, por exemplo, as características de caching e pooling. Como o acoplamento de características já foi exemplificado no Capítulo 4, não será repetido neste capítulo. 


\subsubsection{4 - Acoplar Aspectos com a Base}

No caso do sistema de reservas, a seqüência de reúso do FT de persistência será a seguinte: inicialmente a característica Operações Persistentes será acoplada para que as operações básicas de persistência estejam disponíveis durante a elaboração dos diagramas de interação. Depois disso, os diagramas de interação serão desenvolvidos com o objetivo de descobrir métodos, operações e classes de interface. Em seguida, a característica Conexão poderá ser acoplada nos pontos reais, já que as classes de interface já terão sido identificadas e projetadas.

As classes persistentes do sistema de reservas que foram identificadas para esta iteração são: cliente, hotel, reserva, tipo de acomodação e acomodação. Na Figura 7.7 é mostrado o acoplamento do FT de persistência - mostrado apenas com duas classes - com o modelo de projeto da aplicação obtido até este momento.

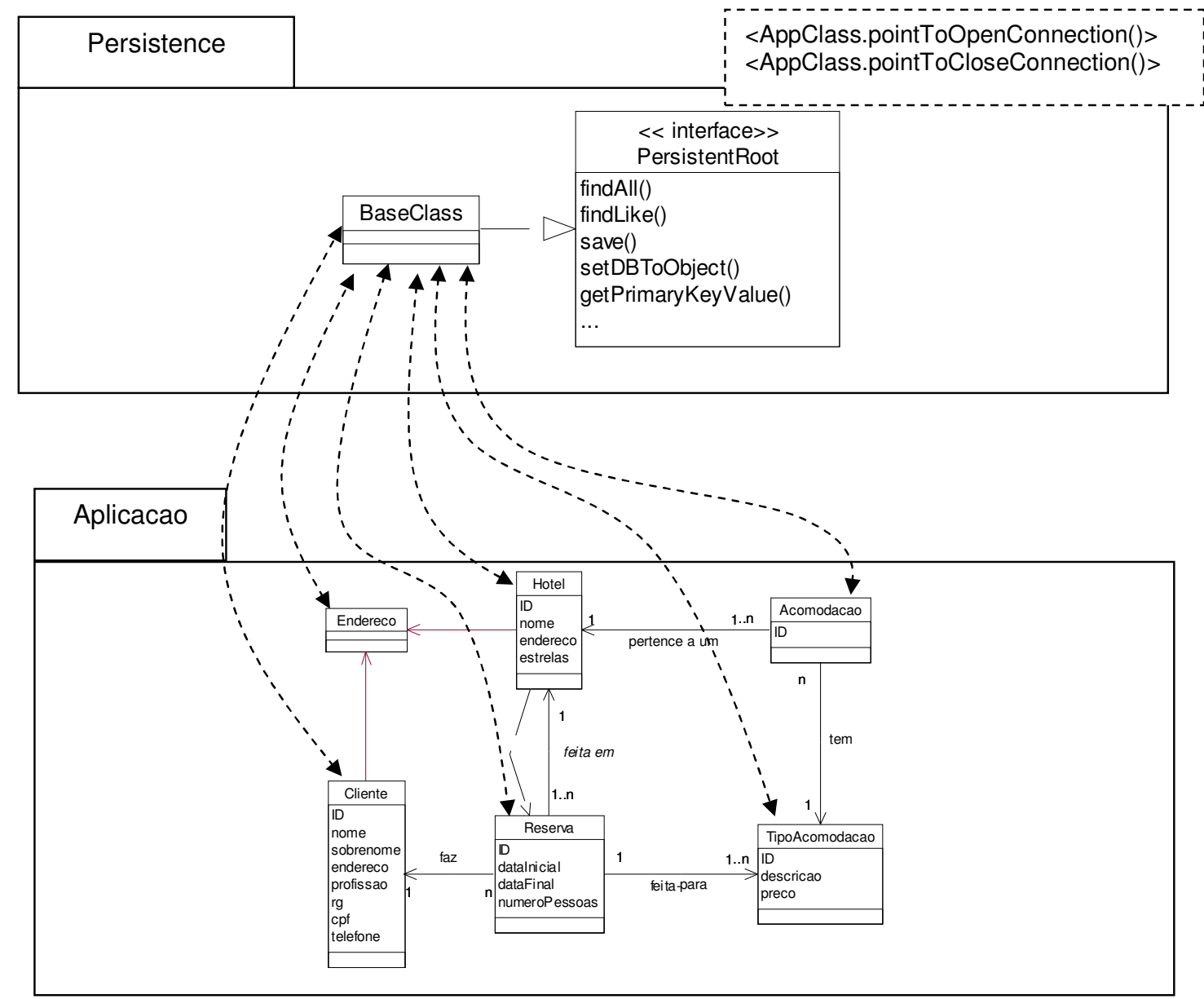

Figura 7.7 - Visão de Acoplamento do FT de Persistência com o Sistema de reservas

Com esse acoplamento realizado, as classes agora estão munidas de métodos básicos de persistência que podem ser utilizados durante o projeto das outras operações e métodos de negócio do sistema. 
Diagramas de colaboração ou de sequiência devem ser elaborados para cada um dos oito casos de uso alocados para esta iteração deles para que seja possível identificar métodos e classes controladoras. O diagrama de colaboração mostrado na Figura 7.8 é referente ao caso de uso fazerReserva(). Note-se que o método save() é proveniente do FT de persistência, e o seu objetivo é armazenar o objeto atual em algum mecanismo de persistência.

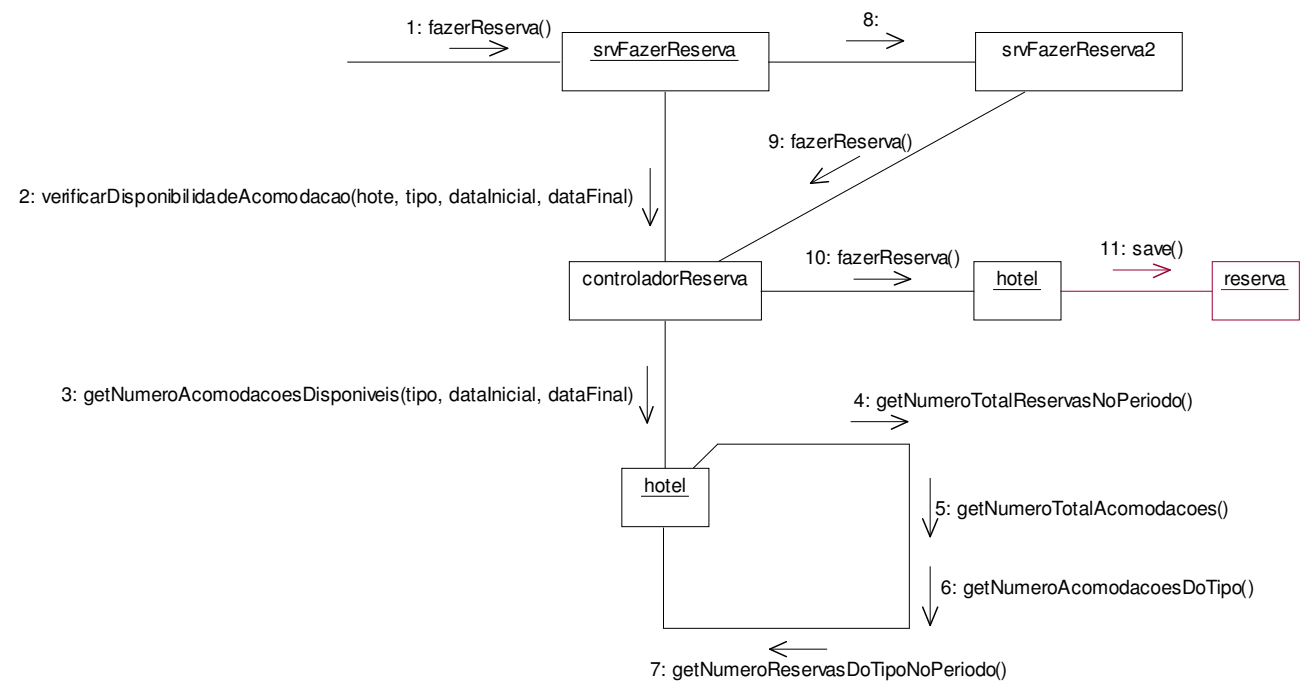

Figura 7.8 - Diagrama de Colaboração para a Operação Fazer Reserva

Como a utilização do FT de persistência fornece um conjunto de métodos prontos para as classes de aplicação persistentes, a elaboração dos diagramas de colaboração para os casos de uso gerenciadores de dados faz pouco sentido se o objetivo for a identificação de métodos. Esses diagramas só serão necessários se o objetivo for a descoberta de classes controladoras. Entretanto, se a criação desses diagramas realmente for necessária, deve-se cuidar para que as operações de persistência tenham o mesmo nome das operações que o framework disponibiliza.

\subsubsection{5 - Desenvolver Modelo de Classes de Projeto}

A elaboração do modelo de classes de projeto deve ser feita com cuidado quando a decisão foi utilizar o FT de persistência. Isso ocorre porque seu uso impõe certas restrições à arquitetura do sistema e, se essas restrições não forem consideradas no modelo de classes de projeto, o acoplamento do FT de persistência, seja neste ponto do processo ou no final, pode exigir mudanças de projeto significativas.

Com a criação dos diagramas de colaboração e a descoberta de métodos e outras restrições de projeto, o modelo conceitual começa a ser transformado no modelo de classes de projeto, em que as classes agora representam tipos de uma linguagem de programação. $\mathrm{O}$ 
modelo de classes de projeto pode ser visto na Figura 7.9, já com os métodos que foram descobertos por meio da elaboração dos diagramas de colaboração.

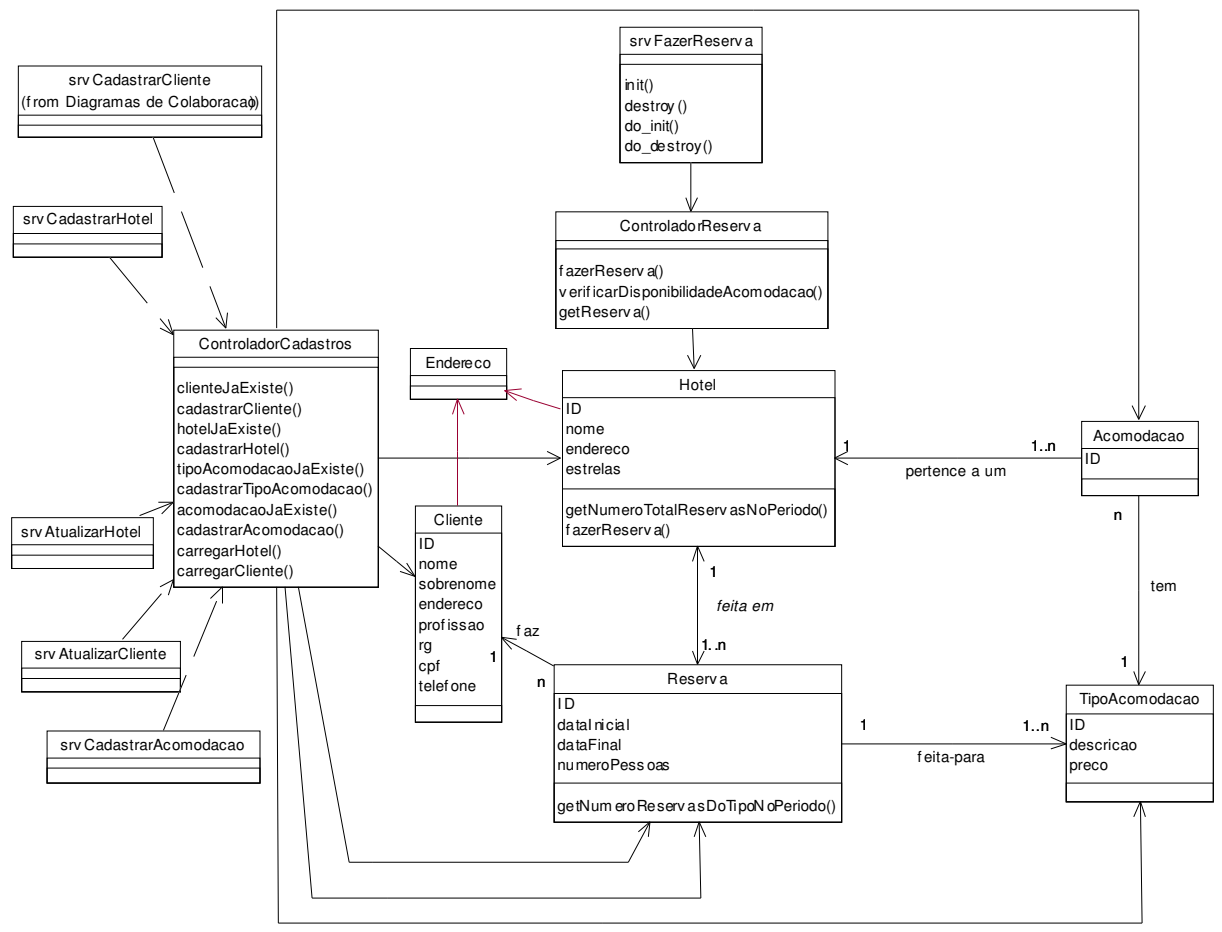

Figura 7.9 - Modelo de Classes de Projeto com Classes Controladoras

\subsubsection{6 - Acoplar Aspectos com a Base}

Depois que os diagramas de interação foram elaborados e as classes de interface projetadas, a segunda parte do FT de persistência, que consiste na conexão com o banco de dados, pode ser instanciada e acoplada ao sistema. Esta segunda parte do FT de persistência possui a etapa de instanciação porque algumas variabilidades precisam ser escolhidas, por exemplo, o tipo da conexão com o banco de dados e o próprio banco que será utilizado.

Na Figura 7.10 é mostrado novamente o acoplamento entre o FT de persistência e o modelo de classes de projeto da aplicação, porém agora com o relacionamento de ligação entre os pacotes. O FT de persistência está sendo representado como um pacote vazio porque já foi mostrado em detalhes no Capítulo 4.

Embora esteja sendo mostrado apenas o relacionamento de ligação entre os pacotes, considere-se a existência das outras linhas de relacionamentos mostradas na Figura 7.7.

Na parte inferior da Figura 7.10 é mostrado o modelo de classes de projeto do sistema de reservas. Note-se que atributos chamados ID foram inseridos em cada uma das classes, respeitando essa restrição que é imposta pelo FT de persistência. 


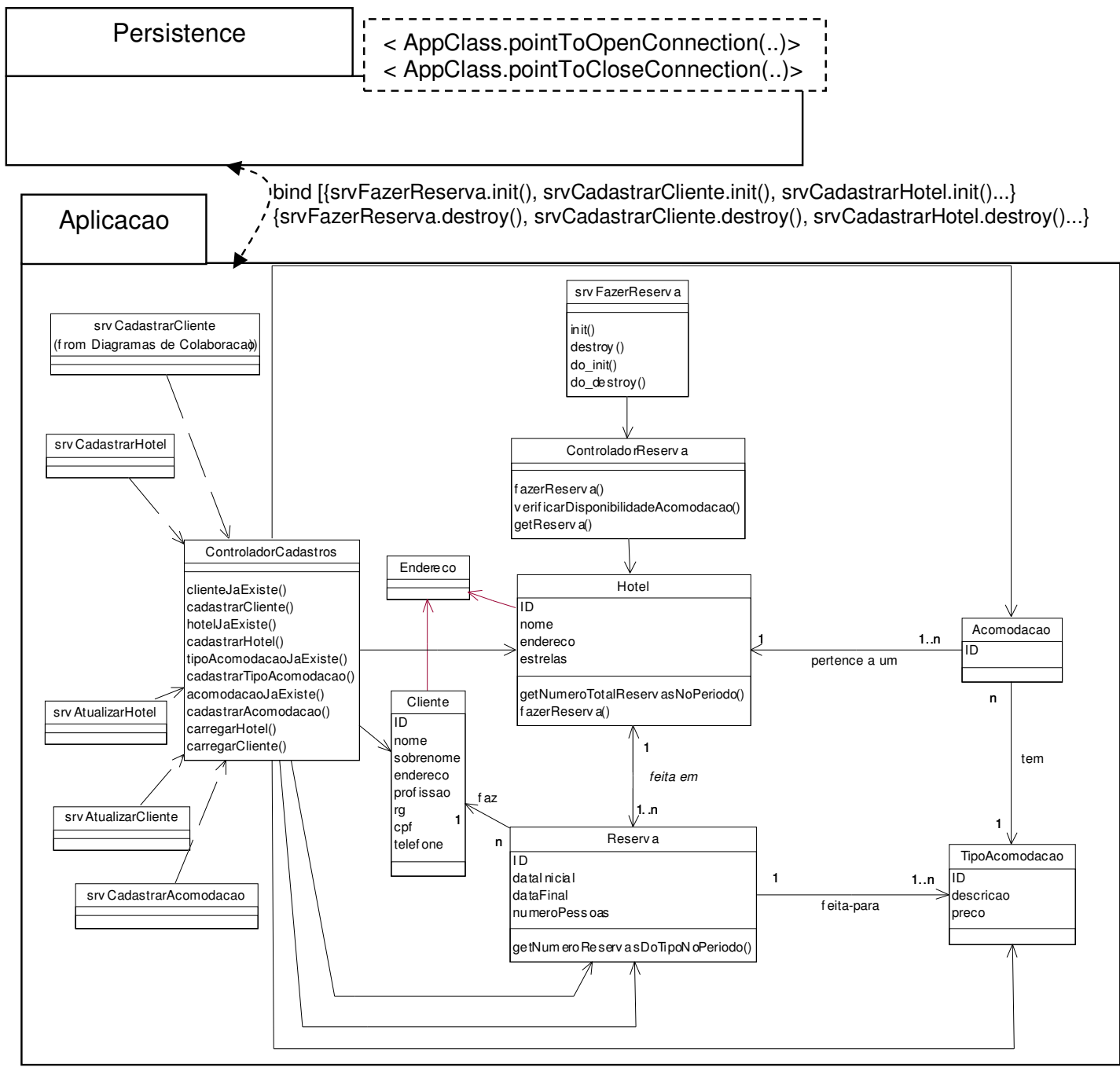

Figura 7.10 - Acoplamento da Parte de Conexão do FT de Persistência com a Parte Base da Aplicação

\subsubsection{7 - Desenvolver Visão da Arquitetura}

Na Figura 7.11 é mostrada a Visão da Arquitetura para esta primeira iteração do sistema de reservas. O diagrama mostra que o FT de persistência afeta estaticamente a aplicação (Krechetov, et al., 2006).

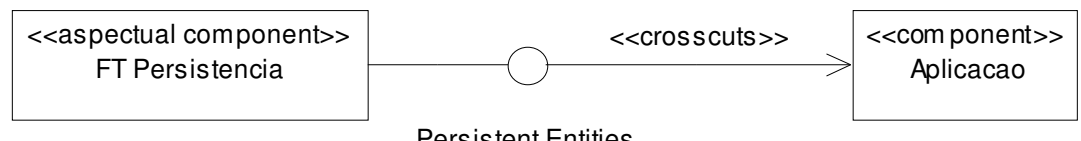

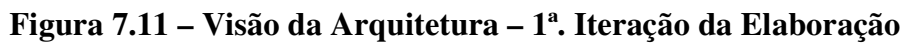

\subsubsection{8 - Registrar Pontos de Junção}

Na Tabela 7.7 é mostrado o Registro de Pontos de Junção para o Sistema de Reservas. Como apenas o FT de persistência encontra-se acoplado ao sistema até este momento, não há possibilidades de conflitos entre FTs ou aspectos. 
Tabela 7.7 - Registro dos Pontos de Junção

\begin{tabular}{|c|l|l|l|}
\hline \multirow{2}{*}{$\begin{array}{c}\text { FT/Aspecto } \\
\downarrow\end{array}$} & \multicolumn{3}{|c|}{ Pontos de Junção Afetados } \\
\cline { 2 - 4 } & \multirow{2}{*}{ Método/atributo/constructor/adendo } & \multicolumn{1}{|c|}{ Unidades de Software } \\
\cline { 2 - 4 } & init() & \multicolumn{1}{|c|}{ Classe } & Aspecto \\
\hline & init() & srvazerReserva & srvCadastrarCliente \\
init() & destroy() & srvCadastrartotel \\
FT de & destroy() & srvFazerReserva \\
Persistencia & destroy() & srvCadastrarCliente \\
& new() & srvCadastrarHotel \\
& new() & Hotel \\
& new() & Reserva \\
& new() & Tipo \\
\hline
\end{tabular}

\subsection{3 - Disciplina Implementação}

\subsubsection{1 - Implementar Classes de Domínio}

Os métodos de negócio que precisam realizar armazenamentos, recuperações e remoções no mecanismo persistente só poderão ser implementados depois que o FT de persistência introduzir suas operações em cada uma das classes. Mesmo se o FT de persistência já estiver acoplado ao sistema, a implementação das novas classes de domínio também só poderá ser feita parcialmente neste ponto do processo, até que as regras de composição do FT sejam atualizadas para considerar também a nova classe implementada. Os métodos de negócio que não precisam acessar o mecanismo persistente podem ser implementados normalmente.

\subsubsection{2 - Implementar Aspectos}

Como pode ser visto na Tabela de Acompanhamento de Implementação de Aspectos (Tabela 7.6), o aspecto de persistência é o único que deve ser implementado nesta iteração. Como há um FT de persistência disponível que pode ser utilizado para apoiar a implementação desse aspecto, o processo de implementação consiste unicamente no processo de reúso desse FT.

Como comentado anteriormente, a posição desta atividade dentro da disciplina Implementação pode variar dependendo do aspecto que está sendo implementado. Neste caso, como a implementação de várias operações de negócio necessita das operações de baixo nível introduzidas pelo FT de persistência, seu acoplamento deve ser feito antes que essas operações de negócio sejam implementadas. É por isso que esta atividade encontra-se antes da atividade Desenvolver Classes Controladoras, pois é nessa atividade que a maior parte das operações e métodos de negócio é implementada.

O processo de reúso do FT de persistência será feito em dois tempos distintos, inicialmente a característica Operações Persistentes será acoplada às classes da aplicação para que seja possível implementar as operações de sistema. Depois disso, a característica Conexão é que será acoplada para que testes possam ser conduzidos. Essa é uma peculiaridade do FT de persistência e pode não ocorrer com outros FTs ou outras implementações de aspectos. 
Em relação à instanciação do FT de Persistência, como a variabilidade escolhida para o sistema de reservas foi "Consciência Total", nada precisa ser feito já que essa é a variabilidade default desse FT.

Em relação à composição com a aplicação, o aspecto MyPersistentEntities, mostrado na Figura 7.12, é elaborado com base nos valores (classes de aplicação) encontrados na visão de acoplamento mostrada na Figura 7.10.

\subsubsection{3 - Desenvolver Classes Controladoras}

Como o FT de persistência já foi acoplado à porção do sistema desenvolvida até o momento, as operações de sistema podem ser implementadas considerando a existência das operações de persistência disponibilizadas pelo framework.

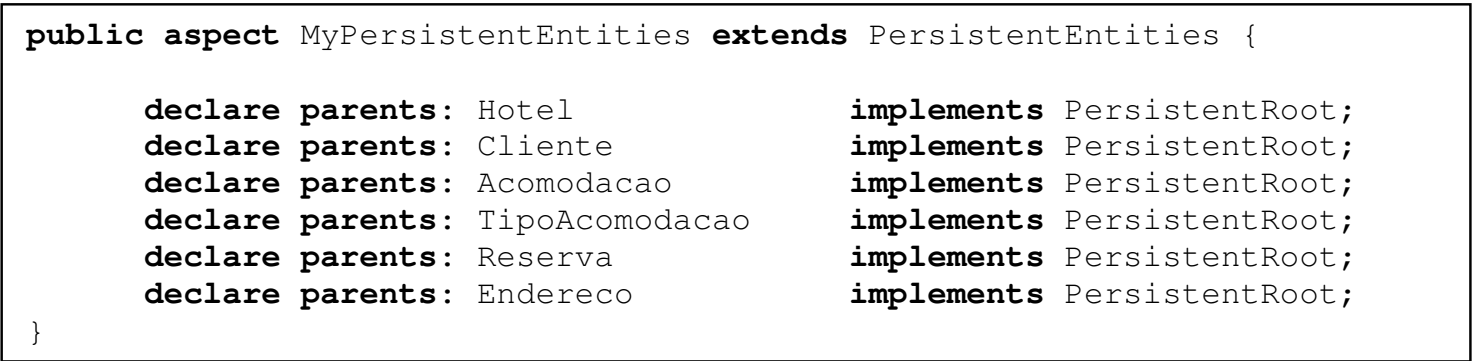

Figura 7.12 - Aspecto MyOORelationalMapping

Como descrito no capítulo anterior, durante a realização desta atividade pode ser necessário realizar adaptações nos FTs. Foi necessário implementar um método na classe Reserva para contar quantas reservas existem em um determinado período para um determinado hotel, independentemente do tipo de acomodação. Essa adaptação pode ser vista na Figura 4.13.

\subsubsection{4 - Implementar Aspectos}

Nesta atividade, o objetivo é terminar a implementação do aspecto de persistência iniciado anteriormente. Deve-se realizar o segundo acoplamento, pois os pontos de junção apropriados para a abertura e fechamento da conexão com o banco de dados já foram implementados.

Em relação à instanciação da característica Conexão, da parte de conexão do framework de persistência consiste na criação de uma classe que estenda uma das classes de variabilidades do FT de persistência. A classe mostrada na Figura 7.13 estende a classe OdbcConnection, indicando que a conexão será via ODBC do Windows.

Em relação à composição, o aspecto mostrado na Figura 7.14 é implementado com base no modelo mostrado na Figura 7.10. Esse aspecto considera que a classe de interface srvfazerReserva e as classes srvCadastrarCliente e srvCadastrarHotel já foram, pelo menos, parcialmente implementadas. Portanto, os pontos de junção identificados 
são os pontos reais de acoplamento, isto é, os pontos de junção em que o FT permanecerá acoplado depois que o sistema estiver em produção.

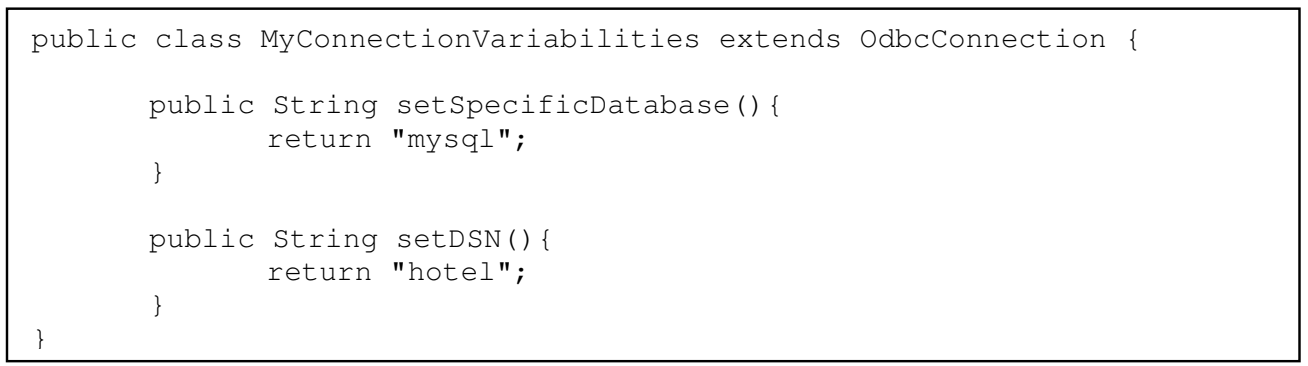

Figura 7.13 - Aspecto MyConnection Variabilities

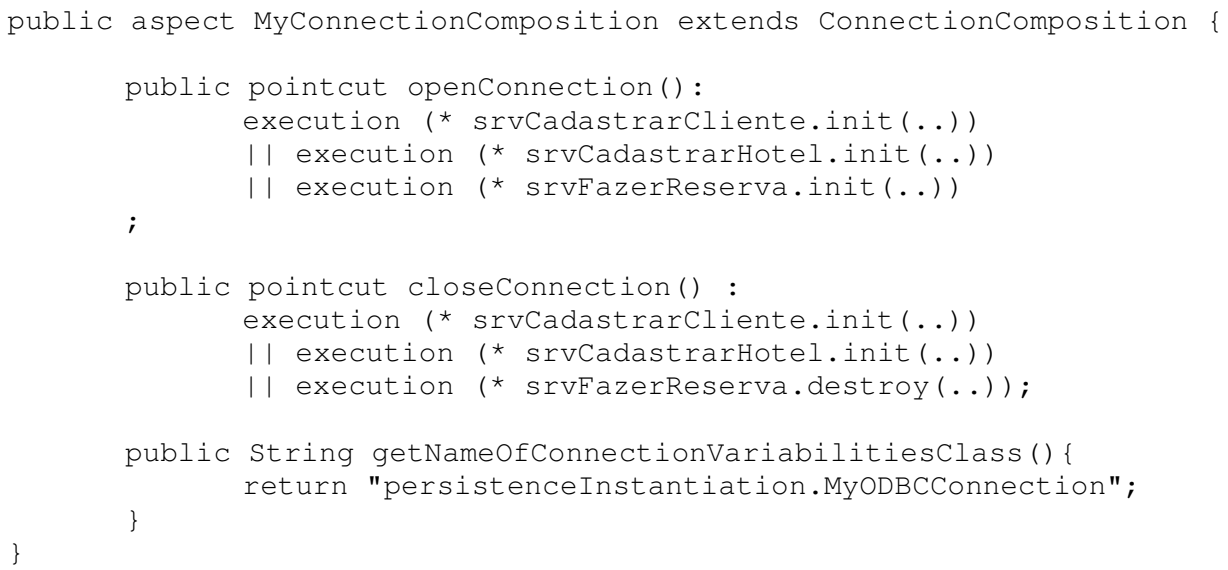

Figura 7.14 - Aspecto de Acoplamento da Conexão

\subsubsection{5 - Testar Sistema}

Foram realizados testes funcinais com o objetivo de averiguar se a porção do sistema desenvolvida até este momento realizava um reserva, assim como foi planejado na fase de concepção. Além desse tipo de teste, o FT de Garantia de Políticas, uma das características do FT de persistência, também foi empregado para garantir, até certo ponto, que o acoplamento do FT de persistência foi feito corretamente.

\section{4 - FASE DE ELABORAÇÃo - $2^{a}$. ITERAÇÃo}

Nesta segunda iteração da fase de elaboração o objetivo é evoluir a porção do sistema desenvolvida na iteração anterior, acrescentando os casos de uso alocados especificamente para esta iteração. Ainda há grande ênfase nos requisitos, já que alguns requisitos e casos de uso ainda não foram descobertos e registrados.

Na Figura 7.15 é mostrada a visão de iteração do sistema de reserva para esta iteração. Os casos de uso destacados em cinza são os que já foram implementados em iterações anteriores. Os vazios são os que ainda precisam ser implementados. Dentre os vazios ainda há dois tipos, os marcados com um "x" e os que não possuem marcação. Os casos de uso 
marcados são os originais, isto é, aqueles que foram originalmente alocados para serem desenvolvidos nesta iteração: Gerenciar Empresas, Alterar Reserva, Ocupar Reserva e Gerar Dados para Faturamento. Este mesmo padrão representacional será usado no restante deste capítulo.

Com o desenvolvimento dos casos de uso alocados para esta iteração pretende-se obter uma versão do sistema que permite a ocupação de uma reserva e a geração de uma fatura referente à estadia do cliente. Essa versão também deve permitir alterar os dados de uma reserva já efetuada e cadastrar as empresas que são conveniadas com o hotel. Os casos de uso que não possuem marcação são incluídos no diagrama por dois motivos: ou por que são nãofuncionais que se relacionam aos casos de uso originais, ou porque foram alocados para serem implementados em iterações anteriores, mas não foram. Esses últimos devem continuar aparecendo no diagrama até que sua situação de pendência seja resolvida.

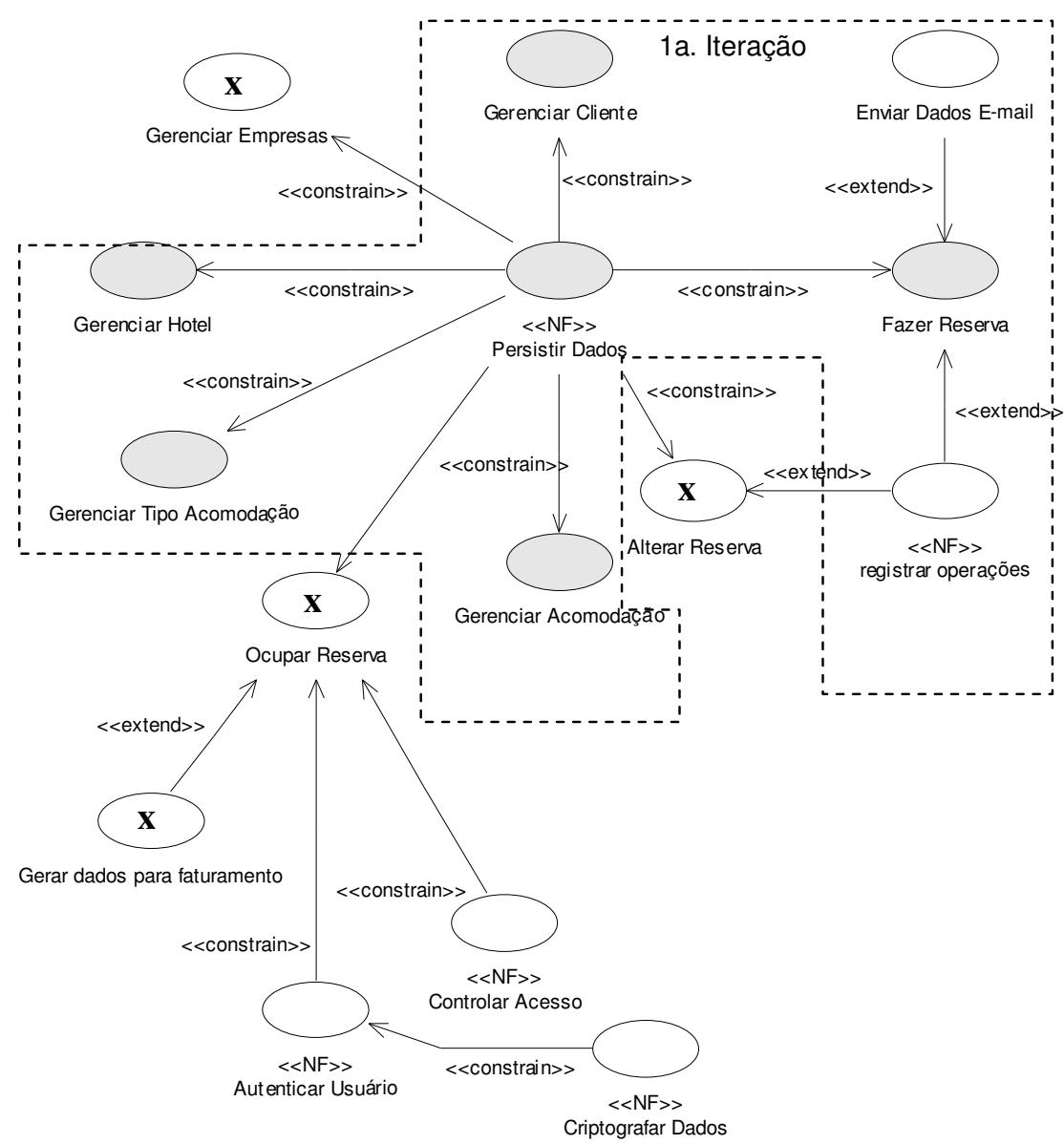

Figura 7.15 - Visão de Iteração para a Segunda Iteração do Sistema de Reservas

A Figura geométrica tracejada na Figura 7.15 também delimita visualmente os casos de uso da primeira iteração. É interessante destacar que o número de relacionamentos de um caso de uso pode aumentar em relação à iteração anterior. Por exemplo, o caso de uso 
Registrar Operações possuía apenas um relacionamento de extensão na iteração anterior, já nesta iteração ele possui dois, um com o caso de uso Fazer Reserva e um outro com o caso de uso Alterar Reserva, o qual acabou de ser acrescentado ao sistema. O caso de uso Persistir Dados também possui mais três relacionamentos de restrição comparado com a iteração anterior, um com o Gerenciar Empresas, outro com o Alterar Reserva e outro com o Ocupar Reserva. Isso já é um indício de que as regras de composição do FT de persistência terão que ser atualizadas.

\subsection{1 - Disciplina Análise}

\subsubsection{1 - Identificar e Registrar Casos de Uso Colaboradores}

Considerando a aplicação do modelo de decisão mostrado na Tabela 6.7, observou-se que os casos de uso Ocupar Reserva e Alterar Reserva possuem um passo em comum que consiste em identificar uma reserva com base em um código que é fornecido pelo hóspede, caracterizando uma funcionalidade que é compartilhada por mais de um caso de uso, respondendo "sim" à pergunta número 1, o que justifica a fatoração desse caso de uso. A segunda pergunta do modelo de decisão auxilia a identificar o tipo de relacionamento entre o novo caso de uso e o seu criador. A resposta para esta segunda pergunta é "sim" - a funcionalidade de identificação de reserva é essencial ao comportamento do caso de uso indicando que o relacionamento entre eles é de inclusão. Na Figura 7.16 é mostrado o diagrama de caso de uso para o novo caso de uso Identificar Reserva.

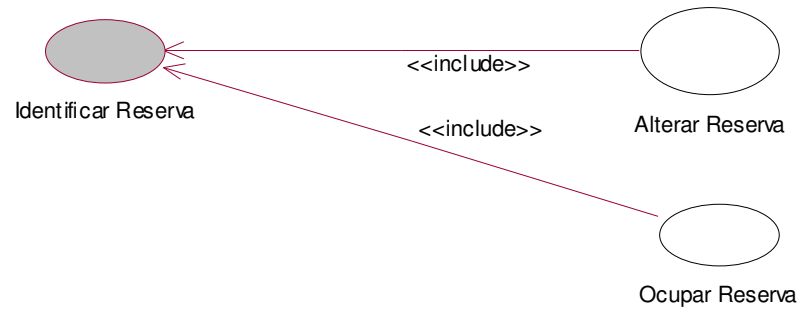

Figura 7.16 - Visão Individual para o Caso de Uso Identificar Reserva

Prosseguindo no processo de análise dos casos de uso, identificou-se que o caso de uso Ocupar Reserva possui um passo que é um cálculo de desconto que não é essencial à funcionalidade de ocupação de uma reserva, respondendo "não" à pergunta número 2 do modelo de decisão e levando à criação de um novo caso de uso chamado Calcular Desconto. O relacionamento desse novo caso de uso com o seu criador será definido como <<extend $>$.

Na Figura 7.17 é mostrado o diagrama de casos de uso para a porção do sistema que deve ser desenvolvida nesta iteração, incluindo os casos de uso colaboradores que foram identificados. Note-se que os casos de uso colaboradores que foram identificados entram na categoria dos originais, representados pelas elipses vazias. Está sendo feito assim porque são 
oriundos dos casos de uso originais, isto é, fazem parte de um comportamento que já havia sido previsto para o sistema.

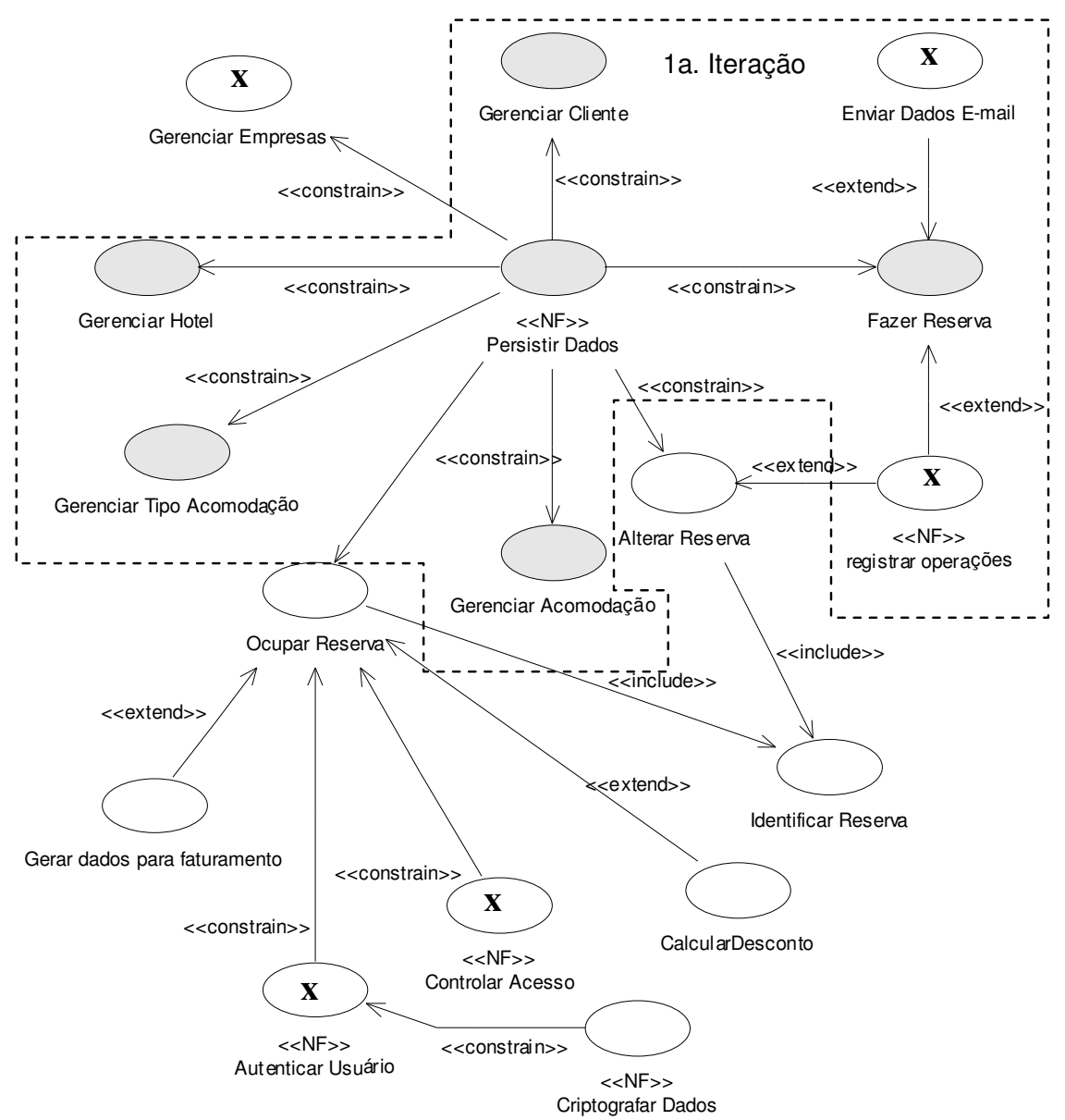

Figura 7.17 - Visão de Iteração para a Segunda Iteração do Sistema de Reservas

\subsubsection{2. - Identificar e Registrar Casos de Uso Candidatos a Aspectos}

Aplicando os critérios definidos para seleção de casos de uso candidatos a aspectos, a Tabela de Candidatos a Aspectos deve ser atualizada (Tabela 7.8). Considerando os casos de uso do sistema de reserva, o critério do "tipo" seleciona os casos de uso Controlar Acesso e Autenticar Usuário como candidatos a aspectos, já que os dois são não-funcionais. O critério "quantidade de relacionamentos" seleciona o caso de uso Identificar Reserva, pois é incluído por dois outros casos de uso. Os critérios "relacionamento de extensão" e "essencialidade" selecionam os casos de uso Calcular Desconto e o Gerar Dados para Faturamento e somente o critério de essencialidade seleciona o caso de uso Gerenciar Empresas.

Note-se que o caso de uso Calcular Desconto por si só não representa a funcionalidade de descontos descrita pelo documento de requisitos do sistema de reservas. A descrição textual desse requisito deixa claro que descontos são fornecidos para clientes que trabalham em empresas conveniadas com o hotel, mostrando que o cálculo de descontos é específico 
para determinadas empresas. Apesar de que o caso de uso Calcular Descontos por si só possa ser considerado como não-essencial, já que não são todos os hotéis que fornecem descontos, a funcionalidade de descontos descrita no documento de requisitos envolve também o conceito das empresas conveniadas, fazendo com que o caso de uso Gerenciar Empresas também faça parte dessa funcionalidade transversal. Assim, o conceito "Empresa" também faz parte da funcionalidade de descontos.

Tabela 7.8 - Tabela de Candidatos a Aspectos

\begin{tabular}{|l|c|l|c|}
\hline \multicolumn{1}{|c|}{ Caso de Uso } & \multicolumn{1}{|c|}{ Tipo (F/NF) } & \multicolumn{1}{c|}{ Critério } & $\square$ \\
\hline Persistir Dados & Não-funcional & Número de relacionamentos e Tipo & $\square$ \\
\hline Registrar Operações & Não-funcional & Tipo & $\square$ \\
\hline $\begin{array}{l}\text { Enviar Dados por E- } \\
\text { mail }\end{array}$ & Funcional & Um relacionamento de extensão & $\square$ \\
\hline Controlar Acesso & Não-Funcional & Tipo & $\square$ \\
\hline Autenticar usuário & Não-Funcional & Tipo & $\square$ \\
\hline Identificar Reserva & Funcional & Quantidade de relacionamentos & $\square$ \\
\hline Calcular Desconto & Funcional & Um relacionamento de extensão/essencialidade & $\square$ \\
\hline Gerenciar Empresas & Funcional & Essencialidade & $\square$ \\
\hline $\begin{array}{l}\text { Gerar Dados para } \\
\text { Faturamento }\end{array}$ & Funcional & Um relacionamento de extensão/essencialidade & $\square$ \\
\hline
\end{tabular}

\subsubsection{3 - Desenvolver Modelo Conceitual}

Na Figura 7.18 é mostrado o modelo conceitual para a porção do sistema tratada nesta iteração, em que os novos conceitos estão destacados em cinza. Como o conceito Empresa é oriundo do caso de uso candidato a aspecto Gerenciar Empresa, foi destacado com uma nota.

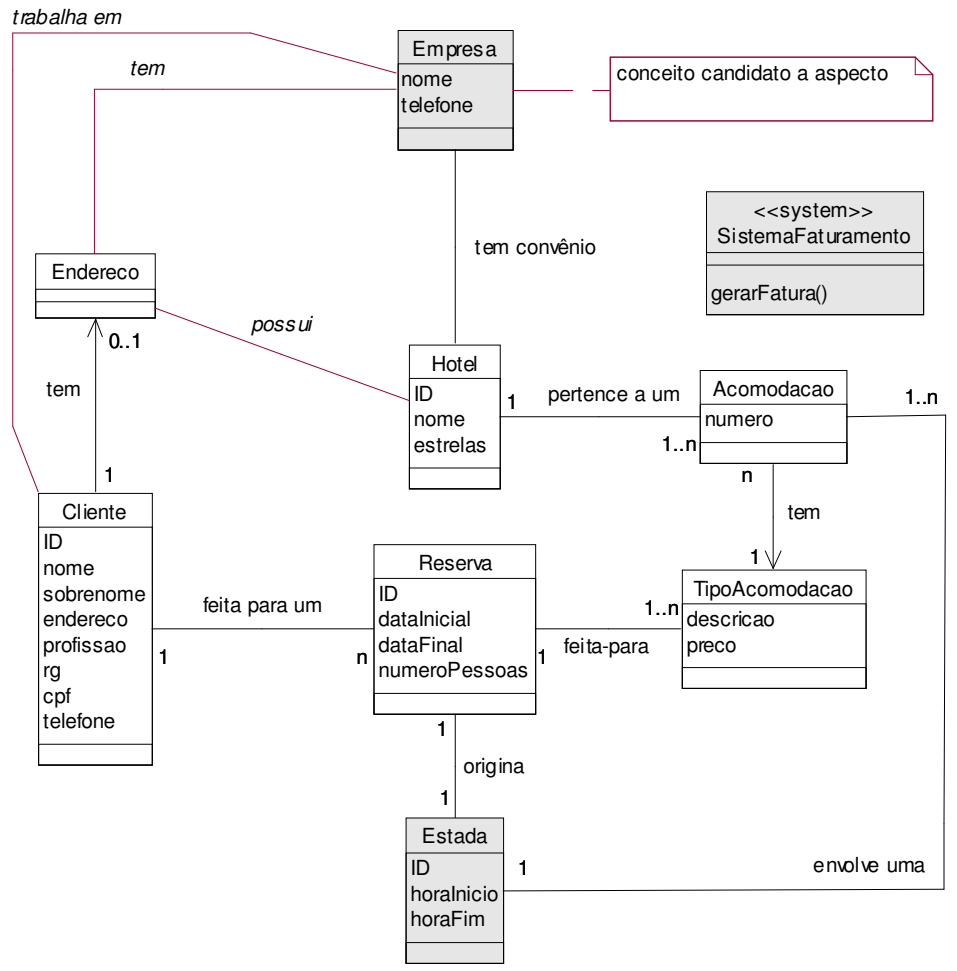

Figura 7.18 - Modelo Conceitual Atualizado 


\subsection{2 - Disciplina Projeto}

\subsubsection{1 - Identificar Aspectos}

A Tabela de Aspectos para o sistema de reservas (Tabela 7.9) possui nesta iteração mais seis casos de uso candidatos para serem implementados com aspectos: Controlar Acesso, Autenticar Usuário, Identificar Reserva, Calcular Desconto, Gerenciar Empresas e Gerar Dados para Faturamento. Na Tabela 7.9 é mostrado o resultado da aplicação dos critérios para cada caso de uso e a decisão final. Os casos de uso Controlar Acesso e Autenticar Usuários foram considerados aspectos pela sua natureza não-funcional, além disso, são exemplos clássicos de aspectos encontrados na literatura. O caso de uso Identificar Reserva, apesar de ser incluído por mais de um caso de uso e ser atômico, não foi considerado um aspecto porque é essencial ao comportamento dos casos de uso base que é incluído. Além disso, ele também não é volátil. O caso de uso Gerar Dados para Faturamento é atômico, essencial à funcionalidade do caso de uso calcular reserva e não é volátil, o que elimina a possibilidade de ser implementado com aspectos.

Tabela 7.9 - Tabela de Aspectos para o Sistema de Reservas - 2a Iteração

\begin{tabular}{|c|c|c|c|c|c|c|}
\hline Casos de Uso & Tipo & Atomicidade & Volatilidade & $\begin{array}{l}\text { Framework } \\
\text { Transversal }\end{array}$ & $\begin{array}{c}\text { Implementa } \\
\text { como } \\
\text { Aspecto? } \\
\end{array}$ & Implementado? \\
\hline Persistir Dados & $\mathrm{NF}$ & - & - & $S$ & Sim & Х \\
\hline $\begin{array}{l}\text { Registrar } \\
\text { Operações }\end{array}$ & $\mathrm{NF}$ & - & - & $S$ & Sim & $\square$ \\
\hline $\begin{array}{l}\text { Enviar Dados } \\
\text { por E-mail }\end{array}$ & $\mathrm{F}$ & $\mathrm{s}$ & $\mathrm{N}$ & $\mathrm{N}$ & adiada & $\square$ \\
\hline $\begin{array}{l}\text { Controlar } \\
\text { Acesso }\end{array}$ & $\mathrm{NF}$ & - & - & $S$ & Sim & $\square$ \\
\hline $\begin{array}{l}\text { Autenticar } \\
\text { usuário }\end{array}$ & $\mathrm{NF}$ & - & - & $S$ & Sim & $\square$ \\
\hline $\begin{array}{l}\text { Identificar } \\
\text { Reserva }\end{array}$ & $\mathrm{F}$ & $\mathrm{s}$ & $\mathrm{n}$ & $\mathrm{N}$ & Não & $\square$ \\
\hline $\begin{array}{l}\text { Calcular } \\
\text { Desconto }\end{array}$ & $\mathrm{F}$ & S & $\mathrm{s}$ & $?$ & Sim & $\square$ \\
\hline $\begin{array}{l}\text { Gerenciar } \\
\text { Empresas }\end{array}$ & $\mathrm{F}$ & $\mathrm{s}$ & $\mathrm{s}$ & $\mathrm{N}$ & Sim & $\square$ \\
\hline $\begin{array}{l}\text { Gerar Dados } \\
\text { para } \\
\text { Faturamento }\end{array}$ & $\mathrm{F}$ & $\mathrm{s}$ & $\mathrm{n}$ & $\mathrm{N}$ & Não & $\square$ \\
\hline
\end{tabular}

O caso de uso Calcular Desconto necessita uma análise mais profunda. Ele é atômico porque não é possível dividir sua descrição para eliminar o compartilhamento, não é essencial ao comportamento do caso de uso base porque existem sistemas de reservas que não fornecem descontos para empresas conveniadas, e é volátil, pois os cálculos e os valores de descontos podem ser alterados a qualquer momento. O importante a ser observado é que esse caso de 
uso colaborador está atrelado ao caso de uso de gerenciamento de empresas, pois os descontos são oferecidos apenas para as empresas que são conveniadas com o hotel.

Seguindo a linha de raciocínio do critério da essencialidade, identifica-se que podem haver sistemas de reservas que não fornecem descontos para empresas conveniadas. Da mesma forma, o critério da volatilidade também pode ser aplicado, pois nada garante que o hotel fornecerá esses descontos para sempre. Portanto, não é apenas o caso de uso calcular desconto que é volátil e não-essencial, mas sim toda a funcionalidade de fornecimento de descontos para empresas conveniadas, inclusive o caso de uso Gerenciar Empresas. Assim, deve-se acompanhar com cuidado essa funcionalidade no decorrer do desenvolvimento com o objetivo de verificar as modificações que ela exige na porção do sistema que já está desenvolvida e qual a estratégia de implementação que será utilizada. Como se trata de um requisito volátil, sua implementação deve ser feita de forma a não criar dependências da parte base para ela, o que facilitaria a remoção dessa funcionalidade em algum futuro próximo. Se houver dependências, essas devem ser implementadas de forma que o requisito volátil dependa da parte base, e não o contrário. Assim, como os casos de uso Calcular Descontos e o Gerenciar Empresas possuem particularidades que justificam sua implementação com aspectos, serão implementados com essa tecnologia.

Um ponto importante é quanto à existência de FTs para apoiar a implementação desses casos de uso. Certamente o único FT que pode apoiar a implementação de Gerenciar Empresas é o FT de persistência, já que esse caso de uso consiste nas operações básicas de persistência sobre o conceito Empresa. No caso de Calcular Descontos, não havia um FT que pudesse ser utilizado para apoiar sua implementação, assim, decidiu-se por implementar um novo FT para esse interesse volátil.

O primeiro passo foi realizar uma análise mais profunda nesse caso de uso com o objetivo compreender seu comportamento. Após entrevistas com os interessados no sistema, constatou-se que a funcionalidade de descontos deveria ser baseada em faixas de valores, fornecendo diferentes taxas percentuais de descontos para diferentes faixas de valores gastos no hotel, independentemente da empresa conveniada. Na Tabela 7.10 é mostrada a regra dos descontos. Se o valor da conta do cliente se enquadra em alguma das faixas, a respectiva porcentagem mostrada na última coluna da tabela é deduzida desse valor.

Para tornar o reúso mais efetivo o primeiro passo no sentido de criar um FT para essa regra de negócio foi generalizá-la, para que o FT pudesse ser reusado com regras de negócio similares. Assim, a regra de negócio implementada no FT foi a seguinte: um valor $\boldsymbol{x}$ é incrementado ou decrementado em uma determinada porcentagem que depende da faixa de 
valores que $\boldsymbol{x}$ se enquadra. Dessa forma, outras regras de negócio que utilizam a mesma estrutura poderão se beneficiar desse FT. As faixas de valores e a porcentagem são específicas de cada regra de negócio e devem ser informadas pelo engenheiro da aplicação quando o FT estiver sendo reusado. Esse novo FT foi denominado de Cálculo Baseado em Tabela.

Outro detalhe importante é que esse novo FT é dependente de contexto, pois o valor que deve ser incrementado ou decrementado deve ser capturado de um código-base. Assim, optou-se por implementar esse FT com todas as alternativas de composição do padrão Capturador de Dados. Maiores detalhes sobre esse FT podem ser encontrados na Seção 3.3.1.

Tabela 7.10 - Faixas de Descontos

\begin{tabular}{|l|l|l|}
\hline \multicolumn{1}{|c|}{ Limite inferior } & \multicolumn{1}{|c|}{ Limite superior } & \multicolumn{1}{c|}{ Porcentagem de desconto } \\
\hline $\mathrm{R} \$ 70,00$ & $\mathrm{R} \$ 100,00$ & $5 \%$ \\
\hline $\mathrm{R} \$ 101,00$ & $\mathrm{R} \$ 200,00$ & $7 \%$ \\
\hline $\mathrm{R} \$ 201,00$ & Não existe & $10 \%$ \\
\hline
\end{tabular}

O caso de uso Enviar Dados por E-mail, está com situação pendente, como pode ser visto pela palavra "adiada" na última coluna da Tabela. Optou-se por manter essa pendência e tentar solucioná-la nas outras iterações.

Observe-se que há determinados casos de uso funcionais transversais que, caso forem considerados aspectos, não podem ter sua implementação adiada. Por exemplo, se o caso de uso Identificar Reserva fosse considerado um aspecto, deveria ser implementado nesta iteração, pois é uma funcionalidade necessária para se realizar uma reserva. Os casos de uso que não serão implementados com aspectos podem ser retirados dessa tabela e também da Tabela de Candidatos a Aspectos.

\subsubsection{2 - Selecionar Aspectos para a Iteração Atual}

Embora os casos de uso alvo desta iteração sejam quatro - Controlar Acesso, Autenticar Usuário, Calcular Desconto e Gerenciar Empresas - os demais descritos na Tabela de Aspectos, e que ainda não foram implementados, devem ser novamente analisados. Como a quantidade de casos de uso originais desta iteração é superior às demais, optou-se por não implementar os casos de uso apoiadores, isto é, aqueles que aparecem na visão de iteração simplesmente porque possuem relacionamentos com os originais. Isso é possível porque casos de uso apoiadores geralmente não são relacionados diretamente com a funcionalidade principal do sistema.

Os casos de uso Controlar Acesso e Autenticar Usuário são exemplos clássicos de requisitos adequados para serem implementados com aspectos e sua natureza permite que sejam protelados e adicionados depois que a parte base do sistema esteja finalizada. Apesar da existência de FTs que podem auxiliar em sua implementação, optou-se por não sobrecarregar 
a iteração para não extrapolar os prazos. Os casos de uso Calcular Desconto e Gerenciar Empresas, apesar de fazerem parte da mesma funcionalidade transversal, podem ser implementados em iterações distintas. O caso de uso Gerenciar Empresas pode ser implementado facilmente por que consiste nas operações básicas de persistência sobre o conceito Empresa, e a existência do FT de persistência auxilia nesse sentido. Entretanto, sua implementação deve ser feita de forma a não criar dependências da parte base para com ela. Portanto, apenas o caso de uso Gerenciar Empresas será implementado nesta iteração, já que é o único original desta iteração. Na Tabela 7.11 é mostrada a Tabela de Acompanhamento da Implementação dos Aspectos para esta segunda iteração da fase de construção.

Observe-se que o requisito não-funcional de persistência também pode afetar outros requisitos transversais, como é o caso do Gerenciar Empresas. A implementação desse caso de uso, que também será feita com aspectos, é afetada pelo FT de persistência.

Tabela 7.11 - Tabela de Acompanhamento da Implementação de Aspectos para o Sistema de Reservas $2^{\mathbf{a}}$ Iteração

\begin{tabular}{|c|l|}
\hline No. Iteração & \multicolumn{1}{|c|}{ Aspecto } \\
\hline $1^{\mathrm{a}}$. da elaboração & Persistir Dados \\
\hline $2^{\mathrm{a}}$. da elaboração & Gerenciar Empresas \\
\hline
\end{tabular}

\subsubsection{3 - Desenvolver Diagramas de Interação}

Uma situação que pode ocorrer nesta atividade é a necessidade de modificar um diagrama de interação, já elaborado em iterações anteriores, por causa da inclusão de um caso de uso selecionado como aspecto. Por exemplo, o caso de uso Gerenciar Empresas foi eleito como aspecto e será implementado nesta iteração. A presença desse caso de uso nesta iteração faz com que o gerenciamento de hotéis e de clientes também tenha que ser alterado, pois durante o cadastro de um novo hotel precisam ser informadas as empresas conveniadas e durante o cadastro de um cliente deve ser informada a empresa em que ele trabalha.

\subsubsection{4 - Projetar Aspectos}

Como pode ser visto na Tabela de Acompanhamento da Implementação de Aspectos (Tabela 7.11) o caso de uso Gerenciar Empresas foi selecionado para ser implementado nesta iteração. Esse caso de uso consiste nas operações básicas de persistência sobre o conceito "empresa", permitindo que uma empresa seja armazenada, atualizada e ou removida do mecanismo persistente. Como essas operações são apoiadas pelo FT de persistência, o projeto e a implementação dessa parte é simples e rápida. Contudo, o impacto mais significativo que esse caso de uso traz para o sistema ocorre nas classes Hotel e Cliente, que precisam ser modificadas com a inclusão de um relacionamento com a classe Empresa, como pode ser visto no diagrama conceitual mostrado na Figura 7.18. Isso deve ser feito porque o hotel 
precisa saber quais são as empresas que mantém convênio com ele e um cliente necessita informar a empresa que ele trabalha. A inclusão desses relacionamentos implica em modificações na classe Hotel e Cliente. Na classe Hotel deve ser acrescentado um atributo que é uma lista de empresas, criar um novo construtor, e incluir dois outros métodos de acesso a esse atributo. Na classe Cliente deve-se também acrescentar um atributo do tipo Empresa, criar um novo construtor e dois novos métodos de acesso.

Como foi comprovado anteriormente, o caso de uso Gerenciar Empresas faz parte de um requisito volátil que não é essencial ao sistema de reservas, e por isso, não é desejável que a parte base do sistema possua uma dependência estrutural com a classe Empresa, ou mesmo uma dependência mais fraca, como a presença de um alguns métodos que referenciem essa classe. Além dessa modificação na parte base do sistema, a classe controladora de cadastros também deve ser modificada com o acréscimo de outros métodos relativos à classe Empresa, também criando dependências indesejadas. Portanto, o relacionamento existente entre essas classes, e inclusive a inserção de novos métodos, deve ser feito de forma transparente para a parte base do sistema, sem que essa fique dependente da classe Empresa. Uma das formas de incluir esses relacionamentos e esses métodos nas classes Hotel e Cliente é por meio de declarações intertipo da linguagem AspectJ.

Na Figura 7.19 é mostrado o projeto do caso de uso Gerenciar Empresas como um tema-base. A classe Hotel é apresentada com dois novos métodos de acesso a atributos, um novo construtor e um novo relacionamento com a classe Empresa. A classe Cliente, da mesma forma, possui um relacionamento de associação com a classe Empresa, um novo construtor e dois novos métodos de acesso a atributos. Quando esse modelo for composto por intercalação com a parte base da aplicação, as classes com o mesmo nome serão agrupadas em apenas uma, e os métodos e relacionamentos que estão projetados, e que não existem nas classes correspondentes, serão incluídos nelas.

\subsubsection{5 - Desenvolver Modelo de Classes de Projeto}

A elaboração dos diagramas de colaboração mostrados na atividade anterior auxilia na identificação de novas operações, métodos e classes que devem ser adicionadas no diagrama de classes de projeto. Assim, na Figura 7.20 é mostrado parcialmente o diagrama de classes de projeto atualizado do sistema de reservas. Deve ser observado que esse modelo de classes é o modelo que já foi composto com o FT de persistência em momentos anteriores, porém toda

parte relativa ao FT de persistência não está sendo exibida para melhorar a legibilidade. As classes atualizadas com a inserção de novos métodos foram Hotel, ControladorReserva e Acomodacao. Note-se também a adição das classes Estada e srvocuparReserva, e do 
sistema de faturamento SistemaFaturamento. A classe ControladorCadastros não está sendo exibida com todos os seus relacionamentos para facilitar a visualização.

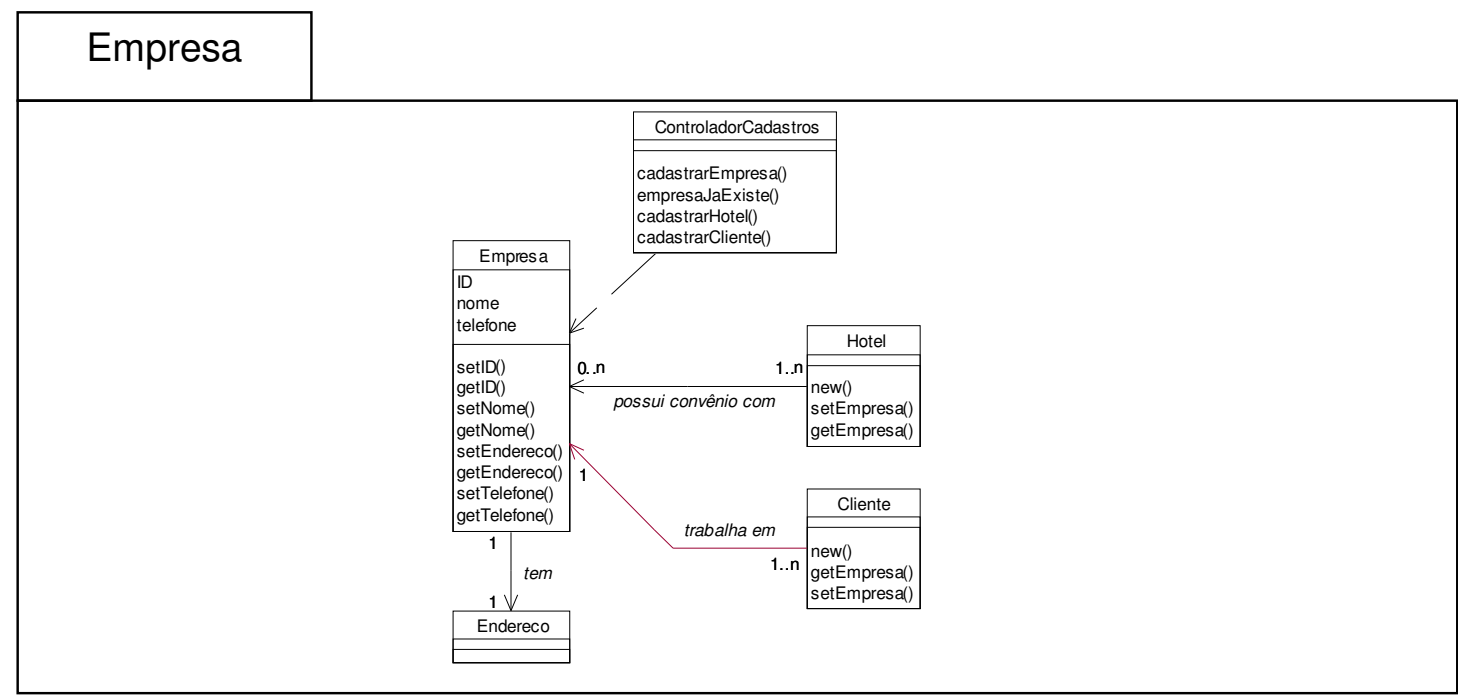

Figura 7.19 - Projeto do Aspecto Funcional Gerenciar Empresas

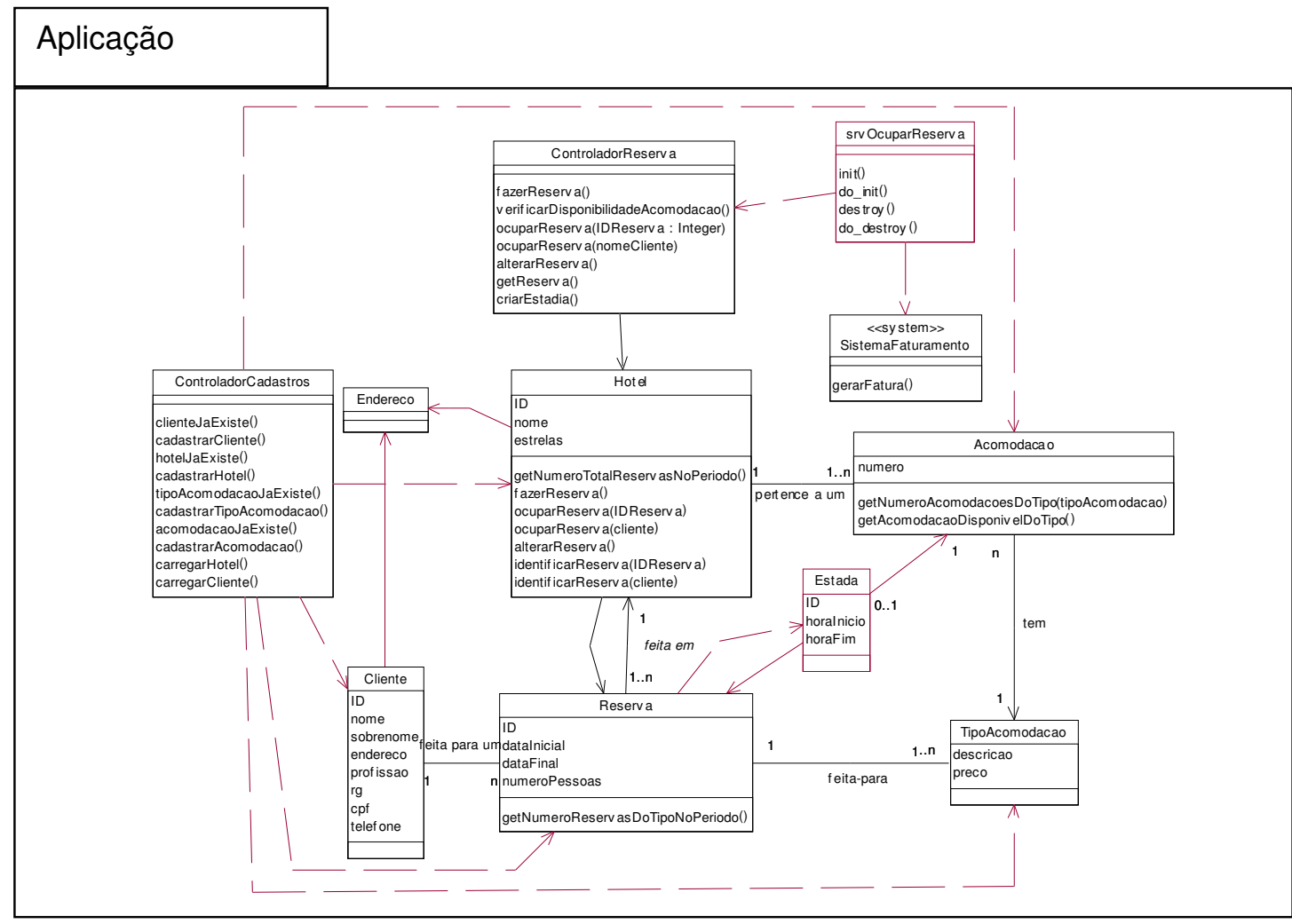

Figura 7.20 - Modelo de Classes de Projeto para o Sistema de Reservas - 2a. Iteração

\subsection{3 - Projetar Acoplamento dos Aspectos com a Base}

Como o único aspecto funcional do sistema de reservas foi projetado como um tema-base, a composição entre a porção já projetada da aplicação com esse tema-base é feita por meio de um relacionamento de intercalação. Assim, os elementos que possuem os mesmos nomes são agrupados em apenas um. 
Na Figura 7.21 é mostrada a composição entre os temas Aplicação Base e Empresa e a Figura 7.22 mostra o tema resultante dessa composição. Note-se o aparecimento da classe Empresa, seus relacionamentos com a classe Hotel, Endereco e ControladorCadastros e dois novos métodos na classe controladorCadastros, o cadastrarEmpresa() e o empresaJaExiste().

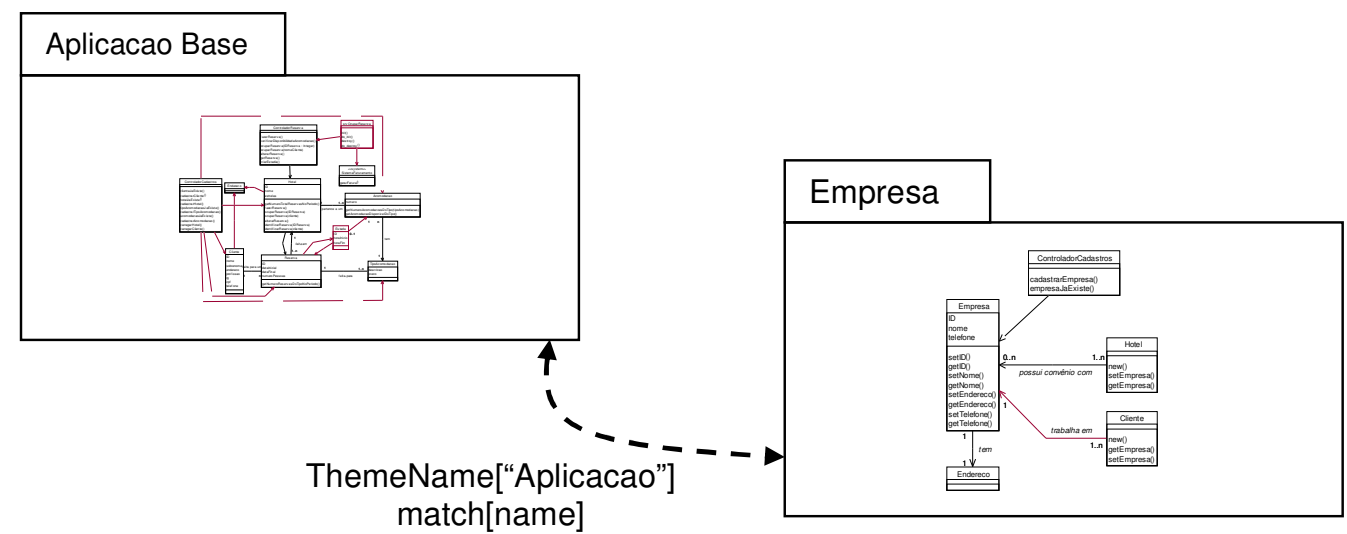

Figura 7.21 - Composição entre Temas Base

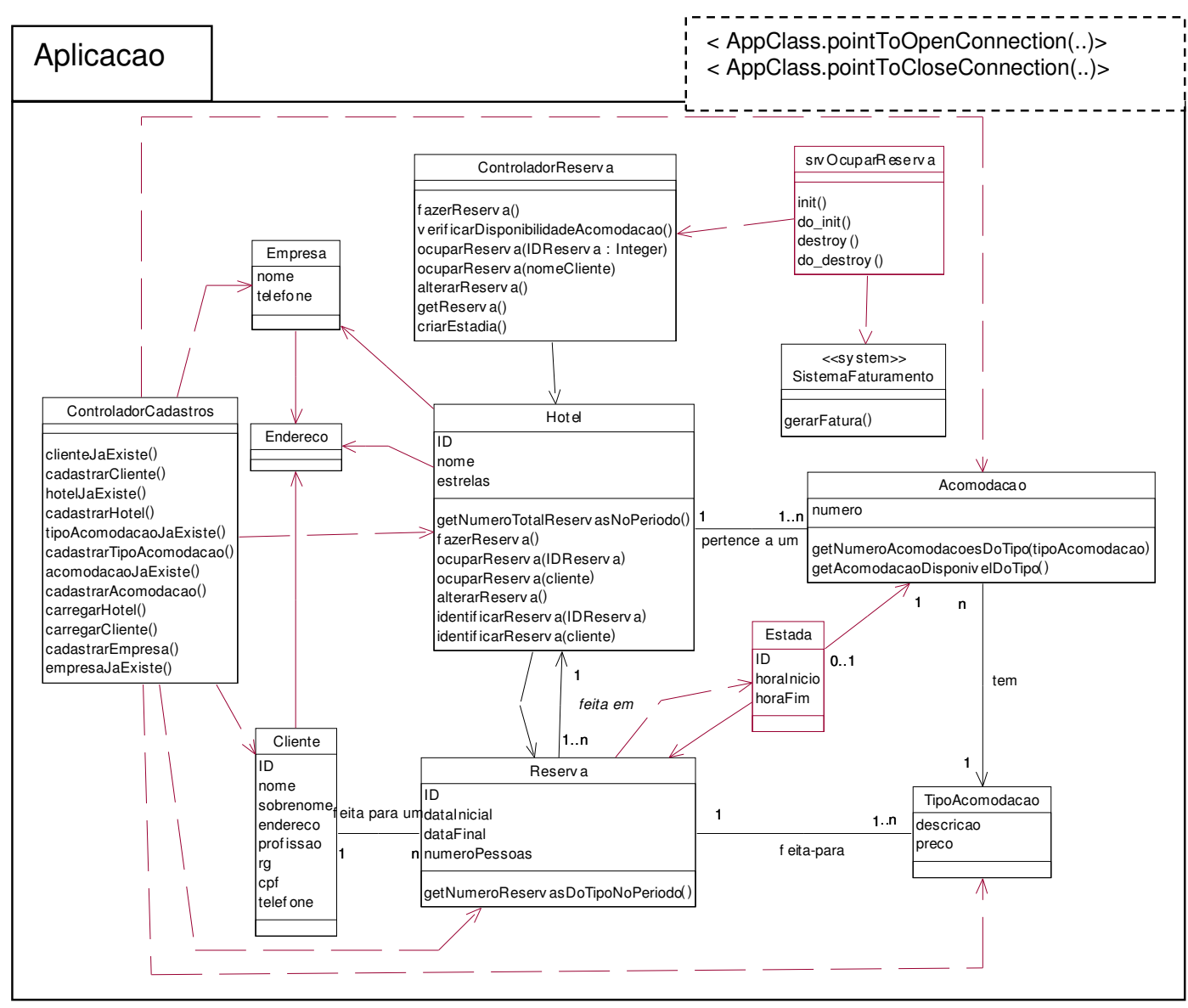

Figura 7.22 - Tema resultante da composição - Modelo de Classes de Projeto - 2a. Iteração 


\subsubsection{7 - Desenvolver Visão da Arquitetura}

Esta atividade tem como objetivo desenvolver ou evoluir a Visão da Arquitetura do Sistema. Ela sempre deve ser realizada após o acoplamento de algum FT ou aspecto ao sistema. Como a atividade anterior projetou e acoplou o aspecto Empresa ao sistema, a Visão da Arquitetura deve ser atualizada como mostra a Figura 7.23. Note-se que o relacionamento de entrecorte entre esse aspecto e o componente-base é estático.

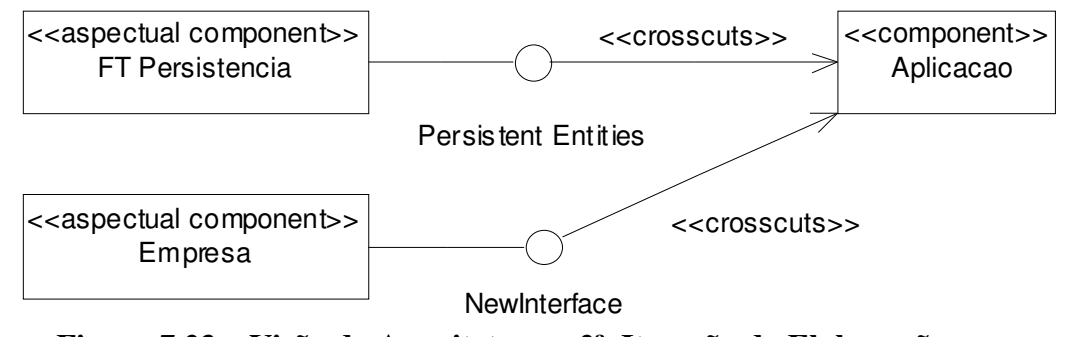

Figura 7.23 - Visão da Arquitetura - 2a . Iteração da Elaboração

\subsubsection{8 - Registrar Pontos de Junção}

Como o novo aspecto incluído no sistema realiza apenas modificações estáticas não será necessário registrá-lo no Registro de Pontos de Junção.

\subsubsection{9 - Atualizar Regras de Composição}

Nesta iteração, as classes Estada, Empresa e srvocuparReserva foram adicionadas ao modelo de classes de projeto. A classe Estada e a classe Empresa são classes persistentes porque possuem tabelas correspondentes no banco de dados e a classe srvOcuparReserva é uma classe de interface, em que a conexão com o banco de dados deve ser aberta e fechada. Portanto, as regras de composição devem ser atualizadas para que o FT de persistência também afete esses novos elementos de projeto.

Na Figura 7.24 é mostrada a atualização realizada nas regras de composição, as quais estão destacadas em negrito. A primeira operação gabarito agora também considera o método init() da classe srvocuparReserva. A segunda operação gabarito, responsável pelo encerramento da conexão com o banco de dados agora considera o método destroy(), também da classe srvOcuparReserva e, por último, a terceira operação gabarito considera o construtor da classe Estada, e o construtor da classe Empresa. Embora essas classes não estejam sendo exibidas considere sua existência dentro do pacote.

Como comentado anteriormente, sempre que as regras de composição de um FT que já foi acoplado ao sistema são atualizadas, deve-se também atualizar o Registro de Pontos de Junção e analisar se há pontos de junção compartilhados por dois ou mais aspectos/FTs. Sendo assim, a Tabela 7.12 mostra o Registro de Pontos de Junção atualizado para o sistema 
de reservas. Como apenas o FT de persistência encontra-se acoplado ao sistema, não há pontos de junção afetados por dois ou mais FTs.

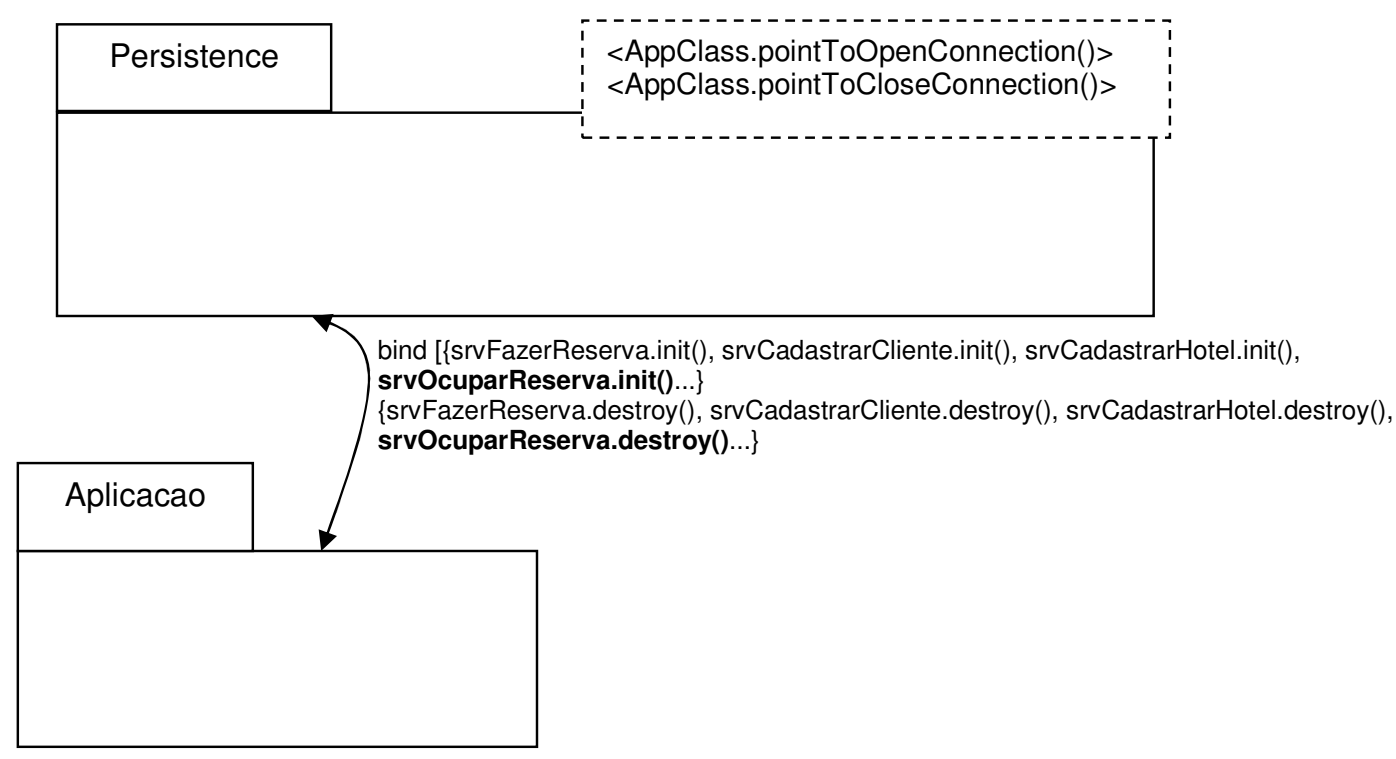

Figura 7.24 - Visão de Acoplamento para o Sistema de Reservas - 2a. Iteração da Elaboração

Tabela 7.12 - Registro de Pontos de Junção - 2a . Iteração da Elaboração

\begin{tabular}{|c|l|l|l|}
\hline \multirow{2}{*}{$\begin{array}{c}\text { FT/Aspecto } \\
\downarrow\end{array}$} & \multicolumn{3}{|c|}{ Pontos de Junção Afetados } \\
\cline { 2 - 4 } & \multirow{2}{*}{ Método/atributo/constructor/adendo } & \multicolumn{1}{|c|}{ Unidades de Software } \\
\cline { 2 - 3 } & init() & \multicolumn{1}{|c|}{ Classe } & Aspecto \\
\hline & init() & srvOcuparReserva & srvFazerReserva \\
& init() & srvCadastrarCliente \\
FT de & destroy() & srvOcuparReserva \\
Persistencia & destroy() & srvCadastrartotel \\
& destroy() & srvFazerReserva \\
& new() & srvCadastrarCliente \\
& new() & srvCadastrartotel \\
& new() & Hotel \\
& new() & Reserva \\
& new() & Tipo \\
\hline
\end{tabular}

\subsection{4 - Disciplina Implementação}

\subsubsection{1 - Implementar Classes de Domínio}

As classes do sistema de reservas que devem ser implementadas nesta iteração são Estada, Empresa e srvOcuparReserva. Embora a classe Empresa esteja relacionada a um requisito volátil, sua implementação pode ser feita com técnicas orientadas a objetos. O que precisa ser analisado com cuidado é o seu relacionamento com as demais classes da parte base do sistema, por exemplo com a classe Hotel e com a classe Cliente. Como comentado na fase de projeto, não é desejável que as classes Hotel e cliente tenham dependências estruturais com a classe Empresa, já que esta é oriunda de um requisito volátil. Portanto, optou-se por implementar os relacionamentos e toda funcionalidade existente entre essas 
classes utilizando as declarações intertipo da linguagem AspectJ. Dessa forma, não haverá dependências em tempo de projeto.

Na Figura 7.25 é mostrado o aspecto EmpresasConveniadas. Esse aspecto introduz atributos e métodos nas classes Hotel, Cliente e ControladorCadastros, referentes ao requisito volátil em questão. $\mathrm{Na}$ classe Hotel, é introduzido um atributo chamado empresa do tipo vetor, que representa o relacionamento estrutural entre essas duas classes. Assim, a classe Hotel torna-se inconsciente da presença desse atributo e possui dependência com o requisito volátil apenas em tempo de execução. Esse aspecto introduz também na classe Hotel os métodos de acesso ao atributo introduzido - setEmpresa () e getEmpresa () - e um novo construtor, o qual considera o novo atributo com um parâmetro. Na classe Cliente são introduzidos um atributo do tipo Empresa, que representa o relacionamento de associação entre essas classes, um novo construtor e dois novos métodos de acesso a atributos. Além dessas introduções, os métodos cadastrarEmpresa() , cadastrarHotel() e cadastrarcliente() também são introduzido na classe controladora ControladorCadastros.

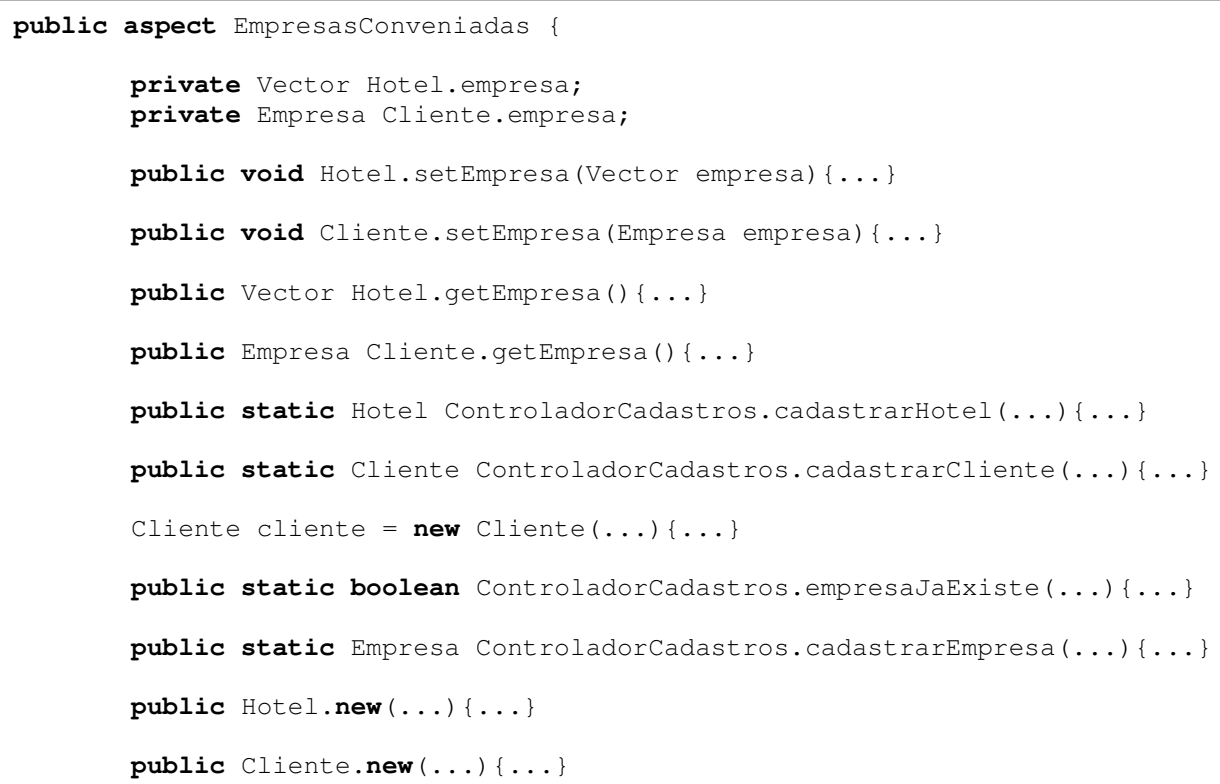

Figura 7.25 - Aspecto EmpresasConveniadas

\subsubsection{2 - Atualizar Regras de Composição}

No caso do sistema de reservas, deve-se apenas atualizar o acoplamento do FT de persistência com as novas classes criadas nesta iteração: Empresa e Estada. O aspecto MyPersistentEntities deve ser atualizado para que essas duas classes também possam ter as operações de persistência introduzidas, como mostra a Figura 7.26. 


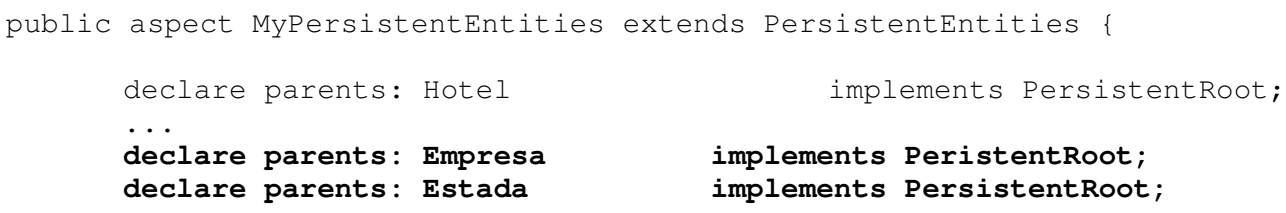

Figura 7.26 - Atualização do Aspecto MyPersistentEntities

Atualizações também são necessárias na conexão com o banco de dados, já que novas classes de interface agora estão presentes no sistema. Na Figura 7.27 é mostrada a atualização realizada em negrito.

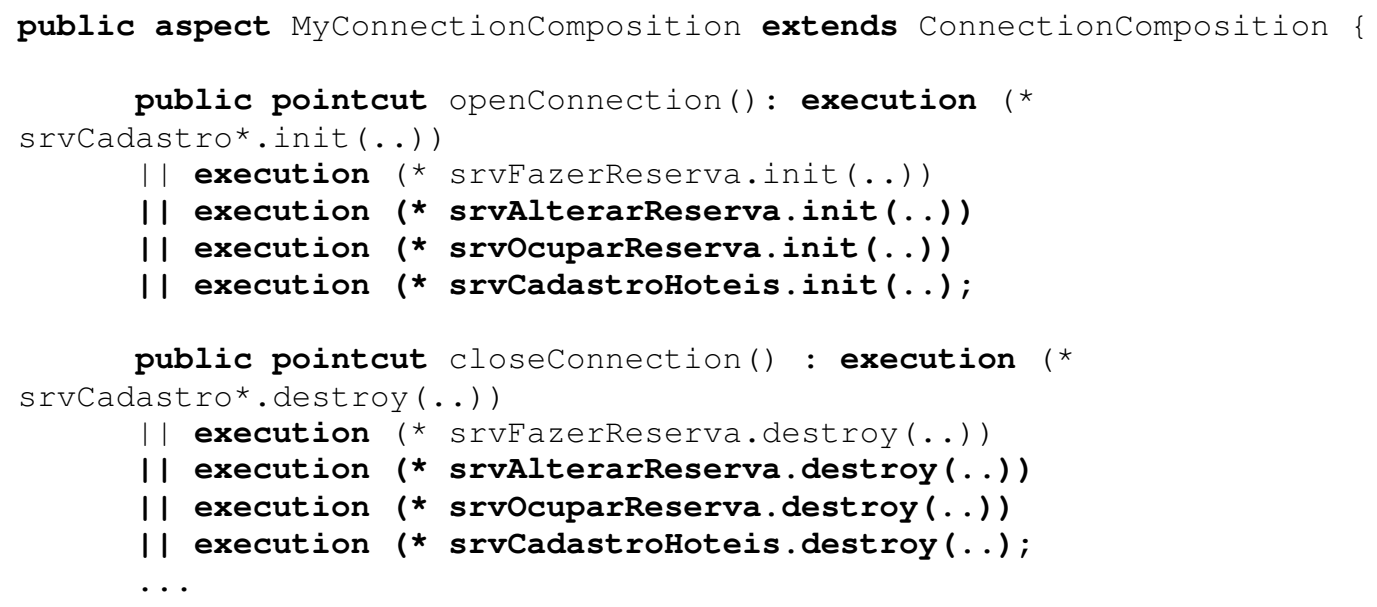

Figura 7.27 - Atualização das Regras de Composição da Conexão

\subsubsection{3 - Testar Sistema}

Analisando a Visão de Arquitetura pôde-se constatar que o único aspecto adicionado ao sistema nesta iteração foi Empresa. Sendo assim, foram realizados testes funcionais com o objetivo de verificar se as funcionalidades que envolviam o conceito Empresa estavam funcionando corretamente.

Como as regras de composição do FT de Persistência também tiveram que ser atualizadas em virtude da adição do caso de uso Gerenciar Empresa nesta iteração, suas funcionalidades também foram testadas novamente.

\section{5 - FASE DE CONSTRUÇAO - $1^{a}$ ITERAÇÃO}

Na Figura 7.28 é mostrada a visão de iteração de casos de uso para o sistema de reservas. Os casos de uso alocados originalmente para esta iteração são os vazios marcados com um "x", isto é, Cancelar Reserva e Não Comparecer. Os casos de uso vazios sem marcação são os que ainda não estão implementados e que possuem situação pendente, isto é, sua implementação foi postergada para iterações futuras. Geralmente são casos de uso não- 
funcionais que foram acrescentados ao sistema em conseqüência de um relacionamento que mantinham com algum caso de uso alocado para a iteração. Os casos de uso destacados em cinza são os que já estão implementados. Nenhum caso de uso não-funcional foi adicionado nesta iteração.

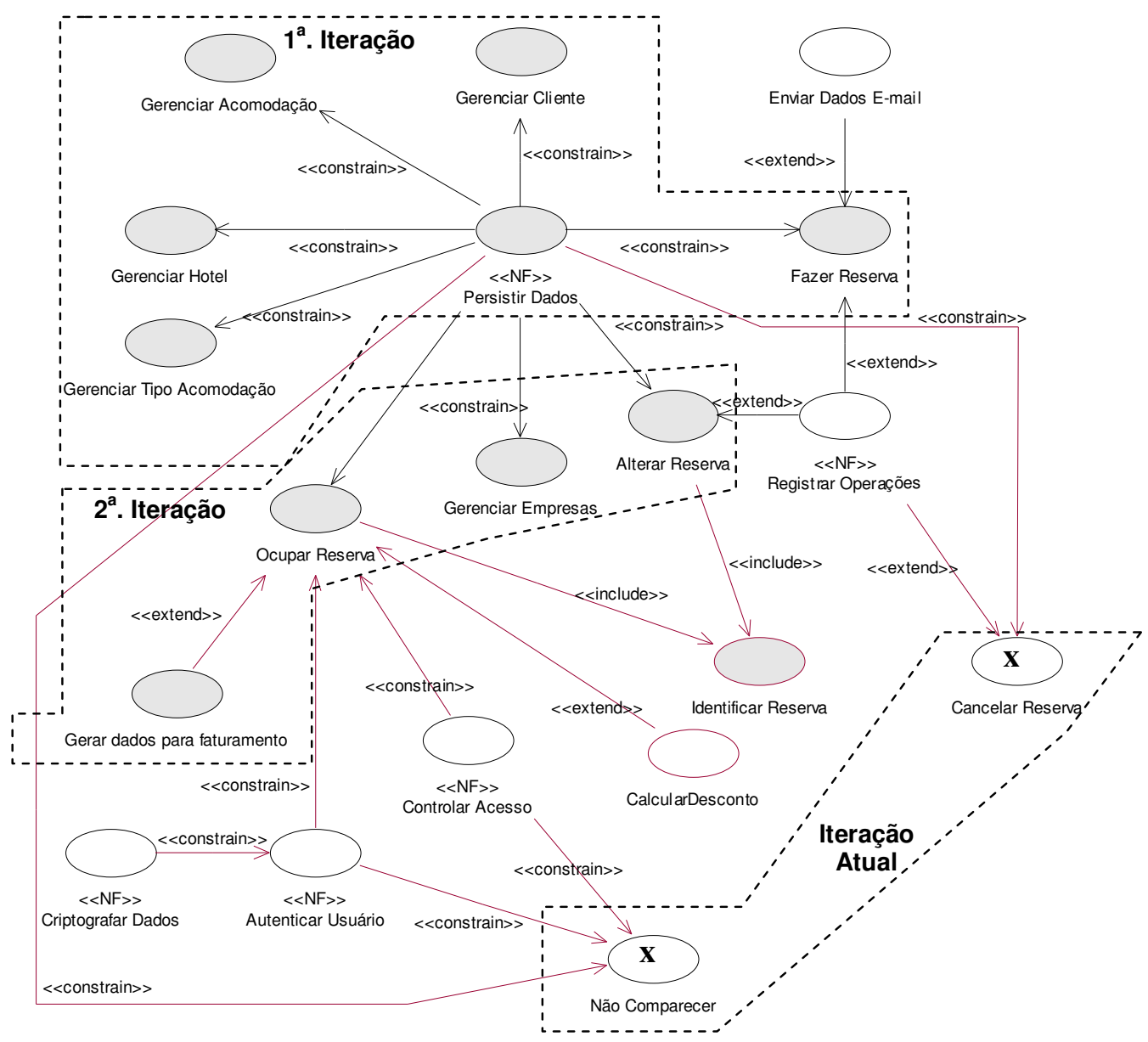

Figura 7.28 - Visão de Casos de Uso da Iteração Atual - $1^{\text {a }}$. Iteração da Construção

Na Figura 7.28 também são mostrados alguns novos relacionamentos que surgiram em decorrência da inclusão dos dois casos de uso alocados para esta iteração. O caso de uso Não Comparecer é restringido pelos casos de uso Autenticar Usuário, Controlar Acesso e Persistir Dados. O caso de uso Cancelar Reserva é restringido pelo caso de uso Persistir Dados e estendido por Registrar Operações. Esses novos relacionamentos são facilmente identificados porque na fase de concepção foram elaborados diagramas de casos de uso para cada requisito não-funcional. Nessa mesma figura também é possível identificar os casos de uso originais da primeira e segunda iterações da elaboração e da iteração atual, os quais estão delimitados por figuras geométricas tracejadas. 
Como nesta iteração não houve a identificação e implementação de nenhum aspecto, apenas as disciplinas de Análise e Projeto serão comentadas resumidamente. A disciplina de Implementação será suprimida.

\subsection{1 - Disciplina Análise}

$\mathrm{Na}$ atividade Identificar e Registrar Casos de Uso Colaboradores, nenhum novo caso de uso foi identificado. Apenas foram acrescentados alguns relacionamentos entre alguns casos de uso.

$\mathrm{Na}$ atividade Identificar e Registrar Casos de Uso Candidatos a Aspectos, nenhum novo caso de uso candidato a aspecto foi identificado para esta iteração. Portanto, a Tabela de Candidatos a Aspectos (Tabela 7.8) permanece a mesma da iteração anterior, a única diferença é que o caso de uso Gerenciar Empresas deve ser marcado como implementado.

Durante a atividade Desenvolver Modelo Conceitual nenhuma tarefa foi necessária porque todos os conceitos utilizados pelos casos de uso Cancelar Reserva e Não Comparecer já se encontram no modelo conceitual, nenhuma atualização foi necessária.

\subsection{2 - Disciplina Projeto}

$\mathrm{Na}$ atividade Identificar Aspectos, a Tabela de Aspectos (Tabela 7.9) também permanece a mesma da iteração anterior, já que não há novos casos de uso transversais nesta iteração.

Durante a realização da atividade Selecionar Aspectos para a Iteração Atual, optou-se por continuar postergando a implementação dos aspectos listados na Tabela de Aspectos (Tabela 7.9) para o final. Isso foi possível porque em geral, os aspectos que estão na Tabela de Aspectos são não-funcionais ou são funcionais que não influenciam diretamente na funcionalidade principal do sistema.

A atividade Desenvolver Diagramas de Interação foi conduzida de forma convencional resultando em dois diagramas de seqüência: um para o caso de uso Cancelar Reserva e outro para o caso de uso Não Comparecer.

$\mathrm{Na}$ atividade Desenvolver Modelo de Classes de Projeto o objetivo é evoluir o modelo de classes de projeto desenvolvido até o momento com base nos diagramas de interação elaborados na atividade anterior. Na Figura 7.29 é mostrado o modelo de classes de projeto atualizado do sistema de reservas. A classe controladora dos cadastros e algumas outras relacionadas não estão sendo exibidas para melhorar a visualização e também porque não sofreram modificações em relação à versão anterior. As classes que evoluíram nesta iteração foram: ControladorReserva, Reserva e SistemaFaturamento. $\mathrm{Na}$ classe ControladorReserva, por exemplo, foram acrescentados os métodos 
identificarReservasNaoOcupadas ().

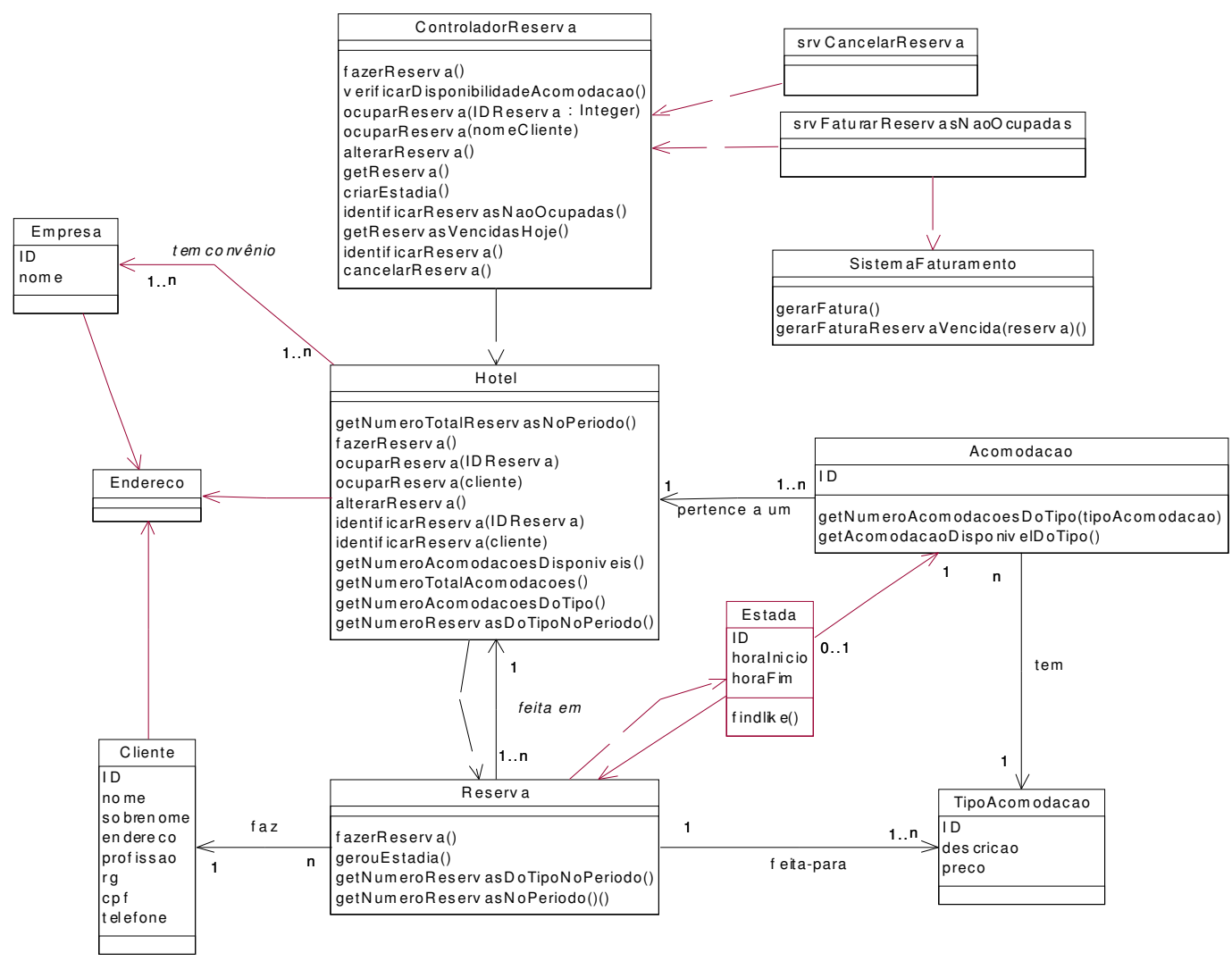

Figura 7.29 - Modelo de Classes de Projeto para o Sistema de Reservas - 1a. Iteração da Construção

$\mathrm{Na}$ atividade Atualizar Regras de Composição, o FT de persistência deve ter suas regras atualizadas. Como não houve o aparecimento de nenhuma nova classe persistente de aplicação nesta iteração, não há a necessidade de atualizar as regras referentes à parte básica de persistência, isto é, a característica Operações Persistentes. Apenas a parte relativa à conexão com o banco de dados é que deve ser atualizada, pois duas novas classes de interface foram adicionadas no sistema nesta iteração: srvFaturarReservasNaoOcupadas e srvCancelarReserva. Na Figura 7.30 são mostradas em negrito as atualizações realizadas.

Na Tabela 7.13 é mostrado parcialmente o Registro de Pontos de Junção para a primeira iteração da construção. Como apenas o FT de Persistência encontra-se acoplado ao sistema, não há dois ou mais FTs que atuam em pontos de junção comuns.

\section{6 - FASE DE CONSTRUÇÃO - 2a . ITERAÇÃO}

Na Figura 7.31 é mostrada a visão de iteração do sistema de reservas para esta segunda iteração da construção. Alguns casos de uso que já foram implementados não estão sendo mostrados para facilitar a visualização. Alguns continuam sendo exibidos porque possuem 
relacionamentos importantes com casos de uso que ainda não foram implementados. Os casos de uso marcados com um "x" são os originais da iteração, os vazios sem marcação são os que ainda não foram implementados oriundos de iterações anteriores e os cinza são os que já foram implementados. Os casos de uso alocados para esta iteração são: Reajustar Valor das Diárias, Consultar Número de Reservas, Listar Reservas por Período e Gerenciar Usuários.

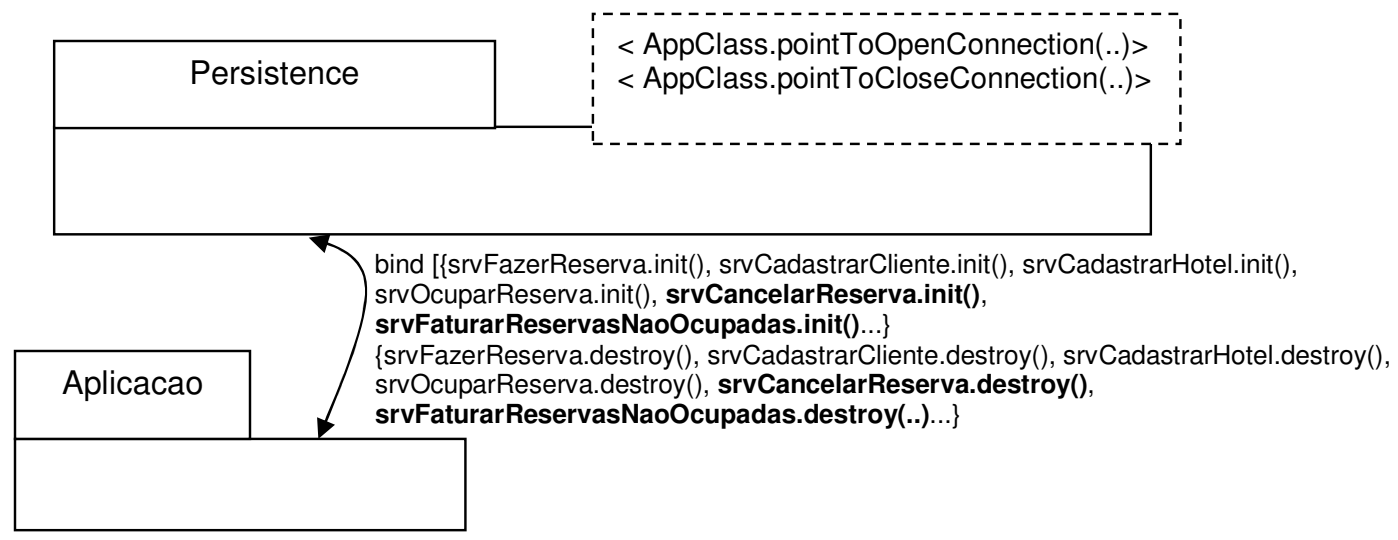

Figura 7.30 - Atualização das Regras de Composição - 1a $^{\mathrm{a}}$. Iteração da Construção

Tabela 7.13 - Registro de Pontos de Junção - 1a. Iteração da Construção

\begin{tabular}{|c|c|c|c|}
\hline \multirow{3}{*}{$\begin{array}{c}\text { FT/Aspecto } \\
\downarrow\end{array}$} & \multicolumn{3}{|c|}{ Pontos de Junção Afetados } \\
\hline & \multirow{2}{*}{ Método/atributo/constructor/adendo } & \multicolumn{2}{|l|}{ Unidades de Software } \\
\hline & & Classe & Aspecto \\
\hline $\begin{array}{c}\text { FT de } \\
\text { Persistencia }\end{array}$ & $\begin{array}{l}\text { init() } \\
\text { init() } \\
\text { destroy() } \\
\text { destroy() }\end{array}$ & $\begin{array}{l}\text { srvCadastrarCliente } \\
\text { srvOcuparReserva } \\
\text { srvCancelarReserva } \\
\text { srvFaturarReservasNaoOcupadas }\end{array}$ & \\
\hline
\end{tabular}

\subsection{1 - Disciplina Análise}

\subsection{1..1- Identificar e Registrar Casos de Uso Candidatos a Aspectos}

Na Tabela de Candidatos a Aspectos para esta iteração (Tabela 7.14) é mostrado que apenas o caso de uso Gerenciar Usuário foi selecionado como candidato a aspectos. O caso de uso Gerenciar Usuários foi selecionado pelo critério “Tipo” porque sua funcionalidade é parte do interesse não-funcional de controle de acesso, que é um exemplo clássico da literatura sobre aspectos.

Os outros casos de uso selecionados para esta iteração não são candidatos a aspetos porque são funcionais, não são voláteis e consistem em operações básicas de consulta ou relatórios do sistema cuja implementação não se torna espalhada por vários módulos.

\subsection{2 - Disciplina Projeto}

\subsubsection{1 - Identificar Aspectos}

Aplicando os critérios específicos desta atividade, o caso de uso Gerenciar Usuários foi identificado como aspecto porque sua funcionalidade é parte do caso de uso Controlar Acesso. Um ponto importante é reavaliar os casos de uso que possuem situação pendente com 
o objetivo de averiguar se devem ser implementados com aspectos ou não. Na Tabela 7.15 é mostrado que o caso de uso Enviar Dados por E-mail ainda está com situação pendente, pois possui a palavra "adiada" na coluna "Implementa como aspecto?". Isso mostra que nas iterações anteriores não havia informação suficiente sobre esse caso de uso que pudesse embasar a decisão de implementá-lo com ou sem aspectos. Como o processo agora está em sua última iteração da fase de construção, há mais conhecimento sobre o sistema e uma decisão pode ser tomada com mais certeza. Na Figura 7.5 é mostrado que o caso de uso Enviar Dados por E-mail estende apenas um caso de uso e, como não haverá mais adição de casos de uso funcionais ao sistema, o número de relacionamentos que esse caso de uso possui provavelmente não aumentará, caracterizando-o como uma funcionalidade restrita e pontual dentro do sistema. Além disso, um estudo das formas possíveis de implementação dessa funcionalidade revelou que seria possível alcançar bons níveis de modularidade mesmo com orientação a objetos, isto é, toda a funcionalidade poderia ser implementada com uma ou duas classes e uma única operação disponibilizada para o código cliente. Em conseqüência disso, optou-se por não implementar esse caso de uso com aspectos. Dessa forma, deve-se projetar esse caso de uso normalmente com orientação a objetos e atualizar os modelos que ele influencia.

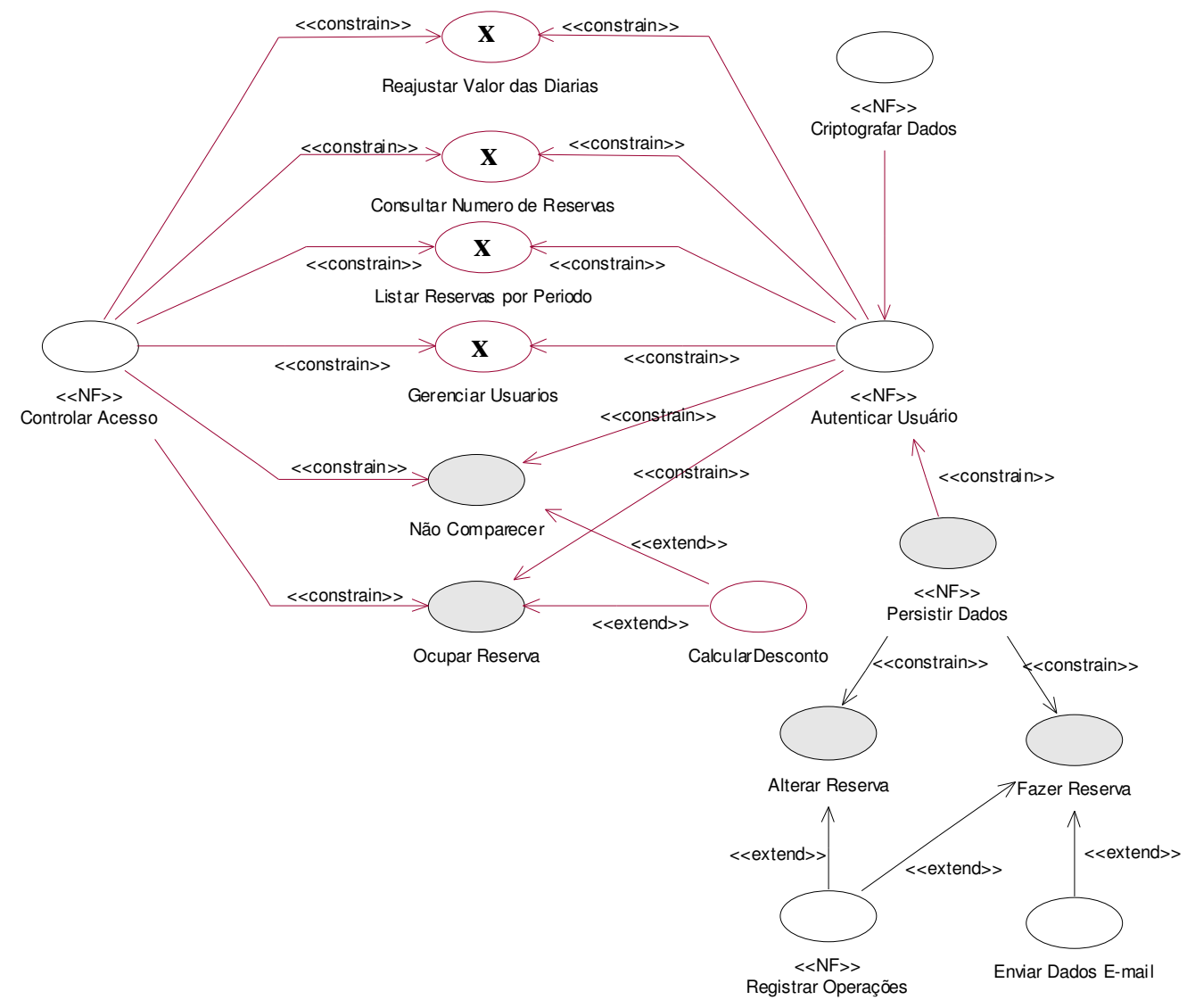

Figura 7.31 - Visão de Iteração para o Sistema de Reservas - 2 ${ }^{\mathrm{a}}$. Iteração da Construção 
Tabela 7.14 - Tabela de Candidatos a Aspectos

\begin{tabular}{|l|c|l|c|}
\hline \multicolumn{1}{|c|}{ Caso de Uso } & \multicolumn{1}{c|}{ Tipo (F/NF) } & \multicolumn{1}{c|}{ Critério } & Implementado \\
\hline Persistir Dados & Não-funcional & Número de relacionamentos e Tipo & $\square$ \\
\hline Registrar Operações & Não-funcional & Tipo & \\
\hline $\begin{array}{l}\text { Enviar Dados por E- } \\
\text { mail }\end{array}$ & Funcional & Um relacionamento de extensão & \\
\hline Controlar Acesso & Não-Funcional & Tipo & \\
\hline Autenticar usuário & Não-Funcional & Tipo & $\bigotimes$ \\
\hline Gerenciar Empresas & Funcional & Essencialidade & \\
\hline Calcular Desconto & Funcional & Um relacionamento de extensão/essencialidade & \\
\hline Gerenciar Usuários & Não-funcional & Tipo & \\
\hline
\end{tabular}

Tabela 7.15 - Tabela de Aspectos para o Sistema de Reservas - 2a. Iteração da Construção

\begin{tabular}{|l|l|l|l|l|l|c|}
\hline Casos de Uso & Tipo & Atomicidade & Volatilidade & $\begin{array}{l}\text { Framework } \\
\text { Transversal }\end{array}$ & $\begin{array}{c}\text { Implementa } \\
\text { como } \\
\text { Aspecto? }\end{array}$ & Implementado? \\
\hline $\begin{array}{l}\text { Persistir } \\
\text { Dados }\end{array}$ & NF & - & - & S & Sim & $\square$ \\
\hline $\begin{array}{l}\text { Registrar } \\
\text { Operações }\end{array}$ & NF & - & - & S & Sim & $\square$ \\
\hline $\begin{array}{l}\text { Enviar Dados } \\
\text { por E-mail }\end{array}$ & F & s & N & N & Adiada & $\square$ \\
\hline $\begin{array}{l}\text { Controlar } \\
\text { Acesso }\end{array}$ & NF & - & - & S & Sim & $\square$ \\
\hline $\begin{array}{l}\text { Autenticar } \\
\text { usuário }\end{array}$ & NF & - & - & S & Sim & $\square$ \\
\hline $\begin{array}{l}\text { Calcular } \\
\text { Desconto }\end{array}$ & F & s & s & S & Sim & $\square$ \\
\hline $\begin{array}{l}\text { Gerenciar } \\
\text { Empresas }\end{array}$ & F & s & s & N & sim & $\square$ \\
\hline $\begin{array}{l}\text { Gerenciar } \\
\text { Usuários }\end{array}$ & NF & s & $\underline{n}$ & S & sim & $\square$ \\
\hline
\end{tabular}

Depois que um caso de uso deixa o estado de pendência, deve-se ainda decidir quando ele deve ser implementado - se na iteração atual ou em alguma outra iteração futura. Em geral, casos de uso que se encontram em situação pendente não são primordiais à funcionalidade central do sistema, caso contrário teriam sido implementados nas iterações iniciais. No caso do Enviar Dados por E-mail, decidiu-se implementá-lo na iteração atual por esta ser a última iteração da fase de construção. Assim, os artefatos devem ser atualizados para considerarem também esse novo caso de uso.

\subsubsection{2 - Selecionar Aspectos para a Iteração Atual}

O Gerenciar Usuário é o único aspecto introduzido nesta iteração. Como ele é parte integrante do caso de uso Controlar Acesso, optou-se por postergar sua implementação de forma que esses dois casos de uso sejam implementados juntos. Assim, optou-se por não implementar nenhum aspecto nesta iteração, fazendo com que a Tabela de Acompanhamento da Implementação dos Aspectos continue sem modificações, como é mostrado na Tabela 7.16. 
Tabela 7.16 - Tabela de Acompanhamento da Implementação dos Aspectos

\begin{tabular}{|c|l|}
\hline No. Iteração & \multicolumn{1}{c|}{ Aspecto } \\
\hline $1^{\mathrm{a}}$. da elaboração & Persistir Dados \\
\hline $2^{\mathrm{a}}$. da elaboração & Gerenciar Empresas \\
\hline
\end{tabular}

\subsubsection{3 - Desenvolver Diagramas de Interação}

Durante a elaboração do diagrama de seqüência do caso de uso Reajustar Valor das Diárias notou-se que esse caso de uso deveria apresentar mais detalhes para ser compreendido adequadamente. A descrição desse caso de uso, como pode ser vista na Figura 7.32, revela na segunda linha que o sistema deve apresentar as opções de reajuste existentes, mas não diz nada sobre quais são essas opções de reajuste. Consultando os especialistas e pessoas interessadas no sistema, identificou-se que seria conveniente a existência de dois "tipos" de reajuste: reajuste com valores fixos e reajuste com valores percentuais. Além desses dos tipos, também seria conveniente se houvesse três "estratégias" de reajuste, uma que pudesse ser utilizada para reajustar todos os tipos de acomodação de uma única vez, outra em que o reajuste pudesse ser feito para tipos de acomodação escolhidos e outra que, além de poder escolher os tipos de acomodação, que também pudesse escolher um tipo de reajuste diferente para cada tipo de acomodação, por exemplo, valor fixo para quartos de Luxo e porcentagem para quartos Simples. Os tipos e as estratégias de reajuste podem variar freqüentemente, o que caracteriza esse requisito como volátil.

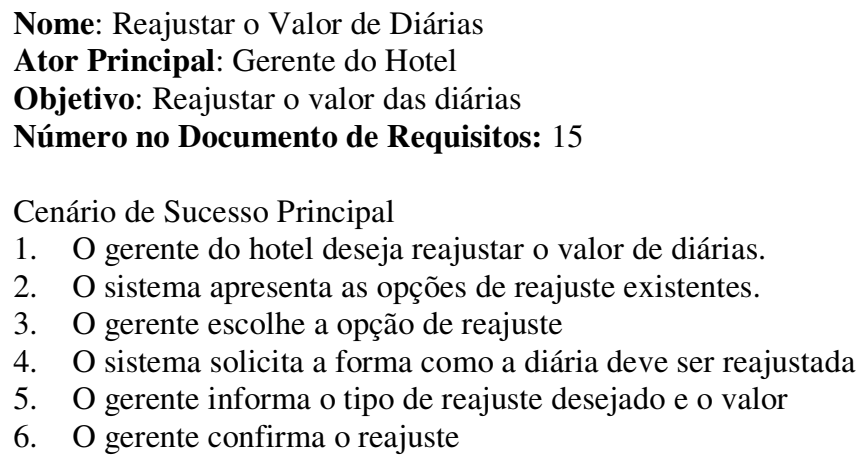

Figura 7.32 - Caso de Uso Reajustar Valor das Diárias

Quando uma determinada funcionalidade é percebida como volátil ou candidata a aspectos, a Tabela de Aspectos deve ser atualizada e os critérios devem ser aplicados com o objetivo de decidir se a nova funcionalidade deve ser implementada com aspectos. Na Tabela 7.17 é mostrada a Tabela de Aspectos atualizada para o sistema de reservas. Se as novas funcionalidades forem casos de uso, elas podem ser listadas juntamente com os casos de uso já presentes na tabela. Se forem funcionalidades menores, aconselha-se dar um nome para identificá-las e listá-las em uma parte separada da tabela, chamada Funcionalidades Extras. 
No caso em questão, a funcionalidade foi nomeada como Estratégias e Tipos de Reajuste e a tabela mostra o resultado da aplicação dos critérios. Essa funcionalidade é funcional, atômica (pois não pode ser dividida em dois ou mais comportamentos distintos) e volátil. Assim, optou-se por implementar esse caso de uso com aspectos. Entretanto, como não havia FT para apoiar a implementação desse caso de uso, optou-se por desenvolver um.

Tabela 7.17 - Tabela de Aspectos para o Sistema de Reservas

\begin{tabular}{|c|c|c|c|c|c|c|}
\hline Casos de Uso & Tipo & Atomicidade & Volatilidade & FT & $\begin{array}{c}\text { Implementa } \\
\text { como Aspecto? }\end{array}$ & Implementado? \\
\hline $\begin{array}{l}\text { Persistir } \\
\text { Dados }\end{array}$ & NF & - & - & $S$ & Sim & $\bigotimes$ \\
\hline $\begin{array}{l}\text { Registrar } \\
\text { Operações }\end{array}$ & $\mathrm{NF}$ & - & - & $S$ & Sim & $\square$ \\
\hline $\begin{array}{l}\text { Enviar Dados } \\
\text { por E-mail }\end{array}$ & $\mathrm{F}$ & $\mathrm{s}$ & $\mathrm{N}$ & $\mathrm{N}$ & adiada & $\square$ \\
\hline $\begin{array}{l}\text { Controlar } \\
\text { Acesso }\end{array}$ & NF & - & - & $\mathrm{S}$ & Sim & $\square$ \\
\hline $\begin{array}{l}\text { Autenticar } \\
\text { usuário }\end{array}$ & $\mathrm{NF}$ & - & - & $S$ & Sim & $\square$ \\
\hline $\begin{array}{l}\text { Calcular } \\
\text { Desconto }\end{array}$ & $\mathrm{F}$ & $\mathrm{s}$ & $\mathrm{s}$ & $\mathrm{S}$ & Sim & $\square$ \\
\hline $\begin{array}{l}\text { Gerenciar } \\
\text { Empresas }\end{array}$ & $\mathrm{F}$ & $\mathrm{s}$ & $\mathrm{s}$ & $\mathrm{N}$ & $\operatorname{sim}$ & Х \\
\hline $\begin{array}{l}\text { Gerenciar } \\
\text { Usuários }\end{array}$ & $\mathrm{NF}$ & $\mathrm{s}$ & $\underline{\mathrm{n}}$ & $S$ & $\operatorname{sim}$ & $\square$ \\
\hline \multicolumn{7}{|c|}{ Funcionalidades Extra } \\
\hline \multicolumn{7}{|l|}{ Nome } \\
\hline $\begin{array}{lr}\text { Estratégias } & \mathrm{e} \\
\text { Tipos } & \mathrm{de} \\
\text { Reajuste } & \end{array}$ & $\mathrm{F}$ & $\mathrm{s}$ & $\underline{\mathrm{S}}$ & $S$ & Sim & $\square$ \\
\hline
\end{tabular}

Assim como o FT de Persistência, Reajustar Valor das Diárias é uma funcionalidade que deve disponibilizar determinadas operações para o código-base utilizar. Algum usuário do sistema é que deve decidir quando é que determinado reajuste deve ser aplicado para as diárias do hotel. Assim, essas operações devem poder ser acessadas pela interface gráfica do sistema.

Depois que o processo de decisão foi realizado, deve-se ainda decidir se a nova funcionalidade deve ser implementada nesta iteração ou postergada para iterações futuras. Sendo assim, a atividade Selecionar Aspectos para a Iteração Atual deve ser realizada novamente com o objetivo de realizar essa decisão e atualizar a Tabela de Acompanhamento da Implementação dos Aspectos. Como o caso de uso Reajustar Valor das Diárias é funcional e foi originalmente alocado para ser desenvolvido nesta iteração, optou-se por implementar a nova funcionalidade aspectual na iteração atual. Portanto, a Tabela de Acompanhamento é mostrada na Tabela 7.18. 
O prosseguimento do processo consiste em elaborar um diagrama de interação para a funcionalidade de reajuste do valor das diárias. Entretanto, como essa funcionalidade será implementada com o apoio do novo FT, esse diagrama só poderá ser elaborado depois que o FT estiver acoplado ao sistema. Isso ocorre porque a utilização desse FT disponibiliza algumas operações prontas que devem ser utilizadas na implementação da funcionalidade e, conseqüentemente, na elaboração dos diagramas de projeto. Assim, neste momento o processo sai de seu fluxo normal para dar lugar ao processo de reúso do FT, o qual consiste na etapa de instanciação e composição.

Tabela 7.18 - Tabela de Acompanhamento da Implementação dos Aspectos

\begin{tabular}{|l|l|}
\hline \multicolumn{1}{|c|}{ No. Iteração } & \multicolumn{1}{c|}{ Aspecto } \\
\hline $1^{\text {a }}$. da elaboração & Persistir Dados \\
\hline $2^{\text {a }}$.da elaboração & Gerenciar Empresas \\
\hline $2^{\text {a }}$. Construção & Estratégias e tipos de Reajuste \\
\hline
\end{tabular}

Na Figura 7.33 é mostrado o modelo de projeto do FT de Reajuste de Valor já com as classes e aspectos que devem ser criados durante a instanciação, os quais estão destacados em cinza. Como o objetivo é que haja três estratégias de reajuste disponíveis no sistema, então as três variabilidades do framework devem ser utilizadas.

A escolha das variabilidades é feita criando-se classes concretas que estendem determinadas classes abstratas do FT. Por exemplo, a criação das três classes: MyAllCategories, MySpecificCategory e MyNonLinearIncrease, determina que as três estratégias sejam introduzidas no sistema, já que cada uma dessas classes estende uma determinada classe abstrata do FT que representa uma estratégia. Se uma determinada estratégia não fosse necessária no sistema, o processo consistiria apenas em não criar uma classe concreta que estendesse a classe abstrata correspondente.

Os métodos que aparecem na classe MyAllCategories são métodos que concretizam métodos-gancho da classe estendida e que têm a função de retornar valores e informações específicas da aplicação-base. Embora as classes MySpecificCategories e MyNonLinearIncrease estejam sendo exibidas sem métodos, esses foram suprimidos para facilitar a visualização, porém considere-se que todos os métodos-gancho foram concretizados. Note-se que durante a etapa de instanciação, o aspecto ReadjustmentPolicy do FT também deve ser estendido e alguns de seus métodos-gancho concretizados.

O modelo de projeto mostrado na Figura 7.33 consiste em um tema-base que será composto com a aplicação. Durante a composição, deve-se informar uma classe de aplicação 
que fará correspondência com a interface IValueIncrease e assumirá todos as operações nela definidas, isto é, os três métodos increaseValue().

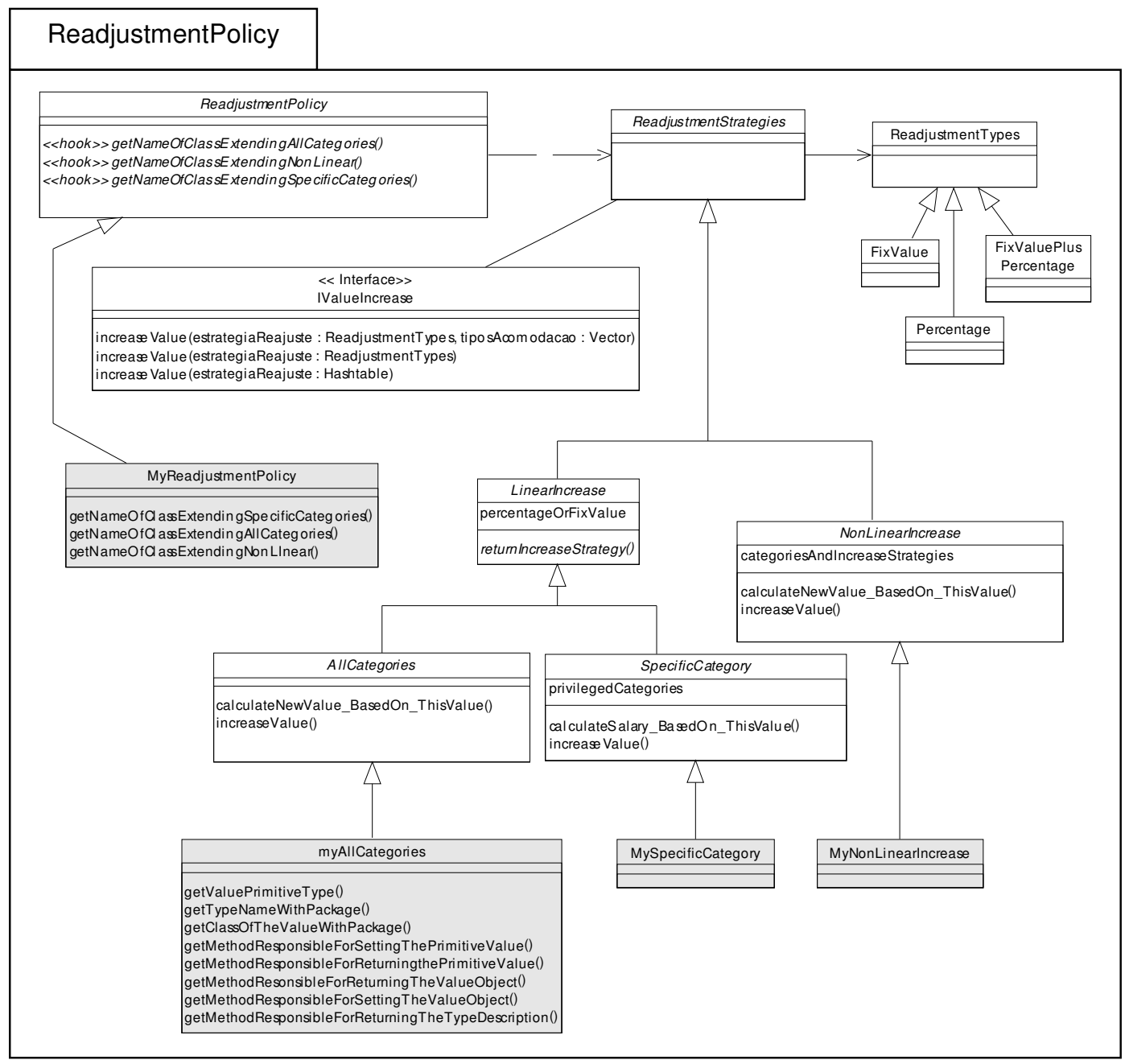

Figura 7.33 - Modelo de Projeto do FT de Reajuste de Valor Instanciado

Na Figura 7.34 é mostrada a composição entre o FT de Reajuste de Valores e a Aplicação-Base. O FT está sendo representado apenas pela interface IValueIncrease e a aplicação apenas pela classe TipoAcomodacao, por questões de legibilidade. $\mathrm{O}$ relacionamento de composição entre os pacotes representa que a classe TipoAcomodacao corresponde à interface IValueIncrease. Dessa forma, os três métodos mostrados na interface IValueIncrease serão introduzidos na classe TipoAcomodacao e podem ser utilizados normalmente durante o projeto e a implementação do sistema. O modelo de projeto resultante da composição não está sendo exibido por motivos de economia de espaço. Depois que o FT foi instanciado e acoplado à parte base da aplicação, o processo pode retornar ao seu fluxo normal para continuar a elaboração dos diagramas de interação. 


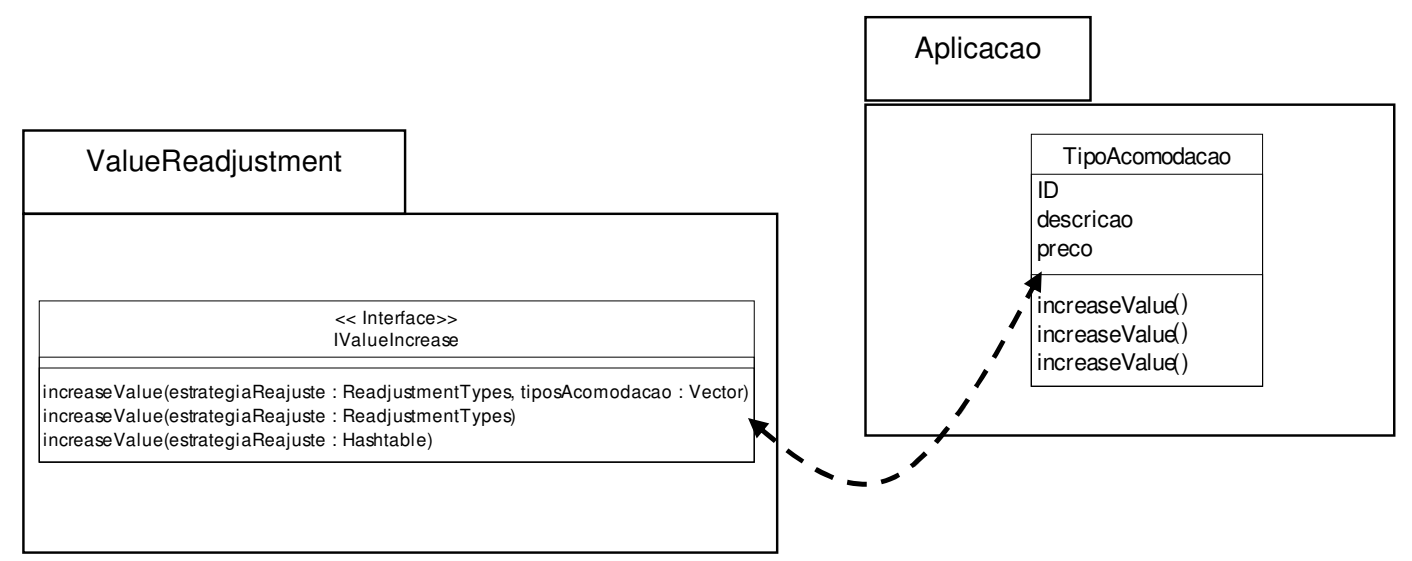

Figura 7.34 - Acoplamento FT de Reajuste de Valor com Aplicação Base

\subsubsection{4 - Desenvolver Visão da Arquitetura}

A atualização que deve ser realizada aqui em comparação com a Visão da Arquitetura anterior, consiste apenas na adição do FT de Reajuste de Valores, como é mostrado na Figura 7.35 .

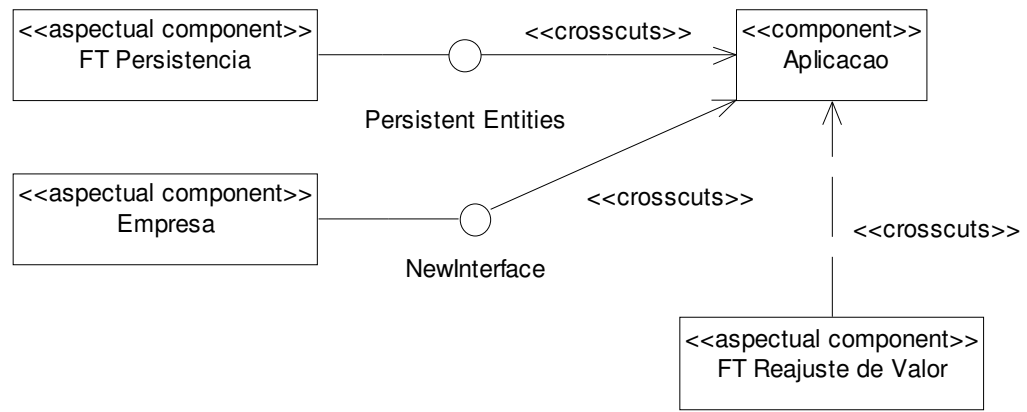

Figura 7.35 - Visão da Arquitetura - 2a. Iteração da Construção

\subsubsection{5 - Atualizar Regras de Composição}

Com o aparecimento das novas classes de interface srvReajustarValorDiarias, srvReajustarTodostipos e srvReajustarTiposselecionados, a parte de conexão com o banco de dados do FT de persistência deve ser atualizada. Assim, na Figura 7.36 são mostradas as atualizações realizadas em negrito.

\subsubsection{6 - Registrar Pontos de Junção}

Depois que as regras de composição foram atualizadas deve-se atualizar o Registro de Pontos de Junção do Sistema. Assim, com base nas regras de composição mostradas na Figura 7.36, o novo Registro de Pontos de Junção está sendo mostrado pela Tabela 7.19. Note-se que, embora um novo FT tenha sido adicionado ao sistema - o de Reajuste de Valores - sua influência é estática, e não precisa ser discriminada nesta tabela. 


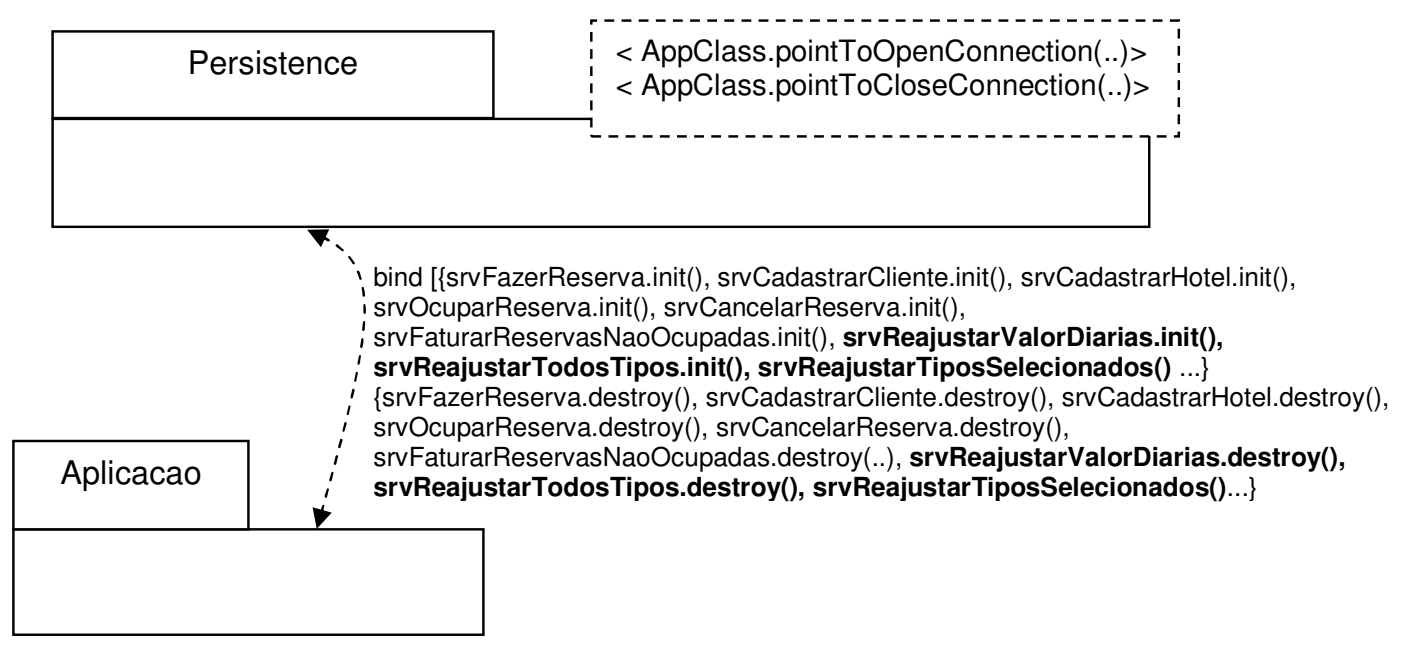

Figura 7.36 - Atualização das Regras de Composição da Conexão

Tabela 7.19 - Registro de Pontos de Junção - 2a. Iteração da Construção

\begin{tabular}{|c|c|c|c|}
\hline \multirow{3}{*}{$\begin{array}{c}\text { FT/Aspecto } \\
\downarrow\end{array}$} & \multicolumn{3}{|c|}{ Pontos de Junção Afetados } \\
\hline & \multirow{2}{*}{ Método/atributo/constructor/adendo } & \multicolumn{2}{|c|}{ Unidades de Software } \\
\hline & & Classe & Aspecto \\
\hline $\begin{array}{c}\text { FT de } \\
\text { Persistencia }\end{array}$ & $\cdots$ & $\cdots$ & \\
\hline
\end{tabular}

\subsection{3 - Disciplina Implementação}

Como se optou por utilizar um FT para a implementação do reajuste de valor das diárias, esta atividade consiste no processo de reúso desse FT. Na Figura 7.37 é mostrada a implementação da classe MyAllCategories, que é uma das classes da etapa de instanciação do FT, como pode ser visto na Figura 7.33. As outras duas classes que também devem ser criadas durante a etapa de instanciação não estão sendo exibidas porque são bastante similares.

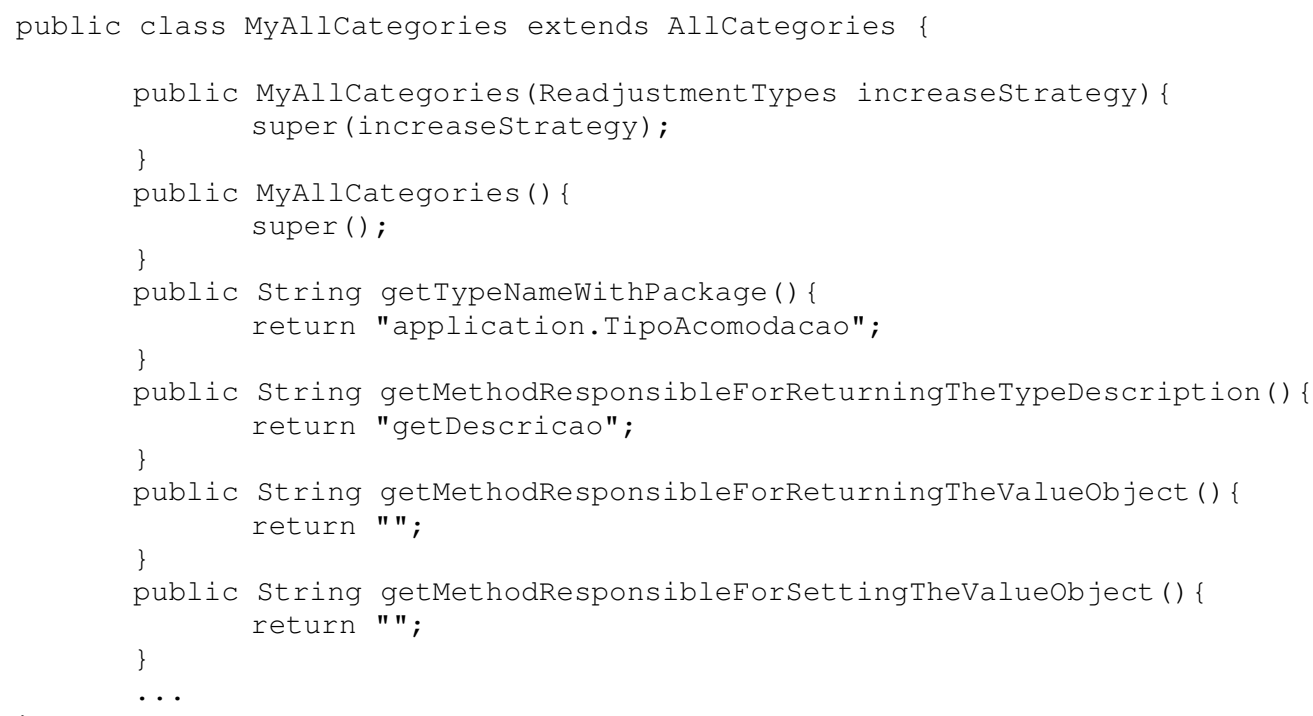

Figura 7.37 - Classe MyAllCategories 
Na Figura 7.38 é mostrado o aspecto MyReadjustmentPolicy, que deve ser criado durante a etapa de instanciação para sobrepor três métodos, mas que também é atualizado na etapa de composição para fornecer as regras de composição que unem o FT com a parte-base do sistema. A regra de composição que deve ser fornecida consiste na declaração declare parents, a qual faz com que a classe de aplicação TipoAcomodacao implemente a interface IValueIncrease do FT.

Depois que o aspecto foi implementado, deve-se atualizar a Tabela de Aspectos para registrar sua implementação. Nesse sentido, na Tabela 7.20 é mostrada a Tabela de Aspectos atualizada. Note-se que a funcionalidade de estratégias de reajuste agora está marcada com um "X", indicando que sua implementação foi realizada. Note-se também que o caso de uso Enviar Dados por E-mail não contém mais a palavra "adiada" na coluna "Implementa com Aspecto?”.

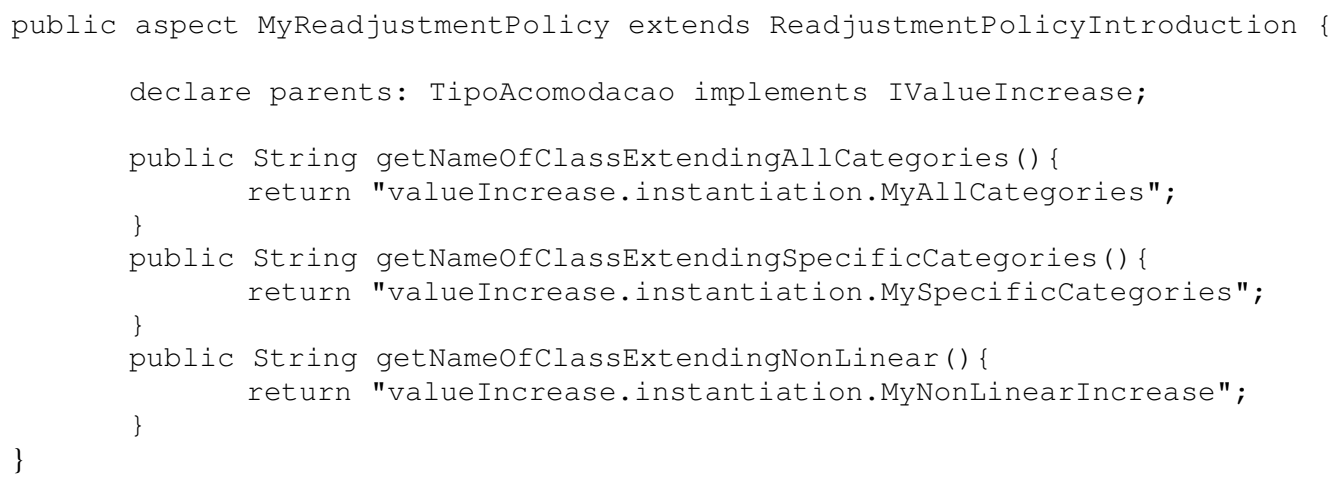

Figura 7.38 - Aspecto MyReadjustmentPolicy

\subsection{4 - Planejar Iterações}

Na Tabela 7.20 é mostrado que ainda há quatro casos não-funcionais (Autenticar Usuário, Controlar Acesso, Gerenciar Usuários e Registrar Operações) e um funcional (Calcular Desconto) que ainda não foram implementados. Assim como foi feito na fase de concepção, os casos de uso devem ser classificados para decidir a ordem de implementação, conforme está sendo mostrado na Tabela 7.21.

Optou-se por planejar três iterações, como é mostrado na Tabela 7.22. A primeira iteração é responsável pelo caso de uso funcional Calcular Desconto e as demais pelos nãofuncionais. A segunda iteração irá tratar de três casos de uso: Autenticar Usuário, Gerenciar Usuários e Controlar Acesso. Isso está sendo feito porque Gerenciar Usuários e Controlar Acesso fazem parte do interesse de Autenticação. 
Tabela 7.20 - Tabela de Aspectos Atualizada

\begin{tabular}{|c|c|c|c|c|c|c|}
\hline Casos de Uso & Tipo & Atomicidade & Volatilidade & FT & $\begin{array}{c}\text { Implementa } \\
\text { como Aspecto? }\end{array}$ & Implementado? \\
\hline $\begin{array}{l}\text { Persistir } \\
\text { Dados }\end{array}$ & NF & - & - & $S$ & Sim & Х \\
\hline $\begin{array}{l}\text { Registrar } \\
\text { Operações }\end{array}$ & $\mathrm{NF}$ & - & - & $S$ & Sim & $\square$ \\
\hline $\begin{array}{l}\text { Enviar Dados } \\
\text { por E-mail }\end{array}$ & $\mathrm{F}$ & $\mathrm{s}$ & $\mathrm{N}$ & $\mathrm{N}$ & Não & 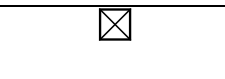 \\
\hline $\begin{array}{l}\text { Controlar } \\
\text { Acesso } \\
\end{array}$ & NF & - & - & $\mathrm{S}$ & Sim & $\square$ \\
\hline $\begin{array}{l}\text { Autenticar } \\
\text { usuário }\end{array}$ & $\mathrm{NF}$ & - & - & $S$ & Sim & $\square$ \\
\hline $\begin{array}{l}\text { Calcular } \\
\text { Desconto }\end{array}$ & $\mathrm{F}$ & $\mathrm{s}$ & $\mathrm{s}$ & $S$ & Sim & $\square$ \\
\hline $\begin{array}{l}\text { Gerenciar } \\
\text { Empresas }\end{array}$ & $\mathrm{F}$ & $\mathrm{s}$ & $\mathrm{s}$ & $\mathrm{N}$ & $\operatorname{sim}$ & Х \\
\hline $\begin{array}{l}\text { Gerenciar } \\
\text { Usuários }\end{array}$ & $\mathrm{NF}$ & $\mathrm{s}$ & $\underline{\mathrm{n}}$ & $S$ & $\operatorname{sim}$ & $\square$ \\
\hline \multicolumn{7}{|c|}{ Funcionalidades Extra } \\
\hline \multicolumn{7}{|l|}{ Nome } \\
\hline $\begin{array}{lr}\text { Estratégias } & \mathrm{e} \\
\text { Tipos } & \mathrm{de} \\
\text { Reajuste } & \end{array}$ & $\mathrm{F}$ & $\mathrm{s}$ & $\underline{\mathrm{S}}$ & $S$ & Sim & 邓 \\
\hline
\end{tabular}

Tabela 7.21 - Classificação dos Casos de Uso Aspectuais

\begin{tabular}{|l|l|}
\hline \multicolumn{1}{|c|}{ Casos de Uso } & \multicolumn{1}{c|}{ Tipo } \\
\hline Calcular Desconto & F \\
\hline Autenticar usuário & NF \\
\hline Controlar Acesso & NF \\
\hline Gerenciar Usuários & NF \\
\hline Registrar Operações & NF \\
\hline
\end{tabular}

Tabela 7.22 - Tabela de Planejamento das Iterações do Sistema de Reservas

\begin{tabular}{|l|l|l|}
\hline \multicolumn{2}{|c|}{ Iterações Aspectuais } \\
\hline $1^{\text {a }}$ Iteração & & Calcular Desconto \\
\hline $2^{\mathbf{a}}$ Iteração & & $\begin{array}{l}\text { Autenticar Usuário } \\
\text { Gerenciar Usuários } \\
\text { Controlar Acesso }\end{array}$ \\
\hline $3^{\text {a } \text { Iteração }}$ & Registrar Operações \\
\hline
\end{tabular}

\section{7 - FASE DE CONSTRUÇÃO - 1ª . ITERAÇÃo ASPECTUAL}

Esta primeira iteração aspectual da fase de construção concentra-se no desenvolvimento do caso de uso Calcular Desconto. Na Figura 7.39 é mostrada a visão de iteração para esta iteração.

\subsection{1 - Disciplina Projeto}

Durante a atividade Projetar Aspectos, observou-se pela Tabela de Aspectos (Tabela 7.20) a existência de um FT que pôde ser utilizado para apoiar a implementação do caso de uso Calcular Desconto. Assim, os modelos de projeto desse FT também foram utilizados no projeto. Como o processo de reúso desse FT já foi exemplificado na Seção 3.3, as atividades 
Projetar Aspectos, Acoplar Aspectos e Desenvolver Modelo de Projeto Composto não serão discutidas nesta iteração.

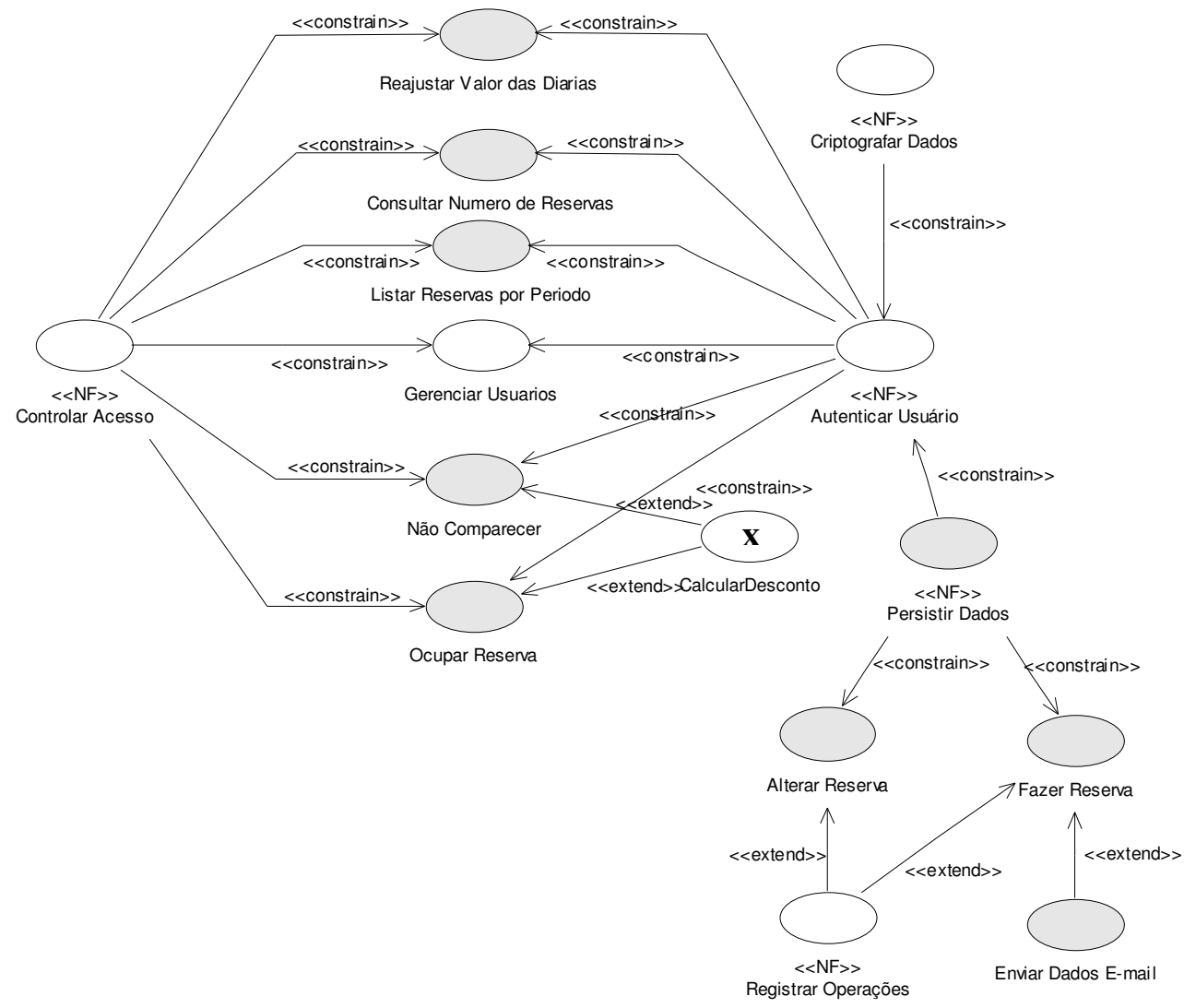

Figura 7.39 - Visão de Iteração - 3a. Iteração da Construção

$\mathrm{Na}$ atividade Desenvolver Visão da Arquitetura, o novo diagrama que agora considera também o FT de Cálculo, pode ser visto na Figura 7.40. Na atividade Registrar Pontos de Junção a Tabela 7.23 foi atualizada, mostrando que o FT de Cálculo está projetado para afetar apenas dois pontos do código-base, como pode ser visto na última linha da Tabela. Como nenhum outro aspecto afeta esse mesmo ponto de junção, nenhuma estratégia de precedência precisou ser definida.

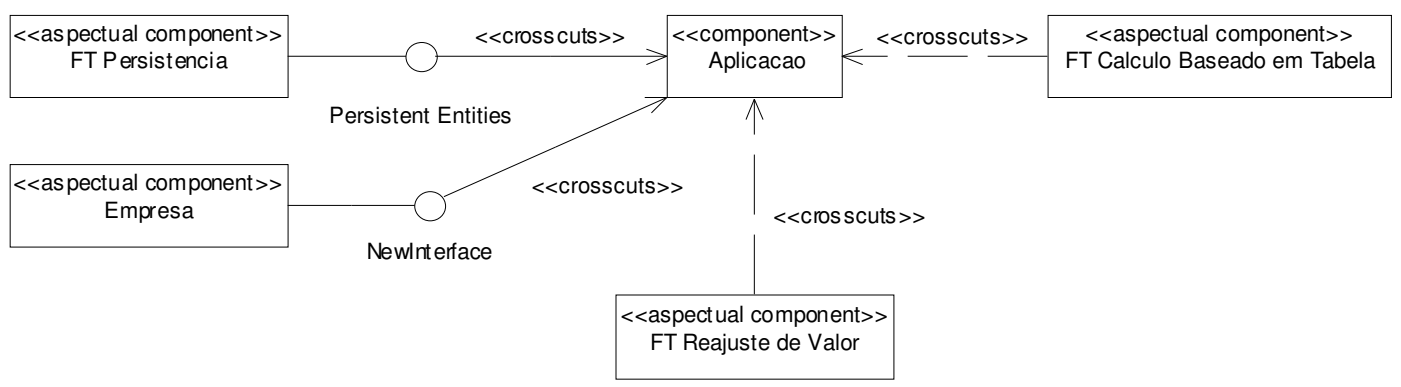

Figura 7.40 - Visão da Arquitetura do Sistema 
Tabela 7.23 - Registro de Pontos de Junção

\begin{tabular}{|c|l|l|l|}
\hline \multirow{2}{*}{$\begin{array}{c}\text { FT/Aspecto } \\
\downarrow\end{array}$} & \multicolumn{3}{|c|}{ Pontos de Junção Afetados } \\
\cline { 2 - 4 } & $\begin{array}{c}\text { Método/atributo/construct } \\
\text { or/adendo }\end{array}$ & \multicolumn{1}{|c|}{ Cnidades de Software } \\
\cline { 2 - 4 } & $\ldots$ & $\begin{array}{l}\text { Classe } \\
\text { Fatura } \\
\text { Fatura }\end{array}$ & \\
\hline FT de Cálculo & $\begin{array}{l}\text { calcularValorTotal() } \\
\text { setValorTotal() }\end{array}$ & \\
\hline
\end{tabular}

\subsection{2 - Disciplina Implementação}

\subsubsection{1 - Implementar Aspectos}

Na Figura 7.41 é mostrado o aspecto MeuAspecto, que é criado para fornecer as regras de composição entre o FT de Cálculo e o sistema de reservas. Esse aspecto estende um aspecto abstrato do FT chamado TBWithReturn e concretiza o conjunto de junção obtainValue com a execução do método calcularValortotal() da classe Fatura. Além disso, dois métodos gancho também são concretizados, o primeiro, chamado getHooksHandlerInstance() retorna uma instância da classe criada anteriormente, enquanto que o segundo, getTablename(), retorna o nome da tabela criada no banco de dados.

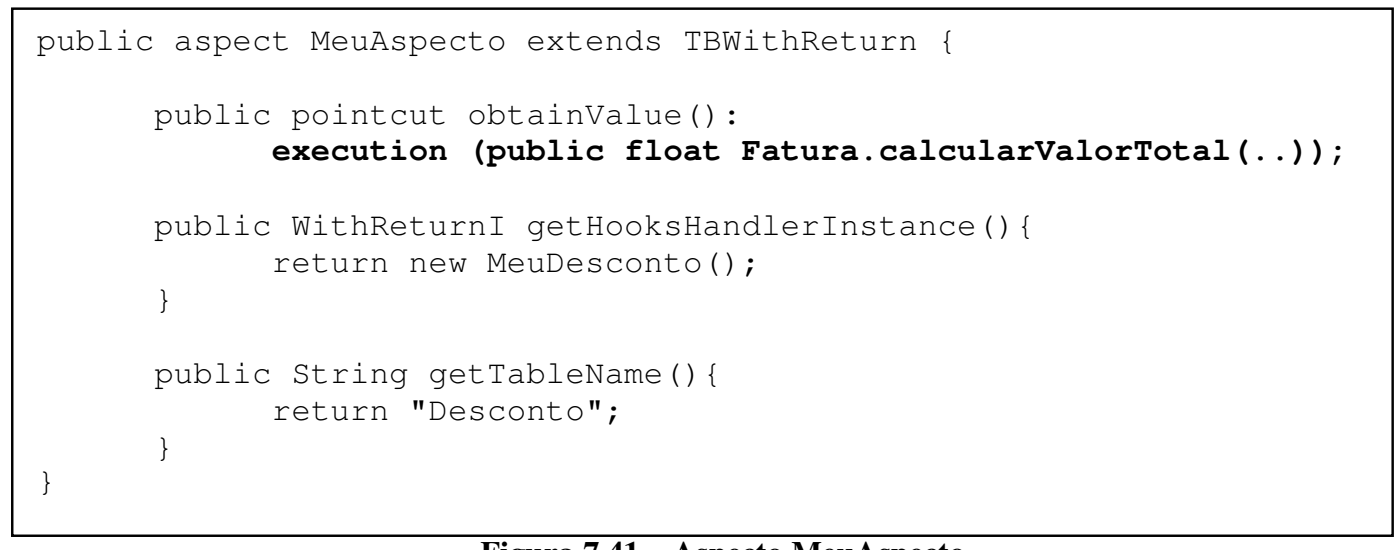

Figura 7.41 - Aspecto MeuAspecto

No caso do sistema de reservas optou-se por remover as alternativas de composição que não estão sendo utilizadas. Isso foi feito porque os benefícios de manutenção que podem ser obtidos com um código mais claro compensa o trabalho futuro de adição de novas alternativas, que pode ou não ocorrer. Sendo assim, o modelo de projeto composto final está sendo mostrado na Figura 7.42. Note-se que as alternativas de composição que foram removidas foram OneStringArgument e WithParameters. 


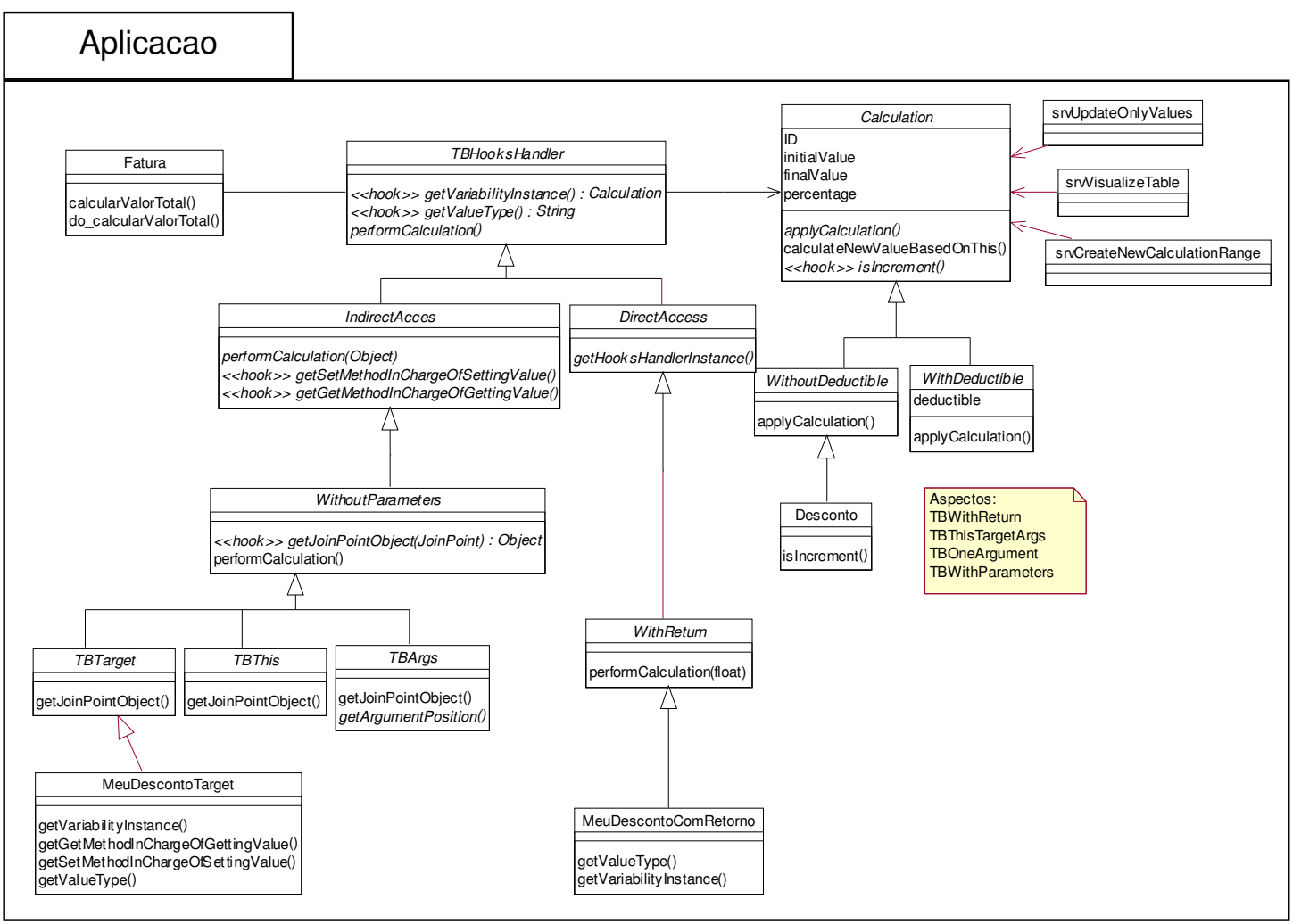

Figura 7.42 - Modelo de Projeto Composto do Sistema de Reservas - 1a. Iteração Aspectual

\section{8 - FASE DE CONSTRUÇÃO - $2^{\mathrm{a}}$. ITERAÇÃO ASPECTUAL}

Esta segunda iteração aspectual da fase de construção concentra-se no desenvolvimento dos casos de uso Autenticar Usuário, Gerenciar Usuário e Controlar Acesso. Na Figura 7.43 é mostrada a visão de iteração do sistema de reservas para esta segunda iteração. Os FTs de Autenticação e de Controle de Acesso podem ser utilizados para apoiar o desenvolvimento desses casos de uso. Porém, como o FT de Autenticação já foi exemplificado na Seção 4.4 esta seção concentra-se no processo de reúso do FT de Controle de Acesso.

\subsection{1 - Disciplina Projeto}

\subsubsection{1 - Projetar Aspectos}

Como há um FT que pode ser usado para a implementação do interesse de controle de acesso, seus modelos de projeto também serão reusados. Na Figura 7.44 é mostrado o modelo de projeto do FT de Controle de Acesso. As classes com estereótipo <<jsp >> são interfaces que permitem realizar o gerenciamento dos usuários, de seus papéis e das operações que os papéis podem executar no sistema. 


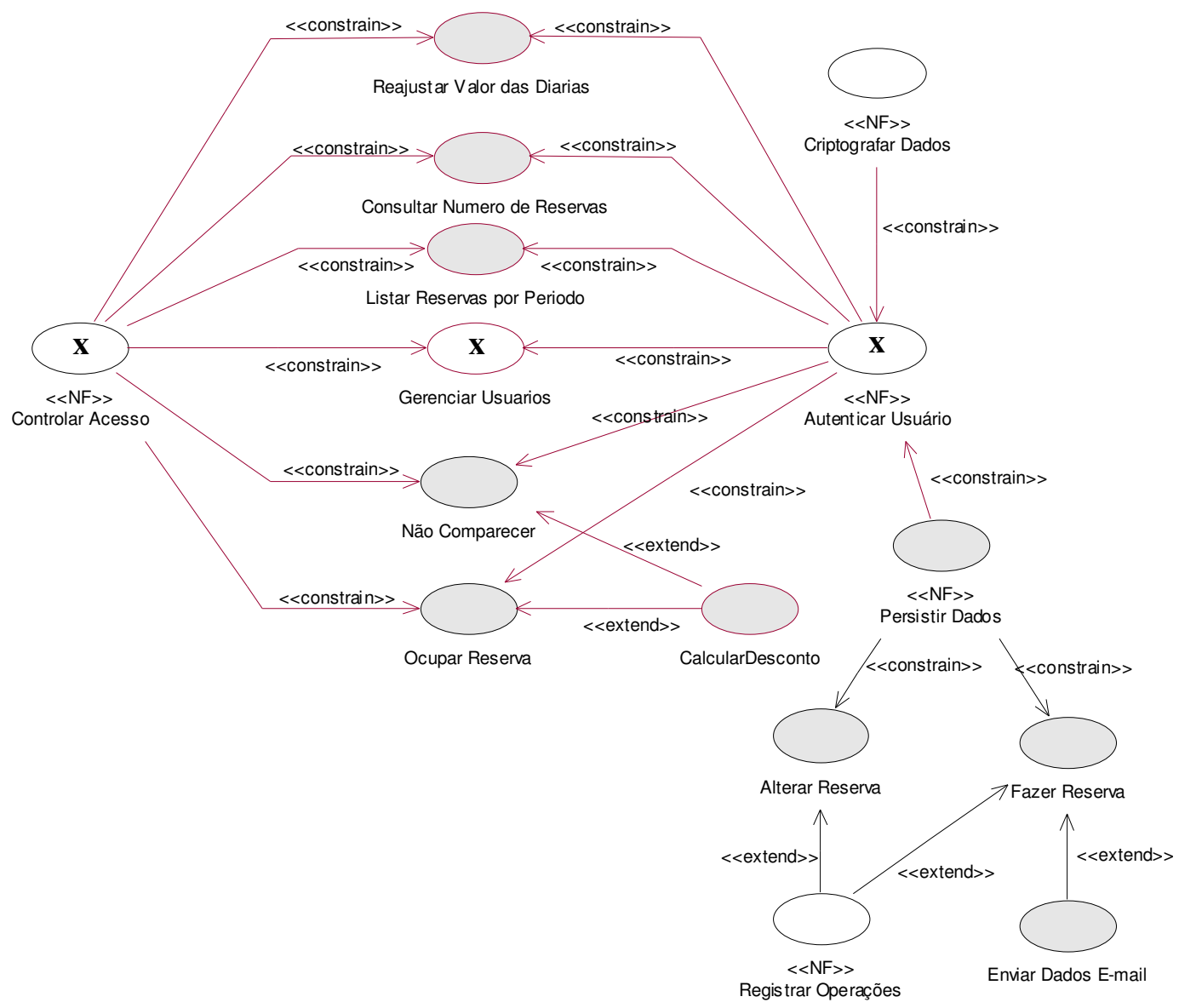

Figura 7.43 - Visão de Iteração para o Sistema de Reservas - 2 ${ }^{\mathrm{a}}$. Iteração Aspectual da Construção

Como o FT de Controle de Acesso inclui o gerenciamento de usuários, o caso de uso Gerenciar Usuário também será implementado nesta iteração.

\subsubsection{2 - Acoplar Aspectos}

Como um FT está sendo utilizado, o primeiro passo é instanciá-lo, o que consiste em projetar uma classe concreta que estende a classe securityoperations do FT sobrepondo os métodos necessários. A sobreposição desses métodos define um mapeamento entre os métodos da aplicação que devem ter o acesso controlado e nomes fictícios, que são usados nas interfaces de gerenciamento de papéis e operações. Na Figura 7.45 é mostrado o modelo de projeto do FT agora com a classe Mysecurityoperations, que deve ser criada para instanciar o framework.

Como o FT de Controle de Acesso depende do FT de Autenticação, antes de projetar a composição do controle de acesso com a aplicação, deve-se realizar a composição entre esses dois FTs, como é mostrado na Figura 7.46. Essa composição é do tipo intercalação, em que as classes que possuem o mesmo nome em ambos os pacotes são transformadas em apenas uma 
e as que possuem nomes diferentes serão adicionadas no pacote resultante. Neste caso, apenas a classe Role será mesclada em apenas uma.

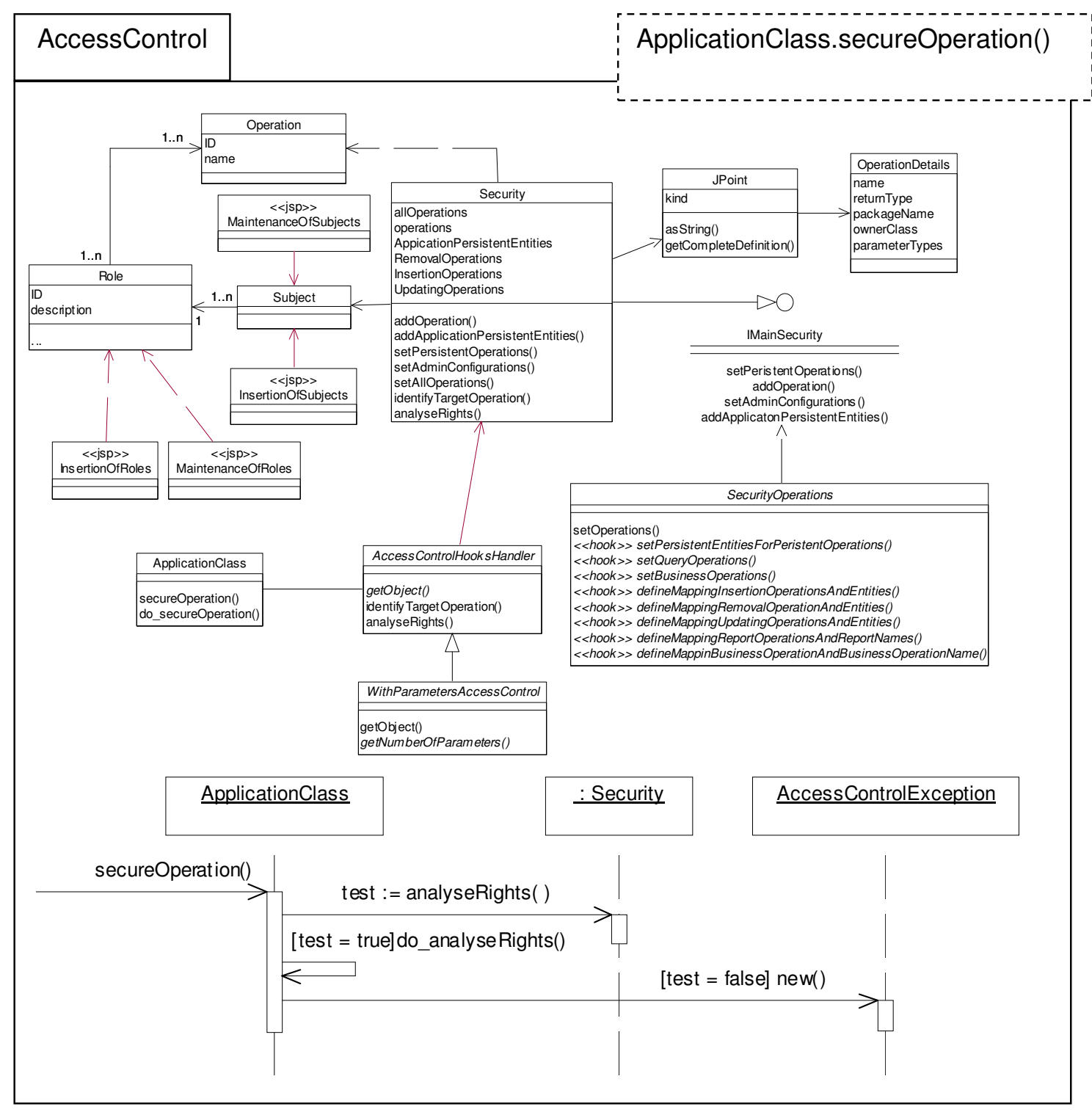

Figura 7.44 - Modelo de Projeto do FT de Controle de Acesso - 3a. Iteração Aspectual

Na Figura 7.47 é mostrado o projeto da composição do FT transversal resultante com a aplicação. Note-se que vários métodos são informados no relacionamento de ligação entre os pacotes. Esses métodos correspondem aos pontos do sistema em que o acesso deve ser controlado.

Na Figura 7.48 é mostrado o modelo de projeto composto. Apenas algumas classes de aplicação estão sendo exibidas para facilitar a legibilidade do modelo. 


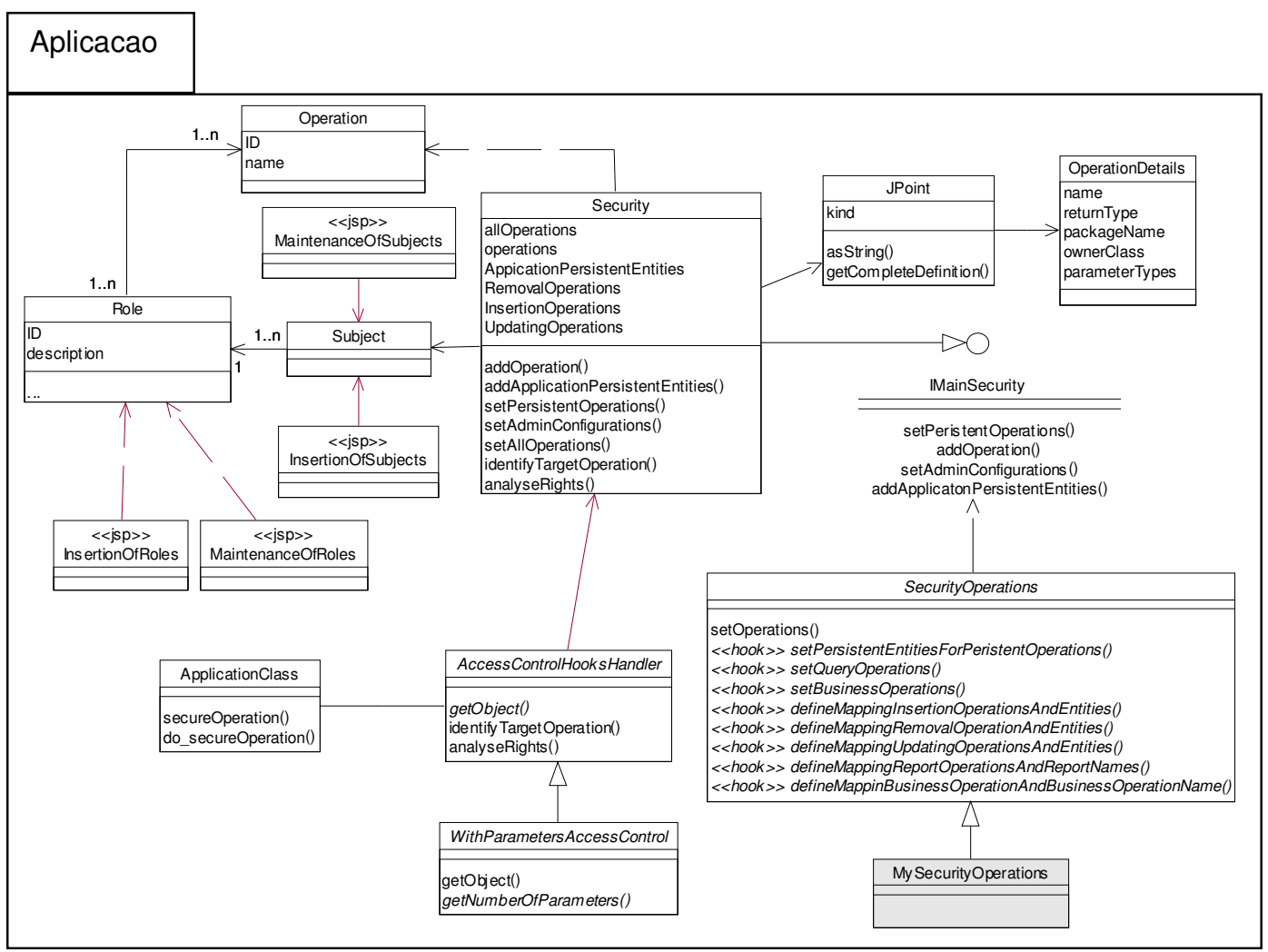

Figura 7.45 - Modelo de Projeto Instanciado

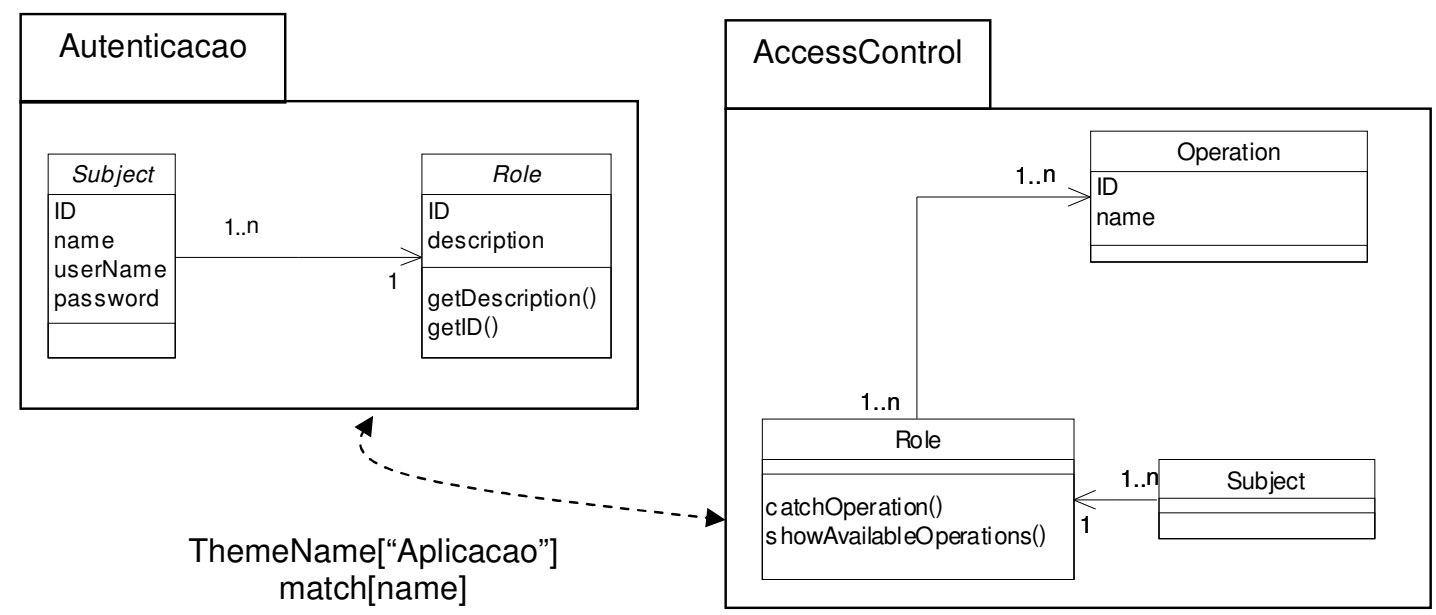

Figura 7.46 - Acoplamento com o FT de Autenticação

\subsubsection{3 - Desenvolver Visão da Arquitetura}

Na Figura 7.49 é mostrada a Visão da Arquitetura para esta terceira iteração aspectual.

\subsubsection{4 - Registrar Pontos de Junção}

A Tabela de Registro de Pontos de Junção deve ser atualizada com os pontos de junção do sistema que foram afetados pelo FT de Controle de Acesso, como pode ser visto na última linha da Tabela 7.24. Pode-se notar que alguns pontos de junção também são afetados pelo FT de Autenticação, entretanto, como o FT de controle de acesso foi projetado para trabalhar em 
conjunto com o de autenticação, ele já possui implementado internamente um mecanismo de precedência que dá prioridade de atuação ao FT de Autenticação.

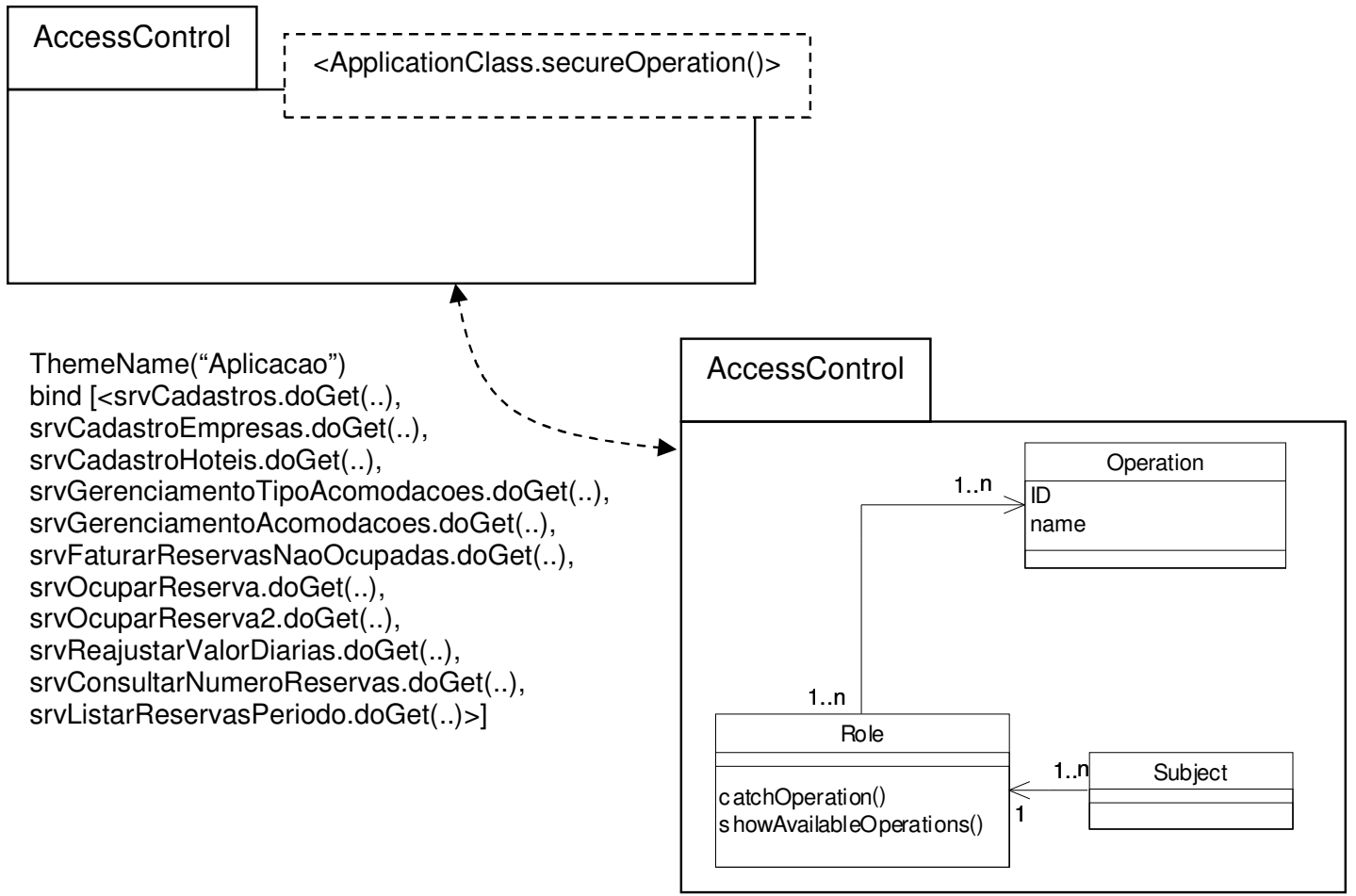

Figura 7.47 - Acoplamento com a Aplicação

\section{9 - CONSIDERAÇÕES FINAIS}

A estratégia de desenvolvimento apresentada neste capítulo considera a utilização do FT de persistência desde a primeira iteração da elaboração, porém os demais FTs são acoplados ao sistema depois que a maior parte da funcionalidade principal está pronta. Essa estratégia permite que a funcionalidade principal da aplicação seja desenvolvida mais rapidamente e de forma mais cuidadosa, já que não há a preocupação com o projeto e a implementação de interesses transversais durante o processo. Um ponto negativo da estratégia adotada é que, dependendo do interesse transversal postergado para o final, modificações podem ser necessárias na parte base.

Uma outra estratégia de desenvolvimento que poderia ser empregada é o acoplamento dos FTs durante o processo, justamente no momento em que são identificados. Quando essa estratégia é usada o acoplamento dos FTs é facilitado, pois os pontos de junção podem ser projetados com vistas ao acoplamento que será feito. Alguns trabalhos recentes mostram que o desenvolvimento de um código-base consciente da existência de aspectos pode trazer benefícios de modularidade e manutenção para o sistema (Griswold et al., 2006). 


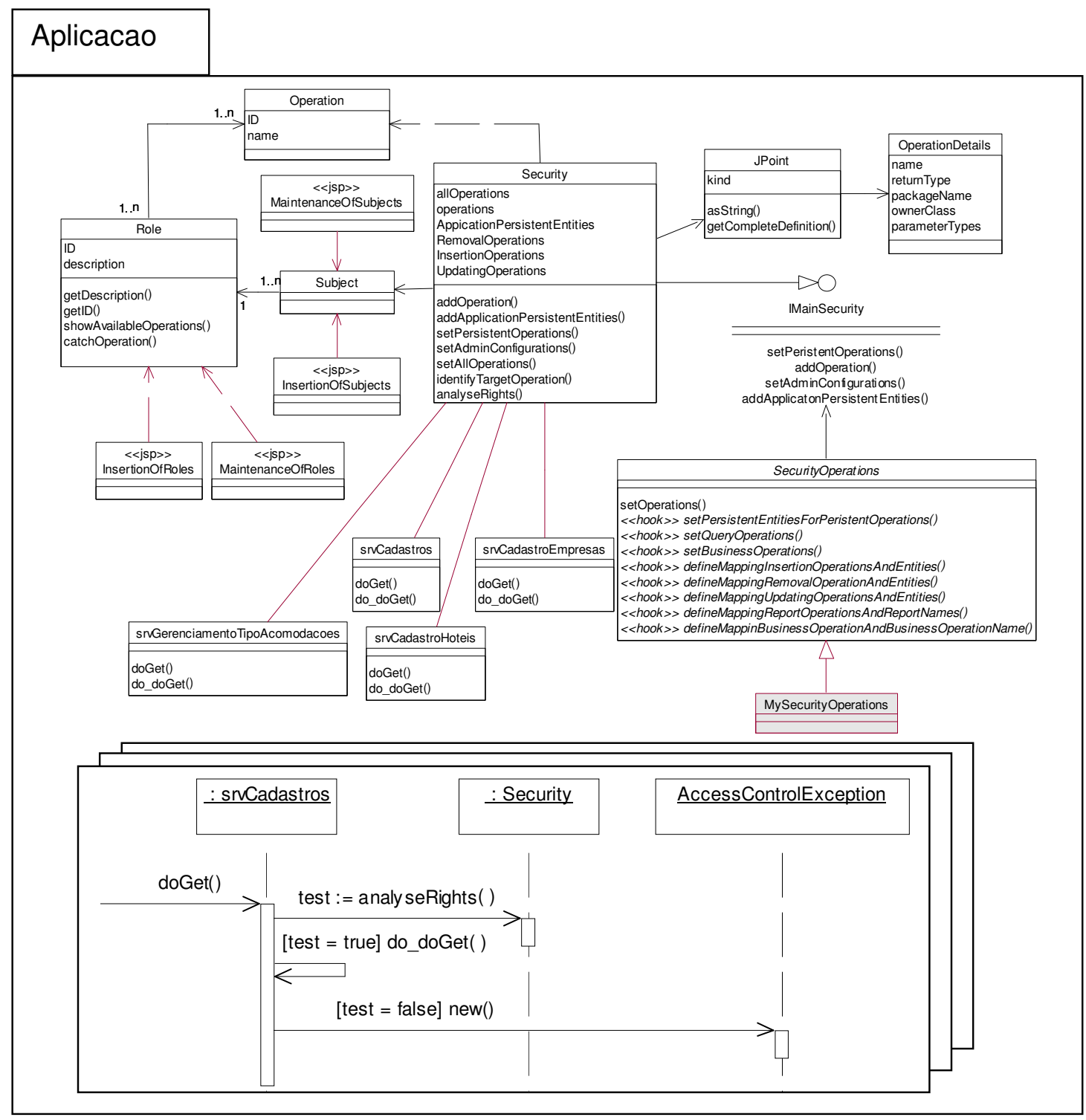

Figura 7.48 - Modelo de Projeto Composto

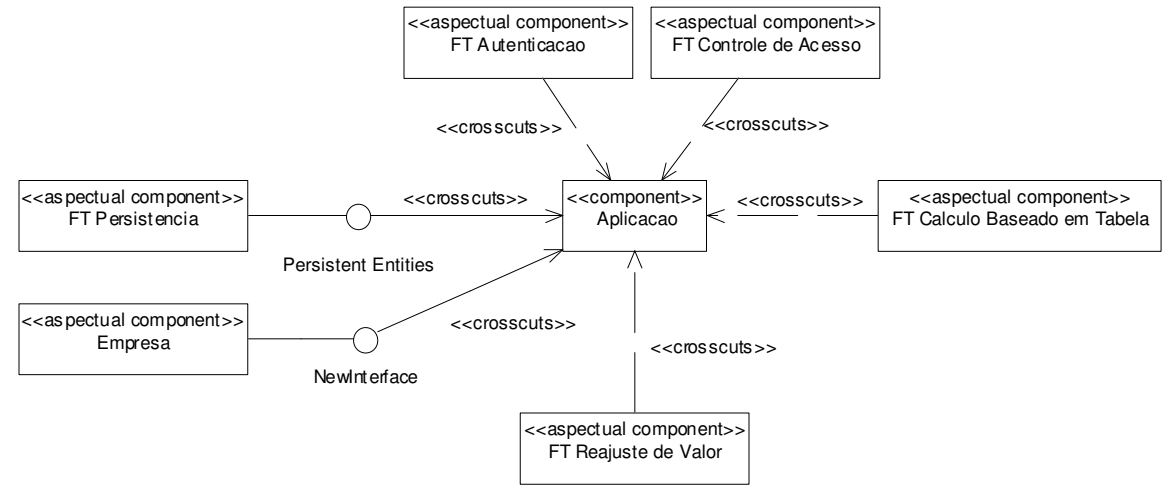

Figura 7.49 - Visão da Arquitetura 
Tabela 7.24 - Registro de Pontos de Junção

\begin{tabular}{|c|c|c|c|}
\hline \multirow{3}{*}{$\begin{array}{c}\text { FT/Aspecto } \\
\downarrow\end{array}$} & \multicolumn{3}{|c|}{ Pontos de Junção Afetados } \\
\hline & \multirow{2}{*}{ Método/atributo/constructor/adendo } & \multicolumn{2}{|l|}{ Unidades de Software } \\
\hline & & Classe & Aspecto \\
\hline $\begin{array}{c}\text { FT de } \\
\text { Persistencia }\end{array}$ & $\cdots$ & $\cdots$ & \\
\hline $\begin{array}{c}\text { FT de } \\
\text { Cálculo } \\
\text { Baseado em } \\
\text { Tabela }\end{array}$ & $\begin{array}{l}\text { calcularValorTotal() } \\
\text { setValorTotal() }\end{array}$ & $\begin{array}{l}\text { Fatura } \\
\text { Fatura }\end{array}$ & \\
\hline $\begin{array}{c}\text { FT de } \\
\text { Autenticação }\end{array}$ & $\cdots$ & $\cdots$ & \\
\hline $\begin{array}{l}\text { FT de } \\
\text { Controle de } \\
\text { Acesso }\end{array}$ & $\begin{array}{l}\text { doGet () } \\
\text { doGet () } \\
\text { doGet () } \\
\text { doGet () } \\
\text { doGet () } \\
\text { doGet () } \\
\text { doGet () } \\
\text { doGet () } \\
\text { doGet () } \\
\text { doGet () }\end{array}$ & $\begin{array}{l}\text { srvCadastroEmpresas } \\
\text { srvCadastroHoteis } \\
\text { srvGerenciamentoTipoAcomodacoes } \\
\text { srvGerenciamentoAcomodacoes } \\
\text { srvFaturarReservasNaoOcupadas } \\
\text { srvOcuparReserva } \\
\text { srvOcuparReserva2 } \\
\text { srvReajustarValorDiarias } \\
\text { srvConsultarNumeroReservas } \\
\text { srvListarReservasPeriodo }\end{array}$ & \\
\hline
\end{tabular}

Embora os FTs utilizados foram acoplados no final do desenvolvimento, nada garante que essa estratégia é possível com qualquer sistema. Novas aplicações precisam ser desenvolvidas seguindo o ProFT/PU para averiguar essa questão. Dois novos FTs funcionais foram desenvolvidos e incluídos no repositório e deu-se início à uma nova família de FTs denominada Regras de Negócio, como já havia sido apresentado na Tabela 4.1. 


\section{Capítulo 8}

Conclusão

\section{1 - CONSIDERAÇÕES INICIAIS}

O trabalho realizado pode ser dividido em duas fases. Na primeira foram definidos, especificados e desenvolvidos os FTs de Persistência e de Segurança. A experiência com o desenvolvimento desses FTs permitiu elaborar uma arquitetura comum para esse tipo de software, a qual é apresentada na Seção 3.3. Ainda nessa primeira fase, o levantamento bibliográfico permitiu a identificação de falta de padronização em relação aos termos utilizados para designar frameworks desenvolvidos no contexto da POA. Assim, foram propostas as definições de Framework Orientado a Aspectos, Framework Transversal e Framework de Aplicações Orientado a Aspectos.

Na segunda fase, o objetivo foi avaliar o impacto da disponibilidade de FTs sobre o processo de desenvolvimento de software. Para isso, um sistema de reserva de uma rede hotéis foi desenvolvido com o cuidado de observar pontos de decisão influenciados pela presença de interesses transversais e dos FTs disponíveis. Durante o desenvolvimento desse sistema, dois novos FTs funcionais foram desenvolvidos, os FT de Cálculo Baseado em Tabela e o FT de Reajuste, dando origem a uma nova família de FTs. Como base nessa experiência, um processo de desenvolvimento de software baseado no PU, incremental e iterativo, e que leva em consideração a possibilidade de implementar os interesses transversais como aspectos, possivelmente usando FTs, foi desenvolvido.

Como parte da pesquisa, dois estudos de caso informais e um estudo de caso formal foram conduzidos com o objetivo de testar e avaliar as vantagens e desvantagens de se usar FTs em relação a outras alternativas, como a implementação orientada a objetos. Esses 
estudos também foram úteis para testar os frameworks e aprimorar sua arquitetura e funcionalidade.

\section{2 - CONTRIBUiÇÕes Desta TESE}

A principal contribuição deste trabalho é tornar o reúso de interesses transversais mais efetivo por meio do fornecimento de um conjunto de técnicas, padrões, diretrizes, implementações e teorias. As contribuições mais específicas são as definições e classificações propostas para designar frameworks desenvolvidos no contexto da POA, a arquitetura de referência e o padrão Capturador de Dados para projeto e implementação de FTs, as famílias de FTs desenvolvidas e o processo ProFT/PU.

A padronização de termos relativos a frameworks orientados a aspectos (Camargo e Masiero, 2005a) evita que o mesmo tipo de implementação seja referenciado de formas diferentes e que tipos diferentes de implementação sejam referenciados pelo mesmo termo. Assim, pretende-se que o termo Framework Transvesal seja utilizado por outros pesquisadores para designar frameworks que tratem de um único interesse transversal.

A arquitetura de referência para FTs, juntamente com o padrão Capturador de Dados, constituem uma forma de projetar e implementar um FT. A parte comportamental do FT pode ser projetada com padrões de projeto convencionais (Gamma et al., 1005) enquanto que a parte de composição com o padrão Capturador de Dados, evidenciando uma clara separação em sua arquitetura. Além de facilitar o raciocínio modular (Kiczales e Mezini, 2005), facilita o processo de reúso, tornando mais clara a divisão dos passos que são realizados nas etapas de instanciação e composição. Além disso, a utilização de uma arquitetura padrão facilita a integração de vários FTs em um repositório único, algo que têm sido buscado por pesquisas mais recentes (Zhang et al., 2004; Mortensen e Ghosh, 2006a; Mortensen e Ghosh, 2006b; Soares, 2004).

Outra contribuição são os produtos gerados pela pesquisa realizada. Três interesses transversais foram implementados de forma genérica: persistência, segurança e regras de negócio. Optou-se por implementar esses interesses como famílias de FTs, em que algumas características também foram implementadas como FTs, facilitando o acoplamento e permitindo que essas características também possam ser reusadas fora de sua linha de produtos original (Weiss e Lai, 1999; Gomaa, 2004). Os interesses transversais foram implementados como famílias para, em parte, ter as variabilidades implementadas como aspectos (FTs) o que facilita o acoplamento e o reúso parcial e para evitar o problema de "overfeaturing", que é causado pela utilização exclusiva de frameworks (Codenie et al., 1997 
apud (Batory et al., 2000)) $)^{24}$. Pretende- disponibilizar os FTs desenvolvidos em um repositório de projetos de software, como por exemplo o SourgeForge (2006).

Outra contribuição desta tese é o processo ProFT/PU. Esse processo é iterativo e incremental e fortemente baseado na identificação e acompanhamento de interesses transversais ao longo do processo. Ele é formado pela união de conceitos, técnicas de modelagem e critérios de outros trabalhos encontrados na literatura (Clarke e Baniassad, 2005; Jacobson e Ng, 2004; Baniassad et al., 2006; Krechetov et al., 2006; Araújo e Moreira, 2003; Araújo et al., 2002). Ele fornece diretrizes e sugestões sobre como reutilizar o projeto e o código de aspectos reusáveis (disponíveis em um repositório, por exemplo) durante o desenvolvimento de um software. Embora ProFT/PU tenha sido criado e exemplificado com a família de FTs desenvolvida no contexto desta tese, não é específico dessa tecnologia. Os critérios de identificação de interesses e os pontos de decisão são aplicáveis ao reúso de aspectos disponíveis na forma de FTs, a uma biblioteca de aspectos (Zhang et al., 2004; Mortensen e Ghosh, 2006a; Mortensen e Ghosh, 2006b) e até mesmo à implementação baseada em aspectos, sem reúso.

\section{3 - LIMITAÇÕES DO TRABALHO EFETUADO}

\subsection{1 - Limitações relacionadas aos FTs}

Uma limitação do trabalho realizado é quanto a carência de experimentos formais que compare o reúso de interesses transversais implementados com FT com o reúso de interesses transversais implementados com orientação a objetos. Embora um experimento tenha sido feito nesse sentido, apenas o tempo de composição foi comparado. Um estudo mais completo deveria avaliar também a manutenção do sistema após o reúso dos FTs.

A utilização dos gabaritos da abordagem Tema durante o projeto não representam adequadamente detalhes da linguagem AspectJ. Assim, é necessário manter um modelo de projeto que represente o comportamento do FT (gabarito) e outro modelo de projeto para representar detalhes específicos da linguagem.

Todos os sistemas utilizados como estudos de caso pertencem ao mesmo domínio de Sistemas de Informação. Assim, o desenvolvimento dos FTs foi feito de forma muito restrita. Pode ser que seu reúso em outros contextos exija um número grande de adaptações, o que pode inviabilizar a adoção dos FTs. Portanto, experimentos em outros domínios poderiam contribuir para a evolução dos FTs

\footnotetext{
${ }^{24}$ CODENIE, W., HONDT, K., STEYAERT, P., VERCAMMEN, A. From Custom Applications to DomainSpecific Frameworks. Communications of the ACM, 40(10), October, 1997.
} 
A utilização única da linguagem AspectJ para o desenvolvimento dos FTs, e consequientemente, de todas as generalizações efetuadas, como, por exemplo, as definições, a arquitetura, o padrão Capturador de Dados, podem ter sido influenciados pelas particularidades dessa linguagem. Um estudo que envolva construções e novos mecanismos disponíveis em outras linguagens orientadas a aspectos poderia levar a melhores soluções na arquitetura proposta.

\subsection{2 - Limitações relacionadas ao Processo ProFT/PU}

A principal limitação do trabalho com relação ao processo apresentado no Capitulo 6 é a carência de ferramentas de apoio. A construção de todos os artefatos manualmente, principalmente as tabelas, é uma tarefa que consome muito tempo e que tende a gerar erros. Apoio automatizado também poderia ser fornecido para a identificação e recuperação de FTs do repositório. Outra limitação do processo é o fato de não tratar da fase de Transição do PU.

\section{3 - SugESTÕES DE TRABALHOS FuTUROS}

Há vários trabalhos futuros que podem ser conduzidos como continuação da pesquisa iniciada por esta tese. Um desses trabalhos é a construção de ferramentas de apoio ao ProFT/PU. Essas ferramentas poderiam auxiliar no acompanhamento do processo e na construção dos modelos de projeto.

Um outro trabalho seria implementar algum mecanismo de suporte à evolução do FT de Persistência. Isso se mostra necessário quando operações muito específicas de consultas precisam ser criadas. Nesses casos, a dificuldade em se criar uma nova operação no Framework ou mesmo na classe de aplicação que instancia o framework, pode inviabilizar seu uso.

Também pode-se investigar uma linguagem de modelagem mais adequada para o desenvolvimento de sistemas em AspectJ do que os gabaritos da abordagem Tema. Embora os gabaritos sejam úteis para descrever o comportamento do interesse transversal, negligencia a implementação. Nessa mesma linha, também pode-se investigar uma notação específica para FTs. Embora Rausch et al. (2003) tenham feito um trabalho neste sentido, ainda há muito para pesquisar. Uma alternativa seria estender o perfil UML-F (Fontoura et al., 2002) para incorporar estereótipos e etiquetas valoradas que representam particularidades específicas de frameworks orientados a aspectos. 
O FT de Garantia de Políticas implementa apenas dois testes com respeito ao FT de Persistência. Esse FT poderia ser estendido para verificar todas as políticas exigidas durante o processo de reúso do FT de Persistência. O mesmo poderia ser feito para o FT de Segurança.

Em relação ao processo ProFT/PU, mecanismos mais elaborados para o registro dos pontos de junção e identificação de conflitos entre aspectos devem ser pesquisados. Outro ponto interessante seria fornecer, juntamente com a documentação dos FTs, não apenas seu projeto, mas também seus modelos de análise. Assim, durante um processo de desenvolvimento, além dos modelos de projeto, seus casos de uso também poderiam ser reusados.

Por fim, um processo de desenvolvimento de Frameworks Transversais poderia ser elaborado. Embora esta tese apresente uma arquitetura para esse tipo de software, não fornece diretrizes que possam ser utilizadas para o desenvolvimento de um FT. 


\section{REFERÊNCIAS BIBLIOGRÁFICAS}

ALDAWUD, O., ELRAD, T., BADER, A. UML Profile for Aspect-Oriented Software Development. In: Proceedings of Workshop of Aspect Oriented Modeling with UML of Aspect Oriented Software Development Conference (AOSD), 2003.

ARAÚJO, J., MOREIRA, A. M. D. An Aspectual Use-case Driven Approach. In: JISBD, pp. 463-468, 2003.

ARAÚJO, J., MOREIRA, A., BRITO, I., RASHID, A. Aspect-Oriented Requirements with UML. In: proceedings of the Workshop on Aspect-Oriented Modelling with UML (held in conjunction with the International Conference on Unified Modelling Language UML 2002), 2002

ASPECTWERKZ WEBSITE. Simple, Dynamic, Lightweight and Powerful AOP for Java. http://aspectwerkz.codehaus.org/

BATORY, D., CARDONE, R., SMARAGDAKIS, Y. Object Oriented Frameworks and Product Lines. In $1^{\text {st }}$ Software Product Lines Conference (SPLC1), 2000.

BANIASSAD, E., CLEMENTS, P.C., MOREIRA, A., ARAÚJO, J., RASHID, A., TEKINERDOGAN, B. Discovering Early Aspects. IEEE Software, pp. 61-70, 2006.

BLAIR, G.S., BLAIR, L., RASHID, A., MOREIRA, A., ARAÚJO, J., CHITCHYAN, R. Engineering Aspect-Oriented Systems. In: Chapter 17 of Aspect-Oriented Software Development, pp. 379-406, Addison-Wesley, 2005.

BERG, K. VAN DEN., CONEJERO, J.M., HERNÁNDEZ, J. Identification of Crosscutting In Software Design. In: Proceedings of the Aspect-Oriented Modelling Workshop (AOM'06) in conjunction with Aspect-Oriented Software Development (AOSD'06), Bonn, Alemanha, 2006.

CAMARGO, V.V., MASIERO, P.C. Frameworks Orientados a Aspectos. In: Anais do $19^{\circ}$ Simpósio Brasileiro de Engenharia de Software (SBES'2005), Uberlândia-MG, Brasil, pp. 200-215, outubro, 2005a.

CAMARGO, V.V., MASIERO, Documentação de Frameworks Transversais com a Abordagem Tema/UML e o Perfil UML-F. In: Anais do $2^{\circ}$ Workshop de Desenvolvimento de Software Orientado a Aspectos (WASP'05) - realizado em conjunto com o Simpósio Brasileiro de Engenharia de Software (SBES'2005), pp. 10-18, Uberlândia, MG, Brasil, outubro, 2005b. (Artigo premiado e convidado para publicação na revista RITA). 
CAMARGO, V.V., MASIERO, P.C. Uma Abordagem de Evolução de Sistemas Orientados a Objetos Apoiada por Frameworks Transversais. In: Anais do Workshop de Manutenção de Software Moderna (WMSWM'05), pp. 18-33, Manaus, Brasil, 2005c.

CAMARGO, V.V., NÏNA, E., MALDONADO, J.C. Um Estudo Comparativo do Tempo de Composição de um Framework Orientado a Aspectos de Persistência e de um Framework Orientado a Objetos de Persistência. In: Anais do $20^{\circ}$ Simpósio Brasileiro de Engenharia de Software (SBES), Florianópolis, Brasil, outubro, 2006 (aceito para publicação).

CAMARGO, V.V., RAMOS, R.A., MASIERO, P.C. Implementação de Variabilidades em Frameworks Orientados a Aspectos desenvolvidos em AspectJ. In: Relatório do $1^{o}$ Workshop de Desenvolvimento de Software Orientado a Aspectos (WASP'04) - realizado em conjunto com o SBES'2004, Brasília, DF, Brasil, outubro, 2004.

CAMARGO, V.V., RAMOS, R.A., PENTEADO, R.A.D., MASIERO, P.C. Projeto Orientado a Aspectos do Padrão Camada de Persistência. In: Anais do $17^{\circ}$ Simpósio Brasileiro de Engenharia de Software (SBES), Manaus-Amazonas, Brasil, pp. 114-129, outubro, 2003.

CAYENNE. http://www.objectstyle.org/cayenne/ (último acesso: 04 de abril de 2006)

CHAPIN, N., HALE, J.E., KHAN, K.M., RRAMIL, J.F., TAN, W. Types of Software Evolution and Maintenance. Journal of Software Maintenance and Evolution: Research and Practice. Vol. 13, pp 3-30, 2001.

CHAVEZ, C. V. G., GARCIA, A., KUlESZA, U.,SANT'ANNA C., LUCENA, C. Taming Heterogenerous Aspects with Crosscutting Interfaces. In: Proceedings of Simpósio Brasileiro de Engenharia de Software (SBES'05), pp 216-231, Uberlândia, MG, Brasil, 2005.

CHAVEZ, C.V.G. A Model-Driven Approach for Aspect-Oriented Design. Tese de Doutorado. Departamento de Computação da PUC-Rio, 2004.

CHEESMAN, J.; DANIELS, J. Uml components: A Simple Process for Specifying Component-Based Software. Addison-Wesley, 2000.

CHEN, K., HUANG, C. On Designing of Access Control Aspects for Web Applications. In: Proceedings of the Workshop on Software Engineering Properties of Languages and Aspect Technologies. Workshop of the $4^{\text {th }}$ Aspect-Oriented Software Development Conference (AOSD’05), Março 14-18, Chicago, USA, 2005.

CIBRÁN, M., D'HONDT, M., JONCKERS, V. Aspect-Oriented Programming for Connecting Business Rules. In: Proc. of the $6^{\text {th }}$ International Conference on Business Information Systems (BIS'03). Colorado Springs, USA, June, 2003. 
CLARKE, S., BANIASSAD, E. Aspect-Oriented Analysis and Design: The Theme Approach. Addison-Wesley, 2005.

COLYER, A., RASHID, A., BLAIR, G. On The Separation of Concerns in Program Families. Technical Report, Computing Department, Lancaster University, 2004.

CONSTANTINIDES C. A.; ELRAD T. Composing Concerns with a Framework Approach. In: International Workshop on Distributed Dynamic Multiservice Architectures in conjunction with the 21st International Conference on Distributed Computing Systems (ICDCS). Phoenix, Arizona, USA, Abril, 2001

CONSTANTINIDES C. A.; SKOTINIOTIS T. Reasoning about a Classification of Crosscutting Concerns in Object-Oriented Systems. In: 2th workshop on aspect oriented software development of SIG (Software Interesting Group), German Informatics Society. Bonn, Alemanha, February, 2002.

CONSTANTINIDES C. A.; SKOTINIOTIS T.; Elrad T. Providing Dynamic Adaptability in an Aspect-Oriented Framework. In: Workshop on Advanced Separation of Concerns ECOOP 2001. Budapest, Junho 17-18, 2001.

COUTO, C.F.M., VALENTE, M.T.O., BIGONHA, R.S. Um Arcabouço Orientado por Aspectos para Implementação Automatizada de Persistência. In: Anais do $2^{o}$. Workshop Brasileiro de Desenvolvimento de Software Orientado a Aspectos (WASP'05), evento satélite do XIX SBES, Uberlândia, MG, Brasil, outubro, 2005.

DIJKSTRA, E. W. A Discipline of Programming. Prentice-Hall, 1976.

EICHBERG, M., MEZINI, M., SCHÄFER, T., Beringer, C., Hamel, K. M. Enforcing System-Wide Properties. In: Proceedings of Australian Software Engineering Conference (ASWEC'04), pages 158-167, Melbourne, Australia. IEEE Computer Society Press, 2004.

ELRAD, T., FILMAN R., BADER A. Aspect-Oriented Programming. Communications of the $A C M$, vol 44, pp 29-32, 2001.

FAYAD, M. E., SCHIMIDT, D. C., JOHNSON, R. Building Application Frameworks: Object-oriented Foundations of Framework Design. John Wiley \& Sons, 1999.

FAYAD, M. E., SCHMIDT, D. C. Object-oriented Application Frameworks. Communications of the ACM, v. 40, n. 10, 1997.

FEATUREC++. URL: wwwiti.cs.uni-magdeburg.de/iti_db/fcc. Último acesso em 5 de julho de 2006.

FONTOURA, M., PREE, W., RUMPE, B. The UML Profile for Framework Architectures. Addison Wesley, 2002. 
GAMMA, E., HELM, R., JOHNSN, R., VLISSIDE, J. Design Patterns: Elements of Reusable Object-Oriented Software. Addison-Wesley, 1995.

GARCIA, A., SANT'ANA, C., FIGUEIREDO, E., KULESZA, U., LUCENA C., von STAA, A. Modularizing Design Patterns With Aspects: A Quantitative Study. In: Proceedings of the Aspect Oriented Software Development Conference (AOSD'05), pp. 3-14, Chicago, USA, 2005.

GOMMA, Hassan. Designing Software Product Lines With UML - From Use Case to Pattern-Based Software Architectures. Addison Wesley, 1a. Edição, 2004.

GRADECKI, J.D. and LESIECKI, N. Mastering AspectJ - Aspect Oriented Programming in Java. Wiley Publishing, 2003.

GRISWOLD, W.G., SHONLE, M., SUlLIVAN, K., SONG, Y., CAI, Y., RAJAN, H. Modular Software Design with Crosscutting Interfaces, IEEE Software, pp 51-60, 2006.

GRUNDY, J. Aspect-Oriented Requirements Engineering for Component-Based Software Systems. In: $4^{\text {th }}$ Symposium on Requirements Engineering, Limerick, Ireland, IEEE, pp. 84-91, 1999.

GRUNDY, J. Multi-Perspective Specification, Design and Implementation of Software Components Using Aspects. In: Journal of Software Engineering and Knowledge Engineering, 20, 6, pp. 713-724, 2000.

HANENBERG, S. Multi-Design Application Frameworks. In: Proc. of the Generative and Component-Based Software Engineering Young Researchers Workshop, Erfurt, October $10,2000$.

HANENBERG, S., HIRSCHFELD, A., UNLAND, R., KAWAMURA, K. Applying AspectOriented Composition to Framework Development - A Case Study. In: Proc. of the $1^{\text {st }}$ International Workshop on Foundations of Unanticipated Software Evolution, Barcelona, Spain, march 28, 2004.

HANENBERG, S., SCHMIDMEIER, A. Idioms for Building Software Frameworks. In AspectJ. In 2nd AOSD Workshop on Aspects, Components, and Patterns for Infrastructure Software (ACP4IS), Boston, MA, March 17, $2003 \mathrm{a}$.

HANENBERG, S., SCHMIDMEIER. A. AspectJ Idioms for Aspect-Oriented Software Construction. In Proceedings of 8th European Conference on Pattern Languages of Programs (EuroPLoP), Irsee, Germany, 25th-29th June, 2003b.

HANNEMANN, J., KICZALES, G. Design Pattern Implementation in Java and AspectJ. Proceedings of the 17th Annual ACM conference on Object-Oriented Programming, Systems, Languages, and Applications (OOPSLA), pages 161-173, November 2002. 
HIBERNATE. www.hibernate.org (último acesso em 4 de abril de 2006).

HIRSCHFELD, R. Aspect-Oriented Programming with AspectS. In: Proceedings of Net.ObjectDays (NODe), Erfurt - Germany, 2002.

HUANG, M., WANG, C., ZHANG, L. Towards a Reusable and Generic Aspect Library. In: Proceedings of AOSDSEC'04 (AOSD Technology for Application-Level Security). Workshop of the Aspect Oriented Software Development Conference, Lancaster, UK, March, 23, 2004.

JACOBSON, I., BOOCH, G., RUMBAUGH, J. The Unified Software Development Process. Reading, MA. Addison-Wesley, 1999.

JACOBSON, I., NG, P. Aspect-Oriented Software Development With Use Cases. AddisonWesley, 2004.

JAML. (2004) http://www.ics.uci.edu/ trungcn/jaml. Último acesso em 9/5/2006.

JBoss (2006). http://labs.jboss.com/portal/jbossaop/index.html. Último acesso em 14/06/2006.

JOHNSON, R. E., RUSSO, V. Reusing Object-Oriented Designs. Rel. Técnico. UIUCDCS 91-1696, University of Illinois, 1991.

JOHNSON, R. E. Components, Frameworks, and Patterns. In: Proc. of the ACM Symposium on Software Reusability, (SST’97), Boston, may, 17-20, 1997.

JOHNSON, R. E., FOOT B. Designing Reusable Classes. Journal of Object-oriented Programming, 1 (2), 22-35, 1998.

KATARA, M., KATZ, S. Architectural View of Aspects. In: $2^{\text {nd }}$ Conference on AspectOriented Software Development (AOSD), Boston, ACM, pp. 1-10, 2003.

KICZALES, G., LAMPING, J., MENDHEKAR, A., MAEDA, C., LOPES, C., LOINGTIER, J., IRVING, J. Aspect Oriented Programming. In: Proceedings of 11 ECOOP. pp. 220242, 1997.

KICZALES, G., HILSDALE, E., HUGUNIN, J., KERSTEN, M., PALM, J., GRISWOLD, G.

Getting Started With AspectJ, Communications of the ACM, vol 44, No. 10, pp.59-65, 2001.

KICZALES, G., MEZINI, M. Aspect-Oriented Programming and Modular Reasoning. In: Proceedings of International Conference on Software Engineering (ICSE'05), St. Louis, Missouri, USA, pp. 49-58, 2005.

KIENZLE, J., GUERRAOUI, R. Aop: Does it make sense? The Case of Concurrency and Failures. In Magnusson, B., editor, ECOOP, volume 2374 of Lecture Notes in Computer Science, pages 37-61. Springer. 
KRECHETOV, I., TEKINERDOGAN, B., GARCIA, A., CHAVEZ, C., KULESZA, U.

Towards an Integrated Aspect-Oriented Modeling Approach for Software Architecture Design. In: Aspect-Oriented Modelling Workshop (AOM'06), in conjunction with AspectOriented Software Development Conference (AOSD'06), Bonn, Alemanha, 2006.

LARMAN, G. Utilizando UML e Padrões - Uma Introdução a Análise e ao Projeto Orientados a Objetos e ao Processo Unificado. 2a . Edição, Bookman, 2004.

LEMOS, O.A., VINCENZI, A.M.R., MALDONAO, J.C., MASIERO, P.C. Teste de Unidade de Programas Orientados a Aspectos. In Anais do 18․ Simpósio Brasileiro de Engenharia de Software (SBES'04) (indicado para best-paper) Brasília, DF, Brasil, 2004.

LEMOS, O.A.L., MALDONADO, J.C., MASIERO, P.C. Data-Flow Integration Testing criteria for Aspect-Oriented Programs. In: Anais do 1o. Workshop de Desenvolvimento de Software Orientado a Aspectos (WASP'04) - realizado em conjunto com o SBES'04, Brasília, DF, Brasil, 2004a.

MENDONÇA, M., ALENCAR, P., OLIVEIRA, T., COWAN, D. Assisting Aspect-Oriented Framework Instantiation: Towards Modeling, Transformation and Tool Support. In: Poster Session of Object-Oriented Programming, Systems, Languages and Applications (OOPSLA'05), San Diego, USA, 2005.

MOREIRA, A., ARAÚJO, J. Handling Unanticipated Requirements Change with Aspects. In: Proceedings of Software Engineering and Knowledge Engineering Conference (SEKE’04), Banff, Canada, June, 2004.

MORTENSEN, M., GHOSH, S. Creating Pluggable and Reusable Non-functional Aspects in AspectC++. In: Proceedings of the $5^{\text {th }}$ Workshop on Aspects, Components and Patterns for Infrastructure Software (ACP4IS'06). Workshop of the Aspect-Oriented Software Development Conference, Bonn, Alemanha, 2006a.

MORTENSEN, M., GHOSH, S. Using Aspects With Object-Oriented Frameworks. In: Proceedings of the Aspect-Oriented Software Development Conference - industry track, Bonn, Alemanha, 2006b.

OJB. http://db.apache.org/ojb/. (último acesso em 4 de abril de 2006).

PAWLAK, R., DUCHIEN, L., FLORIN G., LEGONG-AUBRY, F., SEINTURIER, L, MARTELLI, L. A UML Notation for Aspect-Oriented Software Design. In: Proceedings of Workshop of Aspect Oriented Modeling with UML of Proceedings of Aspect Oriented Software Development Conference (AOSD), 2002.

PINTO, M.; FUENTES, L.; TROYA, J.M.; FAYAD, M.E. Towards an Aspect Oriented Framework in the Design of Collaborative Virtual Environments. In: 8 th IEEE 
Workshop On Future Trends of Distributed Computing Systems (FTDCS). Bologna, Itália, novembro - 2001a.

PINTO, M.; AMOR, M.; FUENTES, L.; TROYA, J.M. Collaborative Virtual Environment Development: An Aspect Oriented Approach. In: 21th international Conference on Distributed Computing Systems Workshops (ICDCSW). Mesa, Arizona, USA, Abril 2001b.

PINTO, M.; FUENTES, L.; FAYAD, M.E; TROYA, J.M. Separation of Coordination in a Dynamic Aspect Oriented Framework. In: Proceeding of the $1^{\text {st }}$ International Conference on Aspect-Oriented Software Development, April 2002.

PREE, W. Hot-Spot-Driven Development in M. Fayad, R. Johnson, D. Schmidt. Building Application Frameworks: Object-Oriented Foundations of Framework Design, John Willey and Sons, p. 379-393, 1999.

PREE, W., KOSHIMIES, K. Framelets - Small and Loosely Coupled Frameworks. ACM Computer Surveys, v.32, n.1, pp. 6-10, 2000.

RAMOS, R.A., CAMARGO, V.V., Penteado, R.A.D. Reúso da Implementação Orientada a Aspectos do Padrão de Projeto Camada de Persistência. In: $4^{\text {th }}$ Latin American Conference on Pattern Languages of Programming (Sugarloaf Plop), Fortaleza, 2004.

RASHID, A., CHITCHYAN, R. Persistence as an Aspect. In: Proc. of the $2^{\text {nd }}$ International Conference on Aspect Oriented Software Development (AOSD), Boston-USA, March, 2003.

RASHID, A., SAWYER, P., MOREIRA, A., ARAUJO, J. Early Aspects: A Model for Aspect-Oriented requirements engineering. In: Joint Int'l Conference Requirements Engineering (RE), Essen, Germany, IEEE, pp 199-202, 2002.

RAUSCH, A., RUMPE, B., HOOGENDOORN, L. Aspect-Oriented Framework Modeling. In: Proc. of the $4^{\text {th }}$ AOSD Modeling with UML Workshop (UML Conference 2003) October, 2003.

ROCHA, A.D., CAMARGO, V.V., MASIERO, P.C. Uso de Aspectos para Verificar Regras de Instanciação de Frameworks. RITA - Revista de Informática Teórica e Aplicada, Volume XI, Fascículo 2, pp 9 - 20, 2004a.

ROCHA, A.D., CAMARGO, V.V., MASIERO, P.C. Uso de Aspectos para Verificar Regras de Instanciação de Frameworks. In: Relatório do $1^{o}$. Workshop Brasileiro de Desenvolvimento de Software Orientado a Aspectos (WASP'04). Workshop realizado em conjunto com o $18^{\circ}$ Simpósio Brasileiro de Engenharia de Software (SBES’04), Brasília, 
DF, Brasil, 2004b (premiado como melhor artigo e convidado para publicação na revista RITA).

ROSS, D. Structured Analysis: A Language for Communicating Ideas. IEEE Transaction on Software Engineering, v.3, n.1, 1977.

SHAH, V., HILL, V. An Aspect-Oriented Security Framework: Lessons Learned. In: Proceedings of AOSDSEC'04 (AOSD Technology for Application-Level Security). Workshop of the Aspect Oriented Software Development Conference, Lancaster, UK, March, 23, 2004.

SOARES, S. An Aspect-Oriented Implementation Method. Dissertação de Mestrado. Centro de Informática (CI), Universidade Federal de Pernambuco (UFPe), Setembro, 2004.

SOARES, S., LAUREANO, E., BORBA, P. Implementing Distribution and Persistence Aspects with AspectJ. In: Proc. the $17^{\text {th }}$ ACM Conference on Object-Oriented Programming, Systems, Languages, and Applications (OOPSLA), pp 174-190, November, 2002.

SOURCEFOURGE. http://sourceforge.net/. Último acesso em 28/07/2006.

STEIN, D., HANENBERB, S., UNLAND, R. Designing Aspect-Oriented Crosscutting in UML. In: Workshop Aspect-Oriented Modeling with UML, AOSD, Enschede, April, 2002.

SUN MICROSYSTEMS. Java Authentication and Authorization Service. http://www.java.sun.com/products/jaas. Último acesso: 17/05/2006.

SUVÉE, D., FRAINE, D.B., VANDERPERREN, W. FuseJ: An Architectural description language for unifying aspects and components. In: Proc. of the $1^{\text {st }}$ Workshop on Software Engineering Properties of Languages for Aspect Technologies (SPLAT'05), Chicago, 2005.

SUVÉE, D.; VANDERPERREN, W.; JONCKERS, V. Jasco: an aspect-oriented approach tailored for component based software development. In: Aspect Oriented Software Development (AOSD’03), p. 21-29, 2003.

SUZUKI, J., YAMAMOTO, Y. Extending UML With Aspects: Aspect Support in the Design Phase. In: Workshop on Aspect-Oriented Programming (ECOOP), Lisboa, 1999.

TARR, P., OSSHER, H., SUTTON, S. Hyper/JTM : Multi-dimensional Separation of Concerns for Java. In: Proc. of the 24th International Conference on Software Engineering. Orlando, Florida, 2002.

VANHAUTE, B., de WIN, B., DECKER, B. Building Frameworks in AspectJ. In: Proc. of the $15^{\text {th }}$ European Conference on Object-Oriented Programming (ECOOP), Separation of Concerns Workshop. pp. 1-6, June, 2001. 
YASSIN, A., FAYAD, M.E. Application Frameworks: A Survey, cap. 29 in M. E. Fayad and

R. E. Johnson. Domain-Specific Application Frameworks: Frameworks Experience by Industry, John Wiley \& Sons, p. 615-632, 2000.

YODER, J. W., JOHNSON, R. E., WILSON, Q. D. Connection Busines Objects to Relational Databases. In: Proceedings on the Conference on the Pattern Languages of Programs, Monticello-IL, EUA. 1998.

ZAKARIA, A.A., HOSNY, H., ZEID, A. A UML Extension for Modelling Aspect-Oriented Systems. In: Proceedings of Workshop of Aspect Oriented Modeling with UML of Aspect Oriented Software Development Conference (AOSD) 2002.

ZHAO, J. Data-Flow-Based Unit Testing of Aspect-Oriented Programs. In: Proceedings of the $27^{\text {th }}$ Annual IEEE International Computer Software and Applications Conference, Dallas, Texas, USA, 2003.

ZHAO, J. Tool Support for Unit Testing of Aspect-Oriented Software. In: OOPSLA 2002 Workshop on Tools for Aspect-Oriented Software Development, Seatle, WA, 2002.

ZHOU Y., RICHARDSON D., ZIV H., Towards a Practical Approach to Test AspectOriented Software. In: Proc. of the 2004 Workshop on Testing Component-based Systems (TECOS 2004), Net.ObjectDays, 2004.

ZUBAIROV, R., HANENBERG, S., UNLAND, R. Modularizing Security Related Concerns in Enterprise Applications - A Case Study with J2EE and AspectJ. In: Hirschfeld, R., Kowalczyk, R., Polze, A., Weske, M. (eds.). Proceedings of NetObjectDays (NODE 2005) and GSEM, Erfurt, September, 19-22, LNI p-69, Gesellshcharf für Informatik, 2005. 


\section{ANEXo 1 - Documento DE REQUiSiTOS DO SISTEMA DE RESERVAS DE UMA REDE DE HOTÉIS}

\section{A.1 Descrição Geral do Sistema}

O Sistema de Reserva de Hotel consiste em um sistema de gerenciamento das reservas das acomodações de um hotel de uma rede de hotéis. Atualmente, cada hotel tem seu próprio sistema, que são incompatíveis entre si. No novo sistema a ser construído, as reservas podem ser feitas por telefone, ligando diretamente para uma central de reservas ou para o hotel, ou então pela Internet.

Cada hotel tem diferentes tipos de acomodação que podem ser reservados por um cliente, cujos dados devem ser registrados no sistema. O cliente pode confirmar, modificar, cancelar ou ocupar sua reserva e receber uma acomodação do tipo escolhido, nesta última situação. Uma vantagem do novo sistema será a possibilidade de oferecer acomodações em hotéis alternativos quando o hotel desejado já estiver cheio. No hotel, será possível fazer as reservas nos balcões de atendimento e nos escritórios. Cada hotel tem um gerente responsável por controlar as reservas, mas qualquer usuário autorizado pode fazê-las. O tempo desejado para fazer uma reserva por telefone ou pessoalmente é de três minutos. Para agilizar o processo, detalhes de clientes que já estiveram no hotel serão armazenados e disponibilizados para uso. O controle do pagamento das locações de quarto e taxas por reserva não ocupada sem cancelamento será realizado por um sistema de pagamento existente. O hotel possui um gerente que é responsável pelo gerenciamento do hotel, acomodações, funcionários, etc, e um administrador do Sistema de Reservas que é responsável por gerenciar o sistema, atribuir permissões de acesso, etc.

\section{A.2 Requisitos Funcionais}

\section{A.2.1 Operações básicas do sistema}

1. O sistema deve permitir a inclusão, alteração e remoção de hotéis, com os seguintes atributos: identificação, nome, endereço, telefone, IE.

2. O sistema deve permitir a inclusão, alteração e remoção de acomodações do hotel, com os seguintes atributos: número da acomodação, descrição, tipo de acomodação e situação atual (vago ou ocupado). 
3. O sistema deve permitir a inclusão, alteração e remoção de tipos de acomodação oferecidos pelo hotel, com os seguintes atributos: código do tipo de acomodação, descrição e preço.

4. O sistema deve permitir a inclusão, alteração e remoção de clientes do hotel, com os seguintes atributos: nome, endereço, cidade, estado, telefone, fax, e-mail e documento de identificação (CPF e RG).

5. O sistema deve permitir a inclusão, alteração e remoção de usuários do sistema, com os seguintes atributos: nome, login e senha.

\section{A.2.2 Reserva}

6. O sistema deve permitir o processamento de reservas de acomodações de um hotel, devendo ser registrados os seguintes atributos: identificação do hotel, identificação do cliente, data de início da estada, data de fim da estada e tipo de acomodação.

Existe vaga de acomodação no hotel se há pelo menos um tipo de acomodação desejado disponível no período solicitado e se após a reserva haverá pelo menos um tipo de acomodação de qualquer tipo disponível no mesmo período.

A decisão se há acomodação disponível dá-se pelo cálculo a seguir: $\mathrm{R}=(\mathrm{A}-\mathrm{B}>0)$ e $($ Ta $-\mathrm{Tb}>1)$

A: total de quartos disponíveis de um certo tipo. B: somatória das reservas existentes para um certo tipo de quarto em um determinado período.

Ta: total de quartos (de qualquer tipo). Tb: total de reservas.

OBS1: O Cálculo é feito para cada dia do período. OBS2: No cálculo do valor contam-se as noites dormidas. Se a reserva é de 04/02 a 10/02, contam-se os dias de 04 a 09, ou seja, 6 dias.

O sistema deve enviar ao cliente os dados referentes à sua reserva e um código da reserva por e-mail.

7. O sistema deve permitir que os clientes que já confirmaram a reserva no hotel cancelem ou modifiquem os dados da reserva.

8. O sistema deve permitir o processamento da ocupação da reserva do hotel, iniciando a estada do cliente no hotel, devendo ser registrados os seguintes atributos: identificação da reserva e número do quarto ocupado.

9. O sistema deve gerar dados referentes às estadas dos clientes para o sistema de faturamento existente, bem como dos casos em que o cliente não ocupou a reserva sem cancelá-la. Neste último caso é cobrado o valor de uma diária do cliente. 
10. Os preços das diárias variam de acordo com o dia da semana e o tipo da acomodação, e descontos são oferecidos para empresas que possuem convênio com o hotel.

\section{A.2.3 Emissão de relatórios e consultas}

11. Consultar se uma acomodação está ocupada ou não.

12. Consultar o número de reservas de um certo tipo de acomodação em um certo dia.

13. Listar as reservas de um certo dia/período.

\section{A.3 Requisitos Não Funcionais}

\section{A.3.1 Segurança}

14. O sistema deve permitir a autenticação de seus usuários.

15. O sistema deve gerar arquivos de registro das operações de reserva, alteração de reserva e cancelamento de reserva realizadas no sistema.

\section{A.3.2 Controle de Acesso}

16. O sistema deve oferecer meios para permitir a execução de operações de acordo com o tipo do usuário autenticado no sistema.

17. O sistema deve permitir a atribuição de papéis aos usuários do sistema e a atribuição de direito de acesso a operações do sistema aos papéis.

\section{A.3.3 Persistência}

18. O sistema deve permitir que os dados necessários para o gerenciamento do hotel sejam armazenados em um banco de dados.

\section{A.3.4 Desempenho}

19. A reserva deve ser feita em menos de 3 minutos (por telefone ou pessoalmente).

\section{A.4 - Glossário}




\begin{tabular}{|c|c|}
\hline Termo & Descrição \\
\hline Rede de Hotéis & Empreendimento que possui vários hotéis. \\
\hline Hotel & $\begin{array}{l}\text { Estabelecimento comercial que possue acomodações que podem ser alu- } \\
\text { gadas por um periodo de tempo. }\end{array}$ \\
\hline Acomodação & Acomodação do hotel que será ocupada pelos clientes - apartamento. \\
\hline Tipo de Acomodação & Estilo de acomodação do Hotel. Exemplo: padrão, luxo e suite. \\
\hline Tipo de Ocupação & $\begin{array}{l}\text { Refere-se à quantidade de pessoas que podem ocupar a acomodação. Ex- } \\
\text { emplo: simples, duplo e triplo. }\end{array}$ \\
\hline Usuário do Sistema & Pessoa que possue acesso às operações do Sistema de Reserva de Hotéis. \\
\hline Papel & $\begin{array}{l}\text { Função que um usuário desempenha no Sistema. Por exemplo: cliente, } \\
\text { recepcionista, gerente de reservas, gerente geral e administrador. }\end{array}$ \\
\hline Cliente & Pessoa que faz reserva de apartamentos do hotel. \\
\hline Recepcionista & $\begin{array}{l}\text { Pessoa responsável por atender os clientes do hotel e realizar operações } \\
\text { como fazer reservas e dar entrada no hotel. }\end{array}$ \\
\hline Gerente de Reservas & $\begin{array}{l}\text { Pessoa responsável pelo gerenciamento das operações relativas às reservas } \\
\text { efetuadas no hotel. }\end{array}$ \\
\hline Gerente do Hotel & $\begin{array}{l}\text { Pessoa responsável pelo gerenciamento do Hotel (funcionários, aco- } \\
\text { modações, etc). }\end{array}$ \\
\hline Administrador & Pessoa responsável pelo gerenciamento do Sistema de Reserva de Hotéis. \\
\hline Reserva & $\begin{array}{l}\text { Procedimento pelo qual um tipo de acomodação fica reservado para um } \\
\text { cliente, garantindo que haverá disponibilidade desse tipo de acomodação } \\
\text { quando o cliente fizer sua ocupação da reserva. }\end{array}$ \\
\hline Estada & $\begin{array}{l}\text { Procedimento pelo qual o cliente ocupa a reserva por ele realizada, re- } \\
\text { cebendo um quarto para acomodar-se e iniciar sua estada. }\end{array}$ \\
\hline Desconto & $\begin{array}{l}\text { Valor subtraido do preço das diárias das acomodações em determinadas } \\
\text { ocasiões. }\end{array}$ \\
\hline Empresa & $\begin{array}{l}\text { Empreendimento que pode fazer convênio com a rede de hotéis e obter } \\
\text { descontos no valor das diárias dos hotéis da rede. }\end{array}$ \\
\hline Backup & Cópia de segurança ou cópia de salvaguarda. \\
\hline
\end{tabular}




\section{Anexo 2 - Formulário de CARACTERIzaÇão do Perfil}

The purpose of this form is to characterize your computer science background. Please fill it out truthfully and as completely as possible. Only a confidential ID\# will appear on these pages.

\section{Professional Experience}

1) What is your proficiency level in English?

\section{Reading}
[ ] basic
[ ] medium
[ ] advanced [ ] expert

\section{Writing}
[ ] basic
[ ] medium
[ ] advanced
[ ] expert

\section{Listening}
[ ] basic
[ ] medium
[ ] advanced
[ ] expert

2) What is your previous experience with software development in practice? (Check the right-most item that applies.)

\begin{tabular}{|c|c|c|c|}
\hline $\begin{array}{c}\text { I have } \\
\text { developed } \\
\text { software on } \\
\text { my own }\end{array}$ & $\begin{array}{c}\text { I have developed } \\
\text { software on as part } \\
\text { of a team, as part of } \\
\text { a course }\end{array}$ & $\begin{array}{c}\text { I have developed } \\
\text { software as part of a } \\
\text { team, in industry, for } \\
\text { less than 5 years. }\end{array}$ & $\begin{array}{c}\text { I have developed } \\
\text { software as part } \\
\text { of a team, in } \\
\text { industry, for } 5 \text { or } \\
\text { more years. }\end{array}$ \\
\hline
\end{tabular}

Please explain your answer. Include the number of months of relevant experience.

a) How many months of experience have you had in manager:

Months of experience: (student) (industry)

b) How many months of experience have you had in analyst:

Months of experience: (student) (industry)

c) How many months of experience have you had in developer (programming): Months of experience: (student) (industry)

d) How many months of experience have you had in tester: Months of experience: (student) (industry)

3) How well you know... 
a) How well do you know the aspect oriented programming concepts?

1 - Expert

2 - Advanced

3 - Medium

4 - Basic

5 - None

Months of experience: (student) (industry)

b) How well do you know Java language?

1 - Expert

2 - Advanced

3- Medium

4 - Basic

5 - None

Months of experience: (student) (industry)

c) How well do you know Aspect $\mathrm{J}$ language?

1 - Expert

2 - Advanced

3- Medium

4 - Basic

5 - None

Months of experience: (student) (industry)

4) Fraction of programming experience spent $\%$ in individual effort (alone) $\%$ in cooperation with others (team) $\%$ in supervision of other programmers (management)

\section{Programming Language Experience}

5) How many programs have you written by yourself of the given sizes using the following languages?

\begin{tabular}{|c|c|c|c|c|c|c|c|c|c|}
\hline \multirow{4}{*}{$\begin{array}{l}\text { Programming } \\
\text { Language }\end{array}$} & \multicolumn{9}{|c|}{ Number of programs with program size (\# of lines) } \\
\hline & $>$ & $>$ & $>$ & $>$ & $>$ & $>$ & $>$ & $>$ & $>$ \\
\hline & 0 & 100 & 300 & 500 & 1000 & 1500 & 5000 & 1000 & 1500 \\
\hline & & & & & & & & 0 & 0 \\
\hline Cobol & & & & & & & & & \\
\hline Pascal & & & & & & & & & \\
\hline C & & & & & & & & & \\
\hline $\mathrm{C}++$ & & & & & & & & & \\
\hline Java & & & & & & & & & \\
\hline Aspect J & & & & & & & & & \\
\hline Delphi & & & & & & & & & \\
\hline (other) Clipper & & & & & & & & & \\
\hline
\end{tabular}




\section{ANEXO 3 - Q1 - QUESTIONÁRIO INDIVIDUAL PARA Participantes do Estudo de Caso}

Nome:

Idade:

Disciplina que está fazendo:

Data:

Curso:

Nível:

Sua graduação:

Nível de conhecimento da linguagem Java:

Nível de conhecimento da linguagem AspectJ:

Nível de conhecimento com programação orientada a aspectos:

Já implementou algo antes em AspectJ? O que?

Conhece alguma outra linguagem orientada a aspectos?

\section{Q2 - Questionário Individual para Participantes do Estudo de Caso}

Utilize a tabela abaixo para marcar o tempo gasto com cada atividade do processo de reúso do Framework Transversal (FT). O tempo despendido em cada atividade também inclui a compreensão do manual.

\begin{tabular}{|c|c|c|c|c|c|c|}
\hline Etapa & Atividades & \multirow[b]{3}{*}{ data } & \multicolumn{4}{|c|}{ Tempo despendido } \\
\hline & & & \multicolumn{2}{|c|}{ Manual } & \multicolumn{2}{|c|}{ Implementação } \\
\hline & & & início & Término & início & Término \\
\hline \multirow{5}{*}{ 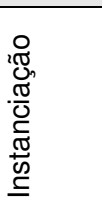 } & Escolher variabilidade & & & & & \\
\hline & Criar a camada de instanciação & & & & & \\
\hline & Implementar variabilidade & & & & & \\
\hline & Criar tabela & & & & & \\
\hline & Preencher a tabela & & & & & \\
\hline \multirow{5}{*}{ 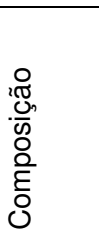 } & $\begin{array}{l}\text { Definir mapeamento OO- } \\
\text { Relacional }\end{array}$ & & & & & \\
\hline & $\begin{array}{l}\text { Definir as variabilidades de } \\
\text { conexão }\end{array}$ & & & & & \\
\hline & Determinar a conexão & & & & & \\
\hline & Identificar ponto de junção & & & & & \\
\hline & Fornecer regras de composição & & & & & \\
\hline
\end{tabular}


Anote também em local separado o tempo gasto com quaisquer outras atividades relacionadas com o estudo de caso, por exemplo: o estudo de um determinado comando da linguagem AspectJ.

\section{Responda as questões abaixo:}

\section{Em relação aos manuais}

1) Em que nível o manual de reúso auxilia o processo?

2) Você sentiu falta de alguma outra fonte de documentação durante o processo de reúso, por exemplo diagramas de classes, de seqüência, use-cases, etc ?

3) Em que nível o documento que descreve as alternativas do padrão auxilia na escolha das alternativas de composição? O que esse documento poderia conter para auxiliar ainda mais a identificação dos pontos de junção ideais no código-base?

\section{Em relação ao processo de reúso}

4) Em qual das atividades (dentro de cada etapa) você obteve mais problemas de implementação e porque? Quais foram esses problemas?

5) Você acha que as alternativas de composição do padrão são suficientes para todos os casos de acoplamento? Justifique sua resposta.

6) Em que nível de dificuldade vc categoriza a atividade "identificar ponto de junção"?

7) Cite algo que poderia apoiar de forma mais direta a atividade "identificar ponto de junção" (manuais, ferramentas, diretrizes).

8) Antes de encontrar o ponto de junção ideal para o acoplamento, quais foram suas tentativas? Tentou acoplar em local errado? 


\section{ANEXO 4 - RELATÓRIO DE IMPLEMENTAÇÃO DO FRAMEWORK DE PERSISTÊNCIA E SEGURANÇA ORIENTADO A ASPECTOS}

Disciplina: Seminários Avançados em Engenharia de Software

Professor: Paulo César Masiero

Aluno:

1 - O Processo

a) O processo proposto representa corretamente as atividades que você realiza ou deveria ser modificado? Neste caso, que atividades você acrescentaria ou removeria?

b) Qual foi o grau de iteratividade do processo realmente requerido por você? Essa iteratividade deveria ser representada no processo proposto?

c) Qual é a sua opinião sobre a agilidade/eficiência do processo?

2 - Tempo

a) Marque o tempo gasto em cada uma das fases do processo.

b) Relate os tipos de erros e o tempo que foi gasto para solucioná-los. Relate se os erros foram oriundos de problemas do manual, do engenheiro de aplicação (você), ou de problemas do framework.

3 - Experiência com o framework de persistência

a) Relate sobre a facilidade/dificuldade de instanciação.

b) É muito restrito ou as funcionalidades (métodos) que ele fornece são suficientes para o tipo de aplicação que está sendo desenvolvida?

c) Há necessidade de mais variabilidades? Quais?

d) Você acha que ele agiliza o desenvolvimento ?

4 - Experiência com o framework de segurança

a) É fácil ou difícil de instanciar?

b) Ele é muito restrito ou as funcionalidades (métodos) que ele fornece são suficientes para o tipo de aplicação que está sendo desenvolvida? 
c) Há necessidade de mais variabilidades? Quais?

d) O sistema do administrador tem funcionalidades suficientes para gerenciar os papéis dos usuários?

e) Há como burlar o controle de acessso que é feito às operações?

\section{5 - O manual}

a) O Manual dá apoio ao desenvolvimento em cada uma dessas fases?

b) Que fase ele apóia melhor?

c) O que poderia ser feito para melhorá-lo?

\section{6 - Diversos}

a) Relate quaisquer outros problemas ou vantagens que você tenha percebido em relação ao desenvolvimento de uma aplicação com frameworks orientados a aspectos.

b) Você acha que a manutenção será melhorada com o uso desses frameworks? E quanto à evolução da aplicação e dos frameworks? 